
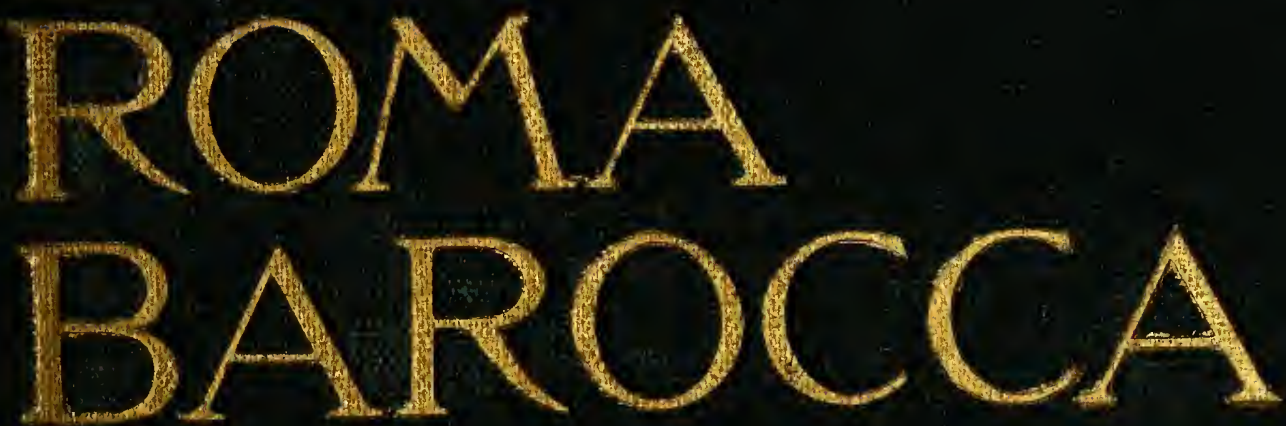
Presented by the Misses Hewitt May 1922. 



CASA EDITRICE D'ARTE BESTET'TI \& TUMMINELLI MILANO - ROMA

"COLLEZIONE ITALIA,"

diretta da ANTONIO MUNOZ

I. ANTONIO MUNOZ. - Roma Barocca.

II. DIEGO ANGELI, - Roma Britannica. (In preparazione). 


\section{ROMA BAROCCA}

\section{CON 355 ILLUSTRAZIONI}

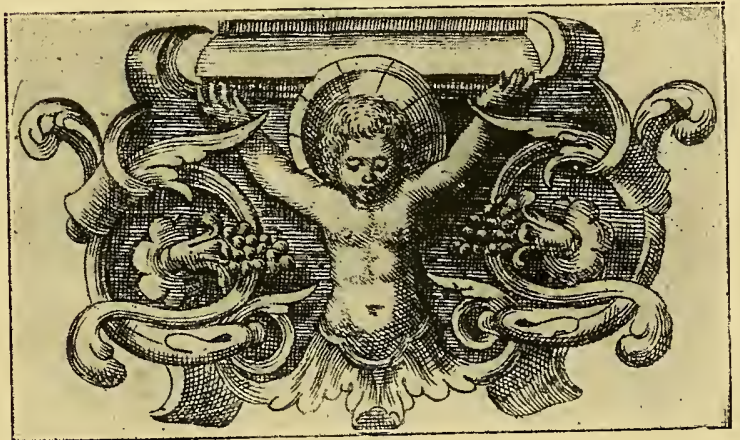

CASA EDITRICE D'ARTE BESTETTI \& TUMMINELLI

MILANO - ROMA 
TUTTI I DIRITTI SONO RISERVATI

Casa Editrice d'Arte Bestettí \& Tumminelli - Milano-Roma.

Zinchi deglí stabilimenti Danesi e Sansaini - Roma. 


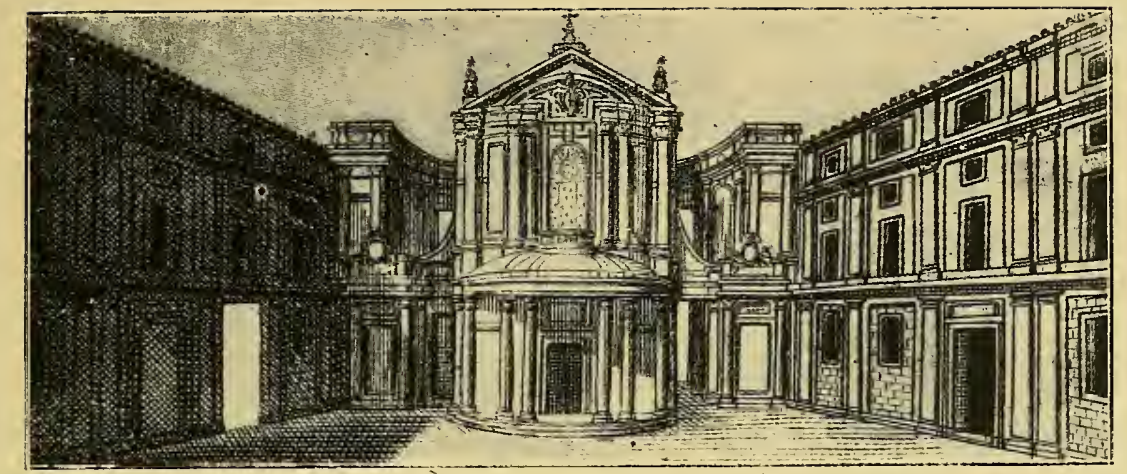

\section{Indice generale}

CAPITOLO I. - Papa Sisto. . . . Pag. 1-26

CAPITOLO II. - La Galleria Farnese . . » 27-52

CAPITOLO III. - Delicium Urbis . . . » 53-93

CAPITOLO IV. - Le Chiese . . . . » 95-129

CAPITOLO V. - Il baldacchino . . . "131-167

CAPITOLO VI. - Apes Urbanae . . . »169-199

CAPITOLO VII. - Borromini . . . . » 201-241

CAPITOLO VIII. - Luce e tenebre . . . » 243-291

CAPITOLO IX. - Donna Olimpia . . . » 293-329

CAPITOLO X. - Felici Faustoque Ingressui - » 331-370

CAPITOLO XI. - Fratel Pozzo . . . » 371-408

Indici. - . + . + . + . Pag. 409

Sommario dei capitoli. . . . . . » 411

Indice delle illustrazioni . • . . . ” 415 



\section{ROMA BAROCCA}





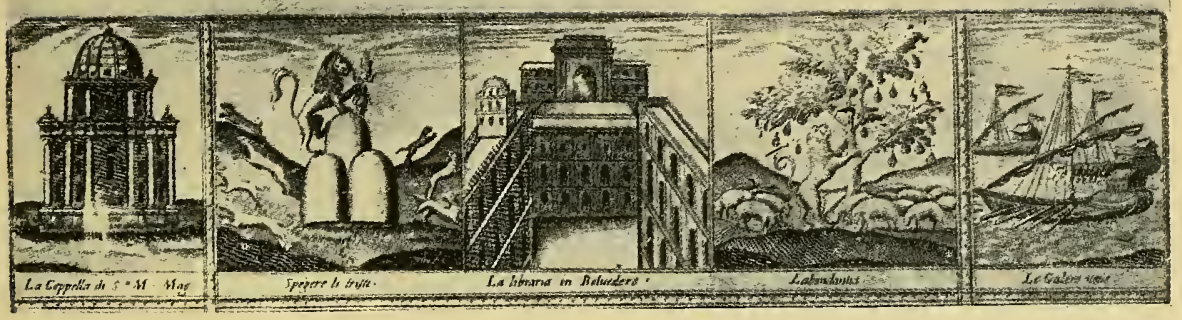

\section{CAPITOLO PRIMO}

\section{PAPA SISTO}

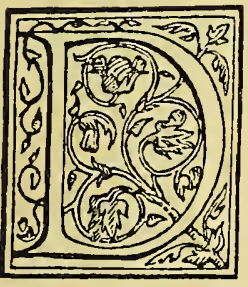

ue figure, fra le tante della sua grande storia, son rimaste vive nella memoria del popolo romano: Nerone e Papa Sisto. Non le gesta e i trionfi di Cesare e di Germanico, non le lotte vittoriose di Gregorio VII, e l'ardore di Cola di Rienzo, non la magnificenza di Leone $X$, o la viva carità di San Filippo Neri, ma la crudeltà dell'incendiatore di Roma, e la implacabile severità del papa francescano, hanno lasciato nell'anima popolare la traccia più profonda. I due nomi del Cesare e del Pontefice affiorano quasi soli alla superficie di quel gran cumulo di cose passate su cui il tempo ha gettato il suo fitto velario; si additano i luoghi immaginarii delle loro gesta ; la torre di Magnanapoli da cui Nerone mirava la città in fiamme, che è invece una costruzione del tardo Medio Evo; la sua tomba sulla via Cassia, che è il sarcofago di un tal Vibio Mariano; si ricordano i loro detti; si invoca per un atto di giustizia il ritorno di papa Sísto, "che non la perdonò nemmeno a Cristo „; e s'intende così, senz' altra specificazione, Fe- 


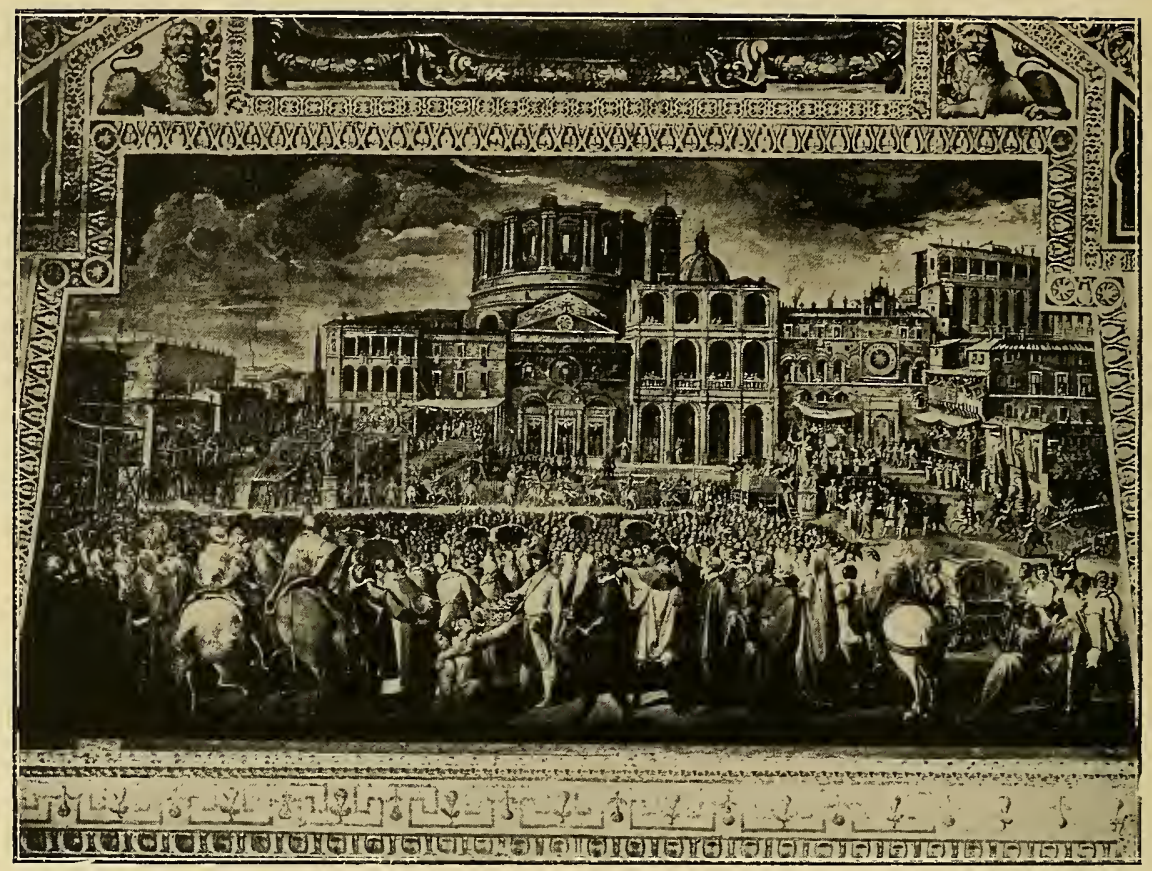

L'incoronazione di Sisto V. Affresco nella Biblioteca Vaticana.

lice Peretti di Montalto, salito al trono il 24 aprile 1585 col nome di Sisto Quinto.

Si racconta che durante il conclave egli si era finto debole $e$ infermo, strascicandosi poggiato a un bastone, per far credere che avrebbe avuto brevissima vita; ma appena ebbe messo in capo la tiara apparve d'un tratto agile ed eretto, così che il cardinal Rusticucci ebbe a dirgli: "Santissimo Padre, bedo che il pontificato è una gran medicina!" E subito, fin dai primi giorni del suo regno, mostrò la fermezza della sua mano, fece sentire che non ammetteva nessun potere al disopra di lui; nè la nobiltà, nè gli ambasciatori stranieri, nè il collegio dei cardinali. Quattro gionni dopo la sua elezione dette un terribile saggio della sua severità: due giovani, che contro le disposizioni di un decreto fino allora poco rispettato, eransi trovati con 


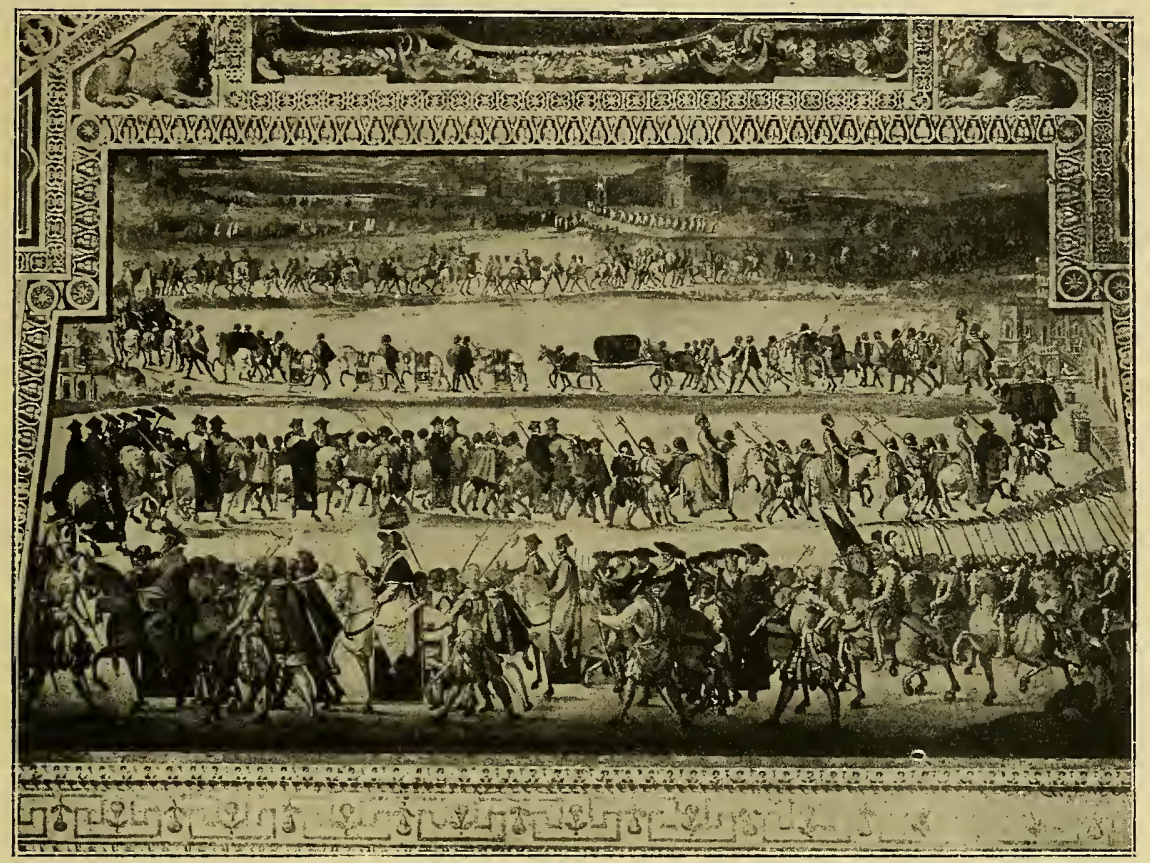

Il solenne possesso di Sisto V, con gli ambasciatori del Giappone. Affresco nella Biblioteca Vaticana.

armi in dosso, furono da lui fatti appiccare di notte, e lasciati sul patíbolo, affínchè il popolo, la mattina dopo, cominciasse a persuadersi che in Roma non era più tempo di tolleranza. Lo stato pontificio era allora infestato dai banditi, tanto più forti quanto più erano stati in passato liberi $e$ temuti: $i$ fuorusciti rubavano, saccheggiavano, uccidevano, ridendosi della Corte, dei magistrati, delle leggi. Il disordine e l'abuso regnavano dappertutto; i governatori vendevano gli uffici; nei tribunali si lamentavano angherie incredibili; i tesorieri erano infedeli; al popolo si faceva mancare il frumento; i carnevali e le feste pubbliche erano "un trofeo d'impertinenze e di dissolutezze ".

Questo era il campo aperto all'opera di papa Sisto, "lo steccato terribile, come dice un biografo, riservato alla sua autorità „. La lotta fu da lui intrapresa con fermezza e insieme 
con prudenza; il papa non volle impedire tutti gli abusi ad un tempo, ma seppe "perdonare, dissimulare, combattere con un solo per volta „.. D'accordo coi principi degli stati confinanti non lasciò ai banditi luogo di rifugio: ovunque erano inseguití e perseguitati senza quartiere, e presi, venivano messi a morte, e non valevano suppliche e intromissioni; Bologna atterrita assistè alla decapitazione di Giovanni Pepoli, della nobilissima e potente famiglia, colpevole di aver dato ospizio a un sicario. "Ricordatevi che regna Sisto " era il motto che bastava a disperdere i banditi, a fermare il coltello degli assassini; nessuno trovava scampo; nessuno otteneva perdono; tutti tremavano in presenza del papa, il quale "haveva, dice un anonimo contemporaneo, maravigliosa effícacia in ogni maniera di dire; ma quando adirato minacciava, accompagnandola con una certa sua naturale fierezza di sembiante, pareva che fulminasse ". Ristabilita la quiete all'interno dei suoi stati, Sisto rivolse la stessa energia all'attuazione dei suoi piani politici: la lotta contro il Protestantismo e la difesa contro i Turchi, continuando cosi l'opera intrapresa da Pio $\mathrm{V}$, che aveva visto il trionfo di Lepanto, e seguita da Gregorio XIII. Cercò di riguadagnare l'Inghilterra al Cattolicismo, e favori largamente l'opera dei Gesuiti per elevare barriere contro la Riforma che dilagava in Germania, e per risarcire in America e nell' Oriente estremo, le perdite che la Chiesa faceva in Occidente. Proprio quando papa Sisto sali al trono si trovava in Roma l'ambasceria dei Giapponesi, venuti a fare omaggio a Gregorio XIII; la prima della numerosa serie di missioni orientali che nel Seicento si videro tra le mura della città; il nuovo pontefíce fece ai principi del Giappone che gli prestarono obbedienza "finezze speciali ",

La severità del costume, la rigidezza dei principî relígiosi, dettero al pontífícato di Sisto Quinto quel carattere di austerità e di compostezza che fu proprio di tutto il periodo detto della Controriforma. La Chiesa, di Roma di fronte al pericolo im- 


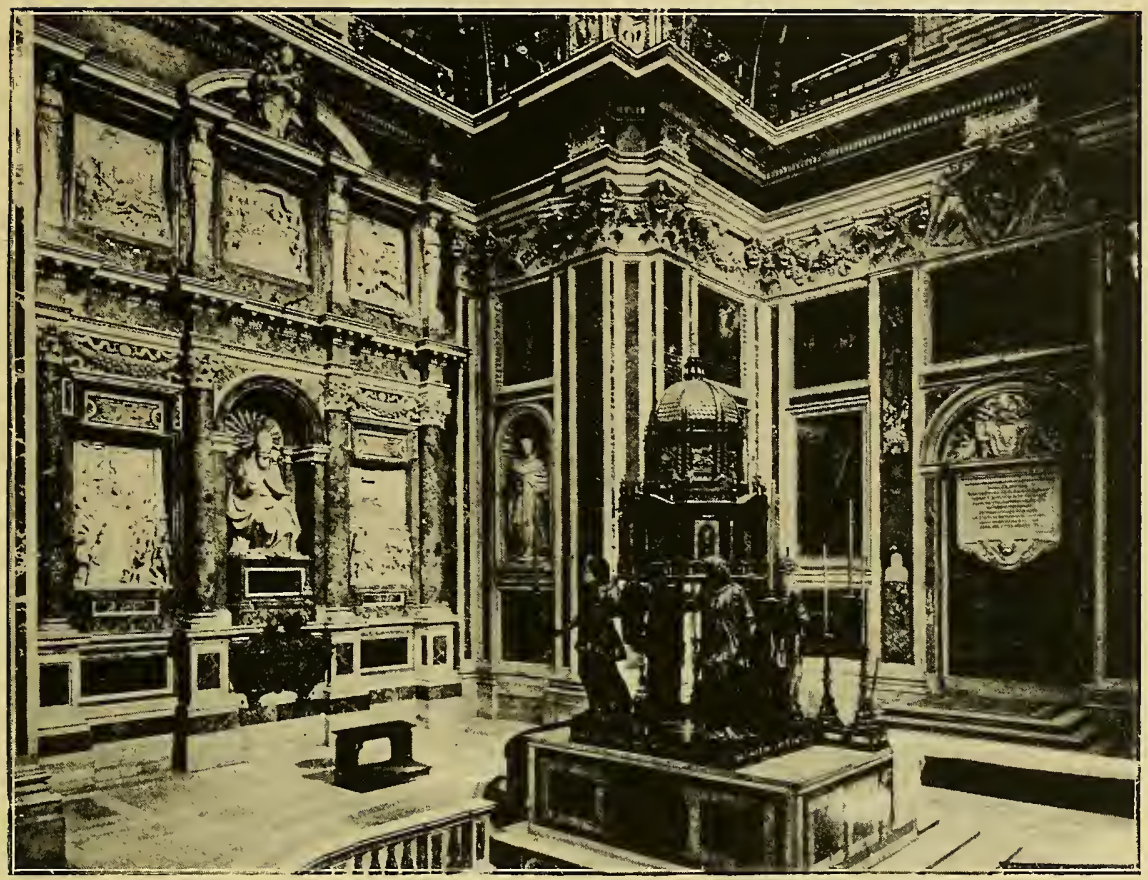

S. Maria Maggiore, la cappella Sístina di Domenico Fontana, (Fot. Alinari).

menso della riforma luterana che le sovrastava, raccolse tutte le sue forze, abbandonò ogni sfarzo esteriore, dimenticando le gioie mondane e il sensualismo paganeggiante del Rinascimento, per tornare alla rigida e pura morale cristiana; e adoperò come armi nella lotta tremenda tutte le sue risorse, tutti i mezzi di cui poteva disporre: la politica, la scuola, la predicazione, la guerra, l'arte. La poesia, la pittura, l'architettura assunsero cosi una funzione morale, insegnativa, che nel primo Cinquecento non avevano avuto; esse non si rivolsero più ai sensi, ma alle anime e alle intelligenze; la Società di Gesù si affermava in ogni campo; dettava le sue leggi anche all'arte, creando forme sue proprie, adatte all'espressione del suo pensiero, all' esplicazione del suo insegnamento. In Roma un fiorentino, venuto però adolescente nella città dei papi, Filippo Neri (1515-1595), che 
Ia Chiesa doveva elevare poi sugli altari (1622), tutto acceso di amore per i poveri e gli umili, ardente di zelo e di carità fondò (1577) la Congregazione 'dell' Oratorio per istruire gli ignoranti nei principii della dottrina cristiana, e per consolare

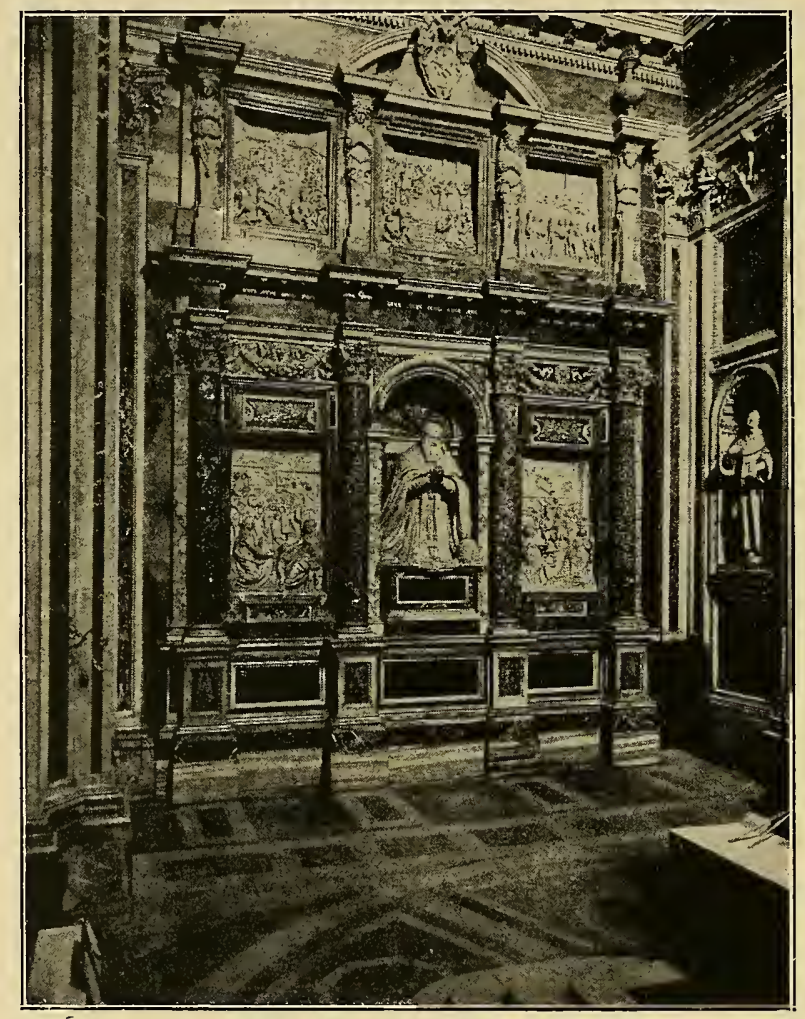

Mausoleo di Sisto V, in S. Maria Maggiore. D. Fontana.

gli infermi; e raccolse intorno a sè uomini insigni per fede $e$ per dottrina, tra $i$ quali Cesare Baronio, futuro cardinale e annalista della Chiesa. San Filippo, confessore e pastore di anime, a cui fu dato il titolo di apostolo di Roma, riuniva nel carnevale i fedeli nella sua chiesa per distoglierli dai disordini; promoveva visite agli ospedali, alle Sette Chiese, alle catacombe, 
iniziando così il culto della Roma Sotterranea; e costruiva la Chiesa Nuova di S. Maria in Vallicella, dapprincipio nuda e severa, e che solo in pieno Seicento doveva ricevere la sua splendida veste di pitture e di stucchi.

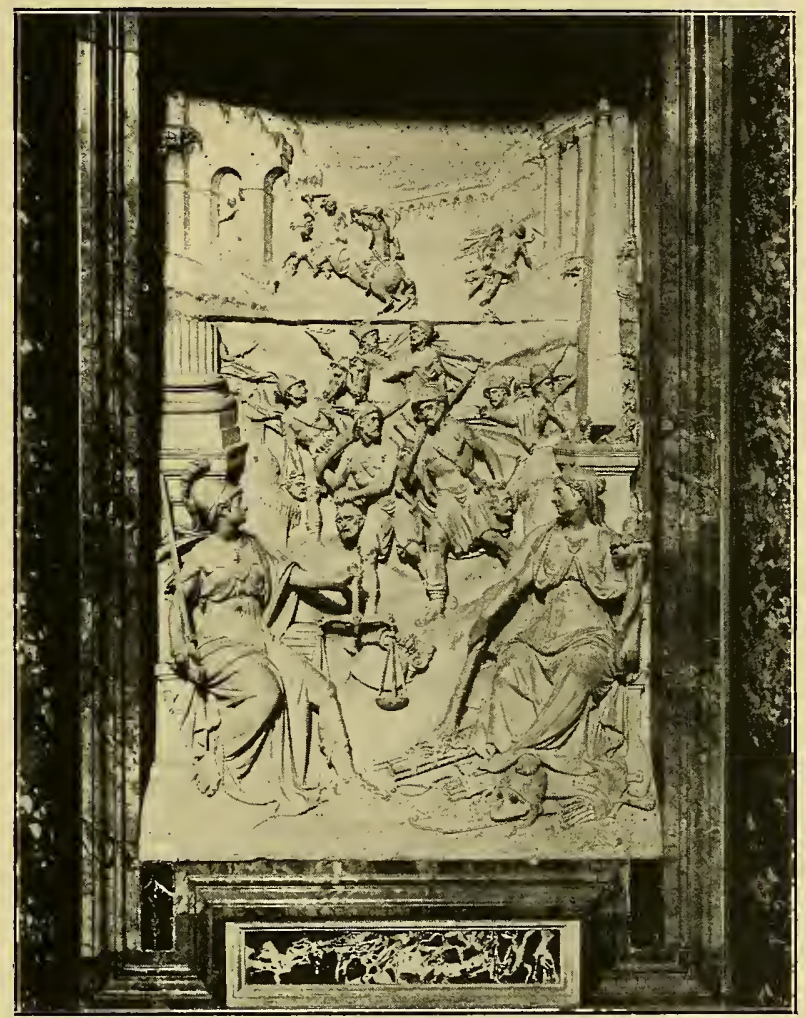

La Giustizia di papa Sisto. Rílievo di Niccolo Fiammingo

Papa Sisto, benchè tutto rivolto a mantenere i suoi sudditi in semplicità di costumi, e scrupoloso nel ristorare le pubbliche finanze, concepì ed attuò in Roma piani grandiosi di rinnovamento e di abbellimento: nato in un piccolissimo paese e da umile gente, seppe mostrare una magnificenza degna degli imperatori antichi. Già da cardinale aveva costruito sull' Esquilino 
la meravigliosa villa Montalto, con un palazzo bellissimo, adorna di statue, di marmi, di peschiere e di fontane, di chioschi e di

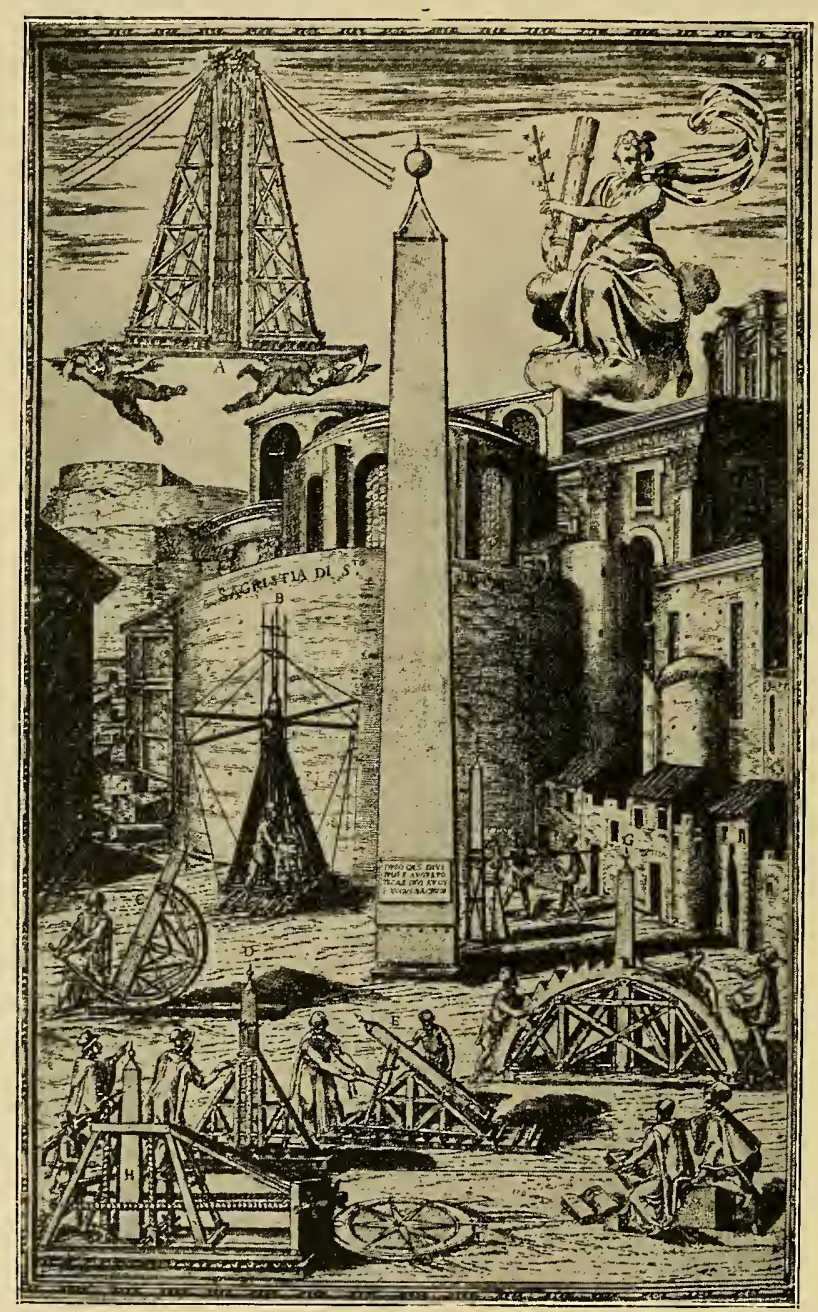

Progetti dei rivali del Fontana pel trasporto dell'Obelisco

pitture: purtroppo nel secolo scorso tutto $\mathrm{fu}$ barbaramente demolito e disperso. Per amore del natio loco, nel 1570, aveva eretto in S. Maria Maggiore, un degno mausoleo al suo con- 
terraneo Niccolò IV $(+1292)$, il benemerito restauratore della Basilica Liberiana, fino allora sepolto in terra con una semplice

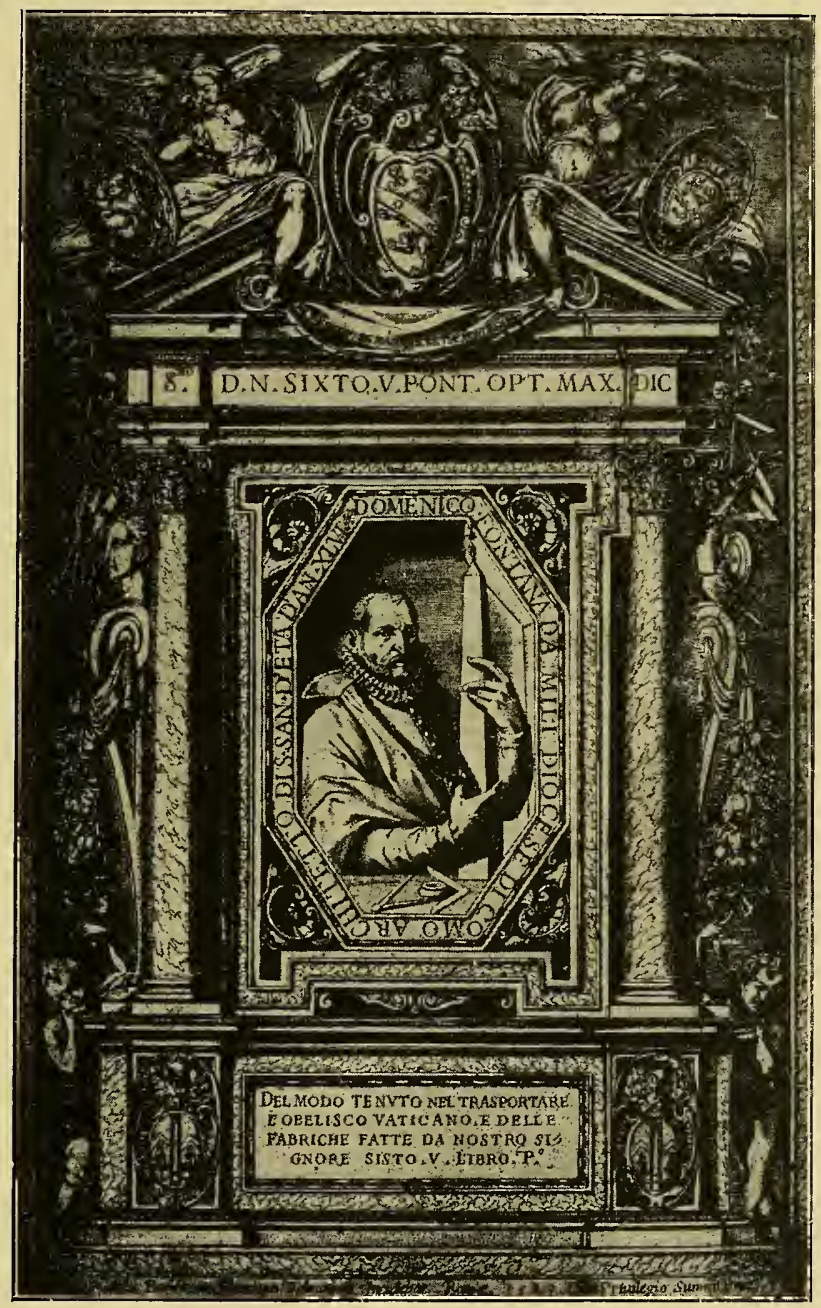

Ritratto di Domenico Fontana nel frontispizio del suo libro.

lapide: lavorarono al monumento Alessandro Cioli e Leonardo Sormani.

A Domenico Fontana, architetto (1543-1607), nato nel 
paesello di Mili sul lago di Como, aveva dato incarico fín dall'ottobre 1584, di costruire nella stessa basilica la Cappella del Presepe; e, divenuto papa, la fece condurre innanzi con larghezza di mezzi, collocando su una parete il grandioso mausoleo del suo benefattore Pio V, e dirimpetto quello proprio. Vasta come una chiesa, Ia cappella che prese poi il nome di Sistina, ha la pianta a croce greca, ed è sormontata da una svelta cupola che poggia su quattro classici arconi; nel mezzo, sotto l'altare che occupa il centro del sacello, il Fontana collocò l'antíca cappella del Presepio, trasportandola con sommo ardimento e singolare perizia, tutta intera, imbragata in una solida armatura. I due sepolcri papali che occupano le pareti laterali hanno la forma di due prospetti architettonici; son come due grandi archi trionfali a doppio ordine, ornati di altorilievi storici celebranti $i$ fasti dei due pontificati. Una policromia abbastanza vivace indica che in questo periodo (1585-90) l'arte si va trasformando: basamenti incrostati di alabastro e di africano, targhe di pietra di paragone, colonne di verde antico pallido, pilastri decorati di portasanta e di breccia, dànno ai due grandi mausolei e a tutta la cappella un aspetto nuovo e vario, che per quel tempo è inusitato. Ma tuttavia, malgrado la diversità delle tinte e la forza degli aggetti, vi è nell'insieme qualche cosa di mesto e di grave; una pesantezza e una freddezza che sono, del resto, proprie di tutte le opere del Fontana; è lo spirito severo della Controriforma che domina e contiene l'artista voglioso di novità.

Ai due grandi mausolei della Sistina ha lavorato un gruppo di scultori lombardi e fiamminghi, tutti di scarso valore, tardi seguaci della tradizione michelangiolesca, freddi e impacciati nei movimenti, goffi nel panneggiare, inesperti nello scorcio. Egidio e Niccolò fíamminghi fanno le fígure stecchite, come marionette di legno; Gio. Antonio Valsoldo, più ampio modellatore, dà ai voltí una strana espressione piagnucolosa: a lui spettano la statua 


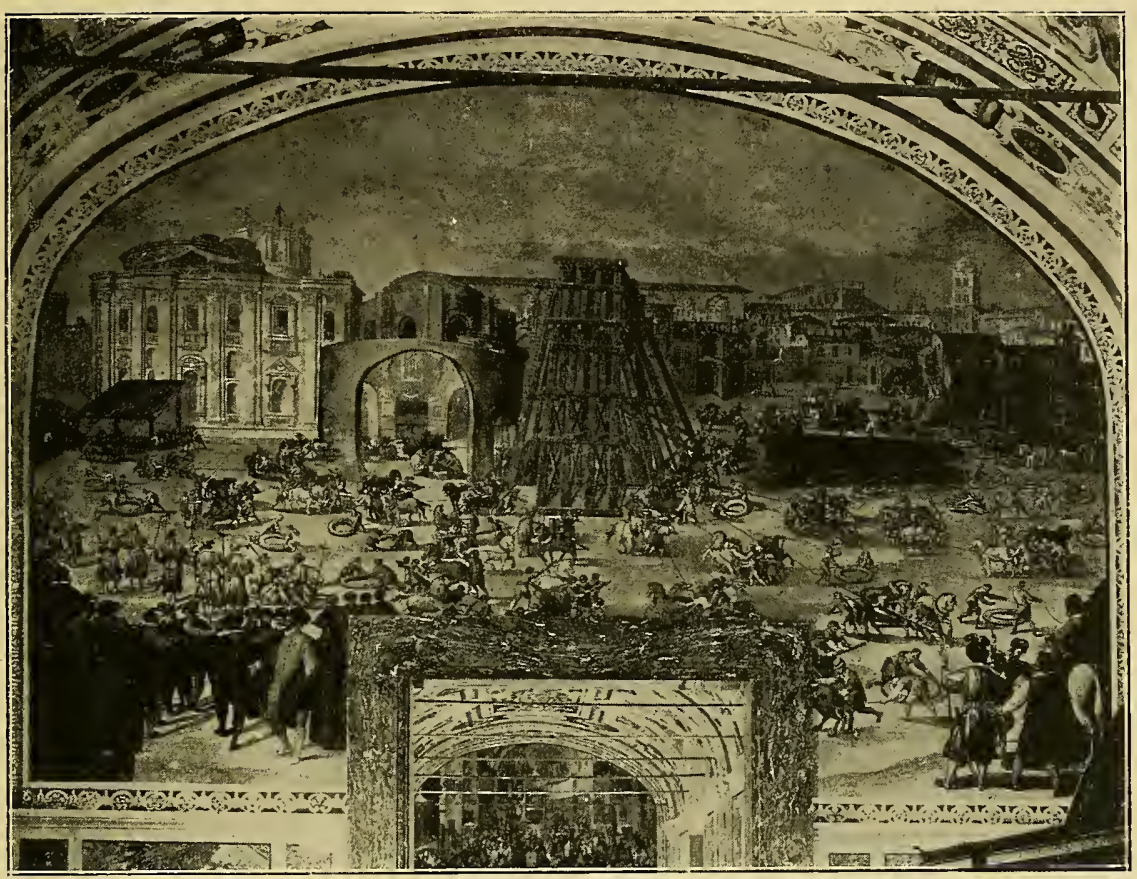

Il trasporto dell'Obelisco. Affresco nella Biblioteca Vaticana.

di Sisto V e il rilievo della Carità del Pontefice; Leonardo Sormanni più rigido e secco ha scolpito il Pio V. Goffi statuoni di santi stanno entro nicchie, e sono opera di altri mediocri scultori : Pier Paolo Olivieri, G. B. della Porta, Flaminio Vacca; nel mezzo, sull'altare, c'è un grande tabernacolo di bronzo dorato, in forma di tempio ottagono sormontato da cupola, decorato di nicchie, di statue, di smalti, e sorretto da quattro angeli di metallo dorato.

Una numerosa schiera di pittori ha affrescato le pareti con storie e fígure del Vecchio e Nuovo Testamento; son tutti maestri dappoco; manieristi che derivano da Michelangelo e da Raffaello, e credono che con quei due sommi l'arte abbia detto l'ultima parola, e che perciò dalle loro opere possano trarsi tutti gli insegnamenti senza ricorrere alla natura, senza rifarsi una preparazione 
propria; o neppure si volgono allo studio diretto di quei grandi, ma li imitano attraverso il Vasari e gli Zuccari; e si sentono capaci di dipingere venti figure in una giornata, quasi gettandole a stampa. Freddi nella composizione, sordi nel colore, sono

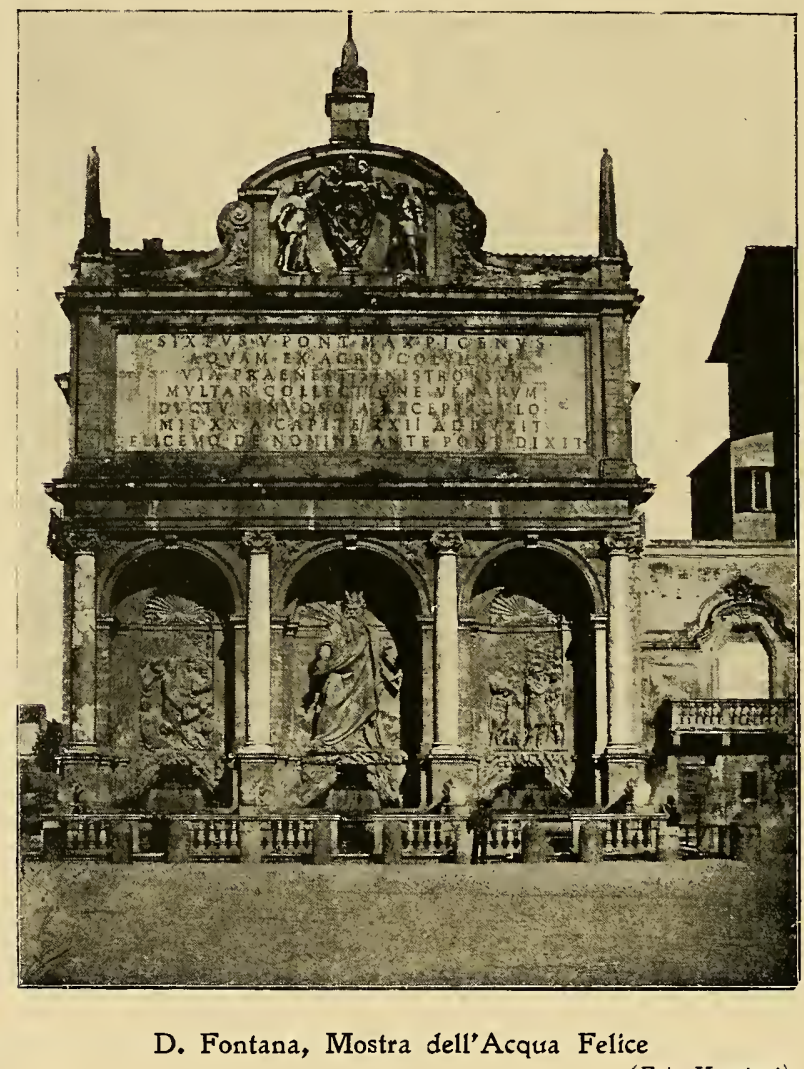

(Fot. Moscioni).

piuttosto che narratori, abili decoratori che sanno bene riempire gli spazii loro assegnati; taluni nei dipinti di genere storico hanno tuttavia una piacevole maniera di sceneggiare; la loro è un'arte cristallizzata, addormentata: la risveglierà il grido possente di Michelangelo da Caravaggio.

L'opera più famosa del pontificato di Sisto Quinto è l'ere- 
zione dell'Obelisco Vaticano, impresa che oggi farebbe sorridere, ma che per quel tempo presentava enormi difficoltà. La bella guglia monolite di granito rosso, meta dell'antico Círco Neroniano, alta venticinque metri e pesante circa un milione di libbre,

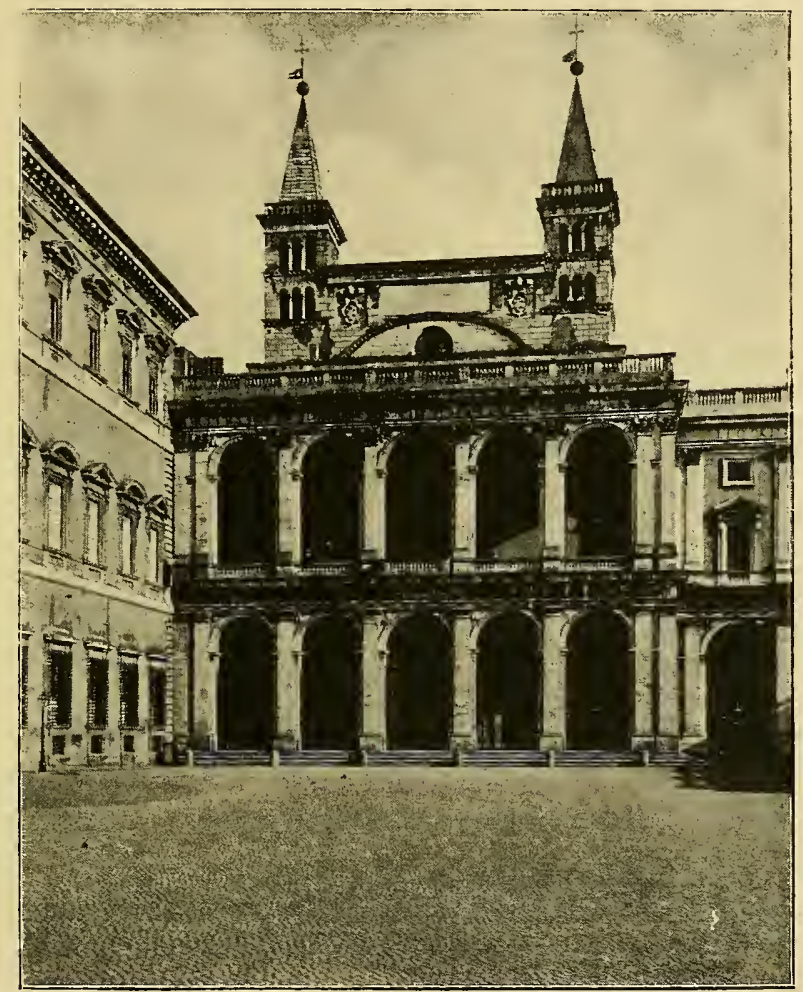

D. Fontana. Loggia della Benedizione al Laterano.

(Fot. Alinari).

era ancora in piedi presso la sagrestía della basilica di S. Pietro: considerandosi difficile il trasporto si chiamarono da ogni parte ingegneri, matematici, dotti di ogni specie, per averne consiglio. Varii furono i pareri: chi proponeva di trasportare l'obelisco diritto, chi disteso, chi poggiandolo su una ruota dentata; Bartolomeo Ammannati, spedito apposta a Roma dal Granduca di 
Toscana, chiese un anno di tempo per riflettere. Domenico Fontana presentò un piccolo modello di legno con entro una guglia di piombo, che si abbassava ed alzava facilmente, e il suo progetto fu approvato. Il maestro cominciò dal fabbricare solide fondazioni per accogliere la gran mole nel centro della piazza; poi fece preparare speciali canapi e verghe di ferro, che per la sola imbracatura della guglia raggiunsero il peso di quarantamila libbre; da Nettuno sí portavano travi di legno così grandi che occorrevano per ognuna sette coppie di bufali. Costruito il castello, foderata e cerchiata la guglia, messi a posto i quaranta argani, il 30 aprile 1586 si iniziò l'operazione. Il Fontana ricevuta la benedizione papale entrò fíducioso nel recinto, ma aveva fatto segretamente preparare $i$ cavalli, per fuggire 1 'ira di Sisto in caso di qualche accidente. Un editto minacciava di morte chiunque osasse di penetrare entro la piazza o di fare il più piccolo rumore, e la forca era rizzata li presso; nessuno fiatava; popolo, nobili, cardinali, erano tutti intenti e trepidanti. Ed ecco che al segnale della tromba $i$ novecento operai $e$ i settantacinque cavalli si mettono in moto: "nel voltar delle ruote, scrive un testimonio dell' impressionante spettacolo, si sentiva tanto strepito e rumore, che pareva la terra si aprisse di sotto e tremasse il cielo di sopra „” Ma il miracolo era compiuto; la mole si era sollevata; tutte le campane di Roma suonarono a festa; da Castel Sant'Angelo si spararono le artiglierie. Il 7 maggio la guglia fu calata orizzontalmente; sospese le operazioni per il gran caldo, il 10 settembre dopo implorato di nuovo l'aiuto divino, si riprese l'opera, con centoquaranta cavalli e ottocento uomini, e mentre l'obelisco si posava sul suo piedestallo tra suoni di trombe e di tamburi, fece l'entrata solenne da porta San Pietro l'illustrissimo Ambasciatore del $\mathrm{Re}$ di Francia, che veniva a rendere la solita ubbidienza al pontefice. Sull'alto della guglia si piantò la croce di bronzo, e nel basamento si incisero varie epigrafi: Ecce crux domini, fugite partes adversae! E a nessuno pareva strano che l'austero 
papa Peretti, per sollevare in alto la Croce, si dovesse servire di una guglia presa a prestito dell'antichità pagana! Il gran rumore fatto intorno a quest'opera è pure un indizio di manierismo ar-

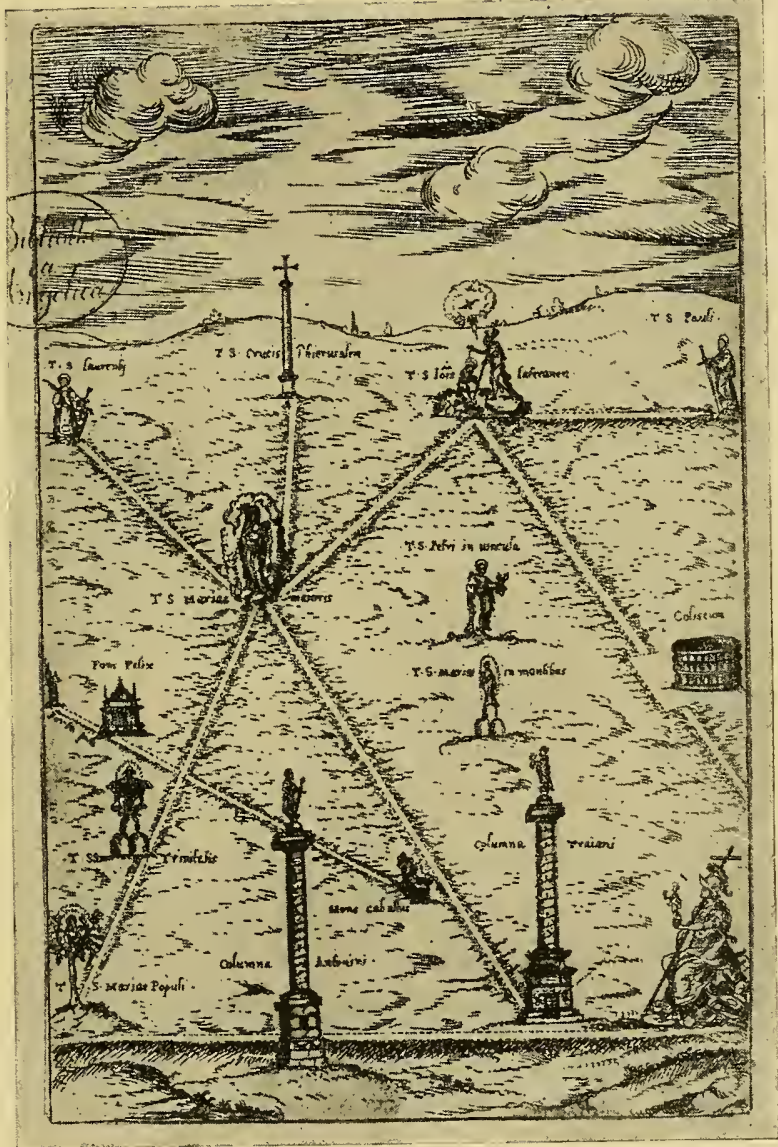

Il piano regolatore di Sisto V. (Incisione dal Bordino).

tistico, che fa più esaltare la bravura tecnica che la bellezza; perchè è forza qui dar ragione a Francesco Milizia, il critico neoclassico dispregiatore del barocco, quella guglia è insipida, nè le aggiunge pregio il basamento così magro e sottíle. 
Domenico Fontana fu creato cavaliere dello speron d'oro $e$ nobile romano, ed ebbe una pensione di duemila scudi, più cinquemila scudi d'oro, e tutto il materiale impiegato nell'opera, che venne stimato ventimila scudi. Tra i suoi aituti c'era un suo nipote, giovane architetto di trent' anni, allora sconosciuto, che più tardi doveva compiere un lavoro grandioso sulla stessa piazza: Carlo Maderno, che molti anni dopo si vantava di questa collaborazione, facendone incidere il ricordo sulla tomba che da vivo si preparò; egli aiutò pure lo zio nell'erezione degli obelischi di S. Maria Maggiore (1587), di S. Giovanni (1588) e di piazza del Popolo (1589), tutti dovuti alla munificenza di papa Sisto.

Nell'anno stesso della sua elevazione al trono, papa Peretti fece intraprendere un'opera che fu utilissima alla città; la condotta dell'acqua, che da lui fu detta Felice, da una località vicina al paesello della Colonna, con un acquedotto lungo ventidue miglia. Anche in questo lavoro impiegò il suo prediletto Domenico Fontana, che disegnò pure la mostra in piazza di Termini, (oggi S. Bernardo). Questa ha la forma di un prospetto, con tre grandi nicchie sormontate da un alto attico in cui è incisa l'epigrafe; sotto la nicchia centrale sta il Mosè di Prospero Bresciano; ai latí le storie di Aronne e di Gedeone di G. B. della Porta, celebre restauratore di anticaglie, e di Flaminio Vacca; due altorilievi imitanti quelli degli archi trionfali romani. La statua del Mosè è cosa quanto mai infelice, tozza, affagottata, pesante: la ragione della cattiva riuscita $\mathrm{fu}$, secondo il biografo degli artisti del Seicento, Giovanni Baglione, che Prospero Ia "volse lavorare colcato in terra, dove egli non poteva scorgere le vedute e le alterationi dei siti; e con tutto che fusse avvertito dagli amici punto non dava lor fede. Ed in quella statua perdè egli tutto 1 'honore che aveasi acquistato per li tempi andati in tante e si nobili fatiche. Prospero nondimeno voleva con grand'ostinatione a tutti mostrare che quella statua era proportionata e bella, ma finalmente scorgendo che ciasche- 


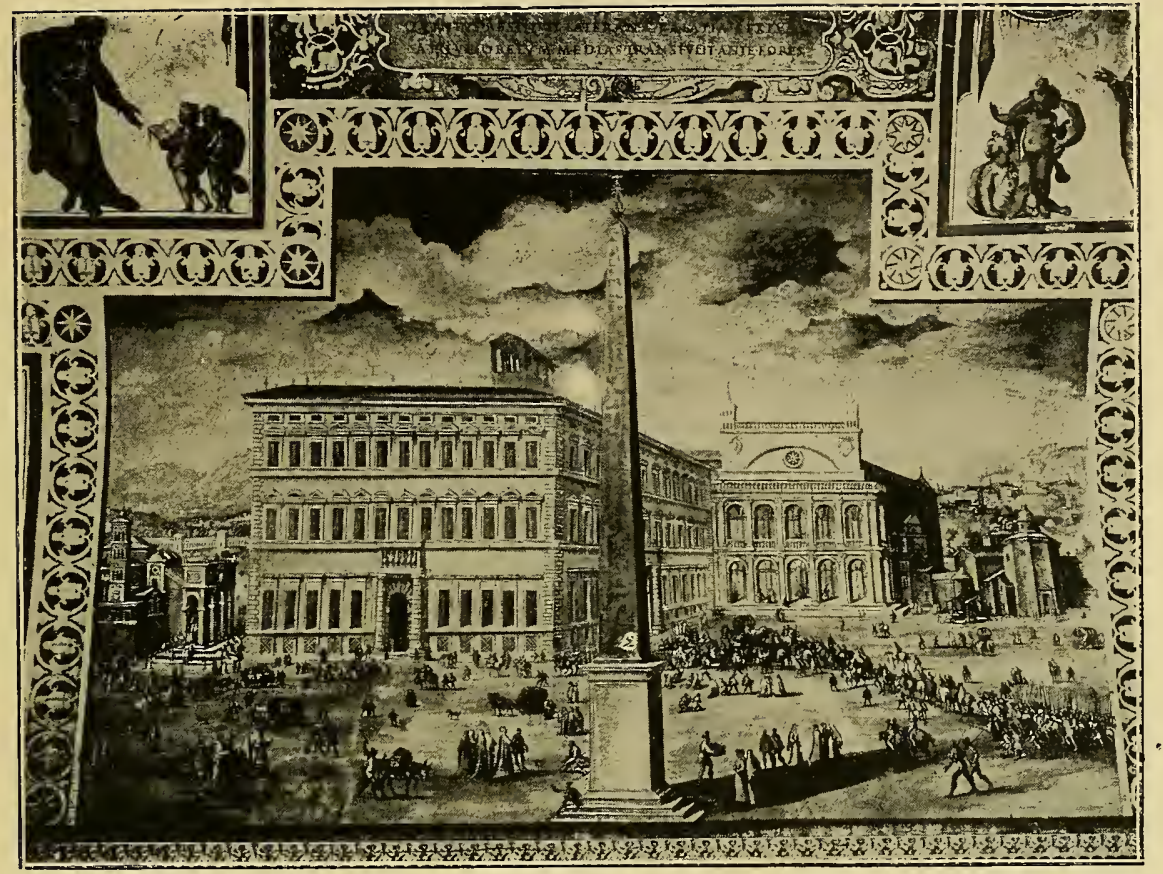

Le fabbriche del Laterano elevate dal Fontana. Affresco nella Biblioteca Vatícana.

duno ne diceva male, di si fatta maniera accorossi che gli venne un humore malinconico, il quale atterrollo et in breve il mandò all’altra vita „,. In verità, prima d'allora, Prospero Bresciano avea eseguito lavori assai buoni, specialmente di stucco, tra i quali gli elegantissimi angioli che reggono torcieri nella cappella Paolina in Vaticano.

Beneficata la città con la condotta dell'Acqua Felice, volle anche papa Sisto migliorare le condizioni della viabilità, specialmente dell'Esquilino, allora quasi disabitato e messo a vigne: aprì le strade da Trinità dei Montí a S. Maria Maggiore, e da questa a $\mathrm{S}$. Croce in Gerusalemme, e quelle da S. Giovanni al Colosseo, dal Quirinale a Porta Pia, dal Viminale al Foro Traiano; e per invogliare $i$ cittadini a fabbricare in quei luoghi ove le basiliche cristiane sorgevano quasi in un deserto, concesse 
privilegi ed esenzioni dalle imposte. Così Roma si andava ripopolando, e vi accorrevano e vi si stabilivano forestieri da ogni parte: si calcola che la popolazione sotto il pontificato di Sisto salisse da 45,000 a 100,000 abitanti.

Speciali cure rivolse il papa al gruppo di fabbriche del Laterano, sempre valendosi dell'opera del suo prediletto Fontana: costrui il portico laterale con la Loggia della Benedizione (1588), di ordine dorico il primo e corinzio la seconda, e fabbricò poi il palazzo vicino, grandiosa mole di impeccabile eleganza, ma un po' fredda; e la Scala Santa. Son queste le opere principali dell'architetto lombardo, che ci dànno la misura esatta del suo valore artistico: è un maestro dotato di larghezza di concezione, che pone una sobria ricercatezza nei particolari, ma è troppo legato alle rigide regole del Vignola, e quindi riesce sempre grave e severo; non sa dar vita e movimento alle grandi masse, e non raggiunge mai le eleganze squisite di Giacomo della Porta suo contemporaneo. A questo artista toccò il tremendo incarico, datogli da Sisto Quinto, di elevare la cupola vaticana che Michelangelo avea lasciato incompiuta, anzi neppure iniziata nella sua parte più difficile, perchè alla sua morte solo il tamburo era costruito. Giacomo della Porta, che il Baglione dice romano, ma che probabilmente era d'origine lombarda, si attenne al modello lasciato dal Buonarroti, non però strettamente; egli fece la cupola piì grande e piì acuta e dette alla lanterna maggiore snellezza; il gigante del Rinascimento si avvícinava di più alle calotte dei monumenti antichi; il maestro della Controriforma si volse piuttosto al tipo delle cattedrali gotiche. L'opera immensa fu iniziata ai quindici di luglio 1588 e finita ventidue mesi dopo nel maggio del 1590, con la collaborazione di Domenico Fontana; e testimonia anch'essa della abilità tecnica degli architetti di questo periodo, che superarono assai quelli del Rinascimento. Il cupolone, così il popolo lo chiama, divenuto il monumento piì caratteristico e rappresentativo della città, sfida impavido i 


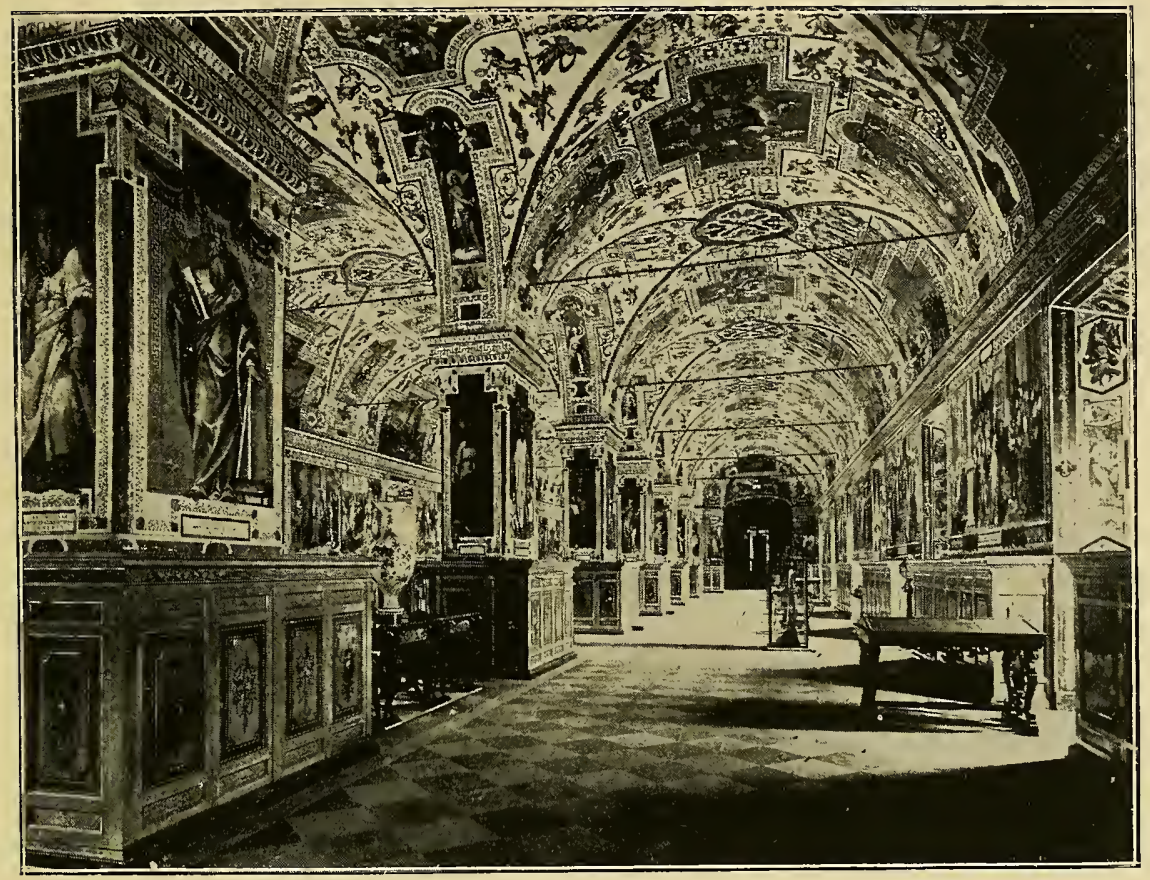

Il salone della Biblioteca Vaticana, architettura di Domenico Fontana.

secoli, e durerà nel tempo lontano, poichè gli uomini che l'hanno costruito, come i Romani antichi, sapevano lavorare per l'eternità. Oltre all'erezione dell'obelisco e della cupola, papa Sisto provvide ad altri abbellimentí del Vaticano, principalmente alla costruzione del palazzo verso la piazza, e della nuova Biblioteca. Per questa il Fontana elevò (1588) un intero braccio di fabbricato a metà del cortíle di Belvedere, guastando così la mírabile architettura di Bramante, e occupò tutto il primo piano della nuova costruzione con un'unica vastissima sala, divisa in due navi da una fíla di pilastri sorreggenti le vôlte a crociera: pareti, pilastri e vôlte son tutti decorati di affreschi ornamentali (le così dette grottesche) di stile zuccaresco, e di quadri storici, con le imprese di Sisto V, le storie dei Concilii e delle Librerie antiche, con variati emblemi. Cesare Nebbia 
orvietano e Giovanni Guerra modenese, furono i pittori che diressero tutta l'opera di decorazione; essi disegnarono le storie e gli ornati, e una schiera di aiutí le colorirono rapidamente, ríuscendo cosi a compiere l'immane lavoro in breve tempo, naturalmente a scapito della buona riuscita. Qui siamo di fronte all'espressione più caratteristica del manierismo facilone che imperava nella pittura sullo scorcio del secolo; l'insieme è tuttavia gaio e festoso; i dipinti che rappresentano la Roma del tempo hanno poi un gran valore per la storia e la topografía. Un quadro murale, ad olio, opera di Pietro Fachetti mantovano, ritrattista di moda, figura papa Sisto in trono assistito dai cardinali Alessandro Peretti suo pronipote e Antonio Caraffa bibliotecario di Santa Chiesa e dal principino Michele Peretti, fanciullo di dodici anni, ai quali il cavaliere Fontana genuflesso mostra i piani della libreria delineati su un foglio, in presenza del Custode di essa e di vari cortigiani.

Così la biblioteca preziosa fondata da Niccolò $\mathrm{V}$ e accresciuta da Sisto IV, trovava un mecenate magnifico in papa $\mathrm{Pe}-$ retti, che non era uomo indotto, e da cardinale aveva iniziato l'edizione delle opere di Sant'Ambrogio; egli sentiva l'importanza che gli studi storici e teologici avevano come arma difensiva contro gli agguerriti dottori luterani, e accanto alla Libreria fondò una Stamperia per provvedere alla pubblicazione delle opere dei Santi Padri, e alla diffusione della fede cattolica; da essa uscì nel 1590 la celebre edizione della Bíbbia Vulgata a cui collaborò lo stesso pontefice.

Numerosissime sono le altre opere che Roma deve alla munificenza di papa Peretti; egli costrui l'edificio pei poveri mendicanti a Ponte Sisto, seguitò il palazzo di Montecavallo, fece fare le fontane della Madonna dei Monti e dell'Aracoeli, il Lavatoio di Termini, il purgo delle lane a Fontana di Trevi, la porta della Cancelleria. Per tutti questi lavori come risulta da un Libro del signor cav. Domenico Fontana architetto obe 
sono notate tutte le spese fatte nelle fabbriche inalzate dalla gloriosa memoria di papa Sisto $V$ dall'anno 1585 al 1589. che si conserva nell'Archivio di Stato di Roma, furono spesi scudi $1,002,245,151,1 / 2$.

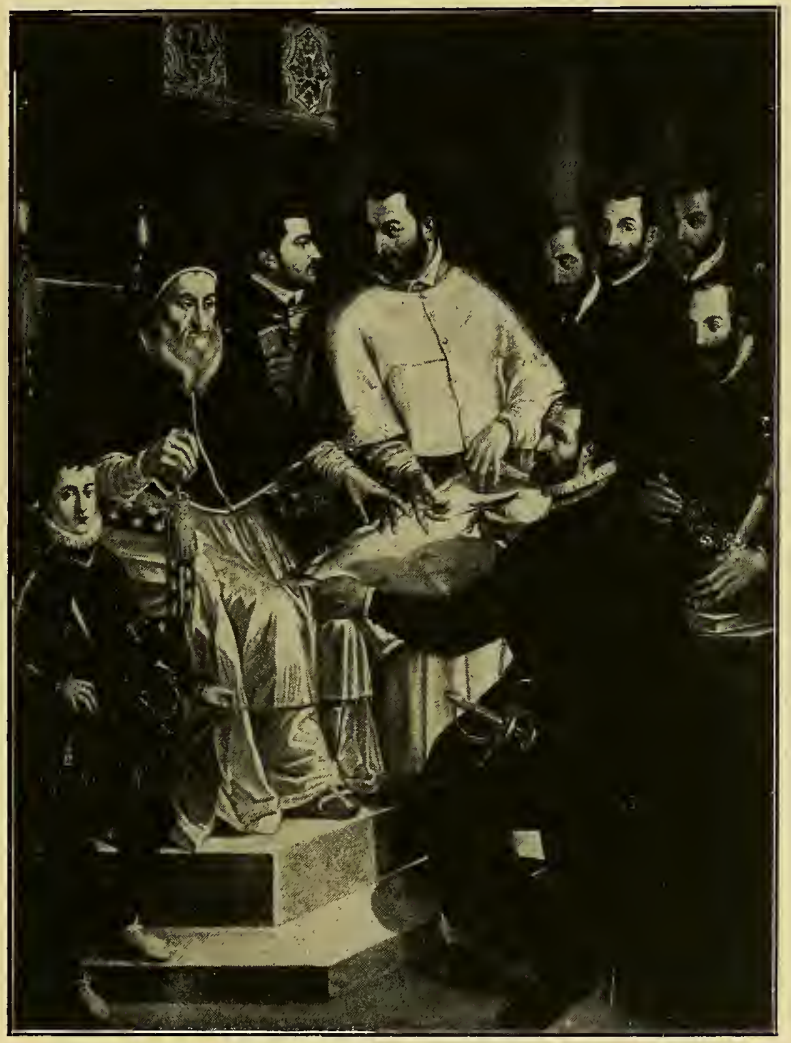

Domenico Fontana presenta a Sisto V la pianta della Biblioteca. Dipinto nella Biblioteca Vaticana.

Verso i monumenti della Roma pagana, papa Sisto non ebbe grande pietà; se ne servì quando gli accomodava per abbellire le piazze della città nuova, come fece con gli obelischi; restaurò la coIonna Traiana e quella creduta allora l'Antonina, per collocare su di esse le grandi statue di bronzo di S. Pietro e S. Paolo, e fece 
pure riparare i colossi del Quirinale per decorare la piazza innanzi al nuovo palazzo papale, ma voleva trasformare il Colosseo in lanificio, e fece abbattere il Settizonio di Settimio Severo, edifizio a piì ordini di colonnati che sorgeva, ancora abbastanza ben conservato, a ridosso del Palatíno verso il Círco Massimo; il Velabro e il sepolcro di Cecilia Metella dei quali era decretata la distruzione, furono salvi per le preghiere dei cardinali Santoro e Colonna. A costoro il papa, pur accogliendone le rimostranze, rispondeva "ch'egli voleva tor via le antichità deformi con ristorare quelle che ne avevano bisogno! ,"

Per dimostrare a papa Peretti la sua gratitudine per i molti benefici ricevuti dalla città, il Senato romano gli eresse nel 1587 una statua bronzea che si collocò in Campidoglio nel palazzo dei Conservatori, ove rimase sino alla fine del Settecento, quando in uno dei frequenti sommovimenti popolari fu distrutta. Ne era autore Taddeo Landini, l'elegantissimo scultore della fontana delle Tartarughe, che ne fu pagato con milletrecento scudi, somma che egli trovò insufficiente. Della statua, lodatissima dal Baglione, ci restano solo un disegno ed un' incisione poco felice del Greuter. Poco mancò che alla morte del papa il popolaccio non la facesse in pezzi, come alcuni anni prima aveva atterrato il simulacro di Paolo IV, trascinandolo a ludibrio per le vie di Roma!

Sisto Quinto non $f u$ immune dalla debolezza che tutti i papi del suo tempo, e i suoi successori, ebbero nel largheggiare eccessivamente in favori verso $i$ parenti, usando $i$ denari della Chiesa; peccò come tutti di nepotismo, e perciò incorse nelle feroci accuse che uno scrittore, parziale per quanto arguto, Gregorio Leti scaglío contro tale piaga del pontificato, nel suo libro Del Nepotísmo, stampato alla macchía. Beneficò splendidamente Ia sorella Cammilla, e la nipote Maria Felice Peretti ne' Damasceni, e creò cardinale il fíglio di lei Alessandro quattordicenne, e Governatore di Roma l'altro figlio Felice di otto anni. Una volta per sempre dobbiamo però osservare che se il nepotismo può 


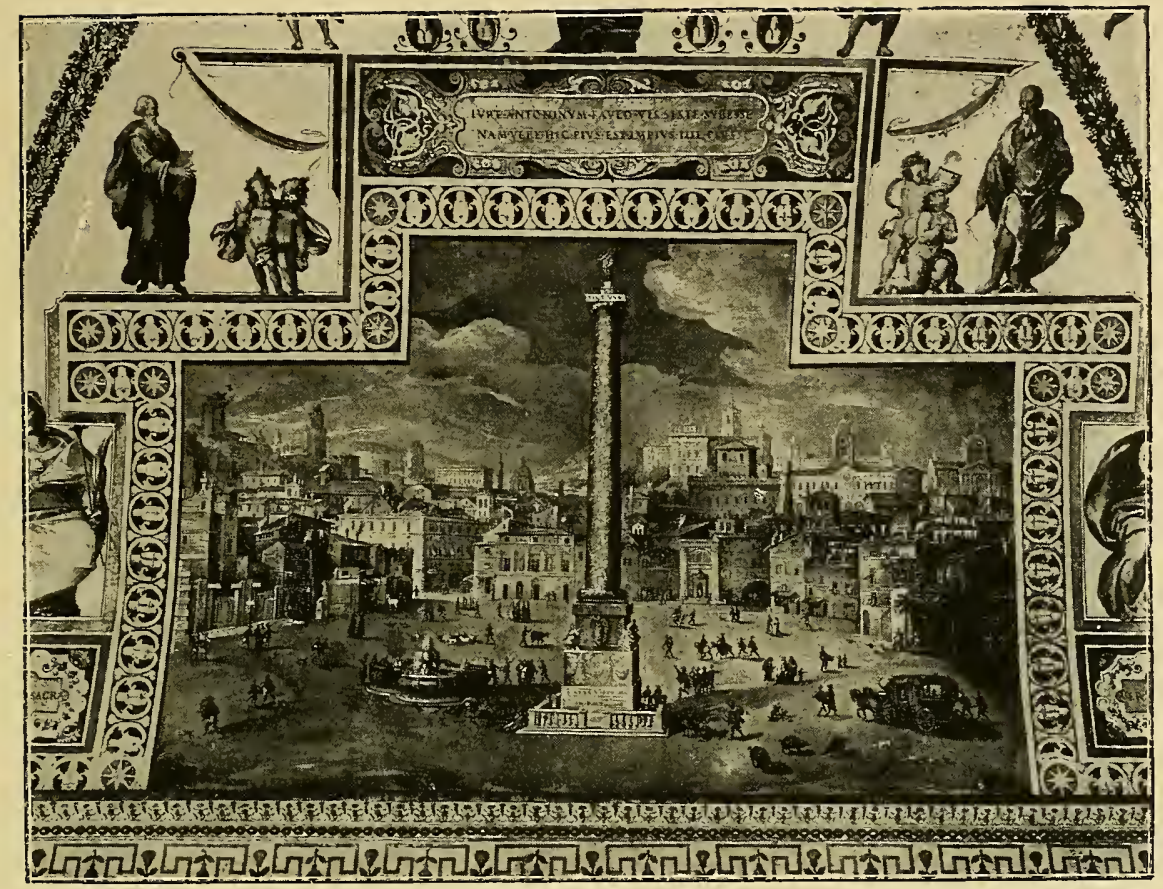

Piazza Colonna al tempo dí Sisto V. Affresco nella Bíblioteca Vaticana.

apparire condannevole dal punto di vista morale, (per quanto occorra riportarsi allo spirito dei tempi), la storia dell' arte e della coltura molto gli debbono: senza di esso il cardinal Scipione Borghese non avrebbe potuto dar vita a tante opere mirabili e raccogliere tanti preziosi tesori artistici, nè le famiglie Barberini, Pamfili, Chigi, avrebbero formato le famose collezioni che ancor oggi il mondo ci invidia.

Malgrado la fermezza della sua mano, papa Sisto ebbe a provare per la sua politica, specialmente dalla Francia, non pochi contrasti, dai quali la sua salute $\mathrm{fu}$ scossa; assalito dalla febbre nell'agosto del 1590, nè volendola curare " perchè era solito rispondere a' Periti come già dir solea l'imperatore Vespasiano che il Principe deve morire in piedi ", peggiorò rapidamente. Un anonimo contemporaneo così narra la sua fine: "Sabato sera 
Ia febbre di Sua Beatitudine si convertì di terzana in continua. Et in oltre la Domenica mattina li vennero quattro accídenti, et perciò fu conosciuto mortale, et il giorno dopo pranzo in fretta mandò per li cardinali Montalto (súo nípote), Pinelli et Giustiniani, a' quali si crede desse qualche avvertimento, o forse fecesi promettere qualche cosa..... e finalmente Lunedi a hore 22 passò di questa a miglior vita ,"

Con gran pompa la salma fu trasportatata in S. Maria Maggiore, ove il 27 agosto si celebrarono solenni esequie. "Si vide tutta la chiesa coperta di bruno e d'ogni intorno sfavillante di faci, e nel mezzo della medesima fu alzato un grande e pomposo catafalco in forma di bellissimo tempio „. Di esso ci restano una incisione, e una descrizione particolareggiata di Baldo Catani; era formato da un basamento a cui si ascendeva per otto gradini di finto marmo nero, sul quale sorgeva una rotonda ad arcate divise da colonne binate, avanti alle quali eran collocate le figure allegoriche della Religione, dell'Autorità Pontificia, della Sicurezza, della Magnificenza, della Providenza, della Fede. Sulla trabeazione eran riprodotte le colonne Traiana e Antonina e i quattro obelischi innalzati da Sisto; una gran cupola, a similitudine di quella vaticana, sormontava la fabbrica posticcia, ed era tutta illuminata da ceri piantati nei costoloni, e portava nel tamburo figurati gli edifici più insigni elevati da papa $\mathrm{Pe}$ retti; il tutto arricchito di vivaci colori, che imitavano il marmo verde, la portasanta, il bronzo, l'oro. Un gran letto mortorio sostenuto da leoni di finto bronzo e coperto di una coltre di broccato, stava nel mezzo del basamento, e quattro figure allegoriche gli sedevano intorno, simboleggianti la Giustizia, la Prudenza, la Temperanza e la Fortezza; e dappertutto nelle basi, nel fregio, nelle cornici eran dipinte imprese e iscrizioni dedicatorie, elementi araldici dello stemma di Sisto, leoni, rami di pere, monti, stelle. Questa complicata costruzione di legno, di tela, di stucco e di cartapesta, fu fatta a spese del cardinal Montalto, 
Alessandro Peretti nipote del papa; ne dette il disegno il Fontana, assistito da Carlo Maderno, e vi lavorarono Giovanni Guerra e Prospero Bresciano. Fu l'ultima opera che Roma ammirò di Domenico Fontana: poco tempo dopo, mentre era occu-

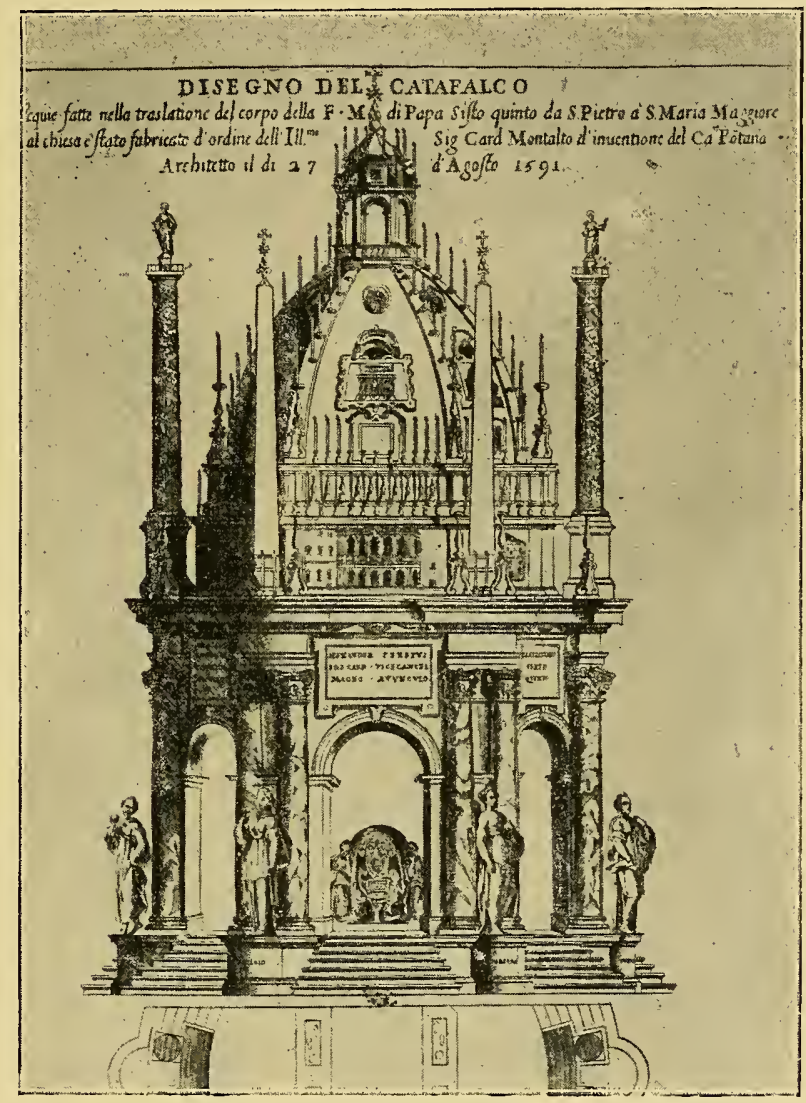

Il catafalco di Sisto V, invenzione del Cav. Fontana.

pato alla costruzione del ponte sul Tevere, al Borghetto, per accuse calunniose mossegli dai suoi rivali, fu da Clemente VIII esonerato dalla carica di architetto papale, $e$ invitato a render conto dei molti denari spesi nelle fabbriche di Sisto. Allora si trasferì a Napoli, accolto con onore da quel Vicerè; e nominato ar- 
chitetto regio, esegui importantissimi lavori: apri la strada di Chiaia, eresse la Fontana Medina, intraprese la fabbrica del Palazzo Reale. Morì di sessantaquattro anni, nel 1607, e fu sepolto nella chiesa di S. Anna della sua nazione lombarda. A Napoli ove imperava il gusto del trito e del sovraccarico, importatovi dalla Spagna, introdusse le forme grandiose dell'arte romana, ed ebbe a collaboratori una schiera numerosa di artisti attratti dal fasto della corte viceregale. Alla Fontana Medina, ricca di statue e di ornati, lavorò tra gli altri uno scultore fiorentino, Pietro Bernini, che proprio in quel torno di tempo, da Angelica Galante napoletana, ebbe, il 7 dicembre 1598, un fígliuolo a cui impose il nome di Gian Lorenzo.

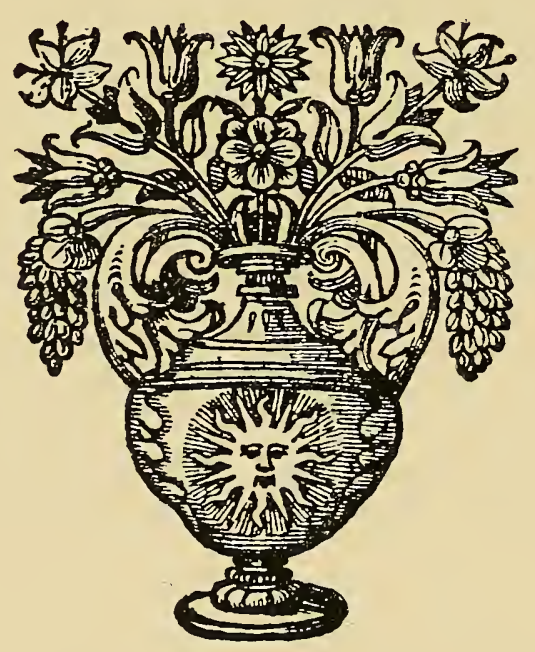




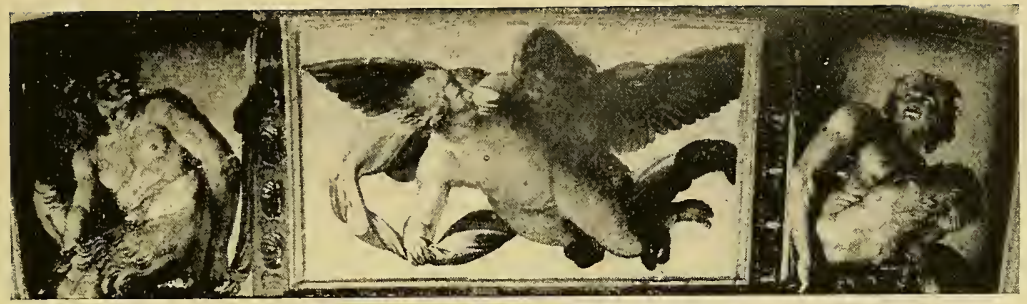

CAPITOLO SECONDO

\section{LA GALLERIA FARNESE}

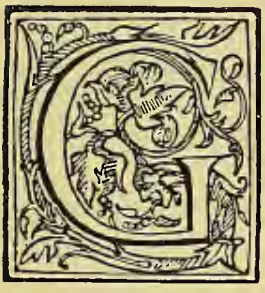

iacomo della Porta, l'elegante architetto e imprenditore che tanto operò in Roma nell'ultimo trentennio del secolo XVI, aveva nel 1589 dato l'ultima mano a una delle più belle fabbriche del Rinascimento, rimasta incompiuta, il palazzo Farnese di Antonio da Sangallo e di Michelangelo. Due anni dopo il duca Odoardo Farnese veniva, appena diciassettenne, elevato alla porpora, e trasferitosi perciò da Parma a Roma, andava ad abitare nel palazzo di famiglia, che il suo predecessore, il celebre cardinale Alessandro, nipote di Paolo III, morto nel 1589, non aveva abitato mai. Il giovane porporato volle completare il sontuoso edifizio, e pensò di far decorare la grande sala del palazzo con le imprese del glorioso suo padre Alessandro. Il 21 febbraio 1595 egli scriveva infatti al fratello duca di Parma e Piacenza: "Ho risoluto di fare dipingere la sala grande di questo palazzo dell' imprese del signor duca nostro padre di gloriosa memoria dalli pittori Carraccioli bolognesi, quali ho perciò condotti ai miei servitii et fatti venire a Roma alcuni mesi or sono,... 


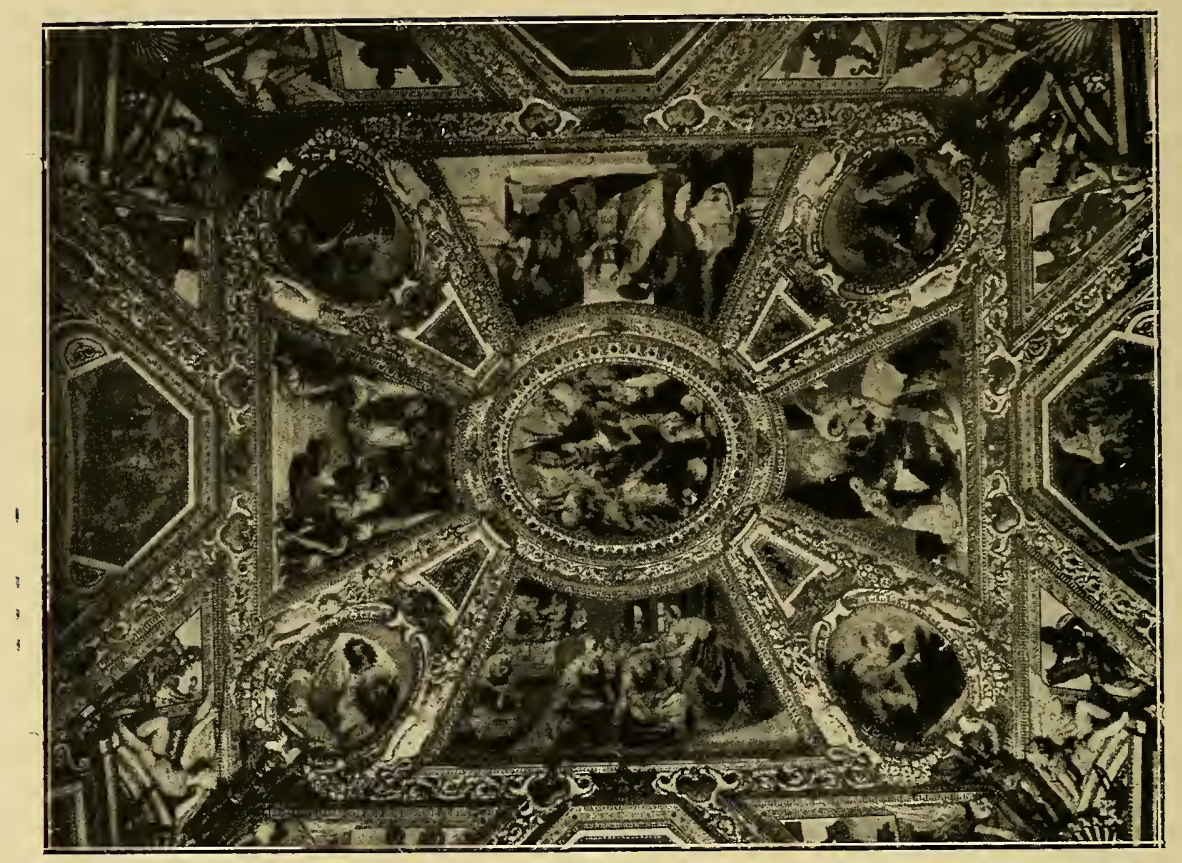

Affreschí di Pasquale Catí nella cappella del Sacramento a S. Maria in Trastevere

(Fot. Alinarit).

A Roma operavano in quel torno di tempo molti pittori, alcuni dei quali salití in grande fama, come Federico Zuccaro, urbinate, decoratore ufficiale della corte pontificia, ingegno versatile, abilissimo tecnico, facile compositore, che aveva viaggiato in Spagna, nelle Fiandre, in Inghilterra, ovunque arricchendo di note nuove e disparate la sua eclettica tavolozza; Antonio Tempesta fiorentino, convenzionale nella composizione, ma piacevole nel colorito; Pellegrino Tibaldi bolognese, che pure era stato in Spagna e dipingeva figure gigantesche ispirandosi a Michelangelo; Giuseppe Cesari, detto il cavalier d'Arpino, grande fa-presto, carico di commissioni, abile frescante, ma freddo nel colore, manierista impenitente che doveva continuare in pieno Seicento le stanche forme zuccaresche. E accanto a questi maggiori una folla di seguaci, $i$ cui nomi il Baglione e $i$ docu- 


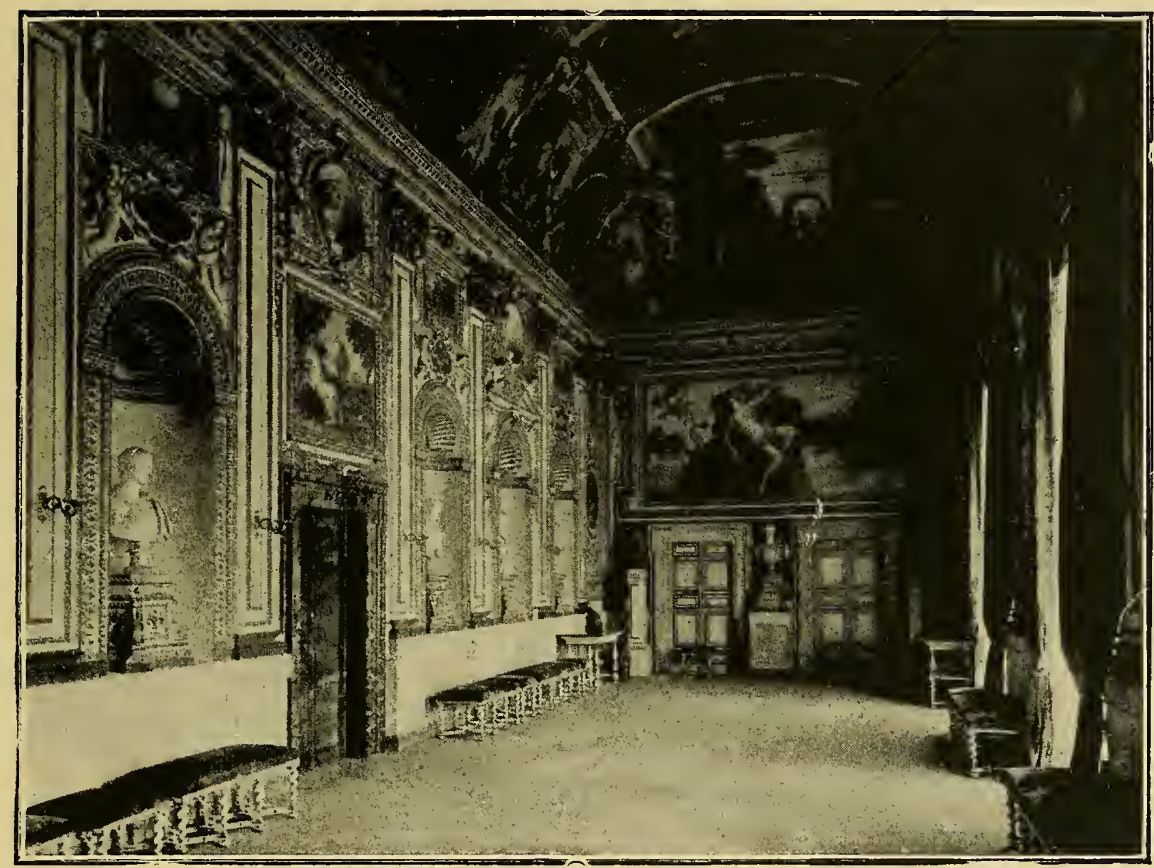

La Galleria dei Carracci nel Palazzo Farnese.

(Fot. Alinari).

menti di archivio ci fanno conoscere a centinaia, e di cui le chiese di Roma conservano ancora le scombiccherature: Pasquale Cati, Paris Nogari, il Pomarancio, il Lelli, il Cossi, il Nanni, il Marchetti, il Viola e tanti altri.

Al giovane cardinale, educato a Parma ove ancora era viva la tradizione correggesca, questi maestri, che sebbene venuti da cosi diverse parti d'Italia, avevano fuso le caratteristiche loro personali e regionali nel crogiuolo del manierismo romano, non potevano certo piacere; ed ecco perchè egli pensò di chiamare i Carracci bolognesi, la cui fama si era sparsa in tutta l'Emilia, e che rappresentavano una corrente artistica anch'essa eclettica, ma più robusta, più ricca di pensiero; avevano un fare più largo, e un più brillante colorito che derivavano dai veneziani. Nè poteva piacere al cardinal Farnese l'arte rude e ri- 
voluzionaria di un pittore lombardo, Michelangelo da Caravaggio, che scuoteva allora dalle fondamenta il castello della scuola manieristica, e attirava già nella sua orbita altri giovani maestri; perchè essa non aveva ancora avuto il riconoscimento ufficiale,

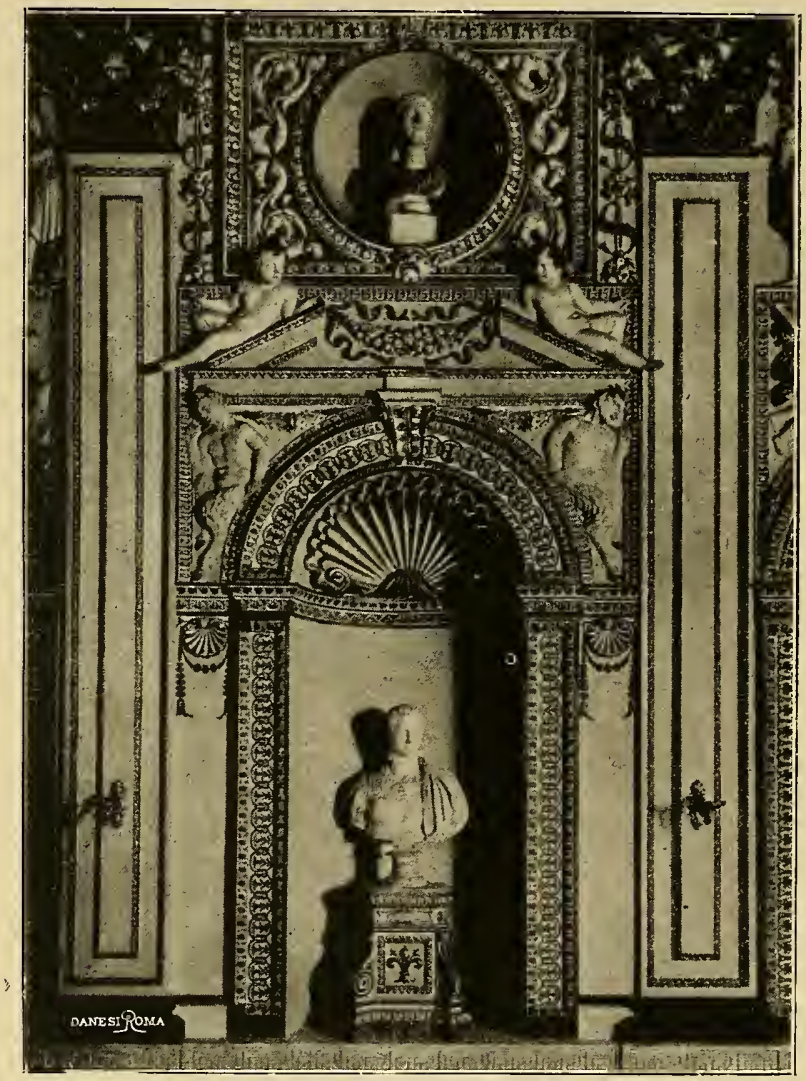

Nicchia con stucchi nella Galleria dei Carracci.

(Fot. Alinari).

e veniva anzi bandita dalle chiese e dai palazzi; non era compresa ancora, e sopratutto era inadatta nella sua tendenza popolaresca a celebrare con servile eleganza le glorie di una casa ducale; era insofferente ad adattarsi alla parte di decorazione. Annibale e Agostino Carracci non erano i primi artisti che 


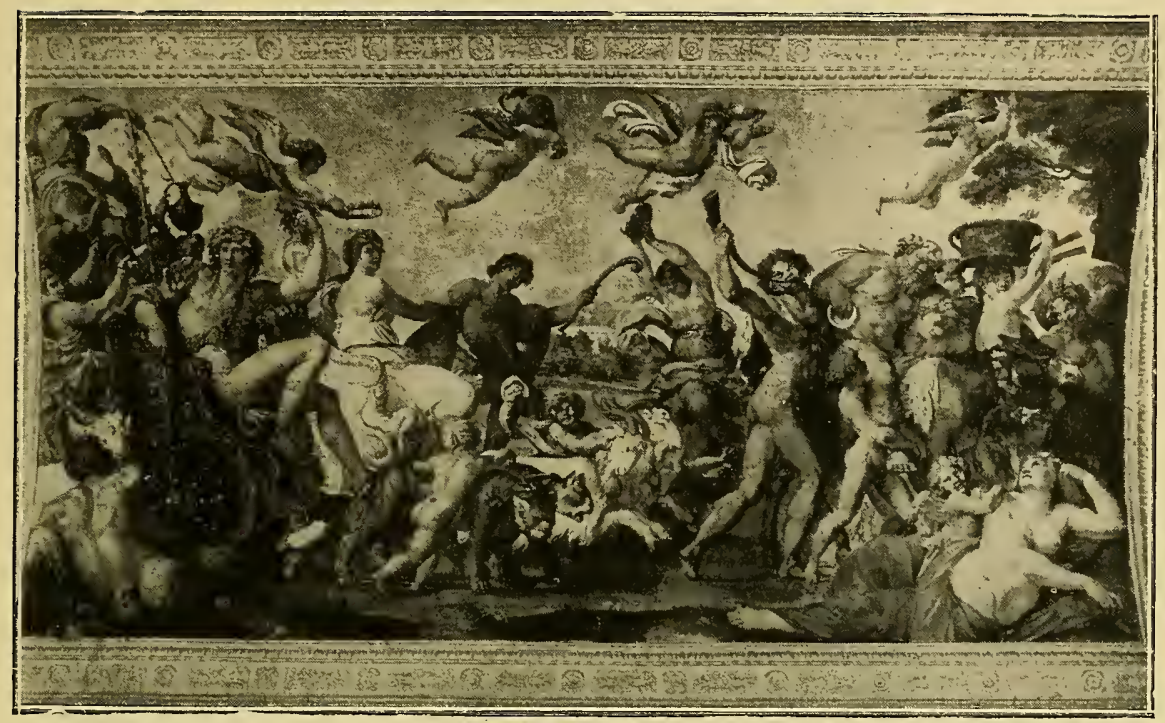

Annibale Carracci, Trionfo di Bacco ed Arianna.

(Fot. Alinari).

la dotta Bologna inviava a Roma; specialmente durante il pontificato del bolognese Gregorio XIII Boncompagni. (1572-1585) molti compatriotti del papa, com'era consuetudine, si erano trasferiti nella città eterna in cerca di fortuna; tra essi Ottaviano de' Nonni detto il Mascherino, architetto e pittore, Baldassarre Croce, Giacomo Laureti, Lavinia Fontana, Però nessuno di loro era riuscito ad affermare la propria personalità e invece l'ambiente romano li avea tutti assorbiti, piegandoli alle forme di moda. Ben diverso era invece il caso dei fratelli Carracci, che dovevano coi loro seguaci, specialmente con Domenichino e Guido Reni, segnare il trionfo della scuola bolognese in Roma. Nella loro città natale i due fratelli Agostino e Annibale insieme col cugino Ludovico di poco maggiore di loro, avevano fondato nel 1585 un'Accademia, detta dei Desiderosi, che era divenuta ben presto luogo di riunione non soltanto degli artisti, ma di quanti professavano studii di filosofia e di scienza; di astronomi, di geografi, di naturalisti, di maestri di anatomia e di medicina, di poeti come 
Claudio Achillini e il celebre cavalier Marino. Ludovico Carracci aveva le funzioni di direttore dell'Accademia; Annibale insegnava la tecnica del disegno e della pittura; Agostino professava la prospettiva, l'architettura e l'anatomia su calchi di antiche statue e sui cadaveri. Gli scolari avevano a disposizione dei modelli viventi, o posavano a vicenda, e potevano consultare Ia ricca biblioteca di Agostino, con una collezione di disegni di varii maestri, e un cospicuo medagliere; era insomma quello dei Carracci un vero prototipo dei nostri istituti di belle arti. $\mathrm{Ma}$ dove quei tre maestri avevano appreso la scienza che dispensavano poi ai numerosi discepoli? L'educazione dei tre Carracci si era formata in modo vario: Ludovico era stato dapprima a Bologna alla bottega di Prospero Fontana, poi a Venezia, dove aveva studiato le opere di Tiziano e del Tintoretto, il quale per altro, visti i suoi disegni lo aveva consigliato a mutare professione. Recatosi poi a Firenze si era dato a studiare in particolare Andrea del Sarto; quindi a Parma si era impressionato vivamente del Correggio, e poi a Mantova, attraverso Giulio Romano, aveva conosciuto le forme raffaellesche. Ritornato a Bologna nel 1578 con questo vario bagaglio di impressioni, intraprese l'educazione artistica dei suoi cugini; Agostino avido di scienza, e di spirito lento e paziente come Ludovico, e Annibale incolto ma pronto e vivace; $i$ due giovani passarono poi allo studio di Domenico Tibaldi incisore, figlio del celebratissimo Pellegrino. Ma le prime opere di Annibale, uscito a diciott'anni dall'Accademia del Tíbaldi, furono aspramente criticate, e allora il giovane se ne andò a Parma a rifare la sua educazione troppo artificiale, che sapeva troppo del chiuso dello studio, alla fresca fonte dell'arte correggesca.

L'impressione che su di lui fecero gli affreschi di S. Giovanni fu immensa: in una lettera del 10 aprile 1580 egli ne scriveva così a Ludovico; "Non potei stare di non andar subito a vedere la gran cupola, che boi tante volte mi habete comen- 
dato, et ancora io rimasi stupeffato vedere una cosi gran machina, cosi ben intesa ogni cosa, così ben veduta di sotto in su con si gran rigore, ma sempre con tanto giudizio, e con tanta gratía, con un colorito ch'è dí vera carne. $O$ Dío che nè Tí-

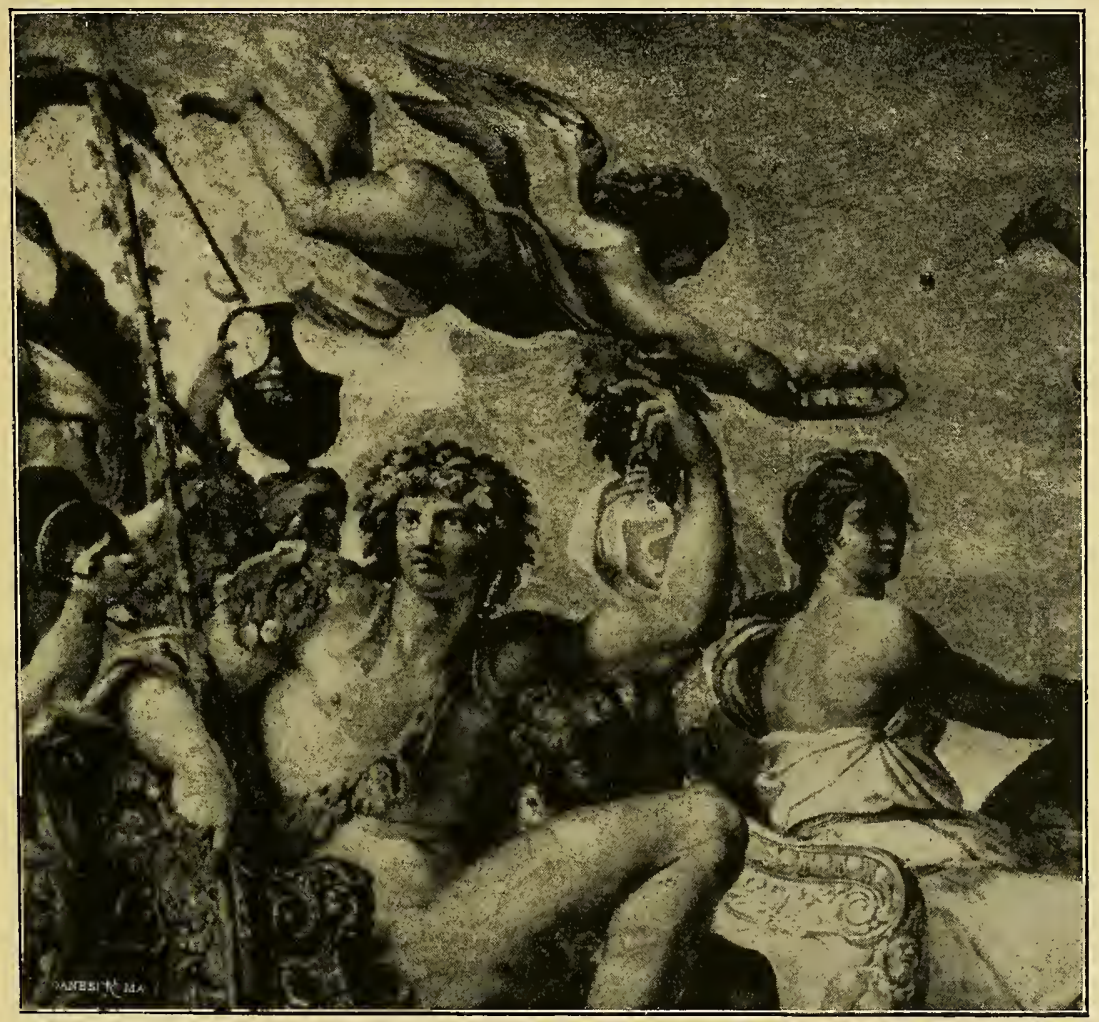

Annibale Carracci, Particolare del Bacco ed Arianna.

(Fot. Alinari).

baldo, nè Nicolino, nè sto per dire l'istesso Raffaello non vi hanno che fare. Io non so tante cose, che sono stato questa mattina a vedere l'ancona del S. Girolamo, e S. Catterina, e la Madonna che va in Egitto della scudella, e per Dio io non baratteria nissuna di quelle con la $S$. Cecilia,.. Insieme con le opere del Correggic, Annibale potè ammirare a Parma anche 
una numerosa serie di dipinti di Tiziano, e scriveva: "Correggio sarà sempre il mio diletto, e Titíano,.. Intanto Agostino, la cui fama come incisore si era largamente diffusa, veniva chiamato a Venezia, ed ivi lo raggiunse Annibale, che si accese di ammirazione per Paolo Veronese. Nel 1582 i due fratelli

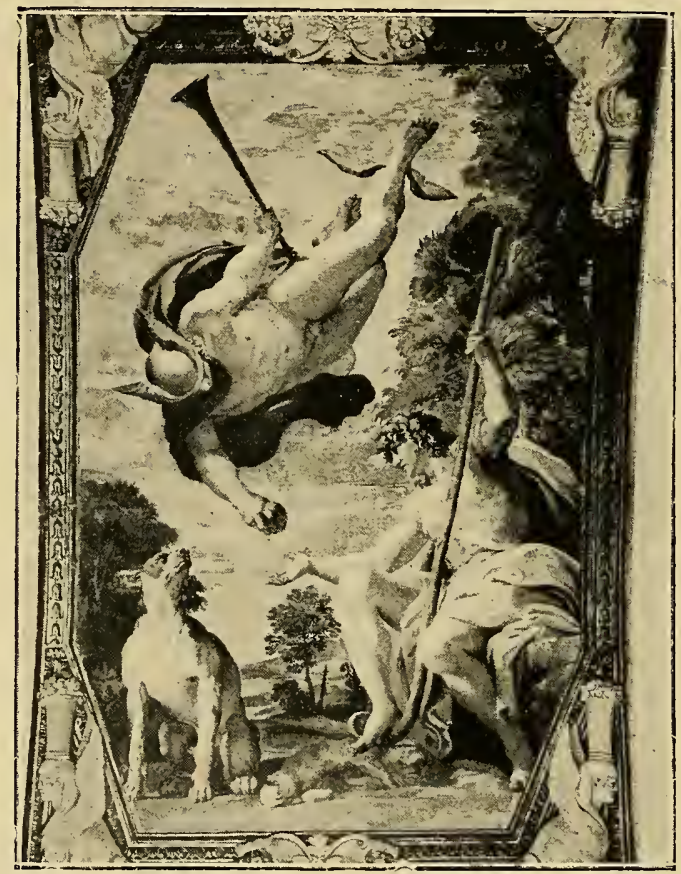

Annibale Carracci, Mercurio e Paride

(Fot. Alinari).

tornavano a Bologna: la loro educazione era compiuta, e nessuno dei maestri locali poteva come essi vantarsi di studii così larghi, di conoscenza così vasta delle altre scuole. Così ben presto, insieme con Ludovico, i tre Carracci acquistarono il primo posto nella pittura bolognese, e nel 1584 compivano un'opera che affermava solennemente la loro bravura; la decorazione di due sale del palazzo Fava, una con le storie degli 
Argonauti, l'altra con episodi dell'Eneide. Sono due esempi notevolissimi del piì largo eclettismo; le composizioni si ispirano a quelle delle Logge di Raffaello, che le stampe avevano divulgato in tutta Europa, ma i tipi sono in gran parte correggeschi, $e$ il colorito veneziano. Le critiche dei rivali furono accanitis-

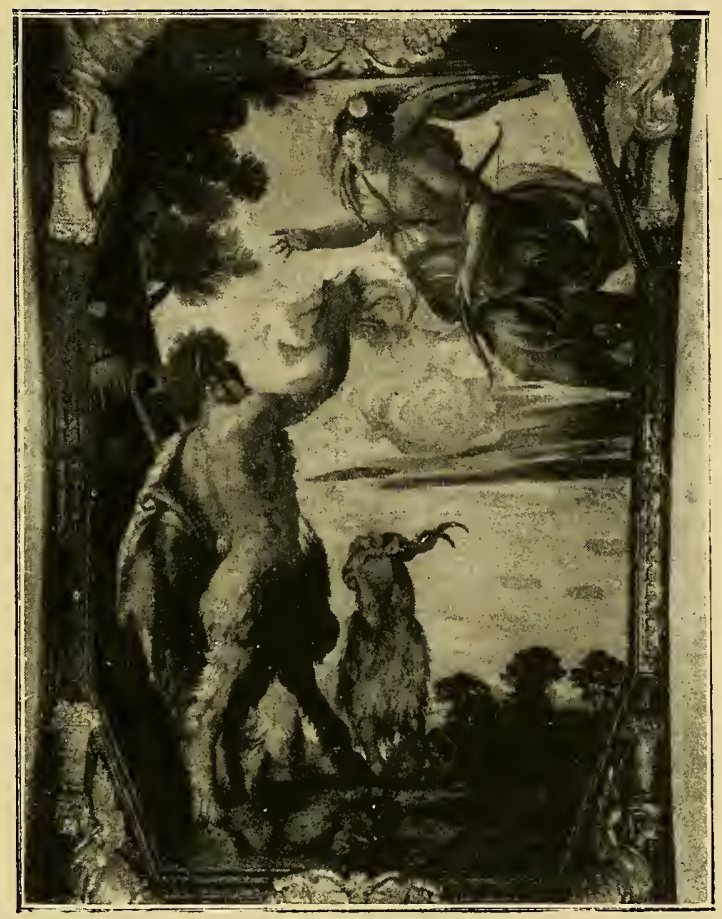

Annibale Carracci, Pane e Diana.

(Fot, Alinari).

sime, ma ormai $i$ tre artisti non temevano piì i giudizi velenosi dei loro concorrenti; le commissioni di quadri per le chiese di Bologna affluivano; l'anno seguente la fondazione dell'Accademía riuniva intorno a loro tutti $i$ giovani, e il trionfo della nuova scuola era assicurato.

Alla chiamata dei Carracci a Roma per dipingere nella Galleria Farnese, contribuì forse sopratutto la fama delle loro 
decorazioni nel palazzo Fava, in quello Magnani, coi fatti della storia romana, e nel palazzo Sampieri, con le fatiche d'Ercole; a Roma dovevan pure ispirarsi dalla mitologia greca, perchè il cardinale Odoardo, per seguire la moda del suo tempo, abbandonava il primitivo progetto di far rappresentare nella galleria i fasti di casa Farnese. Il giovane porporato che voleva far sfoggio di eleganza nella raffinata corte romana, intese subito che l'idea di glorificare in pittura le gesta paterne, era un provincialismo parmigiano, indegno di un principe della Chiesa. Perchè, malgrado i rigori della Controriforma, lo spirito del Rinascimento, bandito dai luoghi sacri, viveva ancora nei palazzi e nelle ville; le sculture antiche erano ricercate avidamente, tanto che se ne facevano numerose falsificazioni, e le favole e le leggende della mitologia classica e della storia romana, si adoperavano ad ornamento delle dimore papali e cardinalizie. Cosi $f \mathfrak{u}$ che Odoardo Farnese, che poteva vantarsi di possedere il più bel palazzo di Roma, volle avere in una sala del primo piano, detta il camerino, rappresentati i fatti di Ercole (forse per commento alla famosa statua dell'Ercole Farnese, ch'era allora ornamento invidiato del palazzo); e nella galleria le favole di Bacco e di Arianna, di Mercurio e Paride, di Aurora e Cefalo, di Diana e Endimione, di Polifemo e Galatea, di Perseo e Andromeda. Non vale la pena di indugiarsi a ricercare chi abbia guidato Annibale e Agostino Carracci nella scelta e nella disposizione dei soggetti; forse fu Monsignor Agucchia; forse Agostino stesso, che a Bologna professava mitologia nella sua Accademia. Certo è che prima di arrivare alla composizione definitiva Annibale, che aveva la direzione artistica dell' opera, passò attraverso studî e ricerche che restano documentate in una serie numerosa di disegni. Trovò finalmente il piano d'insieme che lo soddisfaceva: imaginò nelle pareti della galleria una decorazione architettonica a pilastri $e$ nicchie con stucchi dorati, sostenente una cornice che girando tutto all' intorno separa le mưra dalla vôlta; nelle nicchie col- 


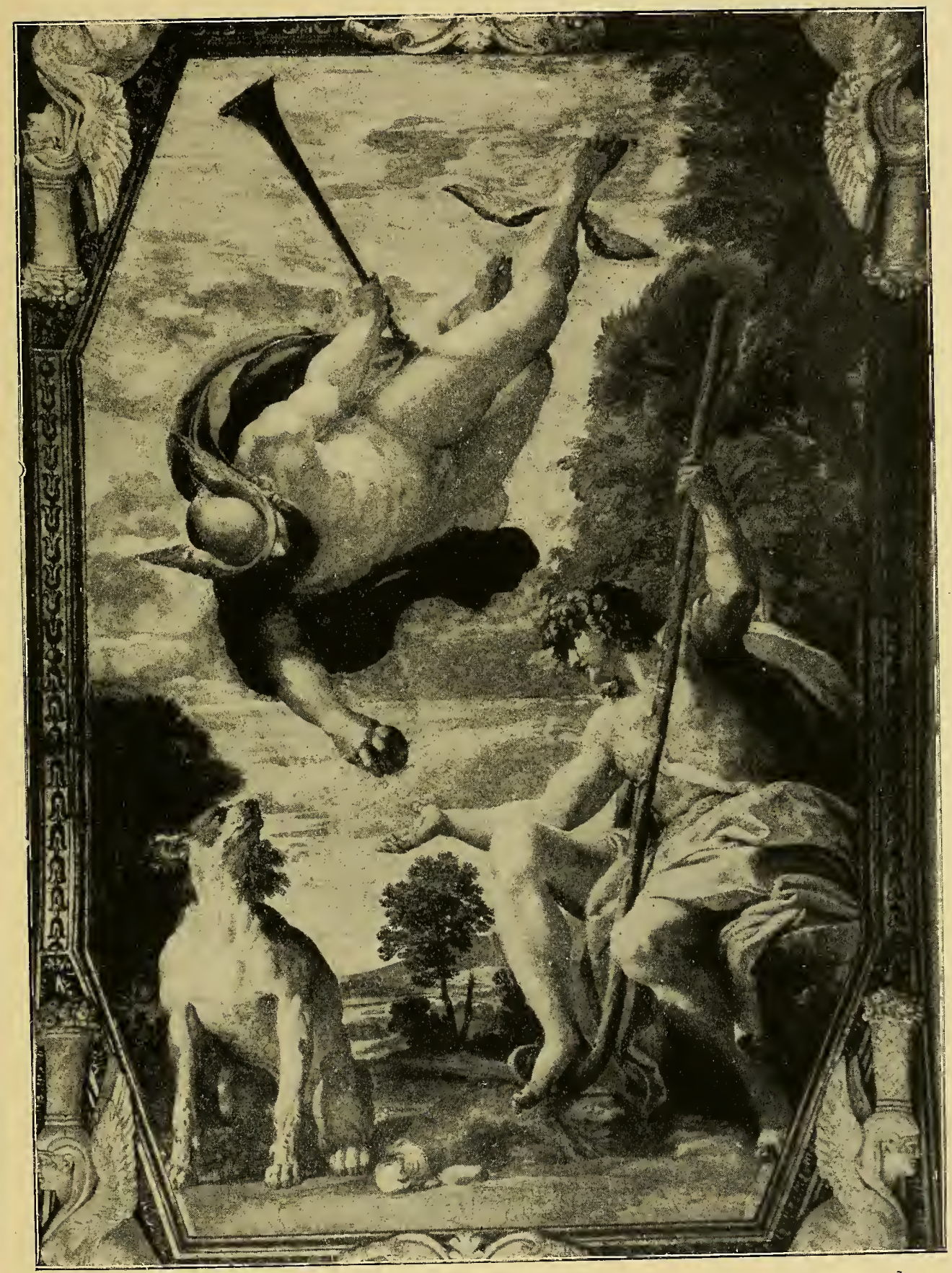

Annibale Carracci, Mercurio dà il pomo d'oro a Paride.

(Fot. Alinari). 


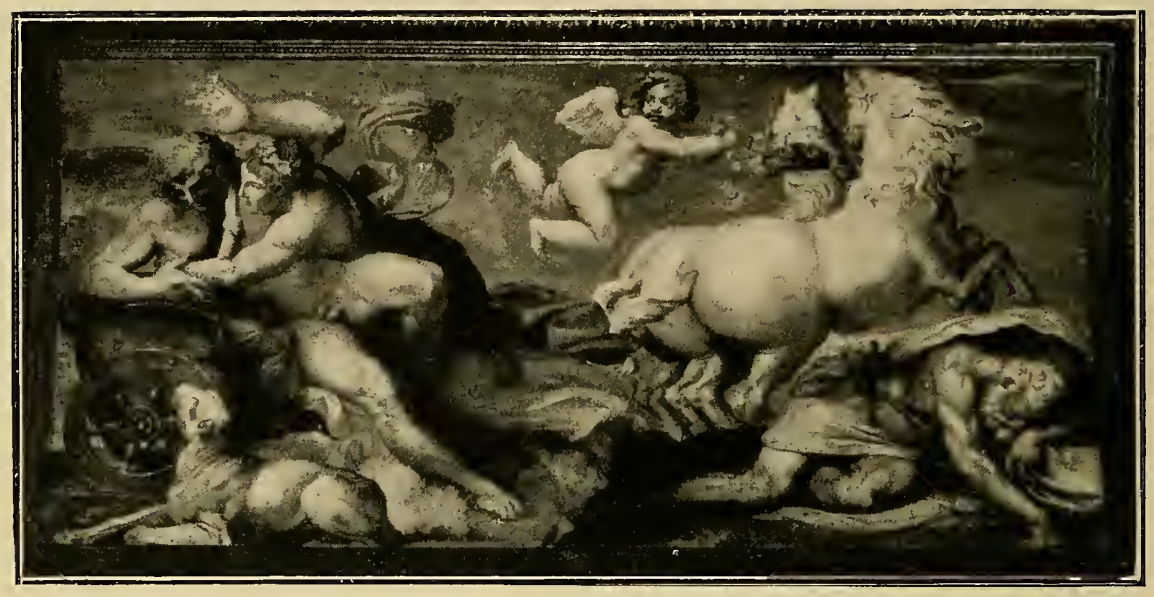

Agostino Carracci, Aurora e Cefalo.

(Fot. Alinari).

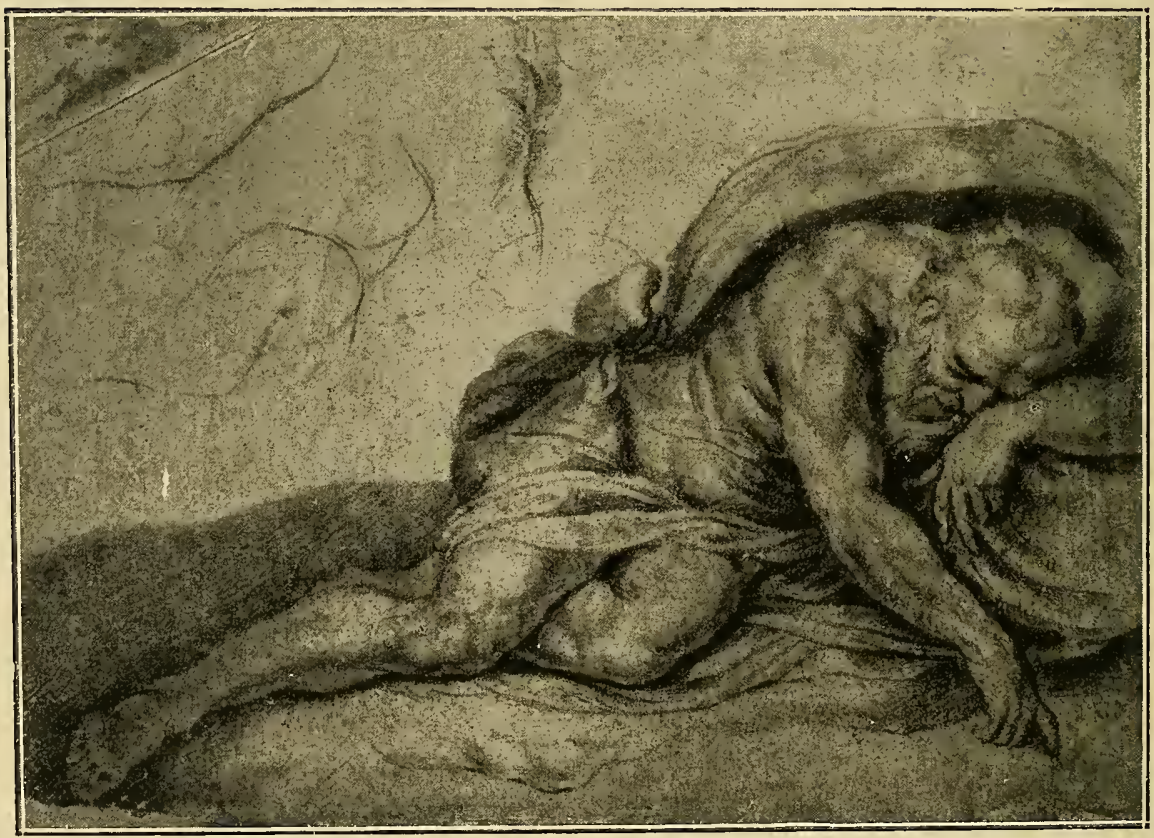

Agostino Carracci, Titone addormentato. Dísegno per 1'Aurora e Cefalo.

(Collez. di A. Munoz). 


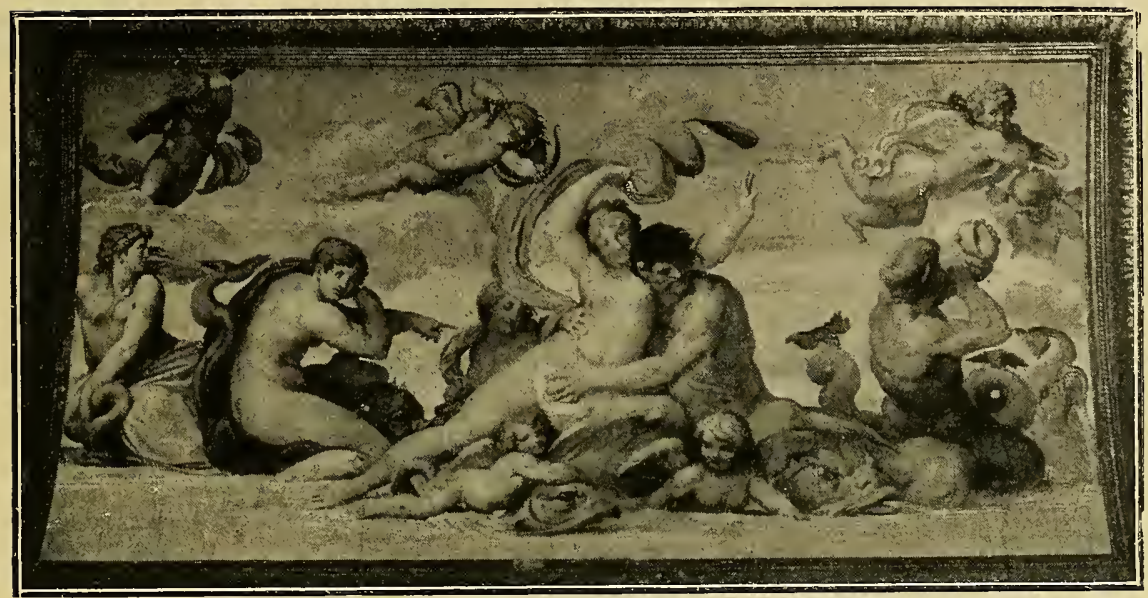

Agostino Carracci, Tritone e Galatea.

(Fut. Alinani).

locò delle statue antiche, e al disopra entro cartelle ornamentali piccoli affreschi con soggetti mitologici. Questo per il lato Iungo di fronte alle finestre; in quelli minori le pareti sono occupate fíno a metà da due grandi quadri rettangolari; al disotto si aprono due porte e tra queste son dipinti giganti nudi, in verde bronzo, alla maniera di Polidoro. La vôlta a schifo-botte porta tutto all' intorno nella parte in curva una specie di armatura con pilastri divisorî sostenuta da cariatidi e da giganti, che arriva fino a un grande rettangolo centrale, che, seguendo la curva della vôlta, sembra un drappo gettato da una parte all' altra a coprire la sala, e gonfiato dal vento. E parimenti sembrano arazzi due altri quadri che, sui lati lunghi della vôlta, dal rettangolo dí mezzo scendono fino alla cornice, e altri due che sono sulle pareti minori; scomparti di minori dimensioni stanno tra le cariatidi dell' armatura, e nel mezzo, ai lati del grande rettangolo. $\mathrm{Ma}$ $l^{\prime}$ 'insieme non dà l'impressione di una costruzione solída, organica, stabile; sembra un padiglione posticcio che sorregga degli arazzi; o come ha detto ingegnosamente un critico, un castello di carte. 
Nel grande spazio centrale Annibale dipinse il Coro trionfale di Bacco e di Arianna, i quali sui loro carri guidati da tigri e da caproni e circondati da fauni e da amorini, muovono verso destra, preceduti da Sileno sopra l'asinello, coronato d'ellera e sostenuto da fauni che danzano e suonano. C'è in tutta la scena, popolatissima di figure, una grande festosità, un senso

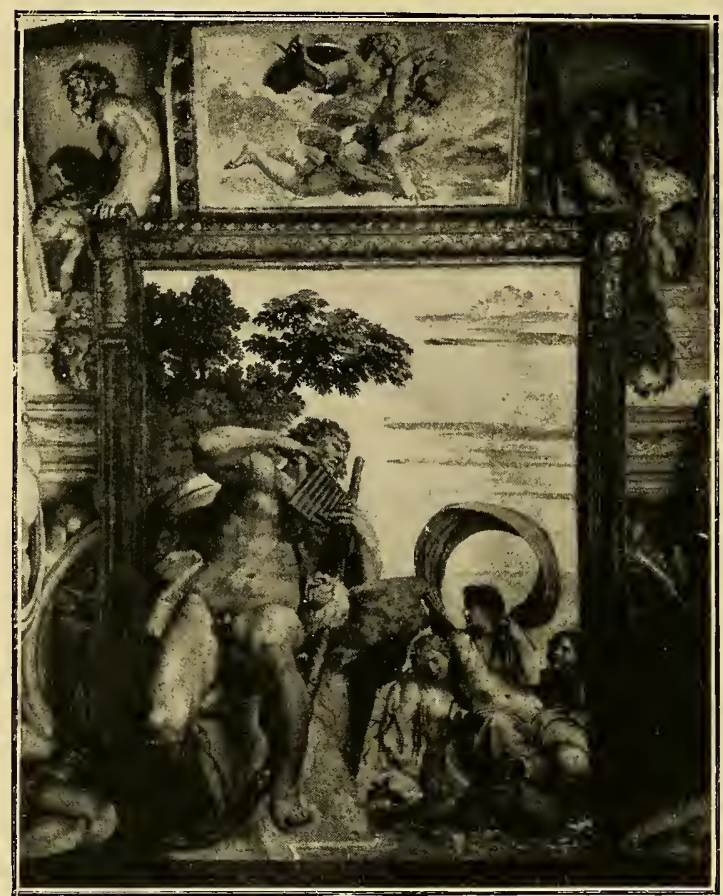

Annibale Carracci, Polifemo e Galatea. (Fot. Alinari).

di piacevolezza e di eleganza che fanno pensare all'influsso delle opere di Raffaello, il cui spirito è presente in tutta la decorazione della Galleria; il Raffaello delle Stanze, ma specialmente quello della Farnesina, che i due Carracci dovettero a lungo, amorosamente guardare. Ci sono, è vero, numerose reminiscenze michelangiolesche, come i nudi che derivano da quelli della Sistina, ma sono motivi tratti quasi di peso da modelli di Mi- 
chelangelo e resi invece con accento raffaellesco, il quale ha assorbito quasi interamente i ricordi correggeschi portati da Parma. E oltre che a Raffaello le pitture della Galleria Farnese fanno pensare agli scolari di lui, a Giulio Romano soprattutto; ma a un Giulio Romano più addolcito, meno robusto, con qualche nota di cangiantismo e di manierismo. Ai lati del quadro cen-

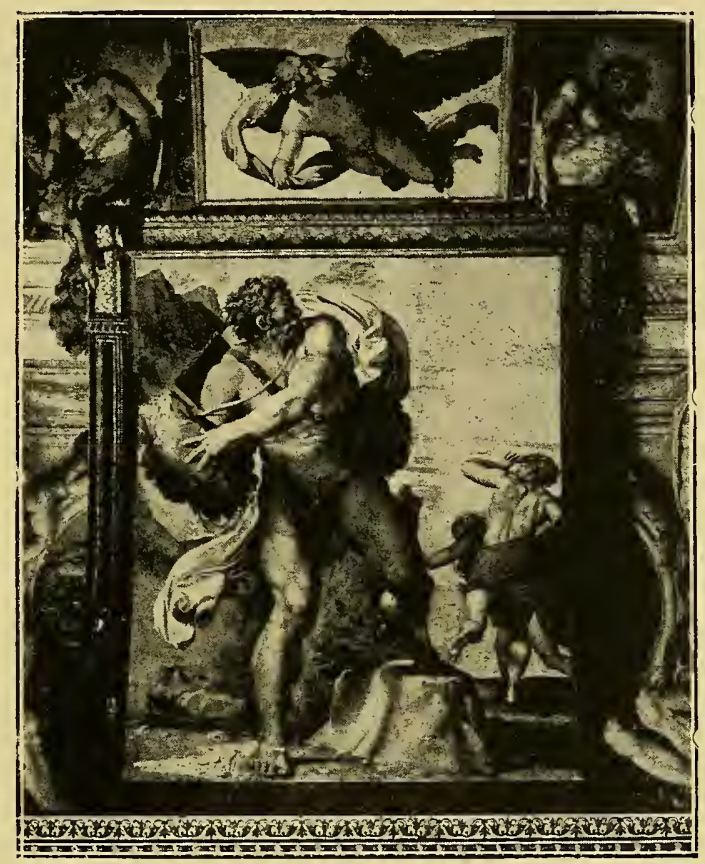

Annibale Carracci, Polifemo e Aci.

(Fot. Alinant).

trale ce ne son due minori; Mercurio che porta il pomo d'oro a Paride, e il Dio Pane che dà il vello a Diana; entrambi di mano di Annibale, che, specie nel primo, richiama Correggio. Al fratello spettano invece $i$ due quadri che scendono sulle pareti lunghe della Galleria, rappresentanti uno Aurora che rapisce Cefalo nel suo carro trainato da bianchi cavalli, mentre il vecchio Titone dorme; l'altro Galatea fra le braccia di Tritone, 


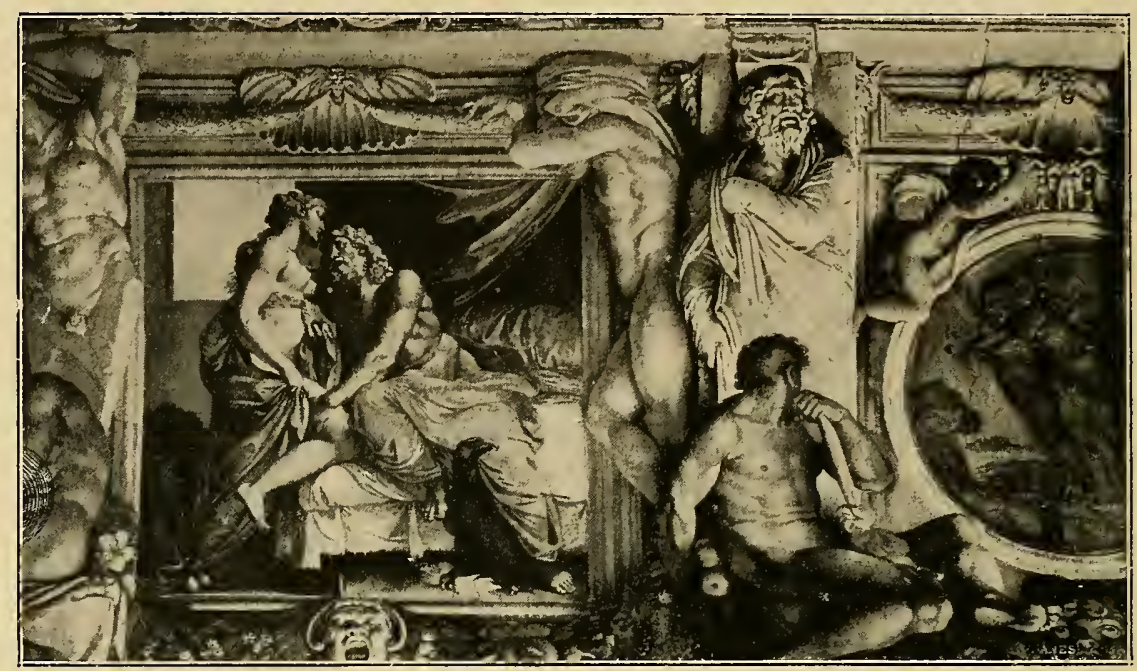

Annibale Carracci e scolari, Giove e Giunone.

(Fot. Alinari).

tra amori e divinità marine: in essi è evidente la mano del debole Agostino, su cui l'ambiente romano ha fatto minor presa, perchè accanto a motivi raffaelleschi si mostrano ricordi bolo-

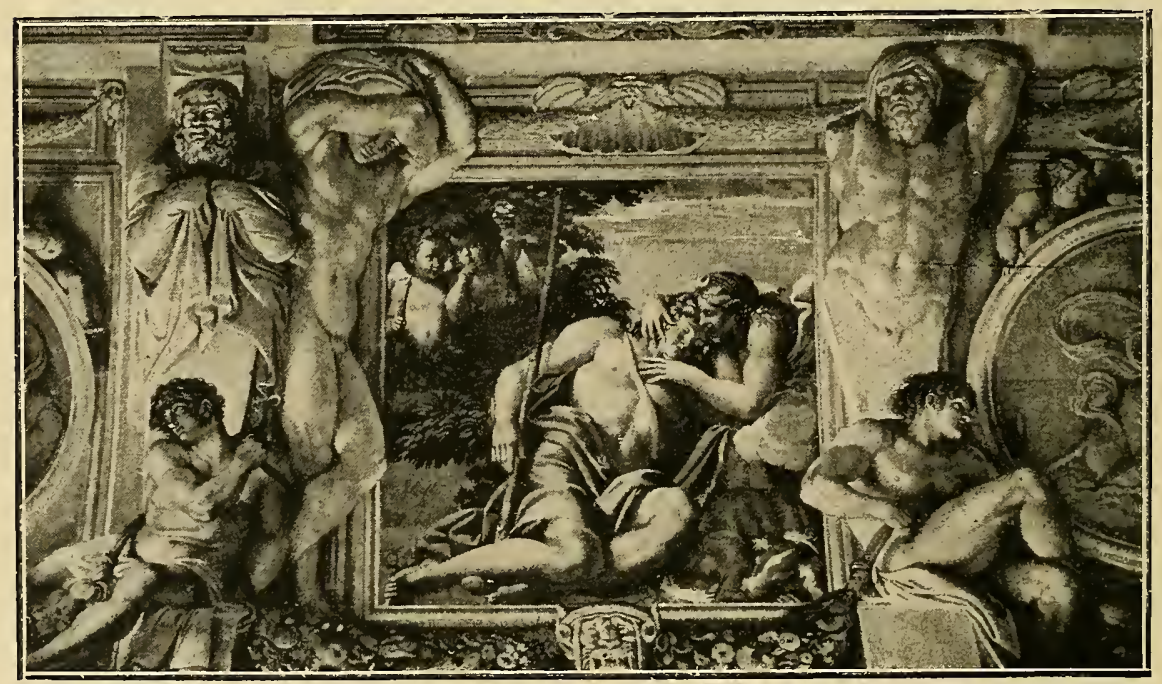

Annibale Carracci, Diana e Endimione.

(Fot. A:inari). 


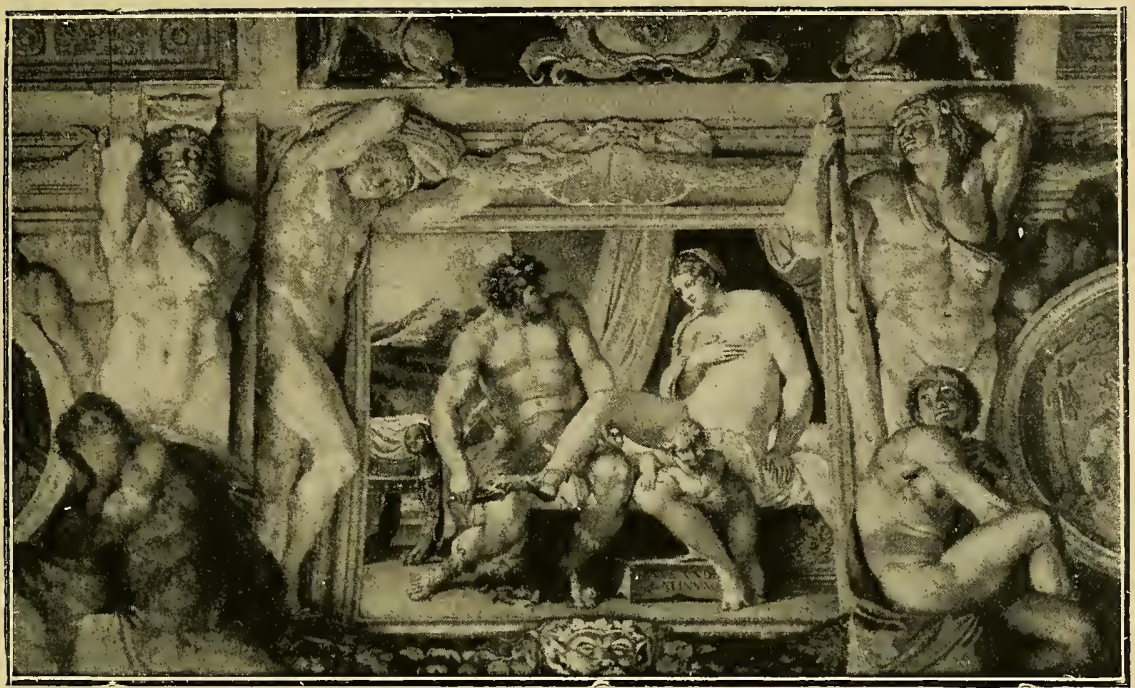

Annibale Carracci e scolari, Venere e Anchise.

(Fot. Alinari).

gnesi: Galatea ha la testa delle Madonne di Innocenzo da Imola. I dipinti del palazzo del Giardino a Parma non lasciano dubbio sulla paternità di questi due quadri; invece riappare la mano

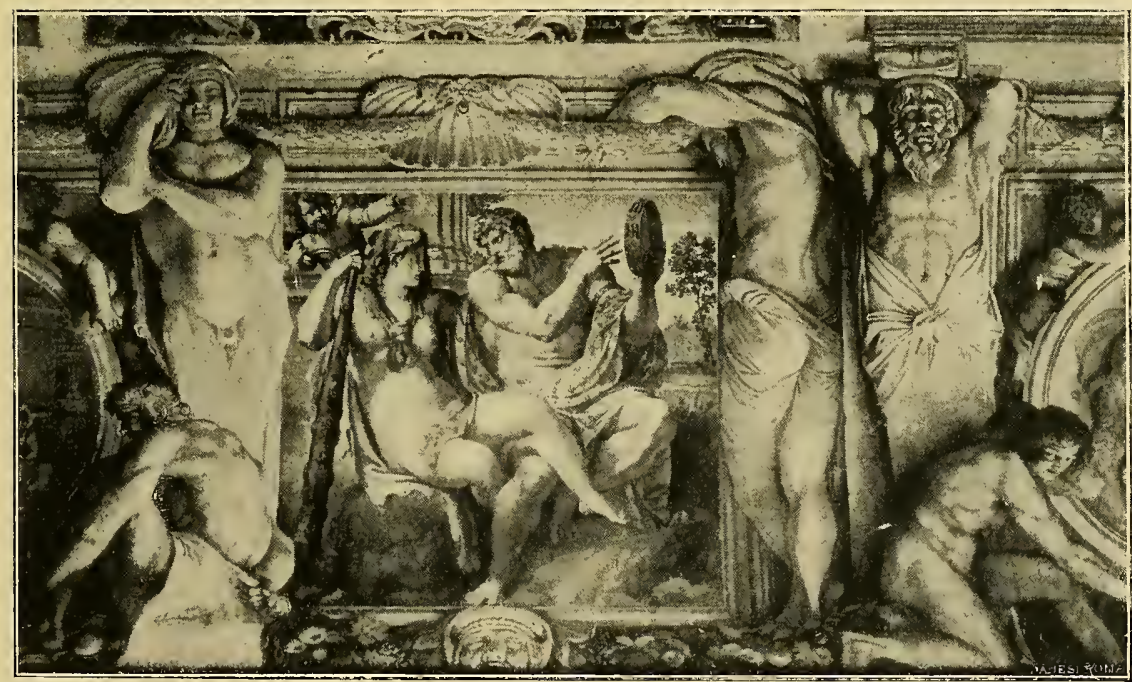

Annibale Carracci e scolari, Ercole e Onfale.

(Fot, Alinari). 


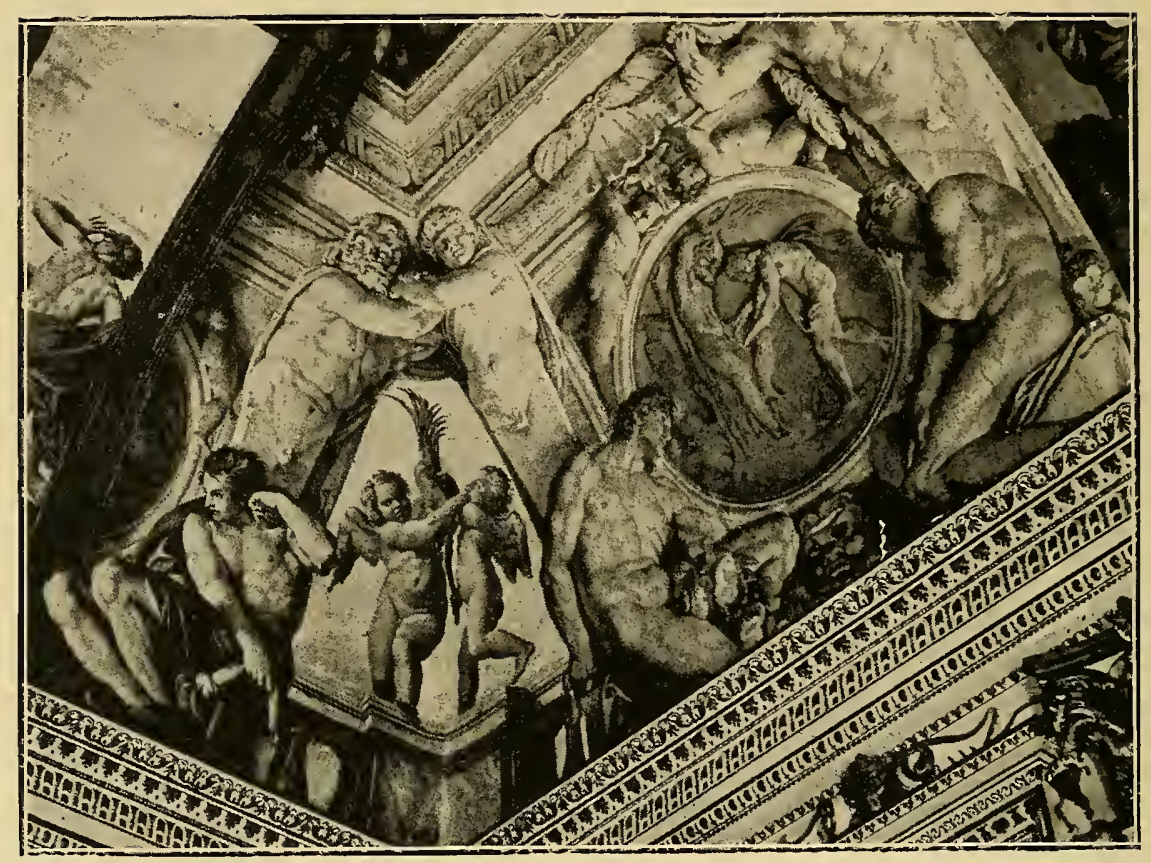

Un angolo della vôlta nella Galleria Farnese.

(Fot. Alinaril.

più robusta di Annibale nei due quadri dei lati minori: Polifemo mentre suona per sedurre Galatea, e quando scaglia il macigno contro Aci. Qualche collaboratore deve essere intervenuto accanto ad Annibale in alcuni dei quattro minori dipinti collocati tra le cariatidi che sostengono l' armatura della vôlta, e rappresentano Giove che seduto sulla sponda del morbido letto abbraccia Giunone; Diana che carezza Endimione addormentato sul monte Latmo, mentre da un cespuglio "si manifestano due Amoretti scaltri; l'uno col dito alla bocca fa segno di silenzio, l'altro con lo strale in mano gode e ride in vedersi la più casta dea soggetta „.. Questi due quadri hanno la forza elegante e il colorito caldo di Annibale; ma gli altri di Anchise che toglie il coturno a una Venere dalla testa tizianesca, e di Ercole e Onfale, si dimostrano opera di un coloritore più fiacco, che 


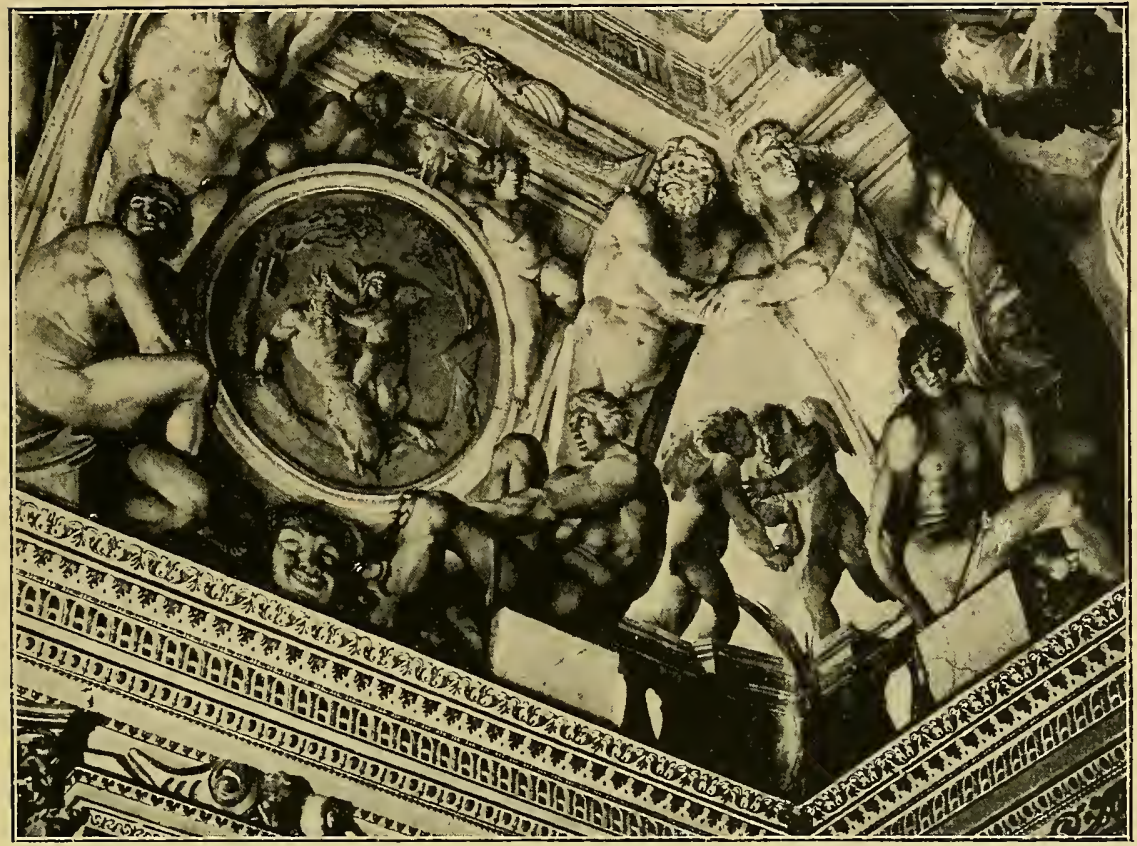

Un angolo della vôlta nella Galleria Farnese.

(Fot. Alinari).

non ha saputo rendere in tutta la sua efficacia il bozzetto del maestro. Ed anche qua e là in alcuni dei nudi seduti avantí alla balaustrata, appare l'intervento di aiuti, mentre meravigliosi son quelli che Annibale, ispirandosi a quelli di Michelangelo, esegui di sua mano, con le cariatidi marmoree, coi putti correggeschi intorno ai medaglioni a finto bronzo; questa parte decorativa è forse la più bella di tutta la vôlta, piena di squisite eleganze, che però sono un po' nascoste e soffocate dai quadri maggiori più appariscenti, più varii di colore.

Al disotto della cornice nei lati minori della Galleria si vedono due grandi quadri, uno raffigurante Perseo che libera Andromeda legata allo scoglio, opera, in gran parte, del Domenichino; l'altro il combattimento tra Perseo e Fineo che si attribuisce, secondo noi a torto, al medesimo artista, mentre pur 
non escludendo qualche sua collaborazione vien fatto di pensare a Innocenzo Tacconi, aiuto dei Carracci anche nei dipinti della vôlta. Sulla porta d'ingresso, incontro alle finestre che guardano sul fiume, è figurata l'impresa di casa Farnese, ossia una fanciulla bionda, seduta, che abbraccia un alicorno, l'animale ferocissimo che si lascia solo prendere per mano di una vergine. Díciamolo subito: Domenichino si rivela qui per un me-

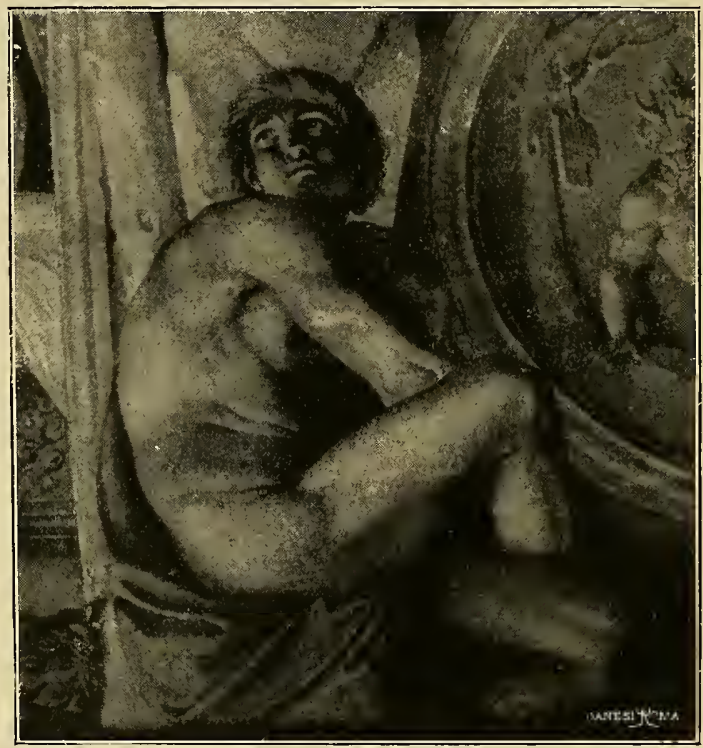

Annibale Carracci, Nudo nella Galleria Farnese.

diocre artista, inferiore assai al suo maestro, perchè ha tutto il convenzionalismo raffaellesco di Annibale, senza raggiungerne la robustezza statuaria michelangiolesca, e il vigore del colorito tizianesco; è biaccoso, cretaceo, molle; disegna anche scorrettamente, drappeggia scolasticamente, e non ha un proprio valore personale: è nülla di più che un aiuto.

Fissiamo ora la data dell'esecuzione della Galleria : Annibale era venuto a Roma nel 1595; qualche tempo dopo sopraggiungeva Agostino, e poi due discepoli dell'Accademia, Do- 
menichino e Francesco Albani; sotto il quadro di Galatea e Polifemo si legge la data 1600, che deve essere approssimativamente quella del termine della vôlta, mentre i quadri inferiori, sono di poco più tardi : tutta l' opera era finita nel 1603.

Siamo dunque proprio all' inizio del secolo, che tutto, secondo l'opinione comune, sarebbe stato dominato dal classico esempio della Galleria caraccesca; poichè per i critici antichi e

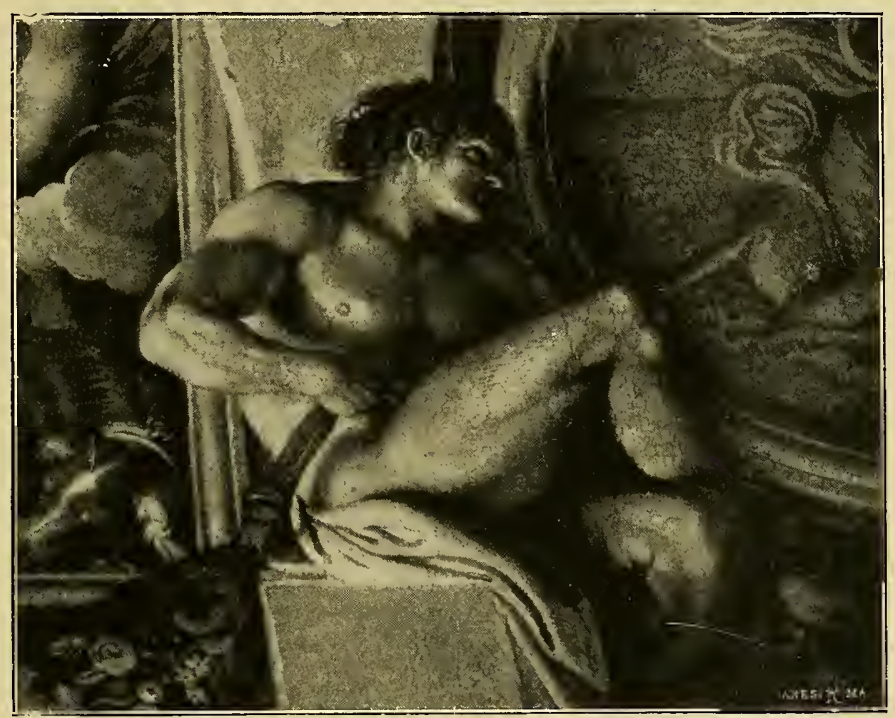

Annibale Carracci, Nudo nella Galleria Farnese.

moderni da qui sarebbe partito il rinnovamento della scuola romana. Niente di più falso; anzi a parer nostro l' effetto dell'opera dei Carracci a palazzo Farnese $f u$ quasi nullo. Certo, accanto alle forme smidollate di un cavalier d'Arpino, testardo perpetuatore del manierismo zuccaresco, accanto ai camaleontici discendenti del Guerra, del Nebbia, del Croce, e compagni, i Carracci apparvero come giganti, come restauratori del buon gusto e della nobiltà dell'età d'oro. Ma la loro riforma non poteva aver forza sufficiente a rinnovare la pittura romana e ita- 


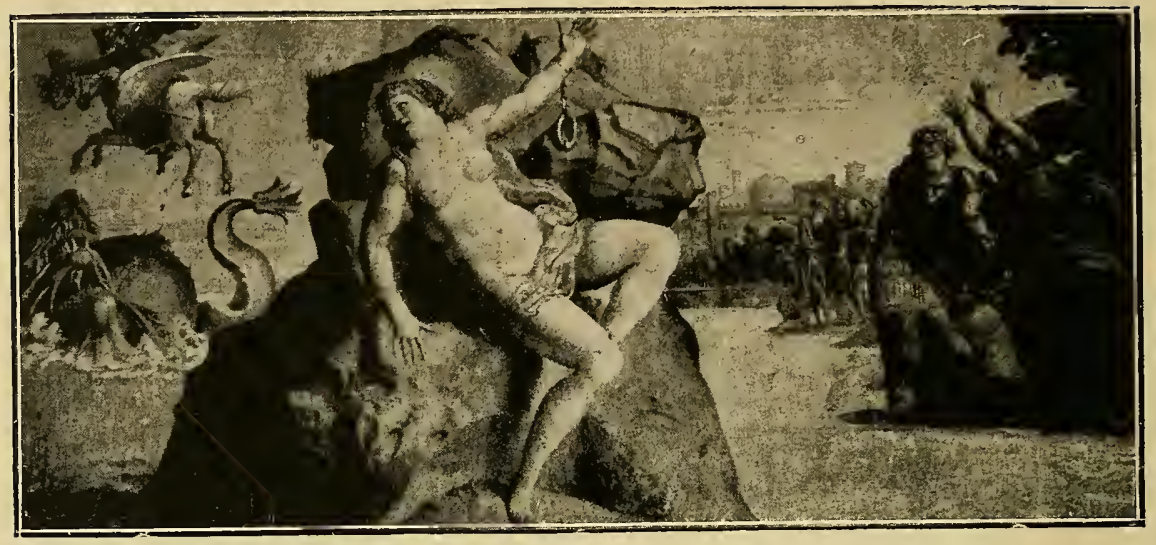

Domenichino, Perseo e Andromeda nella Galleria Farnese.

(Fot. Alinari).

liana, (poichè in questo tempo Roma occupa un posto centrale nella storia artistica della penisola); non lo poteva perchè mancava di spontaneità e di vitalità. Era un ritorno al passato, una artificiale resurrezione di cose morte; un' eco di suoni lontani, non una musica nuova. La ricreazione di elementi raffaelleschi e michelangioleschi non poteva germinare un rifiorimento; era

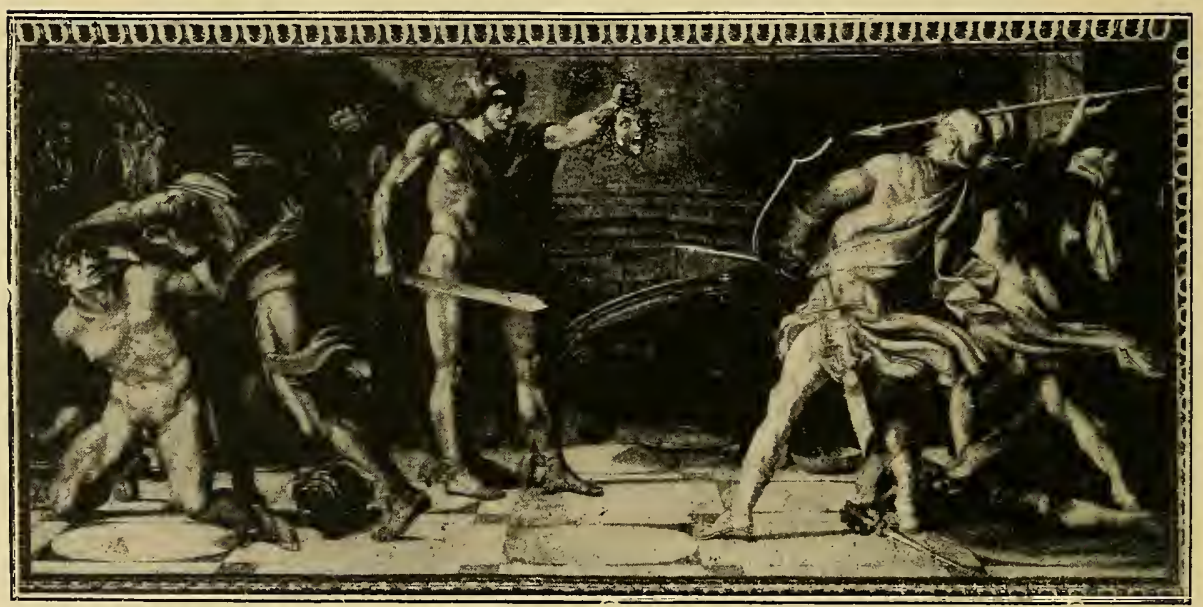

Innozenzo Tacconi. Perseo lotta con Fineo - Galleria Farnese.

(Fot. Alinari). 
in fondo un'altra specie di manierismo, più sapiente, più classico, avvivato da tonalità veneziane, ma pur sempre manierismo. Perciò se nel Seicento romano il filone bolognese ebbe un ampio corso, esso non derivò dalla Galleria Farnese, ma dalla venuta in Roma al seguito dei Carracci, e dalla permanenza dell' Albani, del

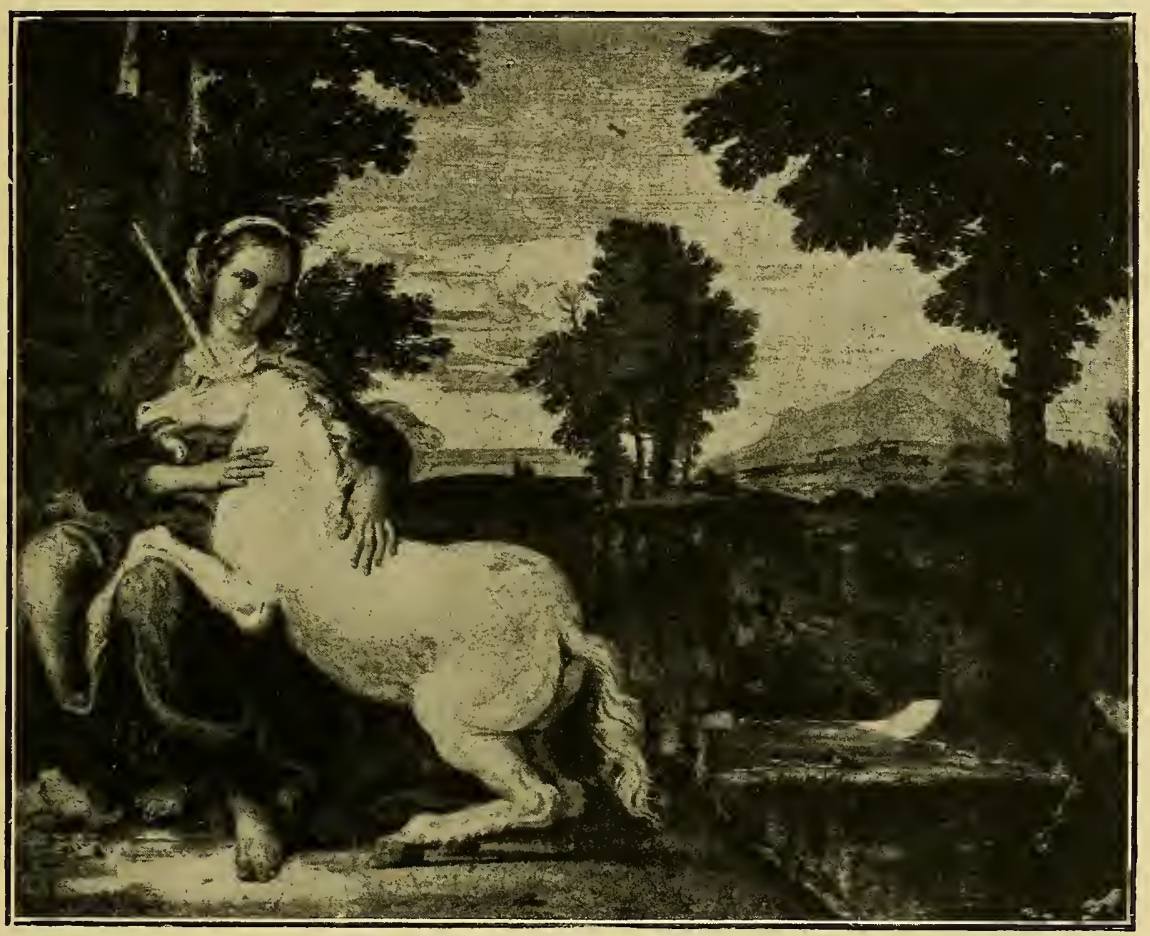

Domenichino, La Vergine e l'unicorno, impresa dei Farnese nella Galleria dei Carracci.

(Fot. Alinari).

Reni, del Domenichino, che ne continuavano, pur modificandola, la maniera. E anche dal punto di vista iconografico la Galleria dei Carracei non ebbe fortuna al difuori della scuola bolognese. Domenichino ne trae ispirazione, e ne copia anche qualche parte nei suoi affreschi di Bassano di Sutri $e$ in quelli del palazzo Costagutí; Guido Reni se ne ricorda per l'Aurora e Guercino 
per il casino Ludovisi; più tardi i signori inglesi e francesi la vorranno imitata nei loro castelli; ma un influsso largo e diretto sull' arte romana mancò. Perchè, sebbene tutto quel mondo di figurazioni classiche avesse a pretesto una moralità, cioè dovesse simboleggiare l'amore umano governato dal celeste, è certo che quel trionfo di Ercoli e di Veneri, di Tritoni e di Amori, quel bagaglio mitologico, eredità del secolo passato, non era più vivo e parlante, non si gustava, non si intendeva più. Ecco perchè vorremmo definire la Galleria Farnese invece che l'affermazione di una nuova scuola, invece che la base della pittura romana del Seicento, l'ultima voce del Rinascimento, l'ultima pagina di un gran libro d'oro. II Seicento non solo non attinse da quella fonte, ma segui anzi una via del tutto opposta; fu animato da un spirito affatto diverso.

Povero Annibale! Dopo otto anni di industriose fatiche si vide offerta per tutto compenso la somma di cinquecento scudi d'oro, avendo avuto in più l'alloggio presso il cardinale e la provvisione del pane e del vino. $E$ pensare che appena settant'anni dopo un solo quadretto, anzi " poche pennellate o per meglio dire scherzi del pennello di Annibale "si pagavano, secondo il Bellori, altrettanto e maggior prezzo della Galleria intera! Il maestro, " di natura malinconico ed apprensivo molto, si aggravò tanto nel pensiero della sua disgrazia, che non si potè mai più rallegrare; e cadde in umore di non più dipingere, e volendo non poteva, necessitato lasciare i pennelli che quella malinconía gli toglieva di mano „. Così non operò quasi più, lasciando i lavori ai suoi allievi, come fece per la cappella di S. Diego, in S. Giacomo degli Spagnuoli a piazza Navona, in cui fece operare Francesco Albani, tanto che il commitente Enrico d'Errera non voleva più pagare il prezzo pattuito, col maestro. Oggi purtroppo gli affreschi con le storie di S. Diego, distaccati e fortemente danneggiati, sono andati lontano, nel Museo di Barcellona. 
In S. Maria del Popolo c'è nella cappella a sinistra del coro una Assunzione della Madonna, di mano di Annibale, dipinta intorno al 1600 , di derivazione correggesca e di colorito tintorettiano, e nella vôlta altre storie dipinte su suo disegno da Innocenzo Tacconi. Altri quadri fece Annibale per S. Onofrio, per S. Gregorio, per gli Aldobrandini e pel cardinale Scipione Borghese, quasi tutti in collaborazione coi discepoli, che insieme con lui formavano il gruppo detto dei bolognesi, i quali dopo

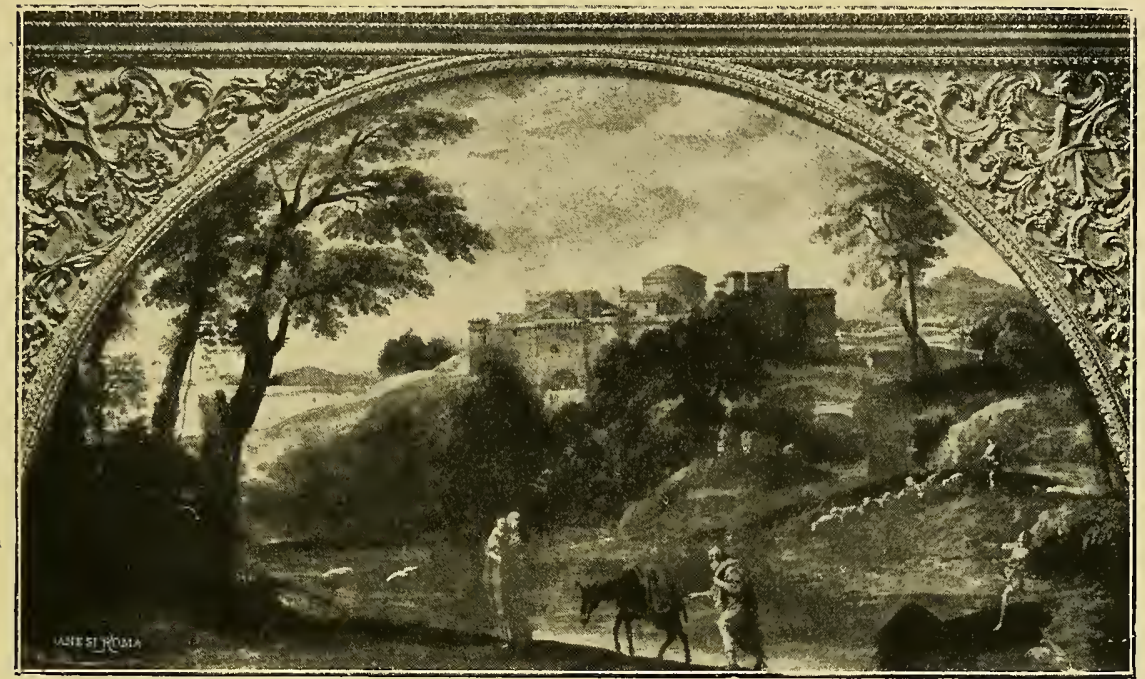

Annibale Carracci. La fuga in Egitto, nella Galleria Doria.

(Fot. Anderson).

la morte del maestro continuarono a lavorare nelle chiese e nei palazzi di Roma. Annibale non aveva perduto a Roma il suo temperamento di gaudente bolognese, amico dei piaceri, grande inventore di burle e di arguzie che non solo spiegava con parole ma con le facezie dei disegni, famosi erano i suoi "dilettevoli ritratti burleschi ovvero caricati, " rei quali usava " trasportare agli animali la rassomiglianza umana; ma più strana imitazione era quella delle cose inanimate, perchè avrebbe trasformato un uomo o una donna ancorchè bella in una pentola o in 
un orciuolo, o in altro ordigno ,.. Nel 1609 tornando da Napoli, dov'era andato per "divertirsi e rallegrare la fantasia "fu colpito da febbre aggravata dalle conseguenze di disordini amorosi, e il 15 luglio morì. Aveva egli stesso manifestato il desiderio di aver sepoltura nel Pantheon, accanto a quella di Raffaello; e nel tempio romano $f u$ esposto sopra un catafalco il suo cadavere, alla cui testa era collocato il suo quadro del Cristo deriso, dipinto pel cardinal Farnese, come ai piedi del letto funebre dell'Urbinate era stata posta la Trasfigurazione. E ai funerali, tra la gran copia di lumi, le preci e i canti, alla presenza della nobiltà romana e di tutta l'Accademia di S. Luca, accorse il popolo, e pareva " che nel luogo stesso si mirasse di nuovo Raffaello disteso sulla bara „. Così ancor oggi il pellegrino devoto che va a visitare la tomba del Sanzio è costretto a pensare ad Annibale, il cui nome è inciso lì presso; e che anche dopo morto vuol illuminarsi della luce del grande a cui aveva cercato in vita di strappare qualche riflesso dell' arte sua immortale. Ma se i corpi stanno vicini, gli spiriti, nel cielo della gloria, sono infinitamente lontani.

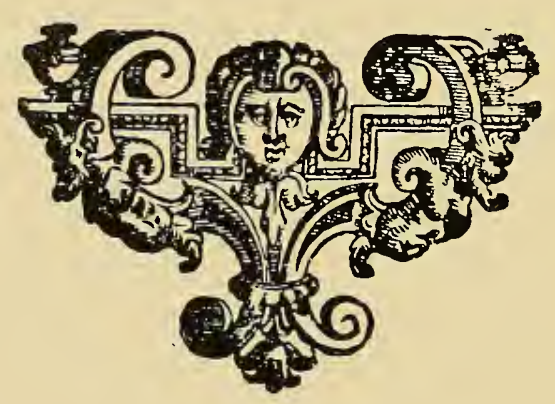




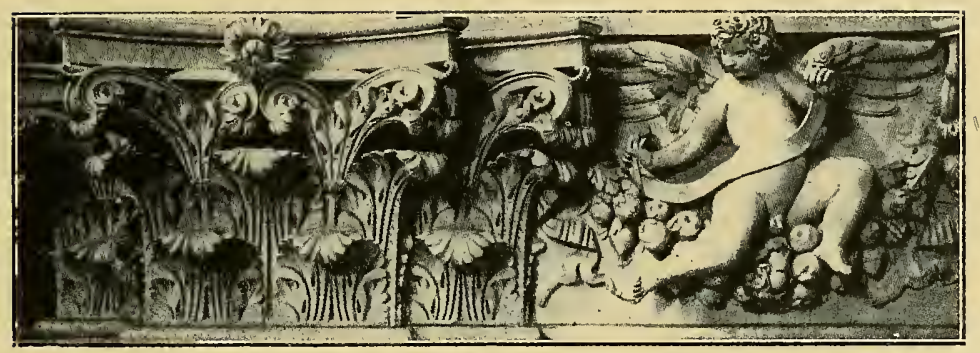

\section{CAPITOLO TERZO}

\section{DELICIUM URBIS}

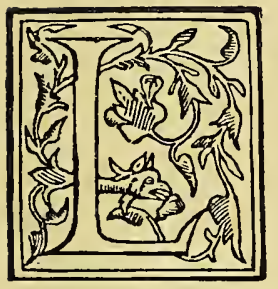

eone XI, di casa Medici, eletto papa il 1 aprile 1605 , succedendo a Clemente VIII Aldobrandini, "non aveva ancora fermate le spalle sotto il grave peso del pontificato ", che dopo ventisei giorni mori: si disse attossicato da una rosa offertagli nella solenne cerimonia del possesso; ma dall'esame del cadavere la diceria apparve infondata. I cardinali si ritrovarono cosi dopo un mese in conclave, divisi nelle stesse fazioni, spinti dallo stesso desiderio di promovere gli amici, e di tenere addietro i rivali. C'erano tra i radunati uomini insigni per dottrina e per rigida coscienza, come Cesare Baronio, e il gesuita Bellarmino; e di nobilissima stirpe, come il Visconti, lo Sforza, l'Aldobrandini, il Giustiniani, il Farnese; la lotta tra i partiti francese e spagnolo fece cadere invece la scelta su un nome che nessuno si aspettava, quello di Camillo Borghese, che sali al trono il 16 maggio 1605, assumendo il nome di Paolo V. II nuovo papa era nato a Roma, cinquantatre anni innanzi, da nobile famiglia; la madre era della antichissima casa degli Astalli, il padre, Marcantonio, era apprezzato giureconsulto. Camillo studiò 
filosofia a Perugia e diritto a Padova; tornato in Roma fuavvocato concistoriale, poi abbreviatore della Segnatura, e vicario della basilica di S. Maria Maggiore, verso la quale cominciò cosi a legarsi di affetto: era il tempo in cui Sisto V vi faceva costruire la cappella che da lui si disse Sistina. Il papa mandò poi Camillo Borghese al governo di Bologna come vicelegato, e più tardi Clemente VIII lo spedi come nunzio straordinario a Fílippo II re di Spagna, e in premio della missione felicemente compituta, al ritorno, nel 1596, lo creò cardinale. Nell'anno santo 1600 si distinse col card. Sfondrati per il gran numero di abiure di eretici che seppe procurare. Era Camillo Borghese uomo di altissima statura e pingue; aveva lo sguardo da miope, e portava piccolo pizzo e baffetti appuntiti che davano al suo volto un'espressione di simpatica vivacità ; egli era amico di tutti, pronto, piacevole, gioviale, amante del lusso, ma di illibato candore di costumi. Appena eletto al pontificato, com'era l'uso del tempo, pensò prima che alle sorti della Chiesa, a quelle della sua famiglia, e tra l'altro volle provvedere alla creazione di un cardinal nipote, e non trovando nella sua più stretta parentela un soggetto porporabile, elesse Scipione Caffarelli figlio di una sua sorella, il quale assunse il cognome di Borghese; egli aveva appena ventinove anni quando cinse la porpora, il 18 luglio 1605, due mesi soltanto dopo l'elevazione dello zio al pontificato. La funzione di cardinal nipote, sebbene non sanzionata ufficialmente, aveva un'importanza grandissima; di regola era quello che dominava in corte e governava la Chiesa con più robusta e giovane mano, quando il papa era già vecchio e stanco, e Gregorio Leti, l'autore dei maligni trattati del Nepotismo e del Cardinalismo, che l'Indice condannò, severamente riprende il cattivo costume. Certi papi abbandonavano addirittura al nipote le redini dello Stato, e si vuole che il debole e malaticcio Gregorio XV dicesse al cardinal Ludovico: Gubernème e fe' $v u^{\prime}$ : datemi da mangiare e al resto pensate voi. 
Scipione Caffarelli-Borghese rappresentò magnificamente la sua parte di Cardinal nipote; di finissimo gusto, amante del. bello e delle raffinatezze, simpatico, cortese, si accattivò le simpatie di tutti, invece di suscitare invidia come i suoi predecessori in quella posizione privilegiata. Egli lasciò che lo zio si dibattesse

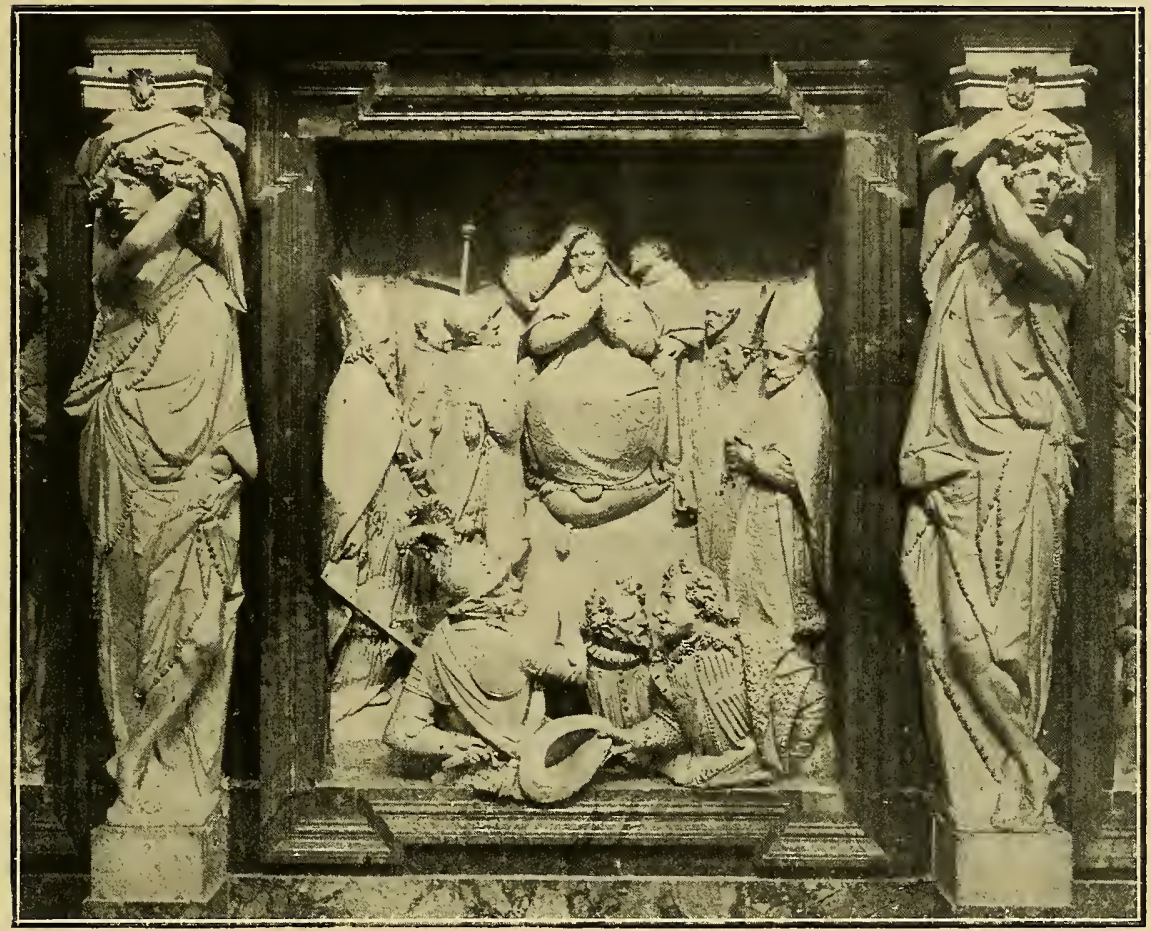

P. Bernini, L'incoronazione di Clemente VIII nel suo sepolcro in S. Maria Maggiore.

negli aspri dissidii con la repubblica veneta, e intrigasse con il duca di Savoia, e si affannasse a pacificare Francia e Spagna, e s'interponesse nelle discordie tra Piemonte e Mantova, e intervenisse nelle guerre di Valtellina, e si dedicò quasi esclusivamente alle più piacevoli cure dell'arte. Anche Paolo $\mathrm{V}$ promoveva e compiva varie fabbriche, ma lo faceva più per devozione e per politica che per gusto personale; così la sontuosa Cappella 
Paolina in S. Maria Maggiore da lui costruita, era destinata ad onorare la Madonna verso la quale egli aveva sempre avuto speciale devozione, e a servire da sepolcreto di famiglia; cosi il compimento del palazzo papale di Montecavallo, era necessario per dare ai pontefici nuova splendida sede; cosi il prolungamento della basilica di S. Pietro e la costruzione della nuova facciata furono da lui voluti per completare il gran domo del cattolicismo. $\mathrm{Ma}$ l'arte durante il pontificato di papa Borghese, che durò fíno

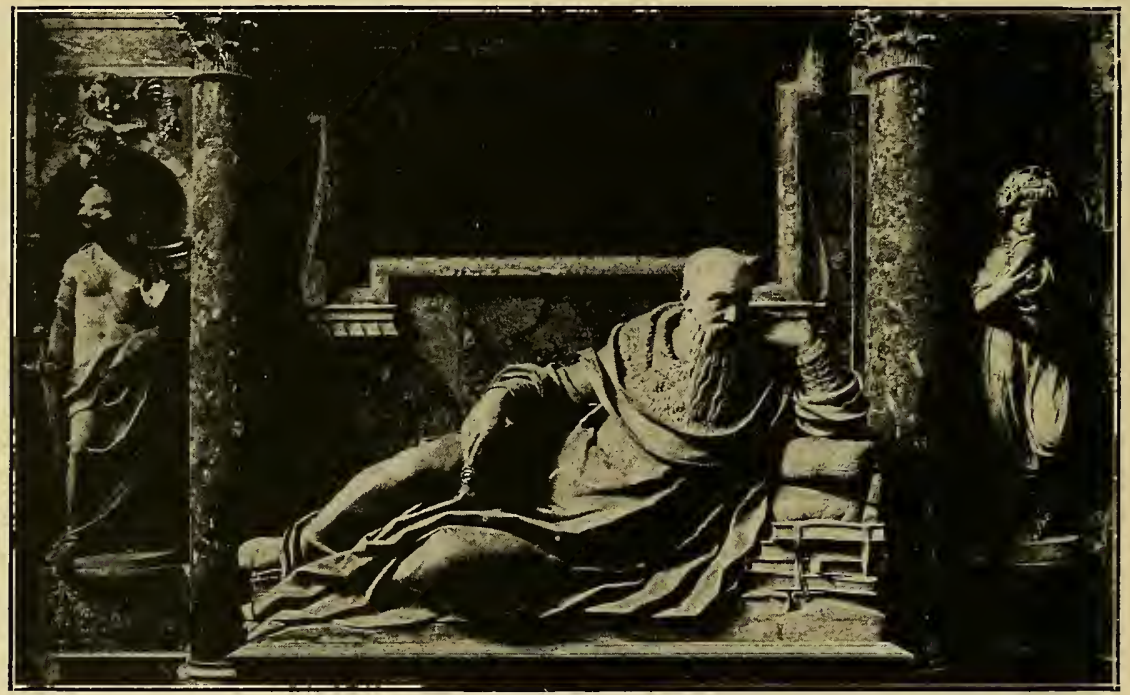

N. Cordier, Il padre di Clemente VIII, nel suo sepolcro alla Minerva.

al 1621, non era ancora del tutto libera dalla cappa pesante della Controriforma; risentiva ancora un poco della gravità dei tempi di Pio V e di Sisto. I Carracci, Guido Reni, Domenichino avevano importato a Roma le eleganti virtuosità della scuola bolognese, e Caravaggio aveva spezzato violentemente la tradizione raffaellesca, ma l'arte ufficiale non era quella; il cavalier d'Arpino dominava ancora con le sue stucchevoli composizioni di maniera, Ottaviano Mascherino e Giovanni Fontana perpetuavano le forme massicce dell'architettura sistina, e un gruppo di scultori lombardi, 
Silla da Viggiù, Antonio Valsoldo, Ippolito Buzio, Stefano Maderna, fiaccamente continuavano la corrente manieristica michelangiolesca. A leggere le biografie del Baglione troviamo decine e decine di pittori, scultori, architetti, che operavano in Roma nei primi due decenni del Seicento; ma quasi nessuno lasciò un' impronta particolare, un'opera degna di ricordo.

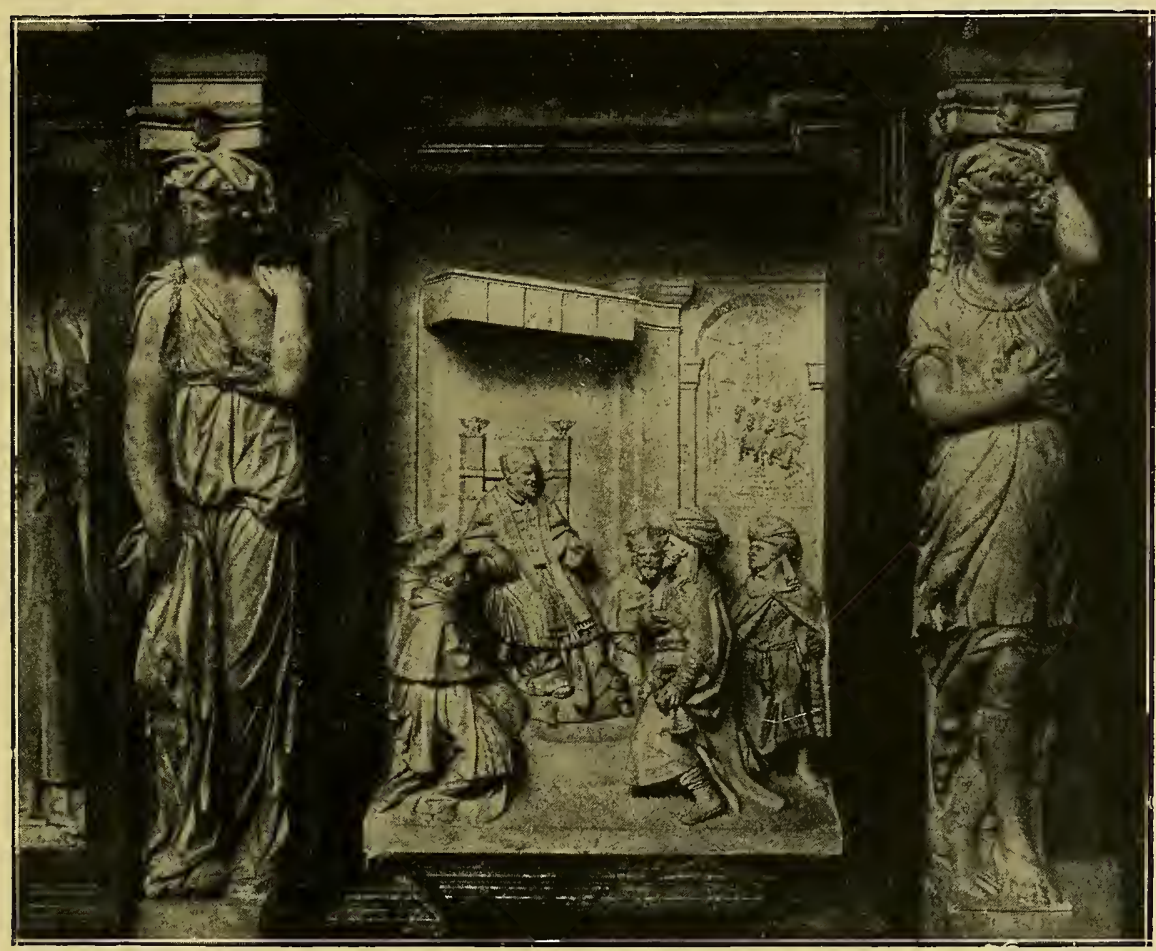

Paolo V riceve i Persiani. Rilievo sulla sua tomba in S. Maria Maggiore.

Costruttore della cappella della Madonna della Neve in S. Maria Maggiore, che comunemente si chiama Paolina, fu Flaminio Ponzio (1560-1612-3) lombardo, ch'era architetto di Nostro Signore e di Palazzo; egli ripetè la pianta della cappella Sistina alla quale la Paolina fa riscontro nella navata opposta della stessa basilica; e vi collocò pure sulle pareti laterali i mau- 
solei di Clemente VIII e di Paolo V, di forma identica a quelli di Pio e di Sisto V; ma se gli schemi sono gli stessi, lo spirito animatore dei due sacelli è essenzialmente diverso. Nella Paolina la policromia è vivissima; arditamente son messe accanto le tinte più forti, e il colore è gettato sui pilastri e sulle fasce a larghe zone; mentre nella Sistina, cornicette, cartelle, stelle araldiche

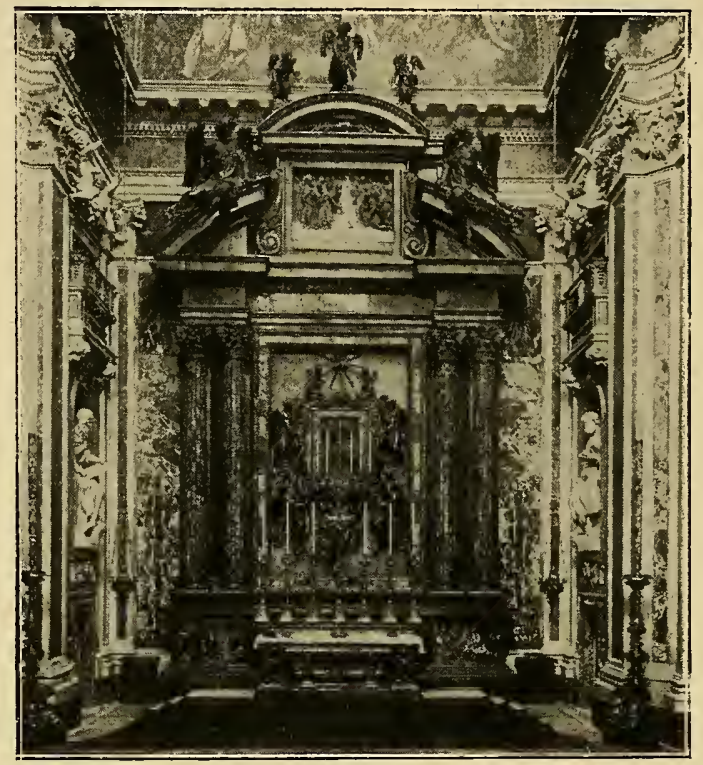

Altare della Cappella Paolina in S. Maria Maggiore.

spezzano di continuo le superfici. Domenico Fontana adoperava i marmi colorati come in un lavoro d'intarsio; Flaminio Ponzio ne riveste le paretí cone con drappi di damasco, dando alla casa della Vergine della Neve una festevolezza che contrasta col severo aspetto del sacello di Sisto V. Tra il pontificato di papa Peretti, implacabile giustiziere, lottatore del cattolicismo, e quello di Camillo Borghese, il papa avvocato, l'uomo gioviale, un mutamento grande è avvenuto negli spiriti; la Chiesa, sfuggita al pericolo che la minacciava dal nord, e rifattasi in Africa $e$ in 


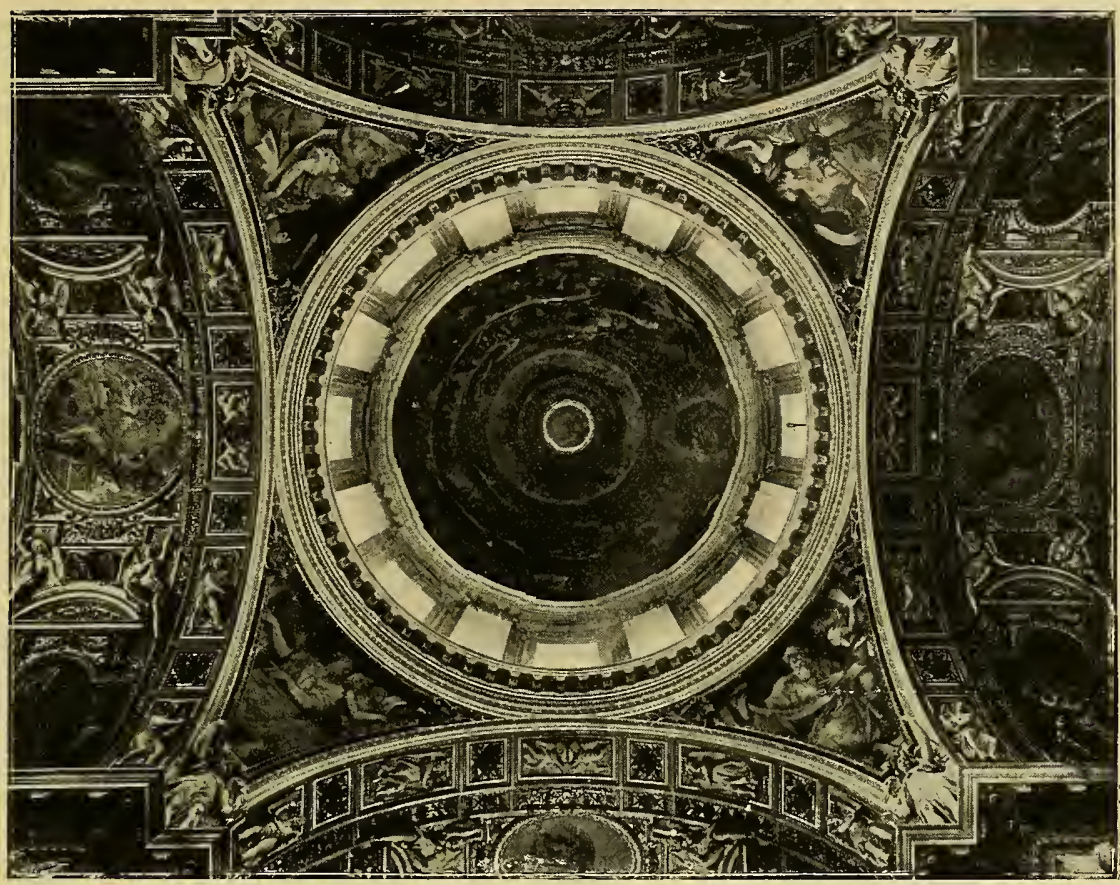

Cupola della Cappella Paolina in S. Maria Maggiore. (Fot. Anderson).

Oriente delle perdite subite in Europa, torna a vita piu libera, respira, si para a festa.

Nei sepolcri di Clemente VIII e di Paolo V sono pure incastrati altorilievi storici che rappresentano $i$ fatti più salienti dei due pontificati; quello dell' incoronazione di papa Aldobrandini fu scolpito da Pietro Bernini, venuto apposta da Napoli a Roma, attratto da questi grandi lavori che si facevano nella Basilica Líberiana; però la sua opera non piacque ed egli dovette calare il rílievo già messo a posto e rifarne uno nuovo (1614). Silla da Víggiù scolpì la statua inginocchiata di Paolo V, cosa quanto mai infelice, affagottata e greve; Stefano Maderna, lo scultore della soave $\mathrm{S}$. Cecilia, esegui il rilievo della spedizione d'Ungheria, irto di armi e scalpitante di cavalli; il vecchio Valsoldo rappresentò la santificazione di Carlo Borromeo; Cristoforo 
Stati di Bracciano il ricevimento degli ambasciatori persiani; e Ambrogio Buonvicino le fortificazioni di Ferrara. Di tutti questi scultori il milanese Buonvicino è certo il migliore; sa muovere i suoi personaggi con disinvoltura, ma non sa dare espressione

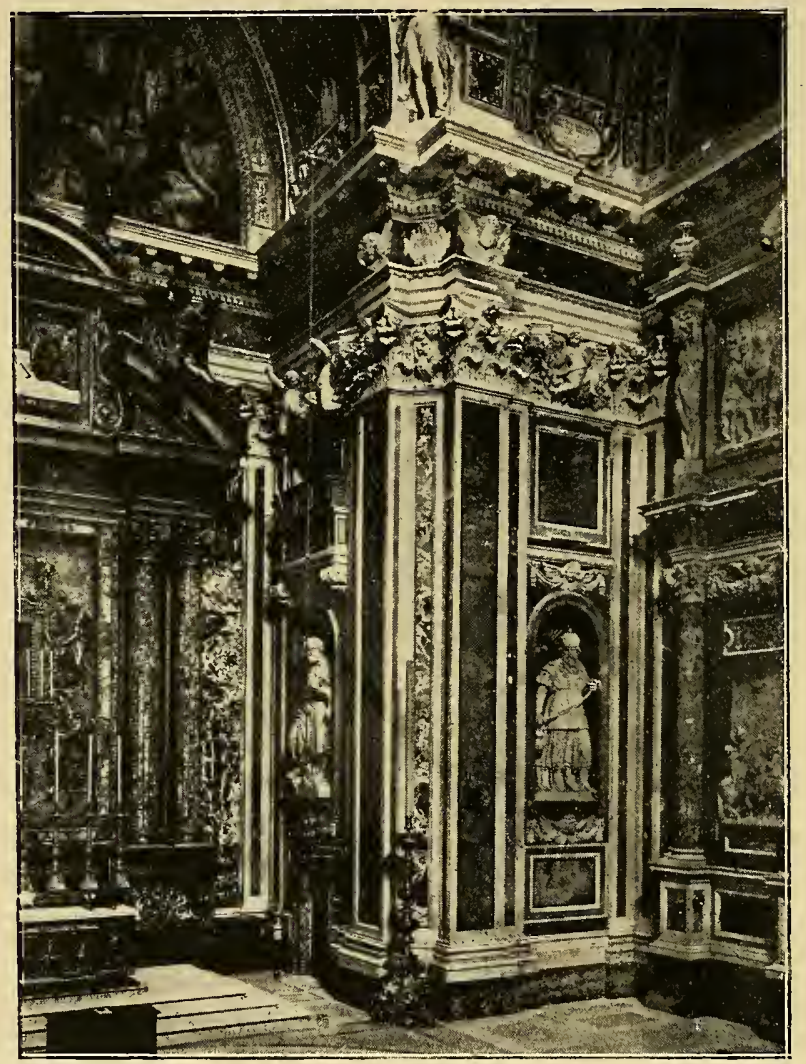

La Cappella Paolina in S. Maria Maggiore.

(Fot. Alinari).

ai visi: qui figurò Carlo Maderno che mostra al papa la pianta della fortezza di Ferrara, tra un gruppo di artisti, di cardinali, di gentiluomini, che si somigliano tutti; nel secondo piano si vedono gli operai intenti a costruire i baluardi. In grandi nicchie che si aprono nei pilastri della cappella son collocate statue di 
santi e di profeti, quelle di Aronne, di David, di S. Bernardo e di S. Atanasio, sono di Niccolò Cordier, detto il Franciosino, scultore lorenese che $\mathrm{fu}$ uno dei migliori artisti della generazione anteriore al Bernini, il quale portò in Roma, dove morì nel 1622

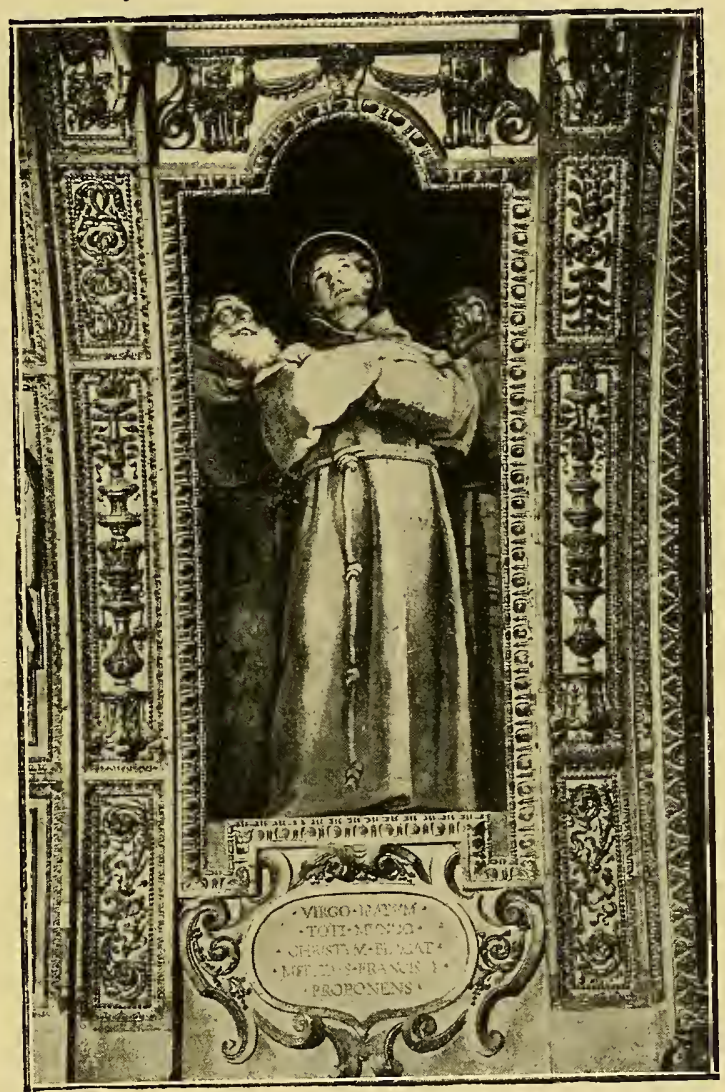

S. Francesco di Guido Reni nella Cappella Paolina.

(Fot. Anderson).

le reminiscenze dell'arte francese, dignitosa e severa, di Jean Goujon e di Germain Pilon.

L'altare della Paolina non è collocato nel mezzo dalla cappella come nella Sistina, ma è addossato alla parete di fondo, ed è un mirabile lavoro disegnato da Girolamo Rainaldí, pre- 


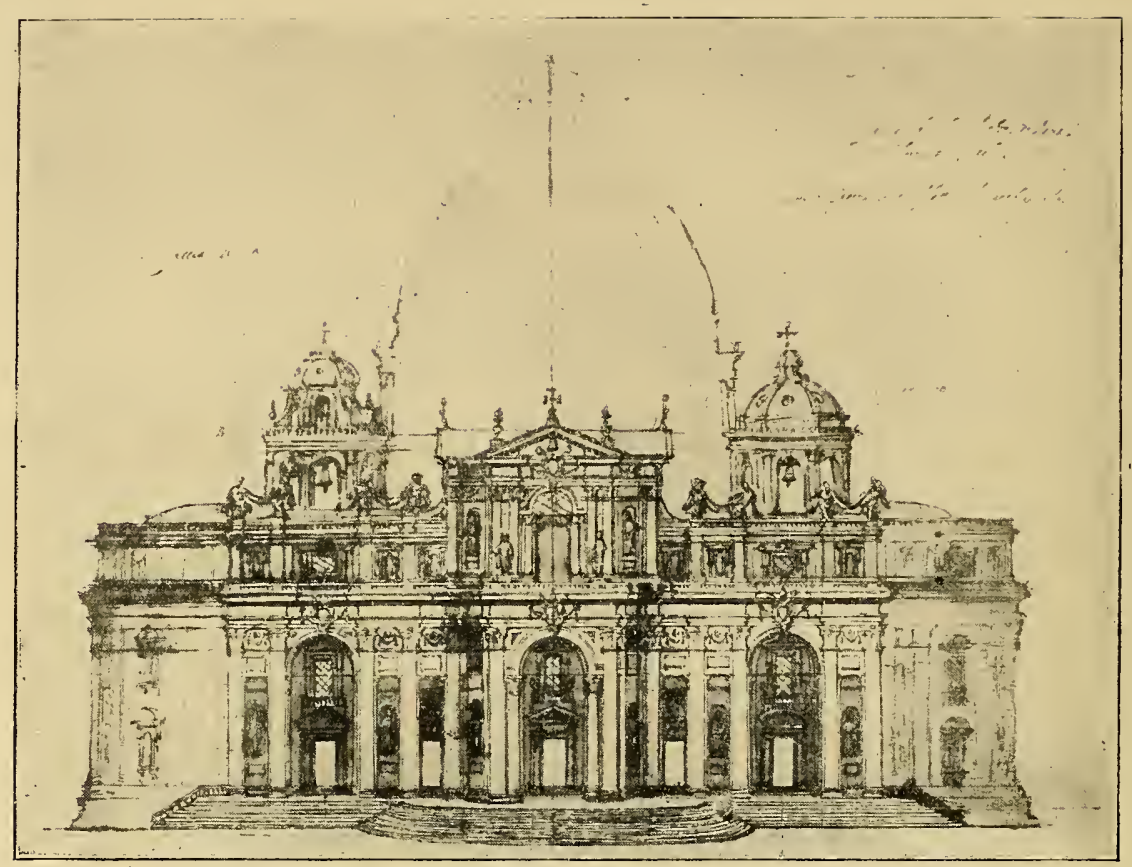

Progetto del Cígoli per la facciata dí S. Pietro. - Firenze, Gabinetto degli Uffizi.

ziosissimo per metalli e per marmi. Quattro colonne di legno rosso pietrificato, listate di bronzo dorato, sorreggono un timpano spezzato, nel quale è incastrata un'edicola con un bassorilievo marmoreo di Stefano Maderna, che rappresenta papa Liberio che traccia sulla neve la pianta della nuova basilica dedicata alla Madonna.

La parte superiore della cappella al disopra della trabeazione, e la cupola, sono decorate con affreschi; nel lunettone di fondo dipinse il floscio Cavalier d'Arpino; nella cupola un elegante maestro toscano, Ludovico Cígoli, ch'era venuto a Roma per concorrere al progetto della nuova facciata di S. Pietro, ma in tutte e due le opere riusci male, più adatto a dipingere piccoli quadri, che grandi composizioni. $\mathrm{E}$ infine nelle mezze lunette laterali e nei pilastri colori fígure e storie di santi, un giovane artista bolognese della scuola dei Carracci, che doveva salire poi 


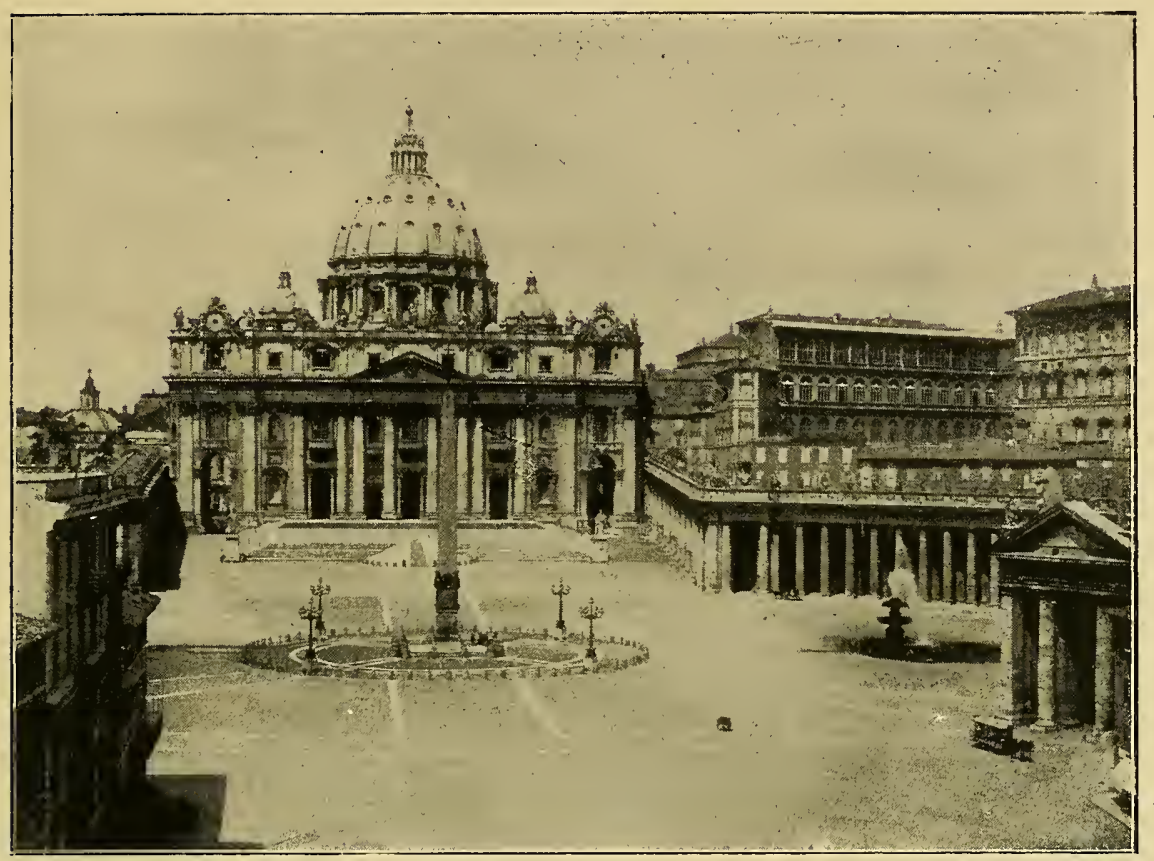

Facciata di S. Pietro di Carlo Maderno.

(Fot. Alinari).

a larghissima fama, Guido Reni, che vi sfoggiò luminose stoffe, si compiacque di forti risalti $e$ di vigorose forme quali piis tardi non ebbe quasi mai.

L'opera più grandiosa compiuta sotto il pontificato di Paolo $\mathrm{V}$ è il completamento della Basilica Vaticana, col prolungamento della parte anteriore, che trasformo la pianta da croce greca in croce latina, e con la costruzione della facciata. Si demoli senza pietà quanto rimaneva in piedi della vetusta basilica costantiniana; la navata lunga, con le cappelle e gli oratorii tra cui quello celebre di Giovanni VII adorno di preziosi musaici; si abbattè il portico con gli affreschi del Duecento, e l'atrio. Ma la distruzione di tante opere d'arte insigni di cui rimangono oggi solo poche reliquie nelle Sacre Grotte e in varie chiese di Roma e di fuori, non può imputarsi agli uomini del Seicento; 
fin dal tempo di Giulio II, quando si iniziarono i lavori d' ingrandimento con Bramante, col Peruzzi, col Sangallo, con Michelangelo, la vecchia basilica era condannata; del resto essa era così fatiscente che poco piì avrebbe potuto resistere. Il prolungamento della croce greca in latina che tanto si è criticato, da quando fu fatto fino ai giorni nostri, perchè ha diminuito l'effetto della cupola, non si deve pure rimproverare all'architetto che diresse il lavoro; fu la congregazione dei cardinali preposta alla Fabbrica che lo decise per ragioni di spazio. Prima di procedere alle nuove opere $f u$ bandito un concorso, al quale presero parte molti architetti $e$ ingegneri; tra essi Flaminio Ponzio, Giovanni Fontana, Carlo Maderno, Girolamo Rainaldi, Ottavio Turiani, Niccolò Branconi, che risiedevano in Roma; da Napoli mandò i suoi disegni l'esule Domenico Fontana, e da Firenze giunse Ludovico Cígoli, pittore e architetto, che presentò ben cinque progetti, conservati ancora oggi nel gabinetto dei disegni degli Uffizi. Dopo maturo esame fu prescelto il progetto del Maderno, del quale Giuseppe Bianco da Narni, maestro falegname, costrù̀ un modello in legno che importò ingentissima spesa. Le fondamenta della nuova facciata furono cominciate 15 novembre 1607; il 10 febbraio dell'anno successivo fu posta la prima pietra, benedetta dal papa nel palazzo del Quirinale; il 21 luglio 1612 la mole immensa che aveva assorbito montagne di travertino di Tivoli, (è alta m. 45, 44, larga m. 114, 69) era compiuta, tranne qualche lieve perfezionamento. Della facciata è convenuto che si debba dir male; da Carlo Fontana al Milizia che chiamò il Maderno il più gran reo di lesa architettura, fino a coloro che ai giorni nostri osano presentare dei progetti per correggerla, la corrente della critica ha fluito con impeto ininterrotto. E pure è un'opera organicamente concepita, perfettamente equilibrata, e mostra come l'architetto abbia saputo risolvere un difficilissimo problema. Pensate: i fianchi esterni erano già costruiti dal Buonarroti e quindi l'altezza del primo ordine era fissata; nè poteva 
il Maderno sovrapporvi un secondo ordine, come era nello schema comune delle facciate di allora (tipo del Gesì), di cui egli stesso aveva dato un magnifico esempio in S. Susanna, perchè in tal modo la cupola sarebbe rimasta per intero nascosta; onde la ra-

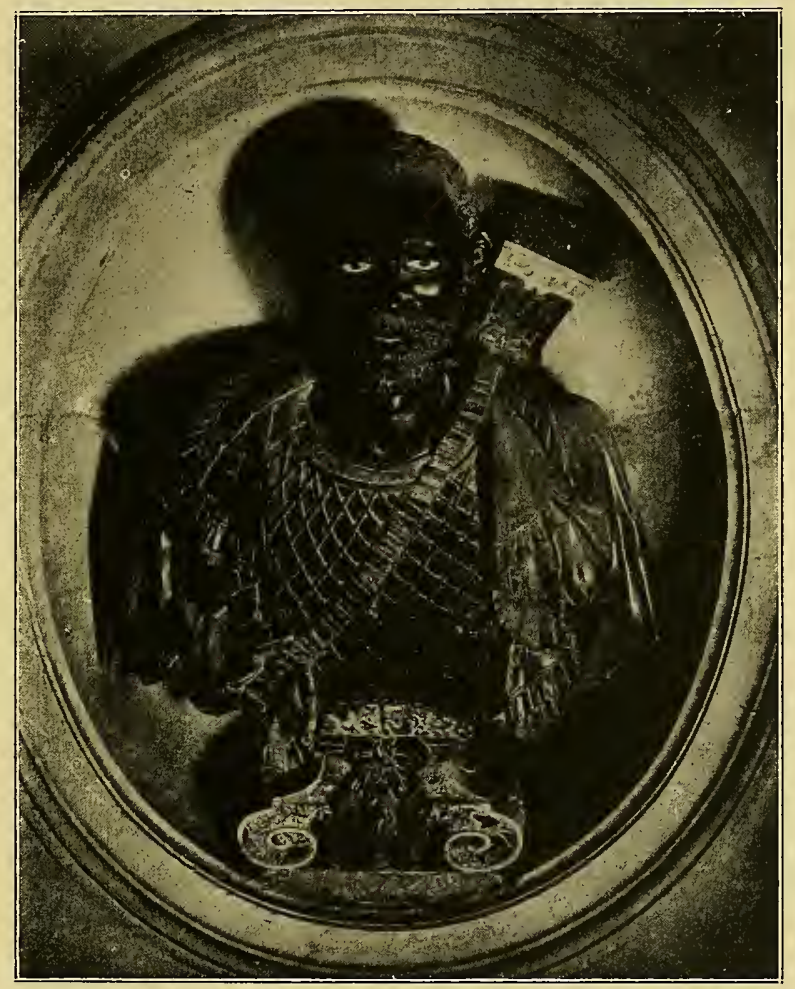

F. Caporale, Busto del Nigrita in S. Maria Maggiore.

gione del basso attico che fa sembrare la facciata piatta e tozza. Ma noi oggi non vediamo il prospetto di S. Pietro quale l'architetto lo aveva immaginato, ossia con le due torri laterali che lo innalzavano e lo sveltivano; limitate invece per ragioni statiche all'altezza della balaustrata esse hanno contribuito all'eccessivo allungamento della facciata della quale sembrano fare parte, mentre dovevano distaccarsene. 
La colpa di ciò va imputata al Maderno stesso, che non tenendo conto della qualità del terreno fece le fondazioni a sacco invece che a mano, così che, non ancora finito, il portico minacciò rovina, e non fu possibile sovraccaricarlo coi campanili; il fatto si ripetè trent' anni dopo quando il Bernini costruì sul lato di mezzogiorno una delle sue torri campanarie, che dovette demolirsi per le lesioni apparse nelle parti sottostanti.

Alla costruzione della facciata e alla ornamentazione del portico lavorò una moltitudine di muratori, capimastri e scalpellini, tra i quali c'era un tal Lione Garuo, lombardo, che aveva tra i suoi aiuti un giovinetto nativo di Bissone, sul lago di Lugano, cioè del paese stesso di Carlo Maderno, di cui era anzi lontano congiunto. Era venuto a Roma, a quindici anni, nel 1614, ad insaputa del padre, spinto dalla passione dell'arte, e si era allogato col Garuo come scarpellino: si chiamava Francesco Castello e portava anche il secondo cognome, forse materno, di Borromini.

Il mecenatismo del papa Borghese si dimostrava anche in altre opere di minor mole; nel 1614 fece condurre dal Maderno una colonna del così detto Tempio della Pace di Campo Vaccino sulla piazza di S. Maria Maggiore, sulla quale si collocò una bella statua di bronzo della Vergine, opera del francese Guglielmo Bertholot; e dentro la basilica costruì una nuova sagrestia, (oggi è il battistero), in cui fu posto un grande altorilievo con l'Assunzione della IMadonna, tutto fiorettato e bambagioso, lavoro del Bernini padre. I canonici grati di tanti benefizi eressero al pontefice dopo il 1614 una statua d'onore, che fu posta appunto nella sagrestia, ma per successive trasformazioni dell'ambiente è andata a finire in un attiguo buio passaggio; e la commisero a un bizzarro artista, Paolo Sanquirico da Parma, canonico di S. Maria in Cosnedin, il quale, narra il Baglione, faceva "ritratti di cera coloriti piccoli; si dilettava di disegnare di fortificatione e ne dava lettione, et anche ammaestrava con regole di architettura, e rappresentava in scena, e contrafaceva linguaggi ,. 


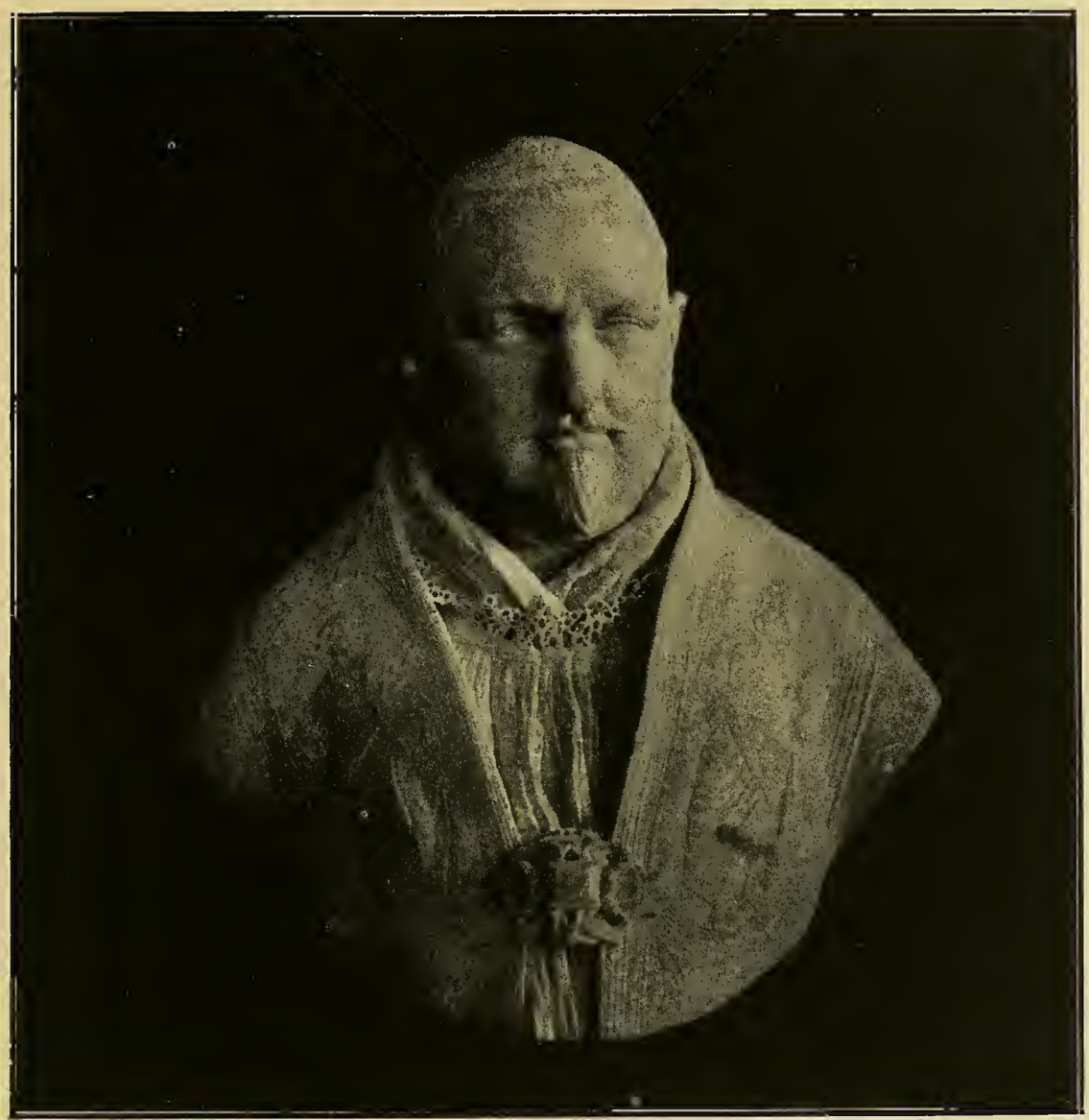

Bernini, Busto di Paolo V nella Galleria Borghese.

(Fot. Brogi)

Però la statua di Paolo $\mathrm{V}$ che nel modello píccolo in cera era parsa molto buona, fu dovuta gettare due volte in metallo, e non riusci bene. E evidente che il piacevole canonico, abituato a fare piccole figurette, si trovava impacciato nel condurre quelle grandi; egli ha talmente affagottato il povero papa, che il corpo sembra quasi non esista più dentro le vesti, e la testa esce fuori da un manichino; il piviale ricadendo a terra forma tutto attorno pieghe che si accavallano come onde spumeggianti. 
Papa Borghese costruì anche la porta e torre d'ingresso del Palazzo Vaticano, che poi cinquant'anni dopo il Bernini demolì per dar luogo ai colonnatí; fece fare la fontana in piazza S. Pietro, e quella di Scossacavalli; la mostra monumentale del-

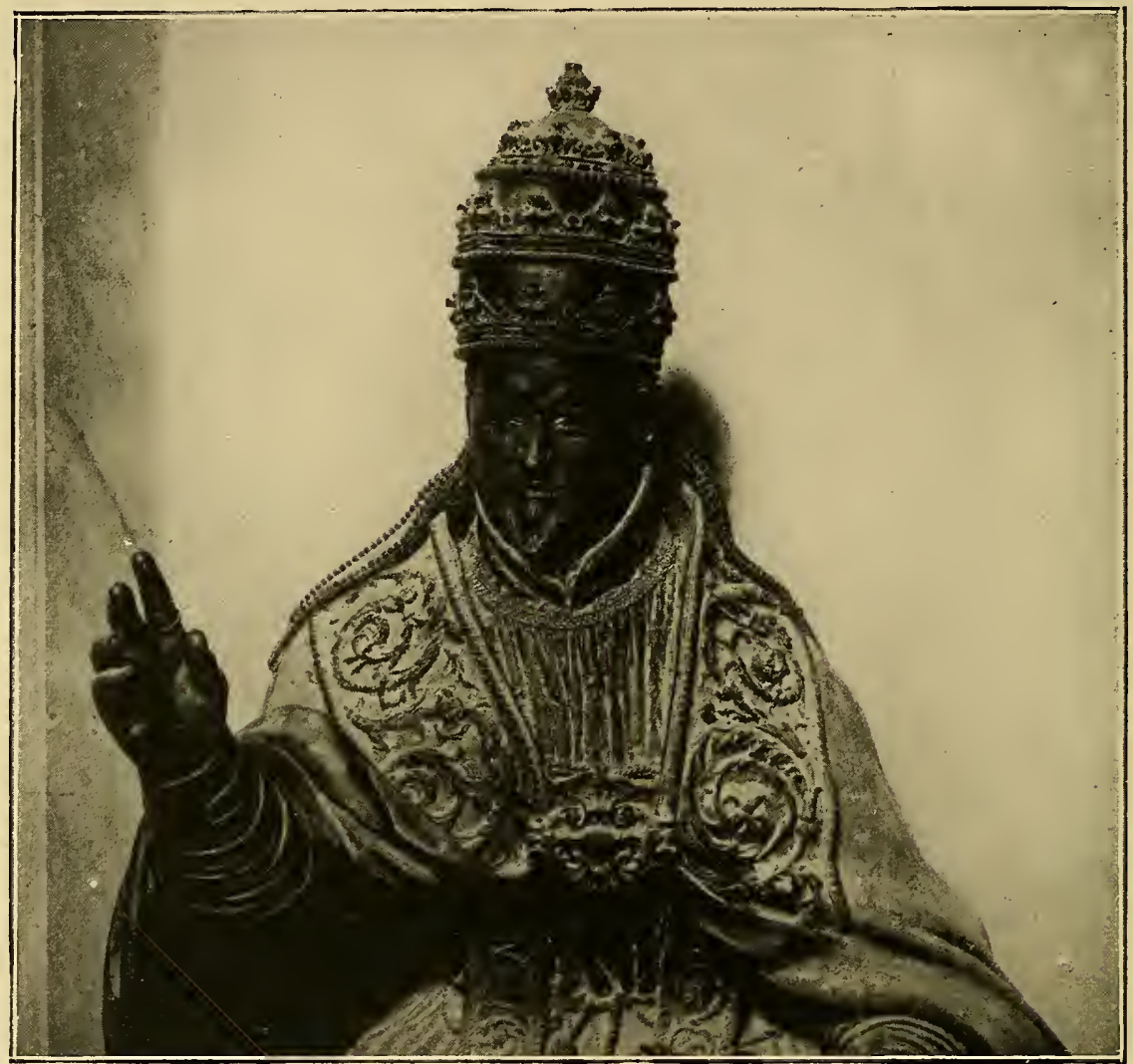

Particolare della Statua di Paolo V, di P. Sanquirico, in S. Maria Maggiore.

l'acqua Paola sul Gianicolo, opera di Giovanni Fontana, fratello di Domenico; completò il palazzo di sua famiglia a Ripetta, palificò la foce del Tevere a Fiumicino; arricchì la Biblioteca Vaticana. Continuando la politica iniziata dai suoi predecessori, Paolo V rivolse le sue cure alla diffusione del cattolicismo nei paesi d'oltremare, e potè vantarsi di vedere inginocchiati avanti al suo 


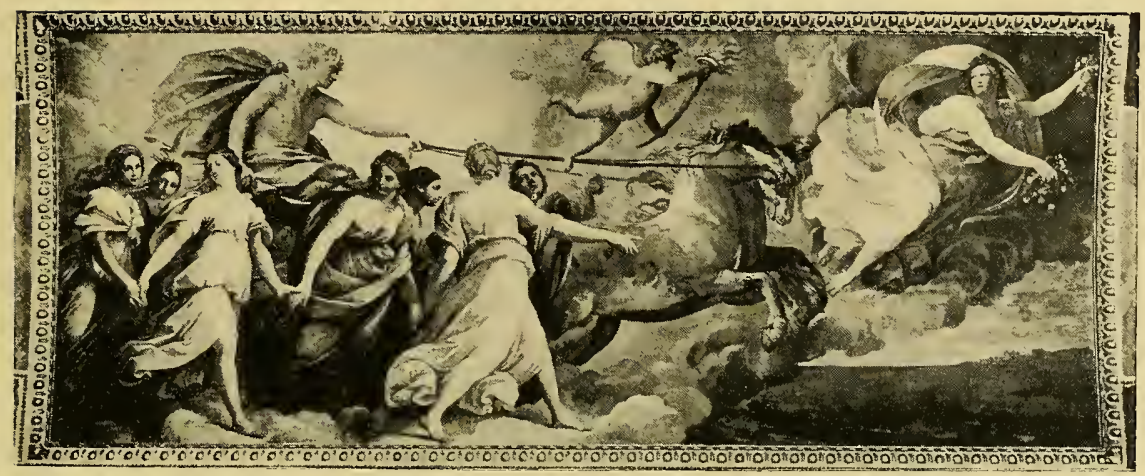

Guido Reni, L'Aurora nel Casino Rospigliosí.

(Fot. Alinari).

soglio gli ambasciatori dei più potenti sovrani di quelle regioni, della Persia, del Congo, del Giappone. La storia dell'ambasceria inviata nel $1607 \mathrm{dal}$ re del Congo, Alvaro, convertito al cattolicismo dai missionari cappuccini, ha qualche cosa di tragico e di comico insieme. I componenti di essa morirono tutti, per gli strapazzi, durante il viaggio, e a Roma non arrivò che il capo, il negro Antonio, che però non potè compiere il suo incarico di presentare al papa la lettera di devozione del suo sovrano, perchè giunse anche lui gravemente ammalato, e mori tre giorni dopo, il 6 gennaio 1608, in Vaticano, dove era ospitato, confortato dalla benedizione del pontefice, che lo nominò marchese. Il giorno stesso, verso le ore 22 la sua salma fu trasportata con solennità a S. Maria Maggiore, e in seguito si celebrarono solenni funerali. Per ricordare l'avvenimento della prestazione di obbedienza dell'ambasciatore negro, si era coniata precedentemente una medaglia, in cui egli era figurato in ginocchio innanzi al papa; la medaglia resta oggi a celebrare un fatto che in realtà non avvenne. Il disgraziato marchese moro $\mathrm{fu}$ seppellito in S. Maria Maggiore, e si pose sulla tomba un busto, opera dello scultore Francesco Caporale, che è un capolavoro di verismo; scolpito in un blocco di marmo nero, col manto giallo, e gli occhi riempiti di bianco, la fronte sfuggente, i capelli e la barba crespi, le labbra 
tumide, i pomelli lustri, gli orecchi allargati, è una perfetta riproduzione del tipo del negro. Nel 1629 in occasione dalla venuta di un altro ambasciatore del Congo, inviato ad Urbano VIII, il monumento $\mathrm{fu}$ rinnovato, conservandovisi il prezioso busto.

Mentre lo zio incoraggiava queste opere ufficiali del suo governo, o per lo meno se ne attribuiva la gloria, il cardinal

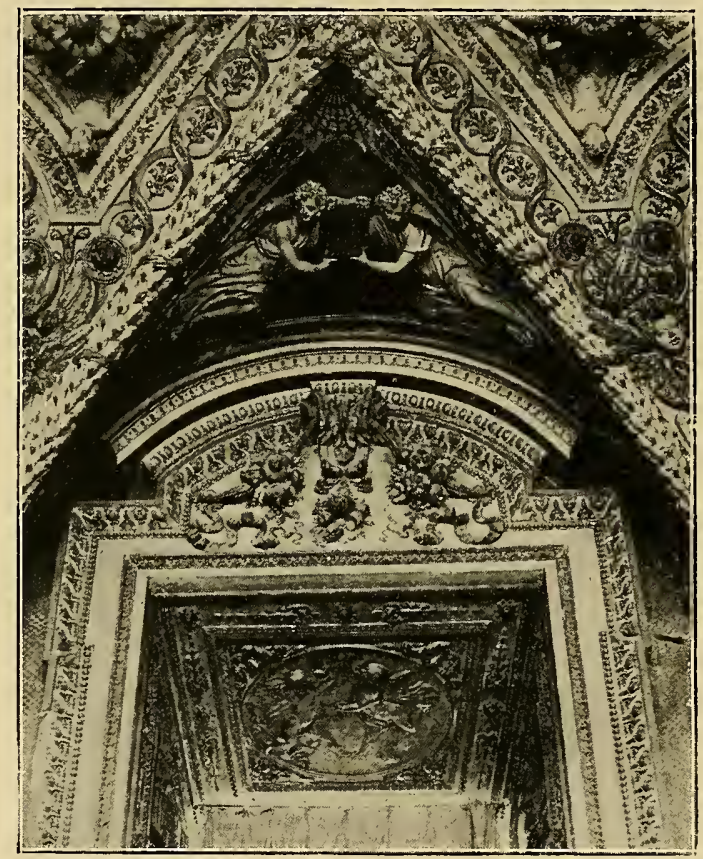

Stucchi nella Cappella Paolina al Quirinale.

Scipione, spirito raffinato, col suo gusto personale, proteggendo e avvicinando i migliori maestri, dava in Roma grande impulso alle arti. Possedeva sul Quirinale un palazzo che si era fatto costruire da Flaminio Ponzio, in vicinanza della sede pontificia, con bel giardino, e un casino in cui Guido Reni aveva dipinto per Iui la celebre Aurora: il palazzo passò poí agli Altemps; oggi è dei Rospigliosi-Pallavicini.

Il cardinal Scipione fu dallo zio colmato di benefici e di 
onori; ebbe la carica di penitenziere maggiore, $f \mathfrak{u}$ arciprete della Basilica Vaticana, bibliotecario di Santa Chiesa, prefetto della Segnatura, legato di Avignone, protettore di Germania; e sbrigava le sue molteplici faccende con garbo e con tatto squisito, gentile con tutti, liberale coi poveri, magnifico con gli artisti, onde gli fu dato l'appellativo di delizia di Roma. Accoppiando la pietà all'amore per l'arte restaurò le chiese di S. Crisogono,

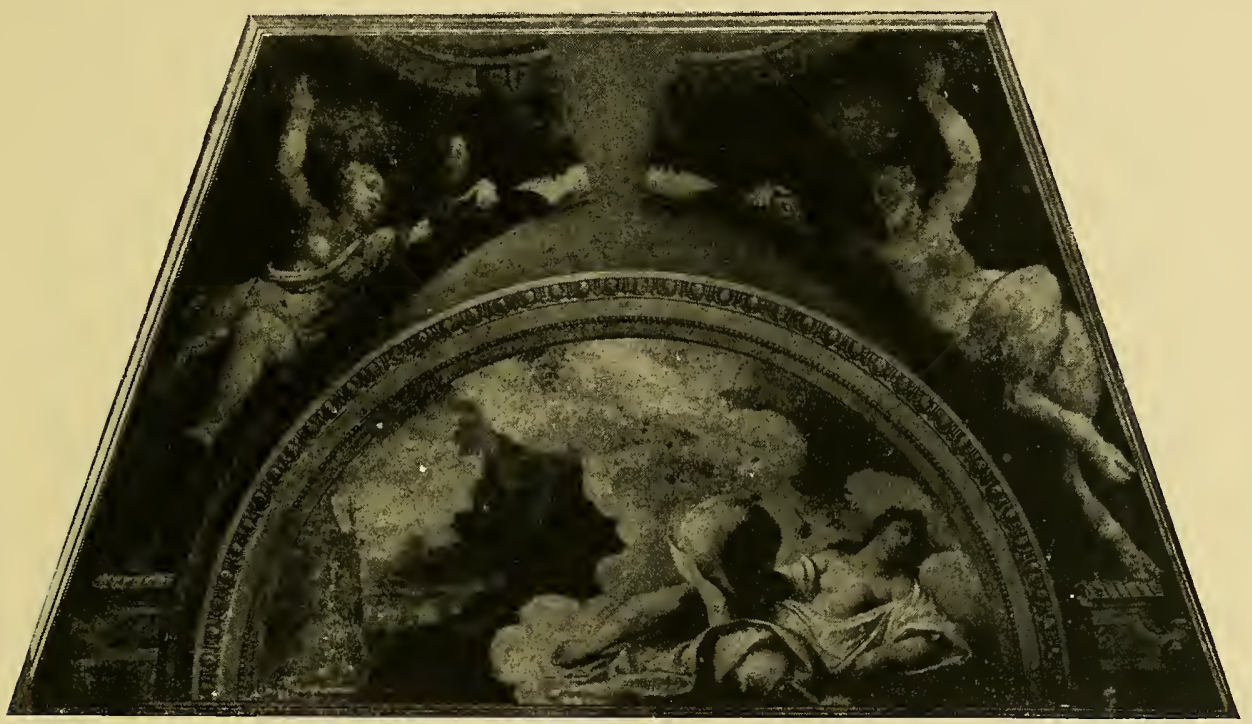

Cigoli, Psiche addormentata - Pinac. Capitolina, già nel Pal. Borghese sul Quirinale.

(Fot. Anderson).

di S. Sebastiano e di S. Gregorio, ove fece costruire il grande prospetto a doppio ordine, e si valse per questi lavori di un architetto romano Giambattista Soria (1581-1651) grande amico di Pietro da Cortona, studioso dell'antico, corretto nelle forme ma un po' compassato.

Oltre al palazzo del Quirinale volle avere un luogo di delizie fuori della città, che rivaleggiasse per lo splendore con la villa dei Peretti sull' Esquilino, e con le più famose ricordate dagli antichi; come per incanto sorse così in poco tempo la Villa 
Pinciana, che ingrandita e modificata al principio dell'Ottocento è l'attuale Villa Borghese. La vaghezza e l'amenità dei boschi e dei giardini, l'affluenza dell'acque, la maestà delle fabbriche, resero la villa del cardinal Scipione famosa in tutta Europa. Si componeva allora di quattro principali recinti; il Giardino Boscareccio, il Piano della Prospettiva, il Parco, i Giardini di Muro Torto. Nel primo recinto si ammiravano la Palazzina, dimora del signore; la Ragneria per cacciare gli uccelli; la pineta con un Casino, una alberata di abetí, due boschetti di lauri, una grotta per conservare $i$ vini, e bellissime statue antiche sparse qua e là $e$ fresche fontane; l'attraversavano molti viali di cipressi, di licini, di olmi, con spalliere di lauri, di bussi, di olivelle, di melangoli e di ginepri. Nel piano della Prospettiva vi era un albereto di lícini, un bosco di lauri, una conigliera, la fontana del Narciso, una fabbrica che serviva di stalla pei cavalli e di serra per gli agrumi, e un Teatro, ossia un piazzale semicircolare con nicchie e statue. Il terzo recinto, detto il Parco, era di piano ineguale, con colline, vallette e pianure, un lago o peschiera, una macchía, albereti di gelsi e di piante silvestri, comodo ricetto di daini, cervi, capriuoli, pecore indiane, lepri, e animali di piuma, struzzi, pavoni, anatre, cigni; l'abbellivano viali di querce, di noci, e di olmi, un boschetto per la caccia de' tordi, un casino ornato di affreschi, con giardinetti segreti, un paretaio. Il recinto di Muro Torto era coltivato a giardino di fiori e d'agrumi, con viali di peri, di brugni, di meli granati, e spalliere di lauri e di cedri, chioschi ombrosi, statue e fontane; in una di queste in forma di navicella eran disposti molti ingegnosi giuochi d'acqua, ognun de' quali prendeva nome da ciò che rappresentava: l'Ombrello, la Nebbia, il Bicchiere, la Stella, la Girandola, la Grandine, la Caccia.

In uno spazioso ed eminente piano, tra' due primi recinti, con due piazze lungo i due lati maggiori, e due giardini segreti cinti di muri, fu costruito il palazzo principale della villa, a due 
piani, con portico e loggia, e due torrette, con saloni e galleria, e nei sotterranei spaziose stanze ad uso di dispensa, bottiglieria, credenza e cucina. Ne fu architetto un fiammingo, Jan van Santen, romanizzato in Giovanni Vansanzio, che decorò le pareti esterne di statue entro nicchie, bassorilievi, targhe, iscrizioni, quasi tutti frammenti classici, che nei restauri posteriori sono in gran

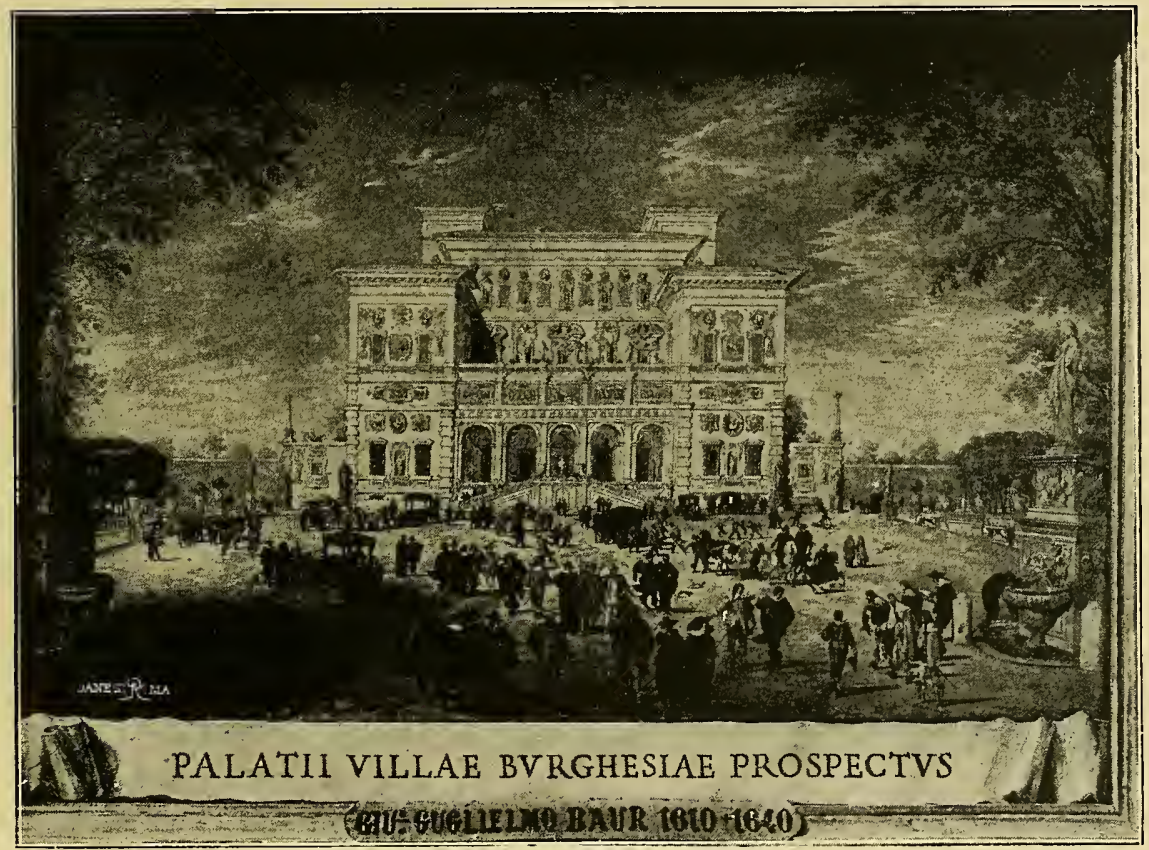

G. Baur, Il Casino della Villa Pinciana - Galleria Borghese.

parte scomparsi: il Vansanzio prima di dedicarsi all'architettura era stato intagliatore in legno e fabbricante di studioli, cioè di quegli stipi e mobiletti d'ebano con intarsiature di avorii, e applicazioni di metallo, così in voga nel suo paese; e ad essi la facciata della palazzina pinciana con tutti quegli ornati assomigliava un po'. L'interno era decorato con affreschi; il loggiato era dipinto dal Lanfranco; e una raccolta splendida di marmi antichi $e$ di quadri arricchiva il lussuoso appartamento e i saloni ter- 
reni. Per tutta 1'Italia gl' incaricati del cardinale facevano incetta di dipinti di celebri autori, e i vescovi e i nobili facevano a gara per compiacere le brame del nipote di Paolo V; quadri di Raffaello, di Tiziano, del Correggio, entrarono a far parte della famosa collezione, che il fine raccoglitore completava con le opere dei migliori artisti viventi; al Domenichino toglieva a forza la Caccia di Diana, e si procurava quadri di Guido Reni, del

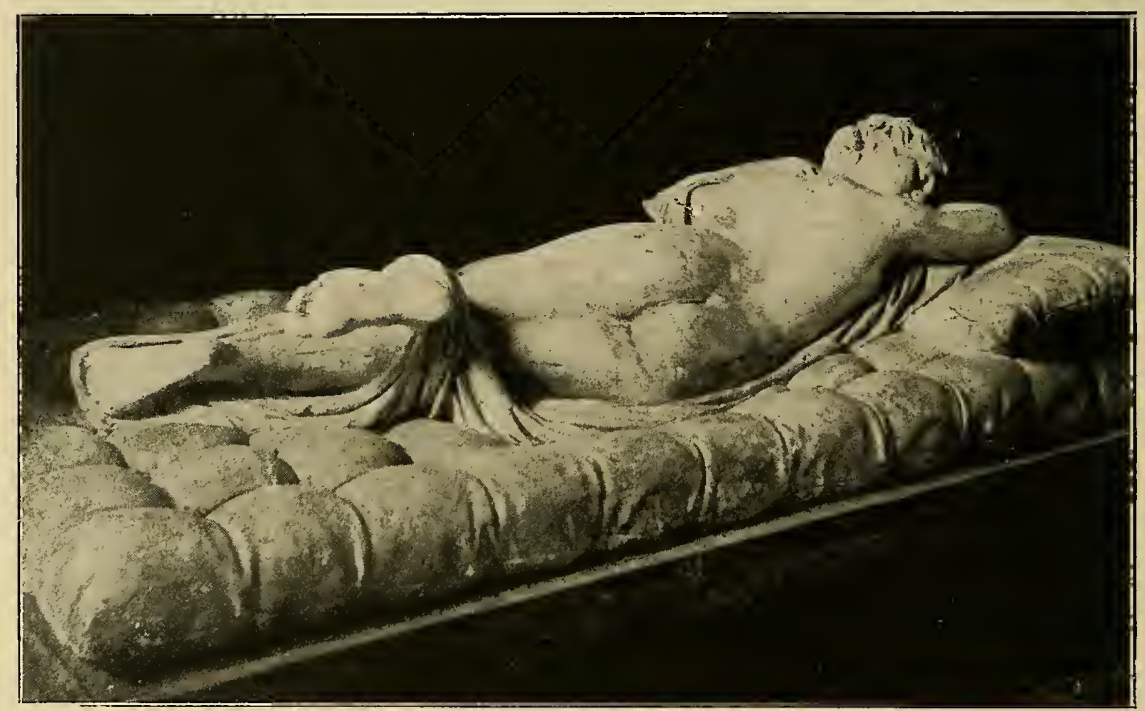

L'Ermafrodito restaurato dal Bernini - Parígi, Louvre.

Lanfranco, di Caravaggio, del Cigoli, del cavalier d'Arpino, dei Carracci. I padri Carmelitani nel cavare i fondamenti della loro chiesa di S. Maria della Vittoria rinvenivano una statua di Ermafrodito dormente, e subito ne facevano dono al cardinale che con munifica ricompensa costruiva a sue spese la facciata di quel tempio, affidandola al suo architetto preferito, Gio. Battista Soria. L'Ermafrodito $\mathrm{fu}$ restaurato da un giovane scultore che il cardinal Scipione incoraggiava nei suoi primi passi, Gianlorenzo Bernini, il quale riportò la figura su un matarazzo di marmo; 


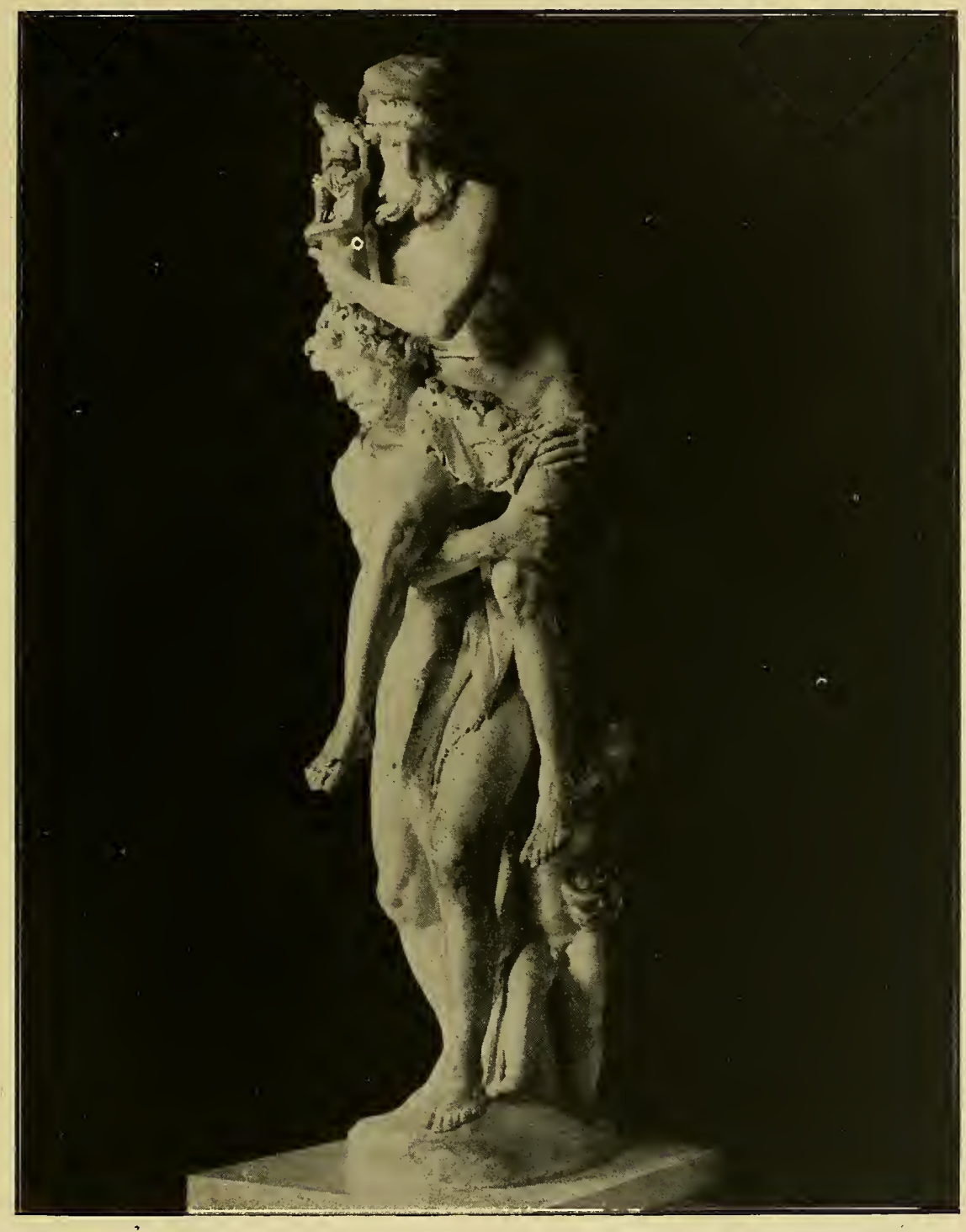

Pietro e Gianlorenzo Bernini, Enea ed Anchise - Roma, Galleria Borghese.

(Foi. Alinati). 
posta su una "gran cassa di noce fregiata tutta con fogliami ed altro di vago intaglio, e sostenuta da otto figurine di rilievo dispostevi attorno " la statua formava l'ornamento principale di una camera del palazzo che da essa prendeva il nome: oggi è al Louvre insieme con gli altri marmi antichi della collezione borghesiana, emigrati nel periodo napoleonico. Il magnifico cardinale accompagnava le sculture classiche con quelle moderne, a preferenza di soggetto mitologico; ai due Bernini padre e fíglio commise un gruppo di ispirazione virgiliana, l'Enea che scampa dall' incendio di Troia portando in salvo il vecchio padre Anchise, il fíglioletto Ascanio, e le statue degli dei Penati: lo stesso episodio era rappresentato nella galleria del palazzo in un quadro di Federico Barocci. Il gruppo marmoreo in cui il manierismo del vecchio Bernini soffoca la fresca ispirazione del giovine Gianlorenzo, è una caratteristica espressione dell'arte plastica tra il 1615 e il '20; c'è l'eco delle forme michelangiolesche, c'è la ricerca forzata della varietà di atteggiamenti, lo sfoggio di bravura e di scienza tecnica, e insieme una finezza di esecuzione, una dolcezza di modellato che la vecchia generazione ignorava e che corregge e ingentilisce le artificiosità tradizionali. Si sente il giovine artista impaziente dei legami a cui l'esperienza paterna lo assoggettava; lasciatelo operar da solo e allora spiccherà il gran volo. Ed eccolo subito dopo (1620 circa) quando il cardinale gli assegna una figura biblica, David, mostrare tutto il suo genio. C'è sì, in quel corpo di giovinetto che nello sforzo del giusto mirare tende tutti i suoi muscoli e le sue facoltà, ancora qualche cosa di duro e di secco, ma la vita trionfa, il movimento si esprime con slancio insuperabile, i ceppi del convenzionalismo sono infranti, e, come ormai vedremo in tutte le opere del Bernini, ogni parte della figura concorre all'espressione dell' insieme, per cui da un solo frammento della statua si indovinerebbe il suo atteggiamento di molla che sta per scattare. "La bellissima faccia di questa figura (scrive il biografo Baldinucci), che egli 


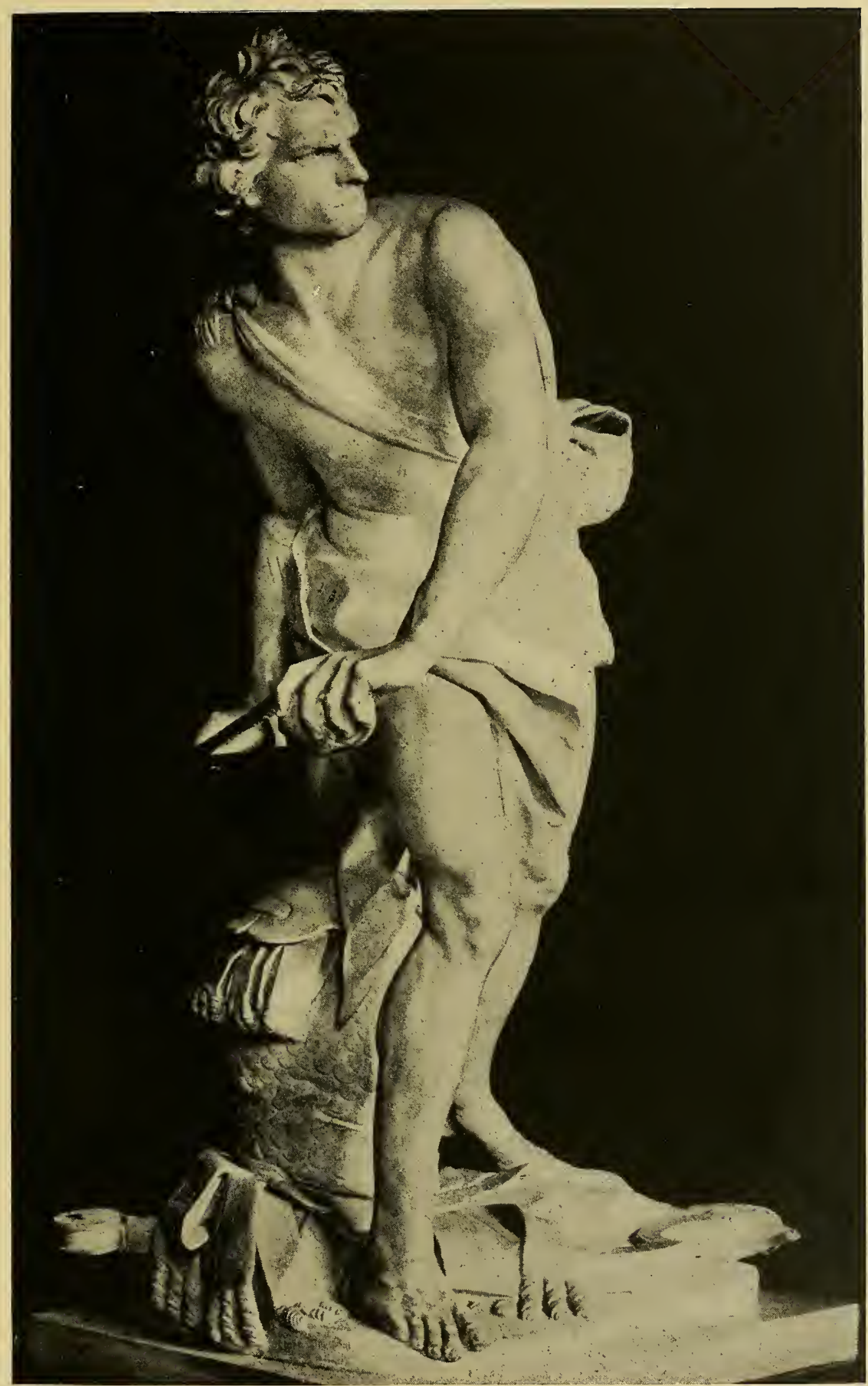

Gianlorenzo Bernini, David - Galleria Borghese.

(Fot. Alinari). 
ritrasse dal proprio volto suo, con una gagliarda increspatura di ciglia all' ingiù, una terribile físsazione d'occhi, e col mordersi con la mandibola superiore tutto il labro di sotto, fa vedere maravigliosamente espresso il giusto sdegno del giovane israelita, nell'atto di voler con la frombola pigliar la mira alla fronte del gigante filisteo, nè díssimile risoluzione, spirito e forza, si scorge in tutte l'altre parti di quel corpo, al quale, per andar di pari col vero, altro non mancava che il moto; ed è cosa notabile, che mentre egli lo stava lavorando, a somiglianza di sè medesimo, lo stesso cardinal Maffeo Barberino volle più volte trovarsi nella sua stanza, e di sua propria mano tenergli lo specchio „. Primo onore dei moltissimi che il cardinale, divenuto poi Urbano VIII, doveva rendere al Bernini. Scipione Borghese volle dal giovane e già celebre maestro due altre opere per il suo palazzo pinciano: una fu il gruppo di Plutone che rapisce Proserpina (circa 1622), l'altra quello di Apollo e Dafne (1623). Mirabile è nel primo il contrasto tra la figura robusta del rapitore dalla testa ferina, e il corpo tenero e gentile della fanciulla, che si attorce nella poderosa stretta e con la mano respinge la faccia spaventosa, e piega il capo per non vederla. Nessuno scultore dell'antichità o del rinascimento aveva saputo dare al marmo la mollezza della carne, come qui il Bernini : la mano dell'orribile dio si affonda nel corpo di Proserpina che palpita e freme. Nel volto della bella creatura l'orrore non è espresso in modo violento; c'è, pur nel grido disperato, qualche cosa di calmo, di composto, che fa pensare agli antichi. Certo Gianlorenzo Bernini, il prodigioso giovane che dopo tanta miseria restituiva la vita alla scultura, aveva rafforzato la prima educazione fatta alla bottega paterna, con lo studio delle cose classiche. Domenico suo figliuolo che ne scrisse nel 1703 la biografia, ci racconta che "per la spazio di tre anni si portò quasi ogni mattina da S. Maria Maggiore presso cui Pietro suo padre haveva fatto fabbricare una commoda Casina, et andava 


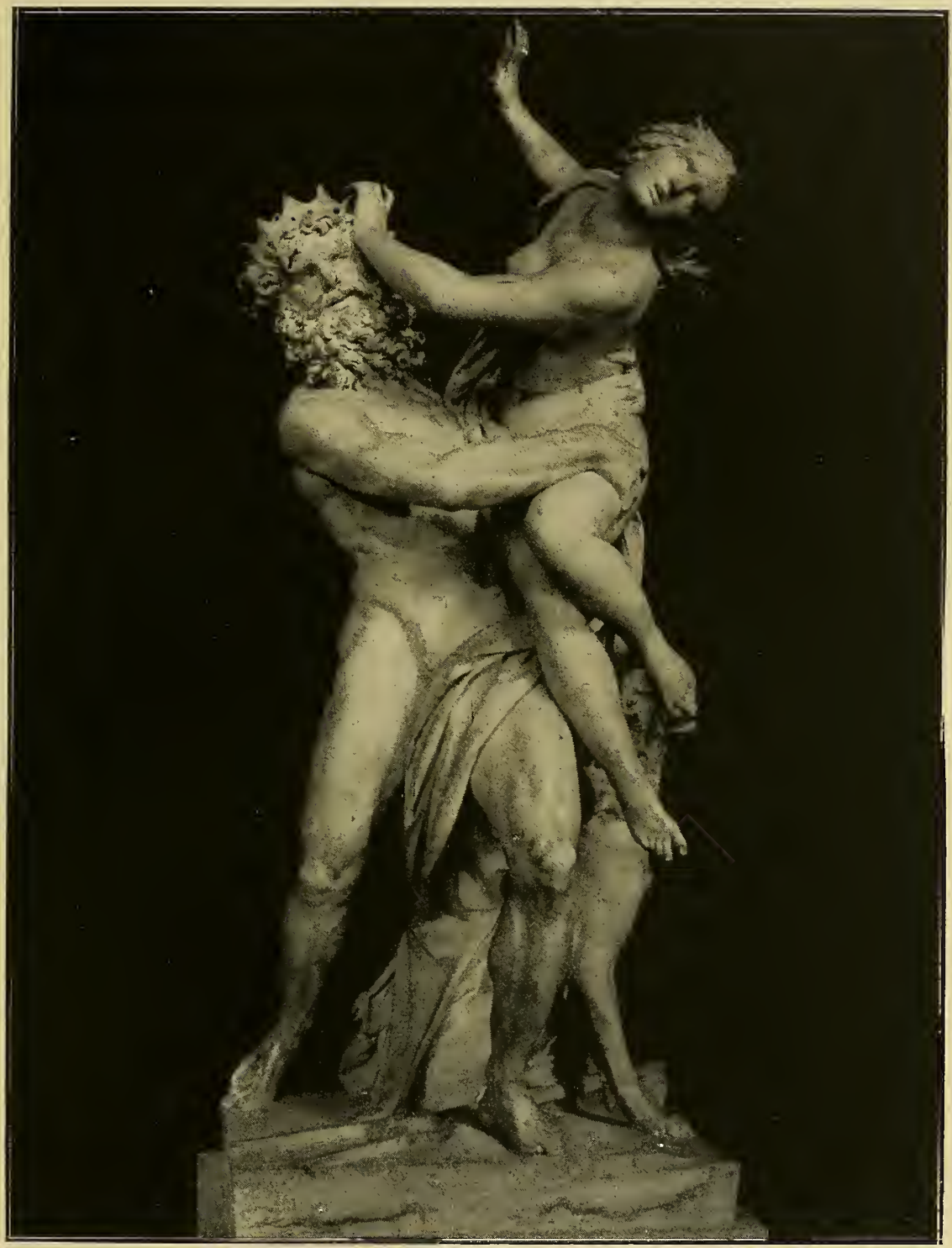

Bernini, Plutone e Proserpina - Galleria Borghese.

(Fot. Alinari). 
a piedi al Palazzo Vaticano, e quindi fino al tramontare del sole si tratteneva a disegnare hor una, hor l'altra di quelle meravigliose statue che l'antichità ha tramandato $a \mathrm{Noi}$, e ci ha conservato il tempo in beneficio e dote della Scultura. Nè altro refrigerio prendeva in tutti quei giorni, che di poco vino e cibo, dicendo che il solo gusto della viva lezzione di quelle morte Statue gli faceva ridondare nel Corpo ancora una non so qual dolcezza, ch'era sufficente a mantenerlo in forza gl' intieri giorni. Sicchè era cosa così solita il non comparir in casa Gío. Lorenzo che il Padre non vedendolo per giorni intieri, nè pure domandava di che ne fosse, certo già della dimora di lui nello Studio di S. Pietro, dove al dir del Figliuolo stavan di casa le sue Innamorate, intendendo delle Statue che vi erano „.. Ancora molti anni più tardi, nel 1665 , ricevuto solennemente all'Accademia di Parigi, egli vi tenne un discorso, in cui ricordò lo studio che da fanciullo faceva delle statue antiche, consigliandolo ai giovani come fondamento necessario dell'arte. Eppure il sentimento che anima le opere del Bernini, anche quelle giovanili che di più avrebbero dovuto risentire 1' infuenza dell'amoroso studio dell' antíco, è tutto diverso da quello dei classici. Vediamo il terzo gruppo fatto pel cardinal Scipione, l'Apollo e Dafne, una delle più mirabili creazioni del maestro. La favola antica poteva offrire al Bernini l'occasione per mettere a profitto la sua conoscenza della statuaria greca e romana, e invece all' infuori dell' imitazione puramente formale della testa di Apollo, derivata da quello di Belvedere, non si può imaginare nulla di più diverso dall'antico del gruppo borghesiano in cui apparisce chiaramente determinata la tendenza pittorica, propria del Bernini, il quale ferma nelle sue opere plastiche un momento dell'azione, mentre gli antichi esprimevano nella scultura il prolungarsi di un atteggiamento, la stabilità. Se si fa il confronto tra il Discobolo classico e il David berniniano, si riconosce subito la differenza profonda di concezione del maestro greco e di quello barocco; nel David è colto 


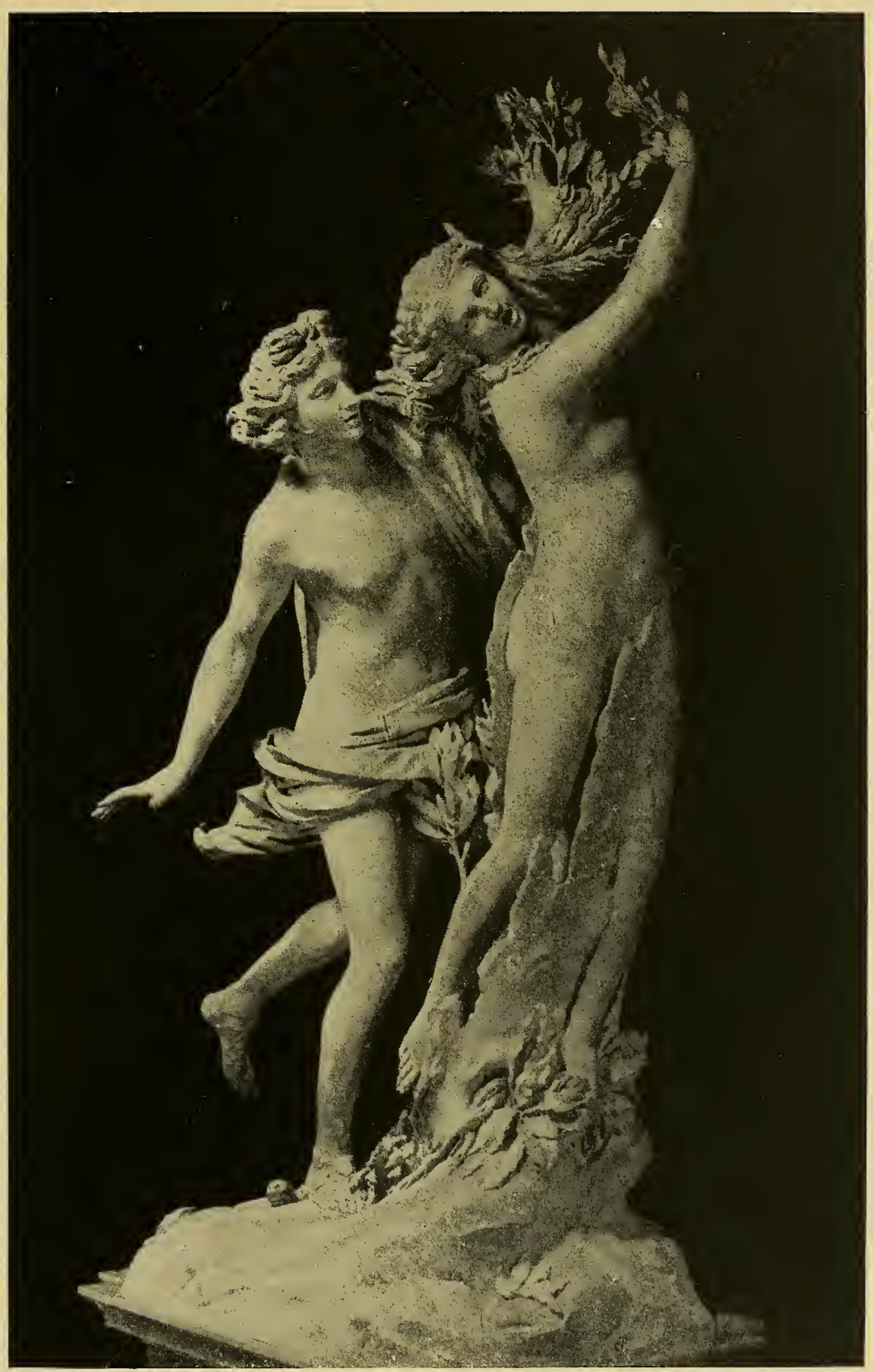

Bernini, Apollo e Dafne - Galleria Borghese.

(Fot. Alinari). 


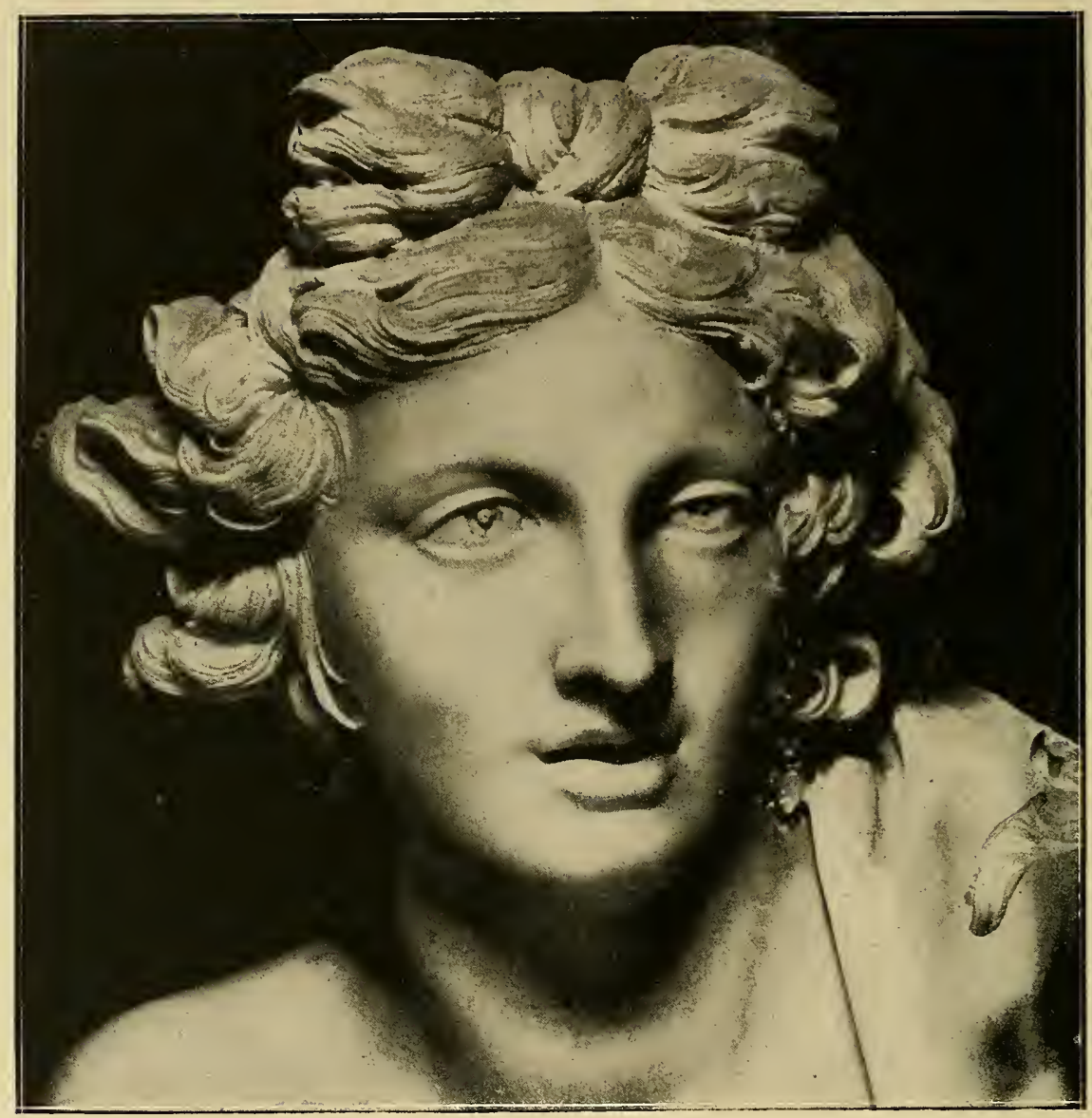

Bernini, Testa dell'Apollo - Galleria Borghese.

(Fot. Anderson).

il momento, anzi l'attimo in cui il giovinetto sta per scagliare la fionda, e si vede bene che egli non potrebbe indugiare in quell'atto; il Discobolo invece, pure nel suo vivace movimento ha qualche cosa di fermo e di calmo, e nell'aggiustare la mira e nel raccogliere le forze pel lancio del disco potrebbe conservare anche a lungo la sua posizione.

Il gruppo di Apollo e Dafne è un miracolo di grazia e di raffinata eleganza; qui il maestro non cerca più, come aveva 


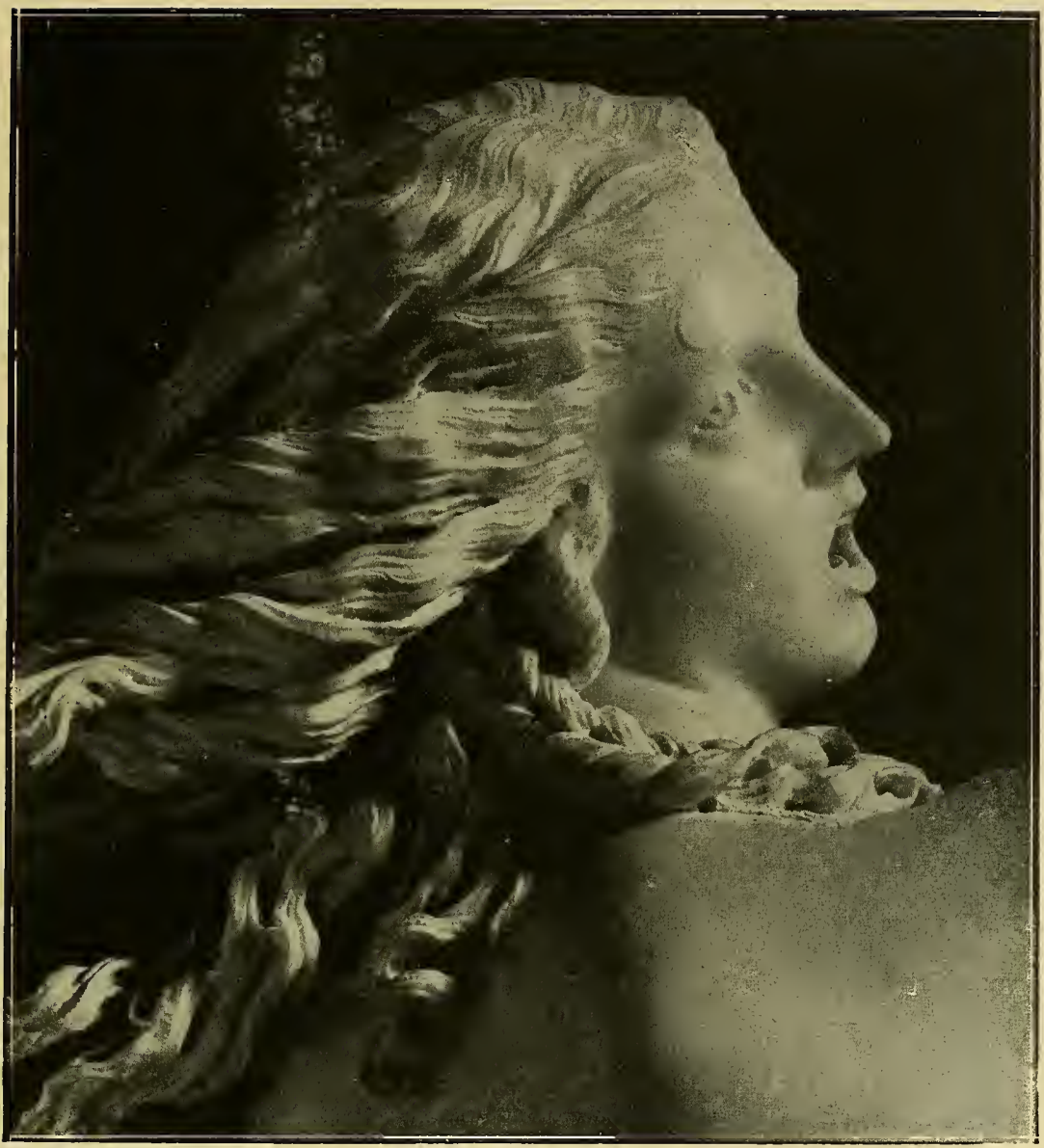

Bernini, Testa di Dafne - Galleria Borghese. (Fut. Anderson).

fatto nel Plutone e Proserpina per un resto di manierismo, il contrasto tra le due fígure, ma tutte e due sono giovani, delicate, fresche. Il bellissimo dio ha raggiunto nella corsa la fanciulla desiata, e mentre col braccio le cinge la vita, la vede atterrito tramutarsi in albero: dai piedi escono filamenti che si abbarbicano al suolo, le dita affusolate delle mani si prolungano in rami fronzuti, e sul corpo delicato sale la dura corteccia che lo racchiuderà inesorabilmente. La bellissima manda un grido 
disperato di spasimo e di terrore, e Apollo la guarda col volto impietrato. È la più bella espressione che la favola antica abbia trovato nell' arte di tuttí $i$ tempi; chè nè Ovidio, nè alcuno scultore antico seppero darle tale venustà : c'è a Copenaghen una statua classica di Dafne, che certo il Bernini conosceva perchè era ai suoi tempi nel casino pinciano fra $i$ tesori del cardinal Scipione, ma è una poverissima cosa in confronto del gruppo barocco. Come gli eroi antichi parevano più nobili $e$ grandi in Corneille che negli scrittori classici, così la favola di Dafne è più bella in questa interpretazione del maestro moderno che nel marmo romano.

Il munifico committente, delizia di Roma, era invidiato per le mirabili cose che raccoglieva nel suo palazzo, e per ingraziarsi il suo successore nel titolo di cardinal nipote, Ludovico Ludovisi, creato dopo l'assunzione al pontificato di Gregorio XV (1621-1624) gli mandò a regalare il gruppo di Plutone e Proserpina. Ma tenne per sè gelosamente quello bellissimo di Apollo e Dafne, di cui si era sparso tal grido che tutta Roma correva a vederlo come un miracolo, e il giovine artista era segnato a dito per le strade come un prodigio. Non mancò qualche occhio casto che si offese per la nudità della fanciulla, e che forse ne trovò strana la presenza in casa di un porporato; ma il cardinale Maffeo Barberini, il futuro Urbano VIII, che era uno squisito poeta toscano e latino, riparò lo scandalo con un distico tornito che dava alla composizione un contenuto morale, e che fu inciso in un' elegante cartella marmorea del basamento :

Quisquis amans sequitur fugitivae gaudia formae Fronde manus implet, baccas seu carpit amaras.

Un'altra bellissima creazione doveva il cardinale ispirare al Bernini, ma di carattere tutto diverso, e $f u$ il suo ritratto. Gianlorenzo che in questi gruppi mitologici appare come un idealizzatore della forma, era al tempo stesso un potente ritrat- 
tista; anzi aveva iniziato la sua carriera così fortunata, appunto con lo scolpire busti ritratti. Dopo quello del vescovo Santoni in S. Prassede, che si vuole scolpito a dieci anni, e che rivela già una rara acutezza d'interpretazione, aveva fatto un delizioso bustino di papa Paolo V, oggi nella Galleria Borghese, piacevolissima cosa, tutto brio e vivacità ; un ritratto più grande in

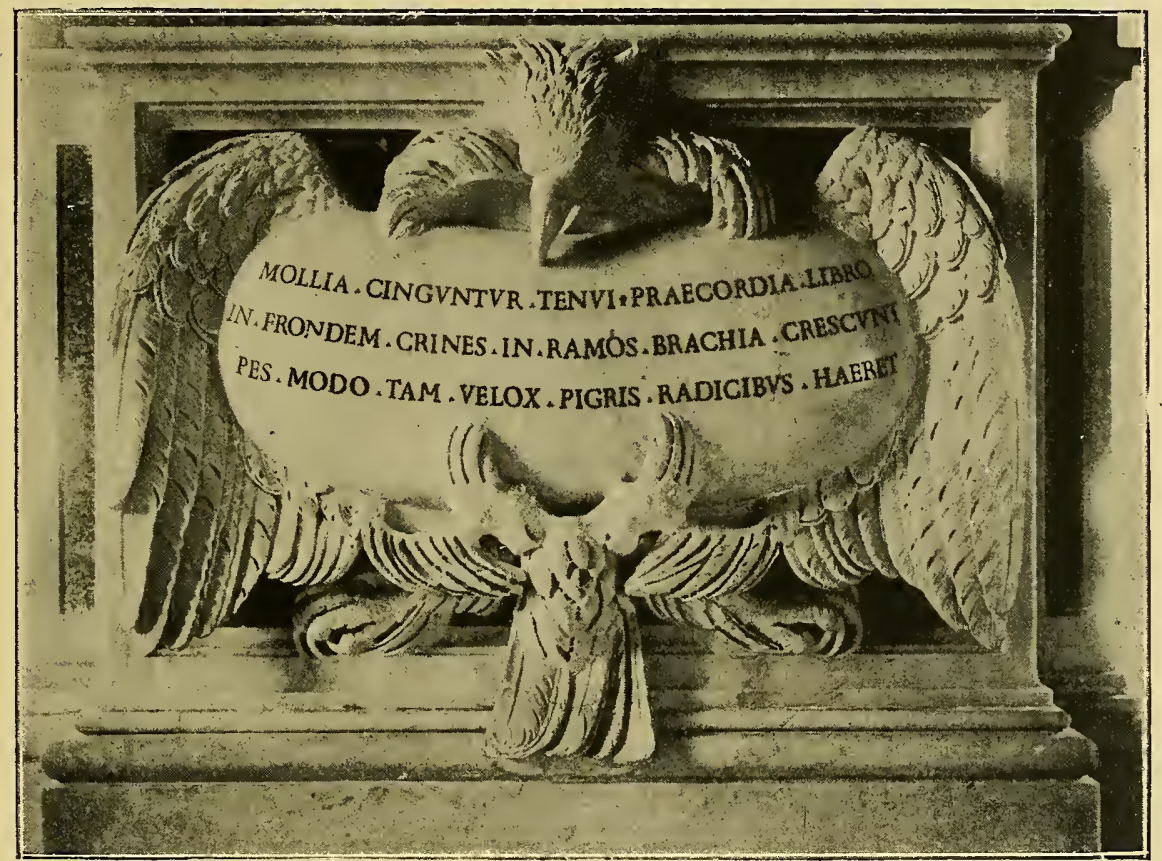

Basamento del gruppo di Apollo e Dafne.

bronzo dello stesso pontefice, di cui rimane solo una copia, $e$ varî bustí di Gregorio XV, in marmo e in metallo, uno dei quali è nella collezione Stroganoff a Roma. Per quest'opera papa Ludovisí lo creò nel 1622 cavaliere di Cristo, e una stampa di Ottavio Leoni, di quell'anno, ce lo rappresenta giovane elegante, con la croce bene in vista sul petto. Il Bernini come ritrattista ci appare dotato di una rarissima qualità, che pochi artisti hanno; quella di sapersi adattare volta per volta al con- 


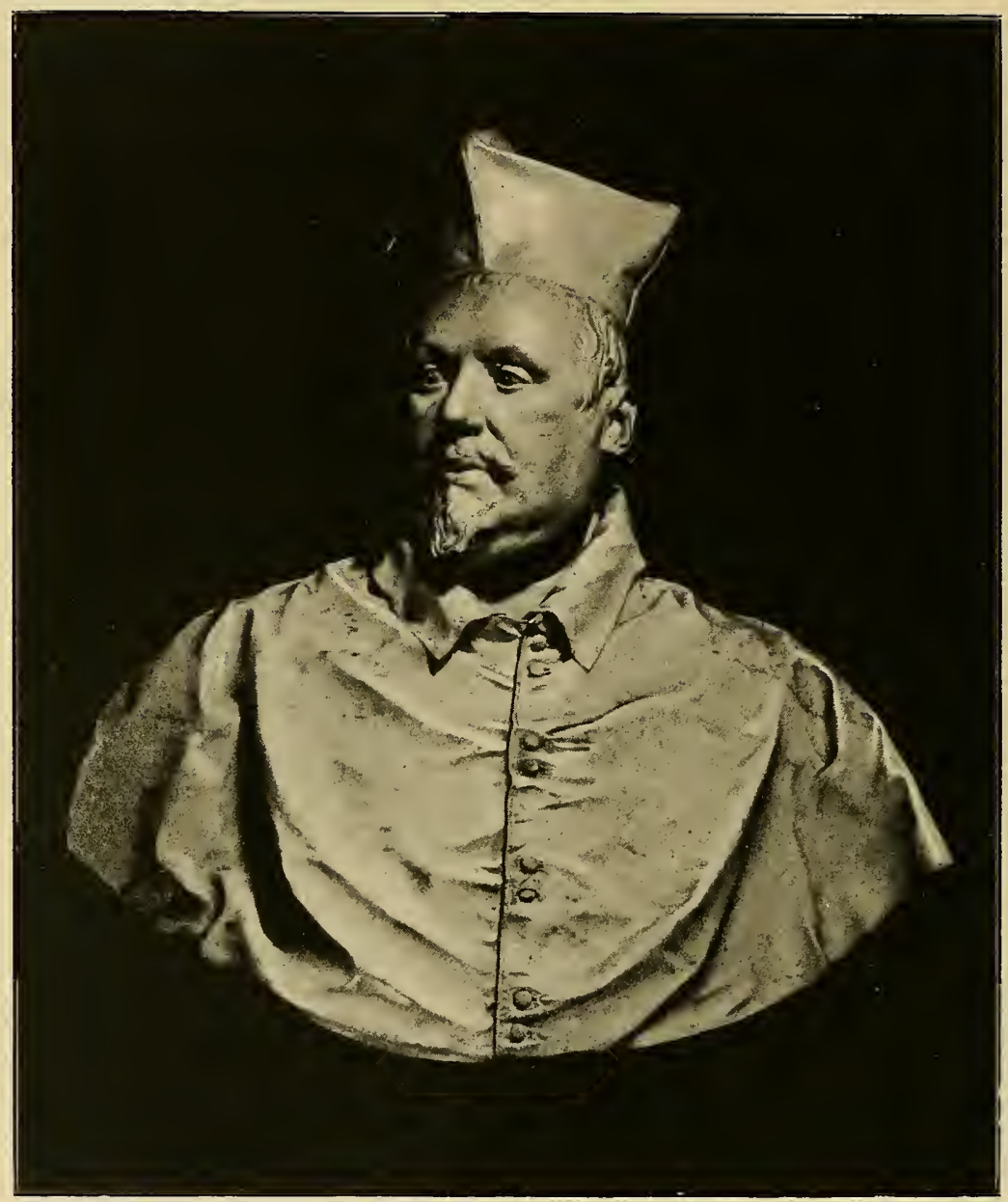

Bernini, Primo busto del card. Scipione - Galleria Borghese.

(Fot. Alinari).

tenuto psicologico del soggetto da interpretare, per cui potè rendere con la stessa effícacia la stanca físionomia del debole Gregorio XV, e la ossuta consunta testa di monsignor Montoya, e la vitalità felice del cardinal Scipione, trovando ogni volta lo stile adatto, la fattura larga e spigliata, o quella rigida e dura. Così trovandosi di fronte alla figura robusta e superba del suo protettore, Bernini si foggiò uno stile nuovo, che il 


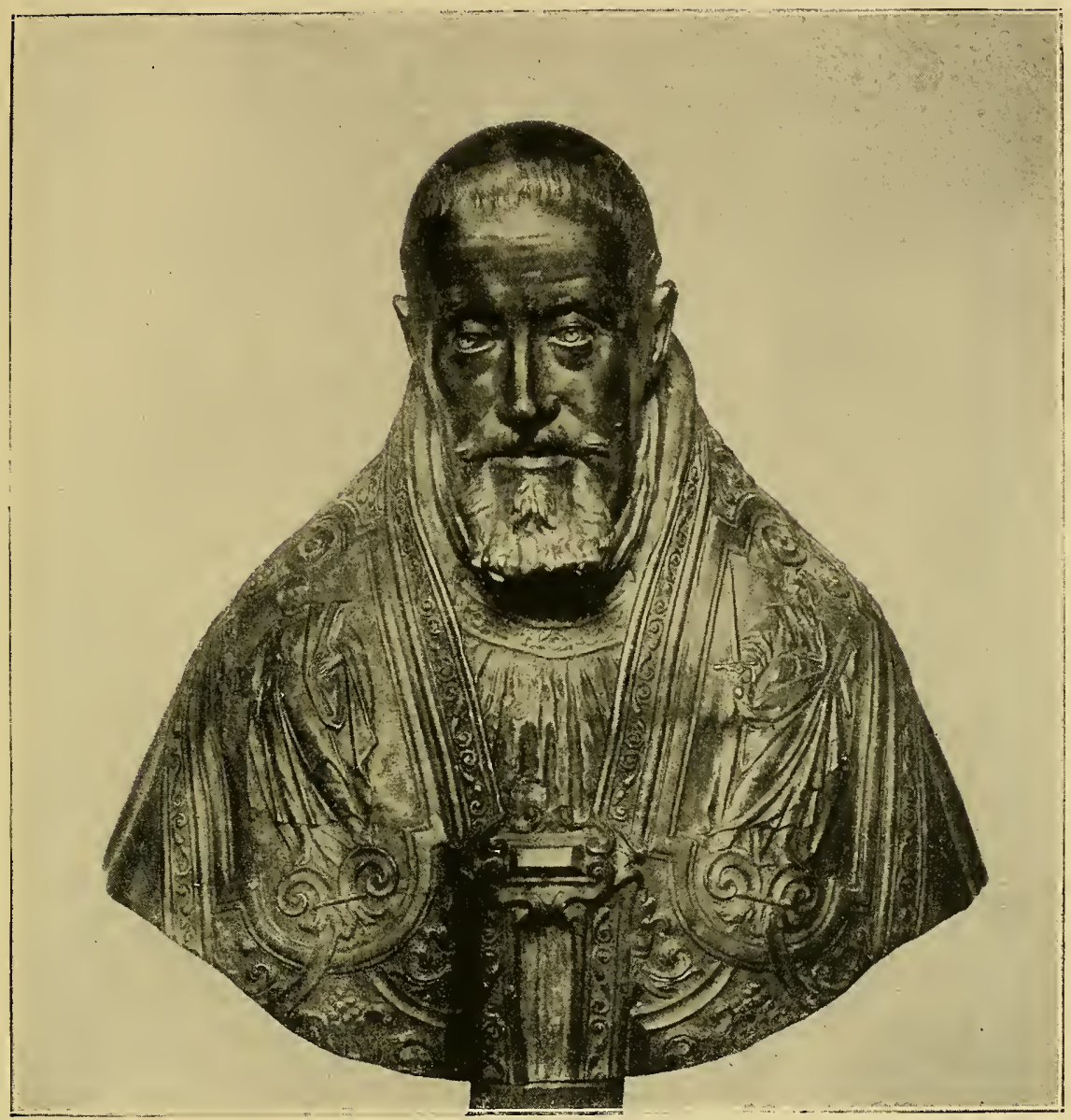

Bernini, Busto di Gregorio XV - Roma, Collezione Stroganoff.

Baldinucci chiama con indovinata espressione maniera grande, tagliando il busto più largamente, dandogli un respiro e un empito più vasto, che fa subito pensare a Rubens. II cardinale ricco, potente, felice, amante della vita raffinata, buongustaio del bel marmo come del buon piatto, impetuoso, esuberante di vita, sbuffante sotto la porpora che gli pesa materialmente $e$ moralmente, fu rappresentato dal Bernini con la berretta un po' 
di traverso, il collare del mantello che sembra allargato con una stratta di mano, per sentirsi piì libero, la bocca un po' aperta per respirare più ampiamente, $e$ in tutto il viso qualche cosa di lucido, di luminoso, di pronto; il tipo dell'uomo di piacere e di comando, che pur nei tratti adiposi manifesta una contenuta energia. È l'uomo a cui tutto arride nella vita, e che cerca le cose piacevoli dell'esistenza profittando della sua posizione privilegiata, ottimo alunno della fortuna, che dell'onnipotenza dello zio pontefice ha diviso solo la parte brillante, lasciandogli le noie e le beghe della politica; non desideroso di intrighi, senza mire ambiziose di governo, felice tra i suoi quadri, tra i suoi marmi, tra i suoi cani da caccia.

Quando il Bernini circa il 1632 scolpì il ritratto del cardinale gli accadde una disgrazia; nel lucidare il busto già compìto si scoprì sulla fronte un pelo del marmo che tutto l'attraversava, e allora l'artista fattosi portare un nuovo blocco in camera sua, in quindici notti scolpi un altro busto; e dopo aver presentato il primo a Scipione, che rimase addolorato del grave difetto, gli scoprì il secondo con grande sua allegrezza. Oggi i due ritratti si vedono accanto nella Galleria Borghese, $e$ il confronto tra essi è particolarmente istruttivo; per quanto il Bernini si sia sforzato di fare il secondo busto in tutto simile al primo, non vi è riuscito, perchè il genio non pù̀ mai copiare, neppure sè stesso; e non più soccorso dalla presenza viva del modello, ha idealizzato un po' la figura del nobile prelato. Baldinucci lo chíma per questo fatto animosissimo, e in verità di quale coraggio, di quale fede doveva essere animato il maestro per riprendere di nuovo un lavoro già finito! Era allora Gianlorenzo Bernini nel periodo più felice della sua vita, pieno di forza e di energia: accarezzato dal munifico Scipione, prediletto dal nuovo papa Urbano VIII, coperto di onori e di ricchezze, lodato e festeggiato, bello e pieno di fuoco, spigliato e pronto; era come disse di lui Fulvio Testi "vera- 


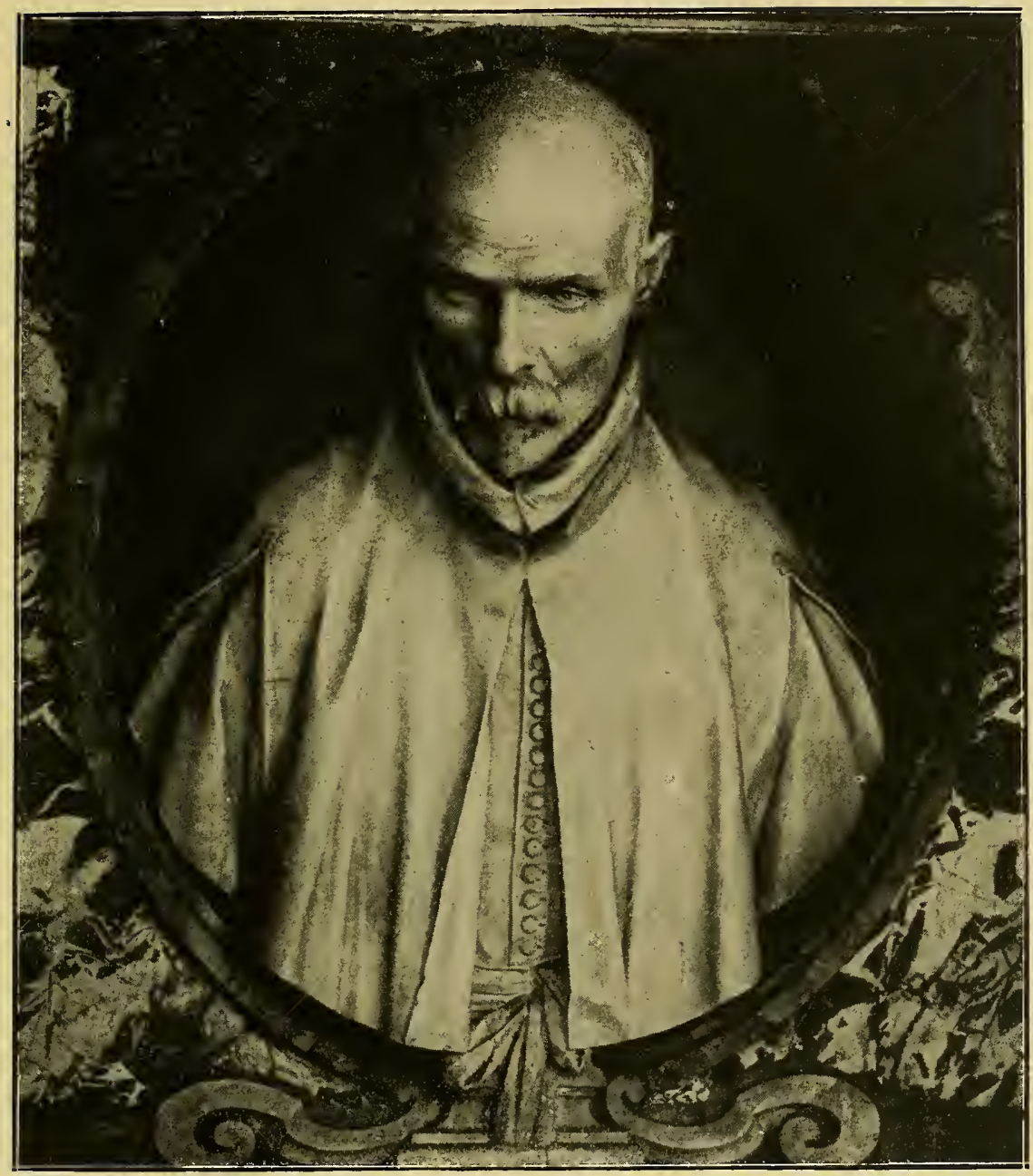

Bernini, Busto di Mons. Montoya - S. Maria in Monserrato.

mente un uomo da far impazzire le genti ,.. E questo accadde a Costanza Buonarelli, bellissima appassionata creatura, moglie di Matteo scultore, che collaborava col Bernini al gran baldacchino di bronzo di San Pietro, l'opera prodigiosa, terminata nel 1633. Tra gli affettí giovanili del bollente Cavaliere, che pare non fossero pochi, il più forte fur questo, e Domenico Ber- 
nini nella biografia apologetica del padre non tace di un certo scandalo, dalle cui conseguenze il maestro si cavò felicemente per la protezione del papa. Mentre di Costanza stava fieramente innamorato, il Bernini ne scolpì il busto, che è oggi a Fírenze, e che è il più bello dei suoi ritratti : la creatura d'a-

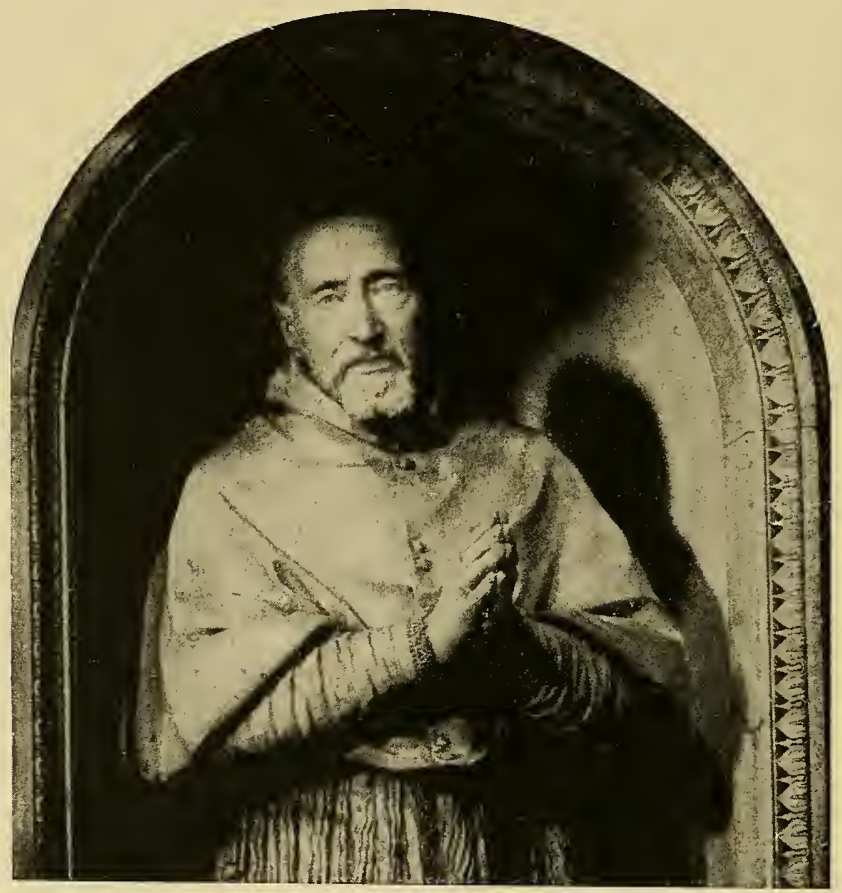

Bernini, Busto del Card. Bellarmino - Chiesa del Gesì.

more, infedele al marito $e$ all'amante, è veramente viva in quel marmo, in cui è figurata coi capelli un po' scomposti, la camiciola leggera aperta sul petto, che lascia intravedere le grazie del seno, lo sguardo ardito, quasi provocante, la bocca sensuale, con un'espressione insieme appassionata e sfrontata, volubile $e$ imperiosa, che promette momenti di delizioso abbandono, e ore di tormentosa gelosia. Quante tempeste nel cuore e nei sensi del Bernini deve aver suscitato questa donna a volte capricciosa 
e pungente, a volte umile e sottomessa, languida e carezzevole, ardente e felina, ai cui piedi l'uomo già celebre e invidiato, deponeva la sua gloria e la sua potenza! II povero Cavaliere aveva perduto la testa a segno che "O ingelosito di lei, o da altra che si fosse cagione trasportato, come che è cieco l'amore,

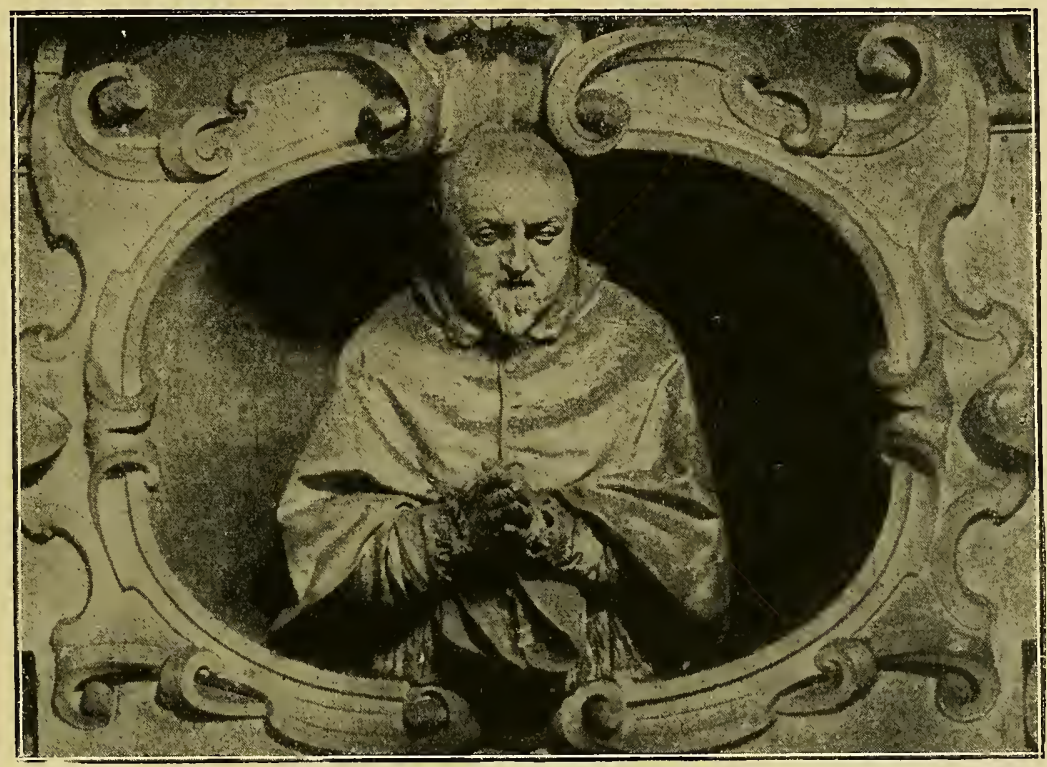

Finelli, Busto del Card. Bandiní - S. Silvestro al Quirinale.

impose ad un suo servo il farle non so quale affronto, come segui, che per essere stato pubblico e dannevole, doveva con non dispregievole pena punirsi. Il Papa assicurato del fatto, diede ordine che all' esilio fosse condannato il servo, ed al Cavaliere mandò per un suo Cameriere l'assoluzione del delitto scritta in pergamena, in cui appariva un elogio della sua virtì degno da tramandarsi alla memoria de' Posteri : poichè in essa veniva assoluto non con altro motivo, che perchè era Eccellente nell'arte, nè con altri titoli era quivi nominato che con quelli di Huomo raro, Ingegno sublime, e nato per 


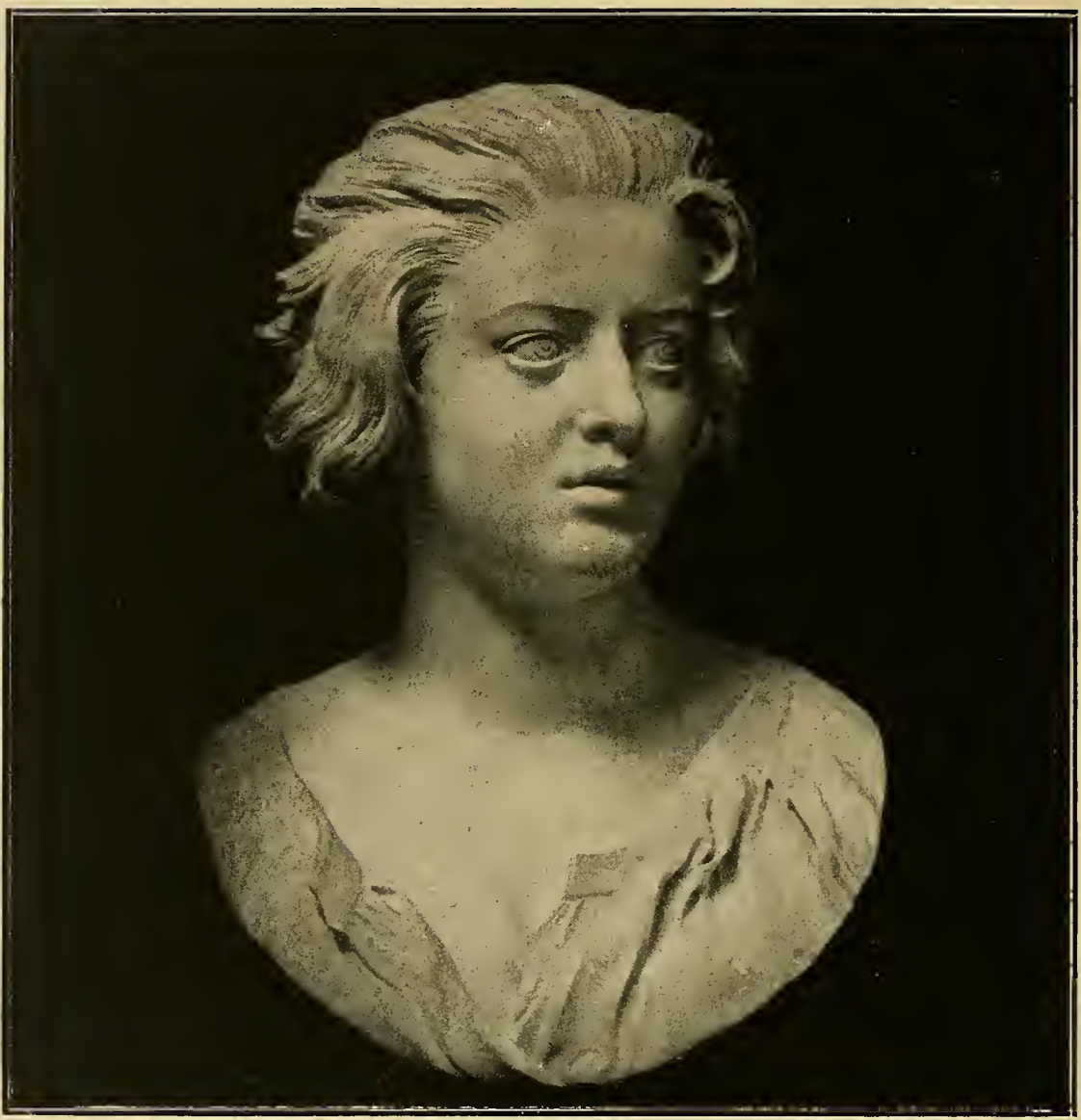

Bernini, Busto della sua amante Costanza Buonarelli - Firenze, Bargello.

(Fot. Alinari).

Disposizione Divina, e per gloria di Roma, a portar luce a quel Secolo ,".

Dí un altro amore del Bernini abbiamo notizia, che finì però in un disinganno pel maestro, poichè la donna che amava sposò invece il di lui fratello Luigi, meccanico e soprastante ai lavori della Fabbrica di S. Pietro. E allora Gianlorenzo oramai quarantenne, volle, seguendo il paterno consiglio di Urbano VIII, metter fine alle tempeste del cuore, e.... prese moglie. Sposò 
la più bella giovane che abbia Roma, figliola di Paolo Tezio procuratore della Corte papale. La fanciulla si chiamava Caterina e aveva appena ventidue anni; non aveva dote, così che il Bernini stesso in forma segretissima le assegnò duemila scudi romani. Il matrimonio fu celebrato il 15 maggio 1639 nella chiesetta di S. Tommaso in Parione.

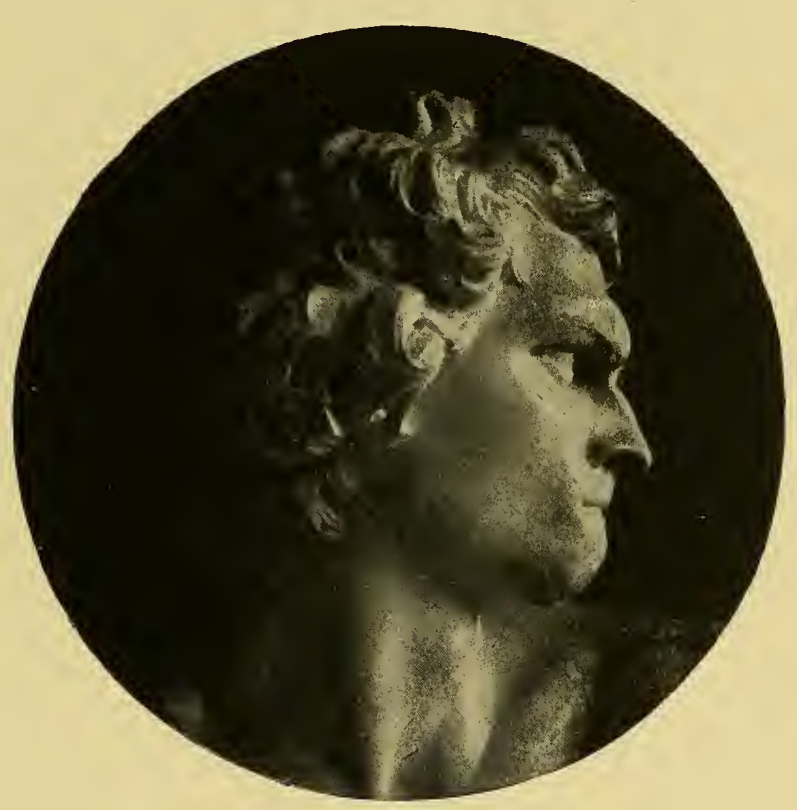

Bernini, Testa di David.

Autoritratto dell'artista. 


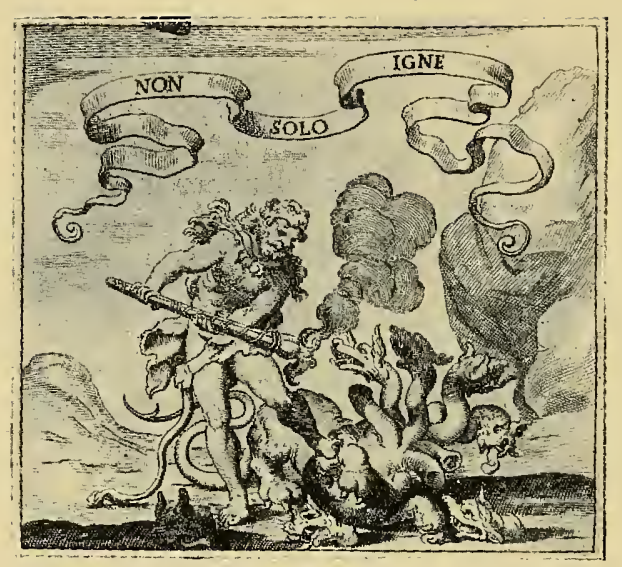




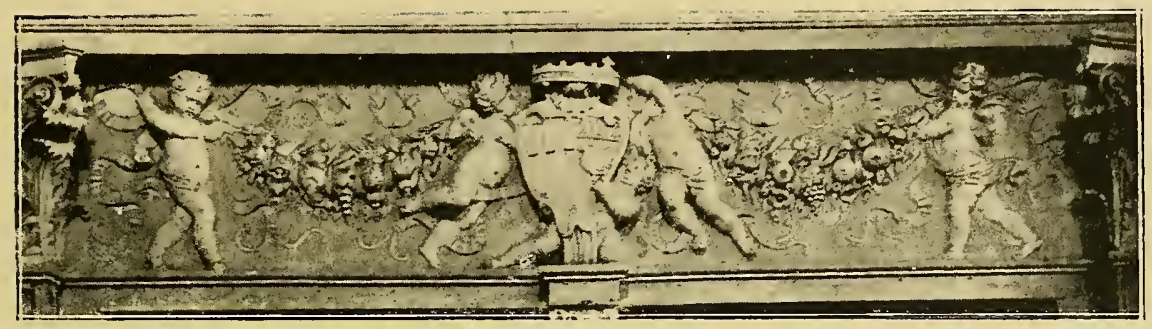

CAPITOLO QUARTO

\section{E C H I E E}

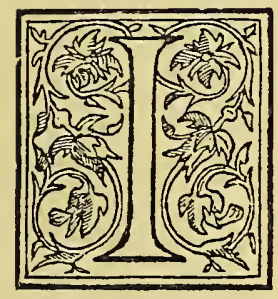

acopo Barozzi da Vignola iniziava nel 1568 la fabbrica della nuova chiesa che il cardinale Alessandro Farnese, nipote di Paolo III, faceva elevare per unirla alla casa professa dell'ordine dei Gesuiti. Il celebre architetto aveva innalzato la chiesa fino alla cornice quando mori (1573), ed allora la direzione dell'opera fu assunta dal suo discepolo Giacomo della Porta (1541-1606), il quale terminò la costruzione dell'interno, coprendolo a vôlta, ed elevò la facciata, che nel 1575 era giunta al fregio, in cui quella data è incisa; il tempio $\mathrm{fu}$ però completato solo nel 1584, e consacrato ai 15 di settembre con grande solennità. La chiesa del Gesù apparve come una novità nell'architettura religiosa, poichè si distaccava completamente, sia per la pianta che per l'alzato e per l'illuminazione, dal tipo che allora era in voga, e da quelli usati in epoche più antiche. Essa richiama in qualche modo la basilica cristiana, a pianta allungata, ma invece delle tre navate ne ha solo una rettangolare, sui lati della quale si apre una serie di cappelle, comunicanti fra loro per mezzo di passaggi 
arcuati; il transetto non ha che pochissima profondità, quasi la stessa delle cappelle, ed è sormontato all'incrocio dalla cupola bassa, sostenuta da un tamburo ottagono; l'abside semicircolare è pure poco profonda; negli angoli che forma con i bracci laterali si elevano due cappelline circolari. L'altare è collocato nel fondo, addossato al muro, e quindi visibile da tutta la chiesa; la luce discende da finestre che si aprono, quattro per lato, al disopra della cornice, e da otto finestrini del tamburo all' imposta della calotta, ed è quindi piuttosto fioca, in modo che il tempio sta in una semioscurità che invita al raccoglimento. Era questo un tipo di chiesa che rispondeva bene alle idee del tempo, allo spirito severo e rigido della Controriforma; e il Vignola, il puritano legislatore dei cinque ordini dell'architettura, creava con esso il modello che per mezzo secolo, finchè appunto continuava l'austera compostezza della chiesa cattolica, minacciata dal pericolo della Riforma luterana, doveva essere adottato in quasi tutte le nuove costruzioni sacre di Roma. Il Rinascimento aveva preferito il tipo di chiesa a pianta centrale, ossia rotonda - a croce greca, sormontata da cupola (il San Pietro di Bramante), che conferiva alle fabbriche un aspetto più armonioso ed elegante; permetteva maggiore illuminazione, e dava l' impressione di grande vastità, potendosi dalla soglia del tempio abbracciare con l'occhio tutto l'insieme, sia nel senso della profondita che in quello dell'altezza, fino al lanternino della cupola; ma tutto questo era a scapito del raccoglimento e del senso di misticismo che doveva ispirare una chiesa cristiana. Invece l'età della Controriforma, che volle ristabilire l'austerità del pensiero e del costume, opponendosi al sensualismo pagano del Rinascimento, creò col Gesù un típo tutto diverso, più adatto allo spirito nuovo, che non doveva parlare piì soltanto all'occhio, ma si rivolgeva all'anima, e con parole gravi e meditate.

Tutte o quasi le chiese romane elevate dal 1575 al 1630 dipendono da quella del Gesù : S. Maria in Vallicella (1575), 


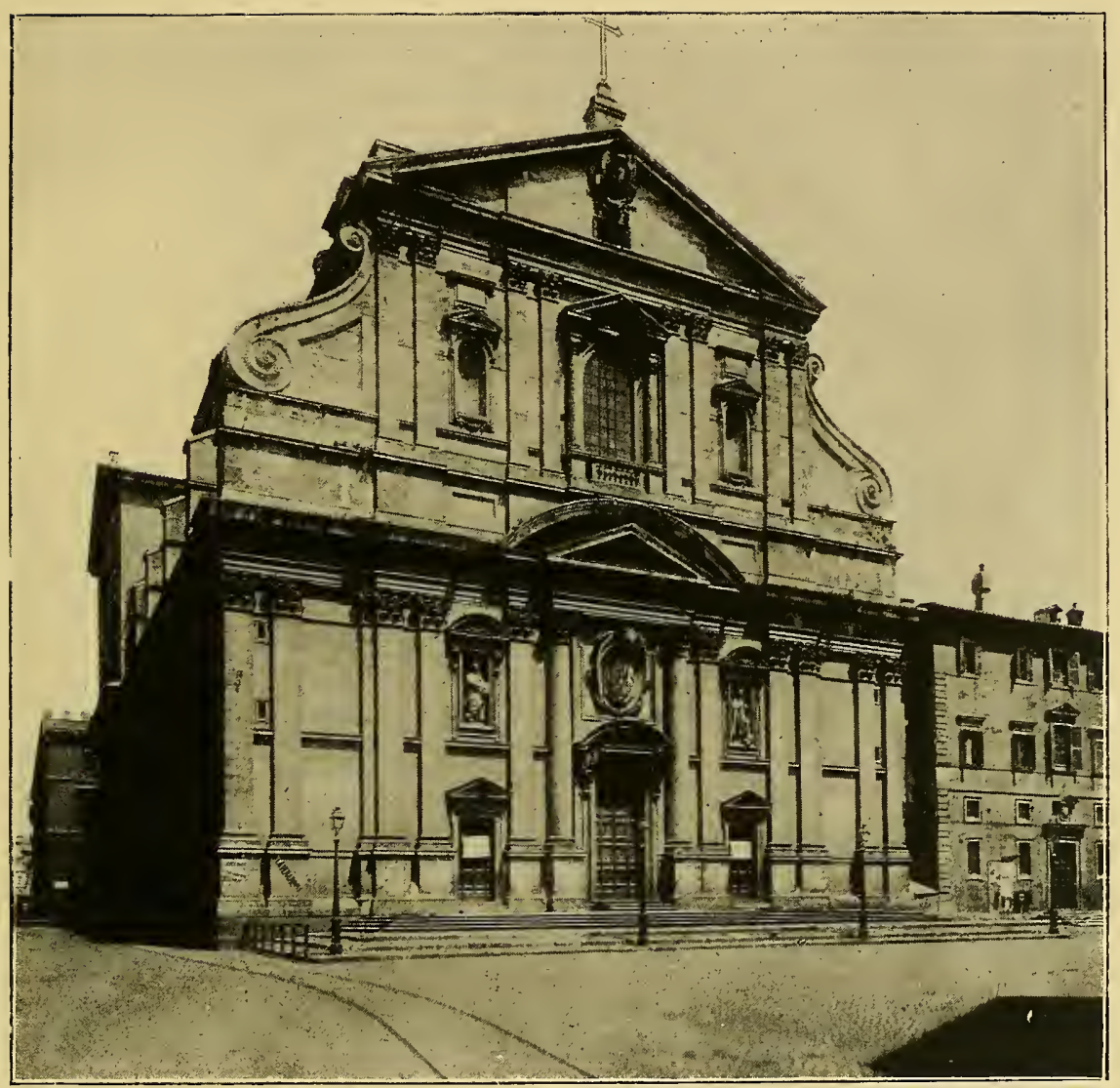

Facciata del Gesì, di Giacomo della Porta.

(Fot. Anderson).

S. Girolamo degli Schiavoni, S. Maria di Monserrato, S. Giovanni dei Fiorentini (1588), lo Spirito Santo dei Napoletani (1584), S. Andrea della Valle (1591), S. Maria della Scala (1592), S. Maria della Vittoria (1605), S. Pietro nella riduzione del Maderno, S. Nicola da Tolentíno (1614), S. Isidoro (1622), S. Domenico e Sisto (1623), S. Ignazio (1626), ripetono più o meno strettamente il tipo vígnolesco del Gesù. In alcune di queste chiese, come in S. Giovanni dei Fiorentini, nella Chiesa Nuova, in S. Ignazio, ci sono in più le 
navate laterali, secondo il modello basilicale, e allora i bracci del transetto diventano di conseguenza molto più profondí. Però è un errore credere, come generalmente si fa, che dalla costruzione del Gesì fino al 1630, che è la data con la quale si può concludere il primo periodo dell'arte barocca, il típo di chiesa a pianta centrale venisse completamente abbandonato: il Vignola stesso costruì nel 1572 S. Anna dei Palafrenieri, in Borgo, che ha pianta ellittica; Francesco da Volterra elevò

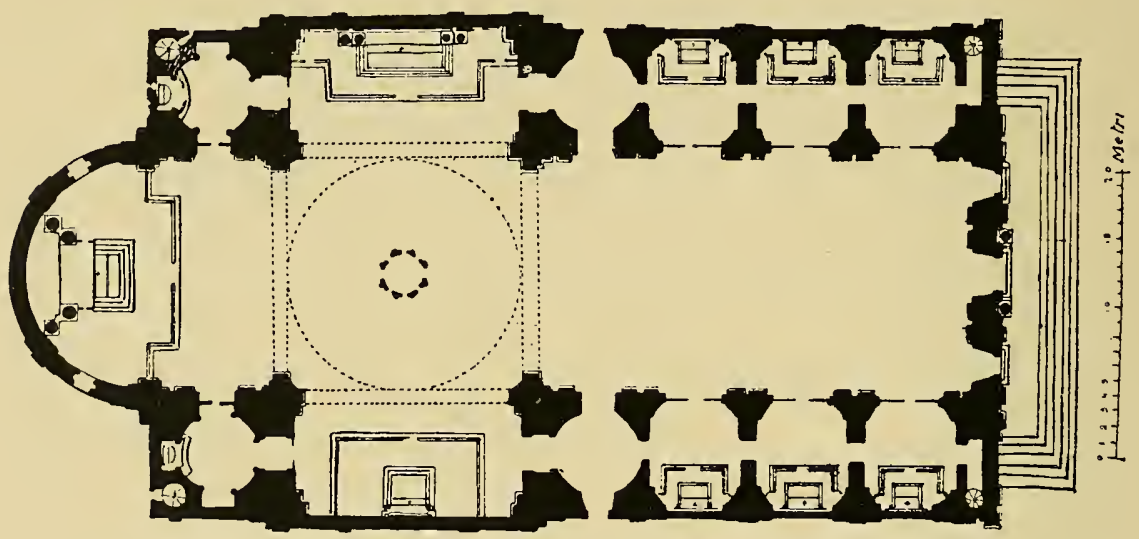

Pianta del Gesì, del Vignola.

S. Giacomo degli Incurabili, al Corso, che conserva ancora intatta la pianta ellittica, con abside profonda, che sembra troppo alta e stretta essendo l'arcone impostato al disopra della cornice che gira tutto intorno alla chiesa; Domenico Fontana e Flaminio Ponzio adoperarono la croce greca nelle cappelle di S. Maria Maggiore, ampie come chiese; e la stessa pianta ha il bellissimo tempio di S. Carlo ai Catinari (1612). Ma è certo che il tipo a pianta allungata predominò in questo periodo, tanto che per adottarlo in S. Giovanni dei Fiorentini si abbandonò il modello di forma circolare con corona di cappelle, disegnato da Michelangelo nel 1559; e lo stesso si fece in 
S. Pietro, pur riconoscendo che si veniva in tal modo a guastare l'armonia del tempio e a nascondere la cupola.

Queste chiese a pianta allungata della Controriforma e del primo trentennio del Seicento, erano quasi prive di decorazione interna; nude, fredde, bianche, come è ancora S. Giovanni dei Fiorentini, come è la navata centrale della Basilica Vaticana; gli stucchi, gli ori, i dipinti, che oggi vediamo al Gesù, alla

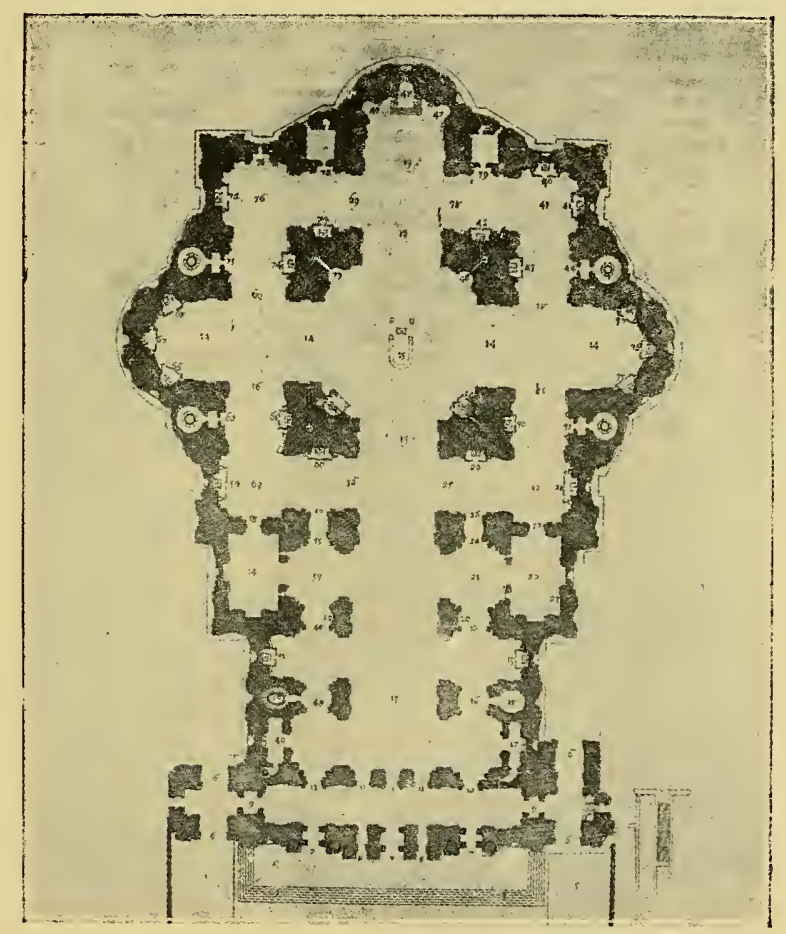

Pianta di S. Pietro dopo i lavori del Maderno.

Chiesa Nuova, alla Vittoria, a S. Ignazio, furono tutti aggiunti dopo, verso la metà del secolo, quando la polícromia predominava. E scomparsa oramai ogni eco dei terrori e degli scrupoli della Controriforma; la forza del Cattolicismo si è riaffermata potentemente in Europa, in Africa, e oltre gli oceani, e allora si 


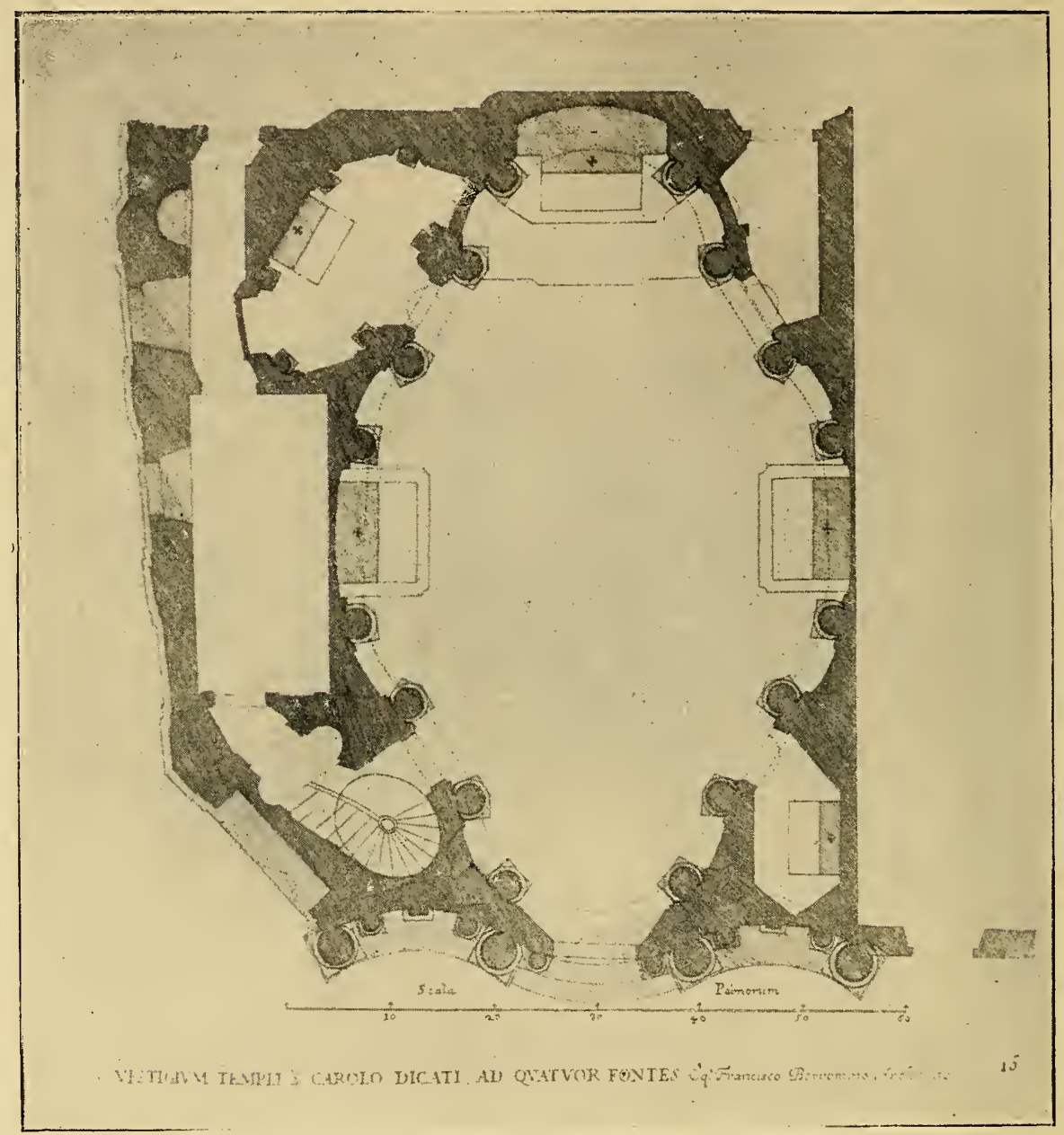

Pianta di S. Carlino, del Borromini.

abbandona il severo tipo gesuitico nella costruzione delle chiese, e si rimette in onore il modello a pianta centrale, più elegante e armonioso, e si cerca di correggere la freddezza delle fabbriche già elevate, con la smagliante ornamentazione. Ecco Pietro da Cortona, il meraviglioso pittore e architetto, che nel 1635-40 inizia la chiesa di S. Luca, a croce greca, sormontata 
da cupola con alto tamburo, con colonne addossate alle pareti, in cui si aprono nicchie, che dànno un continuo risalto di luci e di ombre, di pieni e di vuoti, e un bel giuoco al lume che piove a flotti dalle finestre; ecco il musicale Borromini che dà a S. Carlino (1638-41) pianta ellittica rigonfiata, con colonne alveolate nei muri, così da ottenere un continuo ondeggiamento di linee.

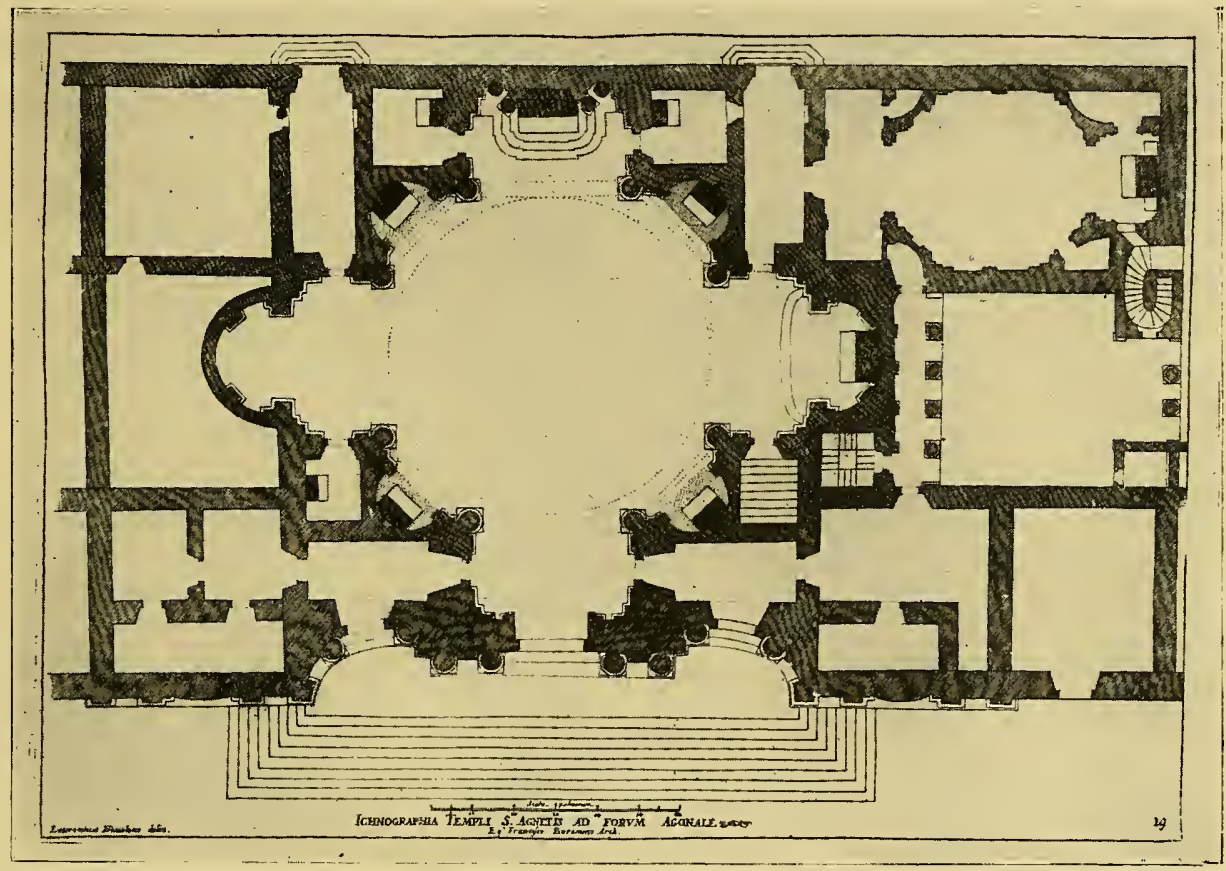

Pianta di S. Agnese in piazza Navona, del Borromini.

Dopo questí esempî c' è tutta una serie di chiese a pianta centrale: S. Agnese a piazza Navona (1653) dello stesso Borromini è a croce greca; S. Andrea al Quirinale del Bernini (1658) è ellittica; rotonda è l'Assunta di Ariccía (1664) dello stesso maestro; a croce greca il suo S. Tommaso di Castel Gandolfo. Nella chiesa di S. Ivo alla Sapienza, Borromini adotta un curioso tipo di pianta centrale, a sei lobi, imitante la forma 
dell' ape araldica barberiniana, in omaggio a Urbano VIII; $\grave{e}$ una disposizione assai ingegnosa, che mentre dà vivace movimento di linee, riesce ad ottenere un effetto di straordinaria

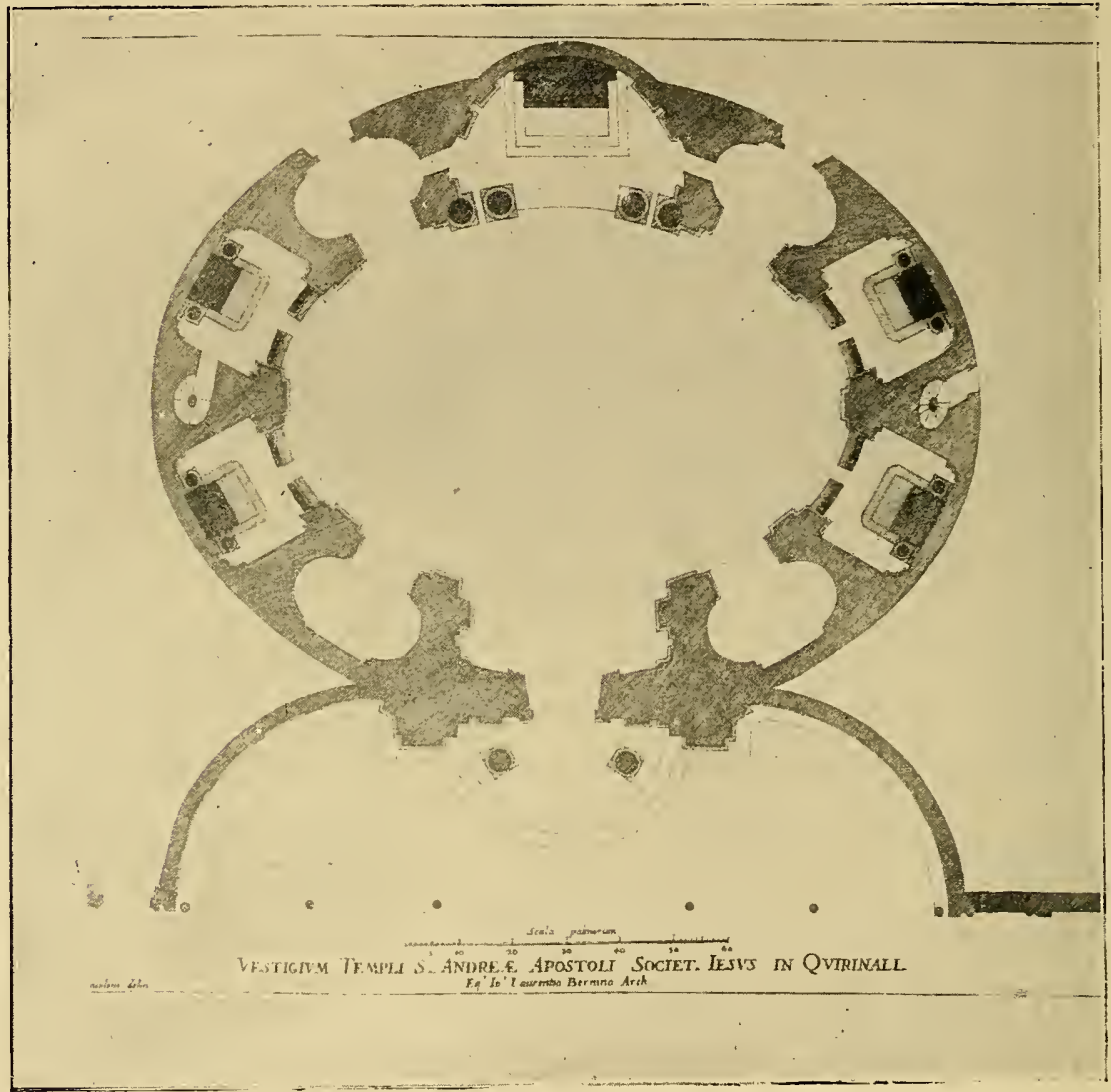

Pianta di S. Andrea al Quirinale, del Bernini.

ampiezza, con i grandi nicchioni alternati, e la cupola che copre tutto il vano della fabbrica.

Carlo Rainaldi nelle due chiese di piazza del Popolo, all'imbocco del Corso, adottò la pianta rotonda e la pianta ellittica (1662-64); Gio. Antonio de Rossi in S. Maria di Campo Marzio, la croce greca; rotonda è la chiesa di S. Angelo Cu- 
stode al Tritone, di Felice della Greca; ellittica quella di S. Celso, di Carlo de Dominicis. Caratteristica è la pianta di S. Maria in Campitelli (1656), di Carlo Rainaldi, fatta di due croci greche, in cui il braccio superiore della prima coincide con quello anteriore della seconda, mentre tutto intorno alle pa-

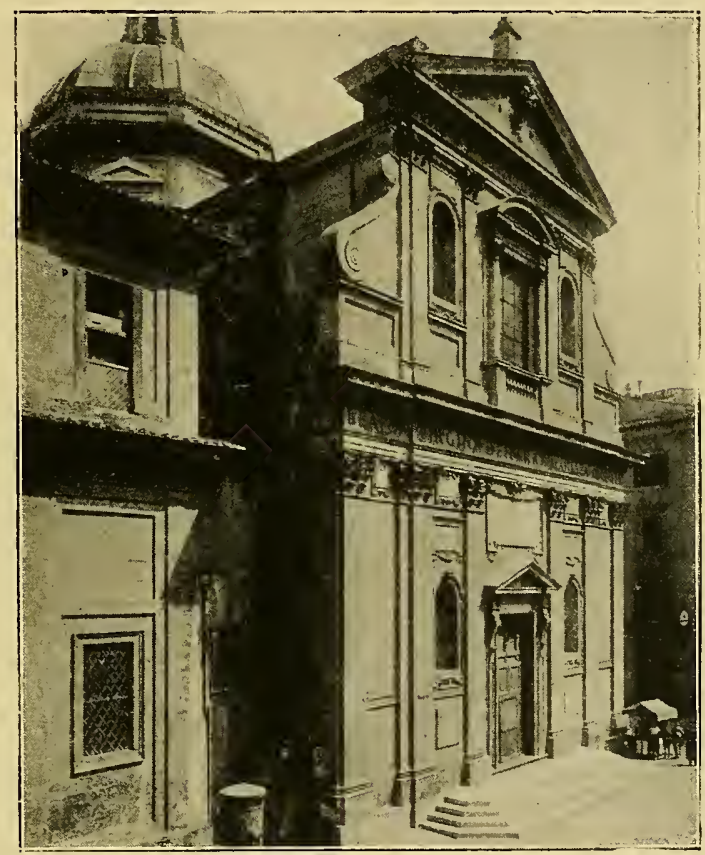

Facciata della Madonna dei Monti di Gíacomo della Porta.

reti e ai pilastri sono addossate colonne, un poco distaccate dal muro, che dànno all'interno un molle ondeggiamento.

Il barocco adottò pure talvolta per le chiese la forma rettangolare semplice, che le rende simili ad un salone, senza absidi e cappelle; e ciò specialmente per gli oratorî interni, di ordini religiosi, nei quali non essendo ammesso il pubblico, non c'era bisogno di separazione tra il clero officiante e i fedeli; 
questo è il tipo che il Borromini usò ai Filippini, a Propaganda Fide, alla Madonna dei Sette Dolori in Trastevere.

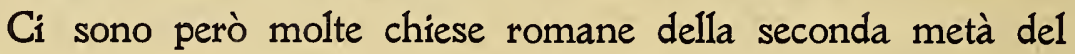
Seicento che presentano invece il tipo a pianta allungata; ma

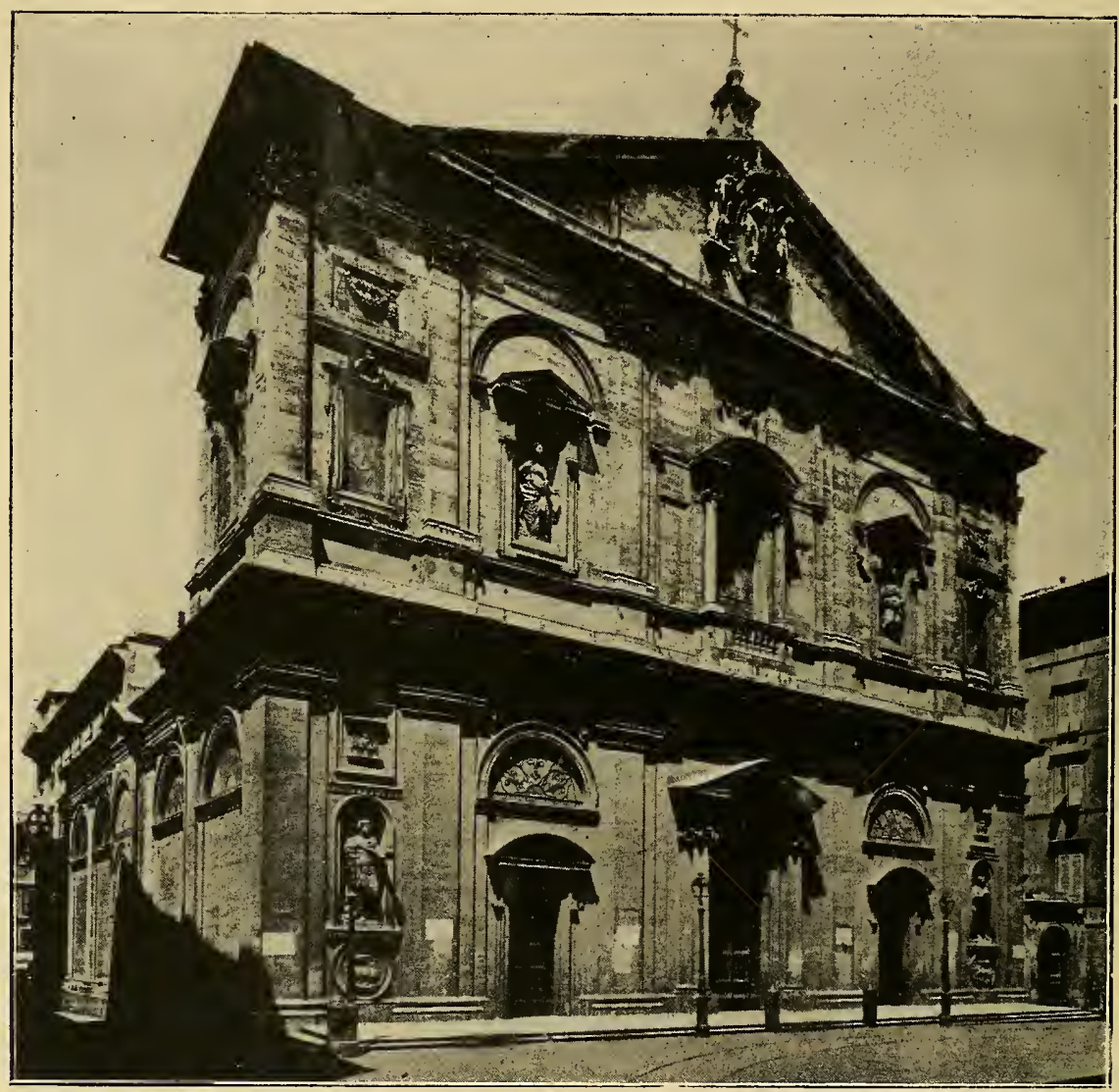

Facciata di S. Luigi dei Francesi, di Giacomo della Porta.

(Fot. Anderson.)

quasi sempre si tratta di fabbriche antiche rimodernate e restaurate nel secolo XVII; le quali, pure avendo assunto un carattere prevalentemente barocco, conservano le tracce dell' ordinamento e della struttura primitiva basilicale. 
La facciata della chiesa, che nel Medioevo e nel Rinascimento ebbe talvolta importanza quasi secondaria, così che molti templi anche insigni ne rimasero privi, perchè essendo essa l'ultima parte della costruzione erano venuti a mancare i mezzi necessari, assunse nell'età barocca un grandissimo valore, quasi di per sè stessa, tanto che in moltí casi alla ricchezza e all'im-

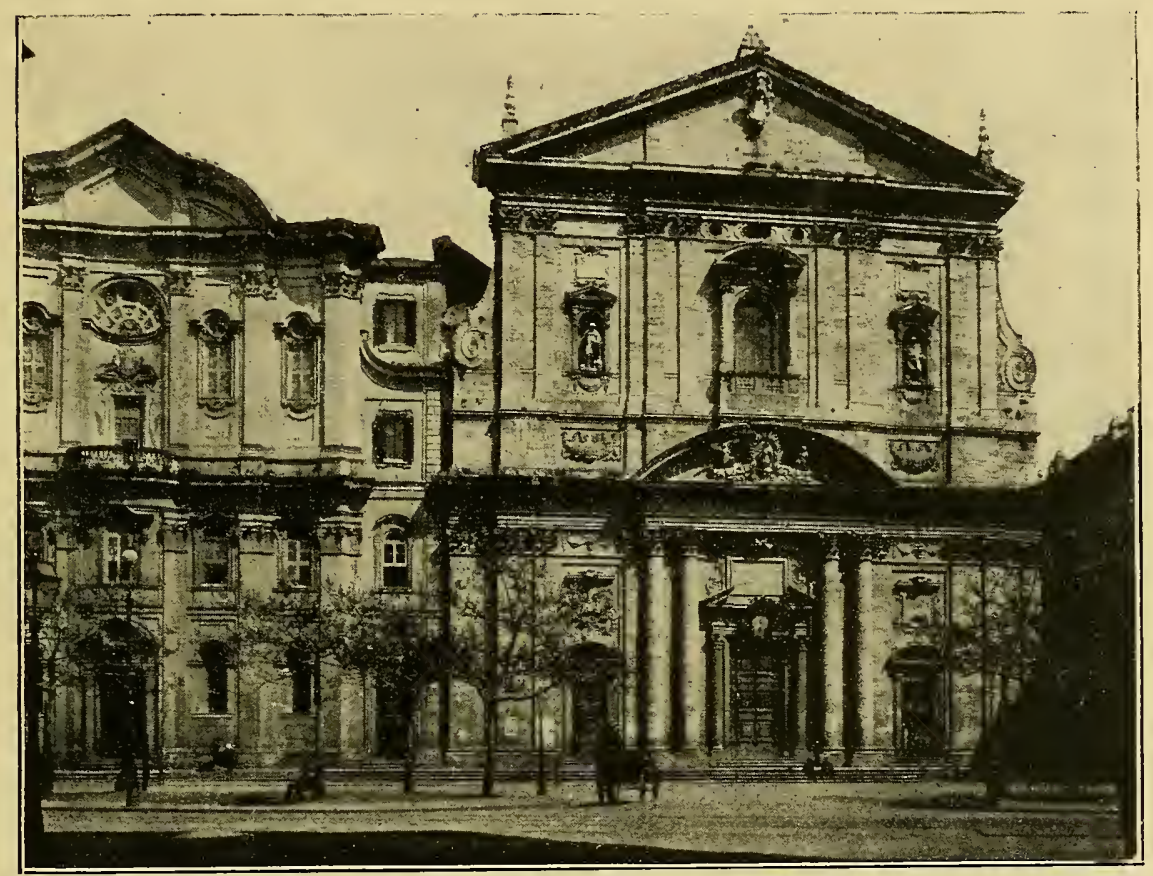

Chiesa e Oratorio dei Filippini, di Fausto Rughesi e del Borromini.

(Fot. Alinari).

ponenza del prospetto non corrisponde l'edificio interno. Cí sono finte facciate che non hanno legame di sorta con la struttura della fabbrica, scenarî grandiosi che nascondono piccole costruzioni, ricchi prospetti in curva che si adattano a edificî a linee rette, semplicissimi.

Nel primo periodo barocco (1600-1630), permane nelle sue linee generali lo schema di facciata usato in Roma nella se- 
conda metà del Cinquecento; formata da due piani sovrapposti, divisi verticalmente in più parti da paraste dello stesso ordine; il piano superiore è di regola più stretto dell'inferiore, fiancheggiato da volute, e sormontato da timpano triangolare. $\mathrm{Nel}$ piano

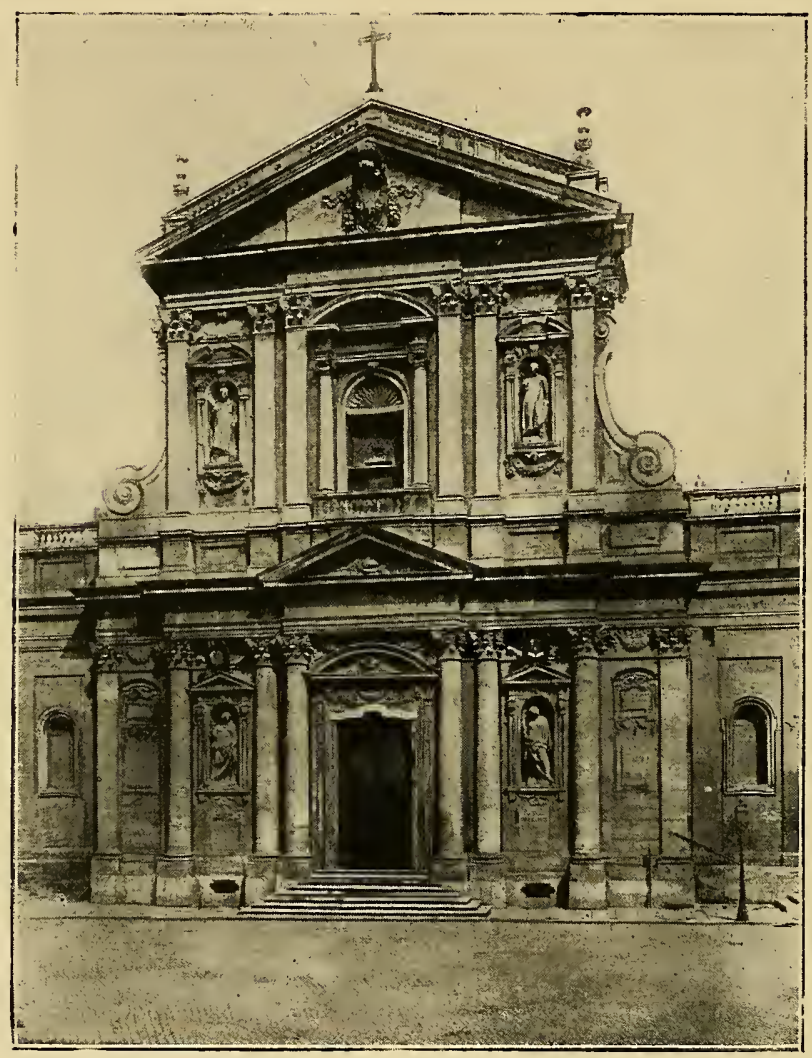

Facciata di S. Susanna, di Carlo Maderno.

(Fot. Anderson.)

inferiore v'è nel centro la porta principale, con colonne laterali e timpano di coronamento; negli interpilastri ai due lati si aprono nicchie o porte minori; nel piano superiore nel mezzo c' è una finestra, e negli interpilastri laterali nicchie; il secondo ordine poggia sulla trabeazione del primo con un alto zoccolo. Questo 
è il tipo di S. Spirito in Sassia (1550) di Antonio da Sangallo, e di S. Caterina dei Funari; il più semplice e piatto. Ma ecco che in alcune fabbriche comincia ad apparire il portale centrale sporgente in fuori dal piano generale dell'ordine inferiore, come a S. Maria dell'Orto (1566); poi alla Madonna dei

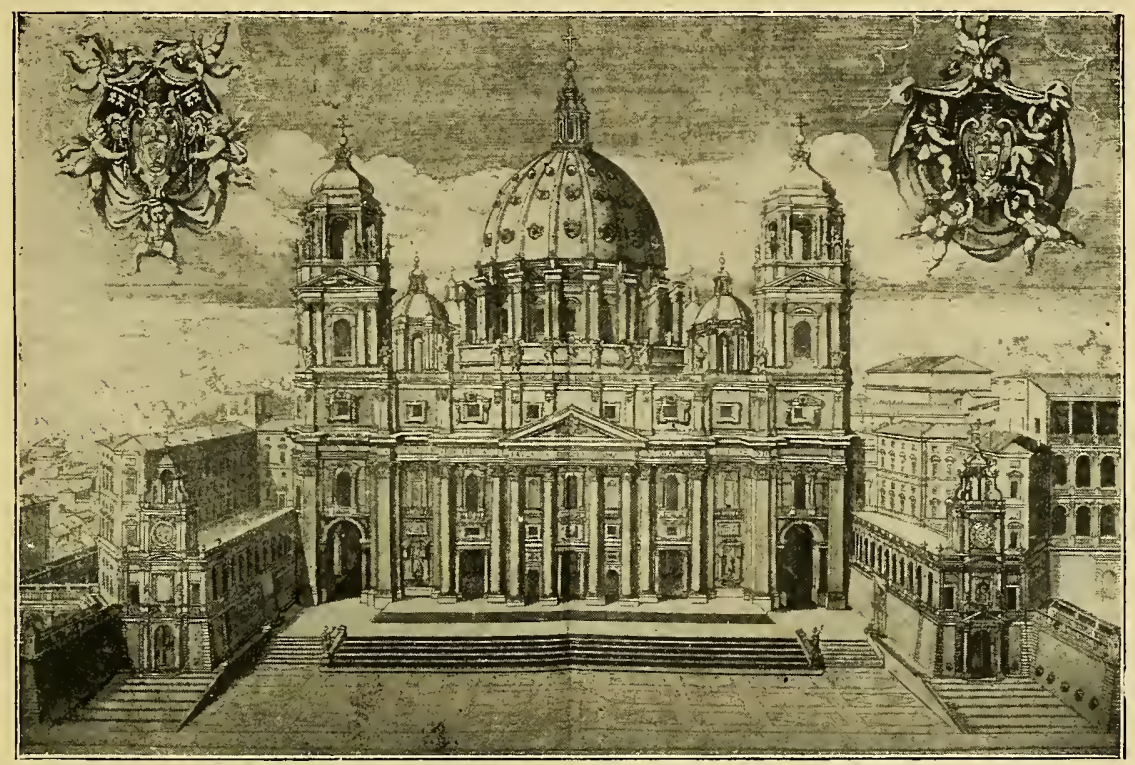

Facciata di S. Pietro nel progetto di Carlo Maderno.

Monti (1580), di Giacomo della Porta, non soltanto il portale ma tutta la parte di mezzo della facciata, nei due piani, si avanza sulle ali laterali più arretrate. $E$ ancora più accentuato era il tipo ideato dal Vignola per il Gesì, che la morte gli impedì di tradurre in atto, e che ci è conservato da un' antíca incisione: triplice è in esso l'aggetto; le ali laterali dell' ordine inferiore stanno in un piano più arretrato; da questo sporge tutto il corpo centrale per l'intera altezza dei due piani, coronato dal timpano; e infine la parte di mezzo è di nuovo in aggetto nei due piani, e persino entro il timpano. Giacomo 
della Porta, succeduto al Vignola, modificò lo schema del maestro, restringendo il primo aggetto alla larghezza di una parasta, dopo la quale si torna al piano delle ali laterali, e di

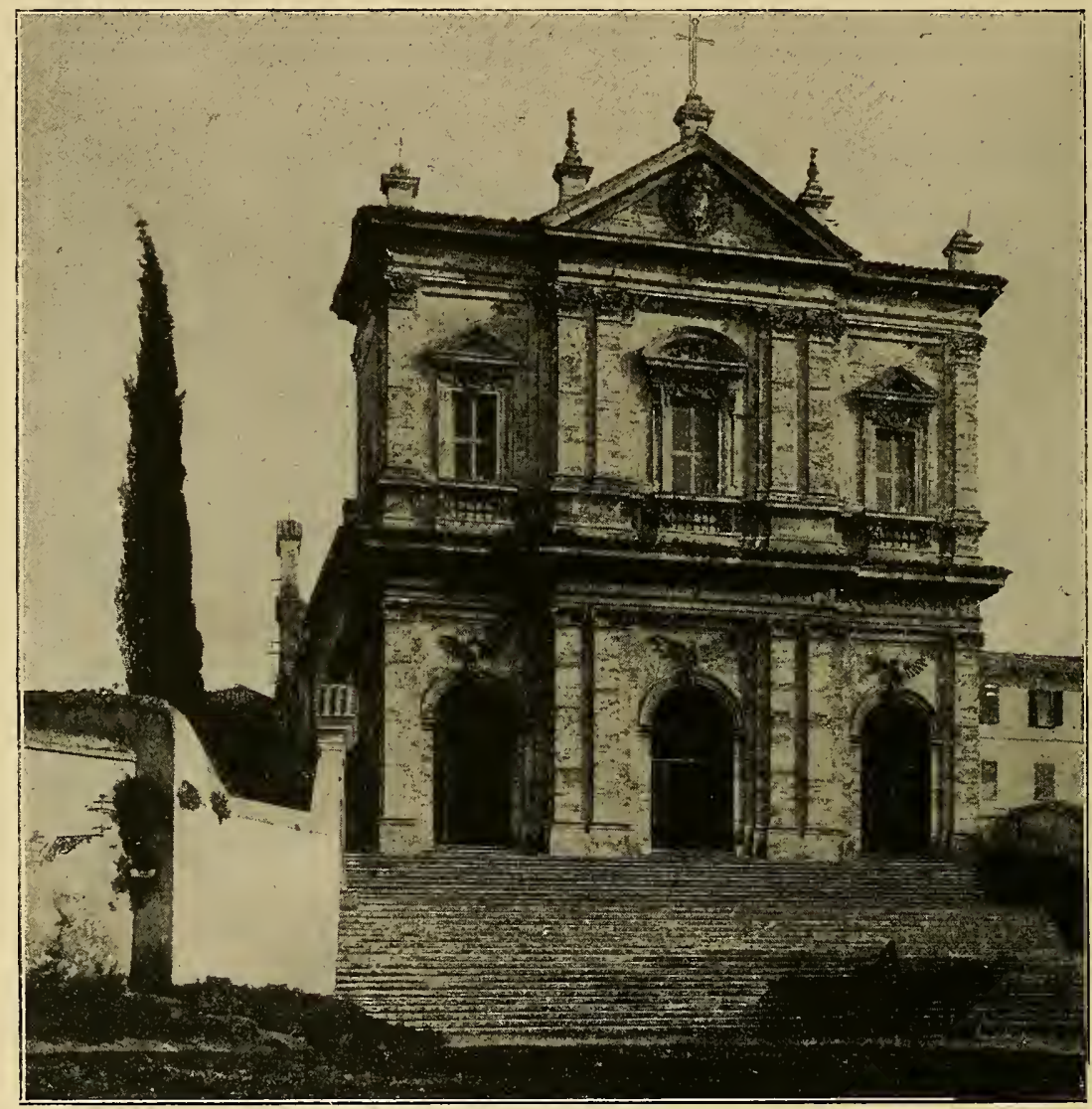

Facciata di S. Gregorio al Celio, di G. B. Soria.

(Fot, Anderson).

nuovo si avanza la parte centrale sulla quale il portale è ancora aggettato: I' insieme è così assai pittorico. Un altro típo meno frequente è quello che lo stesso della Porta adotto in S. Luigi dei Francesi, ove l'ordine superiore assume tutta la larghezza di quello inferiore, ed entrambi si svolgono su un unico piano, 
su cui soltanto il portale e la loggia del secondo ordine sono aggettati.

Vi è poi un altro típo caratteristico di facciata della fíne del Cinquecento, quello fiancheggiato da torri, che sono sporgentí

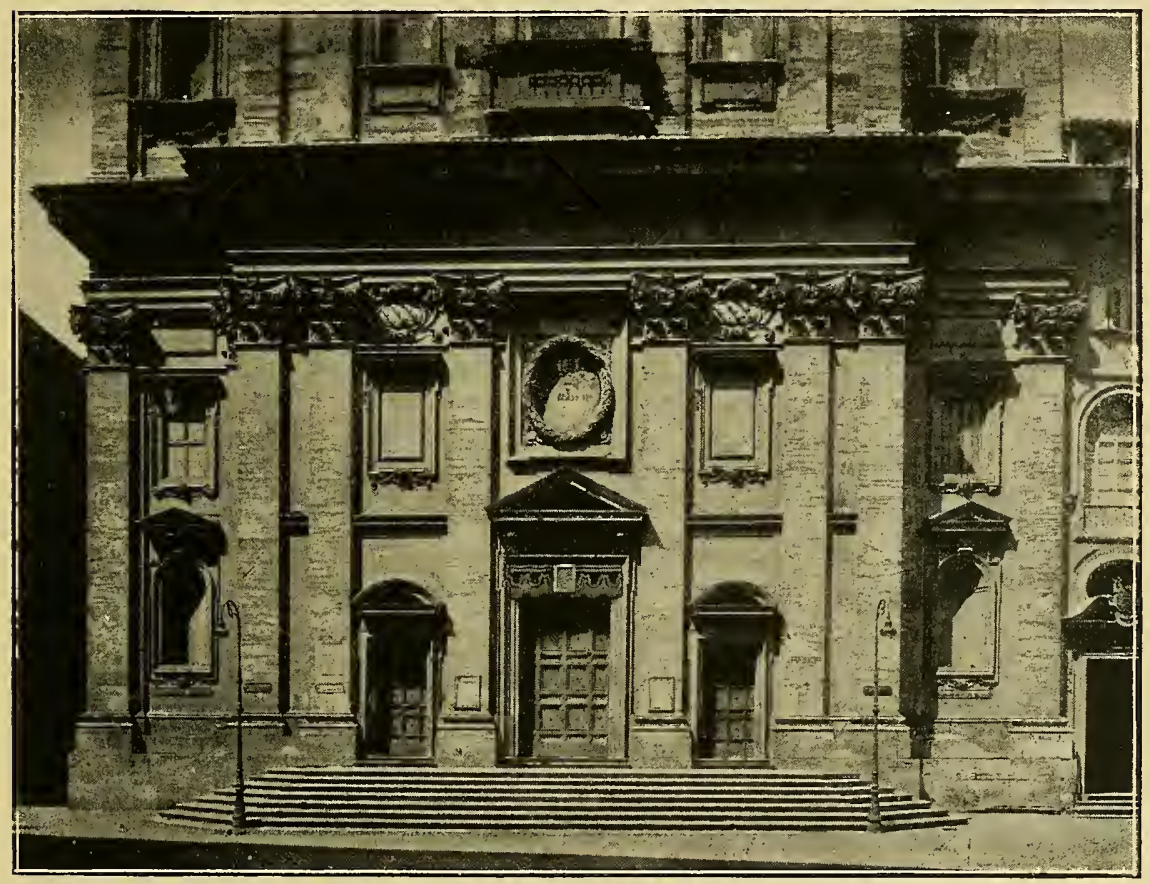

Particolare della facciata di S. Carlo ai Catinari, di G. B. Soria.

(Fot, Alinari).

sul corpo centrale, come alla Trinità de' Monti, o arretrate, come a S. Atanasio dei Greci.

Di questí varî schemi il barocco continuò a preferenza quelli più confacenti alla sua ricerca di pittoricità, quelli cioè in cui più numerose sono le accentuazioni, maggiori i risalti e $i$ contrasti di luci e d'ombre, e si ispirò quindi specialmente al típo ideato dal Vignola pel Gesù. Fausto Rughesi per la Chiesa Nuova (1605) adottò la triplice accentuazione, e raggiunse un 
bell' effetto pittorico, fiancheggiando il portale con due colonne per lato, in luogo delle paraste; e ancora più avanti nell'evoluzione andò Carlo Maderno, che nella facciata di S. Susanna

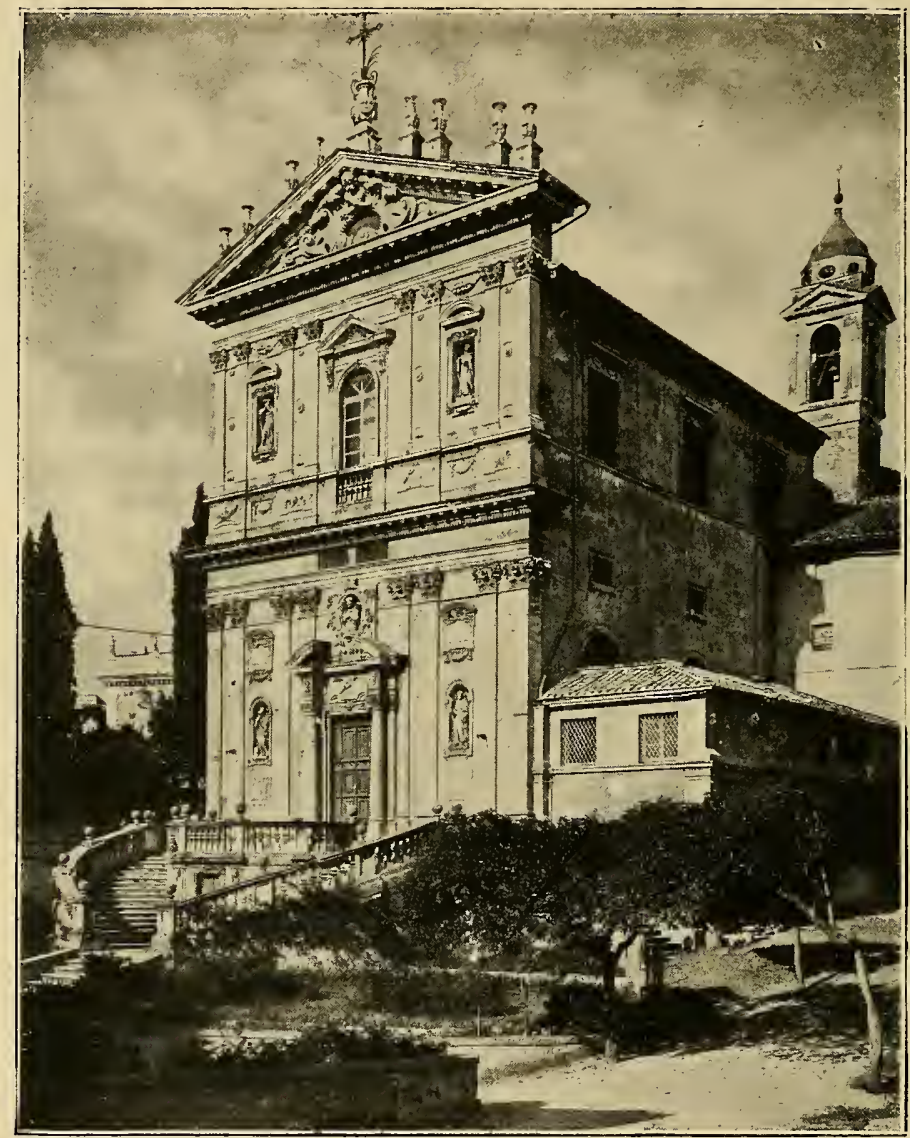

Facciata de' SS. Domenico e Sisto, di Vincenzo della Greca.

(Fot. Anderson)

(1605) ripetè lo schema del Gesù vignolesco, ma sostituì in tutto l'ordine inferiore, tranne che alle estremità, ai pilastri le colonne, non distaccandole però interamente dalla parete, ma alveolandole in essa. L'innovazione segna una data importante per l'architettura barocca, e il Maderno appare perciò veramente come 


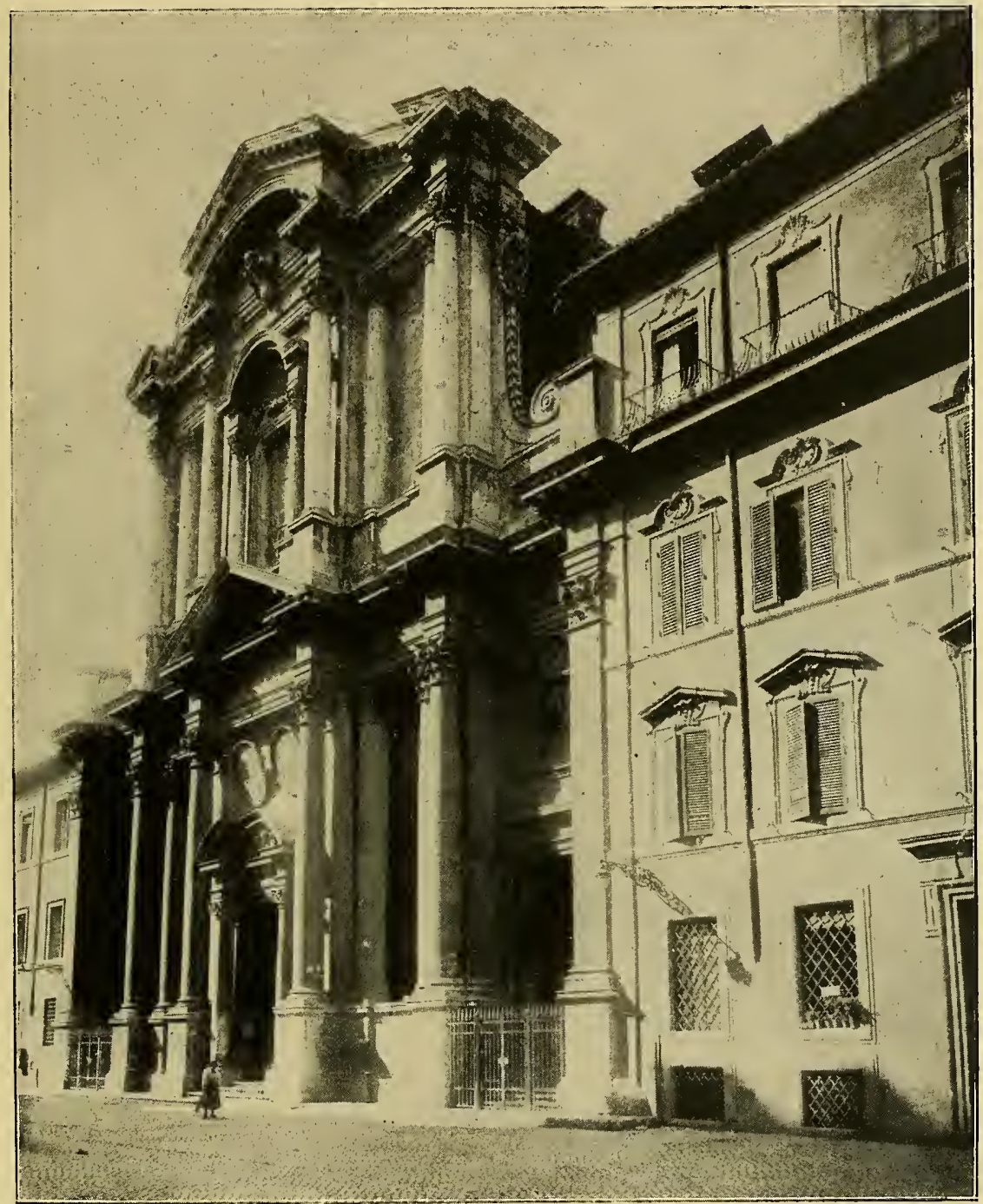

Facciata di S. Maria in Campitelli, di Carlo Rainaldi.

l'iniziatore di uno stile nuovo: pur conservando ancora lo schema cinquecentesco egli lo avviva, lo anima, lo colorisce; apre la via alle ardite ideazioni del Seicento. Oramai il típo di facciata a colonne diviene comune; il Maderno stesso lo ripete in 
S. Pietro (1607), e nel progetto, non attuato, di S. Andrea della Valle (1624); col progredire del secolo lo vediamo usato sempre più arditamente, con le colonne non più incassate nella parete ma libere, come in S. Maria in Campitelli, di Carlo Rainaldi, e non più impiegate a dividere gli ordini in tanti spazii, ma accoppiate e messe a file di tre o quattro come in

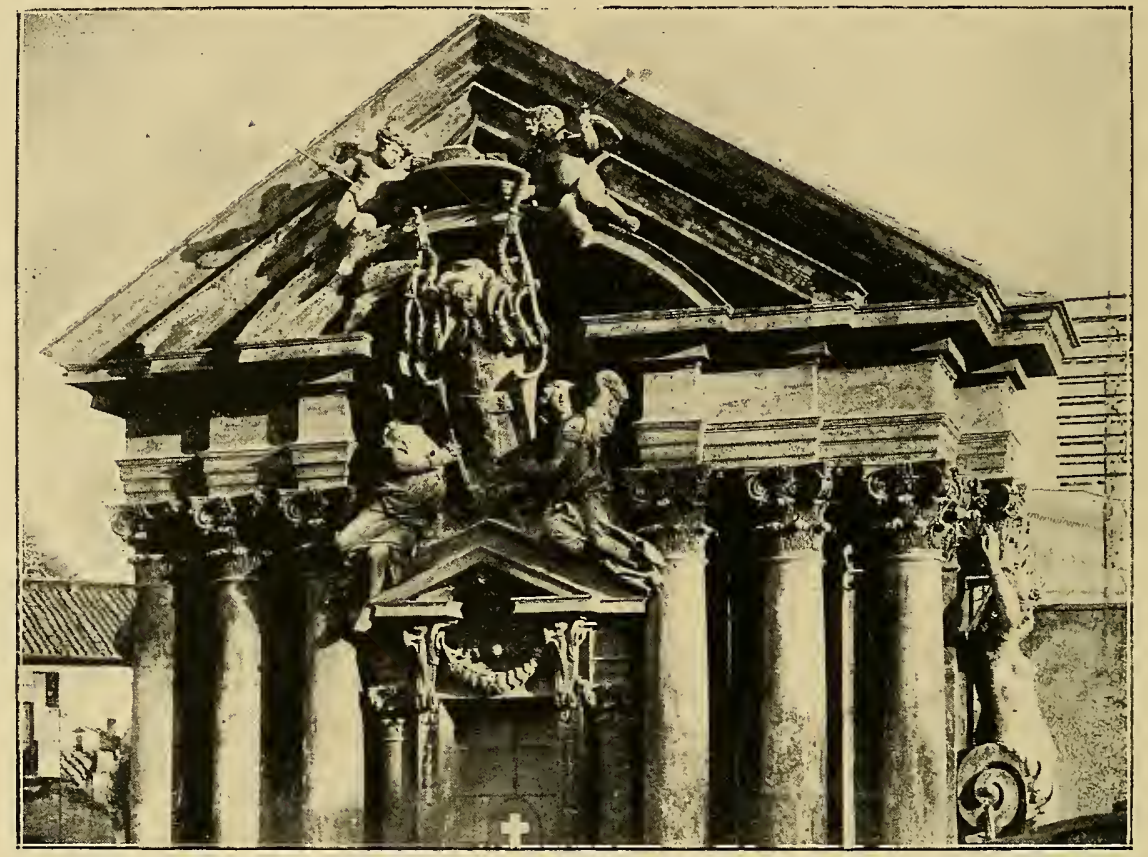

Particolare della facciata de' SS. Vincenzo e Anastasio, di Martino Lunghi iun.

SS. Vincenzo e Anastasio di Martino Lunghi iuniore, il cui prospetto, per I'impiego eccessivo delle colonne nei due piani, fu detto il canneto. Le nicchie diventano assai più profonde come a Campitelli, a S. Ignazio, a S. Andrea della Valle, in modo che $i$ chiaroscuri $e$ i risalti sono molto piì fortí; e le facciate prendono un aspetto vivace, colorito, pittorico, che dà agilità $e$ movimento alle più grandi masse. Tuttavia, anche dopo 
questi esempî, in molti prospetti del Seicento permane l'uso delle paraste in luogo delle colonne, come in S. Maria della Vittoria (1626), in S. Gregorio al Celio (1633), in S. Carlo a Catinari, tutte opere del romano Giambattista Soria; in S. Francesca Romana (1615) di Carlo Lombardo.

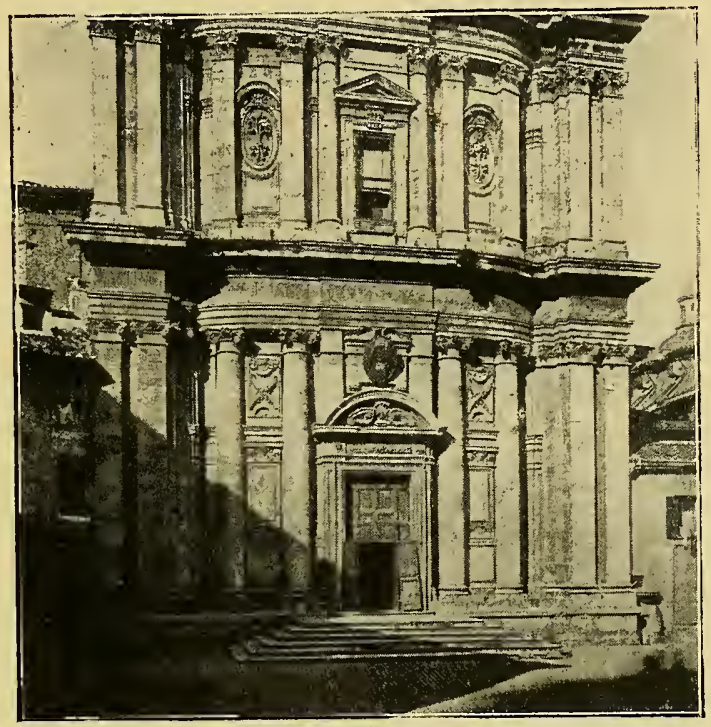

Facciata di S. Luca, di Pietro da Cortona.

Continua pure nel Seicento il tipo della facciata a torri: Maderno lo aveva progettato per la Basilica Vaticana, ma ragioni statiche non gli permisero di attuarlo; Borromini lo adoperò in modo mirabile in S. Agnese a piazza Navona (1653), Mattia de Rossi nell'Assunta di Valmontone (1685), Gírolamo Fontana nel Duomo di Frascati. Una bizzarra applicazione del típo a torri fu fatta al Pantheon, a cui il Bernini appiccicò $i$ due famosi campanili, demoliti in tempi recenti, che il popolo argutamente chiamò le orecchie d'asino.

Comune nel Seicento è il tipo della facciata a portíco, che si vede quasi sempre in antiche basiliche rimodernate, nelle quali 
si conservò l'atrio medioevale, come in S. Crisogono, in S. Sebastiano, in S. Gregorio, restaurate dal Cardinal Scipione Borghese, in S. Francesca Romana, in S. Maria in Via Lata di Pietro da Cortona, in S. Bibiana del Bernini, in S. Bartolomeo all' Isola; ma apparisce anche in costruzioni del tutto nuove:

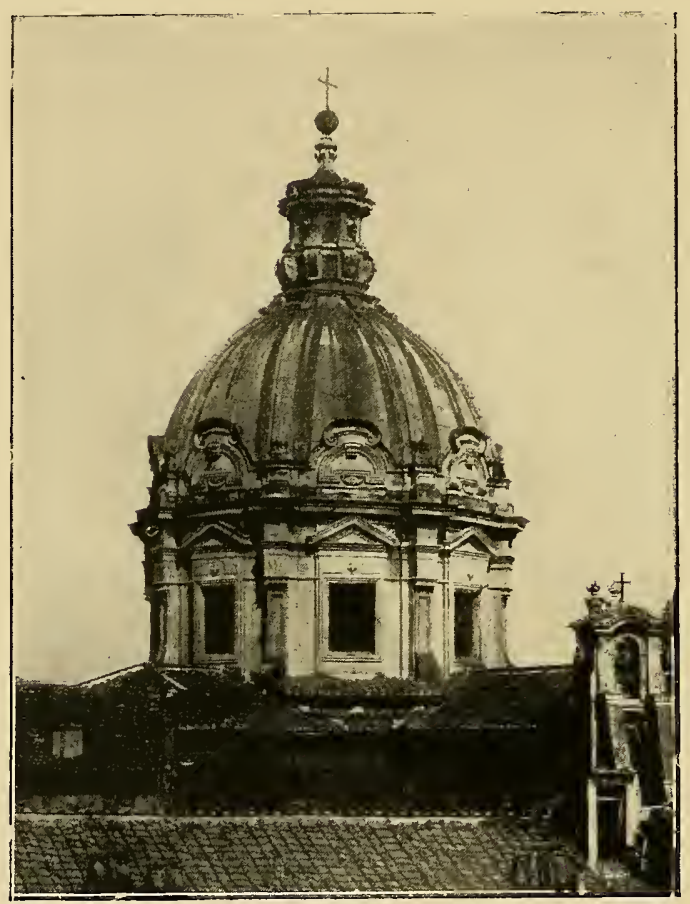

Cupola di S. Luca, di Pietro da Cortona.

S. Caterina a Magnanapoli del Soria, S. Maria dei Miracoli e S. Maria in Montesanto del Rainaldi e del Fontana, l'Assunta di Ariccia del Bernini.

Nelle chiese di piccole proporzioni si adopera il tipo di facciata ad un sol ordine, già usato pure nella fine del Cinquecento (S. Anna dei Palafrenieri del Vignola, 1572); così nella chiesetta del Carmelo, in S. Caio, ora scomparsa; a S. Lucia 
in Selci, a S. Lorenzo in Fonte; qualche volta si vede anche in chiese più grandi, come a S. Francesca Romana e al Gesù e Maria, che sono dello stesso architetto, Carlo Lombardo, e nel colossale prospetto di S. Carlo al Corso, in cui per mantenere un solo piano, l'autore, un povero frate inesperto, dovette

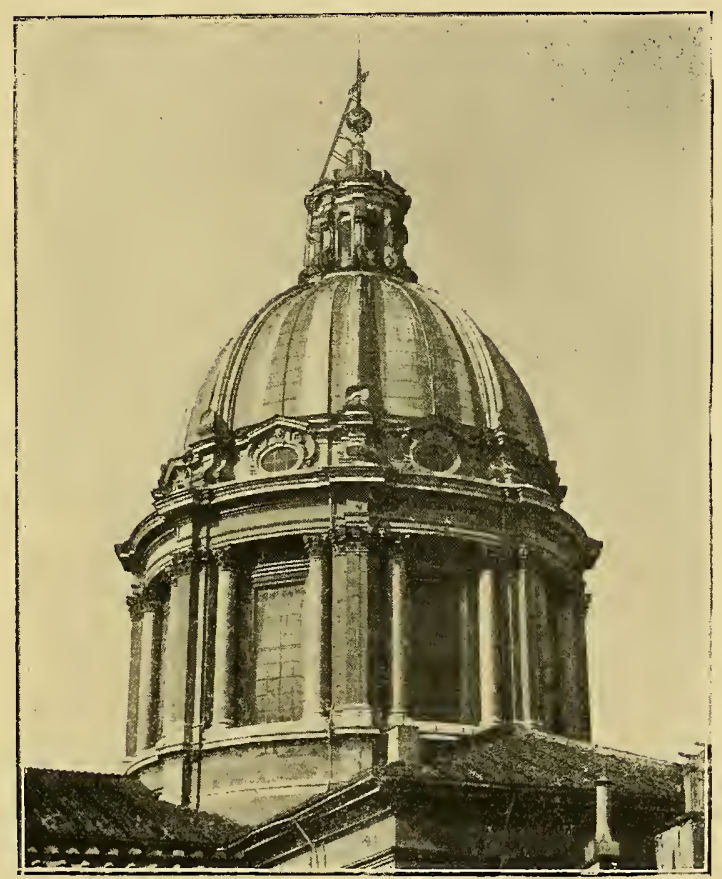

Cupola di S. Carlo al Corso di P. da Cortona (?)

(Fot. Moscioni).

usare colonne mastodontiche e linee massicce e pesanti. In questa categoria rientra pure il S. Pietro del Maderno, che per non nascondere ancora di più la cupola dovette limitare il prospetto ad un solo ordine, sormontato da un basso attico.

Ma la grande innovazione del barocco è la facciata in curva, o con elementi curvilinei, che risponde assai bene al gusto dei tempi nuovi, come quella che ha carattere assai più pittorico 
della facciata a linea retta. Esempî pì̀ antichi di prospetti in curva non mancano; il palazzo Massimi alle Colonne (1535) ha la facciata convessa, ma tale forma gli derivò dall' angustia e dalla tortuosità della strada, e inoltre l'architetto cercò dí far scomparire la convessità, o almeno di attenuarla, col portico aperto del primo ordine, in cui tra gli intercolunnî vuotí l'occhio si perde e non avverte più la curva. La porta del bastione sangallesco di S. Spirito (1543) ha forma concava, suggerita forse dalla ristrettezza dello spazio che non permetteva altrimenti un largo sviluppo; ma anche qui l'effetto della curva è stato attenuato per mezzo di due grandi nicchioni aperti tra le colonne. II barocco invece adotta la linea curva nelle facciate senza timidità, e ne fa anzi un motivo suo prediletto. Comincia Pietro da Cortona a S. Luca, a introdurre convessità parziali negli interpilastri, (1635-59); poi îl Borromini dà ai Filippini il primo esempio di facciata concava, con risalti (1637-41), che ritorna alla Madonna dei Sette Dolori (1652), a S. Agnese (1653), che ha torri laterali in piano con interpilastri convessi, poi una forte concavità spezzata nel mezzo dal portale rettilineo in aggetto, e infine a S. Carlino (1667) l'ultima sua opera, che è a linee ondulate, con due concavità laterali e forte convessità nel mezzo. Le derivazioni sono numerose; tra esse S. Marcello, meravigliosa creazione di Carlo Fontana, S. Caterina a via Giulia, la Maddalena, 1'Assunta di Valmontone. A S. Maria della Pace (1655), Pietro da Cortona adopera linee curve in piì sensi; concave le ali laterali, convessi gli interpilastri del1 'ordine superiore, semicircolare il portichetto: Bernini adotta una specie di portico convesso a S. Andrea del Noviziato (1658); e adopera la linea curva nei colonnati di S. Pietro che altri avevano imaginati a rette spezzate, formanti con la piazza un ottagono.

Una volta introdotta, la linea curva fa rapidamente fortuna, e torna di frequente non solo nei prospetti, ma nelle pareti delle 


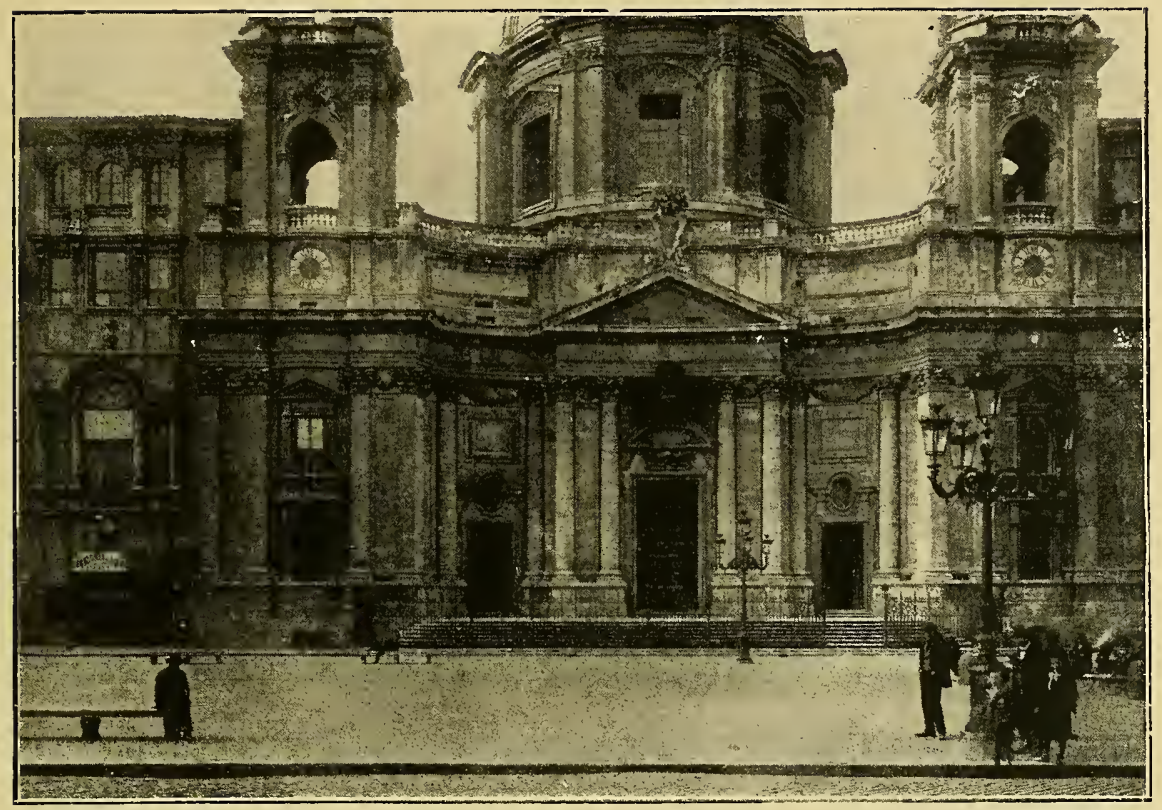

S. Agnese a Piazza Navona, di F. Borromini.

cappelle, nei monumenti funerarî, negli altari. Proprio mentre lavorava al convento dei Filippini, Borromini disegnò un altare per la cappella dell'Annunziata in SS. Apostoli di Napoli; l'opera commessagli dal cardinale Filomarino fu eseguita a Roma e trasportata poi e montata sul posto: è una parete concava, divisa in tre parti da colonne corinzie scanalate; la centrale che forma cornice al quadro, è sormontata da timpano spezzato, e leggermente convessa, cosi che ritroviamo qui lo stesso giuoco che ai Filippini, la stessa dolcezza di curve, ma una maggiore signorilità, quale richiedono la destinazione dell'opera e la materia, ch'è il marmo bianco.

L'altare assume nella chiesa del Seicento una grande importanza; esso è il centro verso cui convergono gli sguardi e i cuori dei fedeli, e gli artisti barocchi lo fanno ricco ed ornato, gli dànno varie e studiate forme per ottenere maggior effetto. 


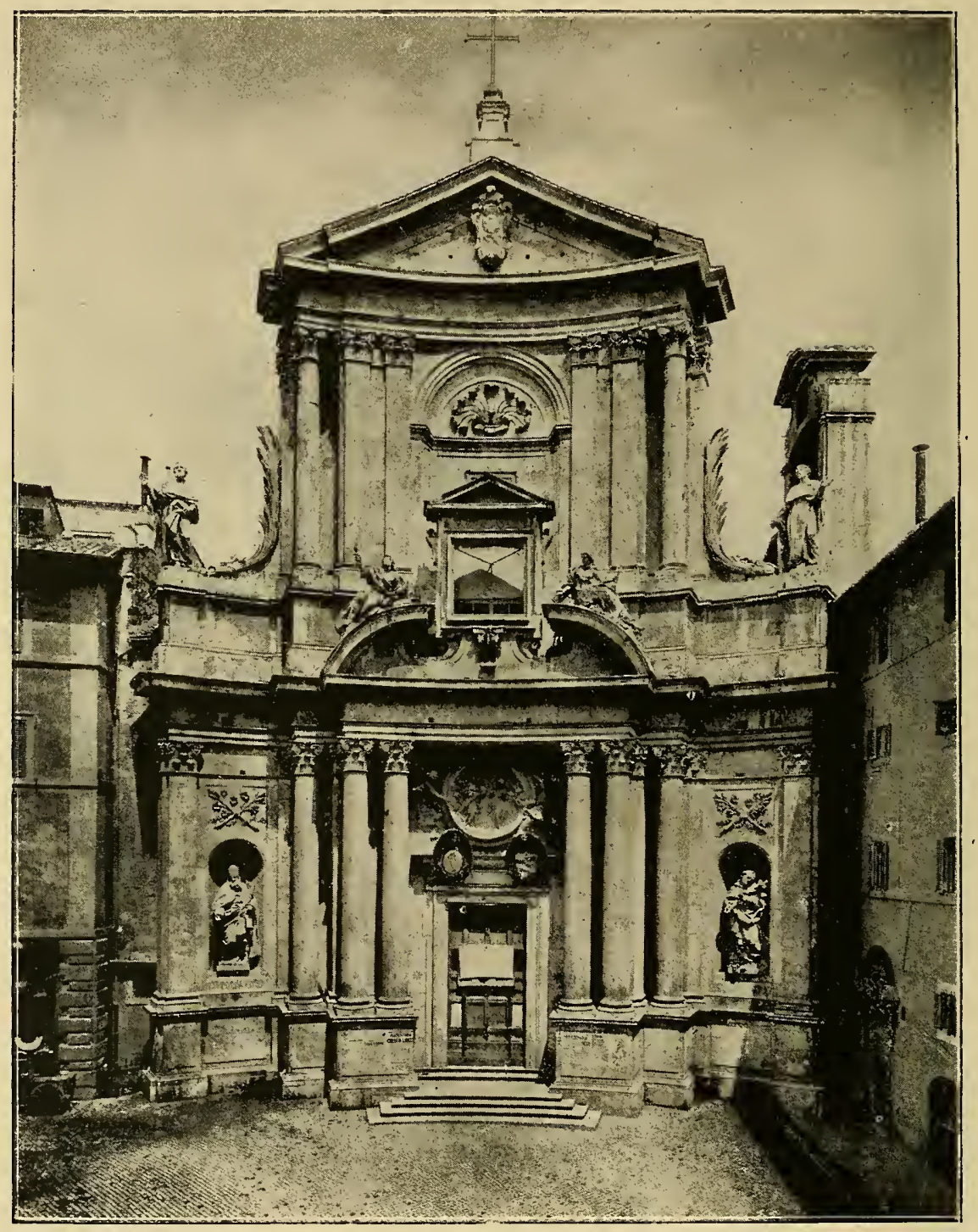

Facciata di S. Marcello, di Carlo Fontana.

(Fot. Anderson). is 


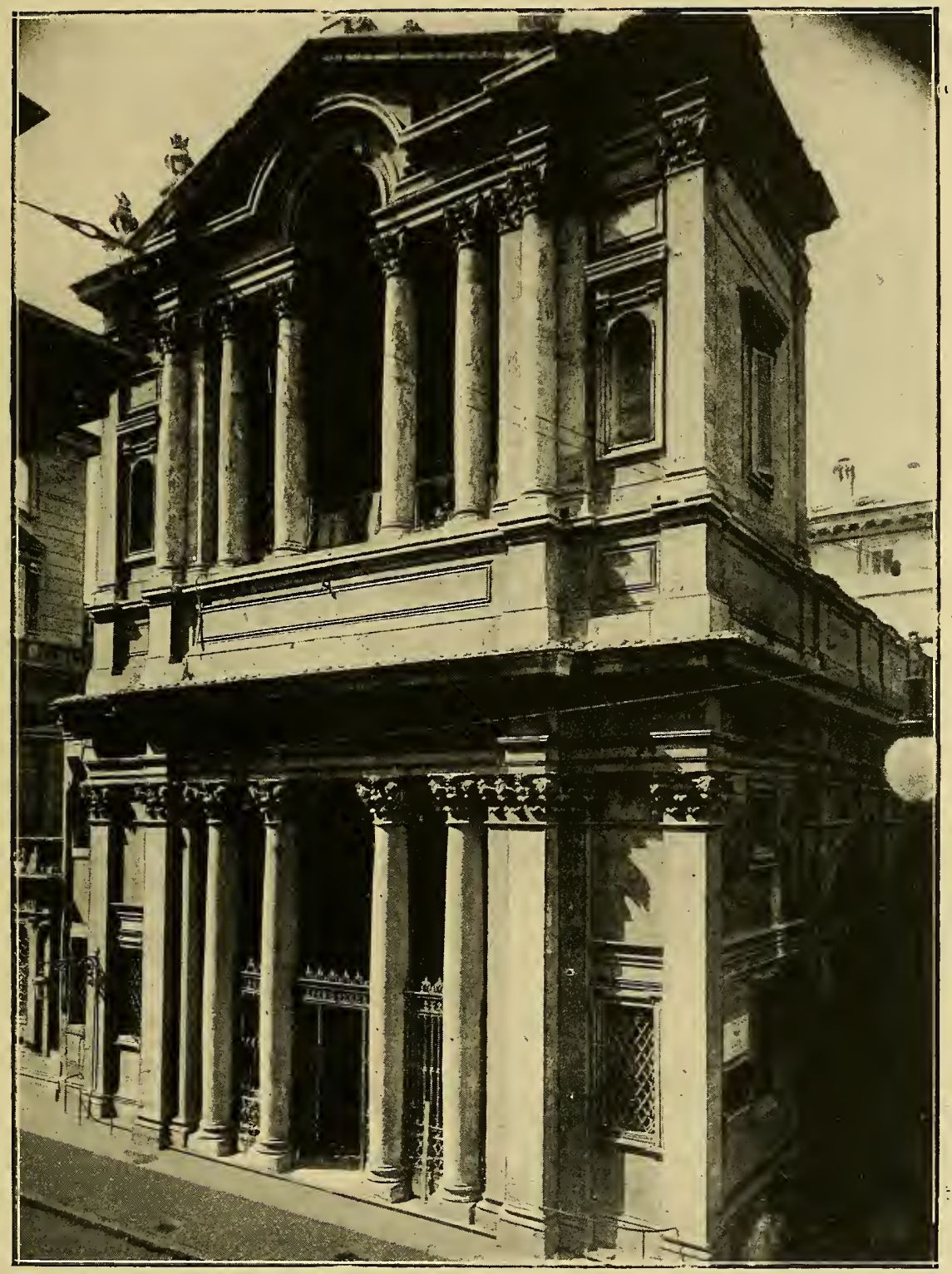

Facciata di S. Maria in Via Lata, di Pietro da Cortona. 


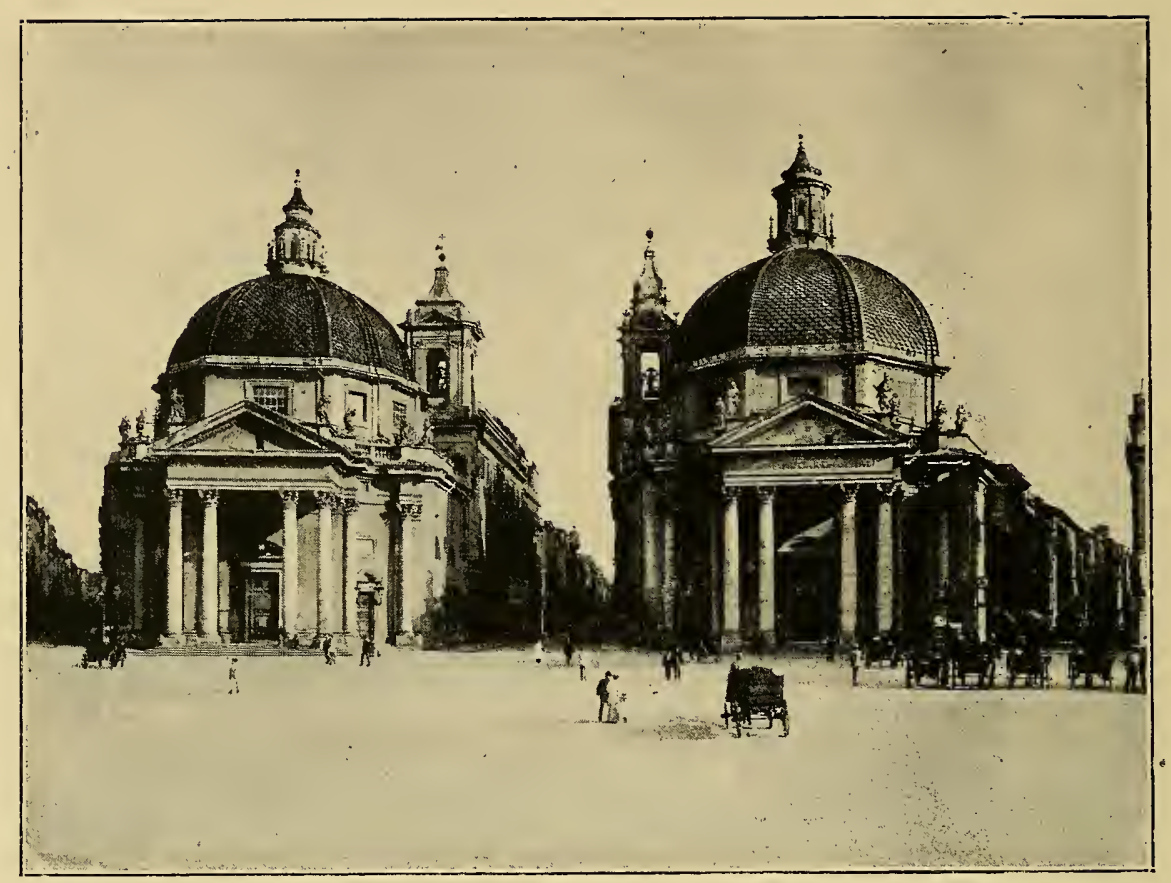

S. Maria in Montesanto e S. Maria dei Miracoli, di C. Fontana e C. Rainaldi. (Fot. Alinari).

Il primo e più comune típo di altare seicentesco è quello addossato al muro di fondo dell'abside o della cappella, sul quale è posto il quadro entro una cornice di legno o di marmo, fiancheggiata da pilastri e da colonne semplici o binate, con tímpano sovrastante: ì la forma derivata dalle edicole classiche del Pantheon, e già usata nel Rinascimento; ma il barocco la arricchisce con marmi preziosi, con stucchi, con metalli, con glorie di angeli, con raggere dorate, con gruppi di statue. A questo tipo appartengono gli altari del Sacramento in S. Giovanni (1600), della Cappella Paolina in S. Maria Maggiore (1611), della Chiesa Nuova, del Gesì, di S. Ignazio, del Gesù e Maria, e quelli ricchissimi di fratel Pozzo, dedicati a $S$. Luigi e a S. Ignazio. 


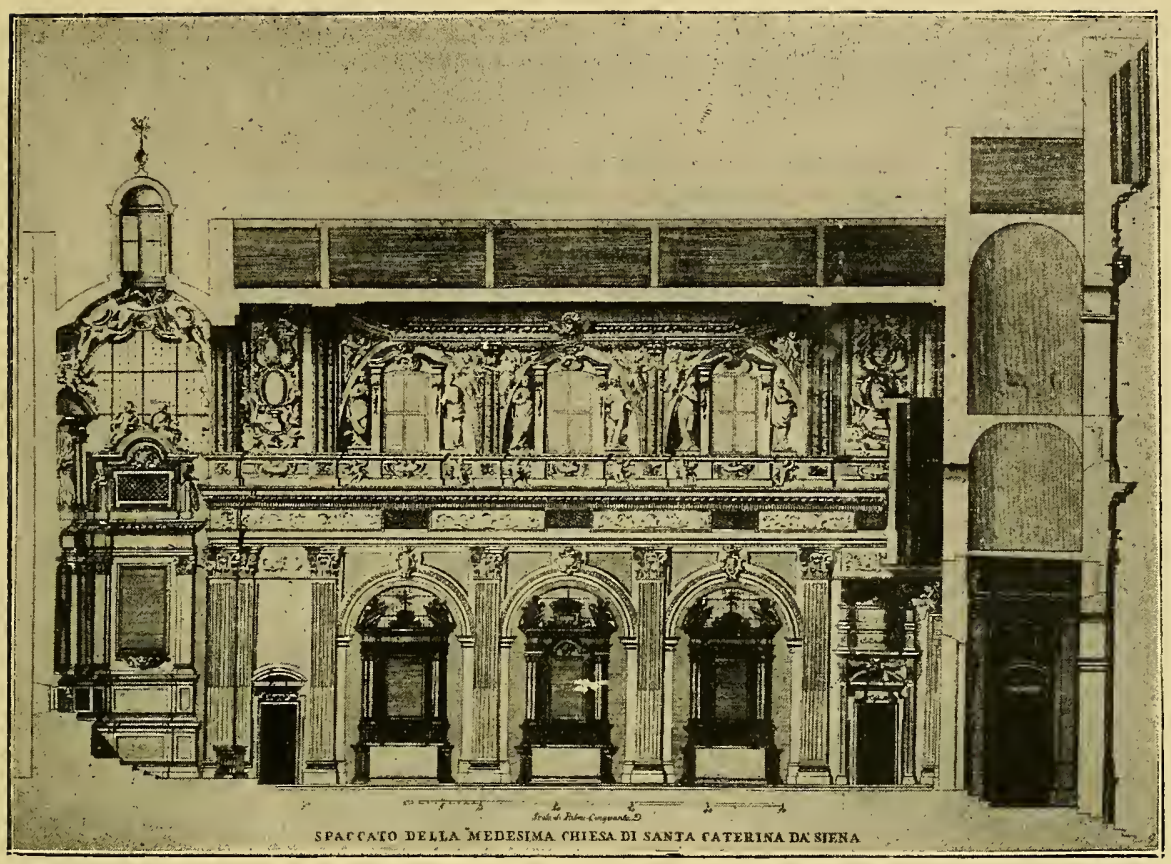

Spaccato di S. Caterina a Magnanapoli, di G. B. Soria.

Un altro tipo è quello dell' altare isolato, in forma di prospetto, sostenuto da colonne e coronato da frontespizio, posto a una certa distanza dalla parete di fondo, o sulla soglia della cappella absidale, in modo da separarla dal resto del tempio; ed è questa la forma usata comunemente nelle chiese conventuali, in cui il coro dei monaci rimane distinto dalla parte riservata ai fedeli; cosi vediamo gli altari di S. Maria del Popolo, di S. Agostino, di SS. Cosma e Damiano, di Aracoeli, di S. Lorenzo in Lucina. Questo tipo perdura fino alla metà del Seicento, poi viene sostituito dall'altare isolato, più basso, su cui si elevano varî gradini per le carteglorie $i$ vasi di fíori e $i$ candelieri, mentre il quadro è collocato a distanza, sulla parete di fondo del coro: è l'altare generalmente in uso nel secolo decimottavo. 


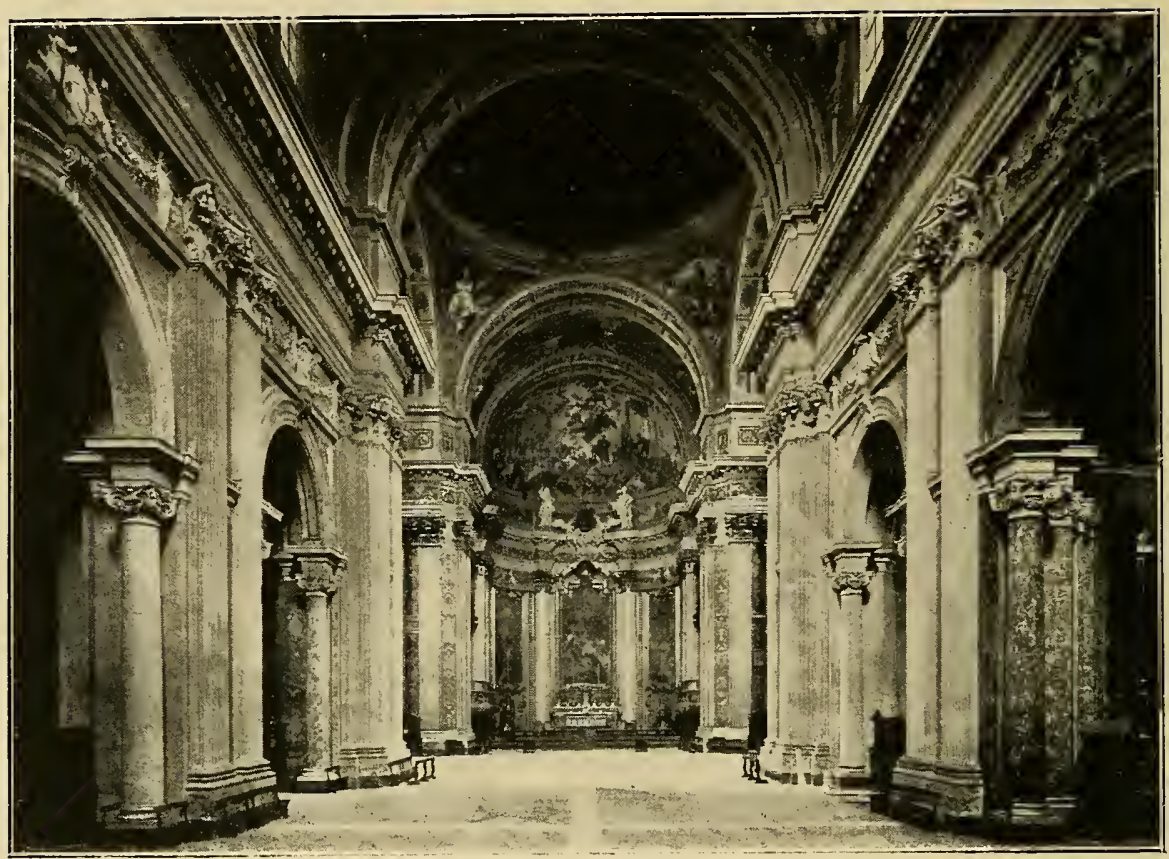

Interno della Chiesa di S. Ignazio.

(Fot. Anderson).

Una innovazione che appare verso la metà del secolo XVII è la sostituzione del quadro d'altare dipinto con grandi altorilievi marmorei; il típo trova la sua più celebre espressione nella tavola dell' Attila di Alessandro Algardi, in S. Pietro (1645), e negli altari di S. Agnese a piazza Navona, di S. Ignazio, di S. Andrea della Valle.

L'altare isolato è talvolta, specie nelle basiliche, coperto dal ciborio o tabernacolo, che è come un piccolo tempietto dentro il tempio maggiore, sorretto da colonne che sopportano un tiburio piramidale o una cupola, usato già nei primi tempi cristiani e nel Rinascimento. Il barocco lo continua nella stessa forma (S. Agnese fuori le Mura, S. Crisogono) fino al tempo in cui il Bernini crea il meraviglioso baldacchino di bronzo di S. Pietro (1624-1633), che è una vera innovazione e sostituisce al taber- 


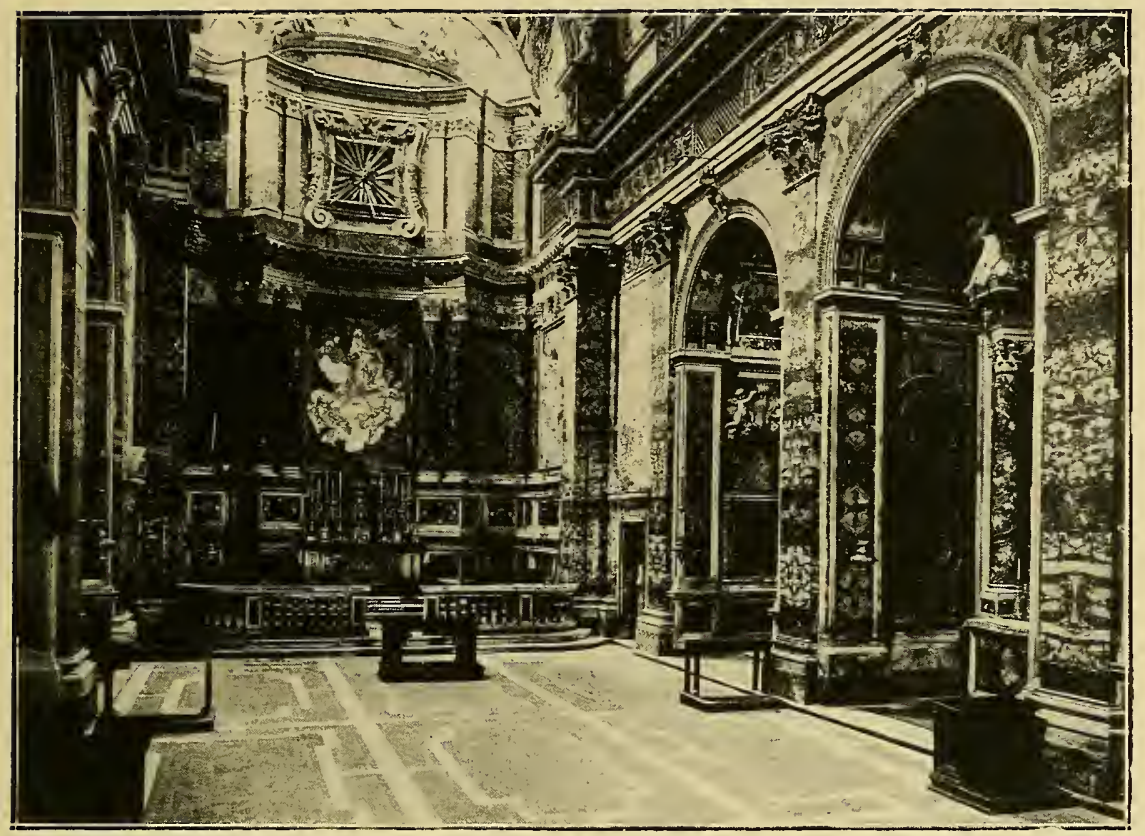

Interno di S. Caterina a Magnanapoli, di G. B. Soria.

nacolo architettonico il baldacchino pittorico, e segna perciò una data importantissima nella storia dell'architettura. Un altro tipo di altare, che si può chiamare più plastico che architettonico, ̀̀ quello che vedemmo nella Cappella Sistina di S. Maria Maggiore (1585) e che il Bernini adoperò nella cappella del Sacramento in S. Pietro (1674): nel mezzo sta un tempietto rotondo di metallo dorato, incrostato di lapislazzuli, custodia dell' ostia santa, e ai lati due angeli inginocchiati pregano a mani giunte; da questo derivano gli altari di S. Spirito in Sassia e di S. Francesco di Paola.

Ma il più rícco e complesso altare del Seicento è quello della Cattedra di S. Pietro, del Bernini (1656-65), che occupa tutta la parete di fondo dell'abside, ed è una vera macchina scenica di effetto sorprendente: su grandi basi incrostate di rosso 
diaspro stanno ai lati della mensa dell'altare quattro colossali statue bronzee dei Dottori della Chiesa, che sorreggono la cattedra di metallo tutta scintíllante d'oro, quasi la portassero in processione come l'arca dell'alleanza; e in alto tra nuvole aurate, intorno alla vetrata su cui brilla la colomba dello Spirito Santo, vola un festoso coro di angeli, mentre una raggera splendente si effonde all' intorno. Innanzi a questa luminosa macchina, è forza riconoscere che nessun altro stile all' infuori del barocco avrebbe potuto raggiungere un effetto così magnifico, avrebbe saputo comporre un così sfolgorante quadro: qui siamo di fronte non solo a un capolavoro del genio berniniano, ma ad una delle opere più insigni che l'arte di tutti $i$ tempi abbia saputo creare.

La Cattedra Vaticana ci ha fatto pensare alle macchine teatrali che il Bernini e moltí altri artisti del Seicento disegnavano realtà per la rappresentazione delle commedie e dei melodrammi, $e$ in il teatro influi fortemente sull'architettura barocca, non soltanto profana, ma anche sacra.

Perfino gli altari prendono la forma del palcoscenico: dopo l'esempio dato dal Bernini nel 1641 nella cappella Alaleona in SS. Domenico e Sisto a Magnanapoli, si vedono spesso altari formati da un alto basamento a linea convessa, come la ribalta di un teatro, fiancheggiati da colonne e pilastri messi a guisa di quinte e sormontati da un timpano; e sul basamento son disposti gruppi marmorei le cui figure a tutto tondo fanno le parti di attori. Spesso dietro i pilastri laterali si aprono delle finestre, che rimangono invisibili al riguardante, dalle quali, proprio come sulle scene, si proiettano fasci di luce sui personaggi; talora il fondo dell'altare, dietro le figure, porta decorazioni dipinte o in stucco, di paesaggi o di cieli, come uno scenario; perchè generalmente questi altari in forma di teatro non sono isolati ma addossati alla parete dell'abside o delle cappelle laterali. 


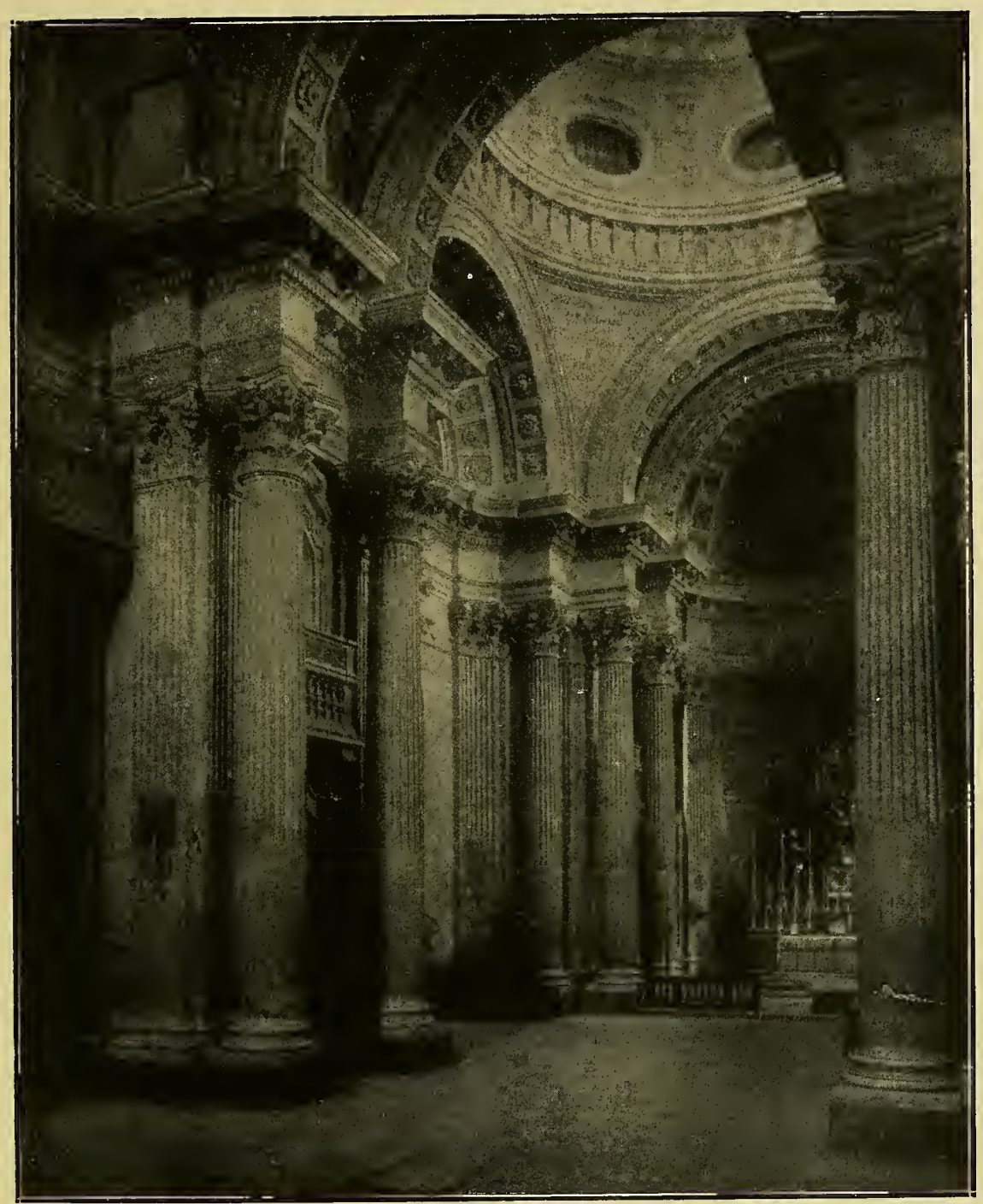

Interno di S. Maria in Campitelli, di Cario Rainaldi. (Fot. Moscioni).

Vediamo l'esempio più antico: l'altare di SS. Domenico e Sisto; nella prima cappella a destra della bella chiesa. Dietro la mensa dell'altare si eleva un grande basamento convesso, rivestito di alabastro con cornice di verde antico, e su di esso 


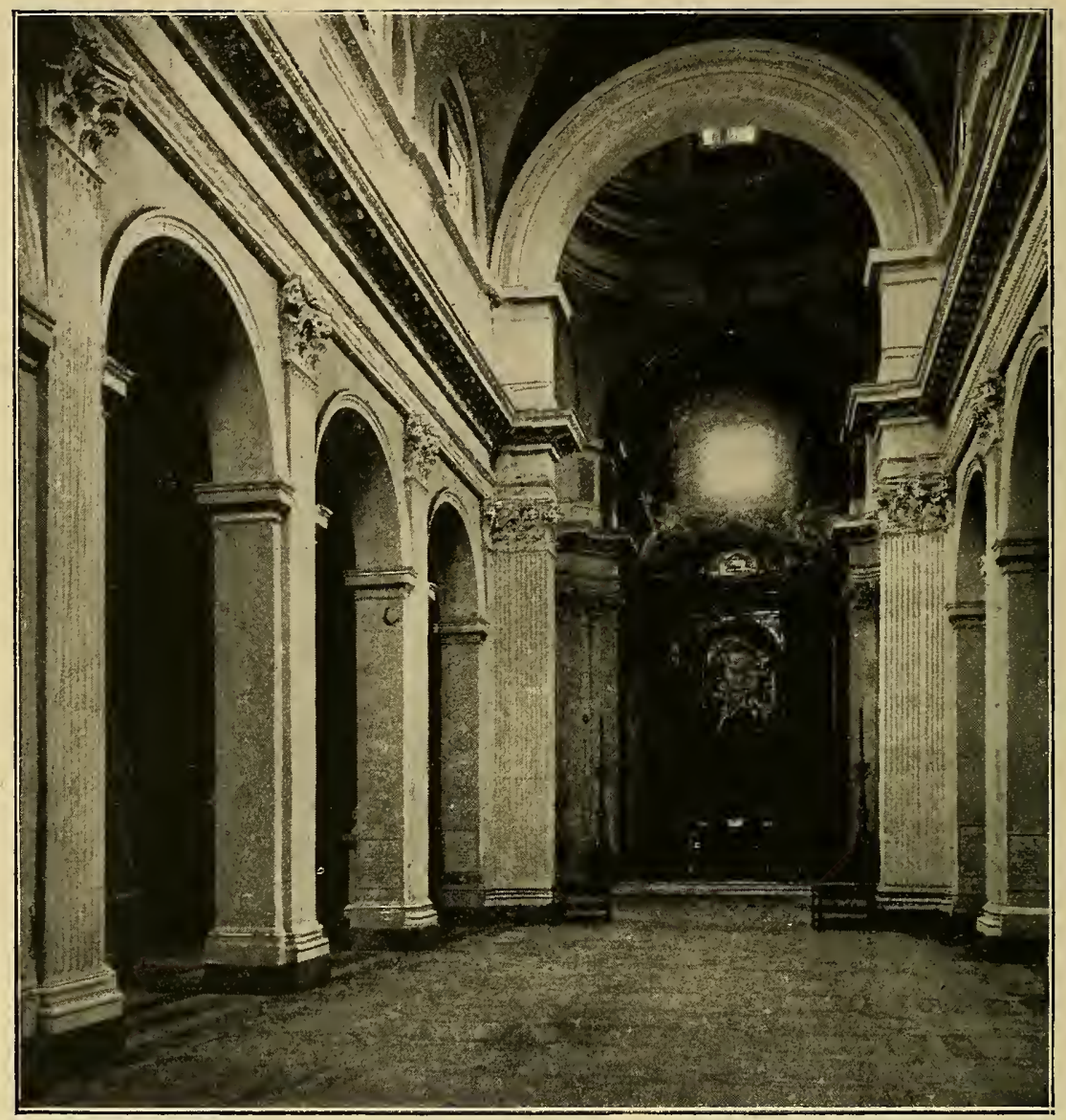

Interno di S. Giovanni de' Fiorentini, di Giacomo della Porta.

è collocato il mirabile gruppo del Cristo con la Maddalena, scolpito su bozzetto del Bernini dal suo prediletto discepolo Antonio Raggi. La donna bellissima si inginocchia avanti al Maestro, e lo guarda come affascinata, protendendo le mani verso di lui, che poggiato alla sua pala di ortolano, con un dolce sorriso che fuggevolmente gli traspare dal volto, abbassa il capo e avanza la destra 


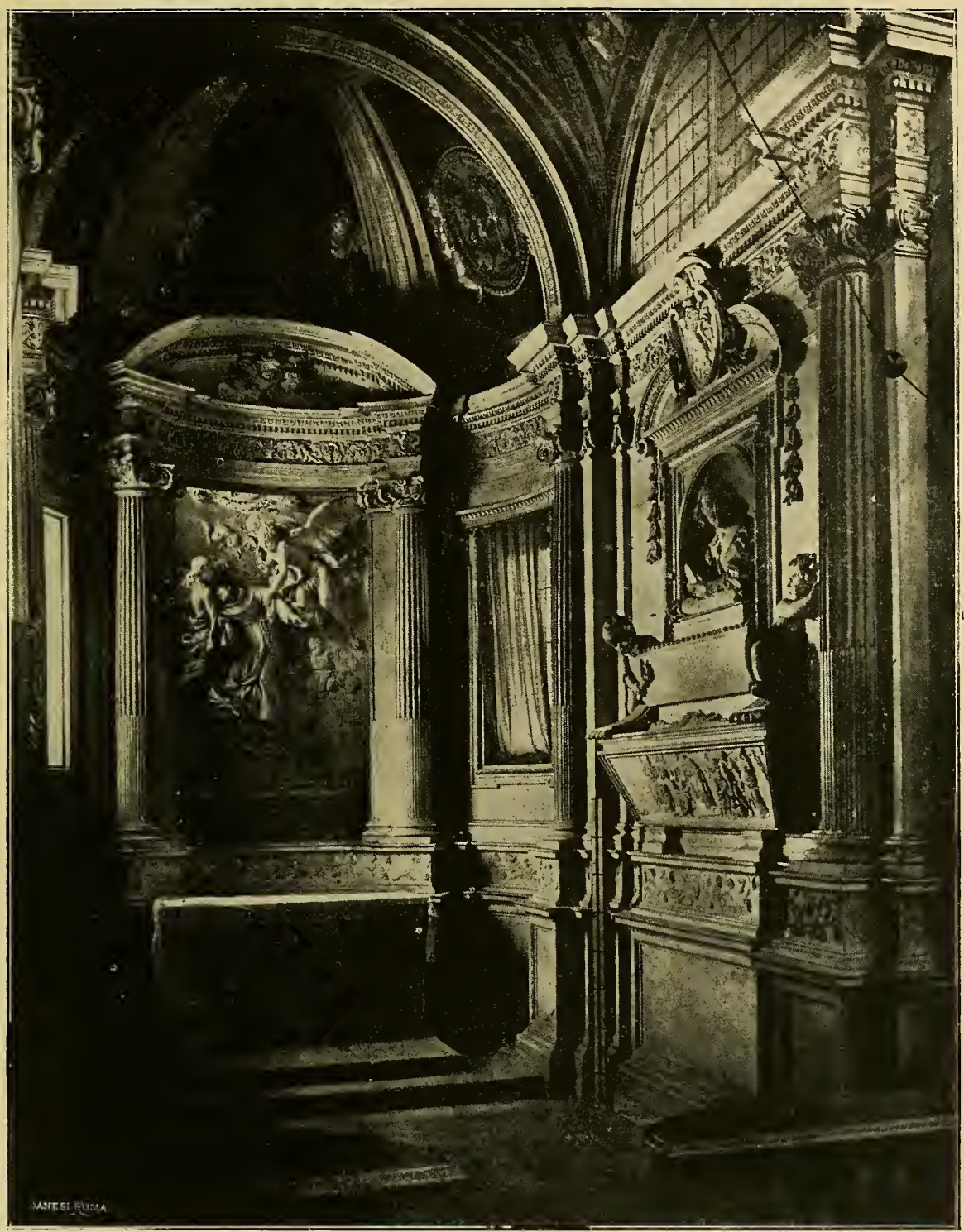

La cappella Raimondi, del Bernini, in S. Pietro in Montorio

come per ritenerla. Vi è qui una situazione veramente drammatica, che risulta dal contrasto tra la passione della donna 
e la serenità del Cristo che la contiene. Sullo sfondo, proprio come in un teatro, è dipinto un paesaggio orientale; a sinistra un gruppo di palme, e lontano la città di Gerusalemme con le sue torri e i suoi templi, più vicino il Calvario con le tre croci; a destra il sepolcro aperto, e su tutto il cielo azzurro solcato da qualche nube leggera.

Pochi anni dopo il Bernini esegui la decorazione della cappella Corner in S. Maria della Vittoria, (1644-47); e anche qui egli dette all'altare la forma di un palcoscenico su cui collocò il gruppo dell'Estasi di $S$. Teresa, e dall'alto fece piovere da un finestrino ovale con vetri gialli, un fascio di luce d'oro, come da un riflettore teatrale.

Un altro esempio di altare ricavato entro un'edicola con finestra nascosta che manda luce sulle figure poste nel mezzo, è quello della cappella Raimondi in S. Pietro in Montorio, che è una delle più fini creazioni del Seicento romano. La cappella, al dir degli scrittori del tempo, fu fatta costruire dal Marchese Raimondi di Savona, patrizio romano, sotto la direzione del Bernini, negli ultimi anni del pontificato di Urbano VIII, cioè tra il 1640 e il ' 44 ; il grande altorilievo che è in fondo all'altare, rappresentante $S$. Francesco che riceve le stimmate, è opera firmata del Baratta.

Un altro grandioso altare teatrale è quello del coro di S. Giovanni dei Fiorentini, col gruppo monumentale del Battesimo di Cristo, scolpito da Antonio Raggi, il gentile discepolo del Bernini. Tra questi altari-scena è il più importante, e di maggiore effetto, perchè collocato proprio nella cappella absidale, di guisa che entrando nella bella chiesa cinquecentesca, apparisce subito in fondo, con straordinario effetto. La grande edicola di rosso cottanello ha nel mezzo un nicchione rivestito di marmo bigio, in cui stanno le due figure del Battista e di Gesù, mentre da lato è un angelo in ginocchio; dall'alto scende una gloria di nuvole, di raggi d'oro e di cherubini. Ai due lati della nicchia, 
ben nascoste al riguardante, si aprono due alte finestre che nelle diverse ore del giorno proiettano luce ora sul volto del Cristo, ora su quello di Giovanni.

$\mathrm{Col}$ progredire del secolo decimosettimo queste ricerche di effetto, questo desiderio di colpire con contrasti violenti, con ricchezza di colori, con sbattimento di luci, diviene più comune; si ricorre allora a motivi bizzarri, a ripieghi stravaganti, che sono la degenerazione del barocco, e annunziano la decadenza. L'acido Milizia si esaspera di fronte alle accartocciature, ai contorcimenti degli ultimi berniniani; ma già prima di lui comincia la reazione; lo studio dei monumenti antichi torna a fiorire; forme più semplici, più classiche, più severe, prendono il posto delle agitate creazioni dei seicentistí. Tuttavia l'eco della grande arte barocca durerà ancora a lungo; e fino ai giorni nostri ne potremo cogliere il riflesso.

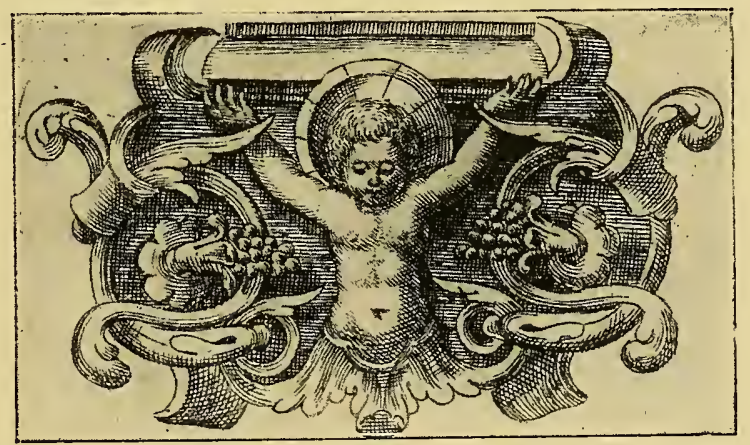




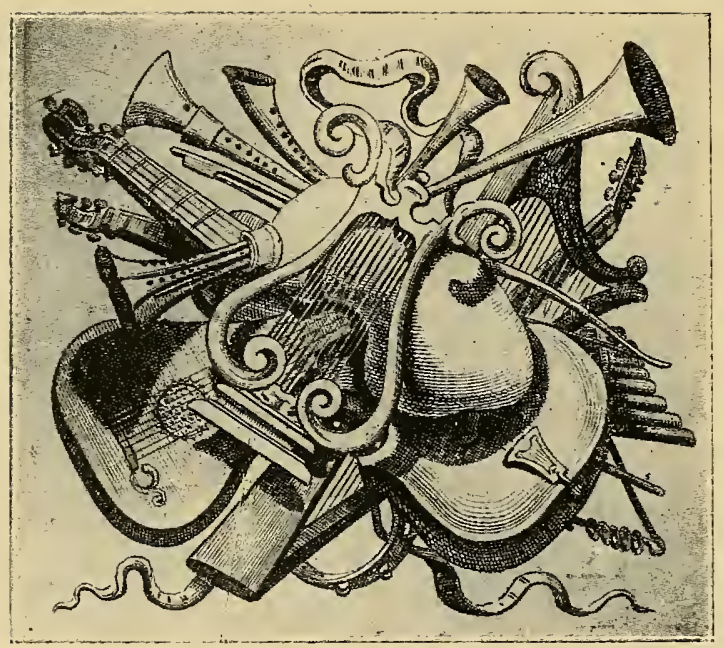




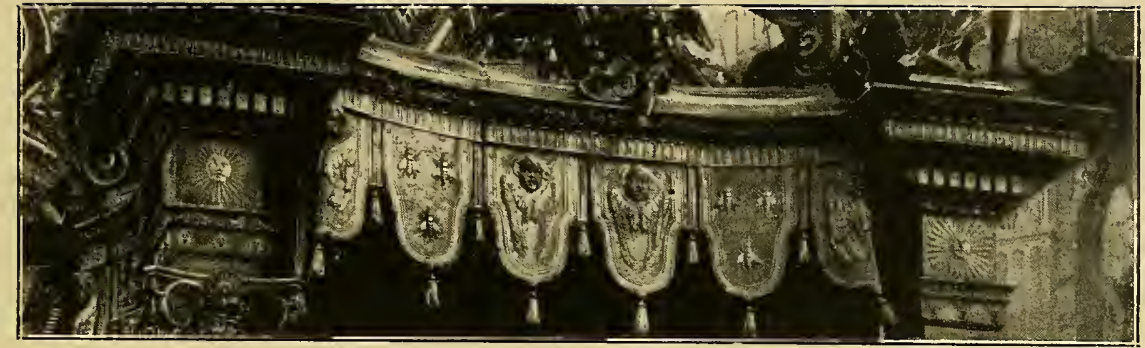

\section{CAPITOLO QUINTO}

\section{IL BALDACCHINO}

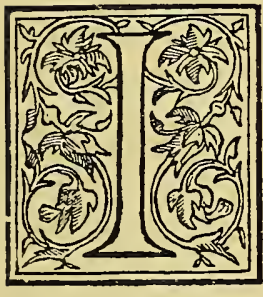

1 giorno di S. Pietro del 1633 tutto il popolo di Roma accorse in festa alla Basilica del Principe degli Apostoli in Vaticano, per ammirare il nuovo meraviglioso baldacchino di bronzo, che con solenne cerimonia erasi inaugurato quella stessa mattina. Per l'opera gigantesca, ideata e diretta dal Cavalier Bernini, si erano impiegati nove anni di lavoro, e ad essa aveva collaborato una schiera di valenti artisti: Andrea Bolgi, Francesco Duquesnoy, Giuliano Finelli, Giambattista Soria, Simone Laghi, Francesco Castelli alias Boromini. Urbano VIII appena salito al trono, nel 1624 , aveva voluto che sulla tomba di San Pietro sorgesse un nobile tabernacolo, e scartati altri progetti, aveva prescelto quello del suo prediletto Bernini, non lesinando mezzi perchè l'opera riuscisse degna, e imponendo per procurarseli nuove gabelle. Mancava il bronzo, e si tolsero i costoloni della cupola della basilica ricavandone 103,229 libbre; altro se ne fece venire da Venezia e da Livorno, e se ne raccolsero in tutto 211,427 libbre. Ma poichè il metallo ancora non bastava, Urbano VIII non esito ad ordinare che si togliesse quello 
delle travi del pronao del Pantheon, cosi che Pasquino esclamava: Quod non fecerunt barbari, fecerunt Barberini! Un contemporaneo ci fa sapere che "tutto il metallo tanto delli travi, quanto degli chiodi di essi che era nel portico del sopradetto tempio era libre quattrocentocinquanta mille e duecento cinquantuna, essendo li chiodi soli libre nove mille trecento settanta quattro „; ma non tutto fu impiegato pel baldacchino, poichè se ne fecero anche ottanta cannoni per Castel S. Angelo. Il Pantheon ebbe in compenso della spogliazione di quegli ornati, che un' iscrizione collocata nel pronao chiama decora inutilia, i due campanili che il popolo argutamente battezzò le orecchie d'asino del Bernini, demoliti nel 1883.

Si cominciò subito col gettare in bronzo le quattro grandi colonne, ognuna delle quali, pesata con un' ingegnosa bilancia ideata da Luigi Bernini, risultò di libbre 27,948; e furono innalzate nel 1626, e indorate; si fece un modello del coronamento che poi fu eseguito in legno, rivestito di lamine di metallo. I disegni che il Bernini forniva in piccole dimensioni, venivano riprodotti al vero da Francesco Castelli o Borromini. Tutta l'opera costò 200.000 scudi, e il Bernini oltre i 250 scudi mensili che aveva ricevuti dal principio del lavoro, ebbe infine un dono di altri diecimila, cosi che in tutto venne a guadagnare non meno di 34,000 scudi, più un canonicato per Vincenzo e un benefiziato per Domenico suoi fratelli, e la nomina di Luigi a soprastante dei lavori di S. Pietro. Tale munificenza del pontefice era veramente giustificata dal meraviglioso lavoro fatto dall'artista; il quale aveva creato un'opera di bellezza eterna, che fece epoca nella storia dell'architettura.

All' incrocio delle navate della basilica, al disotto della cupola, non proprio nel centro, ma notevolmente spostata verso l'abside, si eleva la mirabile mole, svelta e leggera pur nelle sue smisurate dimensioni, poichè dal basamento alla croce che la sormonta è più alta della facciata di Palazzo Farnese. Pensiamo 
di fronte a qual terribile problema si trovava il Bernini! Costruire un tabernacolo in San Pietro, nel punto più visibile, sotto la cupola ideata dal genio di Michelangiolo, dinanzi al coro di armoniose proporzioni, senza turbare l'equilibrio delle linee, senza nascondere il fondo, senza diminuire l'effetto dell' insieme, erano tante difficoltà, che avrebbero fatto tremare l'animo del maestro più provetto. E il giovane cavaliere di ventisei anni, che fino a

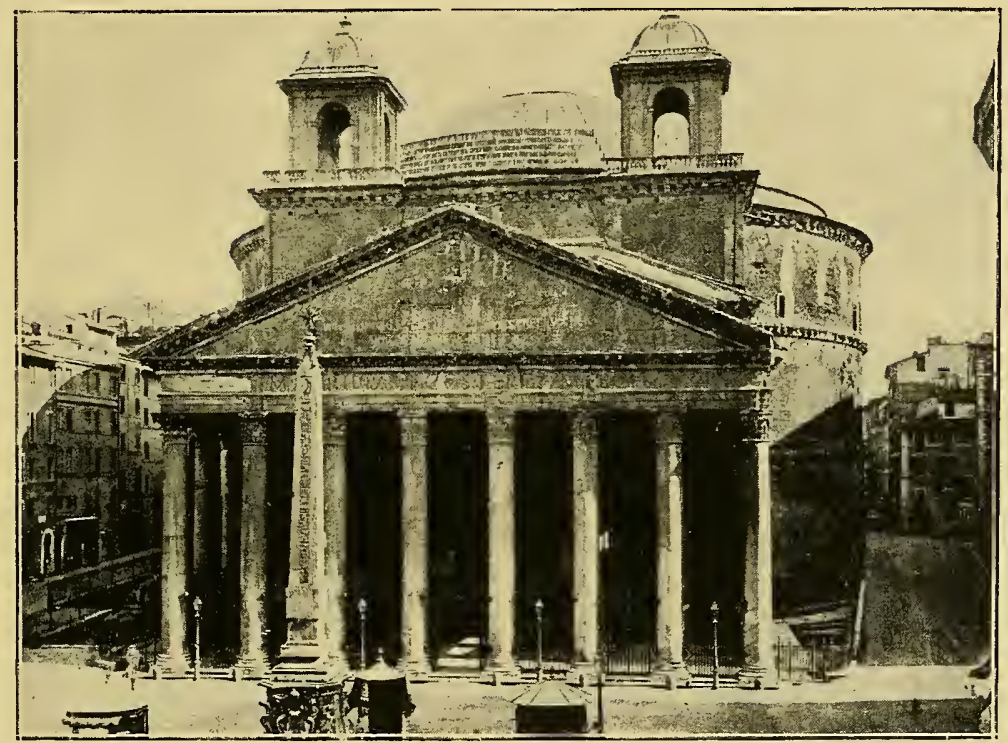

II Pantheon con le orecchie d'asino del Bernini.

quel momento non s'era mai dedicato a lavori di architettura, affrontò con coraggio l'ardua prova, e la superò vittoriosamente. La sua idea fondamentale fu felicissima: egli sostitui al cíborio, al tabernacolo tradizionale del Medioevo e del Rinascimento, in uso ancora al suo tempo, un baldacchino; ossia a un elemento architettonico un elemento pittorico. Il tabernacolo composto di una cuspide o di una cupola marmorea retta da colonne, era qualche cosa di solido, di tettonico, come un tempio minore dentro il maggiore; il baldacchino invece, coperto da un cielo che imita 
la stoffa, è qualche cosa di mobile, di leggero, quasi di provvisorio; non più opera di architettura ma di tappezzeria; e quindi appare non ingombrante e massiccio, ma libero, snello, in modo da lasciar vedere facilmente lo sfondo; e non diminuisce 1 ' impressione di profondità della basilica, ma quasi la aumenta facendo apparire, tra le colonne, l'abside più lontana. A questo concetto di libertà, di leggerezza, di movimento, a cui si ispira 1 ' insieme, obbediscono anche le singole parti dell'opera. Su quattro basi marmoree, che portan gli stemmi di papa Barberini, sorgono le colonne di bronzo a spirale, tanto criticate dal Milizia che le chiamò assurde, e sorreggono capitelli e mensole da cui partono costoloni ricurvi che si congiungono in alto, riuniti in una mensola che sostiene il globo sormontato dalla croce. Quattro bellissimi angeli stanno in piedi sui capitelli e reggono per mezzo di corde un grande ombracolo dorato, che fa da cielo all'altare, $e$ ricade ai lati in squame o lamelle infiocchettate, che si piegano come mosse dal vento; e l'ombracolo stesso s' incurva in modo che tutte le linee sono mobili e addolcite e nessun elemento appare rigido e solido. Le colonne sono divise in tre parti; 1 ' inferiore baccellata a spirale, le superiori rivestite di tralci di lauro fra le cui foglie volano api barberiniane e corrono putti alati; le squame portano teste di cherubini e api; sull'ombracolo stanno putti che reggono attributi pontificali, e sulle volute s'incurvano fasci di palme; e l'oro, sapientemente sparso qua e là, illumina costole e fogliami, cornici e fiocchi, dentelli e vesti, dando al1 'insieme festosità e ricchezza. Mai si era visto nulla di simile; mai l'architettura aveva raggiunto tale leggiadria; nessun maestro mai era riuscito a dare a una mole smisurata come quella, la finezza di un piccolo gioiello. Lasciamo pure che il Milizia venga qui col suo codice alla mano, a enumerare le infrazioni alle buone regole, a sussurrare malignamente di architettura persiana, gotica, cinese! E diamo piena ragione al Guattani, che pure era un archeologo e segretario dell'Accademia di S. Luca, il quale 


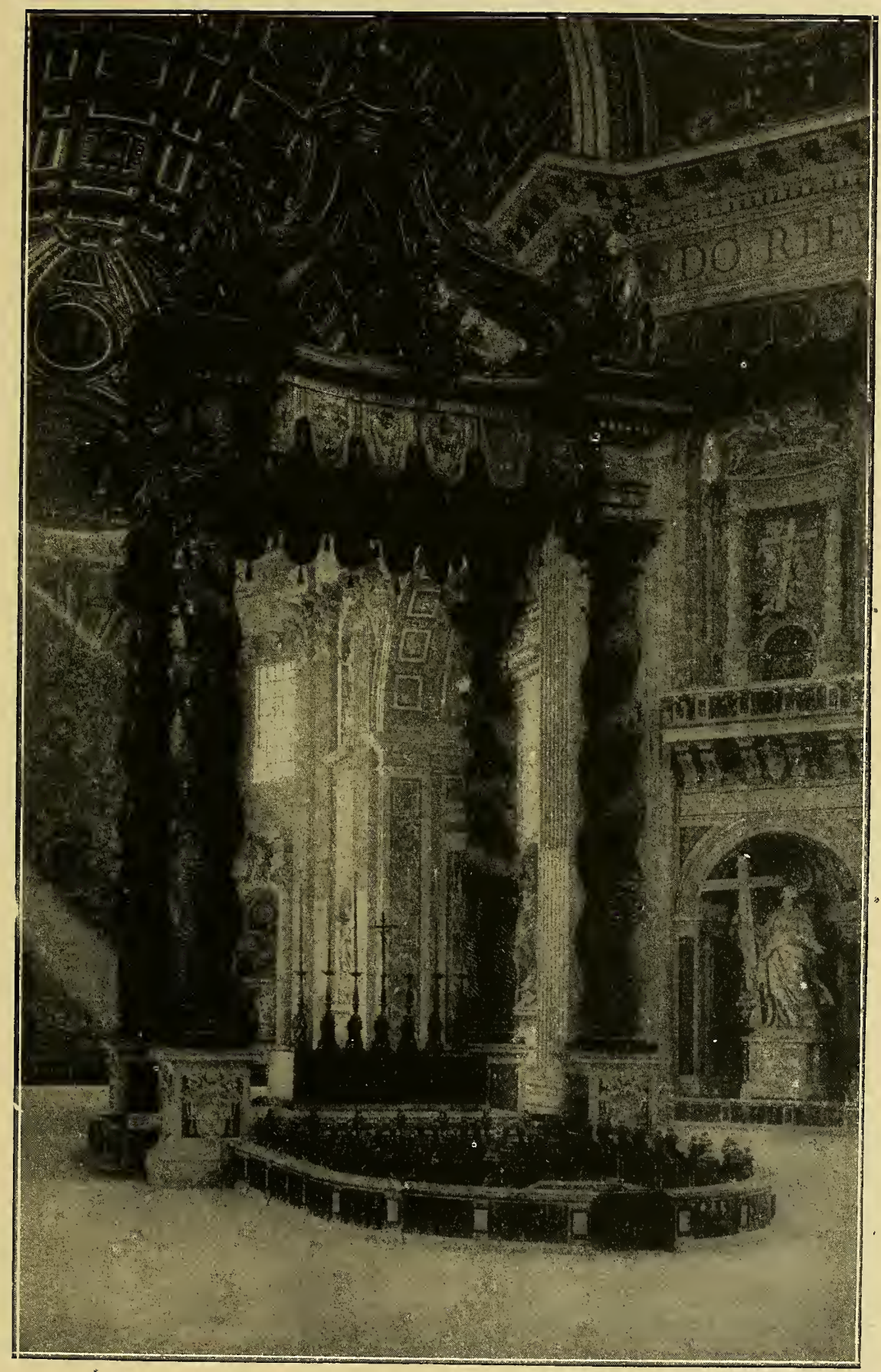


nel 1805, in pieno fiorire delle teorie neoclassiche, scriveva : " La bellissima, arcibellissima architettura greca, colle sue bellissime, arcibellissime regole proporzioni e monotonie, non era al caso questa volta $»$. La critica rivolta alle colonne tortili dimostra poi come il Milizia, pur sempre così cauto, parlasse talora a sproposito. Intanto il Bernini risolse con l'impiego di tali colonne un problema difficilissimo, se si pensa all'effetto monotono, rigido, che avrebbero fatto quattro tronchi lisci e verticali di quell'altezza straordinaria; invece con la divisione in tre parti, e l'avvolgimento a spirale, l'occhio non segue più una linea unica, ma si riposa, passando da una parte all'altra, e accompagnando il dolce movimento delle curve. $\mathrm{E}$ poi il maestro, sempre innovatore, in questo caso rispettava una tradizione antica, poichè si sa che il tabernacolo della basilica costantiniana aveva otto colonne marmoree a spirale, dello stesso tipo, e son quelle che il Bernini adatto, restaurandole, alle logge delle reliquie. Quelle colonne rimontano all'antichità classica, sia pur tarda, e il Medioevo ne riprese il modello, e Raffaello le riprodusse nell'arazzo della Presentazione, e cento architetti le usarono prima del Bernini, a Villa d'Este, alla Minerva, in San Pietro stesso; e Leon Battista Alberti le ricorda, e il Vignola nel suo Trattato dà le norme per disegnarle.

Al suo tempo il baldacchino fece furore; fu per oltre un secolo e mezzo continuamente imitato; ma ciò che è pì̀ strano, è che una di queste imitazioni fu compiuta prima ancora che l'opera originale fosse terminata: è il baldacchino della chiesa di S. Francesco di Spello, simile a quello vaticano, eseguito in legno nel 1631 su disegno di Teodosio Quintavilla, che dovette copiare il modello, pure ligneo, fatto dal Bernini nel 1628. Più tardi, nel 1698, sorse il baldacchino della cattedrale di Foligno fatto su una copia di quello di S. Pietro inviata da Roma dal celebre Andrea Pozzo, architetto e pittore gesuita. Nell'abside di S. Maria in Campitelli si vede infisso al muro un piccolo bal- 


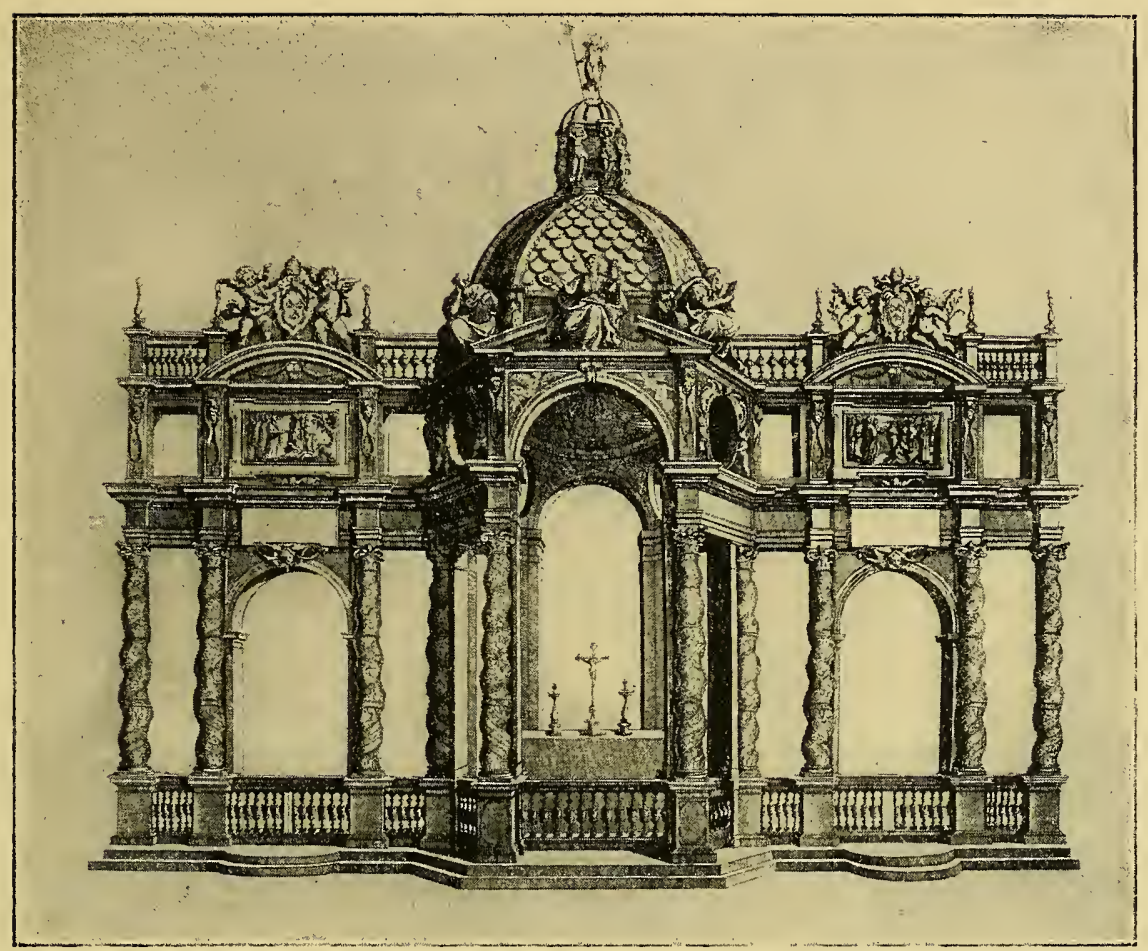

Progetto di Martino Ferabosco pel tabernacolo di S. Pietro.

dacchino di stucco che è una curiosa contaminazione dei due capolavori del Bernini in S. Pietro, cioè del Baldacchino e della Cattedra, perchè è tutto circondato di nuvole e di raggi d'oro, con bellissimo effetto pittorico e teatrale.

Gianlorenzo Bernini un'altra volta riprese il motivo del baldacchino vaticano, quando a Parigi, nel 1665, richiesto da Anna d'Austria, dette il disegno dell'altare maggiore della chiesa del Val-de-Grâce. Ila lo riprese, come sempre faceva, modificandolo profondamente, e trattandolo con più libertà. A S. Pietro si vede ancora il giovane che, pure innovando, mostra un certo ritegno; a Parigi è l'artista maturo, sicuro di sè, che audacemente respinge ogni tradizione, e non ha più freni alla sua fantasia. La pianta dell'altare del Val-de-Grâce è circolare, e le 


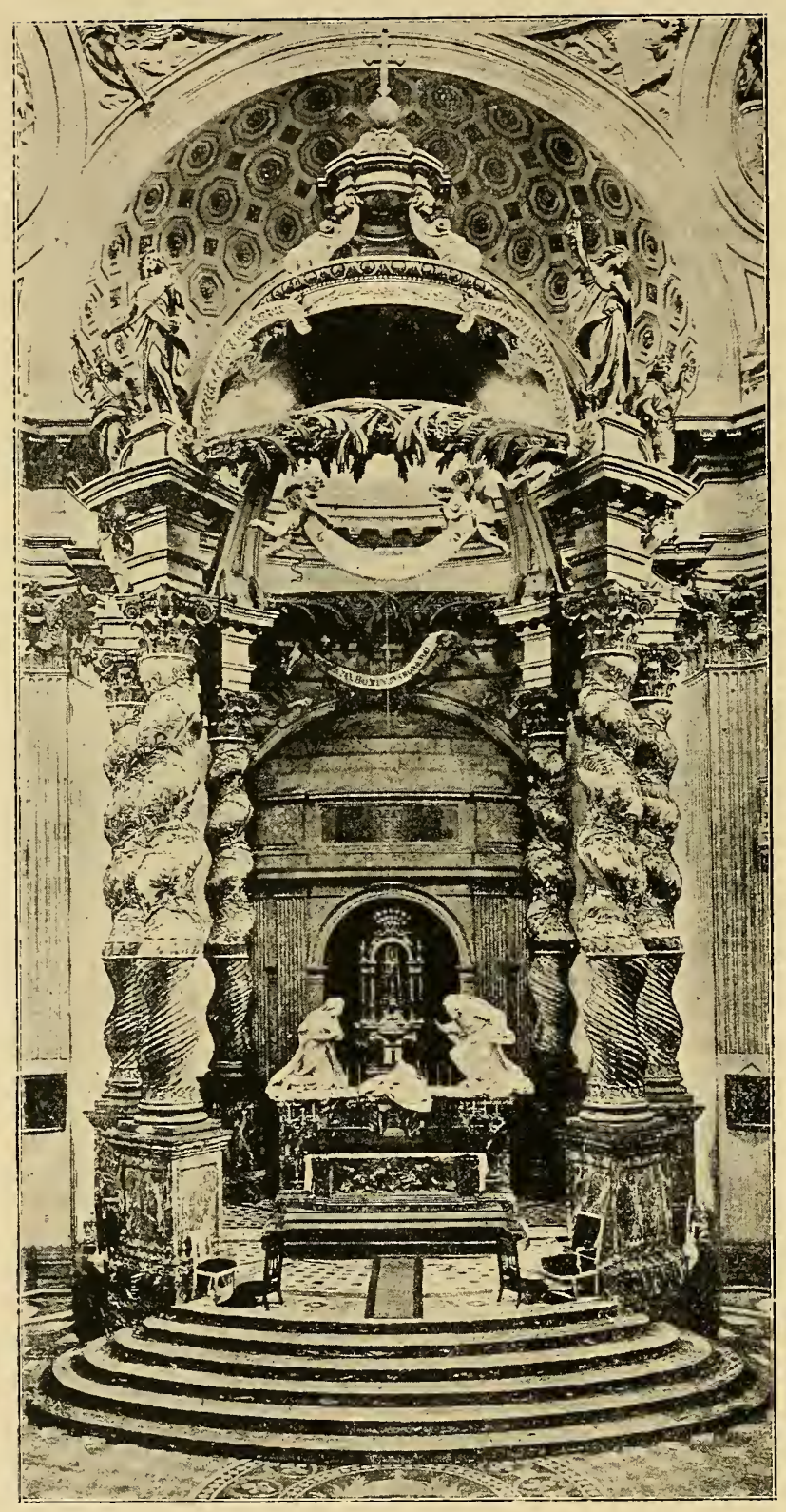

Baldacchino del Bernini, al Val-de-Grâce di Parigi. colonne a spirale invece di quattro sono sei, e disposte in modo che tutte si vedono contemporaneamente anche stando sull'asse, mentre in S. Pietro le due anteriori nascondono le posteriori. $E$ al disopra delle colonne, invece dell'ombracolo, vi sono dei fasci di palme e di fiori gettati da un capitello all'altro, e in luogo delle volute, archi che sostengono il globo e la croce. Concezione mirabile, piena di poesia, per cui al disopra del Bambino disteso sull'altare e adorato dalla Madonna e da S. Giuseppe, si avvolge una corona di fiori, come una decorazione di festa primaverile. 
L'idea di sostituire la cupola tradizionale dei tabernacoli, con un ombracolo simulante il panno, è tutta caratteristica dell'architettura barocca, e per questo il baldacchino di S. Pietro segna nello svolgimento di quest'arte una data significativa, presentando forse il più antico, e certo il più cospicuo esempio, della tendenza dei maestri del Seicento all' impiego di elementi, che per loro natura non sono di carattere tettonico. Drappi, figure umane $e$ animalesche, piante, rocce, fiori, completano $o$ addirittura sostituiscono elementi d'architettura, prendono il posto di architravi, di mensole, di basamentí, perchè essi offrono una facilità di adattamento, una pieghevolezza, una docilità, che i membri architettonici, per quanto sforzati, non possono mai raggiungere; e contribuiscono così assai bene a quegli effetti pittorici che sono spesso il fine ultimo, sempre il desiderio e l'ideale dei maestri barocchi. È pì̀ facile incurvare un ombracolo di panno che un architrave, dar movimento a uno scoglio che a un basamento, ondulare un fascio di palme che una voluta. Ed ecco che il panneggio diviene un elemento di frequente impiegato dal Bernini e dai suoi seguaci, e vediamo il sepolcro di Alessandro Valtrini in S. Lorenzo e $\mathrm{Da}$ -

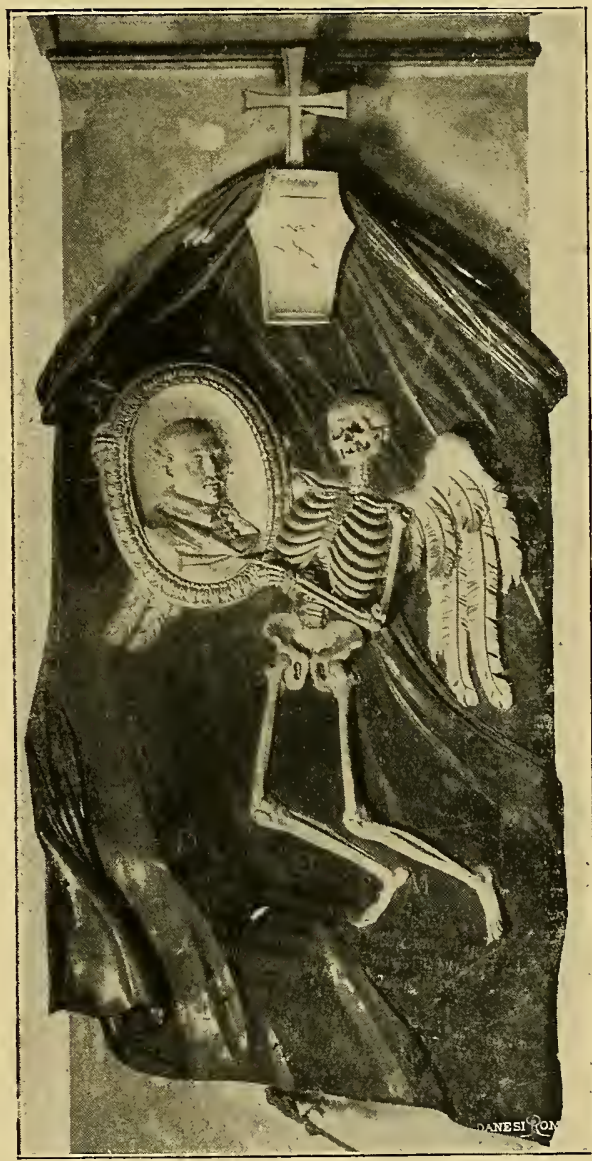

Sepolcro di A. ${ }_{-}^{[}$Valtrini in S. Lorenzo e Damaso. 
maso (1639) e quello di Suor Maria Raggi alla Minerva (1643) composti di un drappo a grandi pieghe appeso alla parete, sul quale è collocato un medaglione col busto del defunto; due esempii imitati poi da altri artisti infinite volte. Ecco che lo stesso Bernini nella Sala Ducale in Vaticano (1665), dovendo unire due ambienti in uno solo, maschera l'arcone di passaggio dall'uno all'altro con un tendone di stucco sollevato da putti, così che il distacco appare meno netto tra le due parti, e non si avverte più la differenza del loro asse. Ecco ancora lo stesso maestro porre per sfondo della statua equestre di Costantino, nell'androne del palazzo pontificio, invece di un arco, di una parete, di un paesaggio, un gran tendone drappeggiato, che il Cornacchini dovette replicare pel suo Carlomagno che fu messo a riscontro al Costantino cinquant'anni più tardi. Qui veramente ci troviamo in presenza di una di quelle illogicità che sono tutte proprie del barocco: come può una fígura a cavallo proiettarsi su uno sfondo di cortinaggio, che dà l'idea di un interno? Ma gli artisti del Seicento di questo non si preoccupano; essi cercano un effetto gradevole, un motivo pittorico, che basta a gitustificare qualunque stranezza di concezione. Un motivo d'architettura, per quanto mosso, non avrebbe potuto avere quel vivace partito di pieghe su cui spicca il Costantino, che sembrano col loro movimento accompagnare I' impetuosa foga del cavallo. Così nel sepolcro di Alessandro VII il Bernini imaginò un drappo di diaspro sollevato da una Morte dorata, e ottenne un pittorico contrasto di pieghe, di luci e di ombre, che certo non avrebbe raggiunto con elementi architettonici. Altra volta, invece di questi motivi di tappezzeria, il Bernini e i suoi imitatori ricorrono all'impiego di elementi naturali: nella Fontana Pamfilia di piazza Navona è posto a base dell'obelísco uno scoglio traforato, tutto a bozze e a massi pittoricamente frastagliati, con effetto che non si sarebbe potuto ottenere con uno zoccolo architettonico; nel palazzo di Montecitorio, o Curia Innocenziana (1650), ci sono massi 


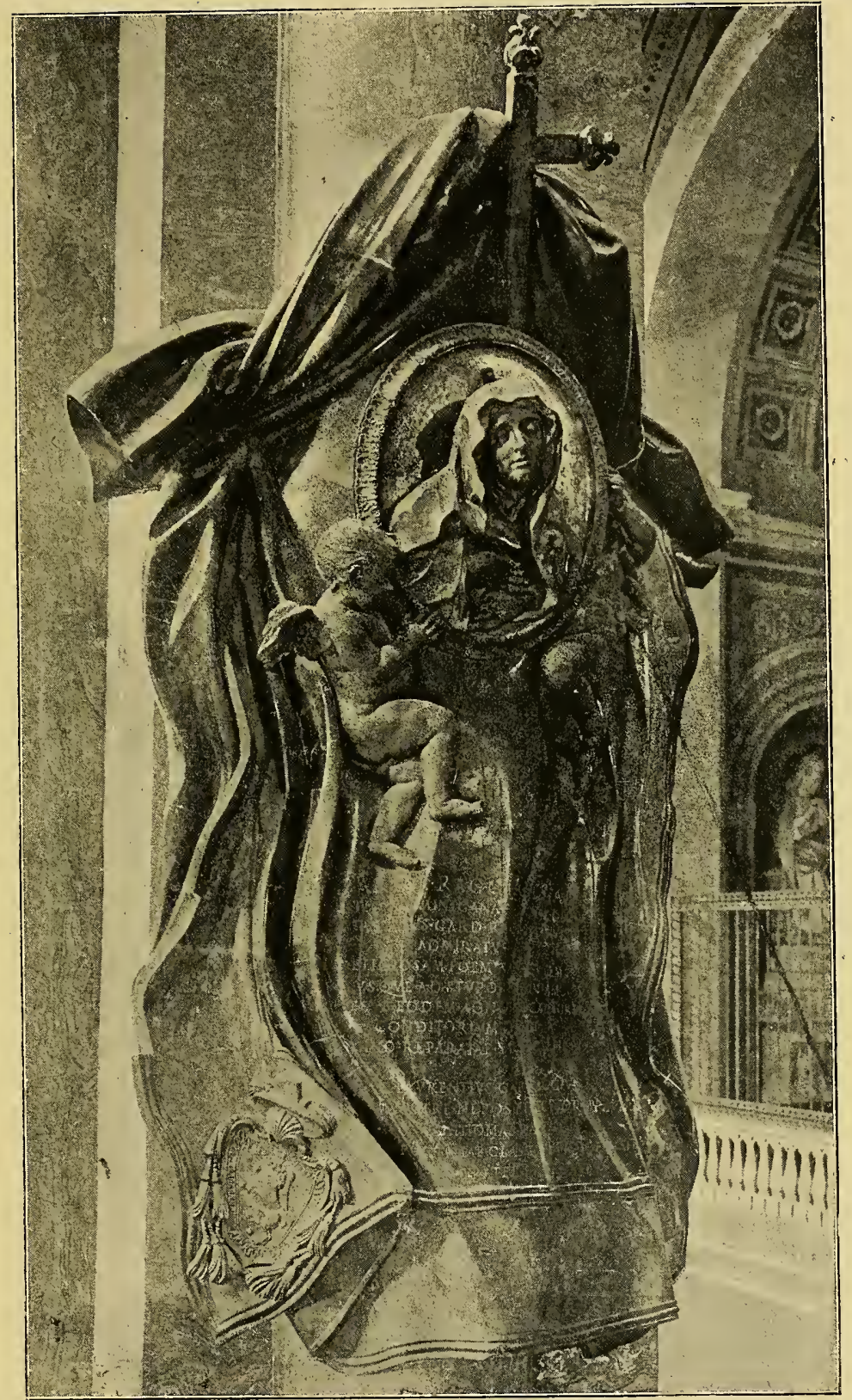

Sepolcro di Suor Maria Raggi alla Minerva, del Bernini. 
di roccia sotto le finestre; e infíne nel progetto del Louvre (1665), tutto il palazzo poggiava su un grande basamento roccioso, al quale il Bernini attribuiva tanta importanza, che si proponeva, benchè già vecchio di sessantasette anni, di scolpirlo da sè stesso!

Nello stesso palazzo di Montecitorio il maestro aveva imaginato ai lati del portale due grandi figure, alte fino al primo piano, che dovevano sostenere la loggia: e le aveva atteggiate con grande libertà di movimento, con le gambe incrociate, i corpi ondulati, le braccia sollevate. Ecco un'altra innovazione; ecco sostituite alle cariatidi stilizzate, formate da un pilastro che termina con una figura umana a mezzo busto, delle intere figure non più addossate alla parete, ma scolpite a tutto tondo, in posizione diversa l'una dall'altra, con panneggi svolazzanti. L'invenzione non è però del Bernini, e ne abbiamo esempi fin dal Cinquecento: $i 1$ disegno di Michelangelo pel mausoleo di Giulio II mostra figure di giovani nudi variamente atteggiati, che fanno da cariatidi; in una sala del palazzo Spada, vi sono figure di giovani, in stucco, che reggono frontoni di cornici. Istruttivo è il confronto tra i monumenti funerari di Pio V e Sisto V nella Cappella Sistina di S. Maria Maggiore (1585-90) e quelli di Clemente VIII e Paolo V, nella cappella Paolina (1606-12): lo schema architettonico dei quattro sepolcri è identico, ma nei primi le cariatidi dell' ordine superiore sono ancora del tipo stilizzato, tradizionale; nei secondi sono figure intere pittoricamente atteggiate.

Negli altari del transetto di S. María del Popolo (1658)e nell'altare laterale di S. Calisto, opere del Bernini, le cornici marmoree dei quadri sono tenute sollevate da angeli, che non compiono quindi un puro ufficio decorativo, ma sono parte sostanziale dell' insieme architettonico. Nella serie di studi che il Bernini fece per l'obelisco della Minerva (1666), vediamo pure la figura umana e uno scoglio pittoricamente sbozzato, sostituirsi al tradizionale basamento architettonico: in uno di quei bozzetti 


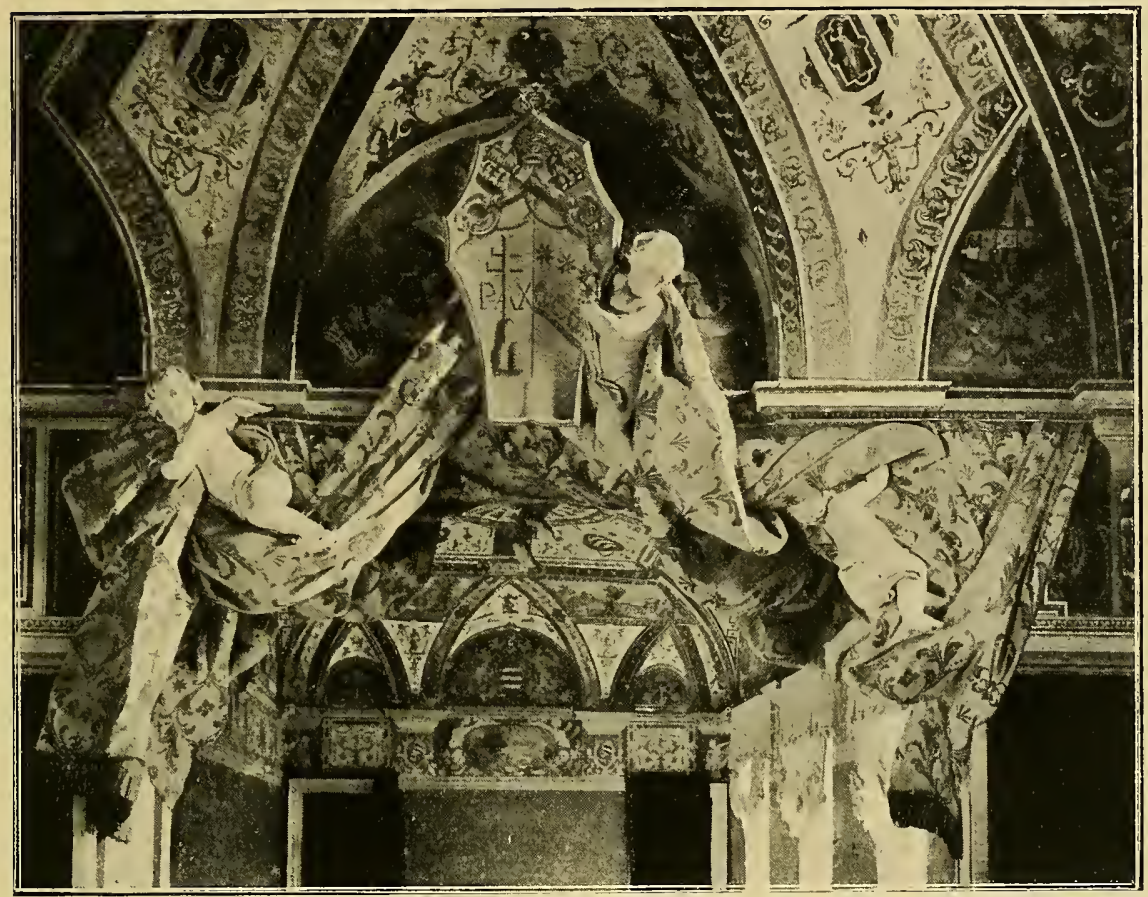

Decorazione della Sala Ducale in Vaticano, di G. L. Bernini.

si vede una roccia vivamente frastagliata, e su di essa un gigante che solleva l'obelisco; in altri schiavi o colossi, come quelli della fontana Panfilia, che lo sorreggono sulle spalle; nel progetto definitivo è un elefante che sopporta la guglia.

Un esempio veramente caratteristico della trasformazione di elementi architettonici in elementi vivi, l'offrono le mezze figure di cariatidi del monumento Olgiati (1626) in S. Prassede, che piangono portando il fazzoletto al viso!

In S. Andrea della Valle Carlo Rainaldi ha sostituito la voluta che fiancheggia la parte superiore del prospetto con una statua d'angelo che appunta l'ala come per sostegno al pilastro; Carlo Fontana nella facciata di S. Marcello pone allo stesso luogo, invece delle volute, dei fasci di palme. 
Nella casa di Federico Zuccari, in via Gregoriana, all'arco del portone $e$ intorno alle finestre sono adattate teste gigantesche di mostri : è opera dell'ultimo decennio del Cinquecento.

Fin dall'antichità la fígura umana o animalesca è adoperata come elemento decorativo nell'architettura, ma ben delimitata entro gli scomparti geometrici della parete, della cornice, del pilastro, e rimane quindi distinta, come accessorio. Nel Seicento le figure divengono invece parte funzionale dell' organismo costruttivo, e perciò aumentano di proporzioni, sostituiscono membrature, invadono gli spazi. Sui timpani delle chiese, degli altari, dei sepolcri non mancano mai figure allegoriche, Fame, Virtù, angeli, santi.

L'uso largamente diffusosi dello stucco permette in questo campo i più nuovi ardimenti; grandi figure coi panneggi svolazzanti si librano nell'aria, si seggono sui pilastri e sugli archivolti, sui timpani e sugli altari; occupano perfino i pennacchi delle cupole, escono dagli spazi in cui dovrebbero essere contenute, coprono con svolazzi le modanature, straripano coi panneggi e coi gesti vivaci delle braccia. Le glorie di nubi bianche o dorate, tra cui volano angeli e puttini, salgono capricciosamente sulle pareti e sui pilastri, fanno da sfondo agli altari, non contenute da nessun freno, non racchiuse da linee geometriche.

La ricerca del vivace e del pittorico rende naturalmente più ricca l'ornamentazione: i fregi, i festoni, le ghirlande, i fasci di palme, si moltiplicano sui prospetti e negli interni, coprono le pareti, salgono sulle cupole, spezzano l'uniformità delle linee. Ed ecco un'altra caratteristica del barocco: l'indeterminato. Vi è nell'architettura del Seicento un pittoresco accumularsi di elementi che spesso si confondono, si incrociano tra di loro, in modo che l'occhio non può a tutta prima discernerli e fissarli isolatamente. Non esiste la divisione netta, geometrica, delle varie parti; non esistono contorni rigidi, lineari; una cornice si sovrappone ad 


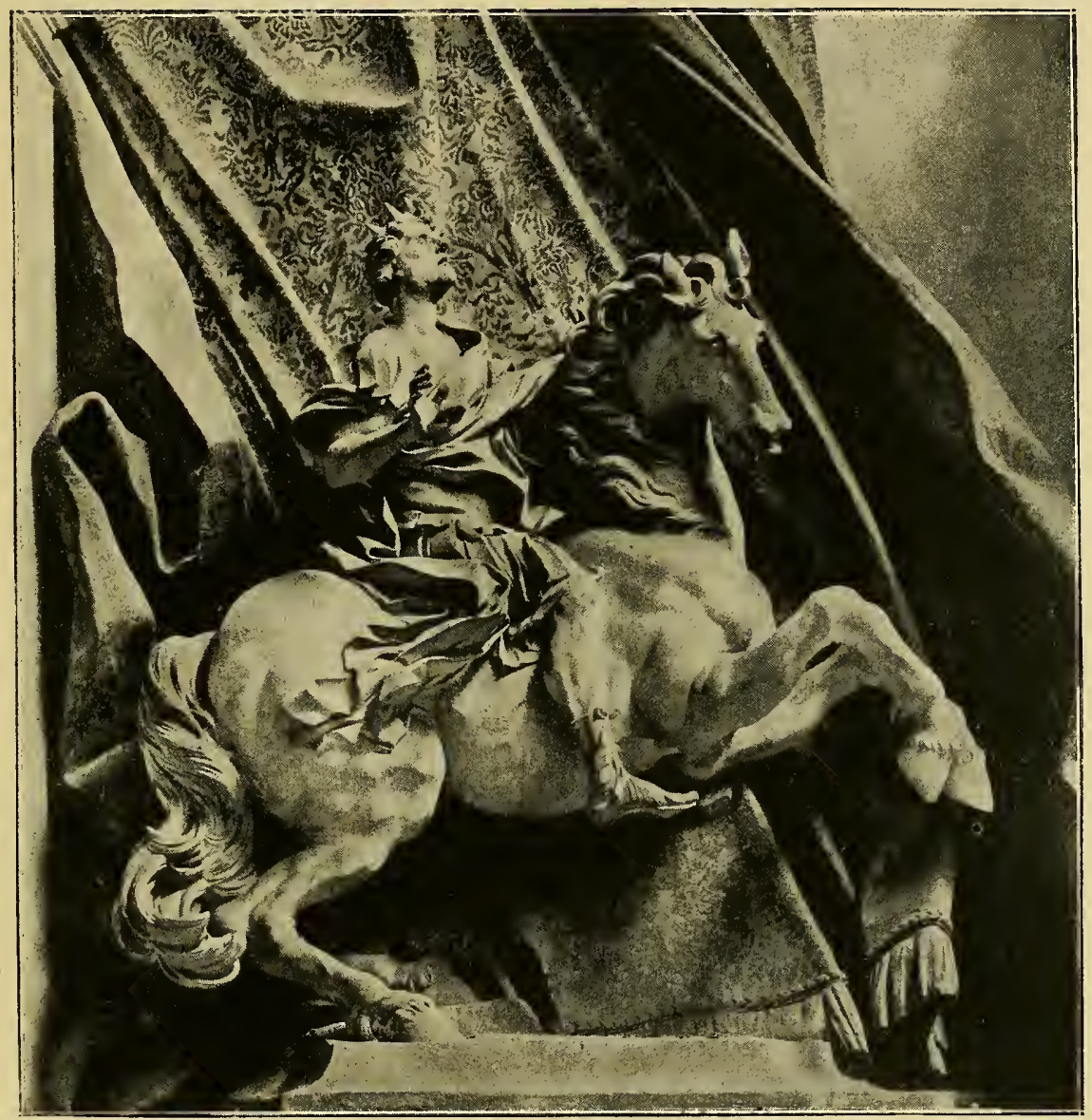

Il Costantino del Bernini, nel vestibolo del Vaticano.

(Fot. Alinari).

un'altra, la interrompe, la nasconde; la ornamentazione di un soffitto o di una vôlta invece di esser contenuta in un campo delimitato ne esce fuori, e va a coprire le membrature laterali; $o$ in una cupola scende dalla calotta $e$ invade il tamburo; 0 al contrario la cornice nasconde in parte le figure del campo centrale: le singole parti non si debbono considerare isolatamente, ma nell'effetto $d$ 'insieme che si produce dal loro sovrapporsi $e$ compenetrarsi. 


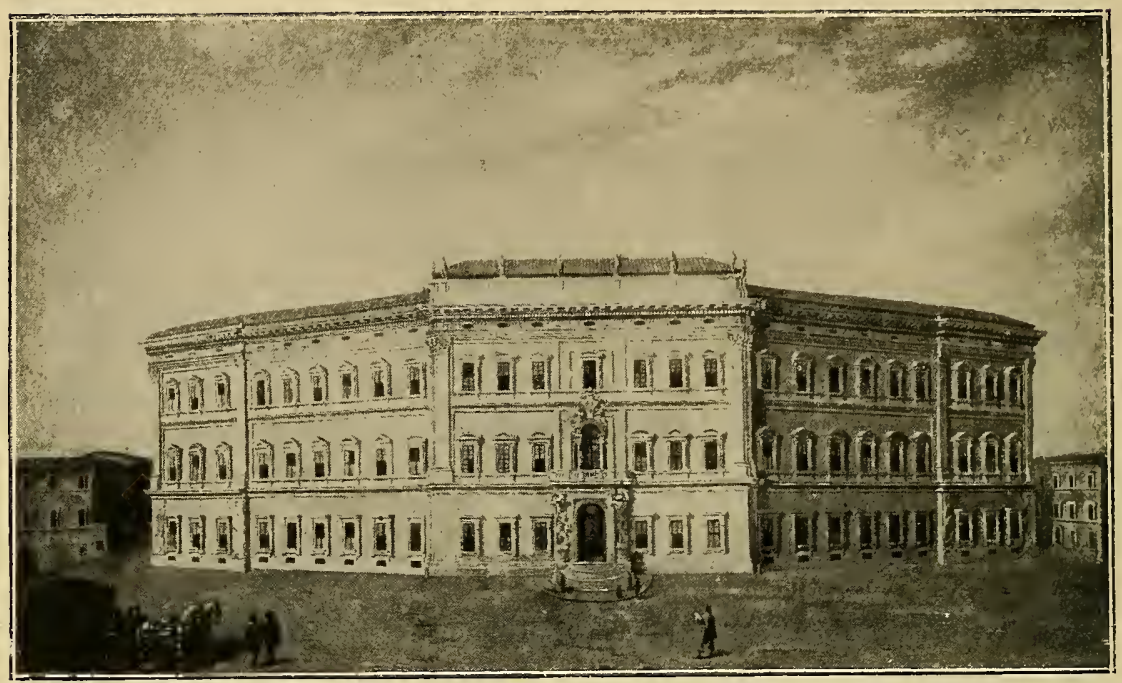

Progetto del Bernini pel Palazzo di Montecitorio - Collezione Doria.

Tutte queste ardite innovazioni, questi elementi estranei trasportati nel campo dell'architettura, dànno all'arte del Seicento un carattere nuovo e spontaneo, che con quello del secolo precedente non ha più nulla a che vedere. È un ciclo nuovo, ricco, fresco, originale, che esprime nuove idealità, nuovi pensieri.

In un edificio dell'antichità o del Rinascimento, ciò che subito ci è dato rilevare è l'ordine, la disposizione regolare delle parti, l'obbedienza a un sistema, il valore e l'ufficio costruttivo e statico dei varii membri, la loro concatenazione, la logica funzione di ognuno di essi. Nel barocco ciò che colpisce è l' effetto d'insieme, è il contrasto di luci, il vario contrapporsi delle masse, il pittoresco fondersi dei vari membri, áei quali non si riconosce a tutta prima, e talvolta neanche dopo un maturo esame, il vero ufficio. Si può dire che la bellezza non è cercata nella forma definita, nella solida struttura del corpo, ma nel movimento delle masse. L'architettura barocca fonda il suo valore non su ciò che è, ma su ciò che sembra, non sulla sua organica conformazione, ma sull'effetto, sull' impressione che pro- 
duce. In fondo, il pittorico si può identificare col movimento: grandi masse costruttive sono messe in moto, disposte cioè su linee curve, ondulate, spezzate, frastagliate. E nell' insieme movimentato anche i singoli elementi si muovono; Bernini fa tesoro della colonna tortile, che è una colonna in movimento; Borromini inventa il timfano a linea spezzata, che è linea in movimento.

La ricerca dell'effetto pittorico dell' insieme porta di conseguenza quasi tutte le innovazioni dello stile karocco, e l' indipendenza completa da tutte le regole e norme geometriche tradizionali. Il libro fossilizzante del Vignola continua ad esser ristampato nel Seicento, ma gli artisti non lo ascoltano; innovano, cambiano, mescolano i varii ordini, in modo da far strappare i capelli ai critici tipo Milizia; l'allineamento, la simmetria, il contrappeso delle masse, sono violati senza ritegno.

Naturalmente a raggiungere l' effetto pittorico contribuisce assai più la linea curva di quella retta; e perciò l'architettura barocca segna il trionfo della curva, e dei piani concavi o convessí.

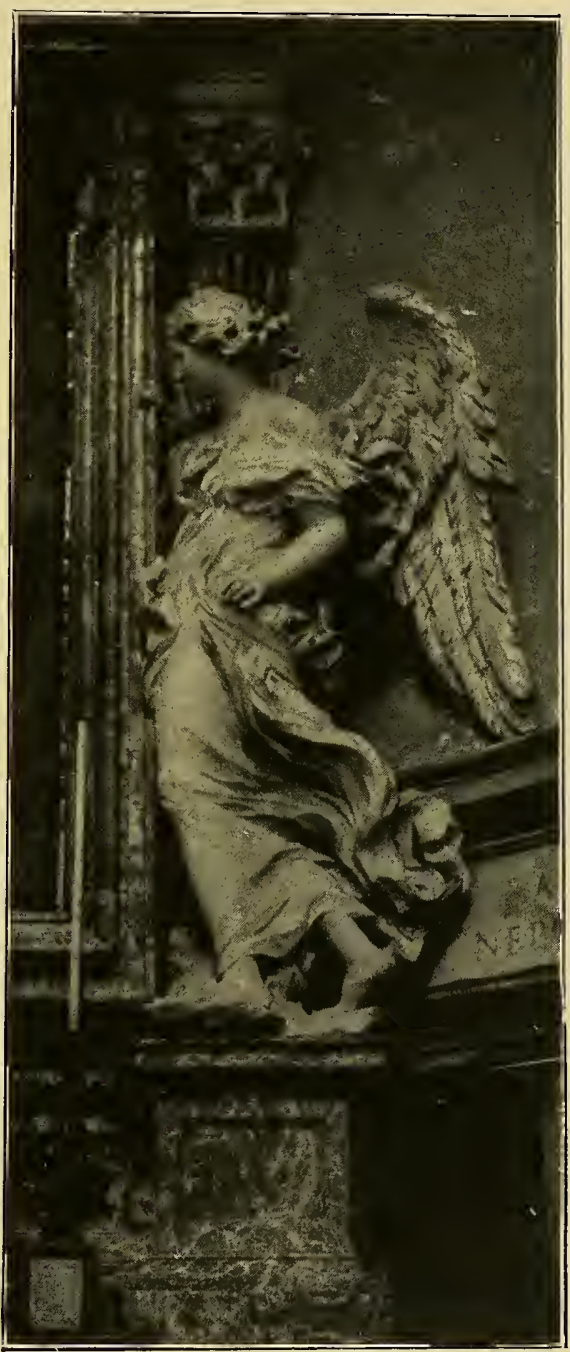

La linea retta spezzata è Angelo reggente un quadro - S. M. del Popolo. 
pure comune nel Seicento; $e$ il Bernini ne dette un magnifico esempio nella Curia Innocenziana di Montecitorio, dividendo il lunghissimo prospetto in cinque fronti, separate da pilastri.

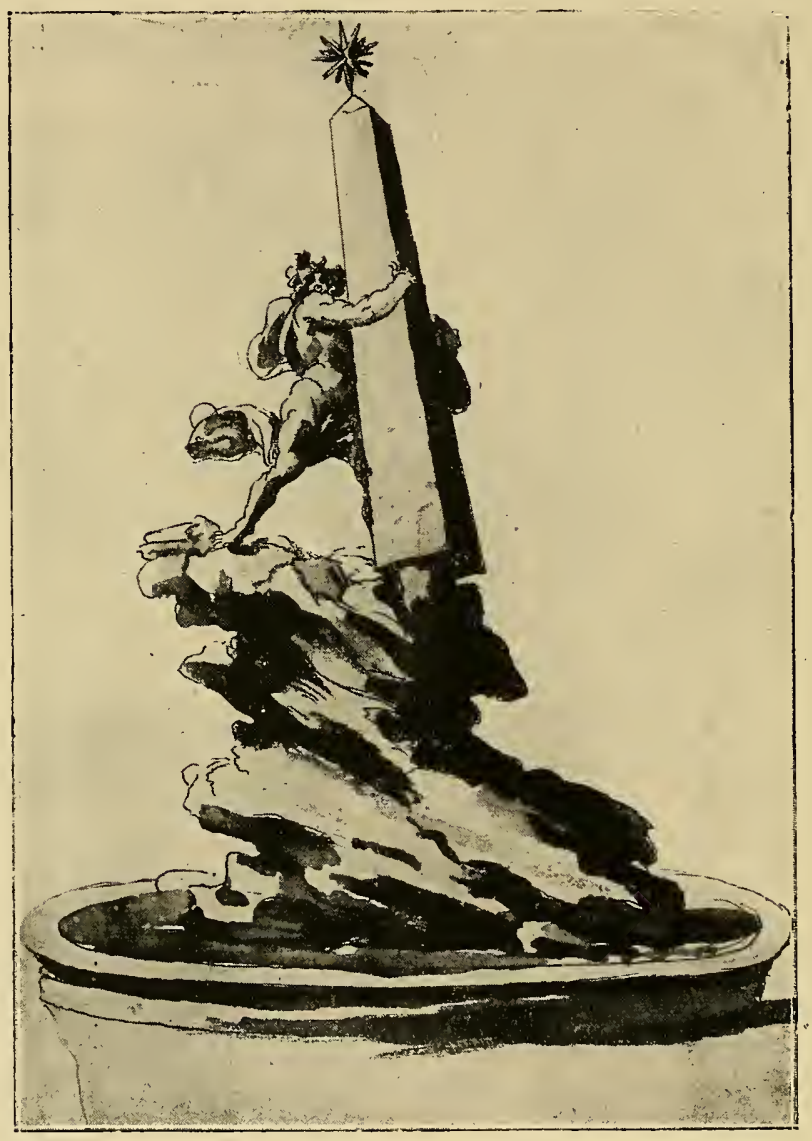

Bozzetto del Bernini per l'obelisco della Minerva.

Un'altra caratteristica del barocco, che pure deriva dalla ricerca del pittorico, è l'impiego di elementi prospettici. L'arco in prospettiva si vede usato comunemente; Maderno lo introduce nell'androne del palazzo Mattei (1616), e Bernini nel terzo ordine del loggiato Barberini, e nel mausoleo della contessa Ma- 


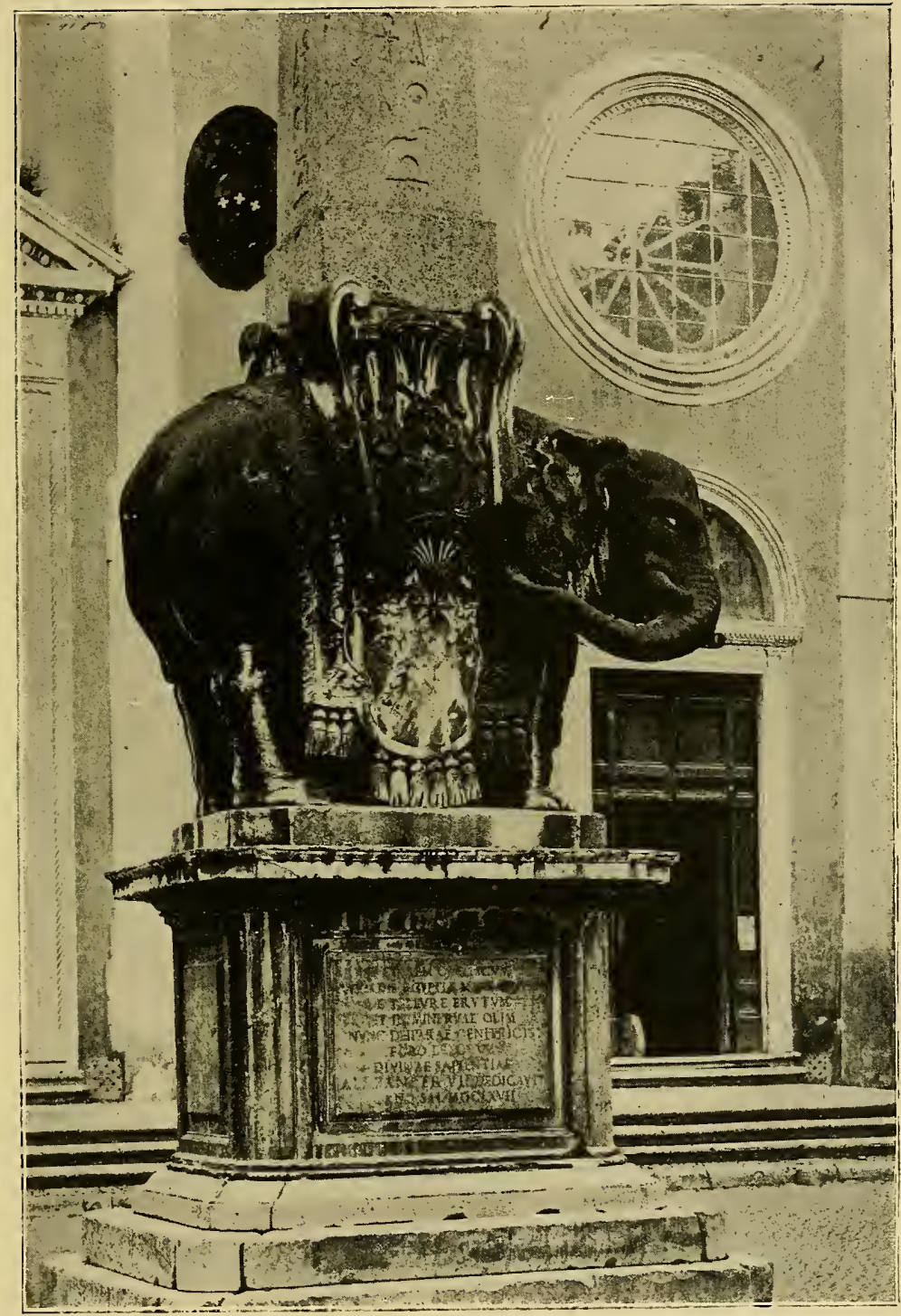

L'obelisco della Minerva sull'elefante, del Bernini. 
tîlde; Borromini disegna prospetticamente le conche e le nicchie absidali delle chiese, come si vede in S. Carlino, nell' Oratorio dei Filippini, a Propaganda; Pietro da Cortona fa lo stesso nel bel portico di S. Maria in via Lata. Ma tutti questi non sono ripieghi di artistí scarsi di risorse, non sono mezzucci adoperati per colpire l'occhio del riguardante; sono invece atteggiamenti meditati, ricerche studiate, espressioni coscienti di un'arte robusta e nuova, che non è balbettio di decadente senilità, ma voce fresca di giovinezza; che non ripete vecchie formole, ma dice parole prima non dette mai.

La stessa novità di mezzi e di intenti si rileva nella scultura del Seicento, che pure è generalmente considerata come un'arte di decadenza, come un'eco affievolita della tradizione michelangiolesca. Per gli ultimi anni del secolo decimosesto, e pei due primi decenni del decimosettimo, quel giudizio è giusto; gli scultori che vedemmo operare nelle cappelle Sistina e Paolina di S. Maria Maggiore, sono quasi tutti poveri figurinai che modellano inerti bambocci di creta; ma ecco, subito dopo, il Bernini che riesce a soffiare in essi lo spirito vitale, e li anima e li fa muovere. Si apre così un ciclo nuovo, si inizia una nuova corrente che erompe impetuosamente, e il cui fluire durerà per oltre un secolo e mezzo, finchè verrà arrestata $e$ agghiacciata nel gelo del neo-classicismo.

Un'espressione caratteristica della scultura del Seicento sono le quattro colossali statue collocate nelle nicchie dei piloni della cupola di S. Pietro, sotto le logge delle reliquie, eseguite tra il 1629 e il '39, che formano tutto un meraviglioso insieme col baldacchino berniniano. Sono queste la Veronica di Francesco Mochi, il S. Andrea del fiammingo Duquesnoy, la S. Elena del Bolgi, e il S. Longino dello stesso Bernini.

Tutte hanno atteggiamenti enfatici, pose teatrali: il S. Andrea si arrovescia sulla croce e gonfia il petto come per emettere un grido possente, mentre col piede destro un po' sollevato e col 


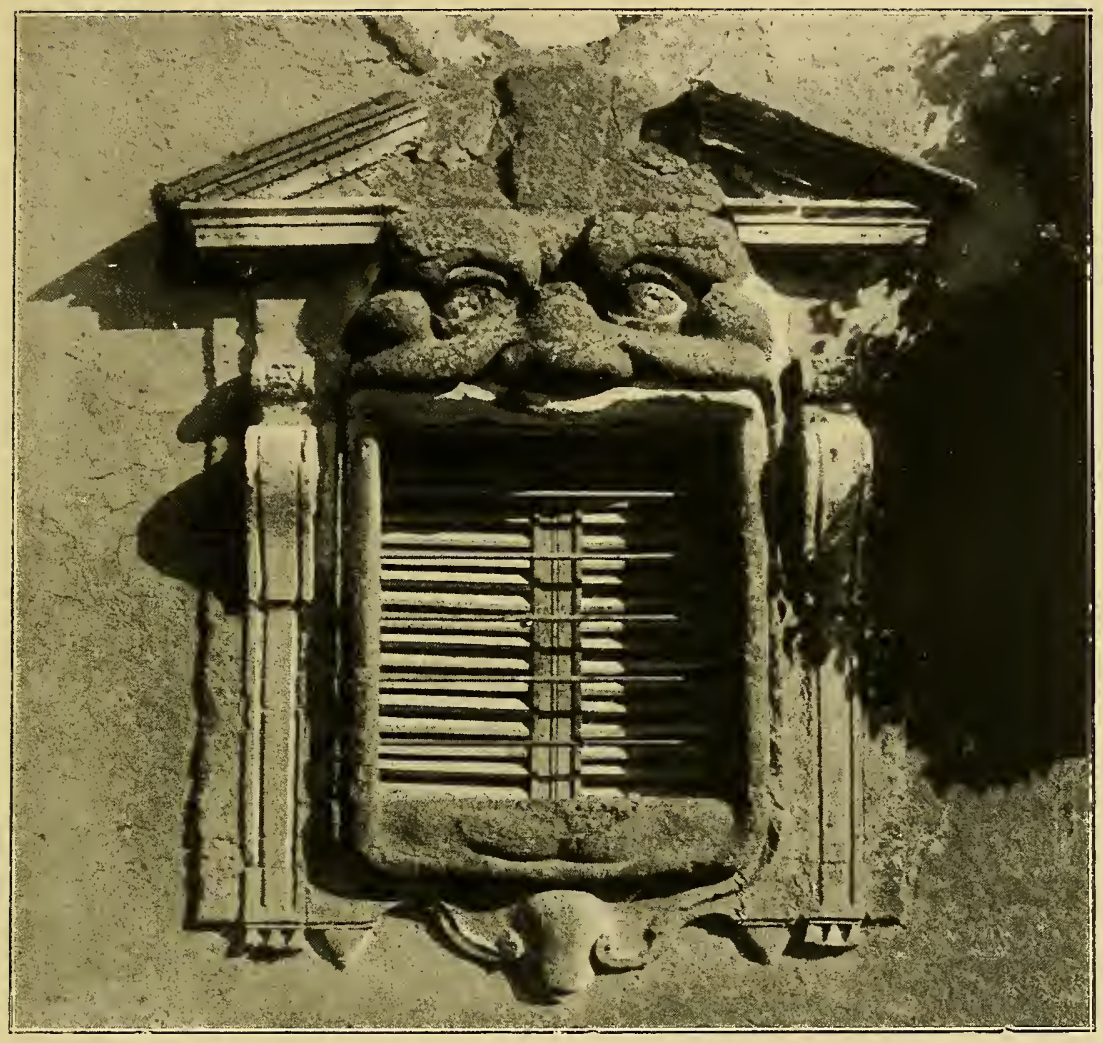

Finestra della casa Zuccari in via Gregoriana.

gesto manierato della mano sinistra rivela la finzione, poichè egli non cade estatico, in una completa dedizione del suo essere a Dio, ma, pur volgendosi al Cielo, pare che studii l'atteggiamento che deve assumere. Il Longino, col piede destro proteso, piegandosi un poco indietro, si appoggia con la destra alla lancia e leva il capo in atto enfaticamente ispirato, mentre con la sinistra fa un largo gesto declamatorio; la S. Elena sorregge la pesantissima croce, e nell'altra mano tiene $i$ chiodi che mostra nella palma; ella pure muove le gambe con un passo di ballerina. Ma più delle altre statue appare strana la Veronica, la quale è rappresentata col sudario nelle mani, come per mostrare 
ai fedeli l'impronta del Volto Santo, ma non sta composta $e$ solenne, come converrebbe al pio atto, ma corre impetuosamente, investita da un colpo furioso di vento che sconvolge le sue vesti e sbatte contro il sudario e lo accartoccia, e con la bocca aperta par che mandi un grido, come una invasata. C'è in questa figura dunque qualche cosa di bizzarro e di illogico che non trova spiegazione; un eccesso di movimento che non è giustificato dal soggetto. E strano apparve l'atteggiamento della Veronica anche ai contemporanei, anzi allo stesso Bernini, il quale si vuole che chiedesse al Mlochi donde veniva quel vento che agitava in tal modo le vesti della santa; al che il Mochi avrebbe risposto con arguzia: "Dalle fessure aperte dalla vostra abilità nella cupola!,, poichè correva allora la voce che il Bernini, scavando le cappelle delle reliquie nei piloni, avesse determinato il manifestarsi di pericolose crepe nella mole michelangiolesca. Un altro contemporaneo, Giambattista Passeri, che scrisse le Vite de' pittori, scultori ed architetti che hanno lavorato in Roma, morti dal 1641 fino al 1673, dice della Veronica: "La rappresentò in atto di moto, e d'un moto violento non solo di camminare, ma di correre, e quì mancò della sua propria essenza, perchè se la parola statua deriva dal latino "sto stas " che significa esser fermo, quella figura non è statua, ma un personaggio che passa e non rimane... Il gesto della figura è singolare, con tutte quelle osservazioni che si richiedono ad un atto di moto. "Contro queste parole del Passeri, che come è noto era pittore, protestò Lione Pascoli, autore anche lui di un'opera sulle "Vite de' pittori scultori ed architetti moderni, (Roma, 1730). È interessante riportare le sue parole: "Figurò la Santa in atto di correre, ed agitata la veste dal vento, vedesi quasi tutto il nudo del corpo distintamente. Quindi additando a braccia alquanto scoperte il sacro lino col divin volto sudante par che dica con occhi, e bocca loquace, "ecco il gran prodigio " agli astanti. E benchè si vedesse artifiziosamente lavorato quel marmo con oscuri gagliardi, 


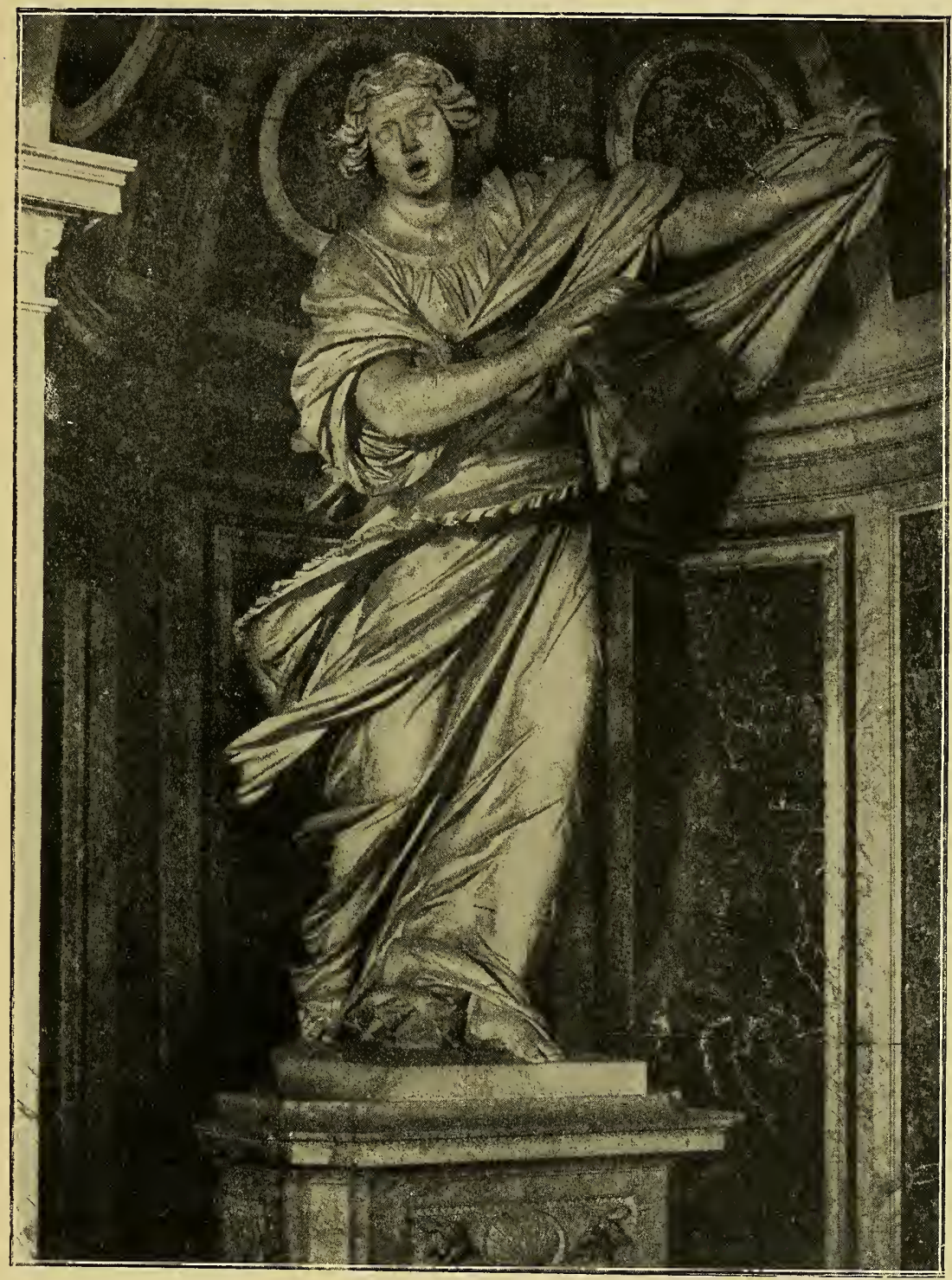

La Veronica di Francesco Mochi, in S. Pietro.

(Fot. Alinari). 
panneggiamenti sollevati, e con esatta proporzione, e disegno in ogni sua parte, non mancarono, siccome non mancan mai alle bell'opere le censure, I' invidie, le maldicenze e le critiche. Fuvi tra gli altri uno sciocco pittore, e quanti ve ne sono alle volte

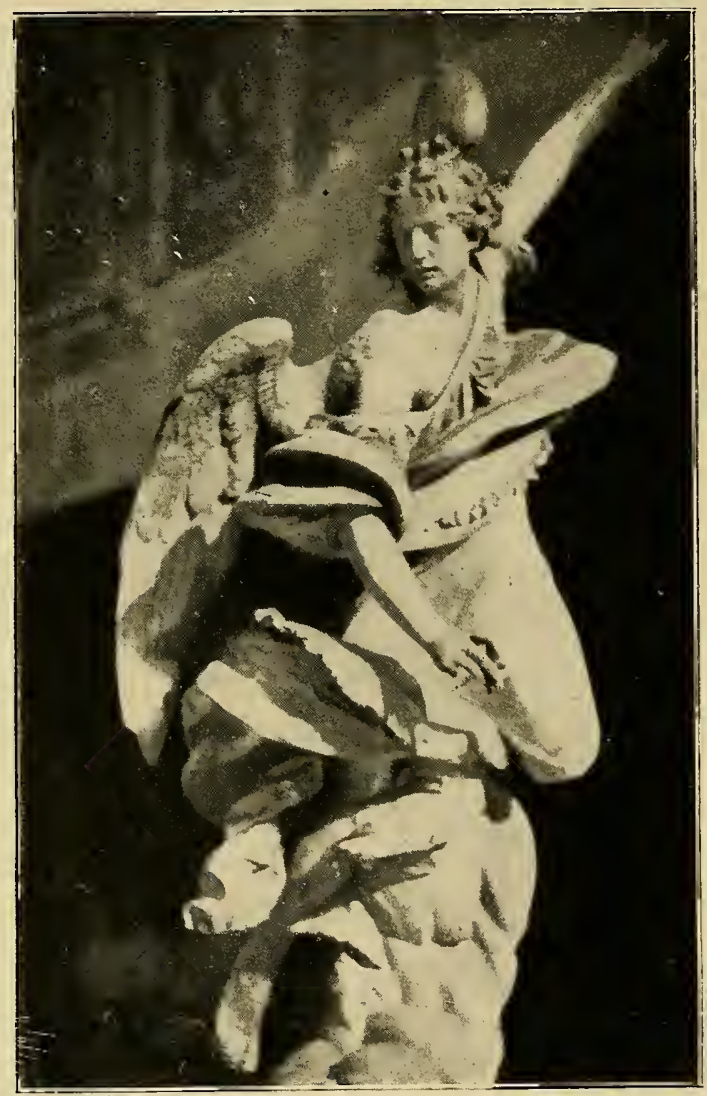

L'Angelo Gabriele del Mochi nel Duomo di Orvieto.

di cotali ignoranti, che parlando allo sproposito si rendono farsi creder sacciuti, scipiti, e ridicoli, che tacciandola, insipidamente disse, che derivando il nome, della statua dal verbo stare non poteva in verun modo fare quel moto; ma star dritta, salda ed immobile. Povero stivale! Bisognerebbe dunque torre ogni azione 


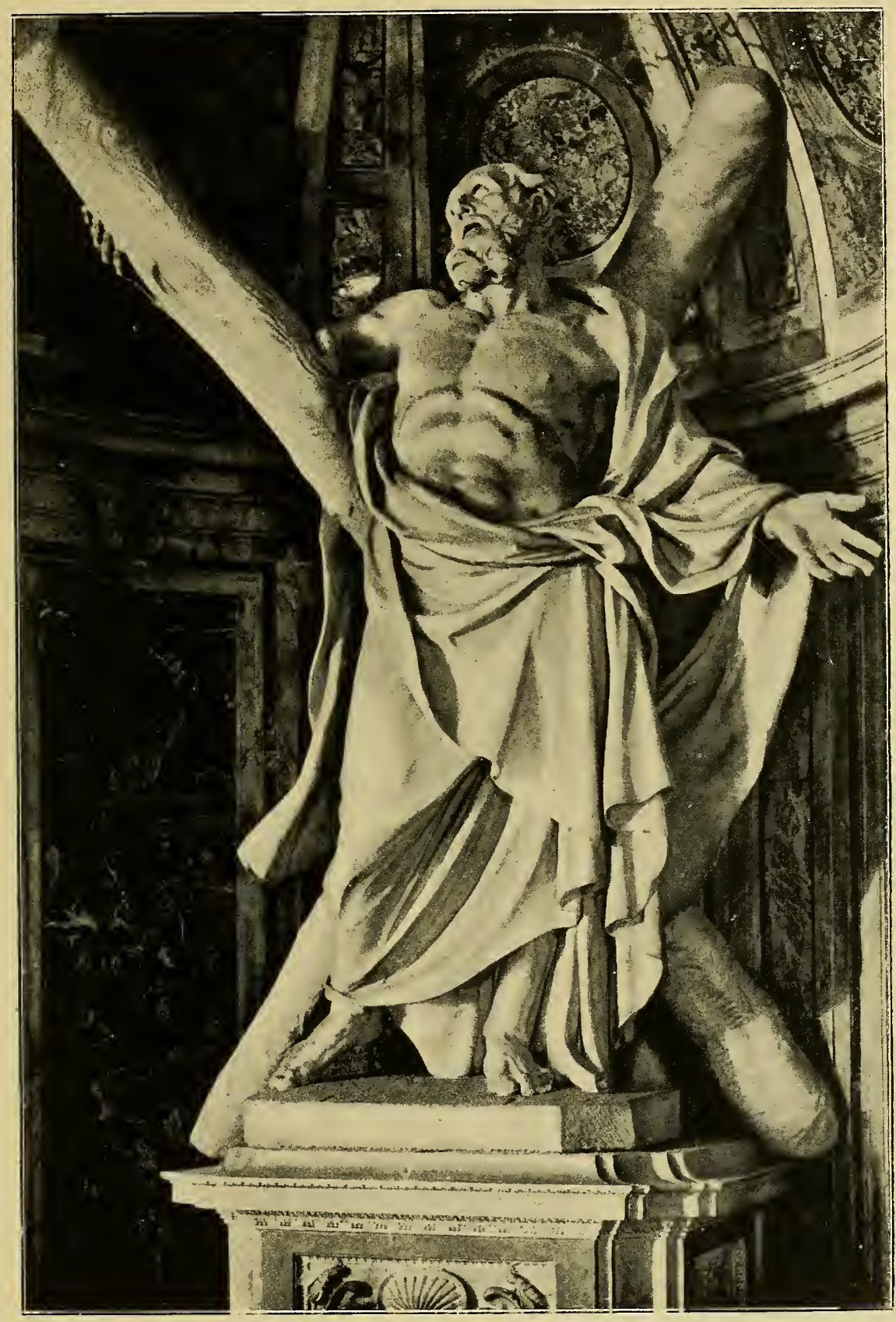

Il S. Andrea del Duquesnoy, in S. Pietro.

(Fot. Alinari). 
a' simulacri! O quanto giusto, e degno sarebbe il toglier loro piuttosto la professione, e il parlare!,".

Il giudizio del Passeri è degno di attenzione: egli trova strano che l'artista abbia dato alla Veronica un movimento non richiesto dal soggetto; ma ammesso che la figura debba correre, le vesti si muovono come farebbero nella realtà; c'è dunque in quella statua un assurdo, uno strano concetto, ma espresso in forma veristica e naturale. Siamo dinanzi a un caso che si ripete spesso nell'arte barocca; e perciò importa domandarci perchè Ia Veronica sia rappresentata in tal modo. La spiegazione apparirà molto semplice, quando la si cerchi in un ordine di idee puramente artistico: il Mochi doveva collocare la sua statua entro un enorme nicchione, che una figura rigida e immobile non avrebbe certamente riempito così bene, come lo riempie la Veronica in corsa, con le vesti sbattute così violentemente. È dunque una ricerca artistica che ha indotto il Mochi a dare alla sua statua quello strano atteggiamento di corsa; egli ha sacrificato l'idea all'effetto, $e$ ha ottenuto un risultato che lo giustifica pienamente. Come abbiam visto gli architetti del Seicento introdurre nelle loro fabbriche elementi arbitrarii o superflui, solo per ottenerne un effetto che a loro sembrasse piacevole, cosi gli scultori si preoccupano più dell'effetto che della ragione che può determinare certi particolari motivi. Era facile riempire la nicchia nel senso dell' altezza, difficile in quello della larghezza; il Bernini $e$ il Bolgi avevan potuto poggiare le loro figure alla lancia $e$ alla croce, con il braccio distaccato molto dal corpo; il Fiammingo aveva l'aiuto della croce trasversale di S. Andrea, ma il Mochi non trovava nel soggetto nessun elemento per dare alla sua statua uno svolgimento orizzontale, e perciò la imaginò in atto di correre. Del resto questo maestro, che, nato in Toscana, appartiene alla tarda corrente michelangiolesca, come il padre del Bernini, fin dalle prime opere mostra una costante ricerca di effetti pittorici, per mezzo del movimento che imprime 


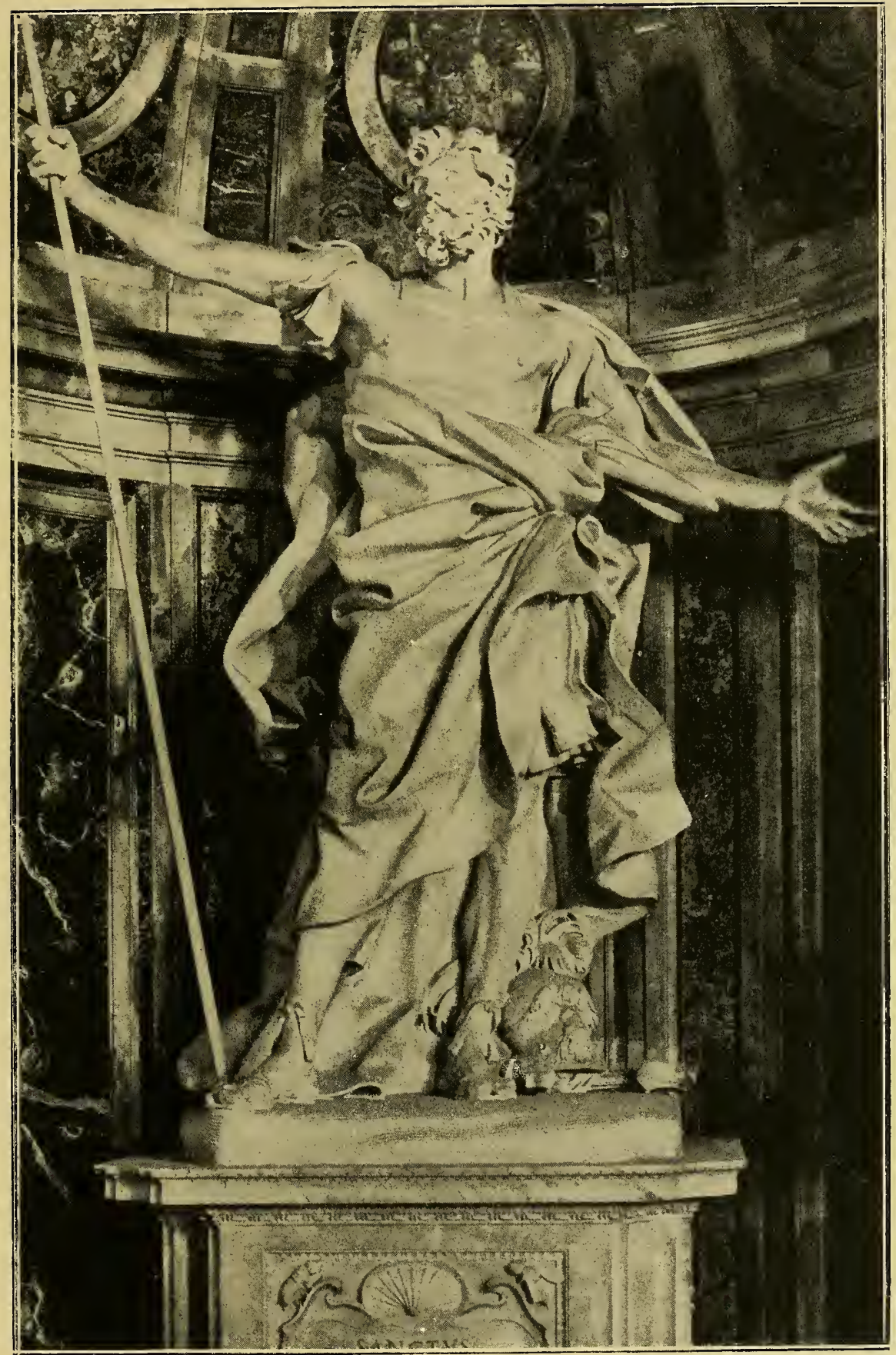

Il Longino del Bernini, in S. Pietro.

(Fot. Alinari). 
alle sue fígure; l'angelo Gabriele del gruppo dell'Annunciazione che scolpì nel 1605 per la cattedrale di Orvieto, è pure rappresentato nell'atto in cui scende impetuosamente tra nuvole, e il vento investe il suo mantello, avvolgendolo intorno al corpo con un giro di spirale: siamo qui al principio del secolo e già ci troviamo di fronte ad un'opera essenzialmente barocca.

Con la ricerca del movimento gli artisti del Seicento riescono ad ottenere effetti decorativi e pittorici, che nessun altro periodo d'arte aveva raggiunto mai. Pensiamo ad esempio alla figura del Fiume. L'antichità classica lo rappresentò sotto l'aspetto di un vecchio disteso sul letto, circondato da una miriade di putti che simboleggiano i suoi affluenti o la fecondità prodotta dalle sue acque; il Rinascimento, riprendendo la rappresentazione del Fiume per decorare giardini e fontane, conservò alla figura l'atteggiamento maestoso e solenne, che dette anche alle divinità marine poste nel centro delle vasche (Nettuno del Giambologna; Nettuno della fontana Medina). Il Bernini invece quando nel 1623 scolpisce il gruppo, oggi in Inghilterra, di Nettuno e Glauco per una peschiera della villa Montalto, dà al Dio marino un vivace movimento rappresentandolo in atto di infilzare col tridente qualche pesce mostruoso, e certo in tal modo la figura, stando all'aperto, doveva spiccare assai meglio che se il maestro l'avesse immaginata rigidamente composta. Ancora più accentuato è il movimento che il Bernini ha dato ai quattro fiumi della fontana centrale di piazza Navona: il Nilo si copre violentemente il capo tirandosi il manto sul viso, il Rio della Plata si rovescia indietro e protende il braccio sinistro come per ripararsi da qualche cosa che gli stia per cadere addosso; il Danubio compie un movimento analogo volgendosi allo scoglio che sostiene l'obelisco. Pensiamo ad altre statue di fiumi da cui forse il Bernini si ispirò: quelle del Tribolo nella fontana dell' Isolotto a Firenze (1576): le tre figure di uomini dai nudi vigorosi preannunziano le statue del Bernini, ma stanno sedute compostamente, 


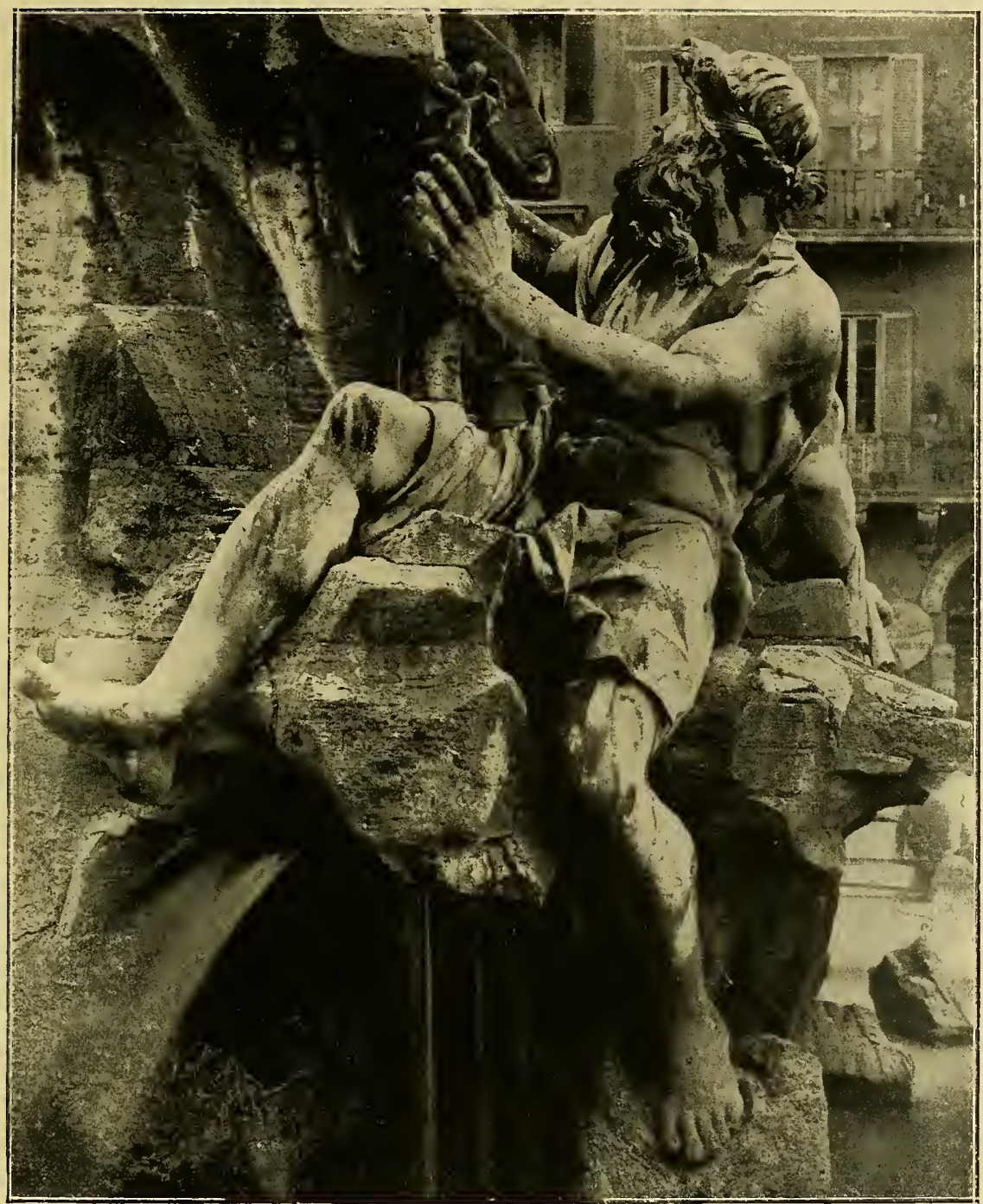

Il Danubio nella Fontana Pamfília del Bernini, in Piazza Navona.

in atto dignitoso. I moti sconvolti dei fiumi di piazza Navona paiono a tutti cosi strani, che il popolo intese la necessità di trovarne una spiegazione, imaginando la notissima storiella della satira che il Bernini avrebbe fatto alla cupola di 
S. Agnese, del Borromini, che stando troppo avanti sulla facciata sembrerebbe dovesse cadere addosso a chi guarda, così che il Rio della Plata farebbe un gesto di terrore, col braccio proteso, come per ripararsene: ma la spiegazione non ha ombra di fondamento perchè sappiamo che la fontana era compiuta nel giugno del 1651, e il Borromini iniziava la fabbrica di S. Agnese solo nell'agosto del '53. Il concetto che ha suggerito al maestro quei moti così agitati, è puramente artistico; poste in un luogo aperto, sedute su quello scoglio così pittoricamente sbozzato, delle figure calme ed immobili come quelle del Giambologna, appena avrebbero spiccato nell' insieme dell'opera; così invece hanno un maggior rilievo, un effetto più pittorico, un contrasto di masse più vivo; tanto è vero che la statua del Gange che non ha l'atteggiamento agitato delle altre, ma siede compostamente, tenendo nelle mani un remo, appare assai meno bella, ed ha minor risalto degli altri tre Fiumi.

Gli esempii di questi effetti pittorici che i maestri barocchi ottengono per mezzo del movimento, si potrebbero moltiplicare. Si pensi all' imagine di $S$. Sebastiano, costantemente figurato nell'arte con le mani legate o dietro il dorso o ad un tronco d'albero: il barocco non può assoggettarsi a una simile immobilità, che contrasta coi suoi canoni estetici, ed ecco Niccolò Cordier che nella cappella Aldobrandini alla Minerva libera alla sua statua di S. Sebastiano il braccio sinistro per permetterle di fare un gesto di dolore. Qui è da notare che siamo proprio sul limitare del secolo del barocco, il quale poi ha sempre attribuito al San Sebastiano gesti più o meno vivaci, come per esempio può vedersi nella statua di Domenico Guidi, in una delle nicchie della facciata di S. Andrea della Valle.

Assai significativo, per rilevare gli effetti che cercano gli scultori del Seicento, è il confronto tra il David di Michelangelo e quello del Bernini. Il grande genio del Cinquecento ha rappresentato il giovine David, dopo la vittoria, eretto, in atteggia- 


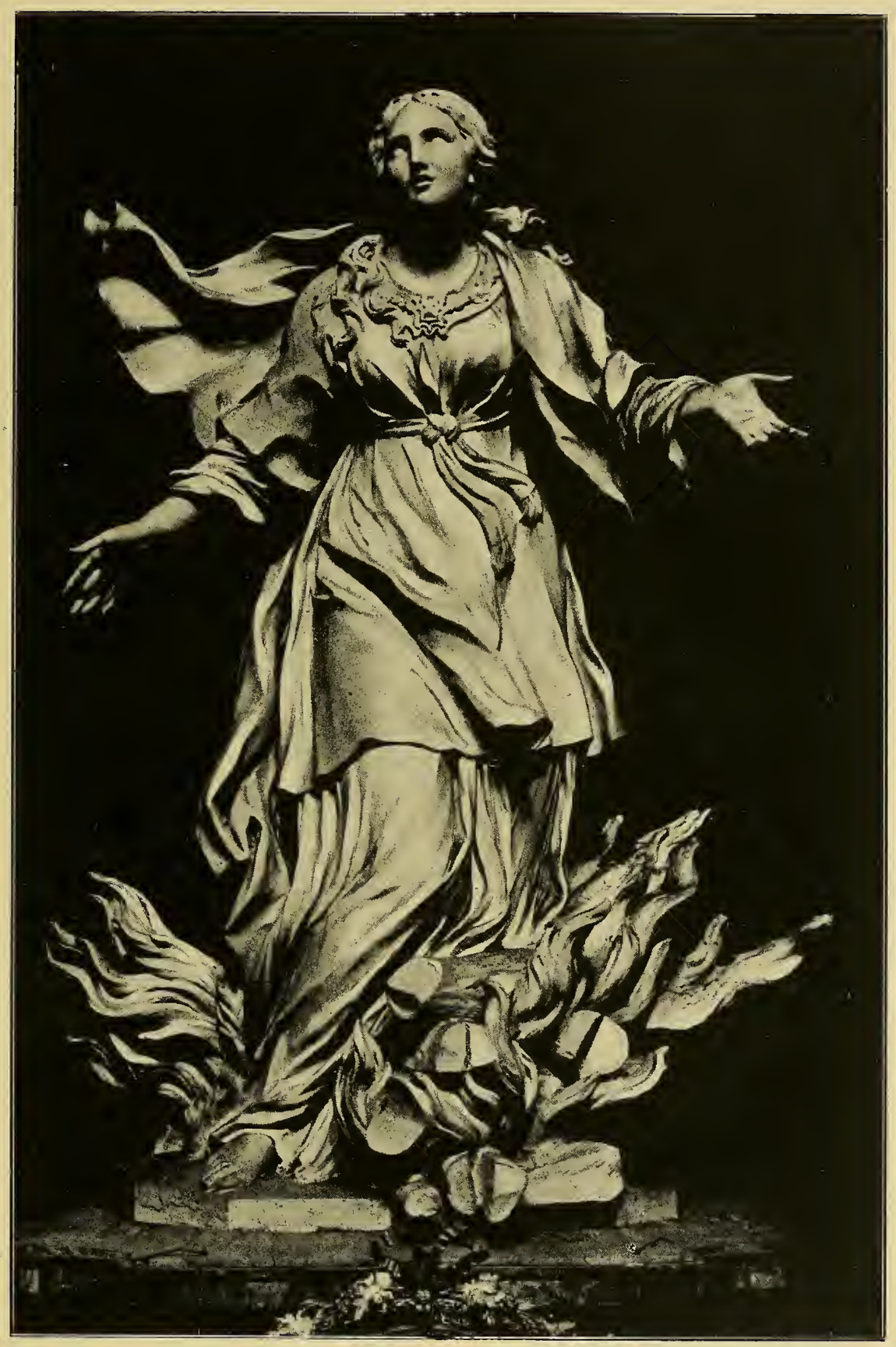

La S. Agnese di Ercole Ferrata, nella Chiesa in Piazza Navona.

(Fot. Alinari). 


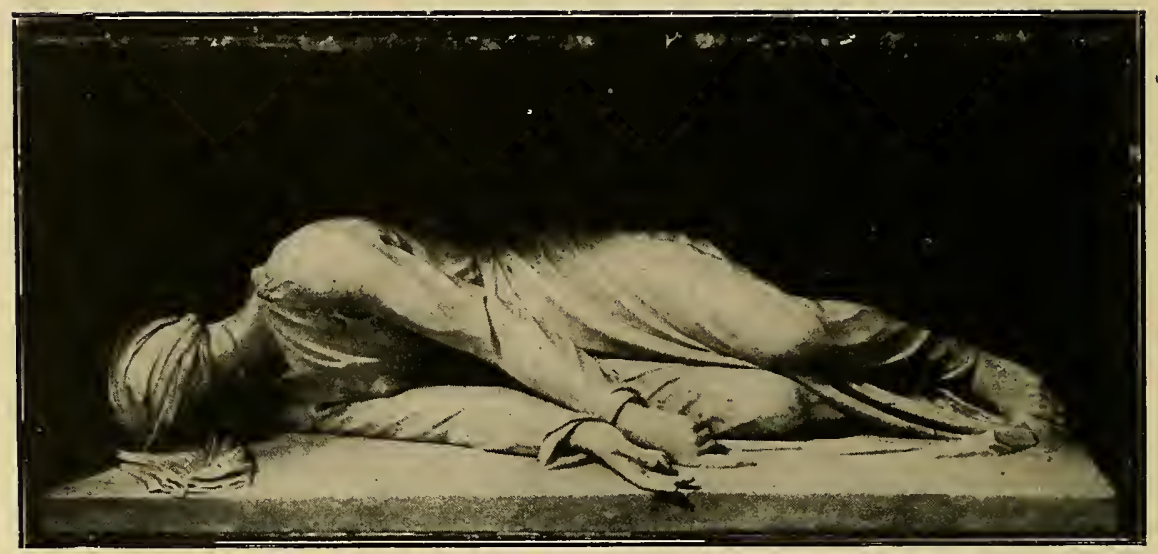

La S. Cecilia di Stefano Maderna.

mento solenne e dignitoso, come un antico eroe, mentre sembra che guardi il nemico atterrato; il Bernini invece ha scelto il momento della lotta, quando l'adolescente sta per scagliare la fionda e aggiusta la mira, e tutto il suo corpo è vibrante e dai piedi ai capelli sembra sprizzar movimento.

E pensiamo ancora alla statua equestre, in cui dall'antichità classica al Rinascimento (Marco Aurelio, Gattamelata, Colleoni) il cavallo è rappresentato immobile o al passo. Nel Seicento invece il Bernini rappresenta in fondo al portico di San Pietro, Costantino che lancia il cavallo a corsa sfrenata; e più tardi alla statua equestre di Luigi XIV dà un movimento così vivace, che fur facile agli artisti francesi di mutarla in Curzio che si getta nella voragine (Versailles).

$\mathrm{Fa}$ eccezione a questa generale ricerca dell' effetto pittorico per mezzo del movimento, una delle più conosciute statue barocche, la Santa Cecilia di Stefano Maderna, nella chiesa omonima in Trastevere, che del resto è proprio dell'anno 1600, quando il nuovo stile era ancora in germe. Ma bisogna pensare che lo scultore lombardo aveva formata la sua educazione artistica lontano da Roma, nel suo paese d'origine, ove ancora áominavano 


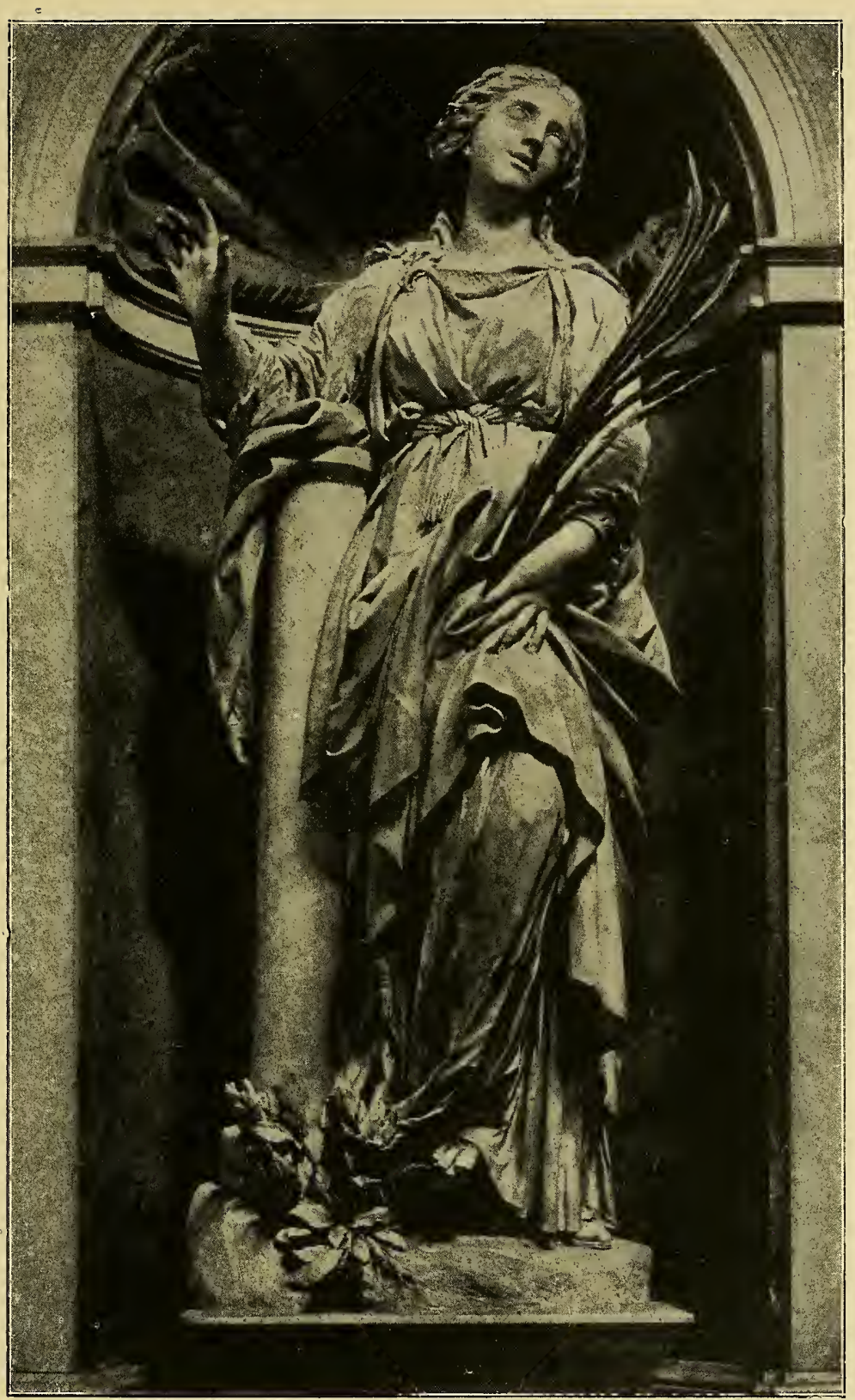

La S. Bibiana del Bernini, nella Chiesa omonima. (Fot. Alinari). 
le forme del puro Cínquecento, e che la posizione così composta della persona e delle vesti fu a lui suggerita dalla quasi miracolosa apparizione del corpo della martire, che fu vista tutta avvolta nei veli, col capo reclinato e le braccia protese, quando il 14 novembre $1599 \mathrm{fu}$ aperto il suo sarcofago; prodigio che valse ad ispirare a un debole artista qual'era il Maderna un'opera così delicata e gentile.

E parrebbe anche contrastare a questa generale ricerca dell'effetto pittorico la composta figura di Santa Susanna, ch'è nell'abside di S. Maria di Loreto (1630); ma è da osservare che l'autore, Francesco Duquesnoy, era stato educato fuori d' Italia, e che per la S. Susanna egli si era posta a modello una statua antica; basta del resto vederlo poco tempo dopo, quando scolpisce la poderosa figura del Sant'Andrea per la Basilica Vaticana, per riconoscere che anch'egli non ha saputo sottrarsi alla nuova corrente dell'enfasi pittorica.

Col progredire del secolo il movimento si va sempre più accentuando: così può vedersi nei monumenti sepolcrali, in cui la figura del defunto (che nei secoli precedenti è distesa sul sarcofago o sul letto, e col Sansovino nei sepolcri di S. Maria del Popolo comincia a sollevarsi ad imitazione delle tombe etrusche), vien posta a sedere o inginocchiata sul mausoleo, e da ultimo sollevata in piedi (monumento di Benedetto XIV). E dalla figura del defunto questa ricerca di moto si trasmette alle imagini allegoriche, alle Virtì, che uscendo dalle nicchie in cui dal Trecento al Cinquecento erano relegate, e separate così dai personaggi del mondo reale, quasi vivessero in una sfera ideale, si avvicinano al personaggio di cui celebrano i meriti, e prendono parte viva alla scena, rivolgendosi ad esso (monumento di Alessandro VII), o piangendo disperatamente come se dopo la morte di lui non vi fosse più per loro speranza su questa terra (monumento del card. Pimentel alla Minerva).

Qualche volta gli scultori barocchi si sono trovati perfino 


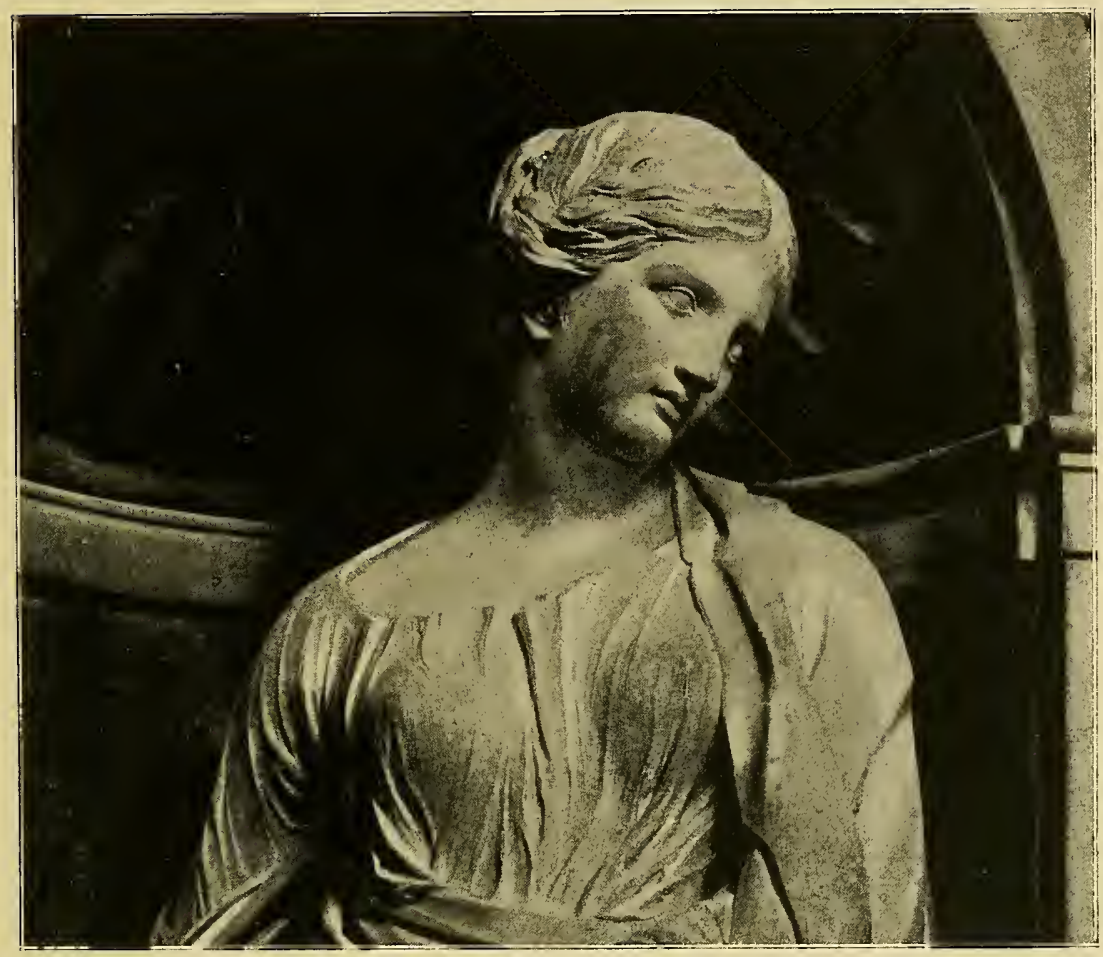

Particolare della S. Susanna del Duquesnoy, in S. Maria di Loreto.

(Fot. Anderson).

nell' impossibilità di rappresentare plasticamente certe loro composizioni, appunto a causa del movimento eccessivo che avevano dato ai loro bozzetti.

Quando Gianlorenzo Bernini disegnò il gruppo della Verità scoperta dal Tempo (1652), imaginò (come si vede nel dísegno originale conservato nella collezione del principe Chigi), il Tempo in figura di vecchio alato che scendeva impetuosamente dall' alto, tenendo una falce nella sinistra, e sollevando con la destra il mantello della bella donna rovesciata all' indietro, rappresentante la Verità. Ma questo ardito bozzetto non si prestava ad esser tradotto plasticamente. Come infatti sostenere la pesante figura marmorea sospesa in aria, distaccata, come è nel disegno, dal 
nucleo del gruppo? E così l'opera rimase incompiuta, limitandosi alla sola figura della Verità, col manto levato in alto da una invisibile forza. Il Bernini aveva concepito il gruppo pittoricamente, e gli fu impossibile esprimerlo plasticamente; e il bozzetto rimane come indice prezioso dell'arte del maestro, perchè sempre i primi schizzi ed abbozzi esprimono più sinceramente l'idea, che poi trova difficoltà ad esser tradotta nella sorda materia.

Il barocco per il suo desiderio di pittoricità giunge a dare moto anche alle cose inanimate; così spesso vediamo agitarsi il panneggio che riveste le figure, come se partecipasse al sentimento che le anima. Il duro saio di carmelitana che ricopre la Santa Teresa del Bernini, è tutto agitato e fremente, tutto mosso da piegoline sottili, come se ad esso si trasmettesse la sensazione violenta $e$ voluttuosa che fa fremere le carni della appassionata donna.

E qualche volta il panneggio ha perfino dei movimenti indipendenti da quelli della fígura che riveste. Quando il Bernini si accinse, durante la sua dimora a Parigi (1665), ad eseguire il busto ritratto di Luigi XIV, non fece prima un bozzetto in creta della figura, ma dopo aver schizzato sulla carta varii disegni cominciò a scolpire direttamente nel marmo. Solo fece alcuni modelli in creta del manto che copre il petto del sovrano, per studiare, come egli diceva, il mobimento da dare al panneggio. E durante le sedute che Luigi XIV gli accordava, iI Bernini desiderava che il sovrano si muovesse e parlasse e non che stesse in posa, perchè voleva ritrarlo così come egli era vivo, e non inanimato e freddo. Questo ci narra il visconte di Chantelou che assisteva al lavoro, e ce lo conferma il Passeri nella vita del pittore G. B. Gaulli detto il Baciccia, che fu amicissimo e devoto seguace del Bernini. Aveva il Baciccia nel fare i ritratti " uno stile tutto contrario al generale e comune; e diceva averlo appreso dal Bernini, il quale nel ritrarre le persone 
non voleva che stessero ferme e chete, ma che parlassero e si movessero. Perchè giusto in que' moti $e^{\prime}$ diceva esser le persone più simili a sè stesse ",

Col progredire dal tempo la ricerca del pittorico per mezzo del movimento arriva all'esagerazione: un turbine impetuoso investe le figure, i panneggi, gli alberi, le piante, e tutto muove, agita, tormenta nella sua irresistibile foga. Sul cadere del Seicento si vedono sui frontoni delle chiese statue che si contorcono stranamente; negli altari appare sulla croce il Cristo rigido nell' immobilità della morte, mentre il panno che gli cinge i lombi ondeggia e svolazza; sui sepolcri le Virtì si agitano con mosse serpentine, si curvano, si girano; fratel Pozzo vuol muovere anche elementi architettonici e inventa le colonne sedute! I defunti sui loro monumenti sepolcrali si levano, si inginocchiano, si alzano in piedi, gesticolano, gridano; il movimento è portato al parossismo; non c'è più una superficie che non sia tormentata, ripiegata, sfaccettata, una massa che non sia agitata in qualche modo.

L'arte barocca si avvia cosi alla decadenza; prepara e giustifica la reazione del neo-classicismo; e mentre gli ultimi imitatori del Bernini si sforzano invano di ravvivare forme gia passate, appare da lungi Antonio Canova.

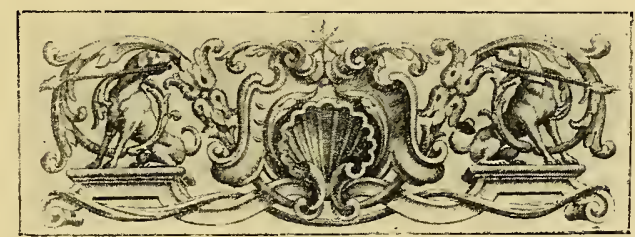




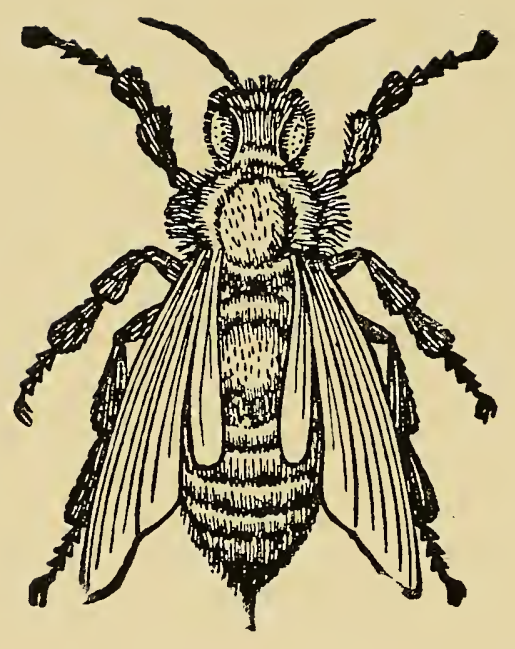




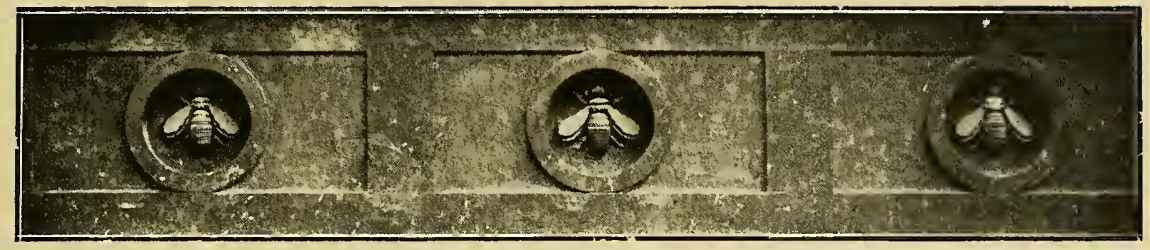

CAPITOLO SESTO

\section{APES URBANAE}

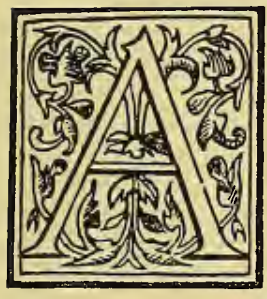

Ila morte di Gregorio XV, avvenuta 1' 8 luglio 1623 , si ebbe una sede bacante durata ventotto giorni, durante i quali, come più volte era accaduto nell'assenza di un governo stabile, si verificarono in Roma deplorevoli disordini, "quali, scrive Giacinto Gigli nel suo Diario, niuno che viva si ricorda in simil tempo aver visto. Non passava alcun giorno senza molte questioni, homicidii, tradimenti. Trovavansi molti huomini et donne uccisi in diversi lochi; et molti ne furono trovati senza testa, et altri furono similmente senza testa raccolti, che erano stati in quel modo gittati nel Tevere. Molte case furono rotte di notte, et arrubbate malamente. Furono sfasciate porte, forzate donne, altre uccise, altre rapite. Cosi di molte donzelle vituperate, forzate, et menate via. Li sbirri poi, che volevano pigliare alcuni in prigione, altri ne furono ammazzati, et altri malamente stroppiati e feriti. Il caporione di Trastevere hebbe delle pugnalate, mentre andava la notte rivedendo la sua regione, et altri caporioni molte volte corsero pericolo della vita.... Et insomma andava il male di giorno in 
giorno così crescendo che, se la creazione del nuovo papa si prolungava, quanto pareva che per le discordie dei cardinali prolungar si dovesse, si dubitava di molti più strani et gravissimi inconvenienti ,.

Finalmente il 6 di agosto, i cinquantaquattro cardinali chiusi in conclave, col nuovo procedimento stabilito dal defunto pontefice, ciò̀ con la segretezza dei suffragi, elessero il fiorentino Maffeo Barberini, che assunse il nome di Urbano VIII. Le trattative erano state assaí laboriose, e il Barberini prevalse specialmente per l'appoggio datogli da Scipione Borghese, che desiderava si scegliesse un cardinale creatura di Paolo V. Il nuovo eletto aveva appena cinquantacinque anni, e la sua fresca età era stata uno degli ostacoli maggiori alla sua nomina; era nato nel 1568 a Firenze; venuto a Roma presso lo zio Francesco, protonotario apostolico, aveva studiato al Collegio Romano, e si era perfezionato, sotto la direzione dei gesuiti, in filosofia. A vent'anni prese il diploma di dottore di giurisprudenza ne l'università di Pisa, e tornato in Roma, si dedicò a studii di lingua greca ed ebraica; fu referendario della Segnatura; poi governatore di Fano; protonotario apostolico; nunzio in Francia nel 1601 per congratularsi con Enrico IV della nascita del Delfino. Tre anni dopo tornò come nunzio ordinario alla corte di Francia, ed ottenne del re il richiamo dall'esilio dei gesuiti, e l'abbattimento della piramide elevata a Parigi in spregio alla Compagnia. Per tutti questi meriti, Paolo V neI 1606 lo creò cardinale; due anni dopo lo inviò vescovo a Spoleto; nel 1617 legato a Bologna; e in altri importanti affari fu pure impiegato da Gregorio XV. La sua nomina riusci inattesa, poichè i votí dei cardinali borghesiani si sapevano rivolti a Ottavio Bandini, che vedendo poi svanire le speranze concepite, in una notte incanuti, e da biondo che era si rivide il giorno dopo in conclave coi capelli bianchi. Disastrose furono le conseguenze del conclave per coloro che vi avean partecipato; la stagione 
estiva caldissima, per cui in Roma infieriva la febbre, e la ristrettezza dell'ambiente, fecero si che dodici cardinali si ammalarono, e i due più aggravati, Peretti nipote di Sisto V, e Gherardi, dovettero uscire, e per poco non mori lo stesso Scipione

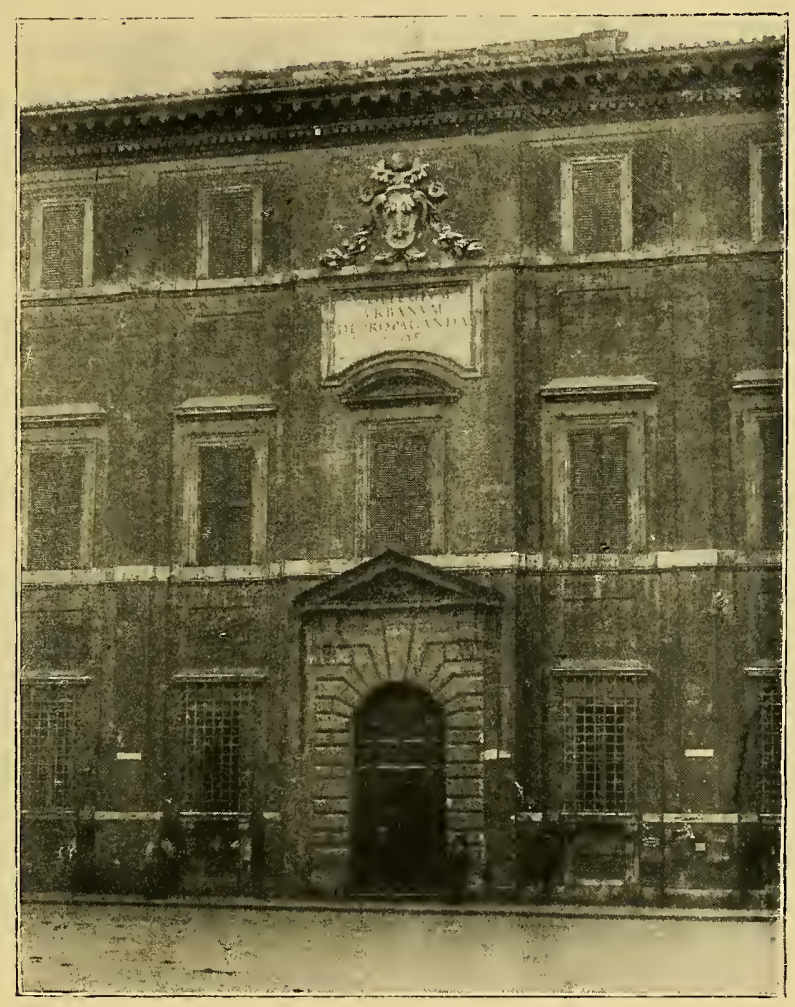

Bernini, La facciata di Propaganda Fide.

Borghese. Finito il conclave molti malati, cardinali e conclavisti, morirono; ed anche il papa cadde infzrmo, così che si dovette differire al 29 settembre la cerimonia dell'incoronazione.

Papa Urbano era amante dell'arte, e poetava in versi italiani e latini, dei quali naturalmente si moltiplicarono le edizioni in tutta Europa; quella del 1631 va adorna di bellis- 
sime incisioni del Bernini, il maestro prediletto dal pontefice. Si racconta anzi che appena salito al Sacro Soglio, il papa fece chiamare il Bernini, e accoltolo con dolci maniere gli disse: "E gran fortuna la bostra, o Cabaliere, di veder papa il Cardinal Maffeo Barberini, ma assai maggiore è la nostra che il Cabalier Bernini biba nel nostro Pontificato ,,!

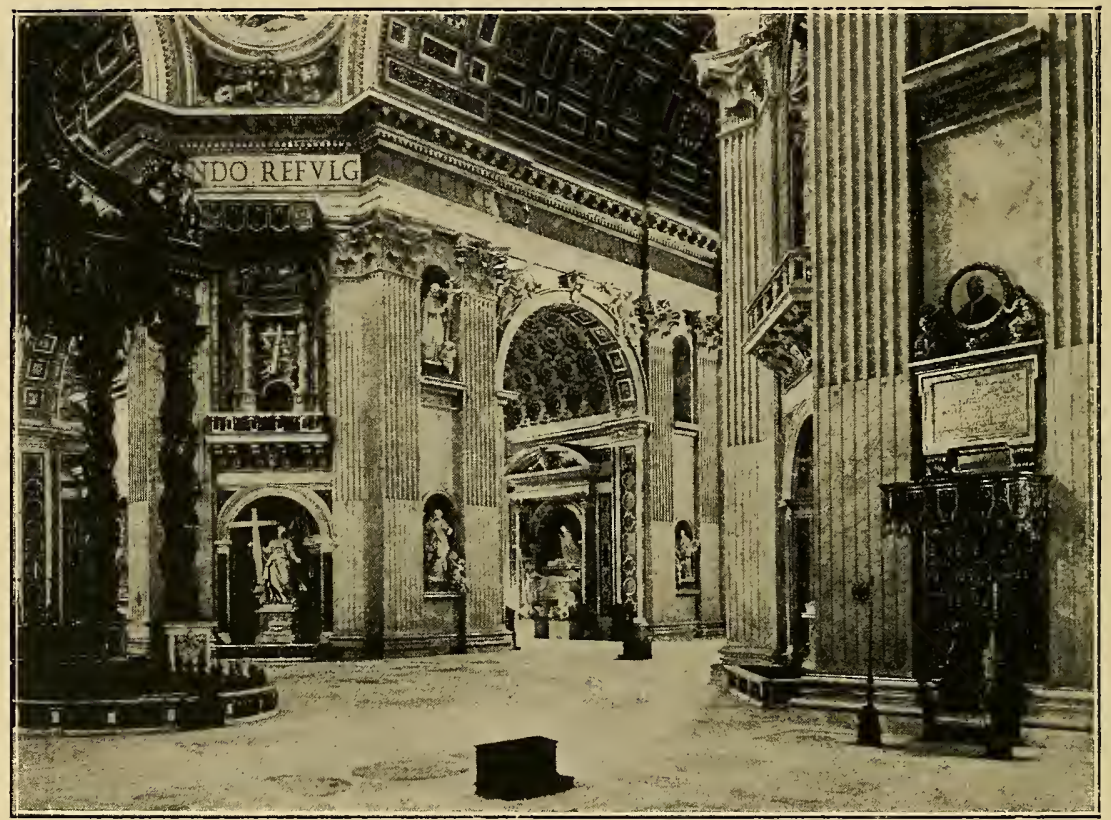

Bernini, Il baldacchino e i nicchioni di S. Pietro.

(Fot. Alinari).

E veramente felice $f u$ l'incontro del papa magnifico con l'artista imaginoso e fecondo, e Roma se ne arricchì di tesori infiniti. Dette subito mano il cavalier Bernini al tabernacolo di bronzo di S. Pietro, la più bella opera di fusione che esista al mondo, come giustamente disse un secolo dopo l'arguto presidente De Brosses; e decorò con statue e stucchi i quattro piloni della cupola, mentre nell'abside della basilica collocava da un lato il sepolcro di Paolo III, di Guglielmo della Porta, e dal- 
l'altro il mirabile mausoleo di Urbano, terminato però molti anni dopo. Per volere del papa il cavaliere che aveva iniziato la sua carriera artistica come scultore, divenne anche pittore e architetto; elevò la facciata della chiesetta di S. Bíbiana, ove collocò sull'altare la dolce statua della santa; innalzò il

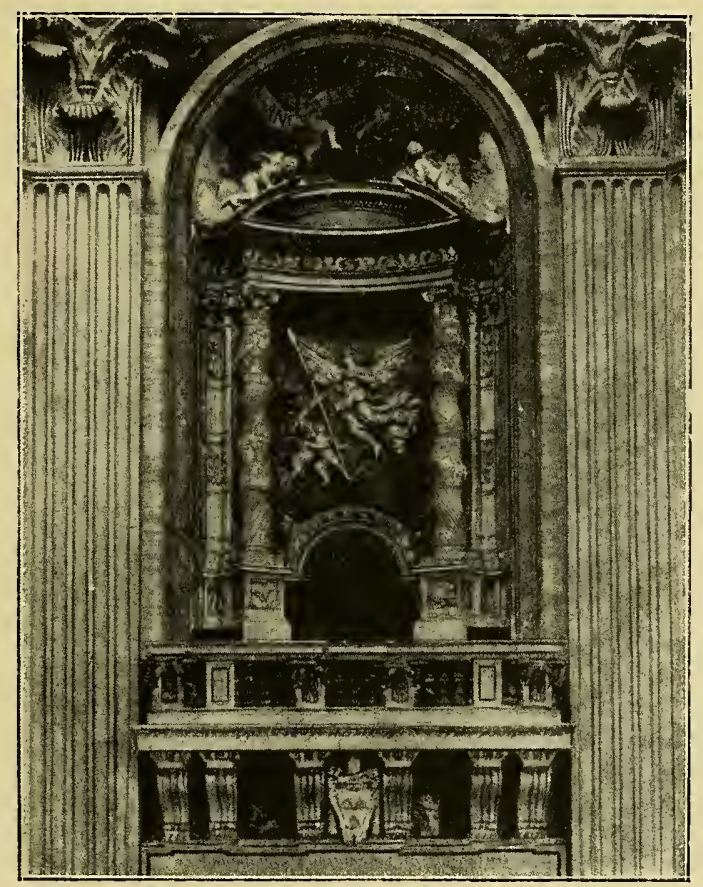

Bernini, Loggia delle reliquie in S. Pietro.

(Fot. Anderson).

prospetto del Collegio di Propaganda Fide; e morto il Maderno nel 1629, assunse la carica di architetto della Basilica Vaticana e del Palazzo Barberini. Lo splendido edificio che D. Taddeo, principe di Palestrina e prefetto di Roma, nipote del papa, faceva erigere alle Quattro Fontane per dimora di tutta la famiglia Barberini, era alla morte del Maderno costruito solo nella parte che guarda verso la piazza, e nell'ala opposta, che conservano ancora oggi il carattere di sobria eleganza, che l'ar- 
tista lombardo aveva appreso dallo zio Domenico Fontana, arricchito da alcune originali mostre di finestre disegnate $\mathrm{dal}$ giovane Borromini; ma il Bernini non tenne nessun conto di quanto era già fatto, e vi incastrò quasi a viva forza il corpo centrale col mirabile loggiato, che ha altezza maggiore delle ali, e taglia perfino nel lato posteriore le parti decorative del pri-

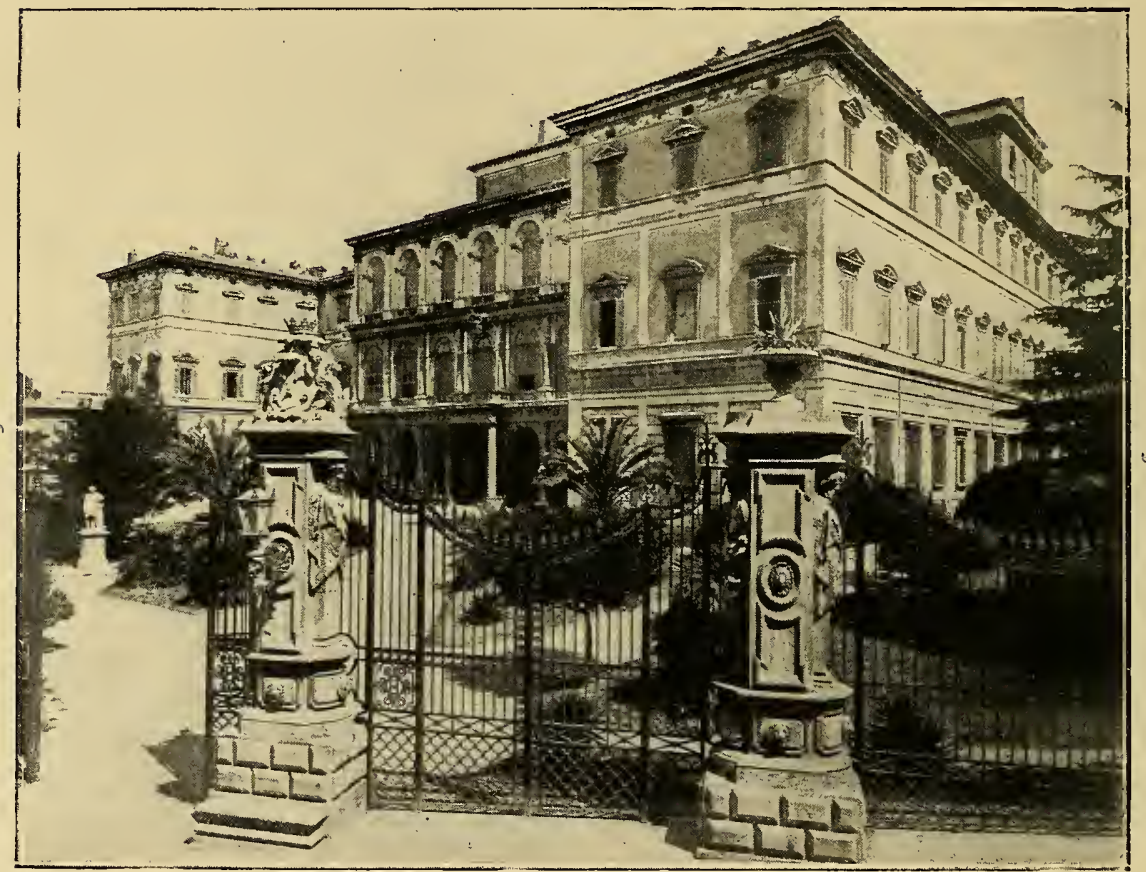

Maderno e Bernini, Il palazzo Barberini.

(Fot. Anderson!.

mitivo edificio. I tre ordini del loggiato, di classica ispirazione, costituiscono un falso prospetto che non trova corrispondenza nei piani interni, ed ha una funzione puramente di apparenza; assai bene studiate sono le due scale, quella nobile a sinistra, e quella a lumaca a destra; ma non può lodarsi la tecnica dell'architetto, che per lasciare aperto il portico inferiore in tutta la sua profondità, ha poggiato in falso enormi muraglie. Una 
splendida villa con un giardino segreto, dava respiro al palazzo, che era all' interno arricchito di marmi, di dipinti, di mobili preziosi. Nel salone del piano nobile Pietro Berrettini da Cortona decorò la vôlta con una grande composizione allegorica, dipinta a fresco, il cui soggetto $\mathrm{fu}$ ideato dal poeta pistoiese Francesco Bracciolini, assai caro al pontefíce. Nel mezzo della

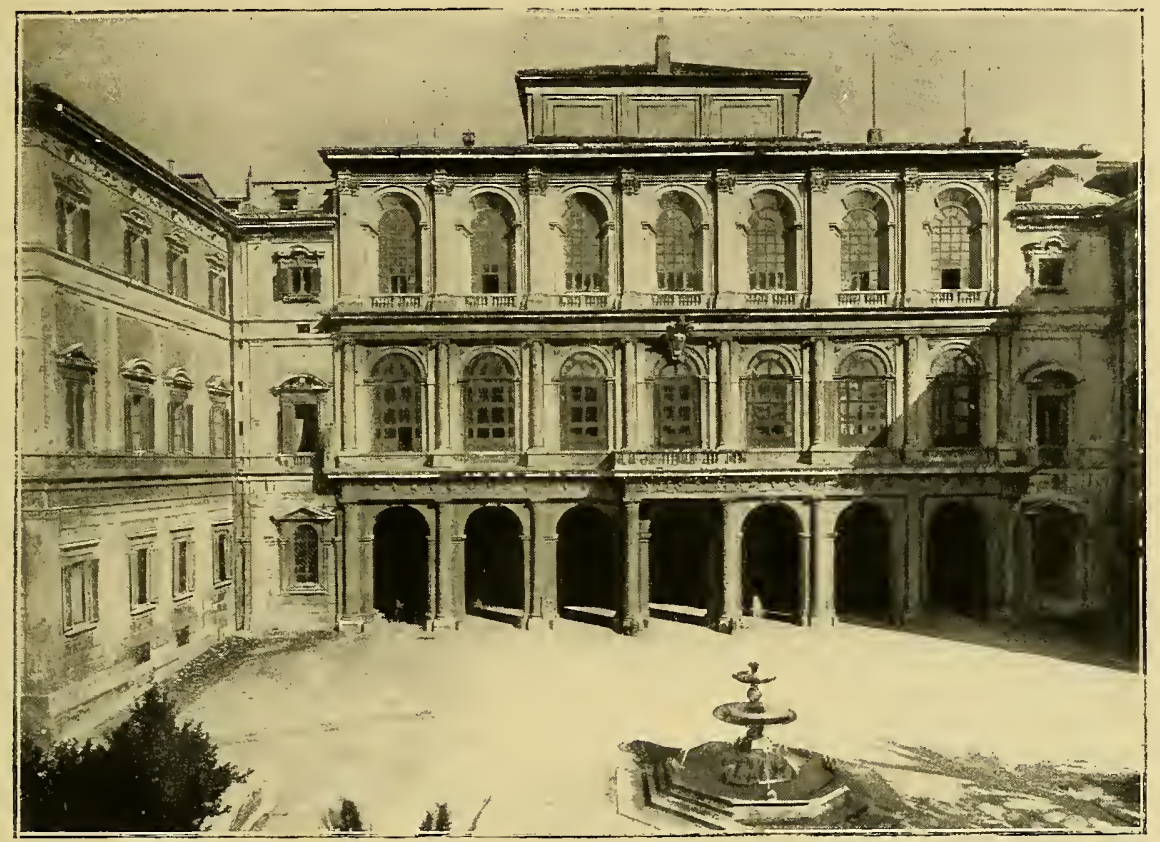

Bernini, Loggiato del palazzo Barberini.

vôlta a schifo, in un'apertura di cielo, Pietro da Cortona fígurò la Divina Provvidenza, circondata dalle Virtù Teologali, e al disotto un coro di donzelle assise sopra lucide nuvole, che simboleggiano la Giustizia, la Pietà, l'Eternità, la Sapienza, la Potenza, la Verità, la Bellezza e la Pudicizia, le quali mostrano di dipendere dalla bocca e dal cenno della Provvidenza; accanto a loro è il Tempo, armato di falce, in atto di divorare 
un fanciullo. A destra della Provvidenza c'è un'altra figura che regge una corona di stelle, e si volge a lei come per incoronarla. L'altra metà dello spazio centrale ha una composizione allusiva alla gloria poetica di Urbano VIII: tre fanciulle, Urania, Calliope, e Clio, reggono un festone di lauro verdeggiante, nel mezzo del quale si veggono le tre Api dello stemma barberino;

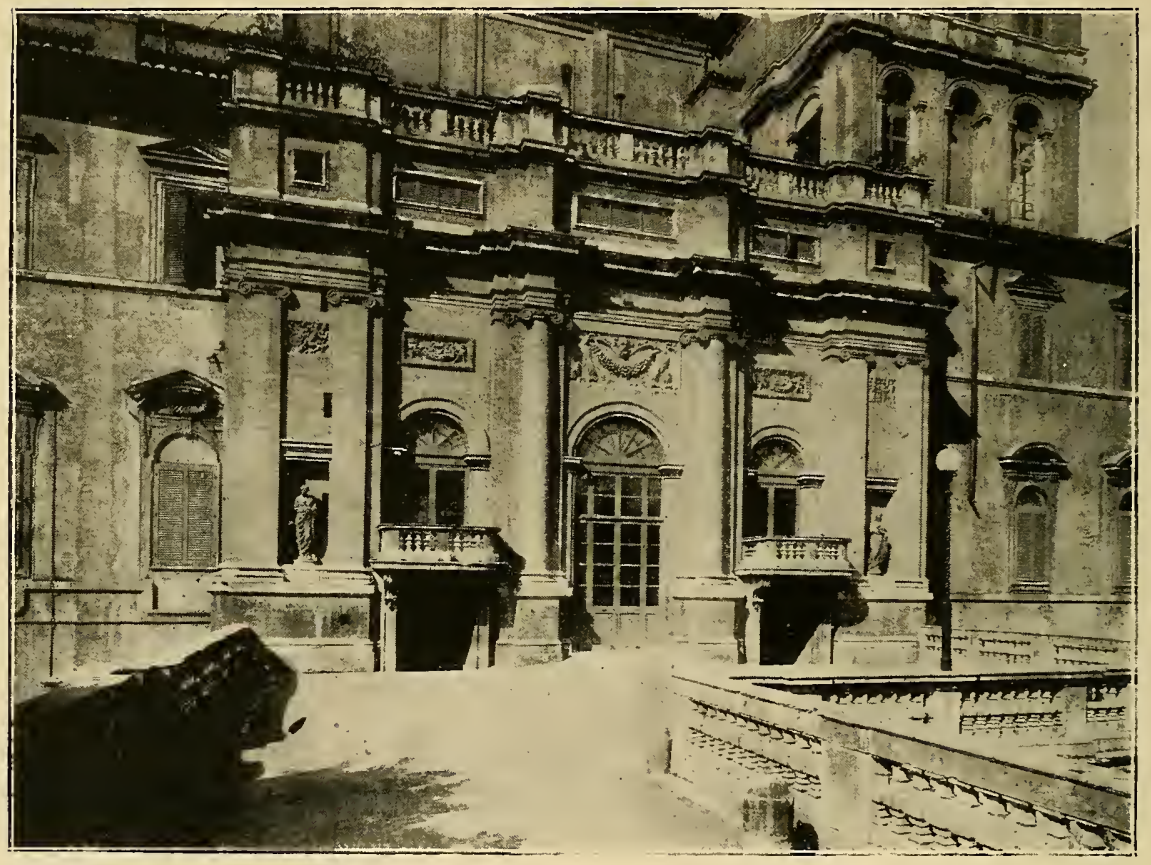

Bernini, Facciata del palazzo Barberini verso il giardino. (Fot. Anderson).

e al disopra due altre donne, Roma e la Gloria, reggon la tiara e le chiavi. La scompartizione della vôlta del salone è ispirata dalla Galleria Farnese, perchè intorno allo spazio centrale gira una solida cornice adorna di festoni, sostenuta ai quattro angoli da trofei di finto stucco, con candelabri, cariatidi, medaglie $e$ tritoni; ma mentre nella sala dei Carracci i quadri sono ben delimitati entro i loro scomparti, e sembrano arazzi appesi 
all'armatura architettonica, qui vediamo composizioni più libere, che a mala pena sembrano contenute nei loro confini, e ne straripano fuori coprendo festoni e cornici. Nei quattro spazii trapezoidali che risultano dalle parti in curva della vôtta, si vedono figurazioni classiche, Ercole che uccide le Arpie; Minerva

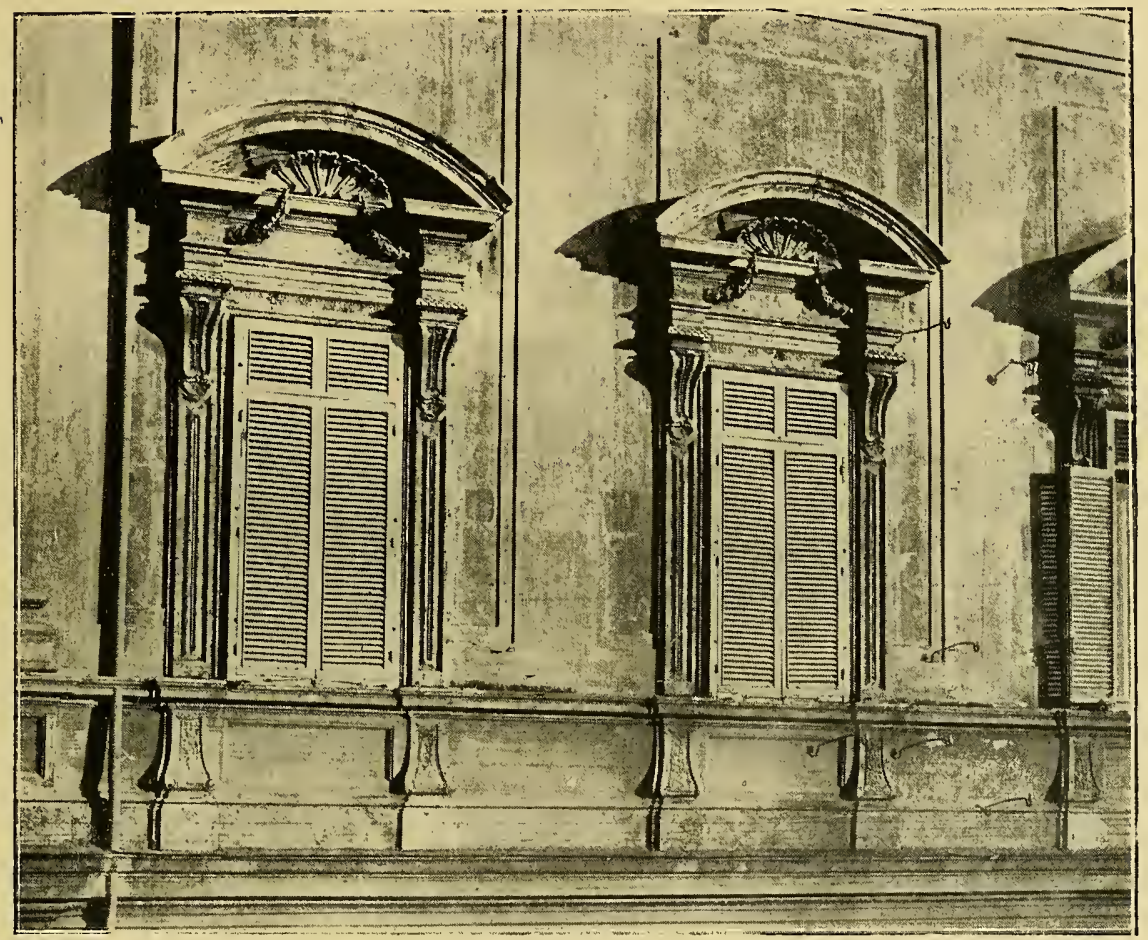

Borromini, Finestre del palazzo Barberini.

che fulmina i Titani, l'officina di Vulcano, e allegorie della Pace e della Religione.

Uno spirito straordinario, un impeto irresistibile dominano in tutta la composizione, dipinta con un colorito caldo che sembra più di pittura a olio che a fresco; lo studio dei Carracci, di Michelangelo, di Raffaello, si mescola a ricordi veneti e correggeschi, espressi con una tecnica che pare quella dei 
cartoni per arazzo, e che il pittore non abbandonerà mai. Nato in Toscana, Pietro da Cortona (1596-1669) venuto a Roma a sedici anni, non perde le sue caratteristiche regionali, e partecipa alle forme della scuola romana ufficiale, che non guarda al rinnovamento caravaggesco.

Nel 1634 il palazzo Barberini era già fínito, compreso il teatro, nel quale proprio in quell'anno, nell'occasione dell'arrivo

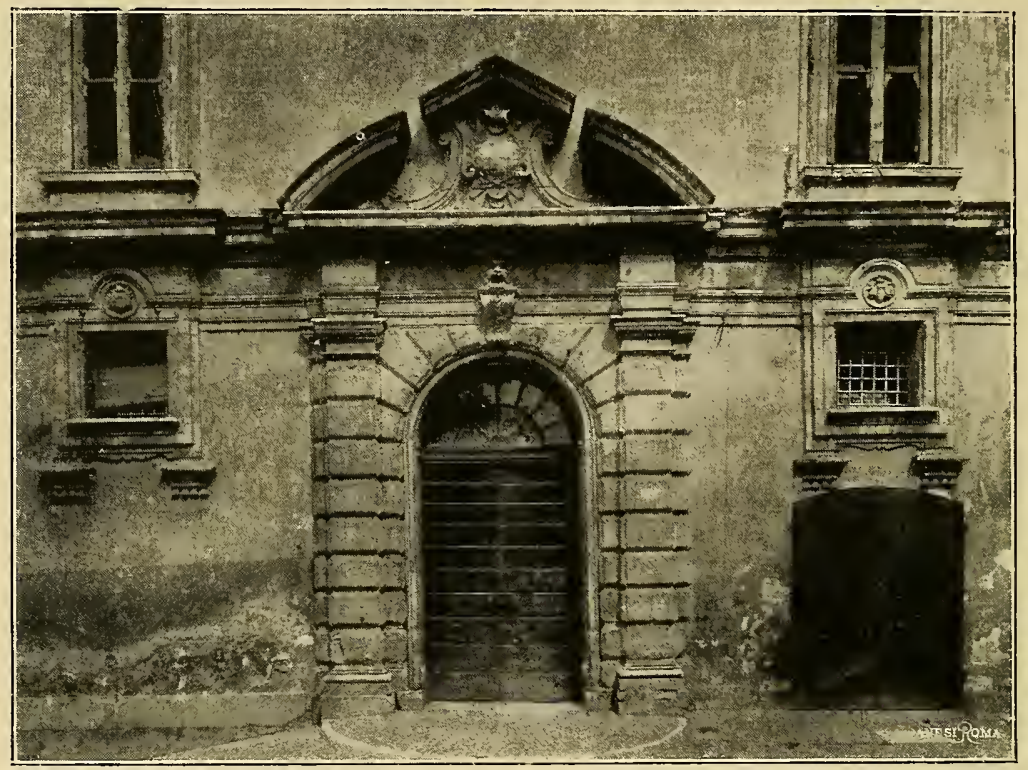

Bernini, Il teatro del palazzo Barberini.

in Roma del fratello del Re di Polonia, "fu dal cardinal Antonio fatta rappresentare l'Historia di Santo Alessio da musici eccellentissimi, et con scene maravigliose, le quali si mutarono più volte, comparendo palazzi, giardini, selve, inferno, angeli che parlando volavano per aria, et finalmente si vidde una gran nuvola a basso, che aprendosi mostrò la gloria del Paradiso ". I versi del melodramma, scritti da un prelato della corte del cardinale Barberini, monsignor Giulio Rospigliosi, il futuro Clemente IX, vennero musicati da Stefano Landi, e si vuole 


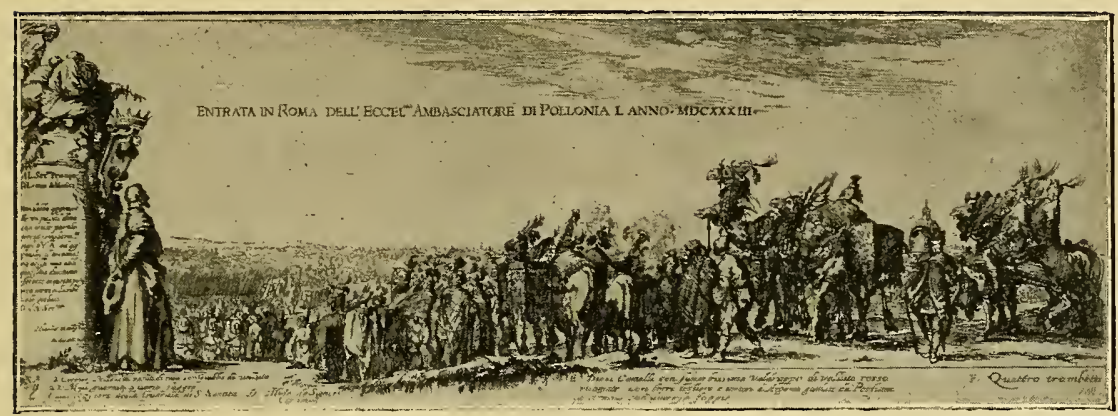

Ingresso dell'Ambasciatore di Polonia in Roma, incisione di Stefano della Bella.

che gli scenari fossero ideati dal Bernini; essi sono riprodotti nella magnifica edizione del S. Alessio data in luce l'anno stesso, ma attraverso le incisioni del Collignon non appare, a dir vero, lo spirito del sommo artista.

Il teatro di casa Barberini divenne presto famoso, e per esso scrissero opere e oratorî il Marazzoli, il Vittori, il Cornacchioli, Michelangelo Rossi, i due Mazzocchi, spesso su parole del fecondo monsignor Rospigliosi.

Avanti alla bella mole del palazzo Barberini, la piazza che porta lo stesso nome formava come una grande corte d'onore, come piì tardi piazza Navona per i Pamfili e piazza Colonna per i Chigi, e quindi si volle decorarla degnamente: il Bernini vi elevò nel 1640 la fontana del Tritone, di gusto squisito nella sua stranezza, in cui non c'è più nessun elemento architettonico, ma il bocciuolo è sostituito da tre delfini e la vasca da una conchiglia aperta. Tre anni dopo lo stesso maestro collocava all'angolo tra la piazza e via Sistina la fontana delle Api, demolita nel 1870 e di recente ricostruita, formata da una grande conchiglia aperta a ventaglio, sotto la quale tre api gettano acqua nella vasca. Il Bernini è il vero creatore della fontana pittorica, che sostituisce nel Seicento il tipo in forma di prospetto che vedemmo prevalere al tempo di Sisto $\mathrm{V}$; e si serve in modo mirabile dell'acqua come elemento artistico. Non è opera sua, ma 
del padre Pietro, la così detta Barcaccía di piazza di Spagna (1627), che ha la forma di una galera armata che sta per affondare, ingegnoso ripiego suggerito dal fatto che l'acqua era a basso livello.

Il cardinale Antonio Barberini, nipote del papa, protettore degli affari di Francia, e grande amico del Mazarino, era un appassionato amante di tutte le arti belle, della pittura, della musica, della poesia, e raccoglieva nel palazzo tesori di ogni genere, quadri e marmi antichi e moderni, manoscritti rari, avorii, miniature, stampe; e dava impulso a una fabbrica di arazzi che ebbe sede proprio in casa Barberini, ma non durò a lungo. L'altro nipote, il cardinale Francesco, sebbene Segretario di Stato, e perciò più assorbito dalle cure politiche, fu anch'egli mecenate e amico dei letterati, e alla sua corte eranvi fra gli altri Cassiano dal Pozzo e Luca Holstenio; l'Accademia dei Lincei lo ascrisse fra i suoi membri. Il fratello del pontefice, D. Carlo, padre di Taddeo, era Generale di Santa Chiesa, e trovandosi a Bologna a causa della guerra in difesa dello Stato ecclesiastico, vi morì il 25 febbraio del 1630 . Il papa che molto lo amava, e aveva acquistato per lui il feudo di Palestrina, volle che il suo corpo fosse portato a Roma, ove gli si celebrarono solenni funerali, a spese del popolo romano, nella chiesa di Aracoeli; e naturalmente fu disegnato dal Bernini il catafalco "con statue e colonne di mirabile artificio "; al maestro fu data in compenso una collana d'oro del valore di trecentoquattro scudi. E nella stessa chiesa, sulla parete d'ingresso, fu posta la targa funeraria in marmo, pure ideata dal Bernini ed eseguita con la collaborazione di Stefano Speranza, sulla quale stanno sedute due figure allegoriche, di freschissima fattura, tra le più eleganti del barocco romano. Fu pure decretata l'erezione di una statua del Generale nella sala dei Capitani nel Palazzo dei Conservatori, e si adoperò un torso di epoca classica, che fu completato da Alessandro Algardi, uno scultore bolognese che da 


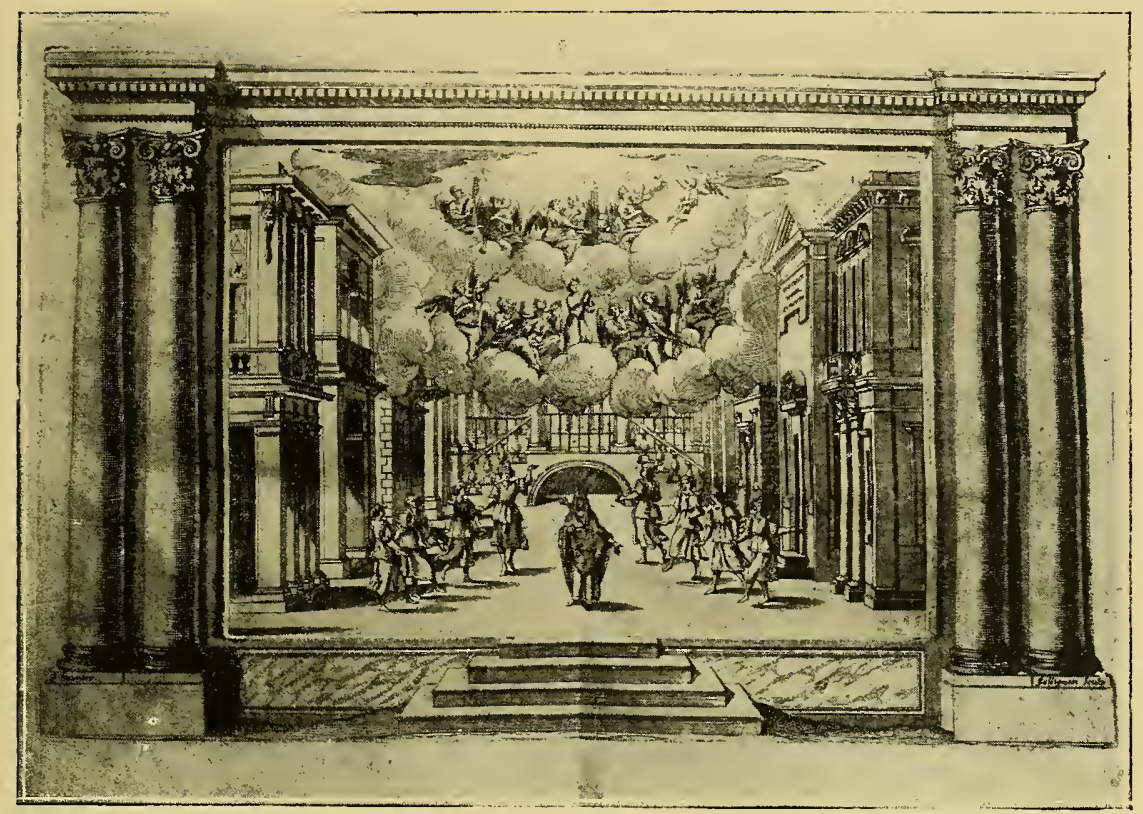

Bernini (?), Scenario del S. Alessio, rappresentato nel Teatro Barberini (1634).

qualche anno si trovava a Roma, e si era fatta una specialità nel restaurare le anticaglie; la testa però, che è una mirabile cosa, ma un po' piccola sul poderoso tronco antico, vi fu aggiunta dal Bernini, ch'era il ritrattista ufficiale di casa Barberini. Papa Urbano manteneva la promessa fatta al maestro, dandogli gli incarichi più ambiti, onorandolo come un principe; e un giorno, con stupore grande dei suoi cortigiani, volle persino recarsi a fargli visita in casa sua, cosa inaudita per un pontefice. Sentiamo come il biografo del Bernini, Filippo Baldinucci, racconta il fatto singolare: "Un giorno il papa chiamò Paolo AIlaleona suo primo mastro di cerimonie e si gli disse: Paolo, noi borremmo oggi portarci in persona alla casa del Bernino, per ricrearci alquanto colla bista dell'opere sue; che ve ne pare? - Padre Santo, rispose Paolo, a me non parrebbe che una si fatta visita di $V$. S. avesse molto del sostenuto, e 


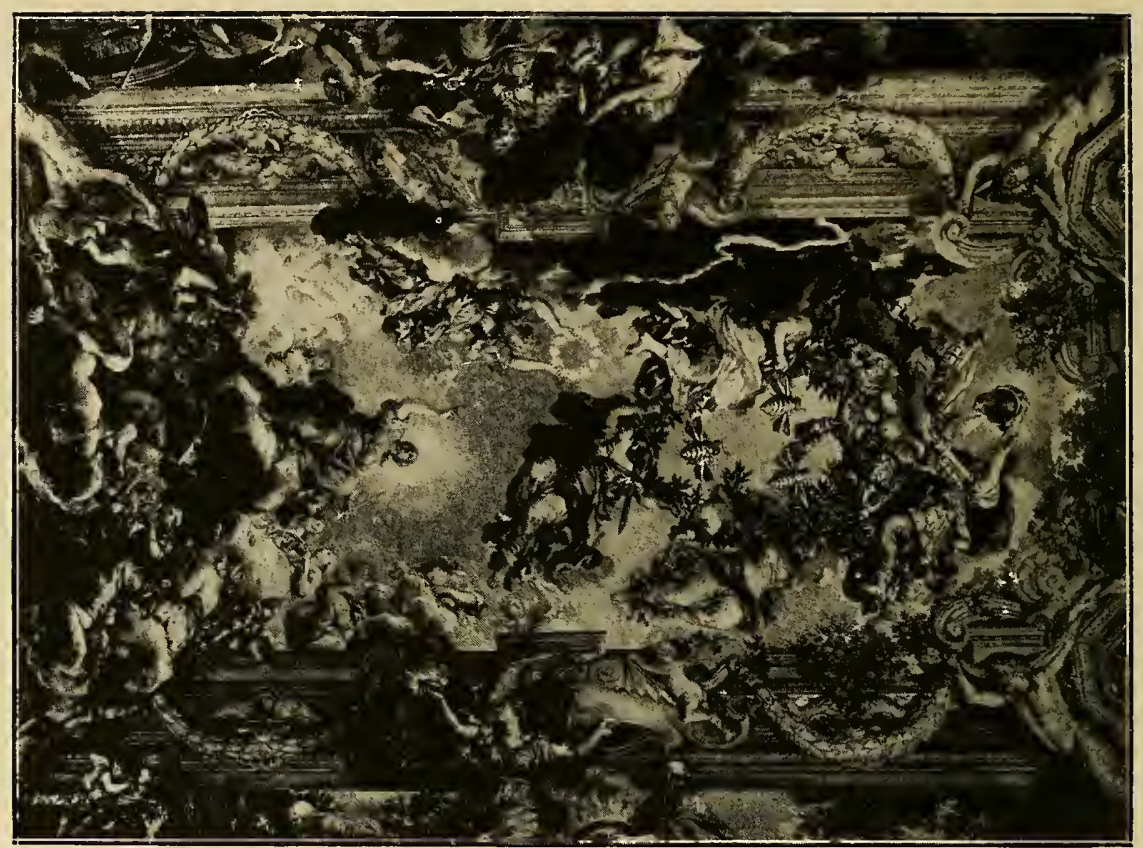

Pietro da Cortona, Allegoria nel salone del Palazzo Barberini.

(Fot. Anderson).

non la loderei. A questo rispose il Papa: Orsì, noi ce n'andremo alla casa de' nostri Nipoti, e ci tratterremo alquanto con quei figliolini. - $O$ questo si che mi piace, disse il cerimoniere. Siete ben boi un ignorante, rispose il Papa, a non conoscere che l'andar noi in persona a bedere $i$ nostri fanciulli sarebbe una vera fanciullaggine, là dove il portare un onore di questa sorte a casa di un virtuoso di quella riga sarà un atto di magnanimità, col quale resterà onorata ed accresciuta insieme la birtì ed in esso, e negli altri. E quel giorno stesso accompagnato da sedici Cardinali se n'andò a casa il Bernino, con meraviglia ed applauso di tutta Roma „. Fu tanto lieto il maestro di questo onore, che nel salone della sua abitazione, che ancora esiste, ed è il palazzo in via della Mercede n. 1l, (adiacente a quello su cui per errore fu collocata 


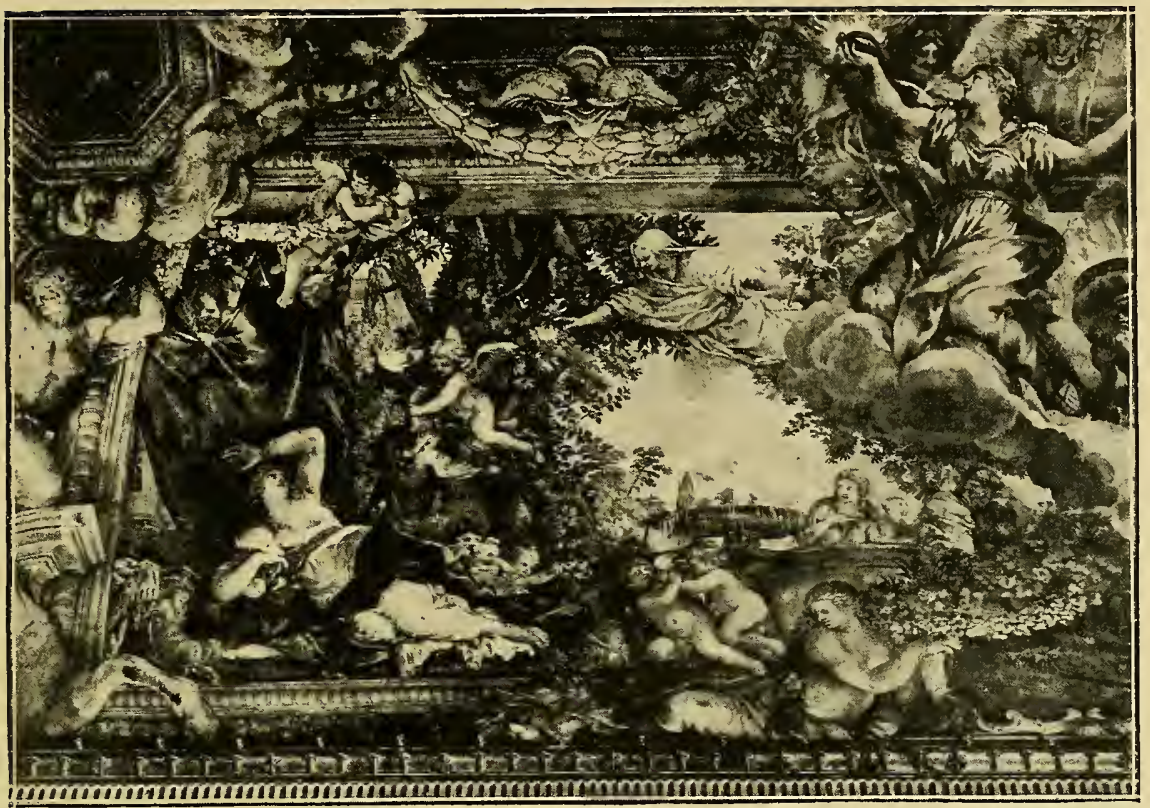

Pietro da Cortona, Affresco nel salone del Palazzo Barberini.

(Fot. Alinati).

la moderna targa commemorativa), fece rappresentare l'episodio in un dipinto nel quale egli si vede inginocchiato tra $i$ suoi famigliari, innanzi alla porta della sua casa, mentre il papa seguito dalla corte, si avanza benedicendo.

Questi tratti di semplice bontà non impicciolivano la figura di Urbano VIII, che sembrava invece volesse far rivivere in sè l'immagine dei grandi papi del Rinascimento, atteggiandosi a Giulio II, mecenate dell'arte e sommo politico. Uno scrittore contemporaneo, venuto dal Belgio a Roma, Teodoro Ameyden, dice che amava mostrarsi principe più che pontefice, duce più che pastore: "Princeps potius videri boluit quam Pontifex, rector quam pastor,...

I tempi non volgevano sereni; ferveva in Europa la guerra dei Trent'anni, e contrariamente ai due suoi predecessori invece 
di favorire l'Imperatore, contro i principi protestanti, Urbano appoggiò la politica francese, forse per contrastare la potenza soverchiante delle due case di Asburgo d'Austria e di Spagna unite insieme; forse perchè era padrino di Luigi XIII, e aveva iniziato la propria fortuna quale nunzio a Parigi, ed era salito al trono col favore del partito francese; forse perchè vedeva lo stato della Chiesa circondato e minacciato dai dominii spagnoli. II papa considerava la grande guerra tedesca non come lotta di religione, ma come contrasto politico, e aveva piacere di veder abbassata l'arroganza di Casa d'Austria, per esaltare il predominio del potere ecclesiastico sul temporale; e mentre pareva tutto rivolto alle tranquille cure della poesia e dell'arte, dirigeva destramente le fila dei suoi intrighi politici, che facevano capo dall'altro lato nelle mani dell'accortíssimo cardinale Richelieu. II contrasto che si era fatto assai acuto scoppiò nel concistoro dell' 8 marzo 1632, quando il Cardinal Borgia ambasciatore ordinario di Spagna, si alzò improvvisamente a leggere una protesta a nome del suo re, contro il ritardo che il papa metteva nell'accogliere le sue richieste. Urbano, acceso di sdegno, gli ordinò di tacere, e poichè il Borgia insisteva, gli grido fortemente: Taceas aut exi!, mentre il cardinal Barberini, generale dei Cappuccini, fece atto di afferrarlo pel braccio, come per trascinarlo fuori. Nacque allora un tumulto; gli eminentissimi si scambiavano apostrofi in italiano, in latino, in spagnuolo; al cardinal Pio si ruppero gli occhiali, mentre il Sandoval tremante di collera stracciava la sua berretta.

Ma non per tale protesta, non per le continue rimostranze di Filippo IV, mutò la politica del papa, il quale quasi provò rincrescimento quando l'eretico re di Svezia, Gustavo Adolfo, il più gran nemico dell'imperatore, morì da eroe sul campo il 16 novembre 1632.

Quello stesso anno è celebre nella storia del papato per la condanna che la Sacra Inquisizione pronunciò contro Galileo, 


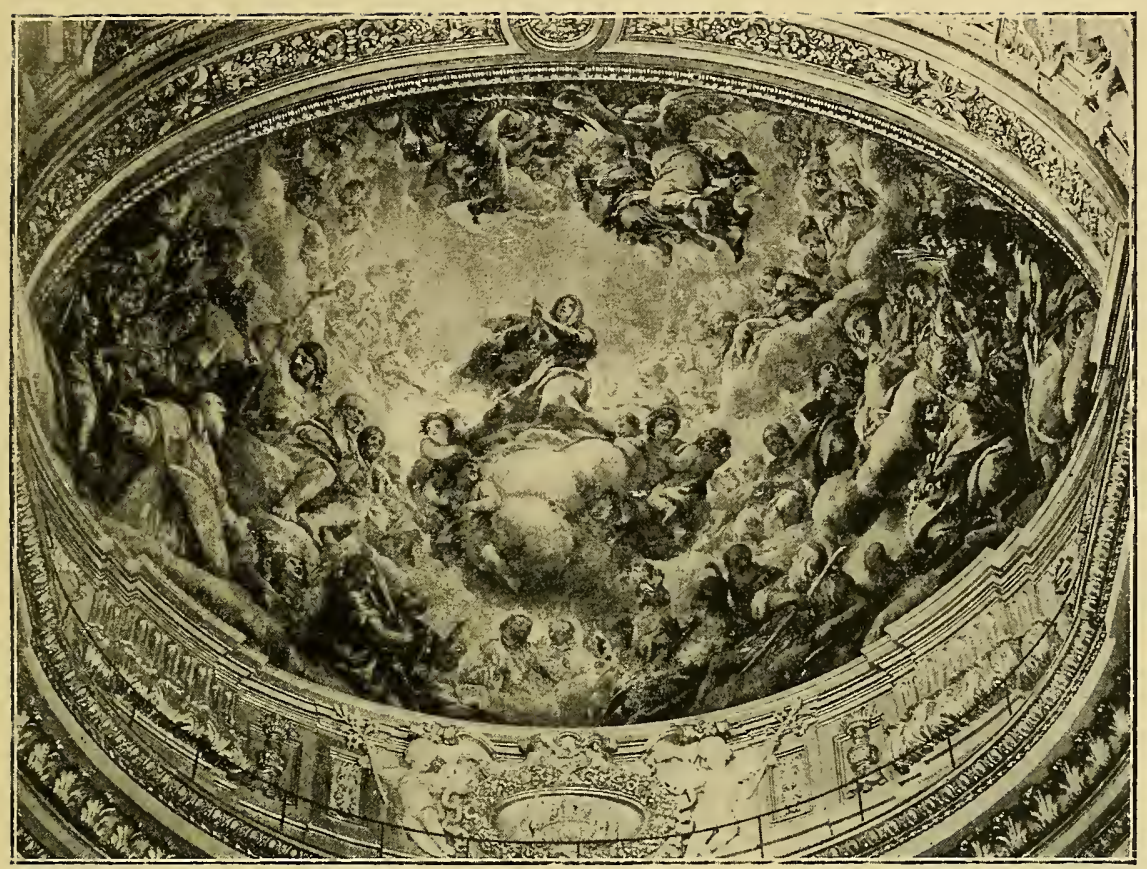

Pietro da Cortona, Affresco nell'abside della Chiesa Nuova.

che tuttavia era stato amico di Urbano VIII, inclinato in un certo momento ad accogliere le sue dottrine: il glorioso vecchio quasi settantenne dovette rinnegare le sue idee e vide limitata per sempre la propria libertà.

Per dimostrazione politica, in accordo ai princjpii a cui ispirava il suo atteggiamento, Urbano VIII volle risuscitare un insigne trionfo del passato, facendo portare in Roma le ceneri della Contessa Matilde, la celebre eroina di Canossa, da lui esaltata in una delle sue odi, perchè simboleggiava il trionfo della Chiesa sull'autorità regia, l'eterno contrasto tra la potestà spirituale e quella temporale; e le fece elevare un mausoleo in S. Pietro, dandone incarico al Bernini. Il monumento, eretto nel 1635, è nell'insieme poco felice, perchè la ristrettezza dello spazio prescelto non permise all'artista libertà e grandiosità di 
concezione; si compone di una nicchia (intorno alla quale per ottenere un effetto di maggiore profondità è disegnato un arco prospettico) in cui sta la fígura dell'eroina in piedi, bellissima donna dalle forme giunoniche, con tunica e manto classici, il capo cinto da diadema, $e$ in mano lo scettro del comando e la

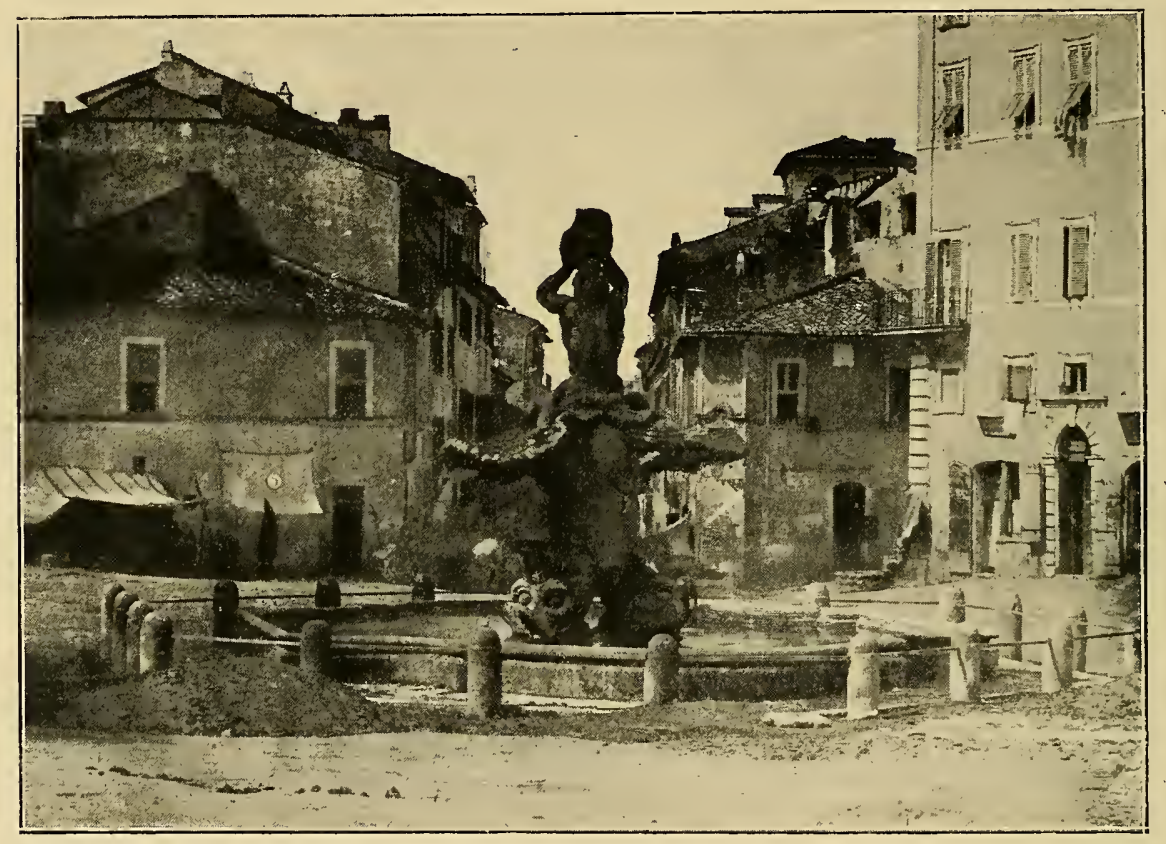

Piazza Barberini e Fontana del Tritone nel 1870.

tiara. Avanti alla nicchia c'è l'urna cineraria, ornata di bassorilievo, e sormontata da putti che reggono una targa. Il mausoleo, che nell'insieme è un po' slegato, è tutto in marmo bianco, ciò che forma eccezione tra le opere del Bernini, che adopera sempre una ricca policromia, mescolando pietre colorate, oro, bronzo.

Il popolo romano che poco si interessava delle lotte politiche di Urbano VIII, e sentiva invece il peso delle tasse, che gli si imponevano oltre misura, non amava troppo il suo 
principe al quale aveva affibbiato il titolo di Papa gabella, ma non potè impedire che gli si elevasse una statua onoraria in Campidoglio. Un decreto del 28 agosto 1590, fatto in sede vacante dopo la morte di papa Sisto, proibiva di erigere in Roma statue a principi viventi e a loro congiunti, e si era così interrotta la consuetudine di elevare in Campidoglio i simulacri dei papi durante il loro pontificato. Il veto era stato sempre

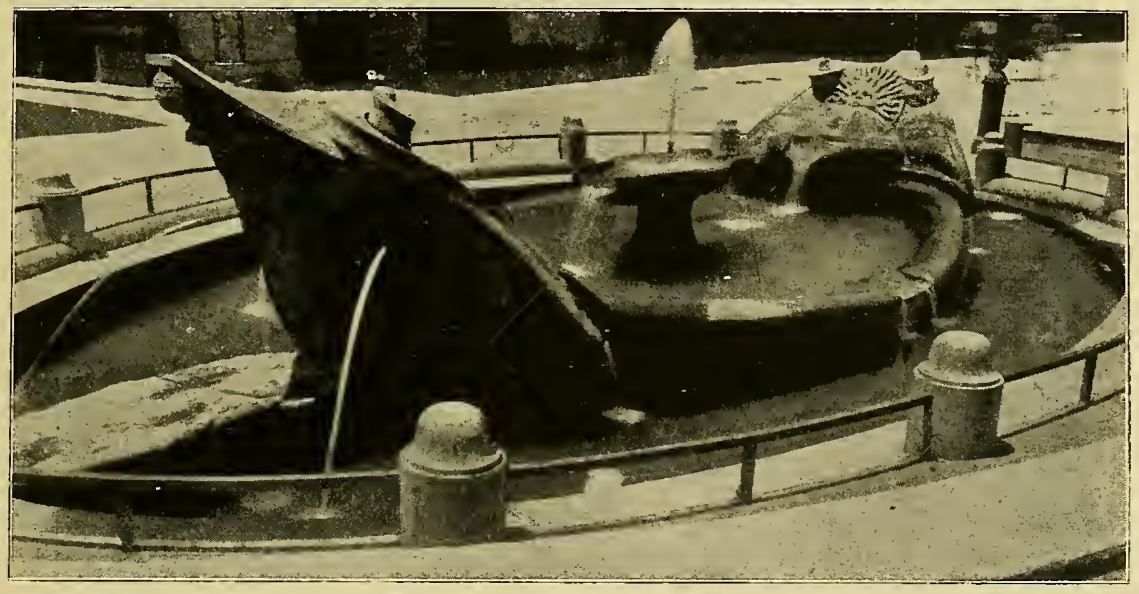

Pietro Bernini, La barcaccia dí Piazza di Spagna.

(Fot. Anderson).

rispettato scrupolosamente, tanto che nel 1626, alla deliberazione dei Consiglieri di porre una statua di Urbano in Aracoeli, fu opposto dal sovrano un rifiuto. $\mathrm{Ma}$ qualche anno dopo il papa non seppe resistere a nuove preghiere, e con breve del 15 gennaio 1634 concesse la chiesta facoltà : fu allora che si fece sparire dalla sala dei Fasti una iscrizione che ricordava il decreto proibitivo del 1590. La statua, commessa al Bernini, era compiuta cinque anni dopo e fu portata in Campidoglio la notte del 23 gitugno 1639. Si era pensato dapprima di fare il trasporto con solennità, ma per timore di dimostrazioni ostili del popolo, ailora gravato di nuovi balzelli, esso avvenne "quasi 


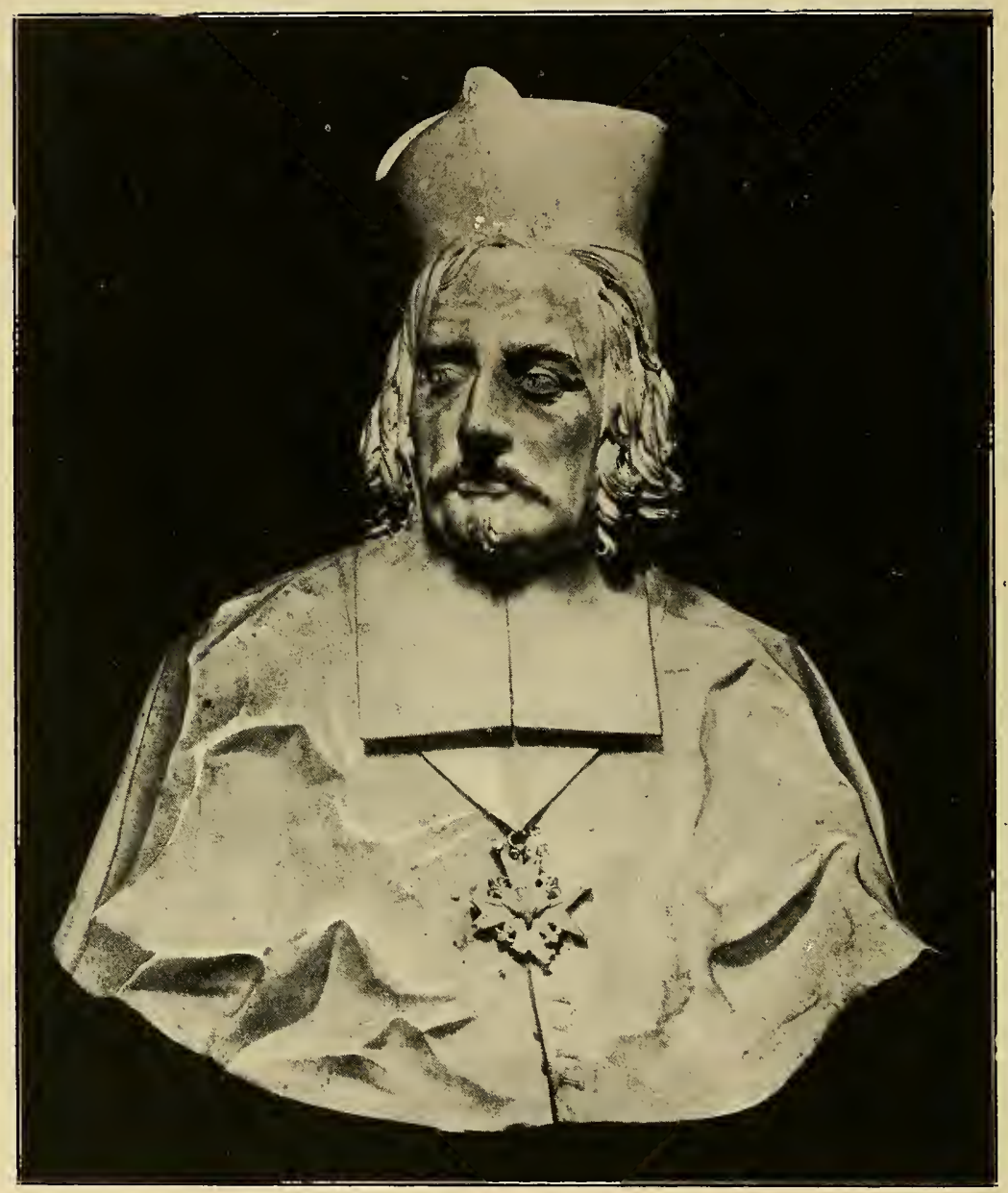

Busto del card. Antonio Barberini nel Palazzo Barberini.

(Fot. Anderson).

secretamente ". E ad ogni modo interessante conoscere, da un manoscritto dal tempo, quali onoranze si erano divisate: Pensiero $c h '$ anno lí Conserbatori nell' allegrezza dell'erettione della statua della Santità di N. Signore Urbano VIII ottimo benefattore del Popolo Romano. Che seguendo, come asserisce il Cav. Bernini di condur la statua in una notte, acciò nel far 
del giorno giunga in Campidoglio venga ricevuta magistralmente dalli Senatore Conservatori et altri offitiali di quei tribunali con la soldatesca de' Rioni. E che nel giorno segue come simil-

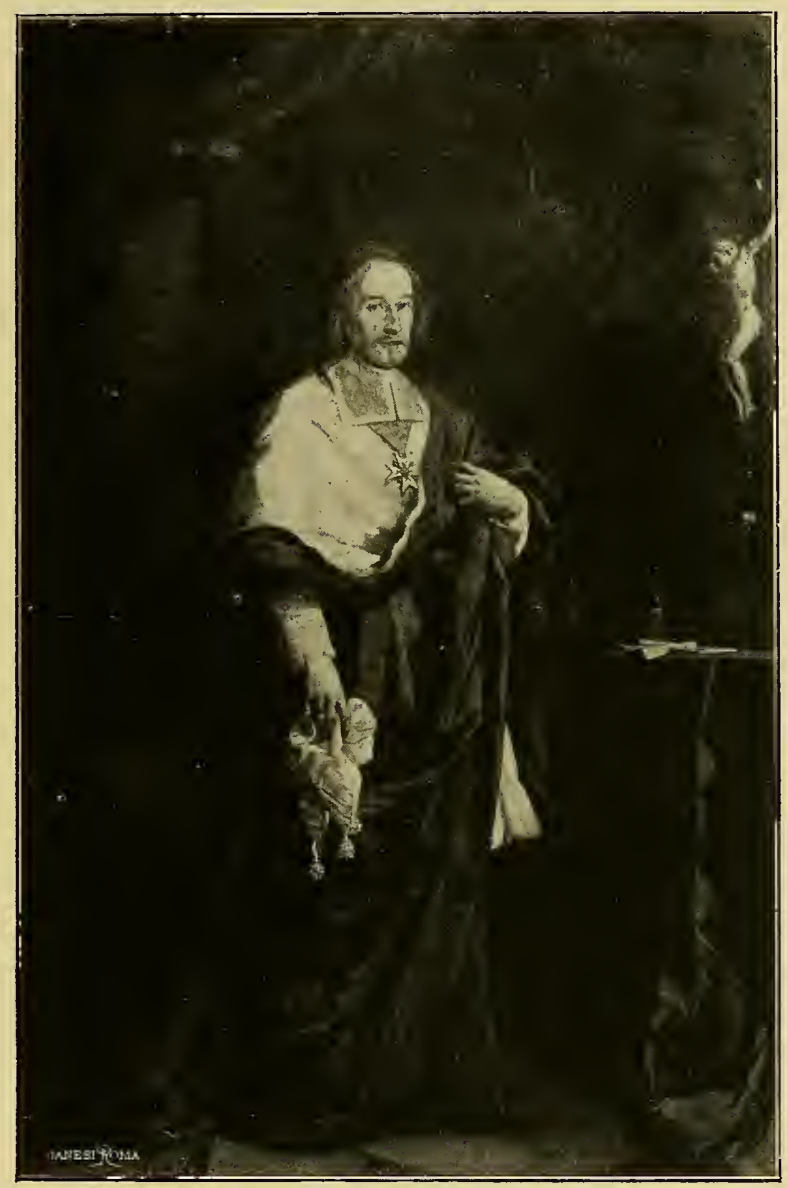

Carlo Maratta, Ritratto del card. Antonio Barberini. Galleria d'arte antica, Roma.

mente si promette dal Cav. Bernini sia eretta sopra il piedestallo, alla cui fontione vi si faccia invito dell'eminentissimi S. S. Cardinali S. Onofrio, Francesco et Antonio Barberini, e Colonna, et delli Ecc. ${ }^{\text {mi }}$ S. S. Principe Prefetto e Duca di Brac- 
ciano, con l'assistenza di numerosissima nobiltà romana alla presenza di cui si reciti da un Avvocato del Popolo, o altra persona, oratione delle cagioni si muove questo Senato a far si celebre ecettione; qual fatto si getta dalle finestre monete d'argento battute dal Popolo in tal memoria, e si distribuisce

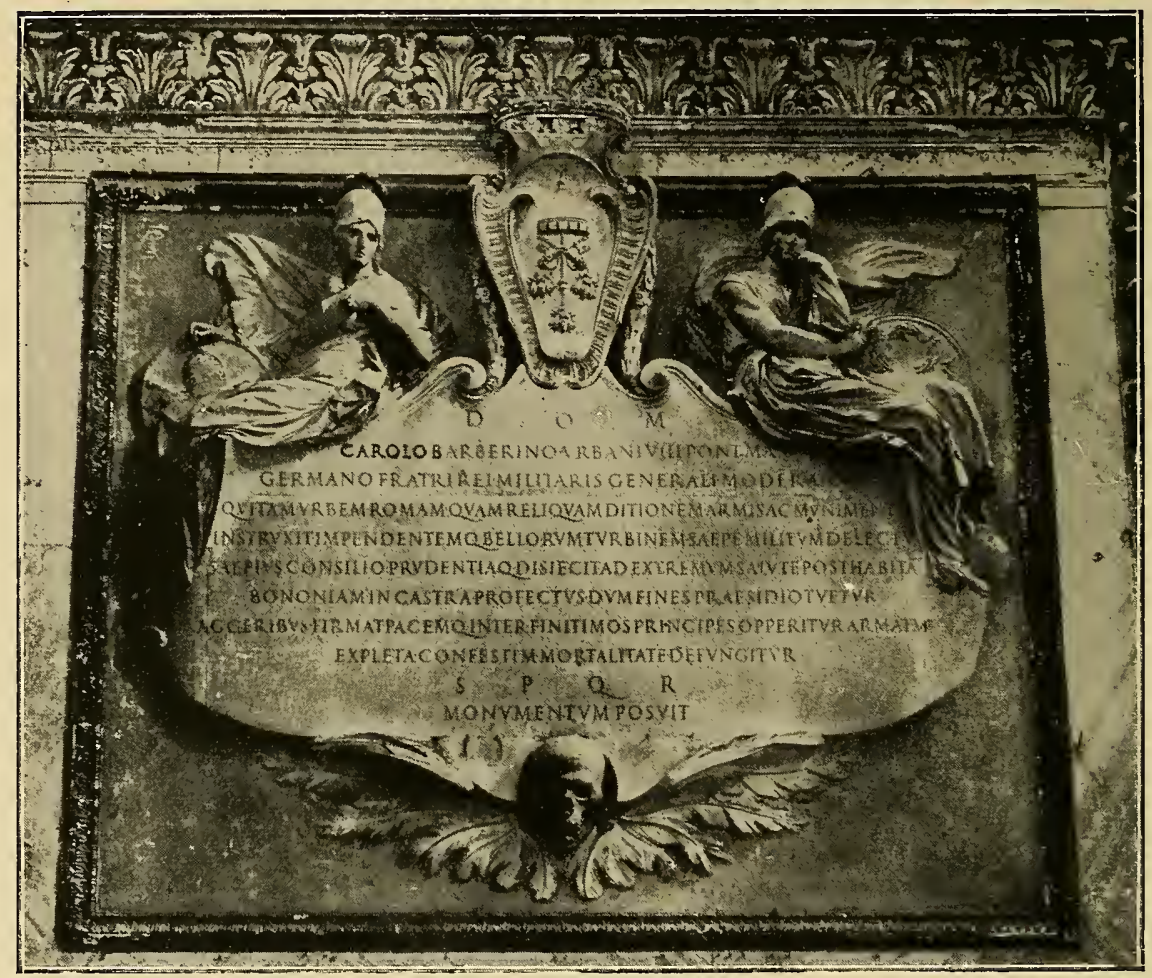

Bernini, Monumento del Generale Carlo Barberini all'Aracoelí.

similmente medaglie per eternar maggiormente la fama di si ottimo, generoso, et oculato Principe „,.

E necessario descrivere ancora una volta l'opera mirabile del Bernini? Nel salone del palazzo dei Conservatori, addossato a una parete, sta su un nobile piedistallo il simulacro marmoreo di papa Urbano: il pontefice siede con maestà regale, e chi- 


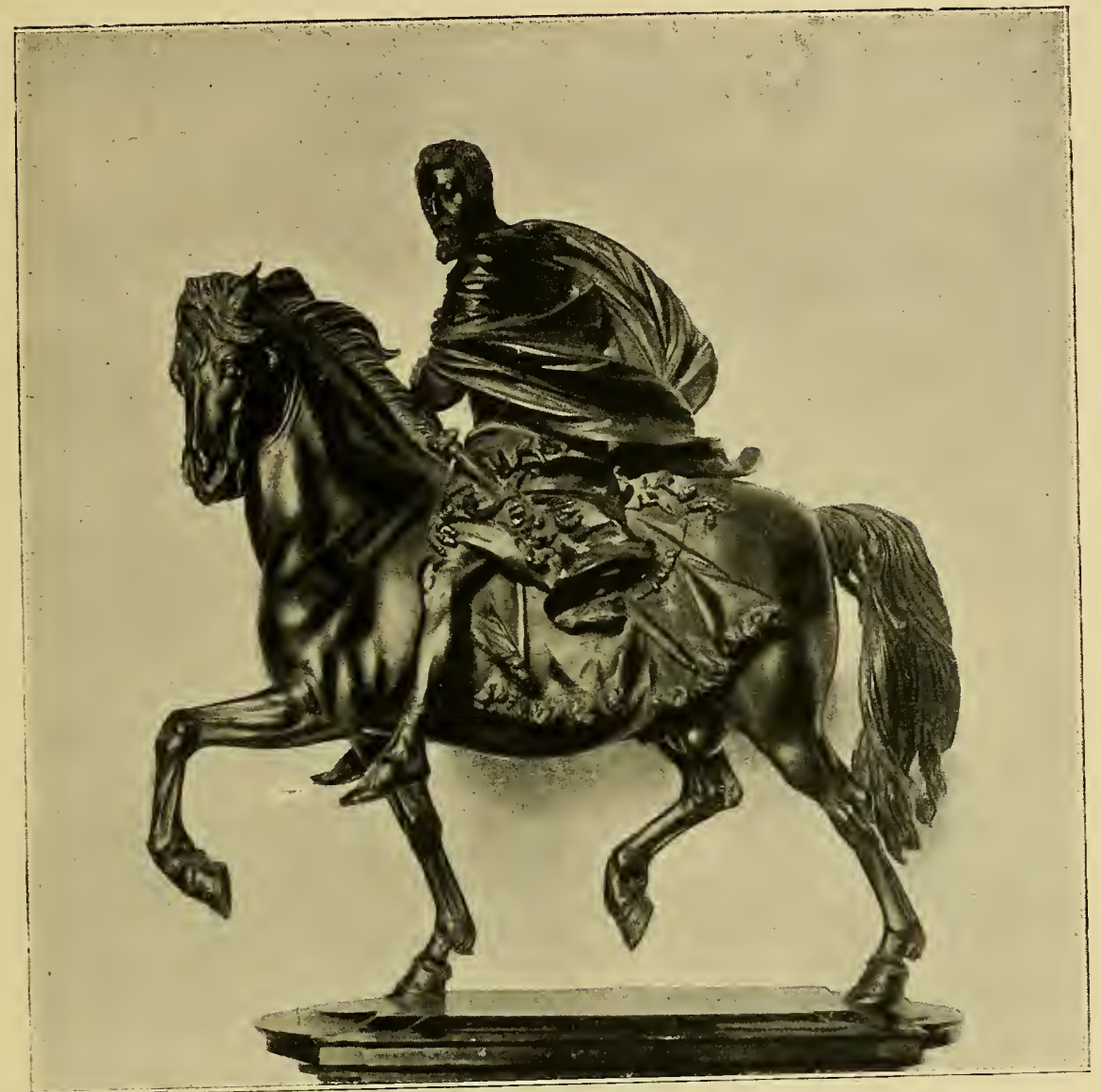

Francesco Mochi, Statua del Generale Carlo Barberini Collezione privata del Principe Barkerini.

nando lievemente il capo in atteggiamento benevolo, leva la destra con gesto di pacificatore, piì che di benedicente. Un ricchissimo manto, largamente drappeggiato, gli copre le spalle, scende dal braccio sollevato, risale a coprire le ginocchia, dando una vita e un'animazione straordinaria alla figura, mentre la sottostante veste ̀̀ tutta mossa da piegoline sottili che dànno al marmo il fruscio della seta. Il Bernini stesso riprodusse la statua, con poche varianti, e tradotta in bronzo, pel monumento 


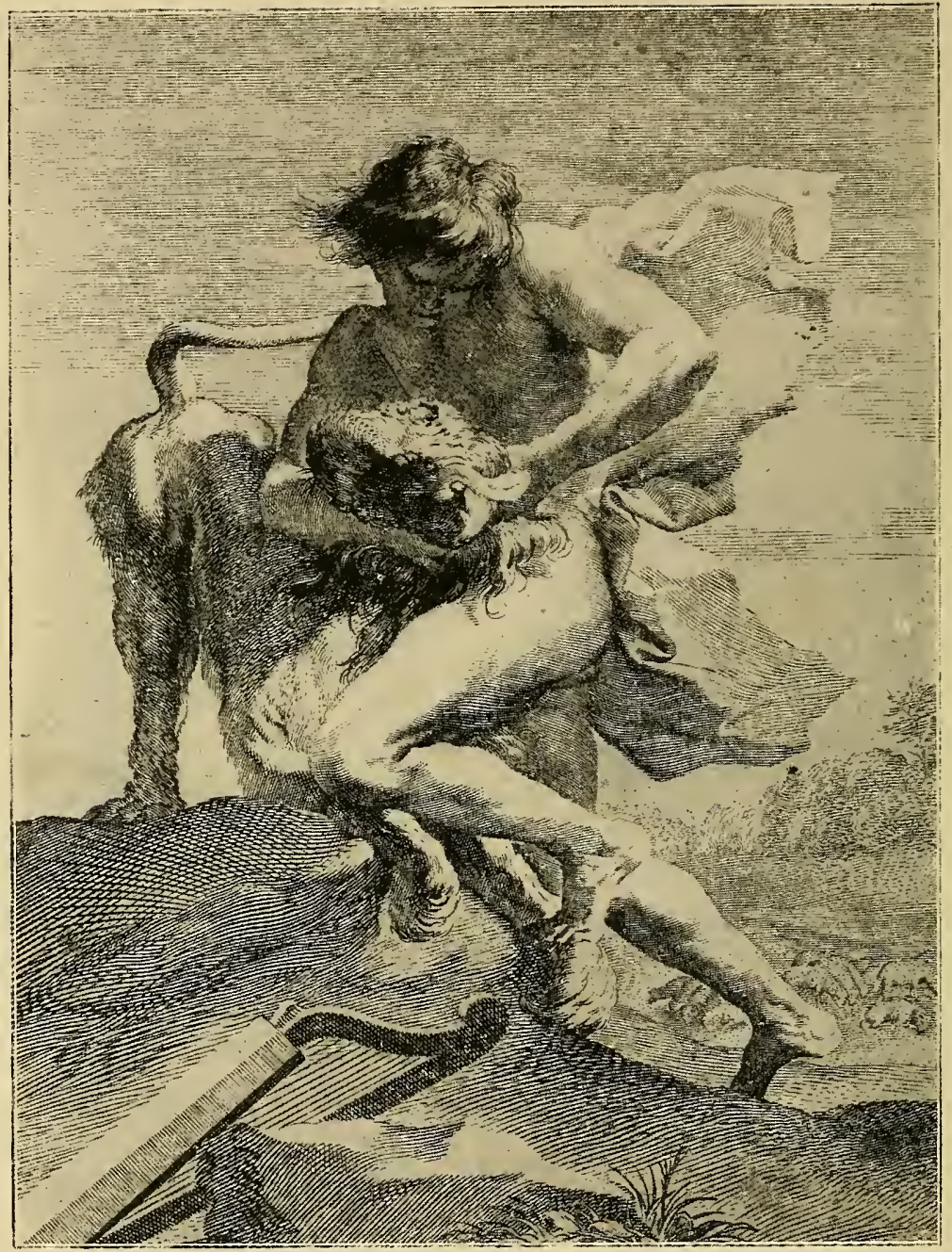

Bernini, David strozza il leone. Frontispizio dei Poemi di Urbano VIII.

funebre di papa Urbano che aveva iniziato fin dal 1628, ma che fu compiuto solo nel gennaio del 1647. Per questa grande opera, che è il capolavoro dell'arte funeraria del Seicento, il maestro si ispirò per lo schema generale dal sepolcro di Paolo III di Guglielmo della Porta, che egli stesso trasportò nel nicchione 


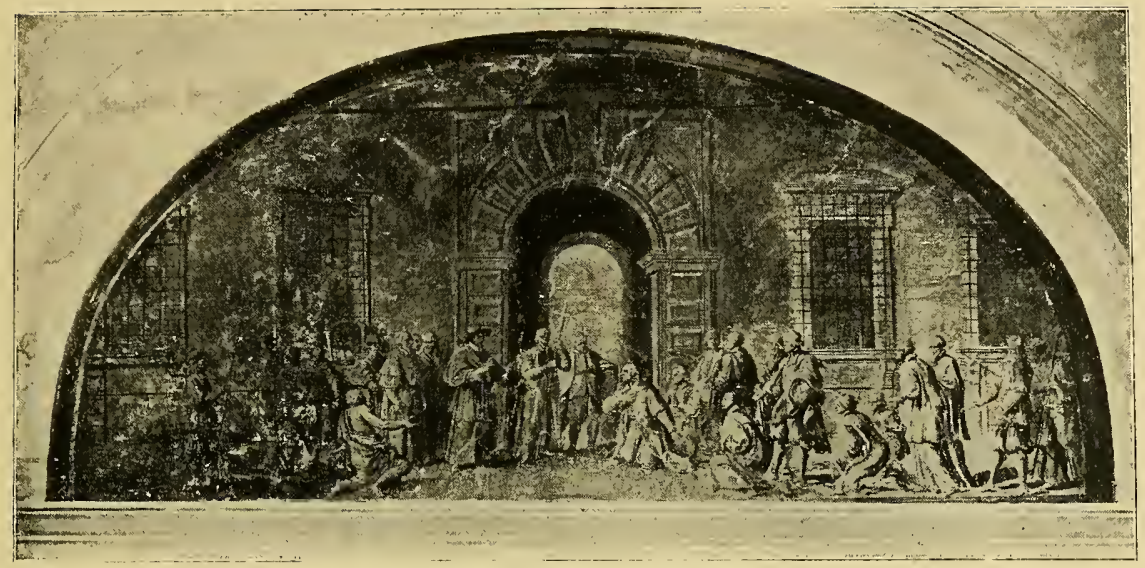

Urbano VIII fa visita al Bernini.

Dipinto nella casa dell'artista in via della Mercede.

di sinistra dell'abside, a riscontro di quello di Urbano che è a destra. Si tratta di un tipo di monumento del tutto nuovo, che non ha più, come i mausolei di S. Maria Maggiore carattere architettonico, ma presenta le varie figure libere, pittoricamente composte, senza nicchie, senza colonne divisorie, senza cornici. $\mathrm{Ma}$ se le linee generali delle due tombe sono le stesse, ben più nobilmente armonico è il sepolcro di papa Barberini, di quello del Farnese: il basamento più elevato non ha bisogno del secondo zoccolo, e la statua del papa vi posa sopra direttamente, e apparisce come una figura viva su un podio. Sulla parte anteriore sporgente, è collocato nel mezzo un prezioso sarcofago di marmo nero sul quale si appoggiano mollemente le due bianche figure della Giustizia e della Carità: queste hanno perduto ogni carattere ideale; sono sempre accompagnate dai tradizionali attribuiti, le verghe, le spade e le bilancie, e i putti, ma coi loro languidi movimenti sembrano due belle donne, che appartengono allo stesso mondo del sovrano che dall'alto del trono leva l'imperiosa destra sulla turba devota dei fedeli. 
Bernin si vivo il Grande Urbano à finto

E si ne' duri bronzi è l'alma impressa,

Che per torgli la fe' la Morte stessa

Sta sul Sepolcro a dimostrarlo estinto.

Così cantò l'ingegnoso cardinal Rapaccioli, e invero se il simbolico scheletro di bronzo dorato, che scrive nel suo libro il nome del defunto, non apparisse accoccolato tra le volute del

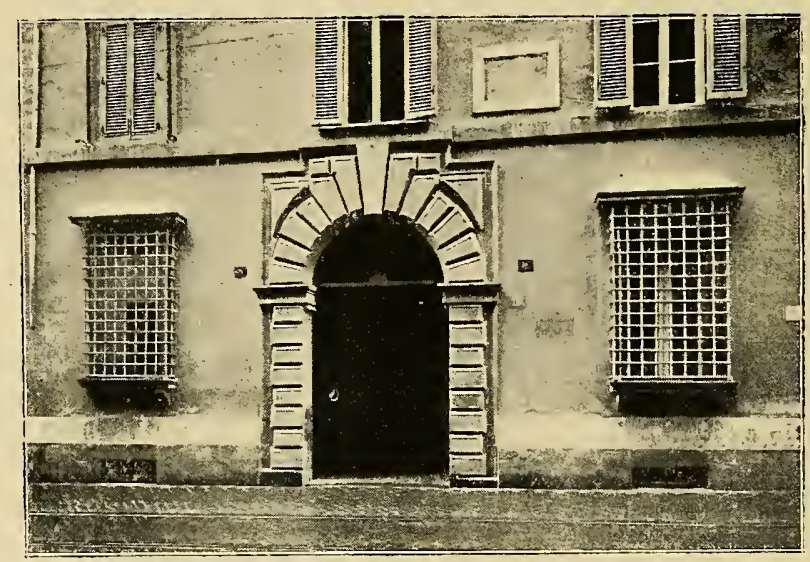

La casa del Bernini in via della Mercede, n. II.

sarcofago, non parrebbe questo un mausoleo funebre, ma un monumento d'onore elevato al più gran papa del secolo, tanto è viva e possente la figura di Urbano nel suo paludamento ricchissimo tutto splendente d'oro. $\mathrm{E}$ vive sono pure le due donne, e uscite finalmente dal mondo ideale ove fino a questo tempo venivano relegate le imagini allegoriche, prendono parte alla composizione, e non stanno più rigide e immote, ma esprimono liberamente e appassionatamente la loro commozione. "La Giustizia - uso le parole dell'acutissimo Baldinucci - appoggiata al sepolcro, coll'occhio alzato, immobilmente fisso verso la figura del Pontefice, pare assorta in profonda estasi di dolore; 
la Carità à in seno un lattante fanciullo, ed un altro maggiore appresso, che accennando anch'egli all'insì, dirottamente piange la perdita di quel gran Padre, mentre ella con pietoso sguardo volta verso di luí, pare che gli dia testimonianza del proprio dolore, e mostri di compatire al suo pianto ,"

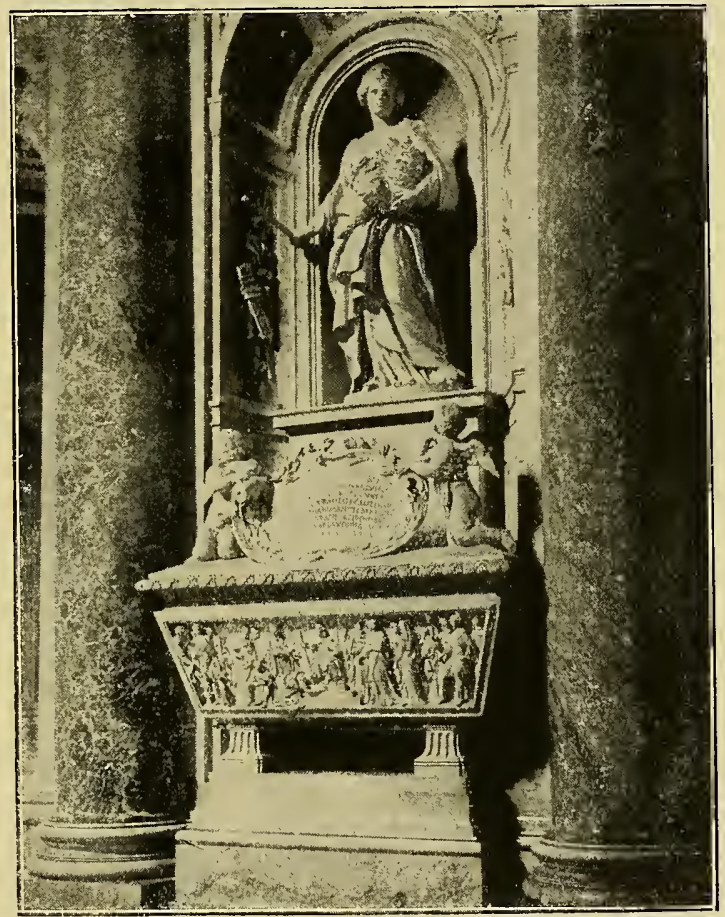

Bernini, Mausoleo della Contessa Matilde in S. Pietro.

(Fot. Anderson).

Col sepolcro di papa Barberini si afferma stabilmente la nuova forma del mausoleo papale, che durerà fino al Canova: non più un prospetto architettonico, ma un trono circondato di figure, non più un sacello ma un catafalco. Le colonne, i pilastri, le cornici, le nicchie, le cartelle, sono soppresse; non c'è più nessuna costrizione, nessuna delimitazione dello spazio; gli elementi dell'opera sono disposti in obbedienza a un concetto 


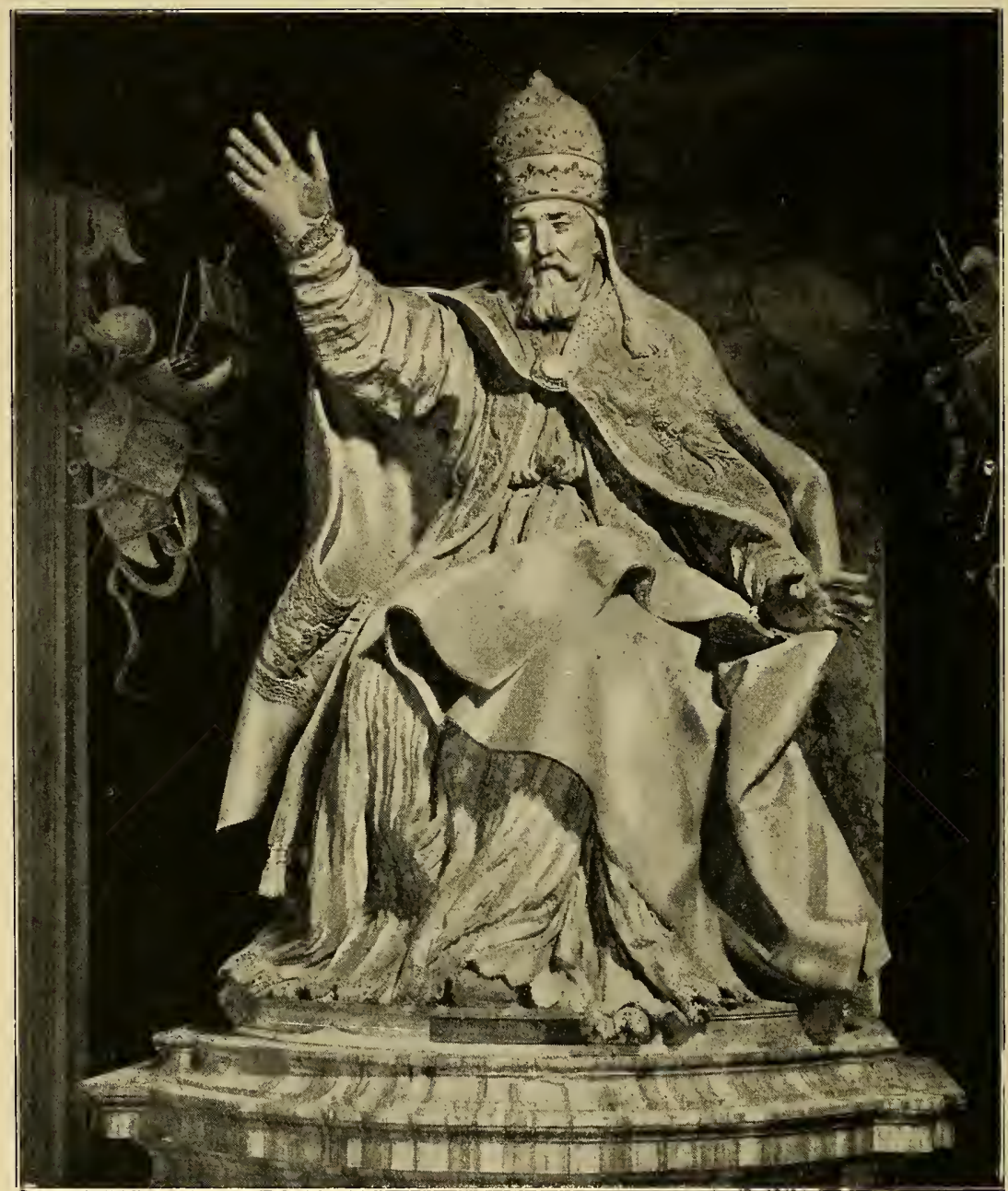

Bernini, Statua di Urbano VIII in Campidoglio.

(Fot. Alinari).

pittorico, non più subordinati, come decorazioni di un ordine architettonico. Urbano VIII non vide compiuto il mirabile mausoleo, che fu terminato quasi due anni e mezzo dopo la sua morte, avvenuta nel 1644, e così narrata dal diarista Giacinto Gigli: "A di 28 di Luglio tra le 10 et le 11 hora mori 


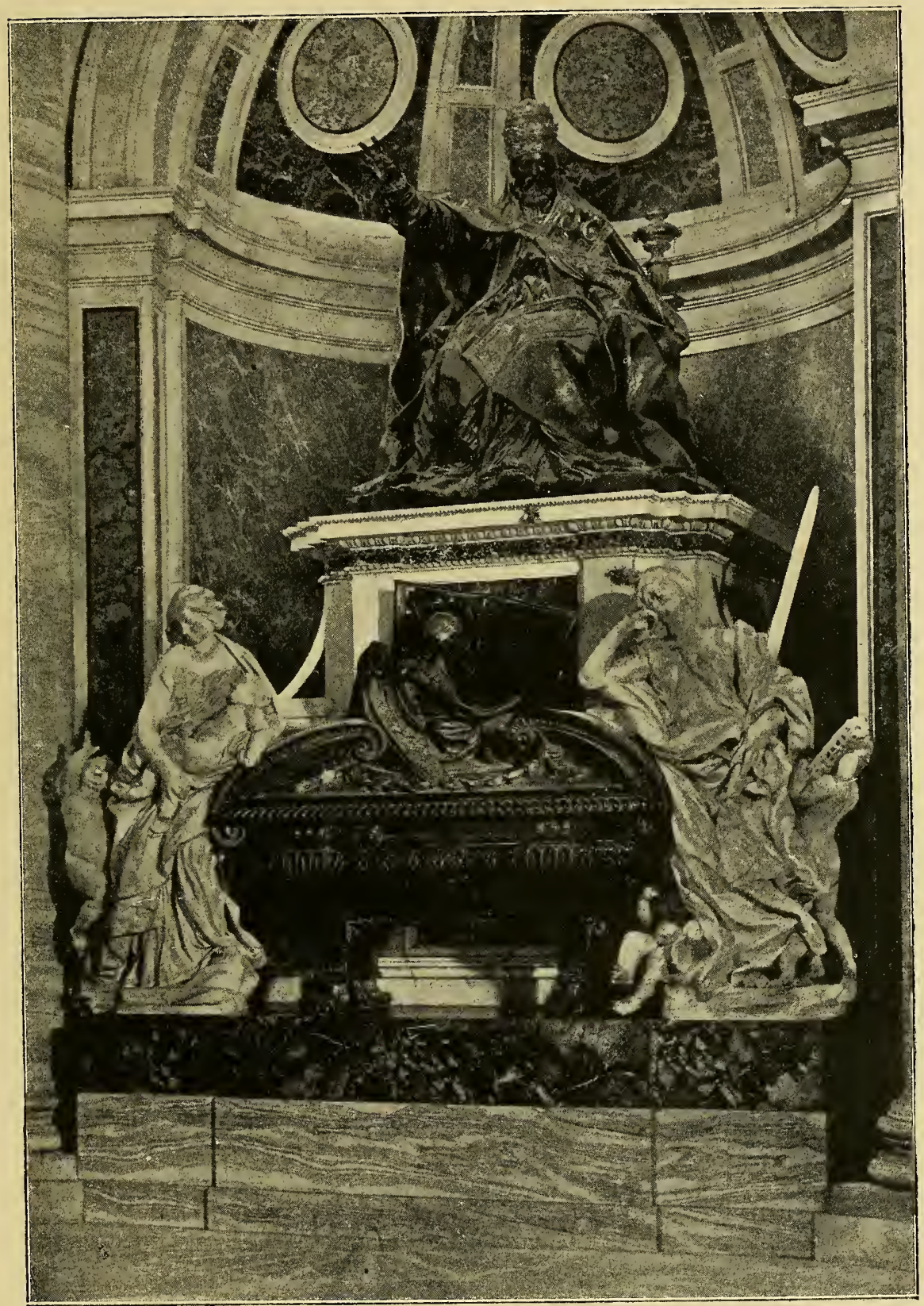

Berníni, Mausoleo di Urbano VIII in S. Pietro.

(Fot. Alinari). 
Papa Urbano VIII havendo seduto otto giorni meno di vintuno anno. Nel qual tempo si potrebbe dire, per un certo modo, che fussero stati doi Pontificati. Perciocchè mentre Urbano visse sano, che furno 14 o 15 anni, governò egli con molta prudenza, et se quando Ia prima volta si ammalò, fusse morto, sarebbe stato da tutti lodato, et riputato felice, et tra gli ottimi Pontefici commemorato. $\mathrm{Ma}$ poichè egli perse la sanità, governando per mezzo de' suoi nepoti, il Pontificato mutò faccia, et con le troppe Gabelle con le quali aggravò i popoli, et con l'infelice guerra, che fư per moltí lagrimosissima, si concitò l'odio contro di tutte le genti, tanto che horamai non ne potevano più, et sentendo che stava male, gli pareva ogni hora mill'anni di sentire che fusse spirato. Fu Urbano assai dotto in tutte le scienze, ma particolarmente nell'Arte Rhetorica et nella Poesia, $f u$ anche molto versato nell'Astrologia, ma la prohibì à gli altri, et accarezzò, o almeno non disprezzò gli huomini dottí et virtuosi. Hebbe egli una grandissima felicità perchè in tanto tempo accumulò tante ricchezze per i suoi Nipoti, quante mai non ha accumulate alcun Papa. Tutti li offitii et Benefitii desiderabili sono vacatí in tempo suo per i suoi Nepoti, et tutti quelli che gli erano nemici sono morti avanti di lui, ma in una cosa parve che non pensasse al futuro bisogno delli suoi, perciocchè non seppe mantenersi l'amicitia, et protettione delli Principi, laonde per diverse cagioni si fece malvolere dall'Imperatore, dal $\mathrm{Re}$ di Spagna, dalli Venetiani, et da tutti gli altri, et appena gli era restata la benevolenza di Francia ,.

Pasquino non risparmiò la memoria del pontefice, e poco dopo la sua morte fece correre per Roma un feroce epigramma:

Questo d'Urban si scriva al monumento: "Ingrassò l'api, e scorticò l'armento ",

E il popolo per sfogare la sua collera contro Papa Gabella non aspettò neppure che fosse spirato, per correre al Campidoglio 
ad abbattere la statua del Bernini. Ma trovò le porte serrate e difese; e allora, guidato da Monsignor Cesarini, un prete fanatico, nemico acerrimo di Urbano, andò al Collegio Romano e mandò in pezzi una statua di stucco del pontefice, ch'era nel cortile. "La verità è, dice l'Ameyden, che il Papa morì all'undici et un quarto, et alle dodici non c'era più statua „.

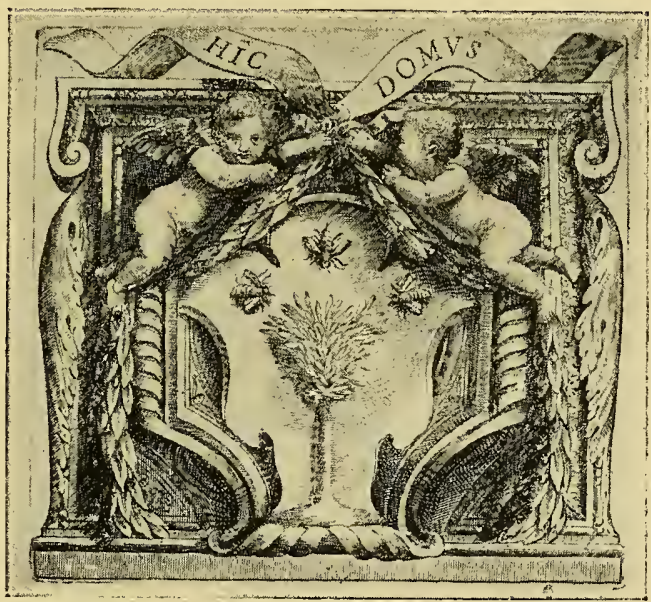




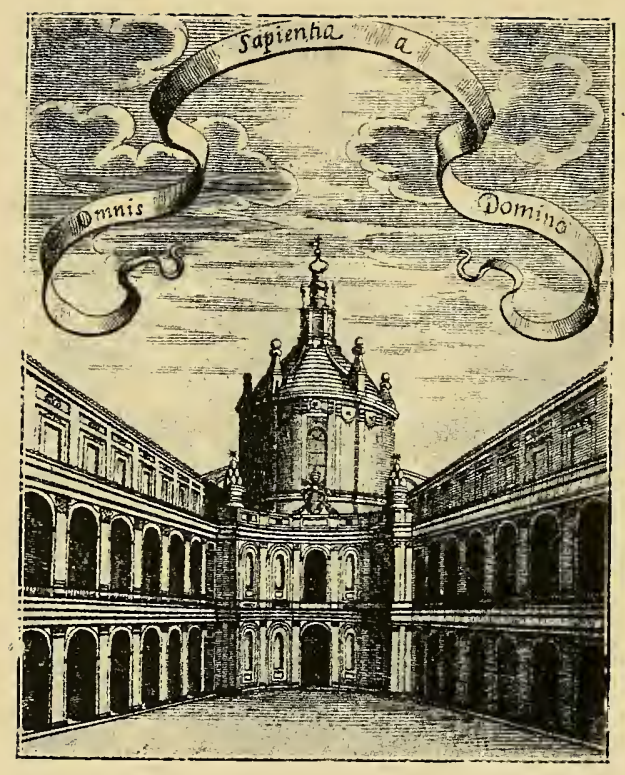




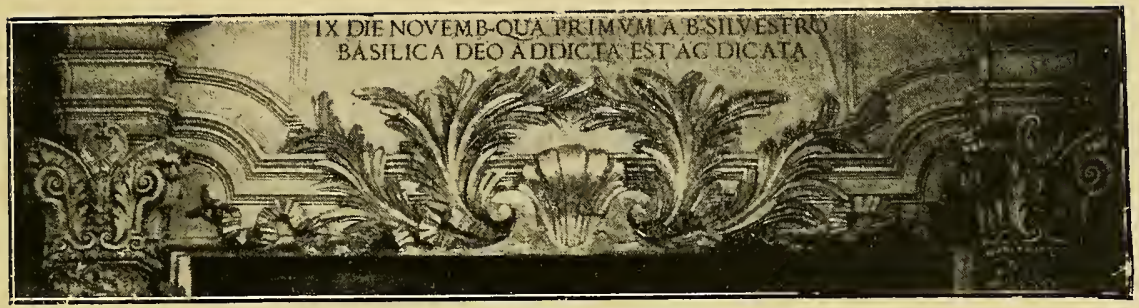

\section{CAPITOLO SETTIMO}

\section{BORROMINI}

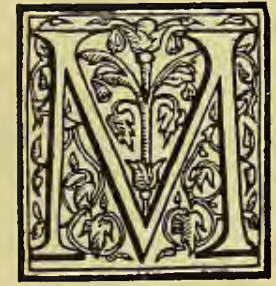

entre gli storici dell'arte continuano ad affannarsi intorno a certi maestri del Quattrocento che 1'Oblio giustamente aveva fatto cadere nell'ombra, mentre vengono riesumate le opere dei più poveri untorelli del così detto secolo d'oro, ci sono figure di purissimi genii, vissuti in altre età, che restano quasi ignote. Cosi Francesco Borromini, il grande rinnovatore dell'architettura del Seicento, il cui influsso da Roma si propagò dapprima rapidamente in tutta Italia, e poi in ogni parte dell' Europa cattolica, è ancora un dímenticato: i più ne parlano con disprezzo, perpetuando il giudizio parziale del Milizia e della scuola neoclassica, ma mostrano evidentemente di non conoscerlo; altri invece lo esaltano, ma non lo conoscono in realtà neppur essi. Del resto nelle stesse condizioni di ignoranza completa la critica si trova di fronte a quasi tutta l'arte barocca, specialmente all' architettura e alla scultura; chi conosce Carlo Maderno, Giambattista Soria, i due Rainaldi, Pietro da Cortona, Carlo Fontana, e lo stesso Bernini come architetto? 
E senza conoscere, e bene, la storia dell' architettura del Seicento in Italia, è impossibile valutare con esattezza l'arte di Francesco Borromini, intendere la vasta rivoluzione che essa ha esercitato, misurare $i$ confini di spazio e di tempo del suo in-

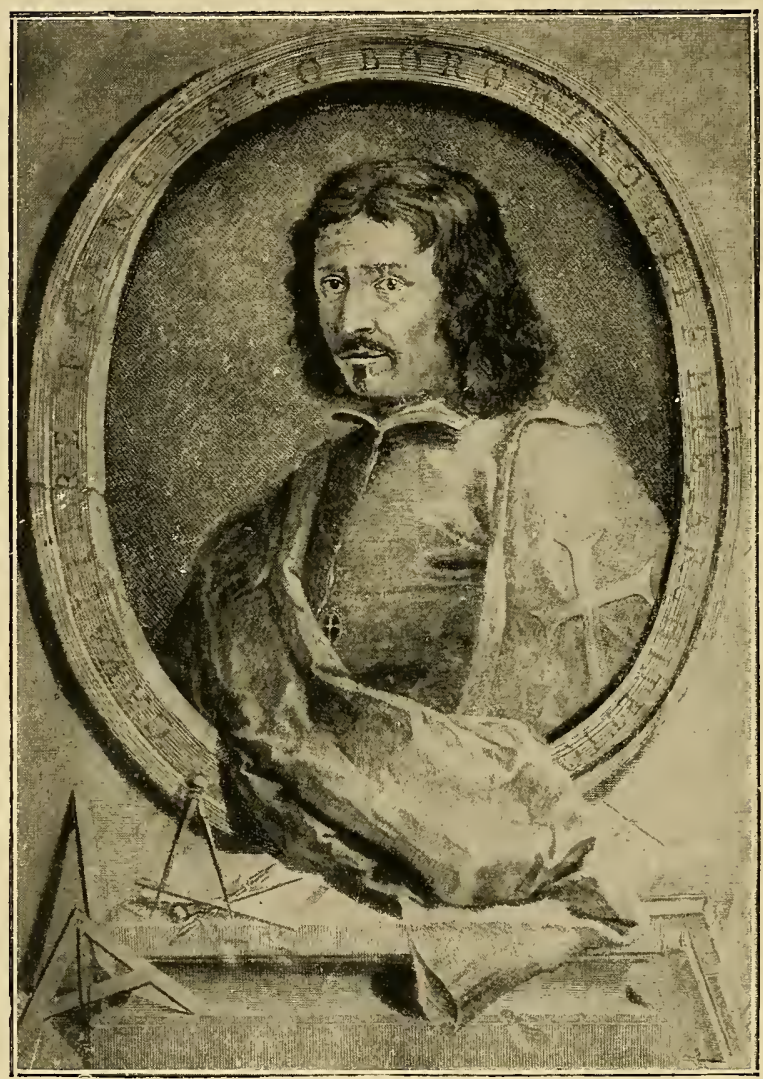

Ritratto di Francesco Borrominí.

flusso. Quando si approfondiscano le ricerche e si eserciti l'indagine sull' arte barocca, si riconosce che quest'influsso è stato immenso, quale forse nessun altro maestro esercitò mai, perchè se Giotto e Michelangelo hanno dominato un intiero secolo, questo fu il loro, mentre Borromini ci appare come un precursore: egli muore nel 1667 , ma le derivazioni dell' arte sua 
sono quasi tutte del secolo successivo; il Settecento in Italia e fuori si può quasi definire come scuola borrominiana, e ci sono opere del maestro che a prima vista si direbbero settecentesche; San Carlino alle Quattro Fontane che è del 1638-41 si daterebbe volentieri verso il 1720 ; i soffitti del palazzo Falconieri si son

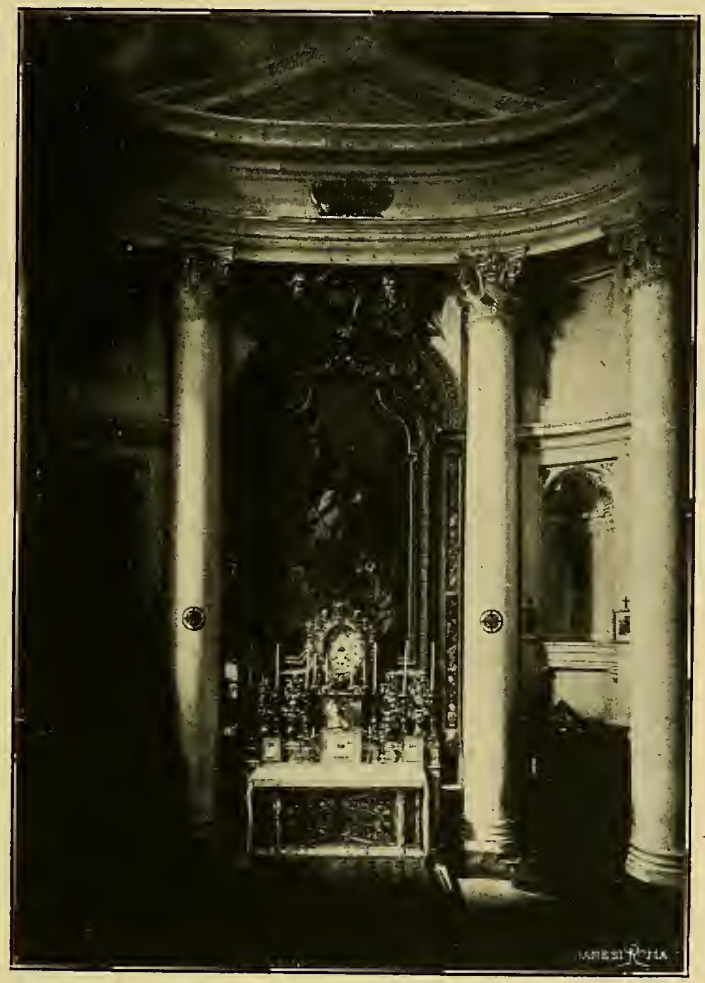

Borromini, Interno di S. Carlino.

creduti sino a poco tempo fa eseguiti nel secolo XVIII. Perchè è in questo periodo che le opere del Borromini trovano il loro ambiente, la loro cornice, le loro rispondenze nel gusto generale, le loro consonanze con il costume, col teatro, con la musica, con la poesia. Pensiamo, per esempio, quanto grande fu l' amore degli architetti barocchi per la policromia, che dal 
principio del Seicento, da quando Flaminio Ponzio parò a festa con drappi di alabastro, di broccatello, di breccia, la cappella Paolina di S. Maria Maggiore (1611), si va facendo sempre più viva, come nella cappella di S. Teresa del Bernini (1647), o negli altari di fratel Pozzo, in cui i marmi e i metalli più ricchi compongono una sfolgorante sinfonia con l'oro degli stucchi $e$ il verde serpentino delle malachiti. Tutti i maestri del Seicento adoperano insieme con la squadra e coi compassi il pennello e la tavolozza, e spogliano dei marmi preziosi i monumenti antichi, o rimettono in attività le vecchie cave abbandonate e ne trovano di nuove, cosi che accanto al giallo, al verde, al rosso antico, all' africano, alla portasanta, al cipollino, alle lumachelle, alle brecce, vediamo apparire il simpatico cottanello delle colonne di S. Pietro, il diaspro di Sicilia, il rosso di Francia, il giallo di Siena, il rosso di Verona, il lapislazzulo, la breccia dei Pirenei.

Questi materiali vivacissimi si stendono a terra nei pavimenti, che paion tappeti orientali, salgono a rivestire pareti $e$ pilastri, decorano altari, tabernacoli e persino monumenti funebri, e arrivano alle vôlte, dove trovano altri accordi nelle pitture e negli stucchi dorati. Ebbene, a tali mezzi rumorosi, a tali ricerche di effetto il Borromini non ricorre mai; il bianco candido del marmo o dello stucco, e il grigio del travertino o della cortina di mattoni, sono i soli colori della sua tavolozza; appena in S. Agnese adopera, negli smussi dei piloni, colonne di cottanello, se pure queste non vennero aggiunte dai suoi successori, e nelle nicchie degli apostoli in S. Giovanni, un po' di verde e di bardiglio; ma il bianco, il colore del Settecento, è il suo tono preferito.

Del resto non soltanto nel campo dei colori Francesco Borromini batte una via a sè; egli fu in ogni manifestazione sua un originale, un solitario, nell'arte come nella vita. Anche nei momenti felici della sua esistenza rifuggì rumori ed onori, 
visse appartato, lontano dalla corte papale, non cercando ricchezze, rifiutando onorevolissimi incarichi, come quello di fornire disegni al re di Francia pel palazzo del Louvre. Ed ecco perchè di lui, della sua vita privata, non sappiamo quasi niente, e non

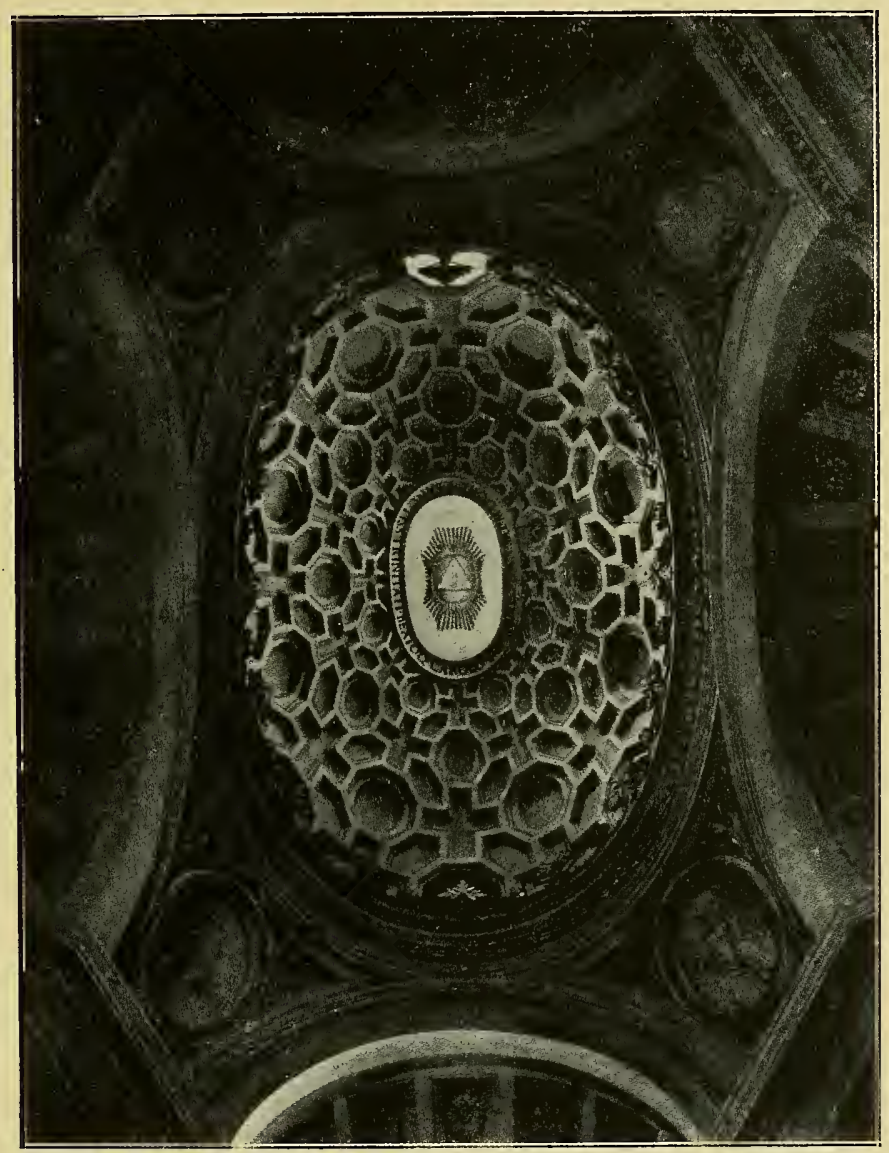

Borromini, Cupola di S. Carlino.

(Fot. Alinari).

ci son pervenute sue lettere, e carte in genere che lo riguardino, mentre conosciamo aneddoti, episodii, pettegolezzi, e abbiamo documenti a sfascio intorno al Bernini. Borromini non fu del suo tempo come artista e come uomo, differenziandosi dagli 


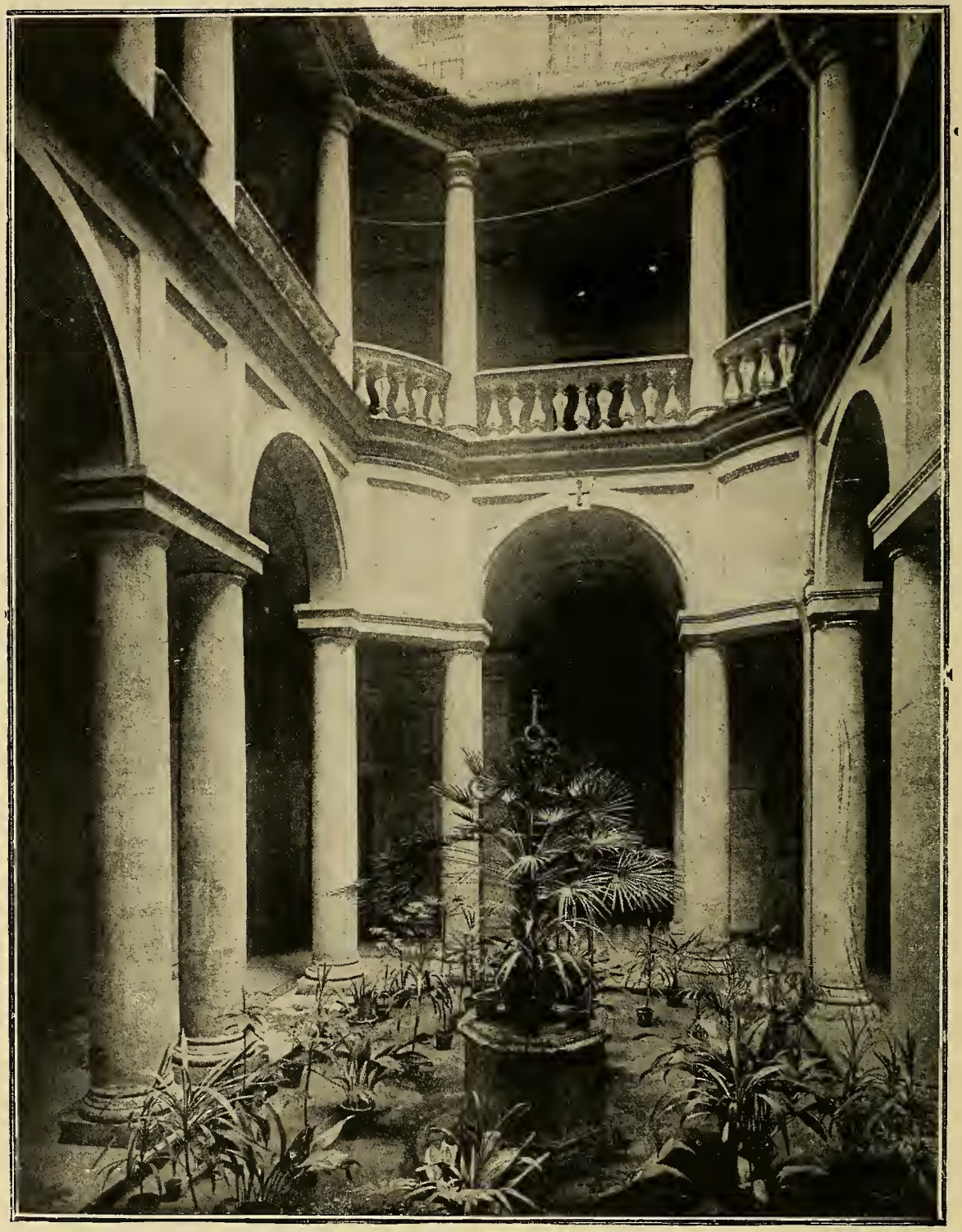

Borromini, Chiostro di San Carlino. 


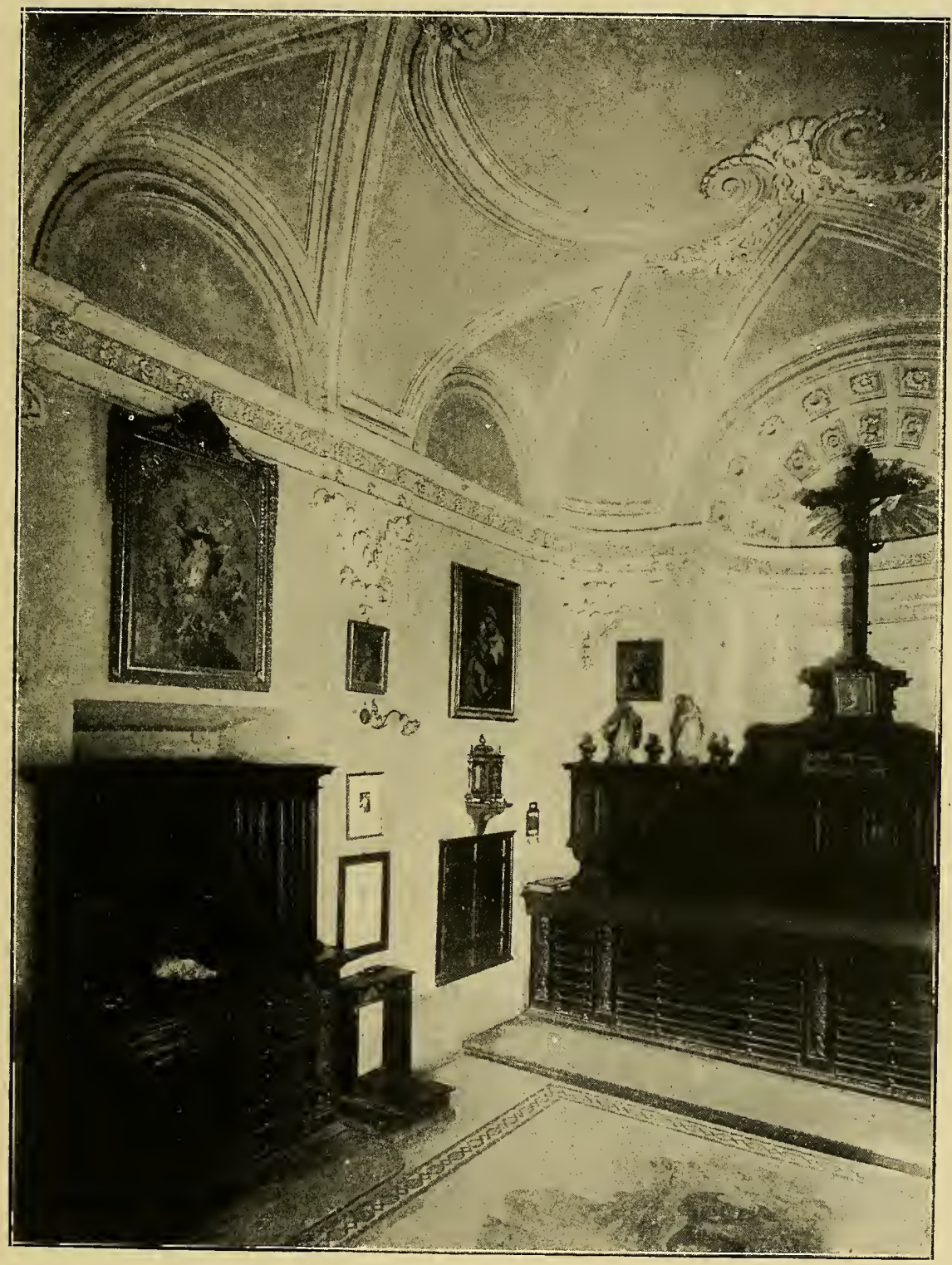

Borromini, Sagrestia di San Carlino. 
altri persino nel vestire: " si rese sempre una figura da esser particolarmente osservata, perchè volle del continuo comparire col medesimo portamento, e abito antico, senza voler seguire le usanze, come si pratíca giornalmente; usò la randiglia alla spagnuola, e le rose tonde alle scarpe, e nella medesima foggia le legaccie alle gambe „. Così scrisse un biografo, il Passeri; e Filippo Baldinucci, che per quanto riguarda il Borromini appare assai bene informato, ci dice che il maestro pativa molto " $d$ 'umore malinconico, o come dicevano alcuni de' suoi medesimi, d'ipocondria, a cagione della quale infermità, congiunta alla continua speculazione sulle cose dell'arte sua, in processo di tempo egli si trovò sì profondato $e$ fisso in un continuo pensare, che fuggiva al possibile la conversazione degli uomini standosene solo in casa, in null'altro occupato che nel continuo giro de' torbidi pensieri, che alla sua mente somministrava del continuo quel nero umore: ed erasi ormai ridotto a tale, che il mirarlo solamente era una compassione, e per lo stralunar d'occhi, e '1 guardar ch' e' faceva, lanciando di punto in punto occhiate spaventose, che mettevano altrui gran terrore „.

Il suo confessore, padre Callera, non lasciava di confortarlo, ma inutilmente, aggiungendosi alla ipocondria anche un "grande affanno, che pareva procedere da alterazione allo stomaco "; un giorno nell' estate del 1667 il Borromini in una delle sue smanie diede alle fiamme tutti i suoi disegni, notizia confermata del fatto che oggi ne restano pochissimi di suoi nelle collezioni pubbliche e private. Nella notte sul due agosto dello stesso anno, I'infelice maestro, stando in letto, contrariato dal suo servitore che obbedendo all'ordine del medico gli rifiutava il lume, si trafísse con uno spadino, e il giorno dopo mori. Intorno al suicidio del Borromini molto si è favoleggiato, attribuendosene persino la causa alla lotta che contro di lui avrebbe fatto il Bernini; giova quindi riportare l'interrogatorio che al ferito fu fatto subire dal giudice criminale. 


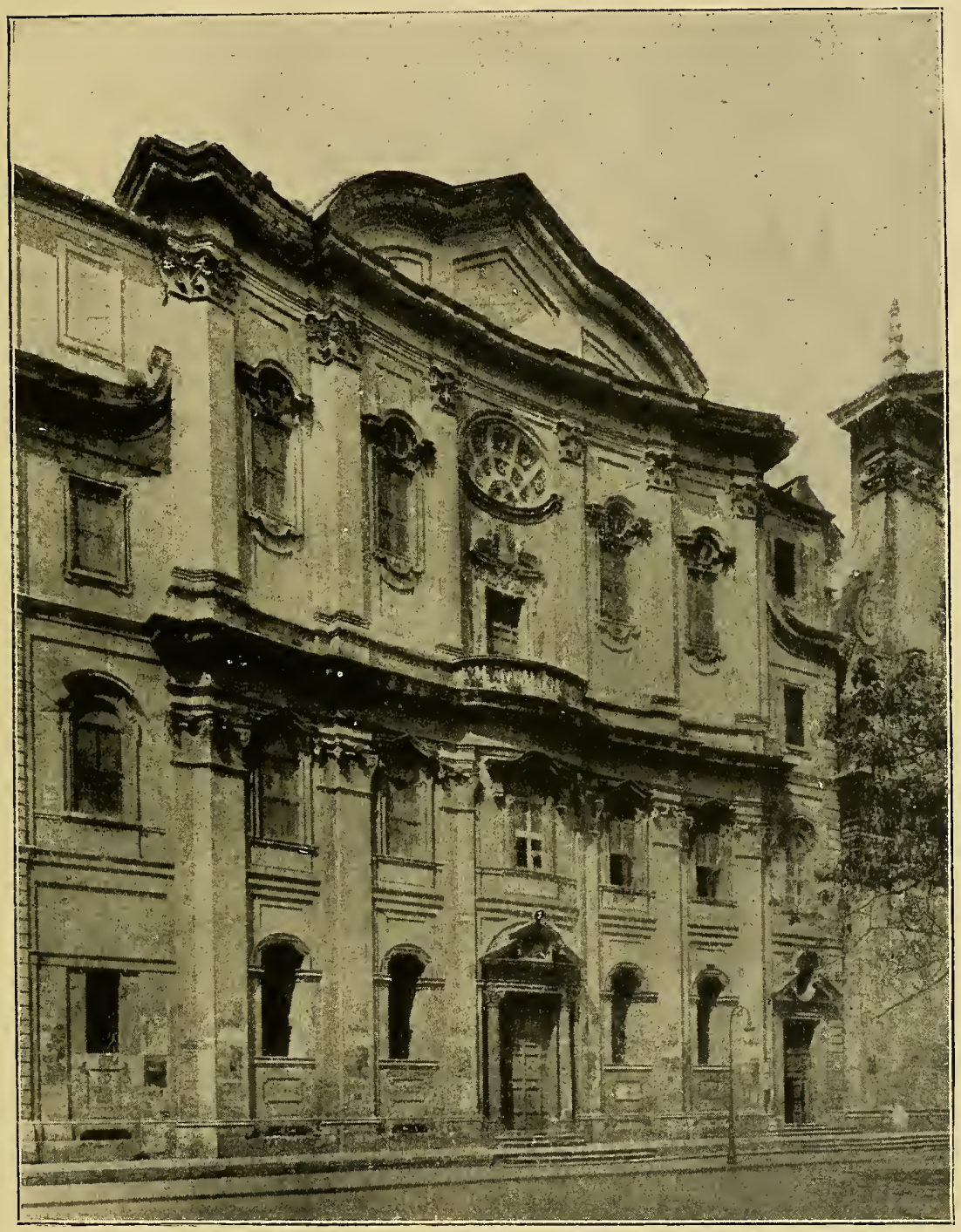

Borromini, Facciata dell' Oratorio di S. Filippo. (Fot. Anderson). 
"Interrogatus quomodo et a quando reperiatur sic vulneratus : Io me ritrovo cosi ferito da questa mattina dall'otto hore e mezza in qua in circa sul modo che dirò a V. S. et è che ritrovandomi io ammalato dal giorno della Maddalena in qua, che non sono più uscito eccetto lo Sabbato e Domenica che andai a S. Giovanni a pigliar il Giubileo, stante detta mia indispositione, hier sera mi venne in pensiero di far testamento e scriverlo di mia propria mano, e lo cominciai a scriverlo che mi ci trattenni da un' hora in circa doppo che ebbi cenato $e$ trattenutomi cosi scrivendo col tocca lapis sino alle tre hore di notte incirca; M. Francesco Marsari, che è un giovane che mi serve quì in casa et è capomastro della fabbrica di S. ${ }^{\text {to }}$ Giovanni Fiorentini, della quale io sono architetto, che se ne stava a dormire in questa altra stanza per mia custodia, che già si era andato a letto; sentendo che io ancora stava scrivendo et havendo veduto che io non havevo smorzato il lume, mi chiamò con dire: Signor Cavaliere è meglio che V. S. smorzi il lume et se riposi perchè è tardi ed il medico vuole che V. S. riposí. Io gli risposi come io haverei fatto a riaccendere il lume per quando mi fussi svegliato et esso me replicò: lei lo smorze perchè io l'accenderò quando V. S. si sarrà risvegliato; e così cessai di scrivere, messi da parte la carta scritta un poco et il toccalapis col quale scriveva; smorzai il lume e mi mesi a riposare. Verso le cinque in sei hore incirca essendomi risvegliato ho chiamato il suddetto Francesco e gli ho detto: è hora di accendere il lume, et mi ha risposto: signor no. Et io havendo sentita la risposta mi è entrata adosso l'impatienza; subito ho cominciato a pensare se come potevo fare a farmi alla mia persona qualche male, stante che il detto Francesco mi havesse negato di accendermi il lume et in questa opinioue sono stato sino all'hotto hore e mezza in circa, finalmente essendomi ricordato che avevo la spada qui in camera a capo al letto et appesa a queste candele benedette, 


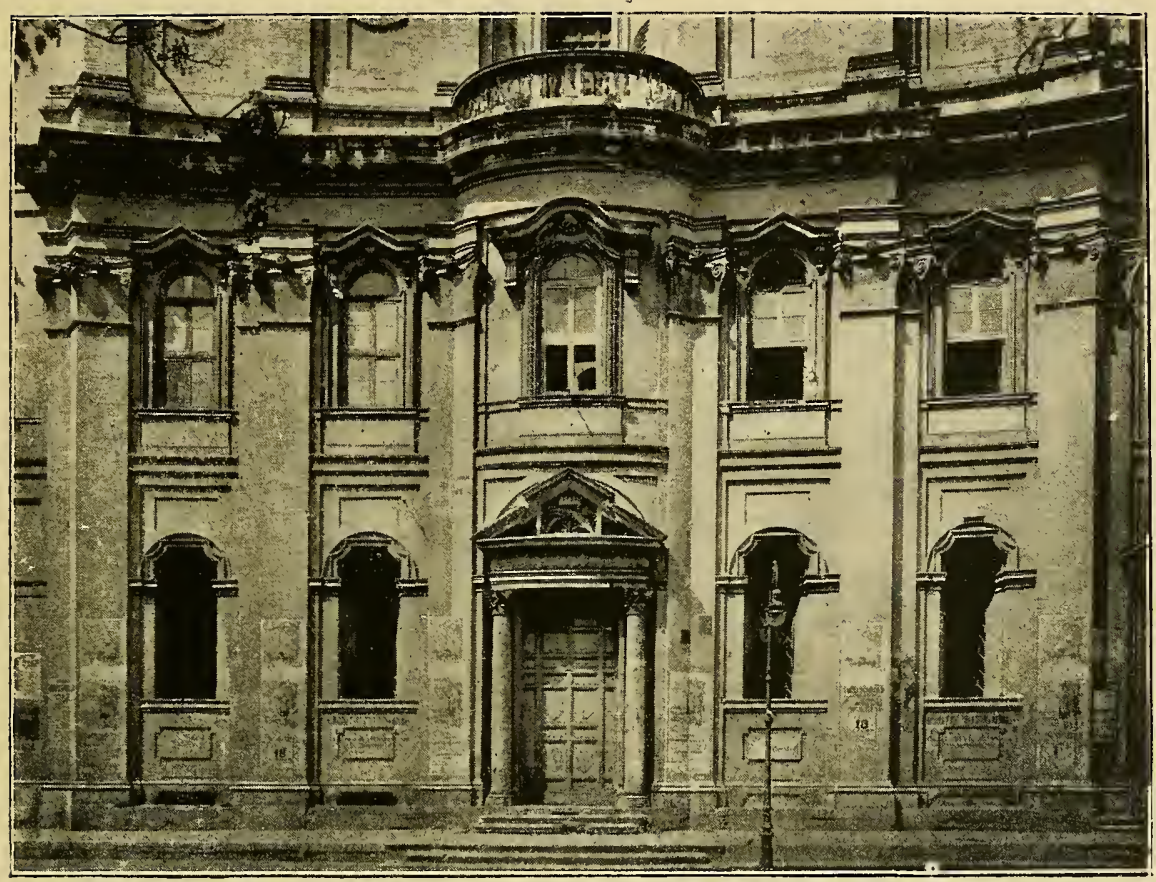

Borromini, Primo ordine della facciata dell’Oratorio.

essendomi anco accresciuta l'impatientia di non havere il lume, disperato ho preso la detta spada quale havendola sfoderata, il manico di essa l'ho appuntato nel letto e la punta nel mio fianco e poi mi sono buttato sopra di essa spada dalla quale con la forza che ho fatta acciò che entrasse nel mio corpo sono stato passato da una parte all'altra e nel buttarmí sopra la spada sono caduto con essa spada messa nel corpo quaggiù nel mattonato $e$ feritomi come sopra ho cominciato a strillare et allora è corso qua il detto Francesco et ha aperto le fenestre che già si vedeva lume, me ha trovato colco in questo mattonato, che da lui e certi altri che lui ha chiamati mi è stata levata la spada dal fianco e poi sono stato rimesso a letto et in questa conformità è successo il caso della mia ferita . 
Il grande rivoluzionario dell'architettura, l'artista ricco di pensiero, che in ogni sua opera accumulò con inesauribile vena motivi nuovi e originali, che si inseguono e si accavallano,

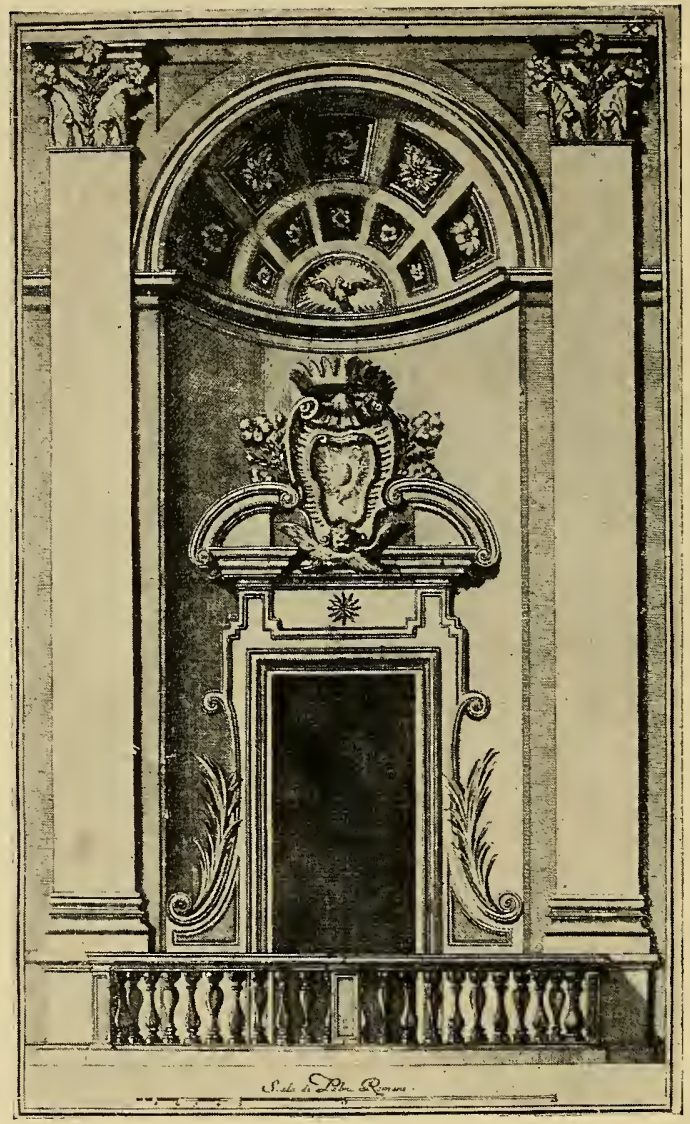

Borromini, Loggia dell'Oratorio.

come le immagini nella poesia del cavalier Marino, ebbe umilissimi principii: fino a trent'anni fu semplice scalpellino. Era nato a Bissone, il paese che tanti suoi figli ha dato per più secoli all'arte italiana, dai Gagini a Carlo Maderno, il 25 settembre 1599; suo padre era Domenico Castelli, architetto di casa Visconti, e il 


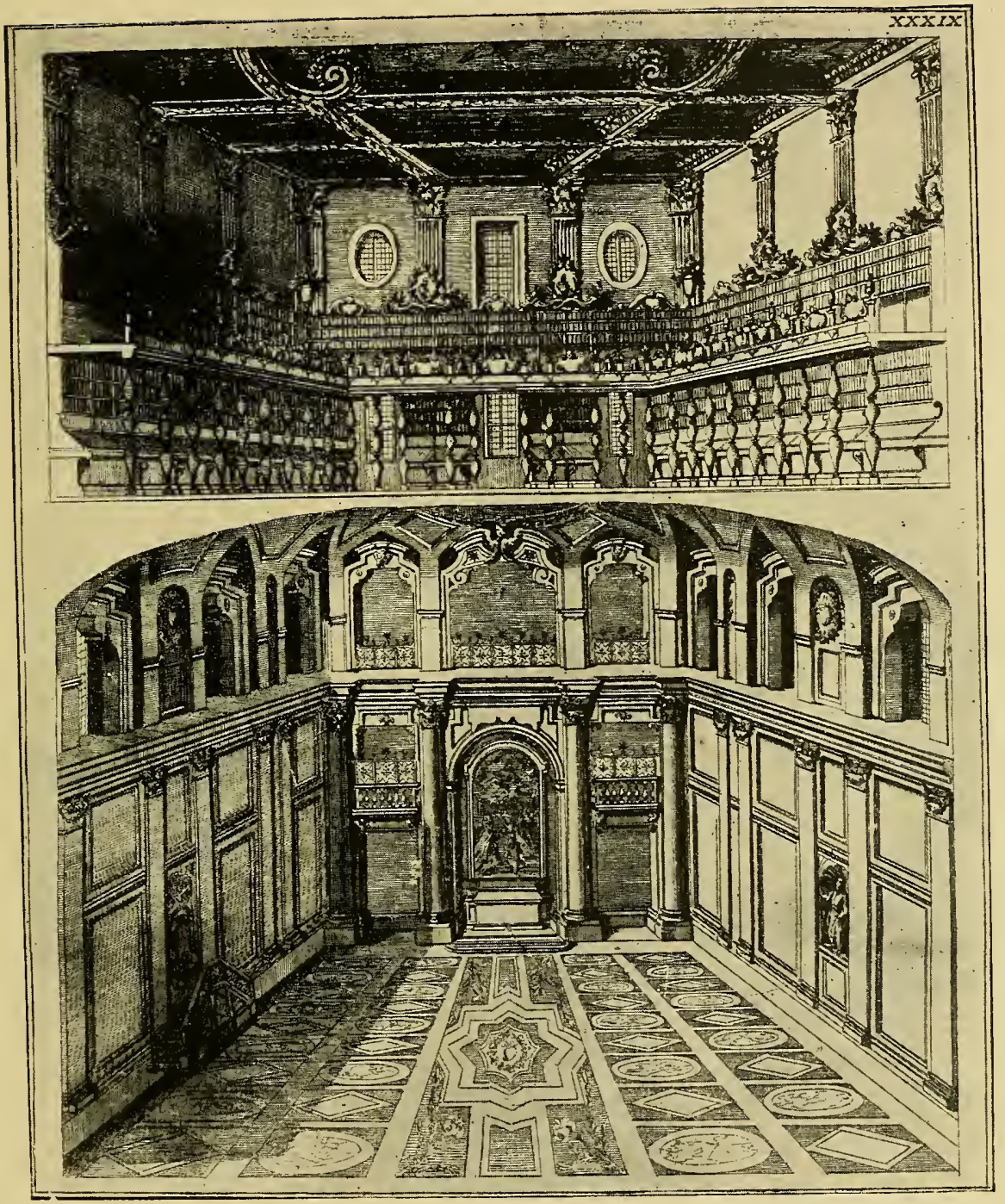

Borromini, Interno dell'Oratorio e della Biblioteca dei Filippini.

figliolo pure dapprincipio si chiamò Francesco Castelli; il cognome di Borromini, forse materno, lo prese verso il 1628. A quindici anni Francesco fuggì da Milano dove studiava come scultore, e venne a Roma, ad insaputa del padre, allogandosi presso il 
suo congiunto e paesano Lione Garogo, mastro scarpellino che lavorava alla fabbrica di S. Pietro: era il 1614 circa, quando si compiva la facciata del Maderno e si lavorava nel portico. Questo ci dicono i biografi concordemente; e infatti i documenti dell'Archivio della Basilica Vaticana confermano che dal 1611 al 1620 lo scalpellino Lione Garo o Garuo, lavorava ai capitelli grandi della facciata e nel porticale, e a varie opere d'intaglio dentro la chiesa. Questo modesto artigiano introdusse nella fabbrica, ove allora per impulso di Paolo $V$ ferveva il lavoro, anche il giovane Borromino, il cui nome apparisce però nei registri per la prima volta solo il 7 gíugno 1624, perchè si vede che sino ad allora era semplice aiuto del Garcuo, che riscuoteva i denari per lui. Le opere che Francesco Castello scarpellino fece per la basilica sono umilissime: la base della Pietà di Michelangelo, la balaustrata dell'altare del coro, scalini e stipiti di porte, stemmi e capitelli. Carlo Maderno, architetto della fabbrica, nativo anche lui di Bissone, e, pare, lontano parente del giovine scarpellino, firmava i suoi conti, e al dir dei biografi antichi, avendo riconosciuto il suo merito, lo adoperava per mettere in pulito i suoi disegni. Quando il Maderno morì (10 gennaio 1629), e nella carica di architetto di S. Pietro gli successe il Bernini, Francesco Castello continuò i suoi lavori negli altari sotterranei delle reliquie, nei piloni della cupola, nelle incrostature dei piloni stessi, nelle porte che dalla basilica vanno in Vaticano. Dall'aprile del 1631 lo vediamo salito in dignità; non è pì̀ intento a lavori da semplice tagliatore, ma fa "disegni grandi dell" opera di metallo", ossia del mirabile baldacchino di bronzo che su disegno del Bernini si erigeva sulle tombe degli Apostoli; in tale lavoro lo troviamo occupato fino al 22 gennaio 1633 quando nei registri si incontra questa nota: "A Francesco Castelli scudi venticinque moneta per il presente mese di Gennaio acciò disegni in grande tutte le centine, piante, cornici, fogliami et altri intagli che vanno dentro 


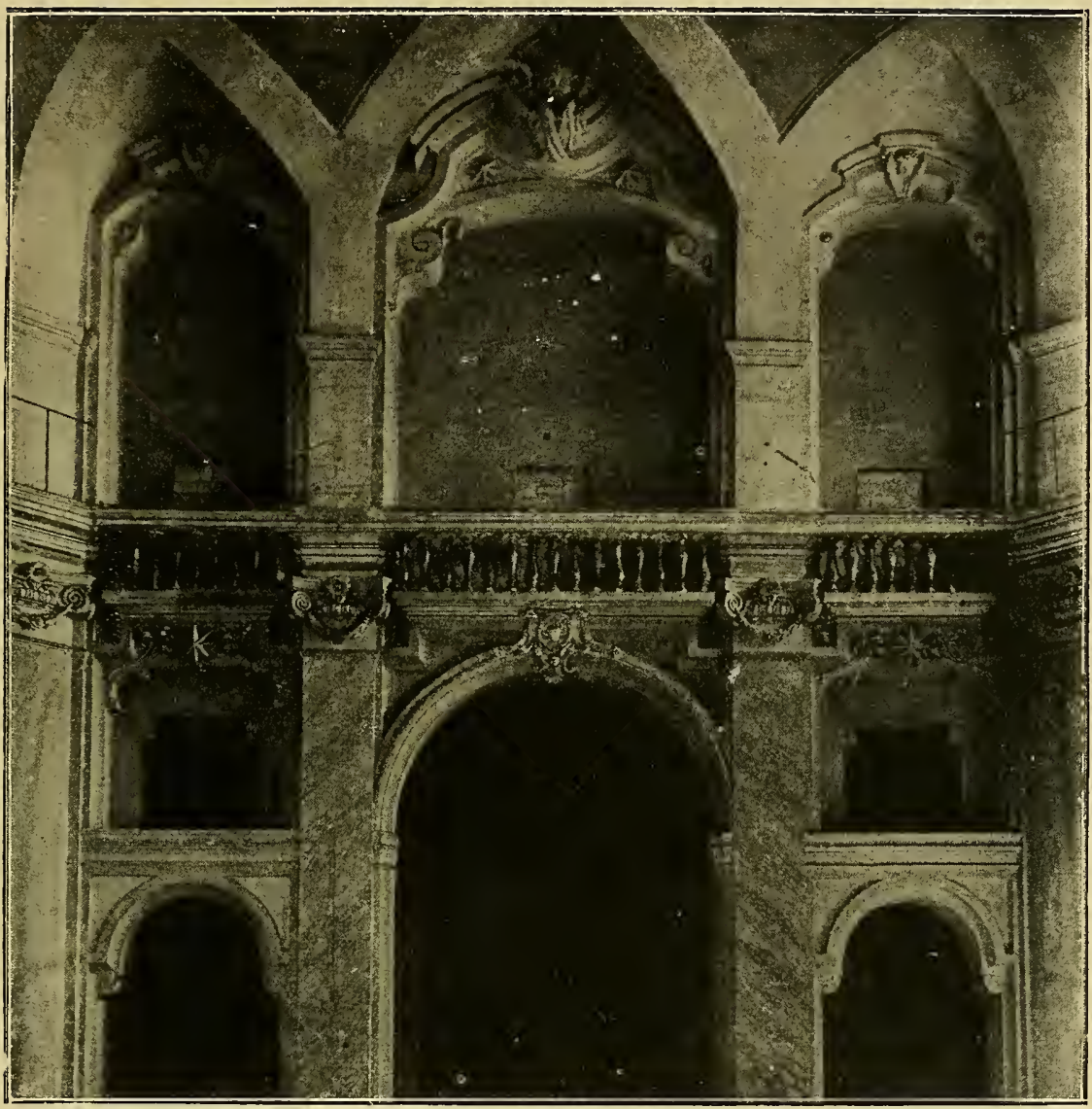

Borromini, Particolare dell’Oratorio dei Filippini.

alle costole et cimase, et di più sia obbligato a segnarli su lí rami e renderli acciò li falegnami et quelli che battono il rame non possino errare „. Per un conto è questa una formula inusitata; è chiara in essa l'intenzione di specificare bene gli obblighi del maestro, quasi dubitando che egli voglia sottrarvisi, e credo che qui si abbia la prova dei dissapori tra il Bernini e il Borromini, il quale sentiva ormai spuntarsi le ali, e mal si sottometteva a lavori cosi modesti ; è quella l'ultima volta che il suo nome appare nei registri della Fabbrica di S. Pietro. 
Questo duro tirocinio del Borromini come semplice scalpellino, non fu privo d'importanza nello svolgimento dell' arte sua di architetto; abituato a lavorare il marmo, a scolpire i particolari ornamentali, ad intagliare capitelli e cornici, a scavare gusci e dentelli, a segnare modini, il maestro rimase sempre in tutta la sua lunga carriera un conoscitore $e$ un amante

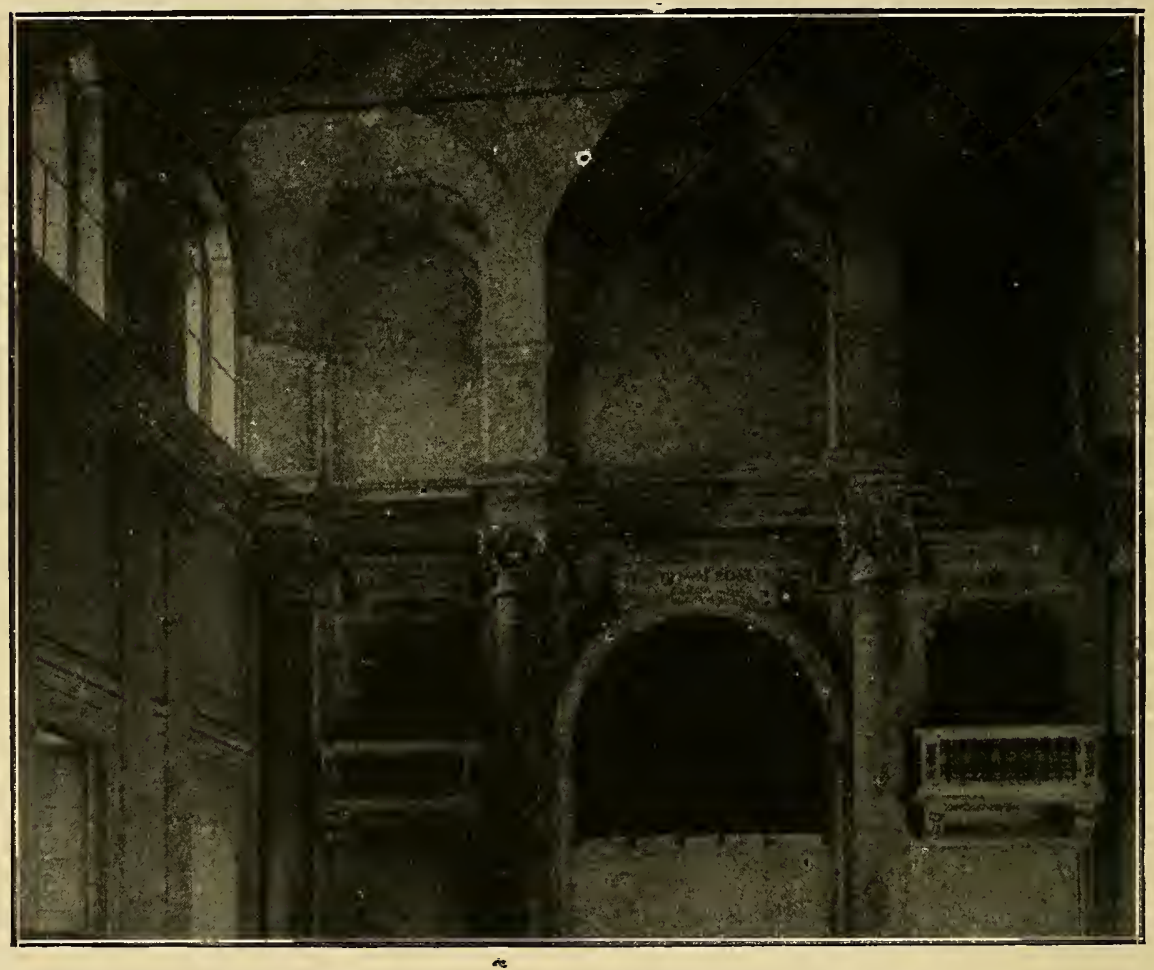

Borromini, Particolare dell'O:atorio dei Filippini.

della pietra, uno studioso cercatore del dettaglio. Il Bernini, architetto venuto dalla scultura e dalla pittura, è più bozzettista; si limita a dare con rapidi schizzi il piano e i profili di una fabbrica, e lascia poi le minori rifiniture alla mano dei suoi aiuti e degli esecutori, per cui tutte le opere sue non hanno quasi mai finezza di particolari. Invece Borromini non dimentica mai 
di esser stato scalpellino, e con paziente amore si occupa dei più piccoli elementi decorativi, e in ognuno di essi mette una ricerca minuziosa, imprime un sapore personale, pone una nota caratteristica. Chi sa che qualche volta egli stesso non togliesse di mano i ferri ai suoi tagliapietra, per indicare loro la curva di una voluta, per correggere la grazia di una foglia!

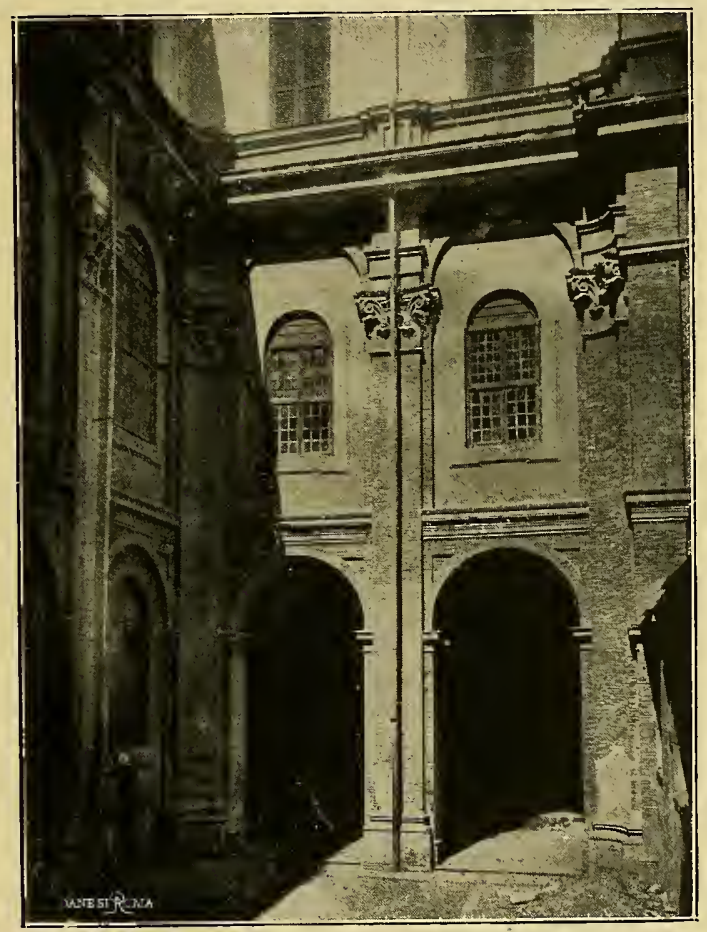

Borromini, Cortiletto dei Filippini.

Al tempo stesso in cui abbandonava i lavori di S. Pietro, il Borromini dovette lasciare quelli del palazzo Barberini alle Quattro Fontane, iniziati anch' essi dal Maderno e continuati poi dal Bernini; le discordanze tra i due maestri erano, secondo i biografi, di indole finanziaria, e sappiamo bene che il Bernini non aveva un carattere facile. Su questo punto della inimicizia 
tra $i$ due più grandi genii del nostro Seicento, credo si sia molto lavorato con la fantasia dagli scrittori antichi; a me appare quasi naturale tra due uomini che esercitano la stessa arte nello stesso luogo, e sarebbe piuttosto da meravigliarsi se tra loro avesse regnato l'accordo.

Occorre determinare con criterii stílistici quale parte il nostro artista abbia avuto nel palazzo Barberini, non soccorrendoci alcuna notizia documentale: l'opera del Bernini si distacca chiaramente dal resto, ed è tutto il corpo centrale con la loggia a tre ordini, cosi poco legato col resto, che non corrisponde con le altezze dei piani interni. Ora nelle alette laterali dal lato della loggia e poi dalla parte verso il giardino ci sono finestre con timpani decorati da un festoncino, e balaustri o mensole sotto il davanzale, che hanno tutto il carattere delle cose posteriori del Borromini, pur riconnettendosi, come è logico, ai tipi del Maderno, e a motivi dell'attico di S. Pietro. Le antiche raccolte di stampe fanno il nome del Borromini per la scala rotonda che sale nell'angolo destro; non è improbabile che l'attribuzione sia giusta, ma dovette qui già intervenire la robusta mano del Bernini, che nel palazzo Barberini introdusse accanto alle timide forme del Maderno un carattere più romano, forte, grandioso, laddove Borromini è più smilzo, sottile, aggraziato.

Anche qui dunque il Borromini lavorava in parti secondarie, in sott'ordine al Maderno e al Bernini, ma ciò malgrado il suo ingegno incominciava a dare bagliori, a esprimersi con un linguaggio nuovo e inaspettato; cosicchè accanto alle sue forme quelle del Bernini appaiono più grandiose e robuste, ma antiquate; questi non fa che riprendere motivi sangalleschi $e$ riprodurre i moduli del Serlio e del Vignola; mentre Borromini precorre già certi atteggiamenti dello stile rococò: e siamo intorno al 1630 !

Ora pensiamo alla condizione di quest'uomo: ha uno scrigno pieno di preziose gioie e non può farne spesa che in 


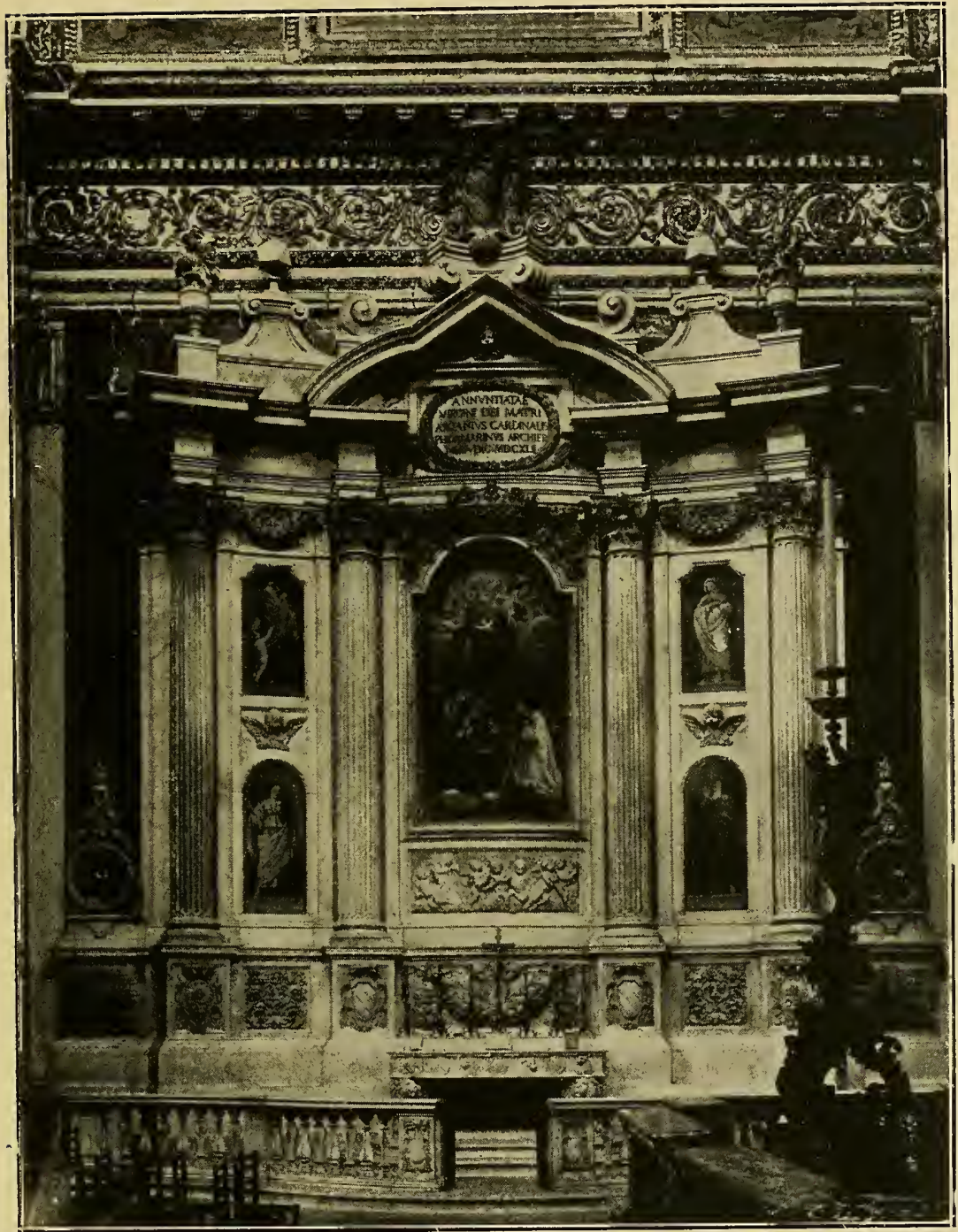

Borromini, Altare dell'Annunziata nella Chiesa dei SS. Apostoli a Napoli.

piccole cose, egli che saprebbe farne gettito con inesauribile larghezza; si sente bastare l'animo a esser condottiero e si vede aggiogato prima al pesante carro del Maderno, un ritardatario, ancora legato all'arte della Controriforma e ai gravi insegnamenti 
di Domenico Fontana, e deve poi lavorare oscuramente alla gloria di un uomo che ha appena un anno più di lui, che già è illuminato dal successo, e con cui sente che saprebbe misurarsi vittoriosamente.

Egli non è che uno scarpellino, e il terribile Bernini non gli permetterebbe certo di fare di più che ricopiare al vero $i$

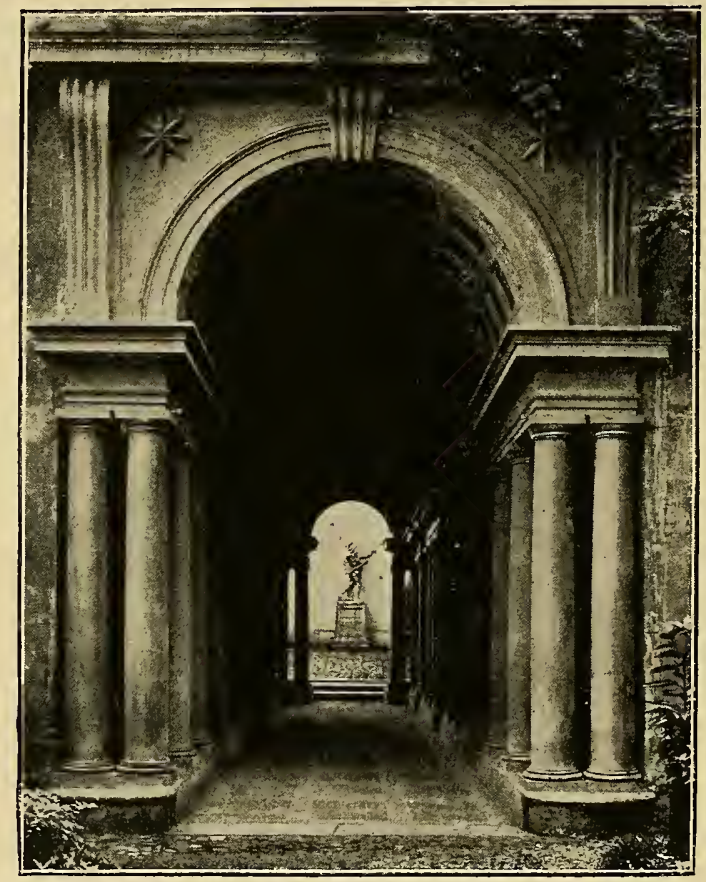

Borromini, Galleria prospettica nel Palazzo Spada.

(Fot. Anderson).

suoi disegni pel baldacchino di bronzo, il miracoloso lavoro che deve dargli nuova e più alta gloria, insieme con la ricchezza: Borromini che collabora all' opera monumentale da tre anni, riceve venticinque scudi il mese, e il Bernini da nove anni ne ha duecentocinquanta, e alla fine dell' impresa ne avrà ritratto pei doni del papa non meno di 34.000 scudi!

Il nostro artista sentiva certo tutto questo, e aveva già 
trentaquattro anni, e la prima giovinezza era fuggita! E allora, poichè nessuno avrebbe chiamato uno scalpellino a far da architetto, Borromini, saputo che il Sodalizio dei Piceni doveva costruire una chiesa in Roma, si presentò ed offrì la sua opera gratuita, che fu accettata nell'adunanza del 12 febbraio 1634 di quella pia istituzione. Ma purtroppo la chiesa, costruita fra

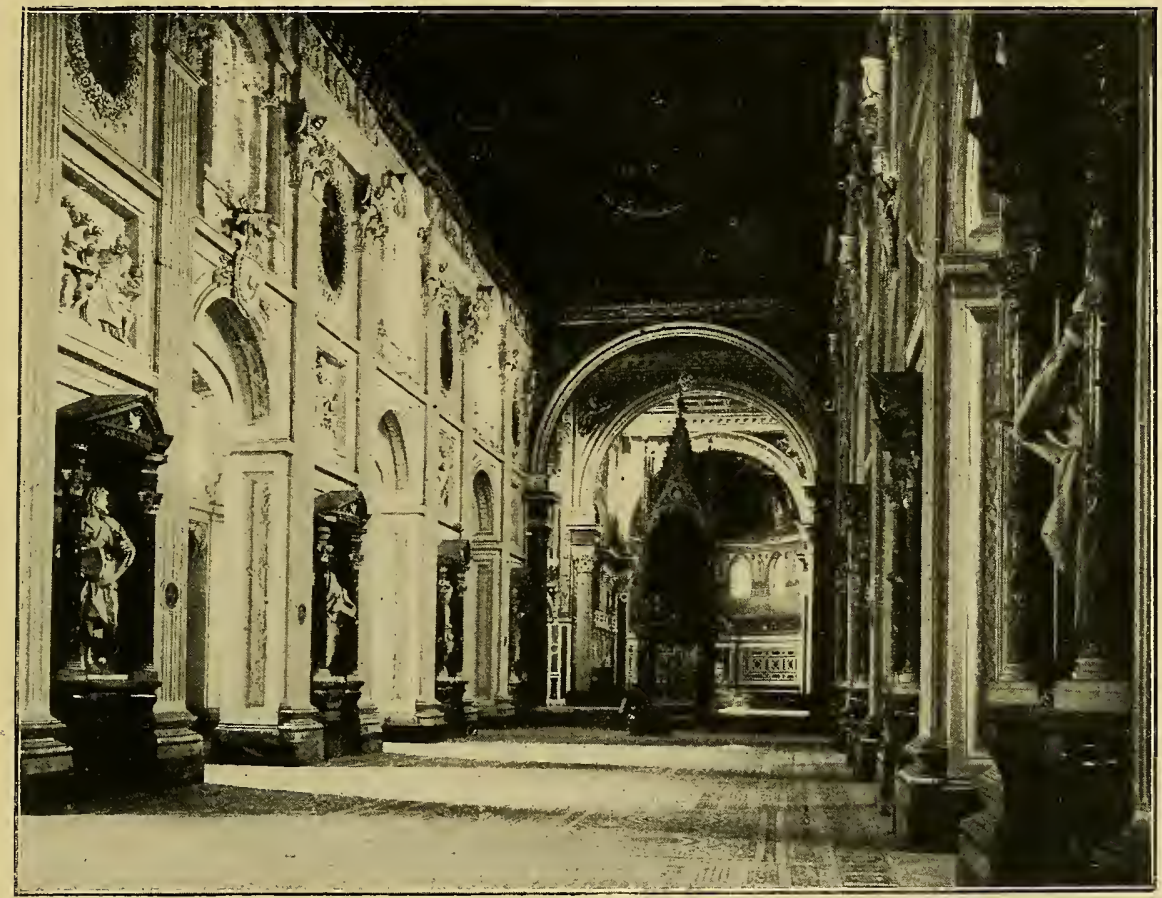

Borromini, Navata centrale di S. Giovanni in Laterano. (Fot. Moscioni).

il 1634 e il '37, intitolata alla "Santa Casa della Madonna di Loreto ", che sorgeva all'angolo tra via di Ripetta e via del Vantaggio, non esiste più, essendo stata interamente rifatta nello scorcio del secolo XVIII e non si può quindi esser sicuri che fosse stata condotta sul disegno del nostro artista. Così oggi la prima opera architettonica del Borromini che noi conosciamo è S. Carlino alle Quattro Fontane: un miracolo. Fu fabbricata 
coll'annesso chiostro tra il 1638 e il ' 41 , tranne la facciata che è del '67, e rivela già tutte le caratteristiche dell' arte borrominiana, la novità della concezione, la nota personale in ogni minuto particolare, la fantasia inesauribile che accumula idee su idee, con facilità, con líberalità prodigiosa, senza sforzo, senza stento. Eppure non è un'opera di getto, una improvvisa.

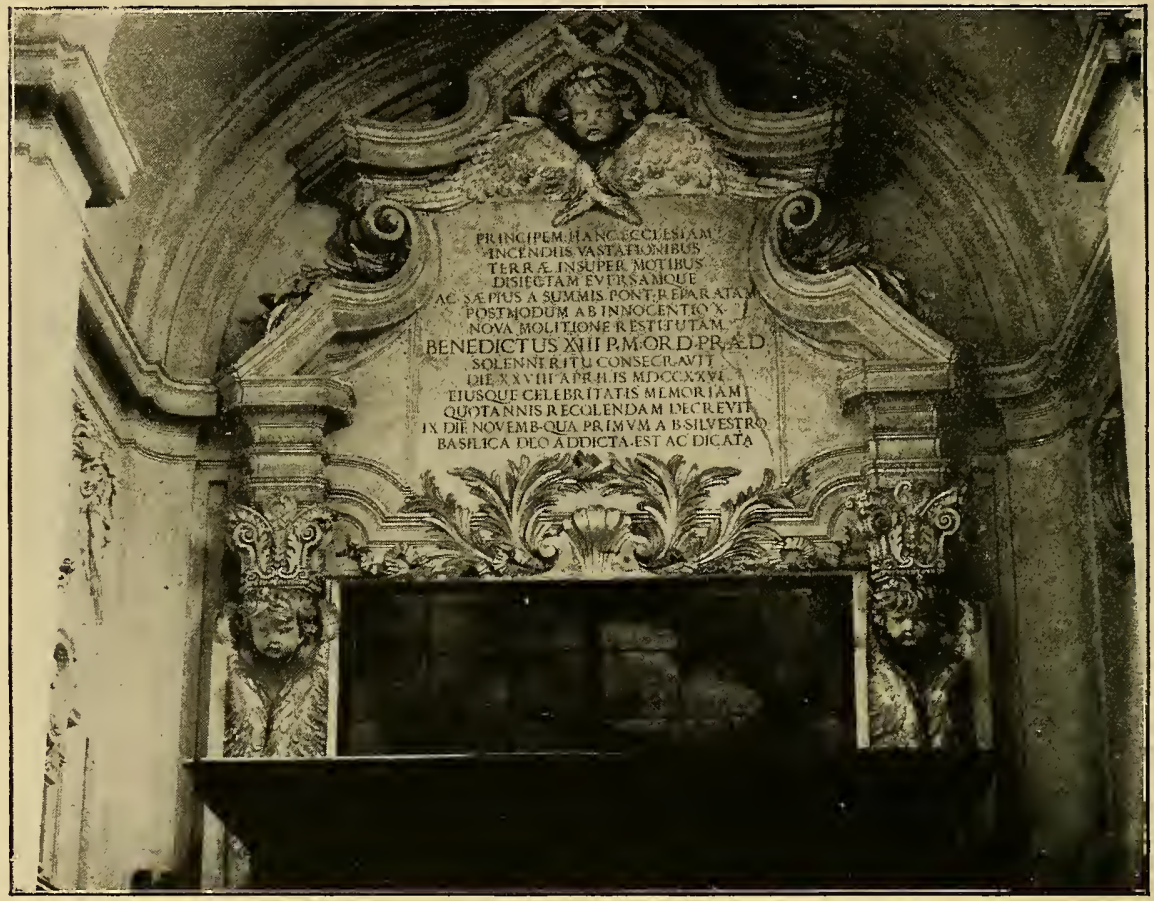

Borromini, Decorazione interna della porta di S. Giovanni.

zione alla Bernini; è invece un organismo logicamente pensato, in cui ogni elemento, ogni modanatura, ogni sagoma è studiata accuratamente, ogni effetto è meditato; in modo che se un solo elemento venisse soppresso ne resterebbe gravemente diminuito tutto $I^{\prime}$ insieme. Questo è un primo carattere che differenzia l'arte del Borromini da quella dei suoi contemporanei: nelle altre fabbriche barocche c'è sempre una ridondanza, una sovrabbon- 
danza di elementi che non hanno alcuna funzione statica $e$ tettonica, e che perciò si possono sfrondare, senza che l'efficienza dell'edificio ne resti diminuita. Quei membri superflui hanno una giustificazione puramente artistica, stanno li soltanto per produrre un certo effetto, per dare all'insieme quella pittoricità che è la caratteristica dell' architettura barocca. Nel Borromini pleonasmí non ci sono mai; eppure egli ottiene l'effetto pittorico più che qualunque altro maestro del Seicento, ma lo fa col movimento che sa dare alle masse, col sapiente uso di elementi

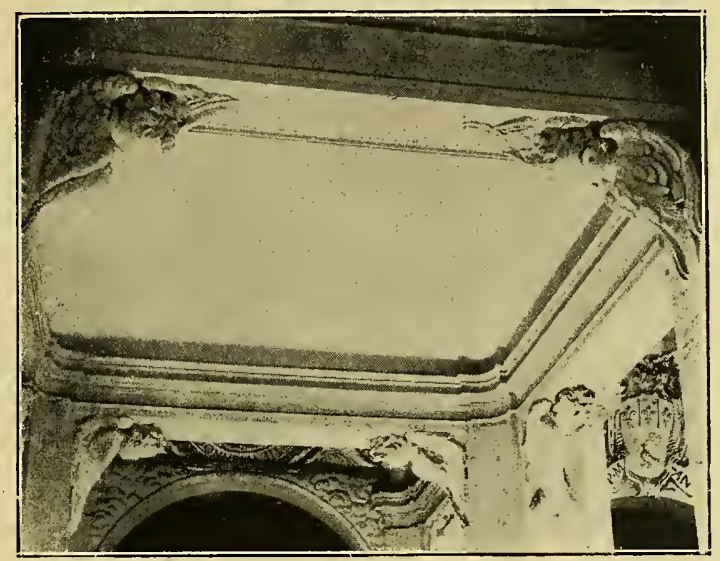

Borromini, Soffitto delle navi laterali in S. Giovanni.

prospettici; così che a lui non si potrebbero rivolgere le critiche che il Milizia, come abbiamo visto, fa al barocco.

La chiesa di S. Carlino ha pianta ellittica, e la porta d'ingresso è collocata sull'asse maggiore dell'ellisse; questa ha nei lati due leggeri rigonfiamenti, che le dànno movimento ondulato, e quattordici colonne, alveolate, nelle pareti e collocate a ineguali distanze, contribuiscono a dare a tutta l'ellisse un ondeggiamento continuo a cui pur concorrono nicchie scavate negli intercolonnii; sulle colonne poggia una trabeazione che ne segue naturalmente l'ondeggiare, e sopporta nei due gonfiamenti laterali 
e sull'altar maggiore, che è di contro all'ingresso, timpani entro nicchie, disegnati prospetticamente, in modo da dar l'impressione di una concavità assai più forte del vero. Una cupola, o meglio

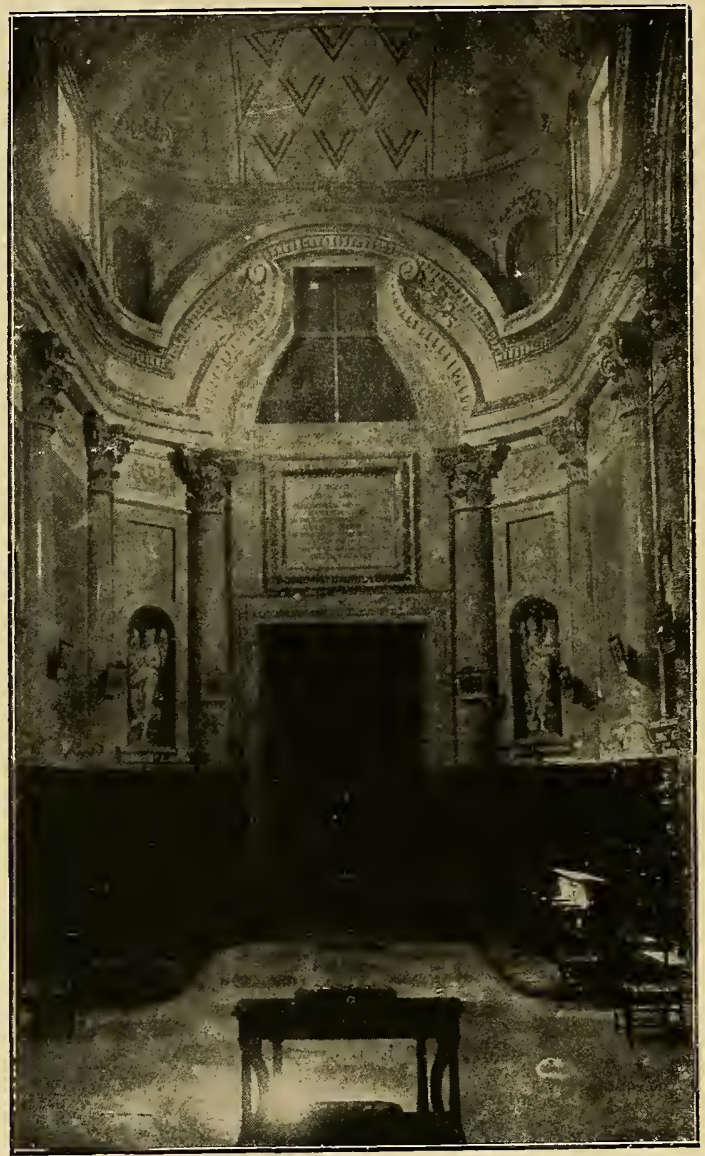

Borromini, Chiesa della Madonna dei Sette Dolori.

calotta, ricopre tutta la chiesa, accrescendo l'impressione di ampiezza, ed è tutta scompartita in profondi cassettoni in cui pure l'occhio si perde, e sormontata da un lanternino dal quale piove cosi poca luce da dare alla chiesa barocca il mistico aspetto di una cattedrale gotica. Elegantissimi sono i particolari, tutti studiati 
accuratamente, meditatamente, perchè concorrano a un unico effetto: le forti modanature delle cornici, i plinti delle colonne tagliati ad esagono, i rosoncini dei cassettoni, il fregio a palmette all' imposta della calotta; il tutto bianco su bianco, con effetti di luce meravigliosi.

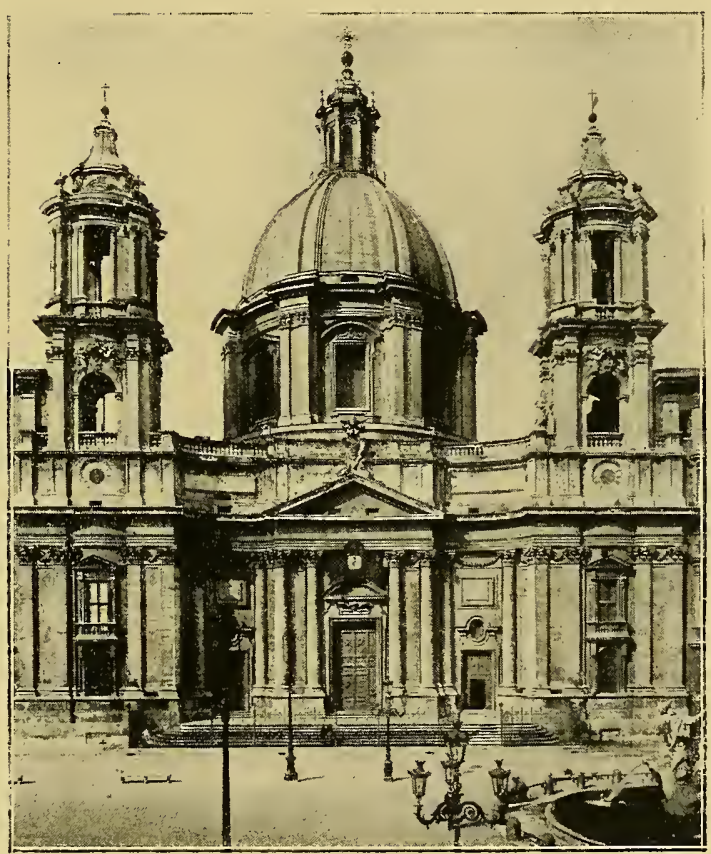

Borromini, S. Agnese in Piazza Navona.

(Fot. Anderson).

Il piccolo chiostro con gli angoli tondeggianti è un altro miracolo di leggiadria, di squisita finezza, ed è insieme solido e robusto.

Durante i lavori di S. Carlino Borromini condusse quelli del convento dei Filippini alla Chiesa Nuova, con l'Oratorio e i due chiostri, terminati nel 1642 . Il prospetto è il primo esempio di facciata in curva, e segna perciò una data importante nella storia dell'architettura. Non è improbabile che l' ardita innova- 


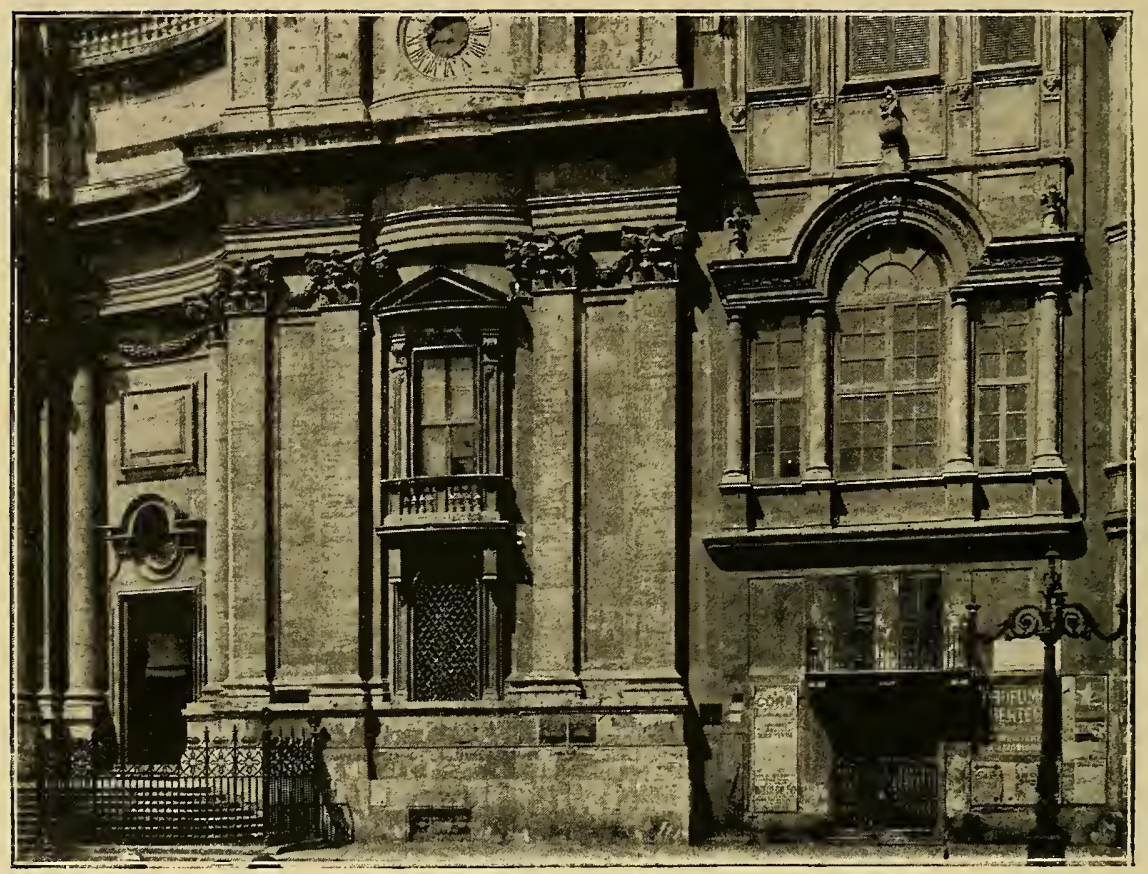

Borromini, S. Agnese in piazza Navona; particolare.

(Fot. Anderson).

zione, destinata a tanta fortuna, sia stata suggerita all'artista da una circostanza del tutto casuale: la facciata dell'Oratorio doveva elevarsi proprio a fianco di quella della Chiesa Nuova, e ad essa congiunta e aderente, e l' effetto non poteva esser che monotono se l'architetto avesse adottato uno dei consueti schemi. Invece, adoperando la linea curva, Borromini è riuscito a distaccare completamente un prospetto dall'altro, e anzi ad otteriere un contrasto gratissimo all'occhio.

La curva concava non ha una linea continua, ma come nelle facciate rettílinee si ottenevano risalti collocando in piani diversi le varie parti, con due o tre aggetti dalle estremità lateralí fino all'asse centrale, così nell'Oratorio dei Fílippini si vedon le ali laterali più arretrate, poi due corpi aggettati, infine la parte di mezzo col portale leggermente convessa, e quindi risaltante su tutto. 


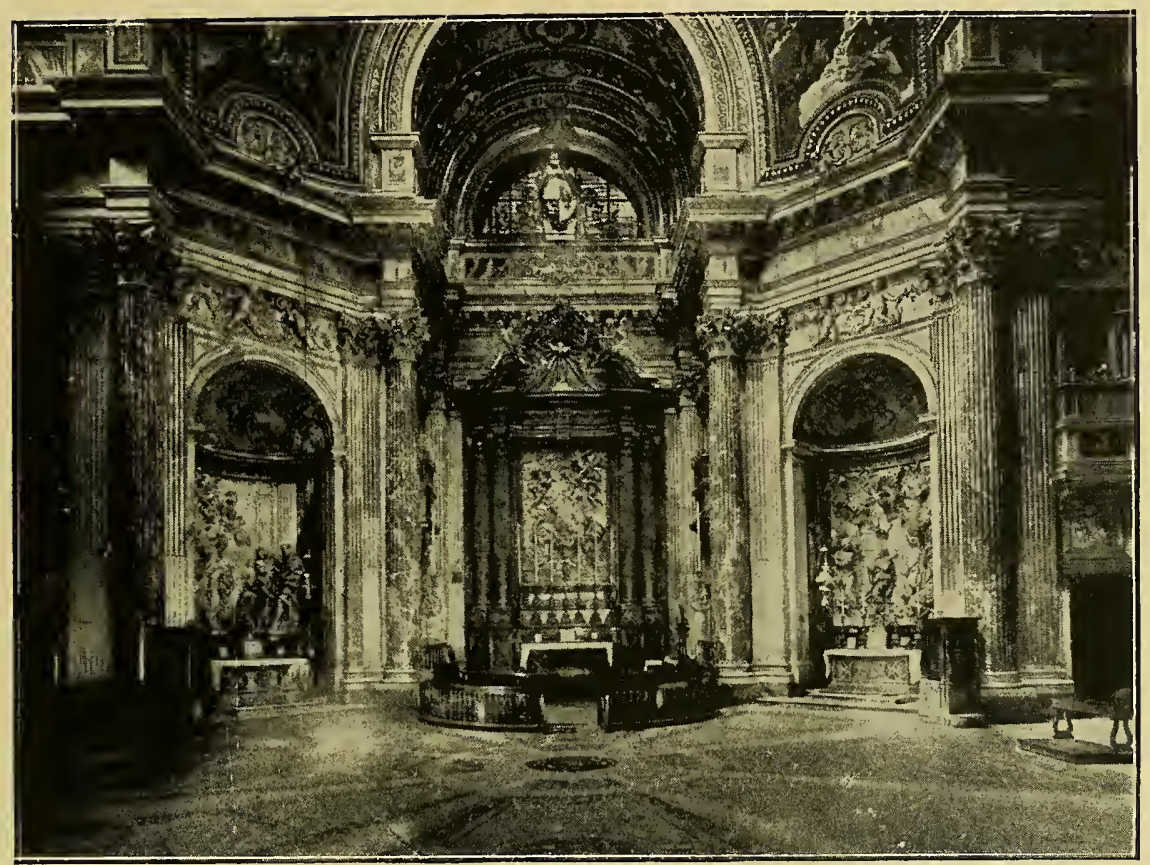

Borromini, Interno di Sant'Agnese.

(Fot. Anderson).

Dentro la grande novità dell' insieme ve ne sono altre a decine nei particolari: di nuovo Borromini appare come un gran signore, che con intelligente prodigalità effonde a piene mani i suoi tesori. Ecco qui i capitelli piatti con due sole volute; ecco dentro le nicchie i timpani a linee spezzate che avranno poí tanta fortuna, la porta col timpano spezzato sormontato da finestra, i pilastri laterali messi per angolo.

Anche all' interno ci sono motivi nuovi; caratteristico fra tutti quello dei due chiostri, grande e piccolo, ad un solo ordine; una di quelle disobbedienze alle buone norme che fanno imbestialire il povero Milizia, che possiamo immaginarci col suo codice alla mano in giro da mattina a sera per giudicare $i$ "rei di lesa architettura ,, com'egli disse riferendosi al Maderno. Eppure quella innovazione borrominiana trova le sue origini in un 
esempio classico, nel Campidoglio di Michelangelo, e non è, credo, una analogia casuale, perche nell'arte del Borromini sono frequenti le reminiscenze del Buonarroti; quando lavorava in S. Pietro, l'impaziente scalpellino che sentiva già pulsare il suo gran cuore, dovette studiare a fondo sulle tracce di quel grande, dovette appagare la sua fame nutrendosi delle midolla del leone.

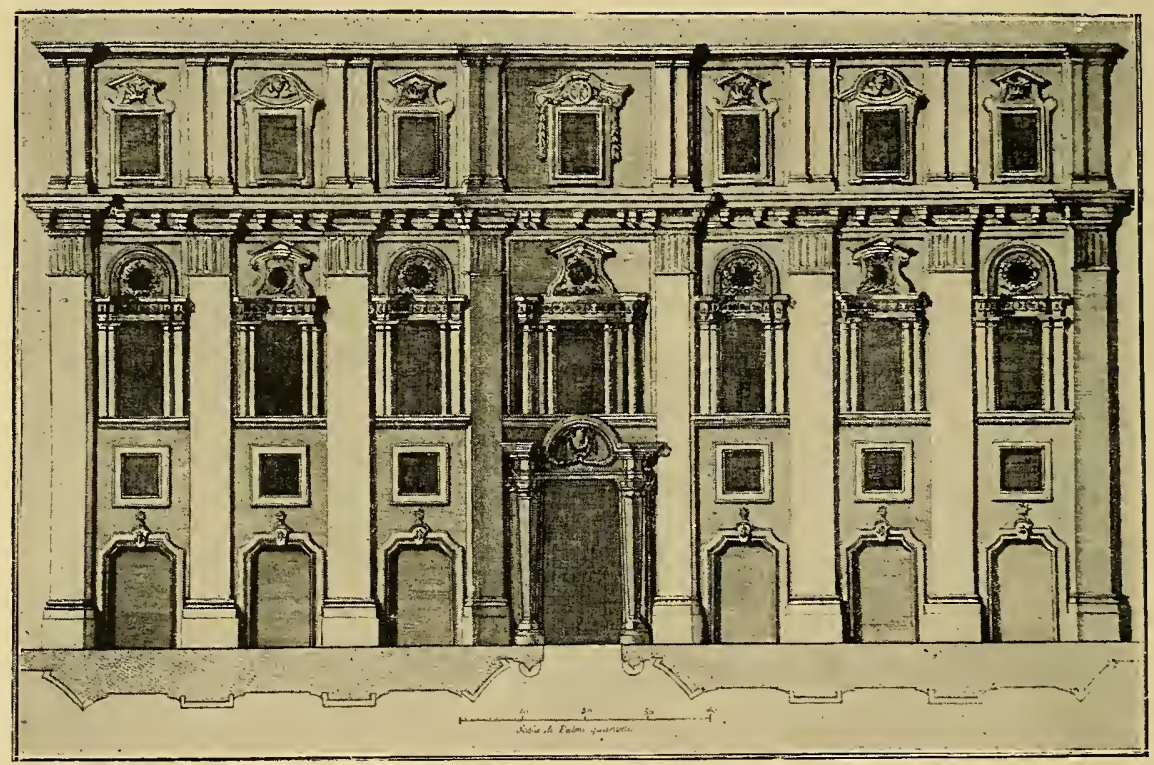

Borromini, Prospetto del Collegio di Propaganda Fide.

Mentre Roma si stupiva di fronte a queste licenze borrominiane, che urtavano a tutta prima, ma s'imponevano presto, attirando all'imitazione perfino il Bernini, un'opera squisita del gran ribelle andava a seminare i germi della rivoluzione nella quiete dell'arte partenopea.

Il vescovo di Napoli, Ascanio Fílomarino, creatura di Urbano VIII, commise al Borromini il grande altare della cappella dell'Annunziata, che costruiva nella chiesa dei SS. Apostoli in quella città : l'opera fu tutta eseguita a Roma, e vi collabo- 


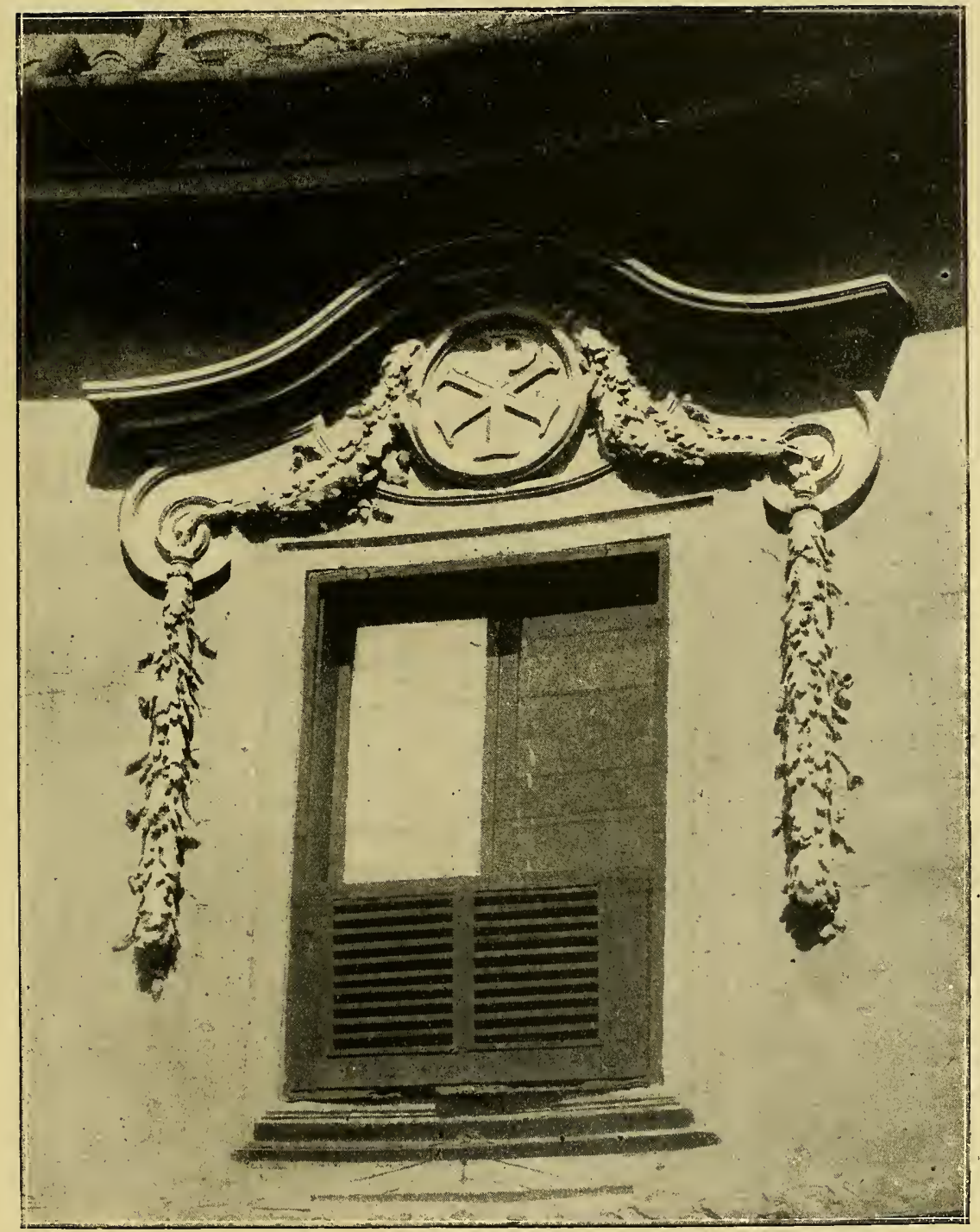

Borromini, Finestra di Propaganda Fide.

(Fot. Moscioni). 
rarono Francesco Duquesnoy, autore del S. Andrea in Vaticano, Andrea Bolgi, scultore della S. Elena, che gli fa riscontro, il Finelli, Guido Reni e Pietro da Cortona. La cappella era consacrata nel 1642, e si vuole che i lavori durassero diciassette anni ; ma non certo tanto si prolungò l'opera dell' altare, che sarebbe stata commessa al Borromini nel '25, quando era intento a scolpire balaustri e gradini per $\mathrm{S}$. Pietro; più probabilmente fu' condotta tra il 1638 e il '42.

Intorno alla stessa data, cioè verso il '40, Borromini costrù̀ la bizzarra galleria prospettica in un cortile del palazzo Spada, fiancheggiata da colonne che vanno impicciolendosi verso il fondo, col pavimento in salita e la vôlta a cassettoni in discesa, così che il corridoio lungo appena otto metri sembra profondo almeno cinquanta. E una sapientissima soluzione di problemi di prospettiva e di geometria, che però non commuove troppo; può servire a dimostrare quanto sopra si disse sul fondamento logico e meditato dell'arte borrominiana. Si è scritto che Borromini copiò la sua galleria di palazzo Spada, dalla Scala Regía del Bernini, ch'è in Vatícano; ma questa è del 1663-66, ossia di ventícinque anni posteriore.

Il pontificato di Innocenzo X (1644-55) segna l'epoca della maggior fortuna del Borromini; come tutti coloro che avevan goduto i favori del papa precedente, il Bernini era caduto in disgrazia, allontanato dalla corte, costretto a demolire il campanile che aveva elevato sul lato meridionale della facciata di S. Pietro. Nel 1647 il nostro iniziava i grandi lavori di restauro e di decorazione della Basilica Lateranense, che dovevan compiersi, come difatti avvenne, per l'anno santo 1650 . Fu allora che andarono distrutti i preziosi affreschi di Gentile da Fabriano e del Pisanello, per cui tanti fulmini furono scagliati, dagli esclusivisti fanatici dei primitivi, contro il Borromini. Di quella perdita, certo assai grave per l'arte, può consolarsi chi in San Giovanni si indugi senza preconcetti ad ammirare la fresca, briosa 


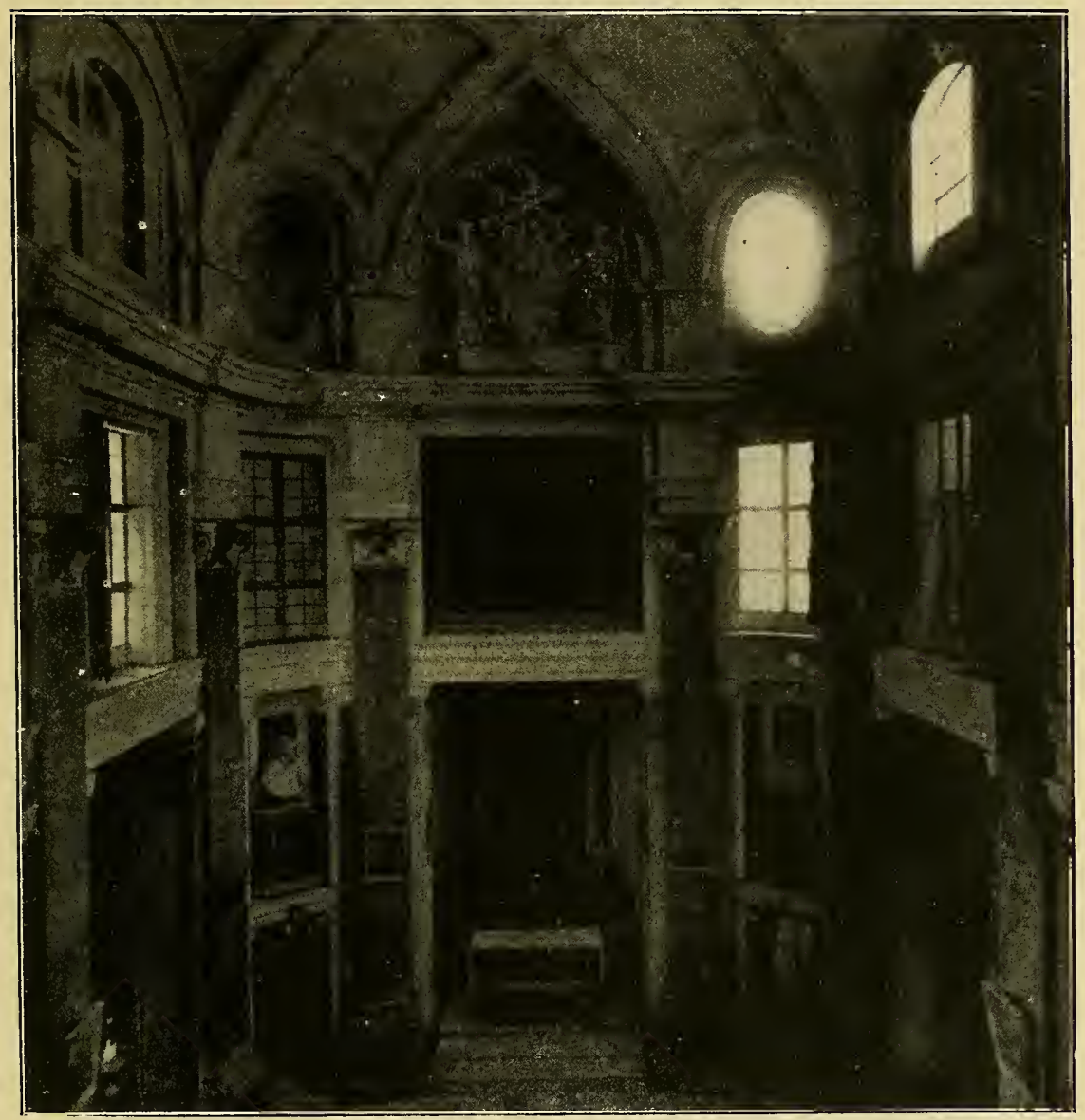

Borromini, Interno dell'Oratorio di Propaganda Fide.

elegantissima decorazione che il maestro vi introdusse, tutta in stucco bianco, di un'impeccabile signorilità, che si direbbe uscita dalle mani di uno stuccatore veneziano del Settecento. E poi perchè incolpare dello scempio il Borromini? Era il yusto del secolo che comandava cosi, e non il capriccio di un solo; il concetto, tutto moderno di rispettare i monumenti e le opere d'arte delle età passate non esisteva allora; gli uomini del tempo nuovo, persuasi che l'età loro rappresentasse il meriggio dell'arte 
di fronte all'alba incerta dei secoli precedenti (per usare le parole del pittore e trattatista Vincenzo Carducho, 1633) non avevano scrupolo di distruggere tante venerande e preziose reliquie, non per spirito di vandalismo, ma per rifare meglio. Le basiliche cristiane e medioevali non potevano considerarsi come musei d'arte; erano monumenti vivi della pietà e della fede, e dovevano rispondere al sentimento della nuova età: un uomo del Seicento non sapeva pregare in un tempio del quinto secolo; la sedia gestatoria di Paolo V o di Urbano VIII non si adattava alle vetuste basiliche costantiniane. Sicchè non fu il Maderno che guastò il vecchio $S$. Pietro, nè il Borromini che distrusse S. Giovanni, nè il Fuga che deturpò S. Maria Maggiore; ma era tutta una civiltà nuova che si faceva largo e pigliava il posto dell'antica.

Borromini durante i restauri di S. Giovanni eseguì altri lavori; proprio contemporaneo ad essi e ispirato allo stesso gusto è il completamento interno del palazzo Carpegna, oggi delle suore del Cenacolo, in via della Stamperia, ove nell' atrio ornò i sottarchi, come al Laterano, con festoni di fogliame in stucco, che paion formati sul vero, e disegnò un'originalissima decorazione sulla porta d'accesso alla rampa, fatta con motivi floreali sostituiti all'architrave, che poi furono imitati da Paolo Naldini nel palazzo Ginnetti a Velletri. E nel 1652 era compiuta una chiesuola che è quasi a tutti ignota, perchè in strettissima clausura, quella della Madonna dei Sette Dolori, alle falde del Gianicolo, di pianta rettangolare, con semicolonne alveolate nelle pareti, e facciata concava, rimasta incompiuta.

La casa Pamphili intraprendeva dopo il 1652 la fabbrica della chiesa di $S$. Agnese in piazza Navona, che doveva divenire la cappella gentilizia della famiglia di Innocenzo $X$, e affidava l'impresa a due architetti insigni, padre e figlio, Girolamo e Carlo Rainaldi; ma il 7 agosto del '53, non so per qual ragione essi venivano dispensati dal lavoro, e sostituiti da Francesco 


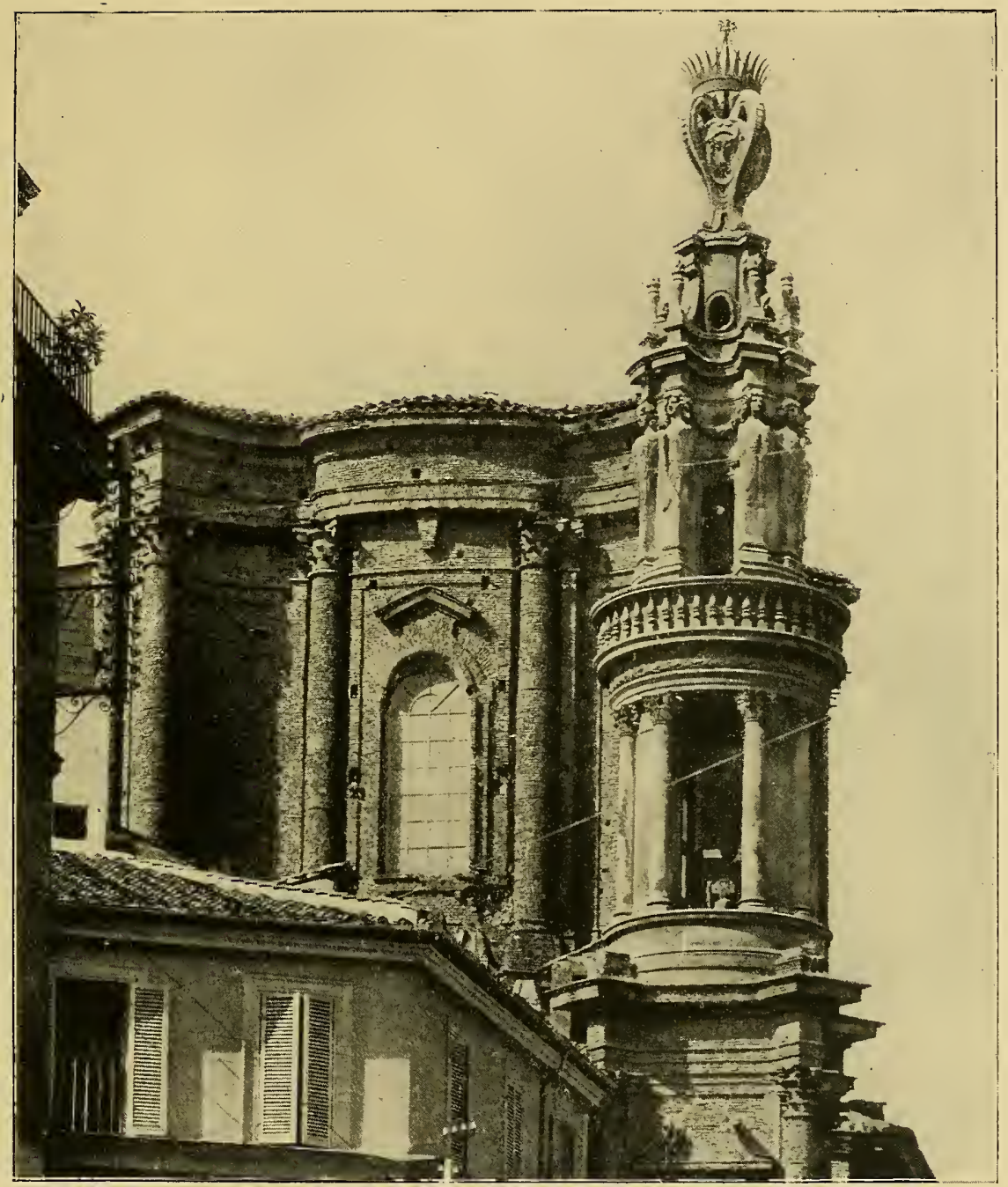

Borromini, Cupola e campanile di S. Andrea delle Fratte. (Fot. Alinari).

Borromini. Questi demolì quasi tutto il già fatto (ci sono intorno a tutto ciò documenti e disegni inediti), e ricostrù la chiesa più indietro, con pianta a croce greca, che dà però l'impressione di una rotonda, tanto è largo il quadrato centrale, su cui si aprono quattro piccole cappelle che formano i bracci; gli angoli del 
quadrato sono smussati, con entro nicchioni e altari, fiancheggiati da colonne di cottanello che addolciscono gli spigoli, e dànno a tutto il tempio un movimento curvilineo. Un'amplissima cupola sormonta il quadrato, poggiata su alto tamburo, ed essendo visibile naturalmente fin dall' entrata contribuisce, piì che in qualunque altra chiesa a pianta centrale, a dare un'impressione di vastità. La facciata in travertino è fiancheggiata da due torri con pilastri binati laterali, e interpilastri concavi, che terminano con svelte guglie, in cui le colonne poste per angolo formano un motivo felicissimo che evita il profilarsi sul cielo degli spigoli retti; dai due corpi laterali partono verso il centro della facciata due linee concave che raggiungono il corpo di mezzo, in piano, col portale fiancheggiato da quattro colonne e sormontato da timpano triangolare; un alto attico corona il primo ordine, e termina con una svelta balaustra. Qui sono evidentissime le reminiscenze della facciata di S. Pietro del Maderno, famigliarissima al Borromini, che però la adattò al caso suo, arcuandola così agilmente con quelle due linee concave che sono gradevolissime all'occhio, attraenti, invitanti. Il maestro non potè personalmente dar l'ultima mano al suo bel lavoro, perchè, per questioni insorte, il 7 febbraio 1657 abbandonava la fabbrica, che allora venne affidata a una commissione di cinque architetti; questi, completando la facciata e la cupola col lanternino, dovettero attenersi però fedelmente ai disegni lasciati dal Borromini, e solo modificarono l'aspetto interno con l'aggiunta di tutti quei dipinti e di quell'oro, che non hanno carattere borrominesco.

Sant'Agnese è il típo rappresentativo di chiesa barocca a pianta centrale, modello di numerose derivazioni e contraffazioni : il Bernini, secondo la tradizione popolare, l'avrebbe criticata, anzi satireggiata; atteggiando una delle statue di fiumi della fontana di piazza Navona in gesto di terrore, con le braccia protese come per ripararsi dalla caduta della cupola, troppo avanzata sul prospetto. Ma non è vero niente di tutto ciò : la Fonte 
Pamfilia fu inaugurata nel giugno del ' 51 e la chiesa cominciata nel '53. Invece il Bernini si ispirò da S. Agnese quando nel '58 costruiva S. Andrea al Quirinale, che è però assai meno bella, e che tuttavia il maestro considerava come il suo capolavoro architettonico.

Dal '49 al '56 Borromini lavorò al palazzo di Propaganda Fide, ove costruì l'oratorio interno, simile a quello dei Filippini,

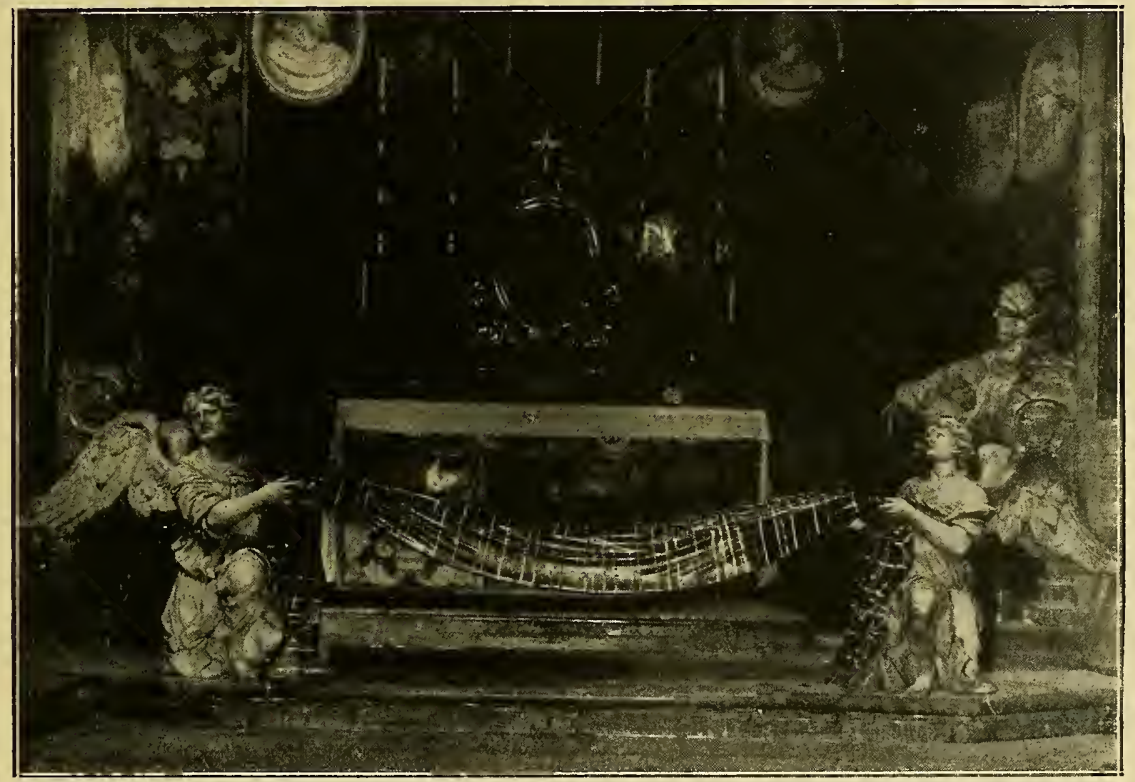

Borromini, Balaustra della cappella Spada, in S. Girolamo della Carità.

(Fot. Anderson).

e il prospetto del Collegio, anche qui profondendo un tesoro di trovate di genio: i pilastri messi per angolo che distaccano la fabbrica nuova dalla vecchia; le fínestre a pianta curvilinea, con colonne invece di stipiti, che dànno una estrema pittoricità; le soprafinestre circondate da rami di palma e da festoni di fiori in luogo di cornici. Si paragoni questo prospetto con quello principale del palazzo su piazza di Spagna che il Bernini aveva disegnato trent'anni innanzi; tra le due opere non par che cor- 


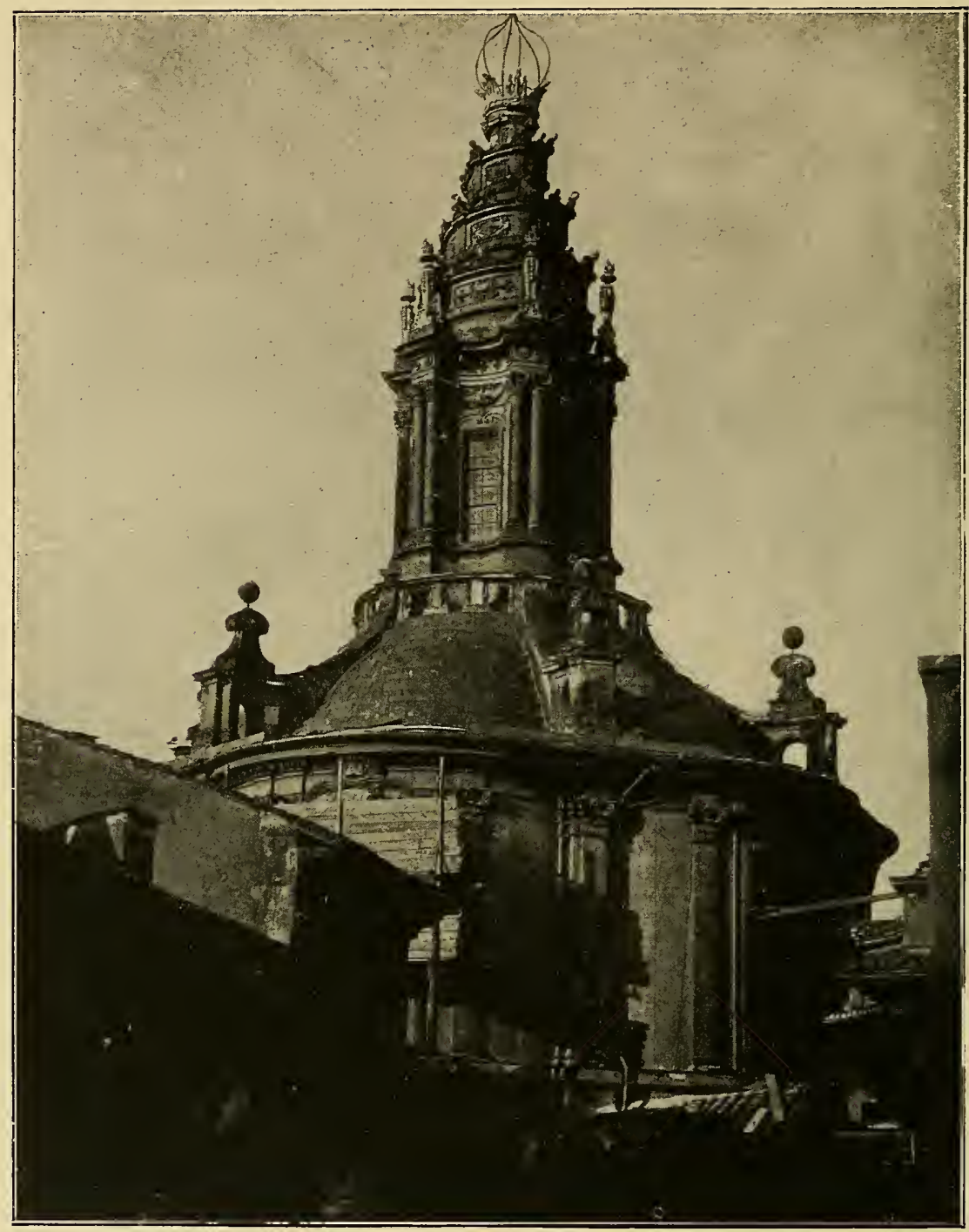

Borromini, Cupola della Sapienza.

(Fot. Moscioni). 


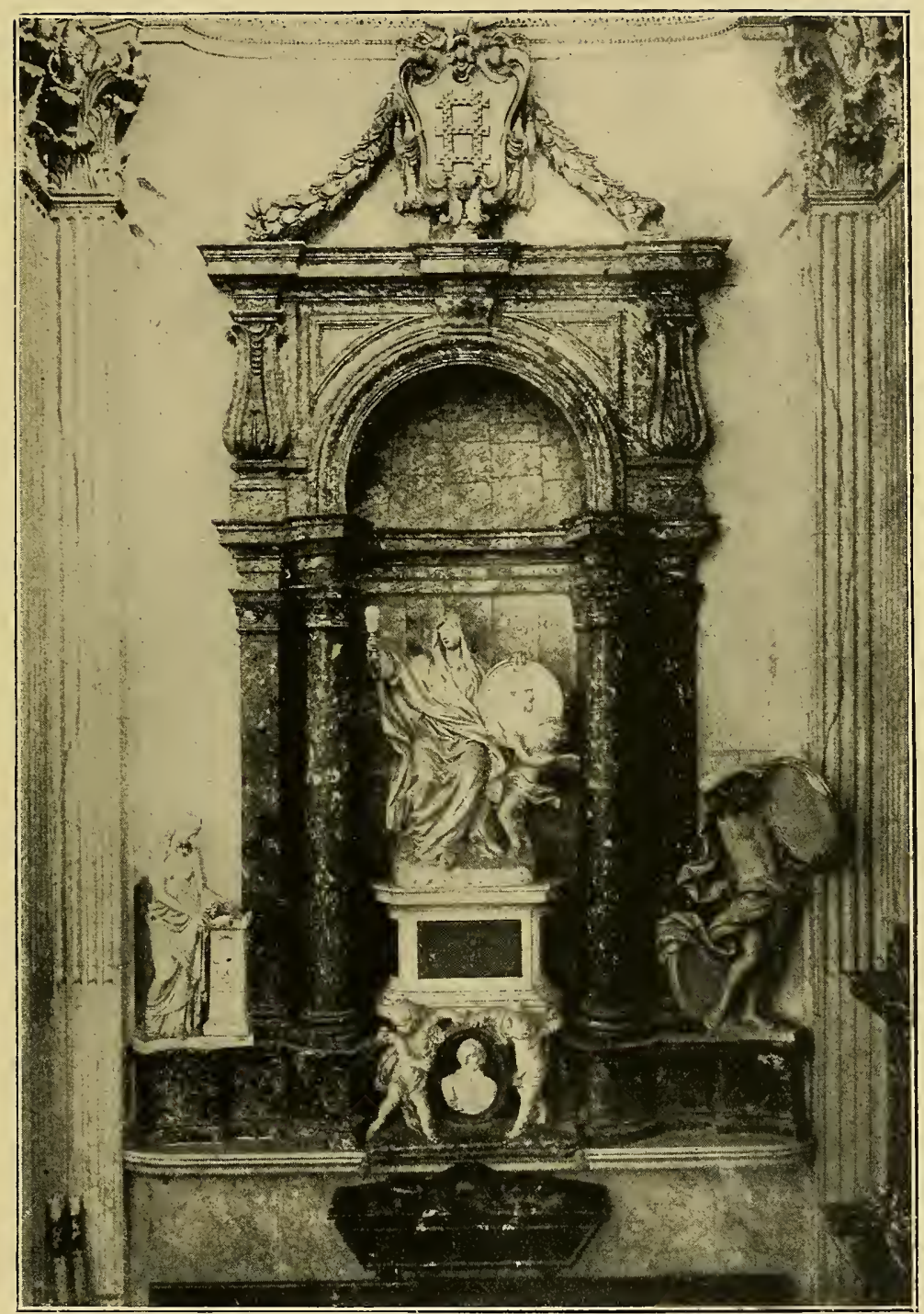

Bcromini, Monumento Falconieri in S. Giovanni dei Fiorentini. 
rano tre lustri, ma tre secoli. E Bernini che abitava di faccia al prospetto di Propaganda, copierà per il suo palazzo Chigi (oggi Odescalchi) a SS. Apostoli, il motivo delle finestre a colonne, che tuttavia limiterà timidamente alla sola finestra della loggia; e qui verranno a copiare i settecentisti, italiani e francesi, ma non riusciranno a carpire, insieme con le linee, lo spirito brillante del Borromini.

Non è possibile esaminare particolarmente tutte le altre opere del maestro: la cupola $e$ il campanile di $S$. Andrea delle Fratte, la chiesa della Sapienza, la facciata di S. Carlino, le decorazioni della cappelletta di S. Giovanni in Oleo, la cappella Spada in S. Girolamo della Carità, i lavori del palazzo Falconieri a Frascati e quelli dell'abside di S. Giovanni dei Fiorentini, i sepolcri del cardinale Ceva e di Clemente Merlini. Alla chiesa di S. Ivo, all'Università, iniziata fino dal 1642 e terminata nel '60, Borromini dette la pianta in forma di un'ape, omaggio al papa Barberini, e ne ricavò così un gioco bellissimo di curve, di nicchie, di spigoli che tagliano la chiesa e la cupola a lobi; $e$ al lanternino dette un coronamento a spirale che sale stringendosi e va a sostenere una corona, come una freccia scagliata contro il cielo, con un moto ascensionale che nessuna guglia ha avuto mai. Milizia brontola qui di bizzarro; altri al suo tempo parleranno di arte indiana e cinese; sia comunque è certo che mai architetto espresse con più vivace slancio l'aspirazione dell'animo e della preghiera verso Dio.

La facciata di S. Carlino porta incisa la data del 1667, e fu compiuta un po' dopo; è a due ordini, quello inferiore a linea ondulata, concava ai lati, convessa nel mezzo, con scompartizioni di colonne, e fínestre circolari e nicchie; quello superiore con tre concavità, e nel mezzo un tamburo in cui apresi la porta-finestra, il quale richiama certi motivi della tarda architettura romana orientale di Petra. Sul portale, in una nicchia ornata, è la statua di S. Carlo, e l'arco della nicchia è coperto 


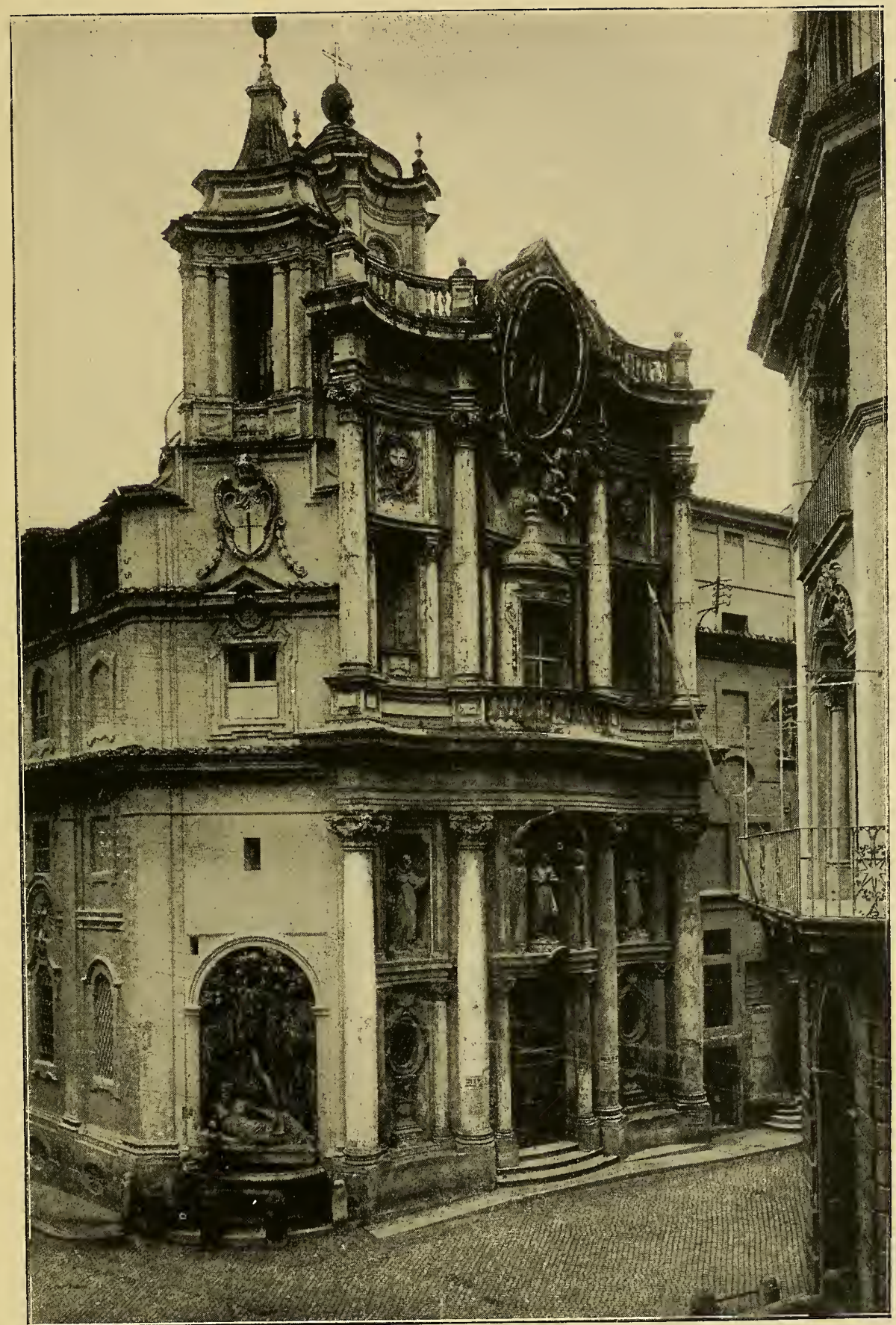

Borromini, Facciata di San Carlino.

(Fot. Alinari). 
da due teste di cherubini alate, leggiadrissimo motivo che piacque tanto al Borromini, il quale impiegò teste di cherubini come mensole nei soffitti delle navate laterali di S. Giovanni, come reggitarghe a Propaganda, come chiavi d'arco ai Filippini, come balaustri nel campanile di $\mathrm{S}$. Andrea, come smussa-angoli nella sagrestia di S. Carlino. Nella facciata di questa chiesa che ora stavamo esaminando, c'è si qualche cosa di eccessivo, di sovraccarico; l'artista ha accumulato troppe cose, troppi pensieri; pare che egli, sentendosi ormai fuggire la vita, abbia voluto spendere tutte le sue risorse, sfoggiare tutti i suoi tesori. E quante ne ha ancora di idee, fresche, giovanilmente rivoluzionarie, questo ipocondriaco vecchio di sessantasei anni! Che miniera, che palazzo incantato egli apre qui ancora una volta ai suoi lontani seguaci! Per ora non tutti lo intendono, non tutti lo apprezzano; ma fra trent'anni i giovani architetti della generazione nuova verranno qui, e a Propaganda, e ai Filippini. Ci verrà Giuseppe Sardi ad ispirarsi per la sua Maddalena, e Ferdinando Fuga per la chiesa della Morte, e fratel Pozzo pei suoi altari, e Antonio Gregorini per S. Croce, e Gabriele Valvassori pel palazzo Doria, e Carlo de Dominicis per S. Celso, e Alessandro Specchi, e Galilei, e Amati, tutti, tutti, verranno qui. Fratel Pozzo porterà le forme del Borromini nella Germania cattolica e nell'Austria, dove ancor oggi rivivono nel cosidetto stile secessionista viennese; e Filippo Juvara, ardente siciliano, le trapianterà in Piemonte, e il capriccioso padre Guarino, e con lui una pleiade di architettí francesi, le trasporteranno a Parigi, da dove ci torneranno sotto l'etichetta del rococò. E quando il berninismo è morto e comincia la reazione, l' impero di Borromini continua ancora nel tempo. Lo stesso Milizia è costretto ad ammettere nelle sue maggiori strambalatezze un certo non so che di grande, di armonioso, di scelto, che fa conoscere il suo sublime talento. "Quest' uomo incomparabile fu un appassionato dell' arte sua, per amor della quale non perdonò a fatica ,; fu sobrio e visse 


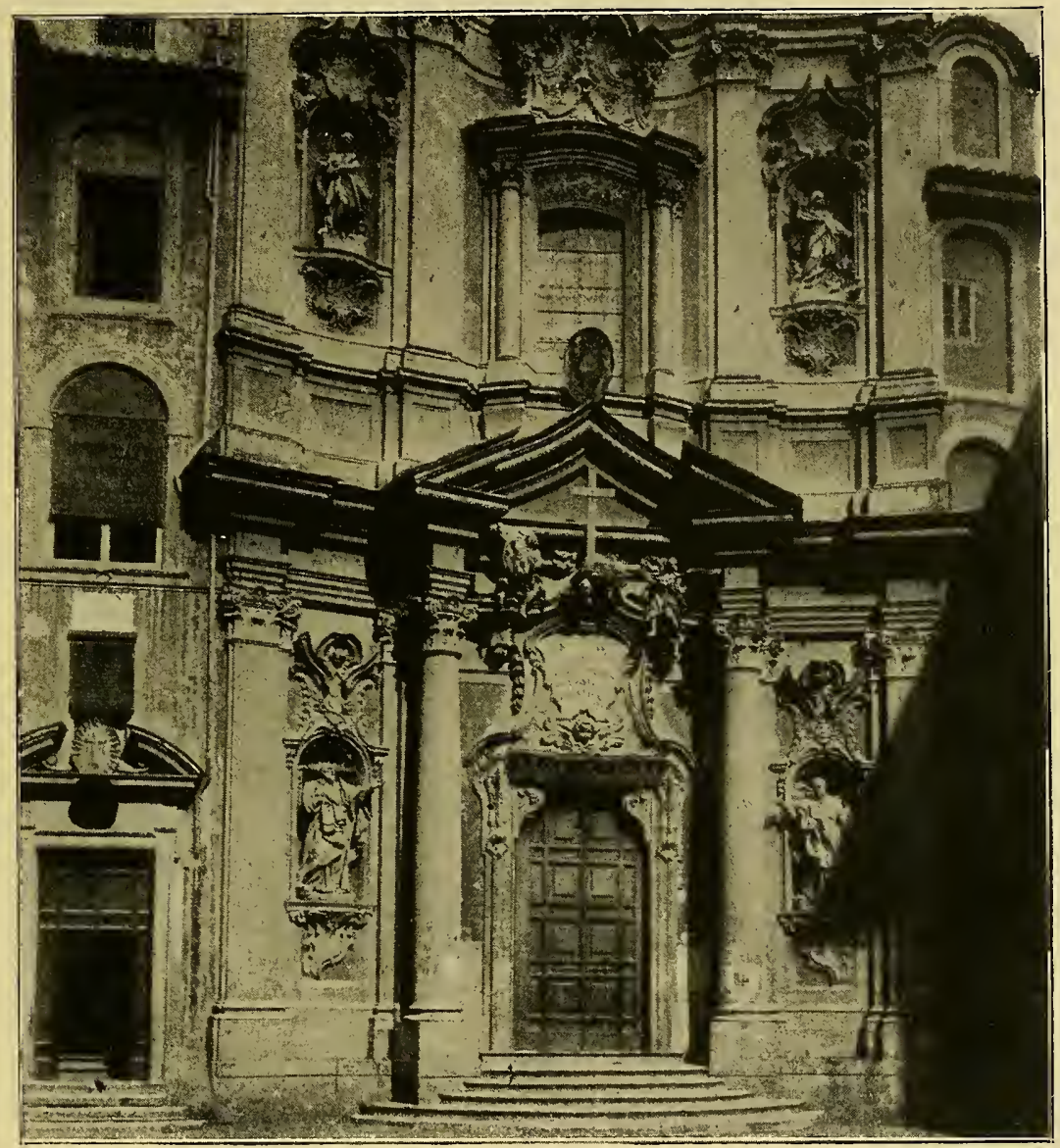

Giuseppe Sardi, Facciata della Maddalena.

castamente; non mendicò mai le lodi e le commissioni, non fu signoreggiato dal desiderio di arricchire: a Propaganda dopo ventíquattro anni di lavoro si vide compensato con quarantacinque scudi, che rifiutò!

Solitario, tutto dedito anima e corpo al suo sogno d' arte, non parve un uomo del suo tempo, e scomparendo non lasciò discepoli diretti, non volle trasmettere a mani indegne la fiaccola sacra: e nessuno avrebbe potuto raccoglierla! 


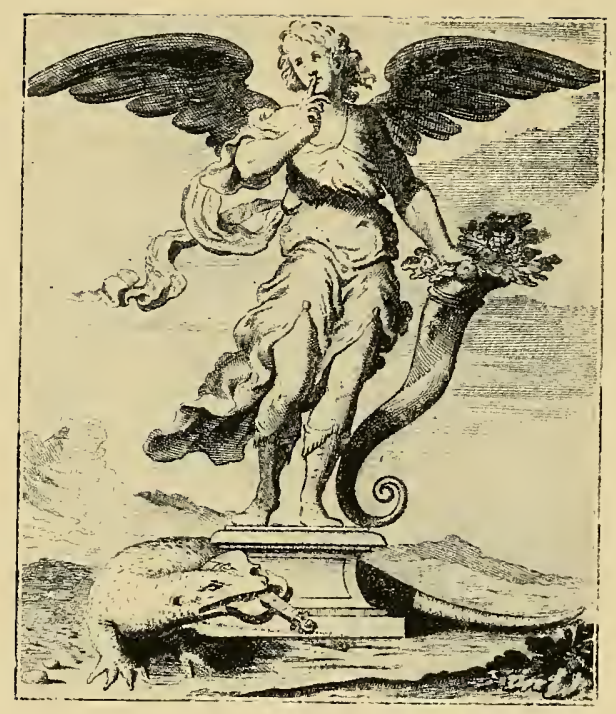




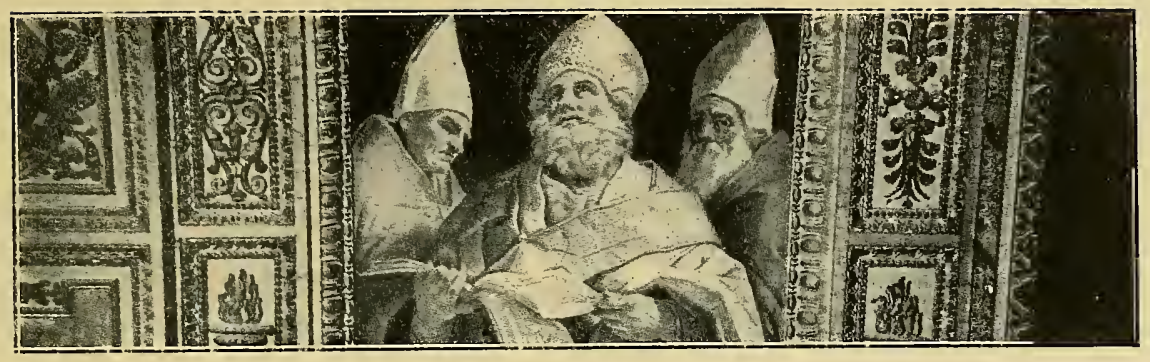

\section{CAPITOLO OTTAVO}

\section{LUCE E TENEBRE}

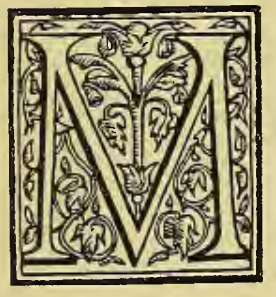

entre Annibale e Agostino Carracci nella galleria di Palazzo Farnese dipingevano favole antiche con ricercata eleganza raffaellesca, un pittore lombardo metteva a scompiglio con forme inattese, la quieta corrente dell'arte romana, e, dapprima irriso, e bandito dal mondo ufficiale, finiva per attirare intorno a sè quasi tutti i giovani pittori. Era questi Michelangelo Merisi da Caravaggio, venuto a Roma dopo aver formata in Lombardia e a Venezia la sua educazione, ma a differenza dagli eclettici bolognesi, conservando un atteggiamento proprio $e$ indipendente, all'epoca in cui Sisto V dava così grande impulso alle costruzioni, e una moltitudine di pittorucci, senza anima e senza vigore, stampavano sulle pareti dei nuovi palazzi e delle nuove chiese le loro manierate decorazioni, e tra essi gli Zuccari e il Cavalier d'Arpino primeggiavano. Caravaggio, in cerca di fortuna, si collegò con quest'ultimo, abilissimo frescante e carico di commissioni, e intanto dipingeva per suo conto quadri di genere e ritratti che trovavano favore tra i mercanti e gli amatori. Nell'occasione che Francesco Cointerel, 
nipote del cardinal Matteo gran benefattore della chiesa di S. Luigi dei Francesi, faceva decorare in quel tempio una cappella, Michelangelo da Caravaggio si trovò a lavorare insieme col d'Arpino. Questi colorì nella volta in tre piccoli scomparti, e a Caravaggio $f u$ affidato il compito di dipingere il

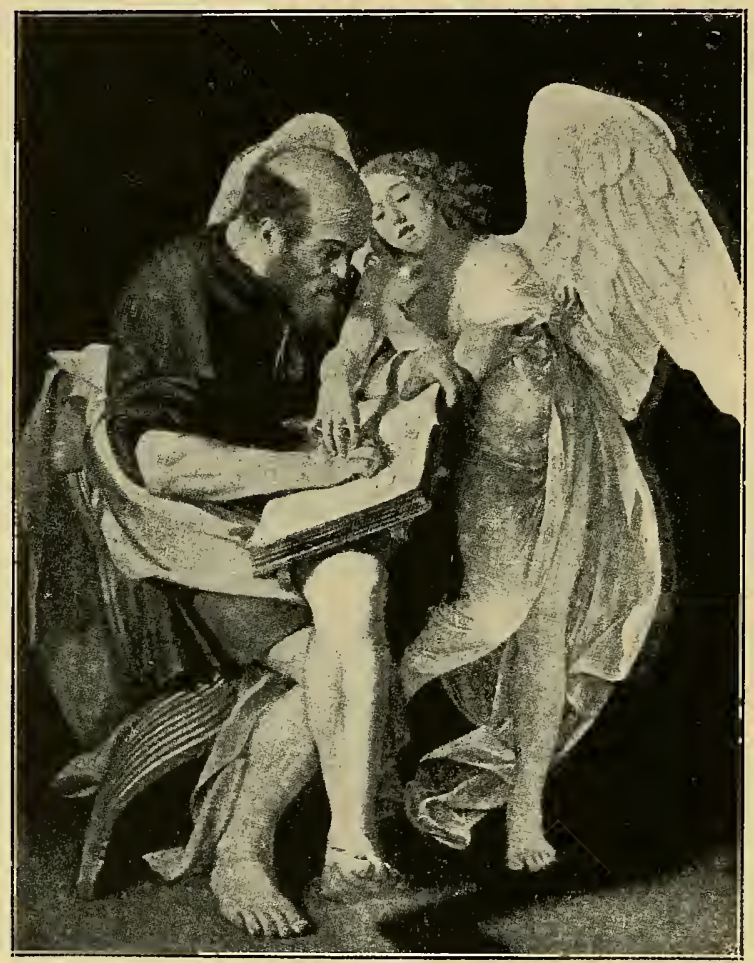

Caravaggio, S. Matteo - Museo di Berlino.

quadro dell'altare, e due tele sulle paretí laterali. Ma il giovane pittore lombardo non assolse il suo compito con soddisfazione del committente, e anzi suscitò un vero scandalo, poichè i preti fecero togliere dall'altare il suo quadro rappresentante S. Matteo in atto di scrivere il Vangelo sotto l'ispirazione dell' angelo, perchè l'apostolo era fígurato senza "decoro nè aspetto di santo, 
stando a sedere con le gambe incavalciate, e co' piedi rozzamente esposti al popolo „.. E in verità nulla di simile si era veduto mai, e i preti di S. Luigi, avvezzi alle forme iconogra-

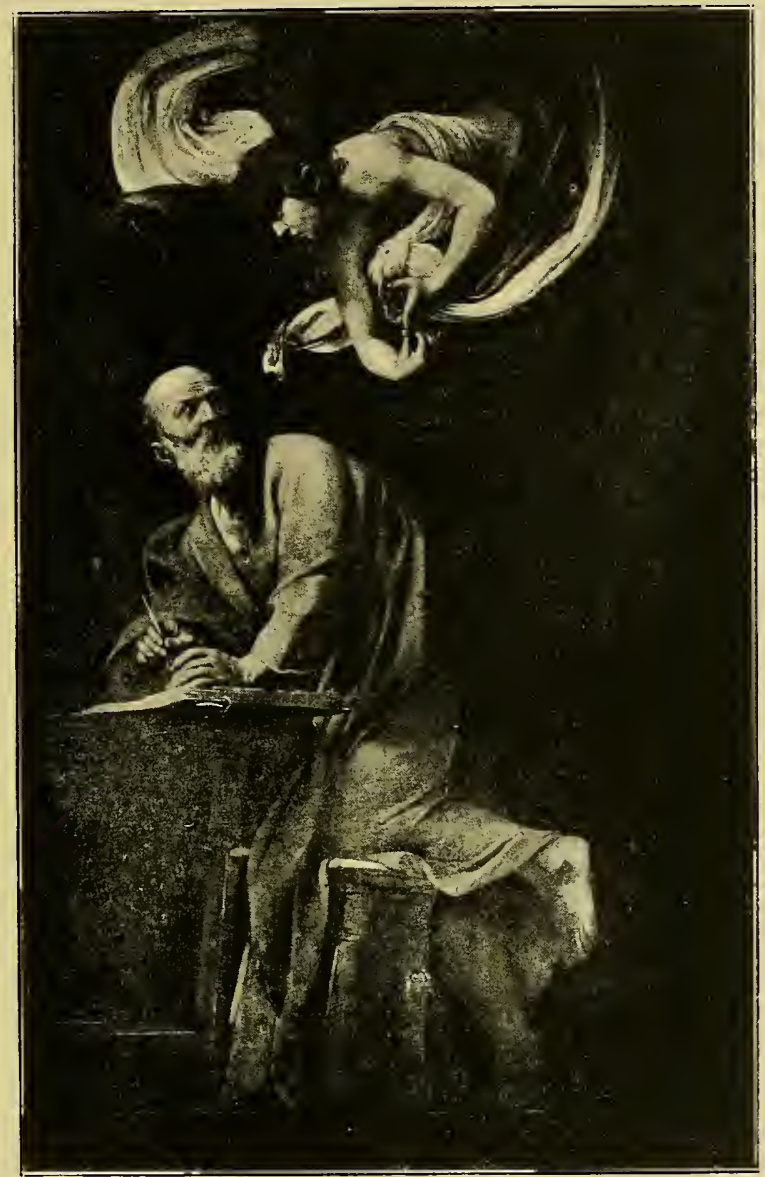

Caravaggio, S. Matteo, in S. Luigi dei Francesi.

fiche tradizionali, avevano ragione di protestare. S. Matteo in quel dipinto, che oggi è al Museo di Berlino, appariva troppo grossolano, troppo umano, e l'alata bianca figura che gli stava a fianco, non bastava a correggerne la rude umanità; era anzi 


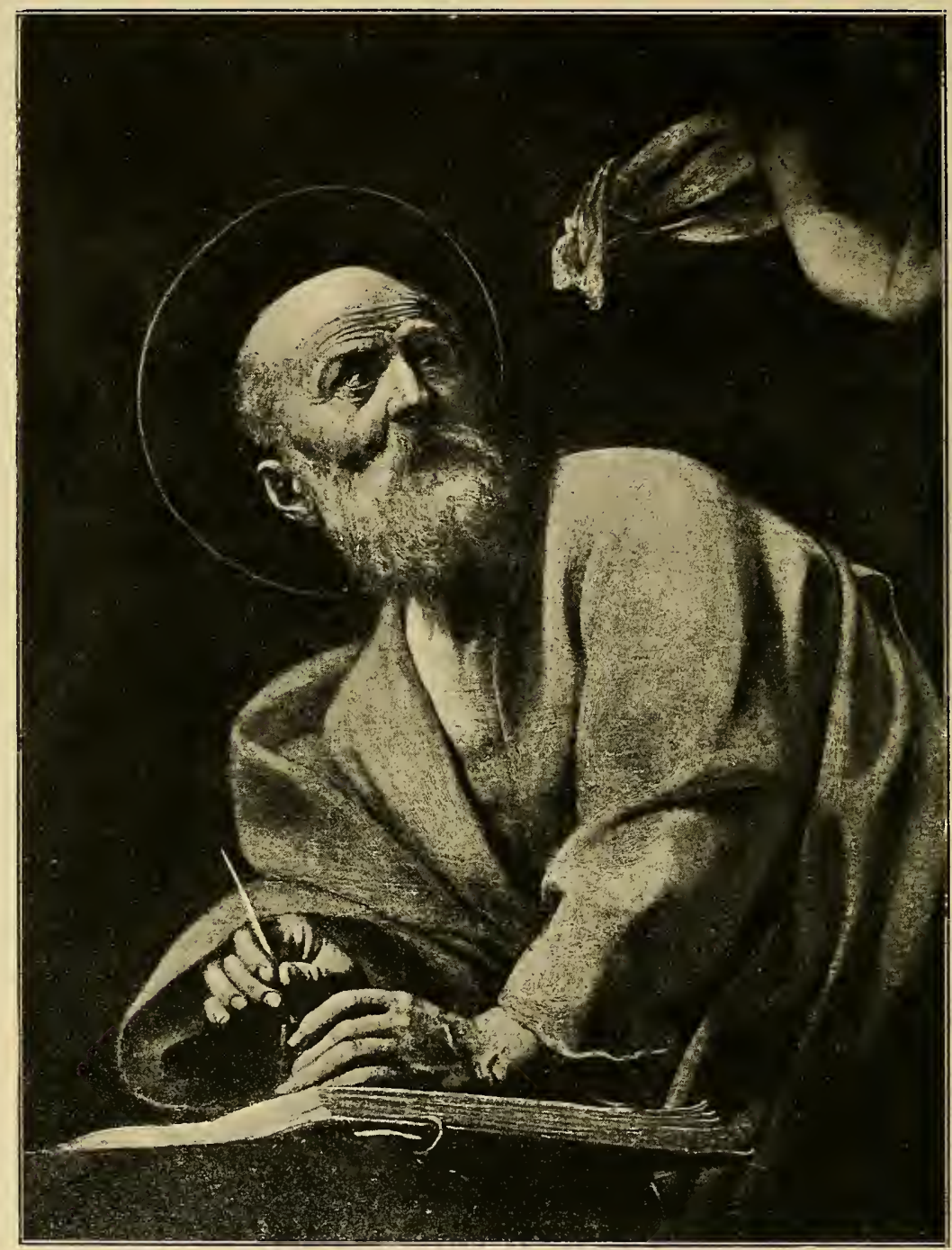

Caravaggio, Particolare del S. Matteo, in S. Luigi dei Francesi.

essa stessa troppo vicina all'uomo, perchè gli angeli, si sa, debbono volare, e non poggiare sulla terra. E Michelangelo dovette cosi rifare il suo quadro, figurandovi il santo che interrompe la scrittura del libro sacro, per volgersi all'angelo, che questa 


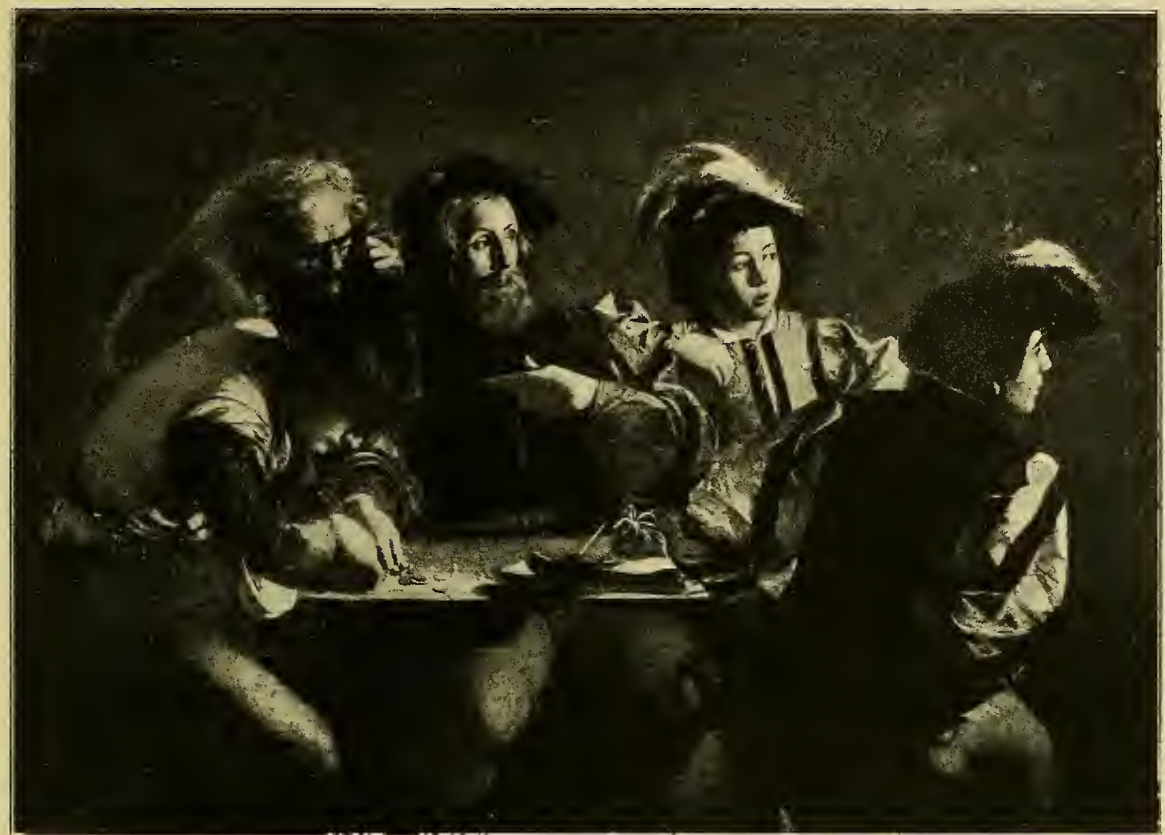

Caravaggio, Particolare della Vocazione di S. Matteo, in S. Luigi dei Francesi.

volta scende dal cielo ad ispirarlo, composizione più consona alla tradizione, più degna del luogo. Sulle pareti laterali, in due grandi tele fígurò la Vocazione di Matteo, che siede al suo tavolo di pubblicano con varie persone, ed è chiamato dal Maestro col gesto della mano; e il Martirio dell'apostolo, ferito sui gradini dell'altare da un manigoldo, tra figure di spettatori atterriti, mentre un capitano impennacchiato alla spagnola dà ordini levando la spada, e un angelo scende a portare al santo la palma, restando librato in alto, poggiato sulle nuvole, come su un solido sostegno.

Invero anche questi due quadri non son fatti per ispirar devozione; il primo sembra piuttosto una scena profana di osteria, dove siedono alla stessa tavola di Matteo tipi di scherani e di avari, così che se ci fossero i boccali del vino parrebbe di tro- 
varsi dinanzi ad uno di quei dipinti di cui si compiacciono i maestri olandesi, dove lanzichenecchi ubriachi si appoggiano coi gomiti sulla tavola, e dalla finestra piove un fascio di luce che li intaglia nella penombra dell'interno. Anche qui la scena è avvolta in una semioscurità, e c'è un giovane dál giubbetto a

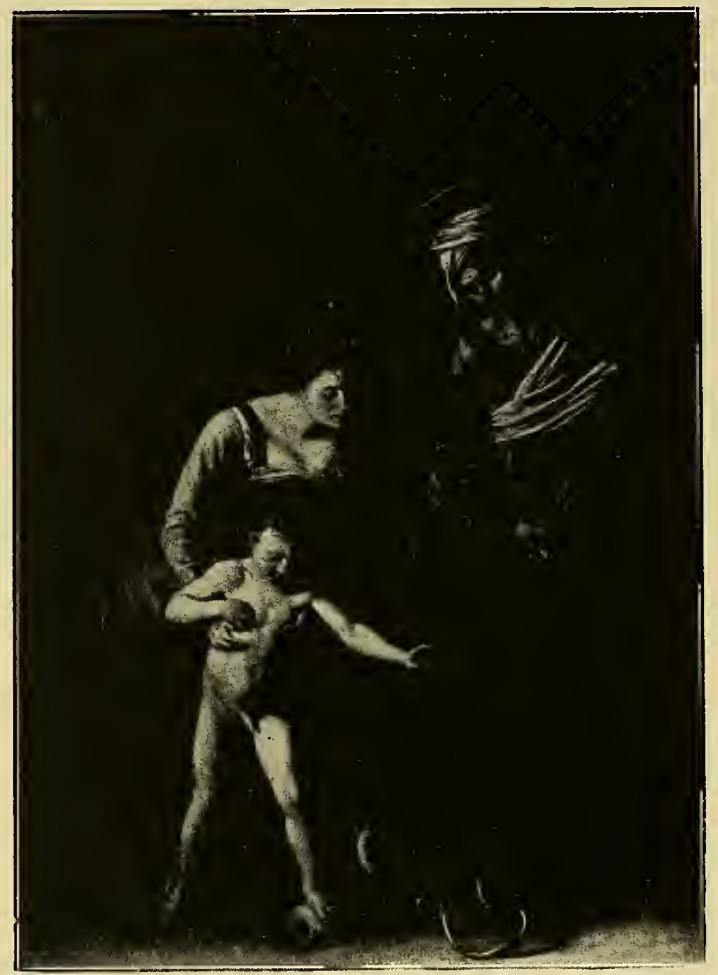

Caravaggio, S. Anna, la Madonna e il Bambino.

Galleria Borghese. (Fot. Anderson).

strisce, visto di spalle, seduto alla brava su uno sgabello, e un vecchio avaro che si regge gli occhiali per contar bene $i$ denari versati a Matteo. Certo in un quadro sacro non si era visto mai nulla di simile, e lo strepito che si levò fu grande. Narra il Baglione che "quest'opera per havere alcune pitture del naturale, e per essere in compagnia di altre fatte dal Cavalier Gio- 
seppe, che con la sua virtù si haveva presso i professori qualche invidia acquistata, fece gioco alla fama del Caravaggio, et era da' maligni sommamente lodata. Pur venendovi a vederla $\mathrm{Fe}$ -

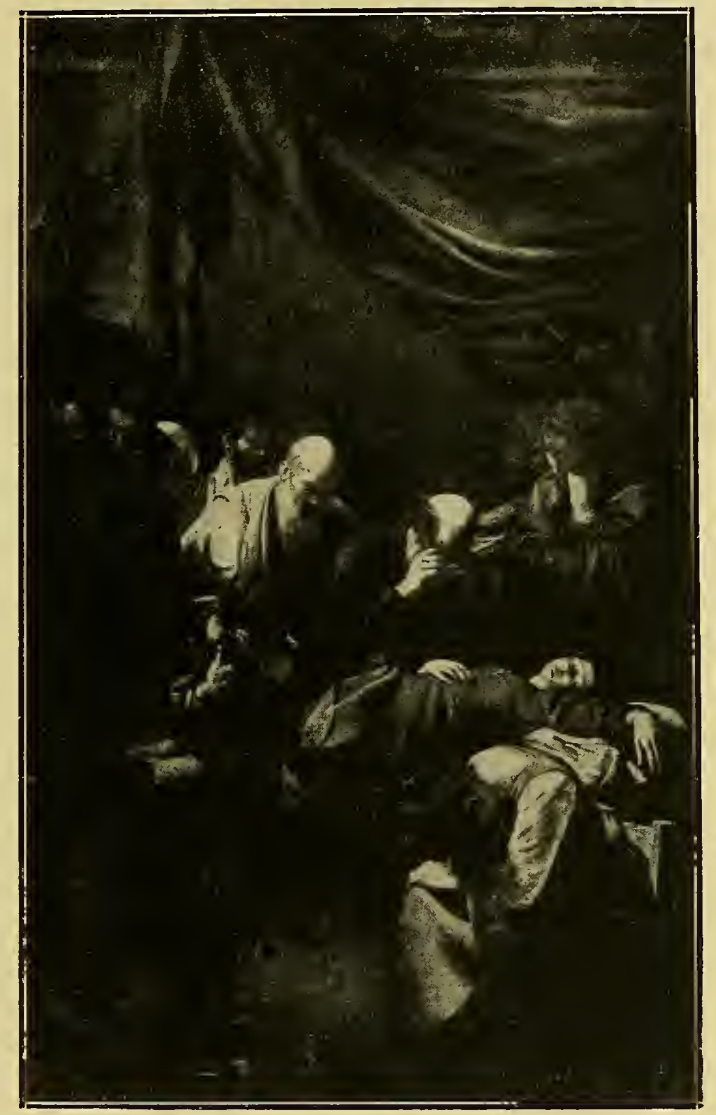

Caravaggio, Morte della Madonna - Parigi, Louvre. (Fot. Alinari).

derico Zucchero, mentre io era presente, disse: Che rumore ì questo? e guardando il tutto diligentemente soggiunse: Io non ci bedo altro che il pensiero di Giorgione nella tavola del Santo, quando Christo il chiamò all'apostolato; e sogghignando, e meravigliandosi di tanto rumore, voltò le spalle, et andossene con 
Dí „.. IMa certo la gelosia faceva velo allo Zuccari, perchè nel quadro della cappella Contarelli, c'è sì il colorito giorgionesco, ma c'è pure una libertà di composizione che va molto al di là di quanto avevano fatto $i$ veneziani del Cinquecento più avanzato, compresovi Tintoretto, e una maniera tutta particolare di

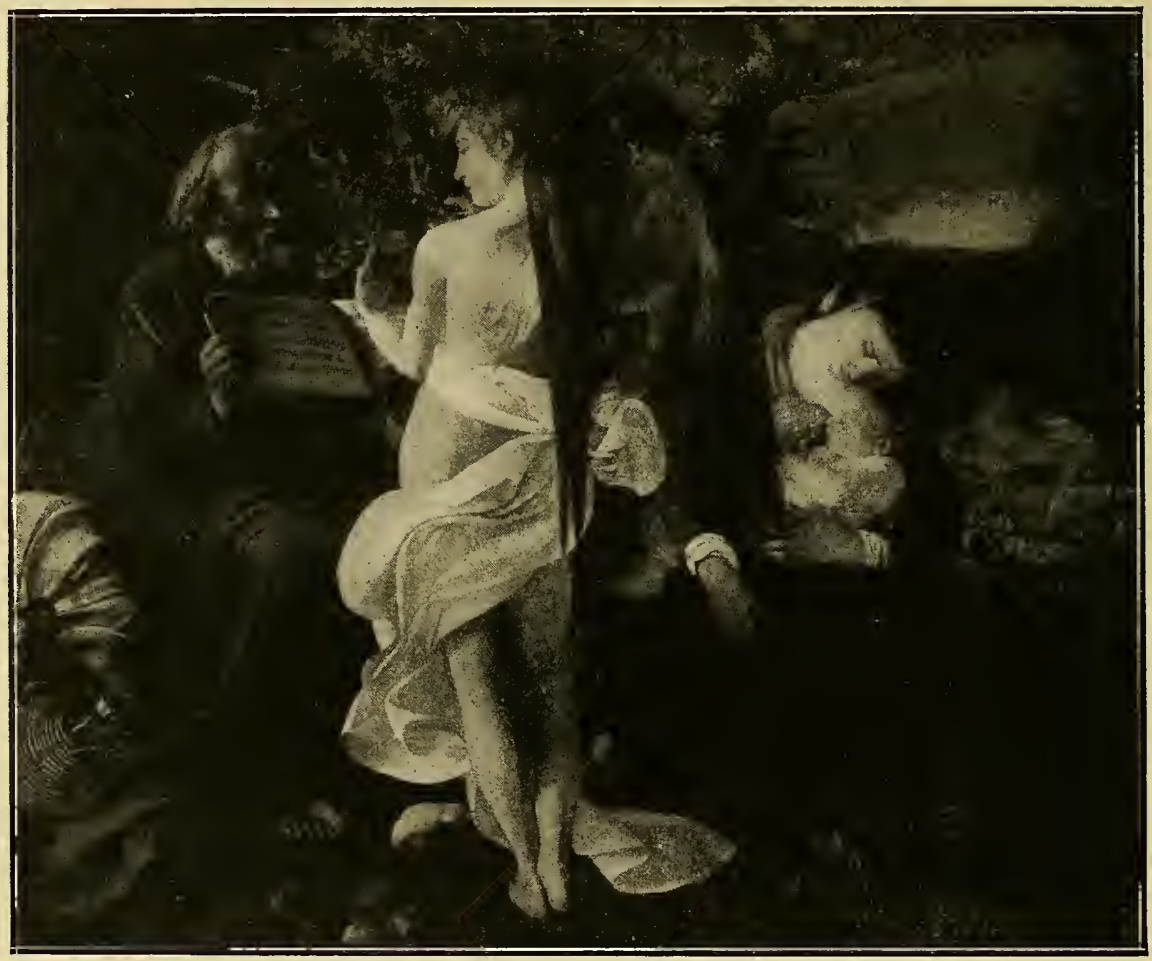

Caravaggio, Il riposo in Egitto - Galleria Doria.

(Fot. Alinari).

delineare $i$ contorni e le masse degli oggetti e delle persone con strisce luminose e ombre tondeggianti, così che le cose acquistano una corporeità risentita, una solidità insolita. Questí forti contrasti si svolgono in una atmosfera generale grigia, nelle due scene laterali; il quadro centrale è poi a fondo nero, sul quale l'artista riesce meglio a proiettare i suoi rilievi di luce. 
Quanto all'invenzione delle sue storie, pensiamo che Caravaggio si ispirasse da certe stampe popolari, quali si conservano ancor oggi in gran numero, che interpretavano $i$ soggetti sacri con uno spirito più largo, piì accessibile alla mentalità del popolo, più spregiudicato, più avvicinato alla vita vissuta, senza ricostruzioni dotte, senza derivazioni letterarie;

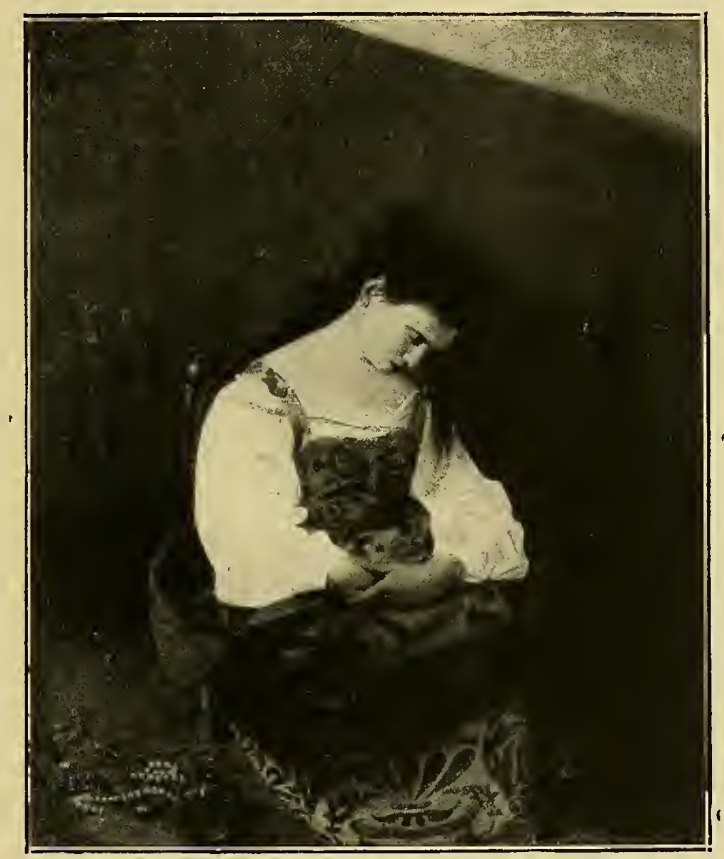

Caravaggio, La Maddalena - Galleria Doria.

(Fot. Alinari).

che pigliavano coi santi certe dimestichezze che l'arte ufficiale dei preti non si permetteva mai. E perciò l'ostracismo alle opere del Caravaggio era naturale, e come il S. Matteo, lo subì la S. Anna con Ia Madonna e il Bambino, fattagli dipingere dai Palafrenieri di Palazzo per la Basilica di S. Pietro, e levatane per ordine dei Cardinali della Fabbrica e donata al cardinal Scipione che la pose nella sua galleria, dove tuttora si vede; lo subi il 


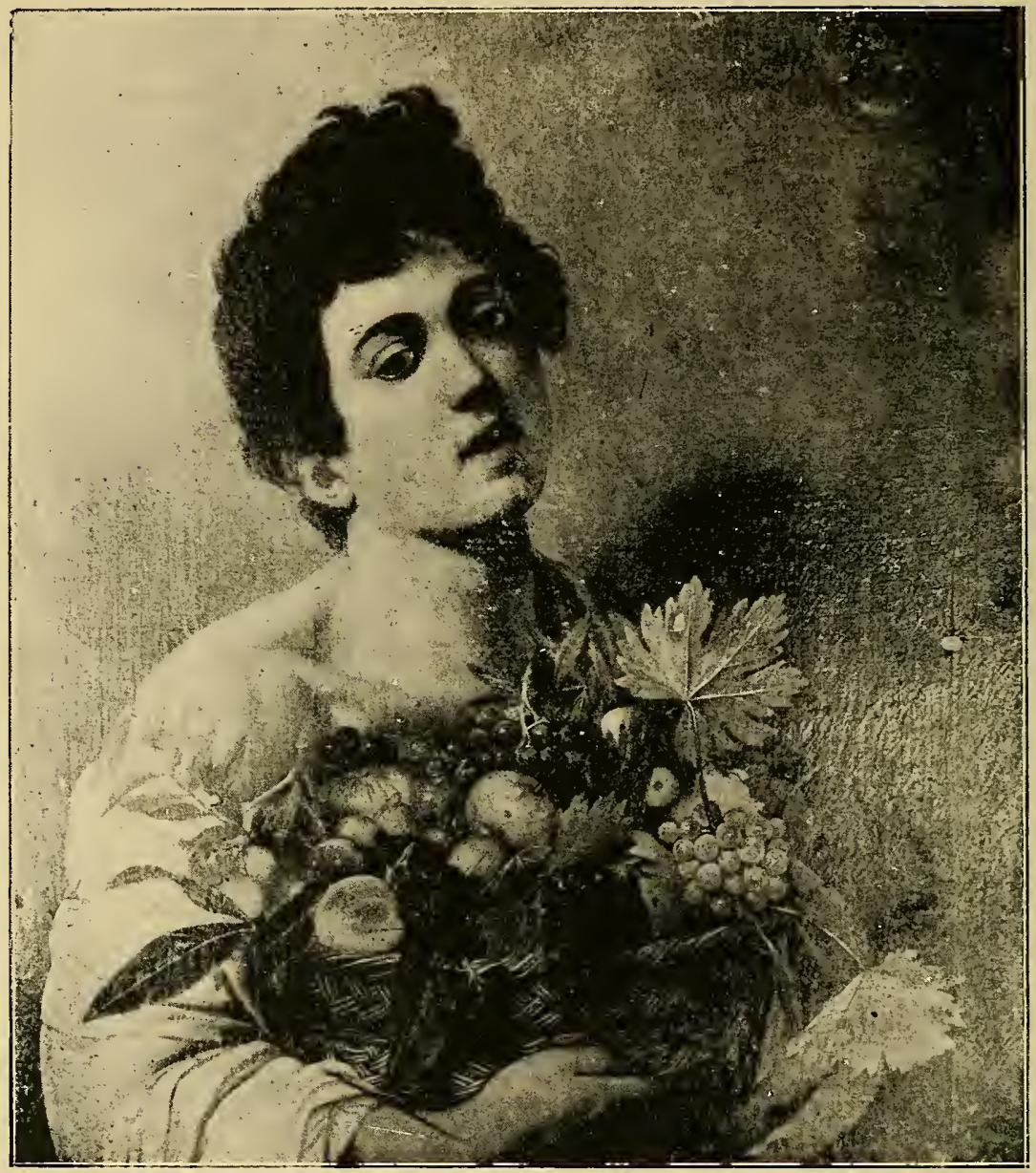

Fanciulla con frutti - Copia da Caravaggio - Galleria Borghese.

Transito di Maria, dipinto per la chiesa della Scala: " perchè havea fatto con poco decoro la Madonna gonfia, e con gambe scoperte, fu levata via e la comperò il duca di Mantova „; oggi è al Louvre.

Per questí suoi atteggiamenti, così discordi dall'arte del suo tempo, Caravaggio venne considerato come un verista spinto, 
che copiava la natura senza discernimento, non aborrendo dal ritrarre le cose più vili e ripugnanti. Ma questo giudizio è profondamente errato, perchè se il maestro lombardo teneva fissi gli occhi al vero, infischiandosi di Raffaello e delle statue antiche, Io riproduceva però attraverso una sua visione tutta personale.

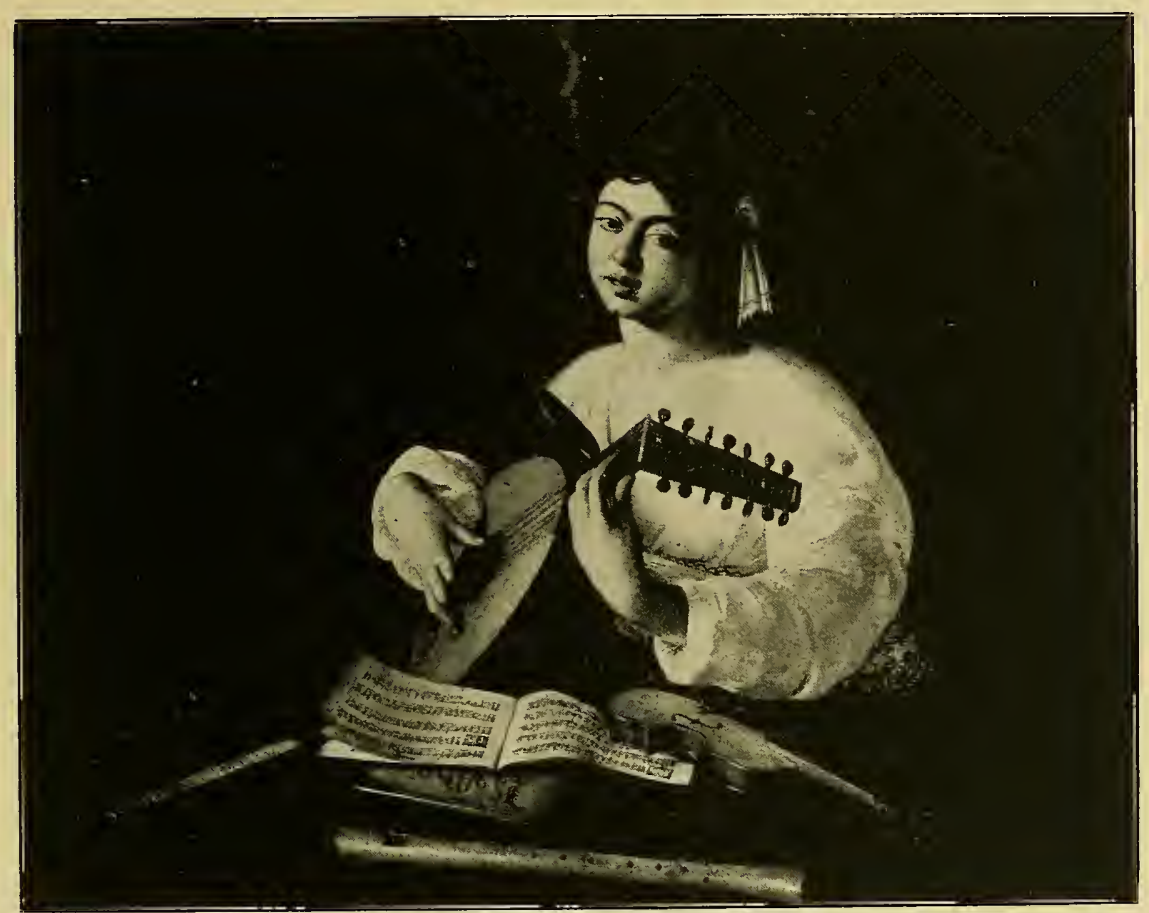

Carlo Saraceni, Suonatrice di liuto - Galleria Barberini. (Fot. Anderson)

Nei suoi dipinti giovanili, come la Maddalena e il Riposo in Egitto della Galleria Doria, e la Suonatrice dell' Ermitage, non solo non c'è traccia di crudo verismo, ma c'è una luminosità chiara, una ricerca di toni delicati. Il Riposo è una festa di colore: in un paesaggio lussureggiante sta il gruppo delle sacre persone; Giuseppe seduto regge il libro di musica a un angelo 


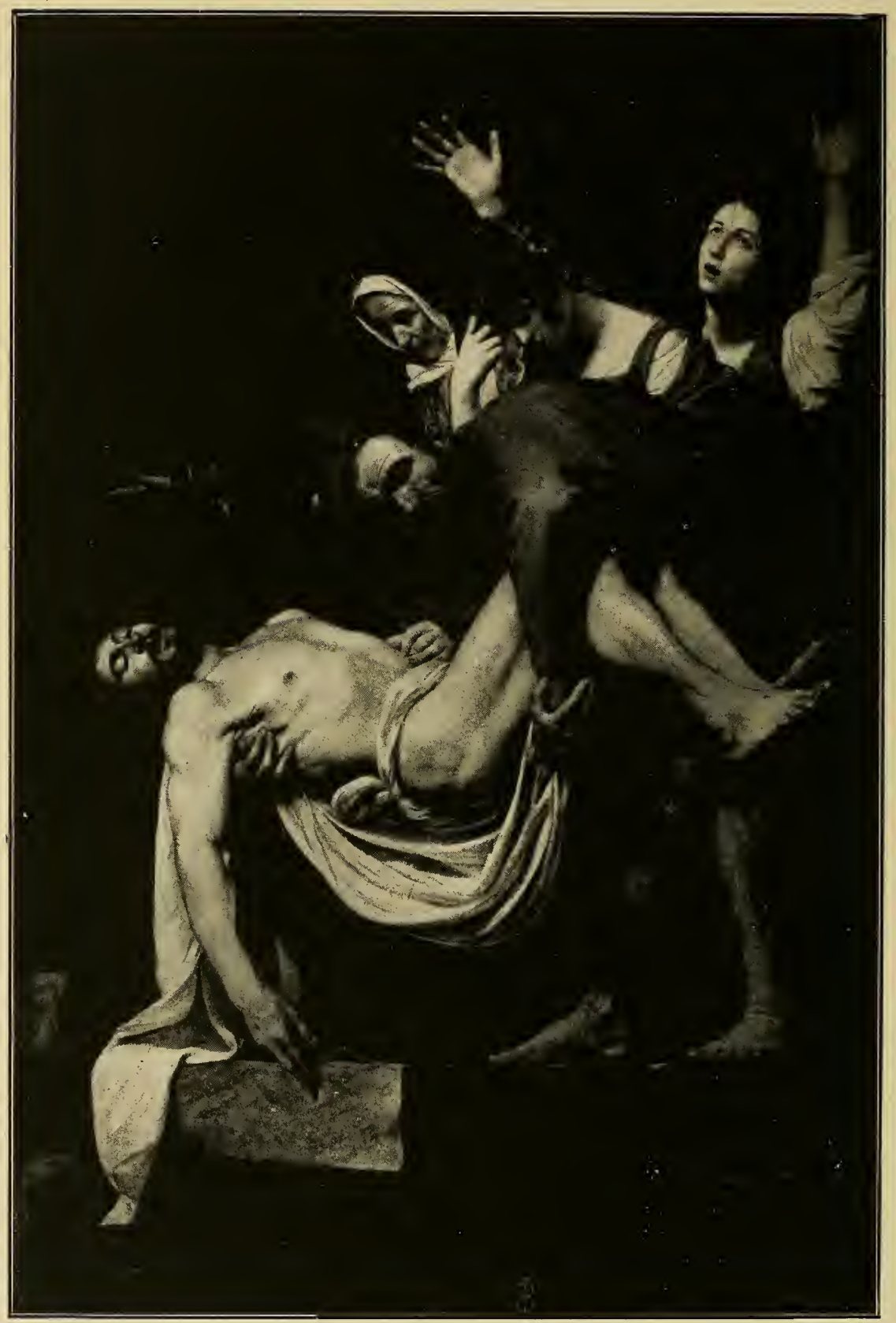

Caravaggio - La Dzposizione - Pinacoteca Vaticana. (Fot. Alinari). 


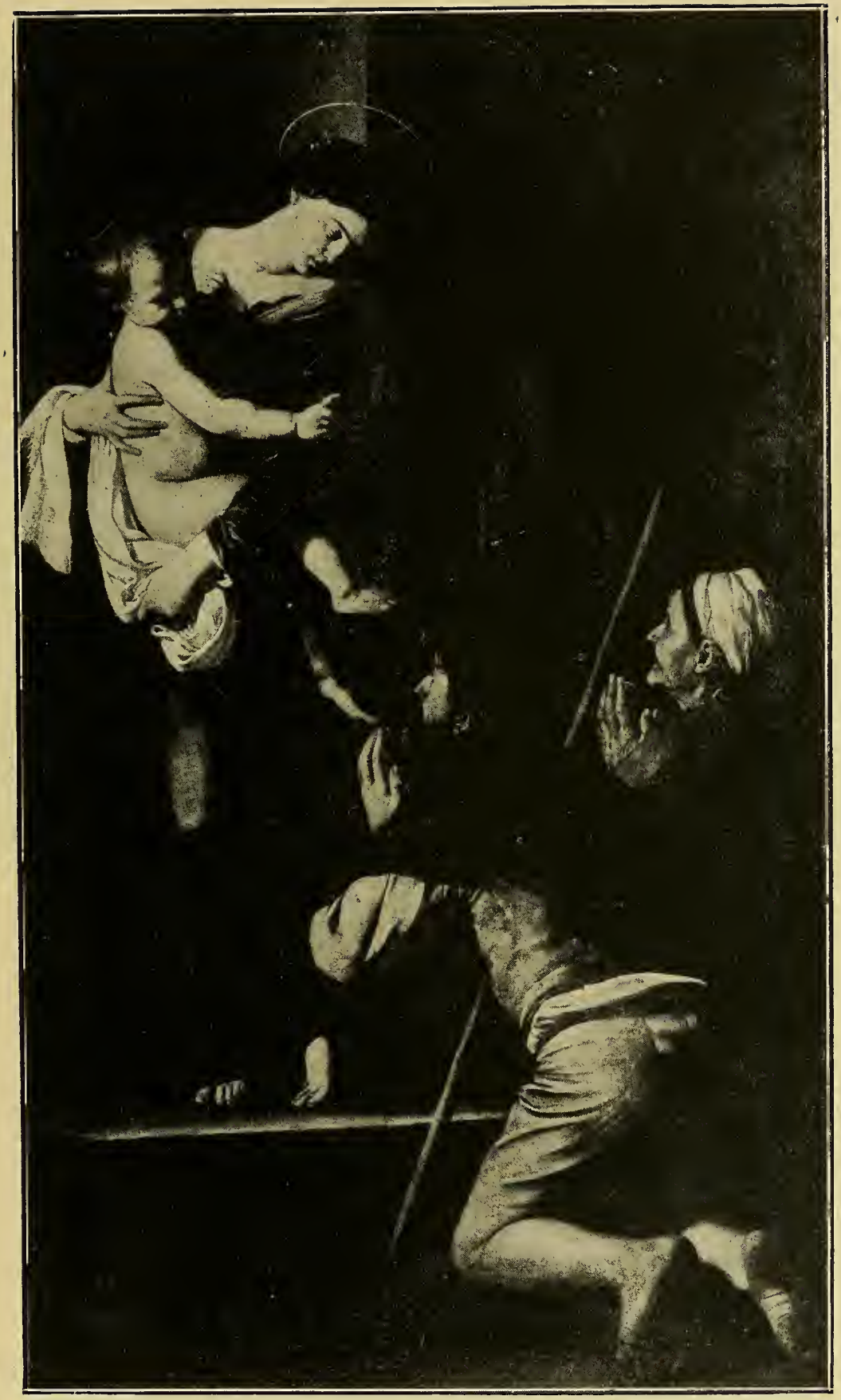

Caravaggio, La Madonna del Popolo, in S. Agostino. 


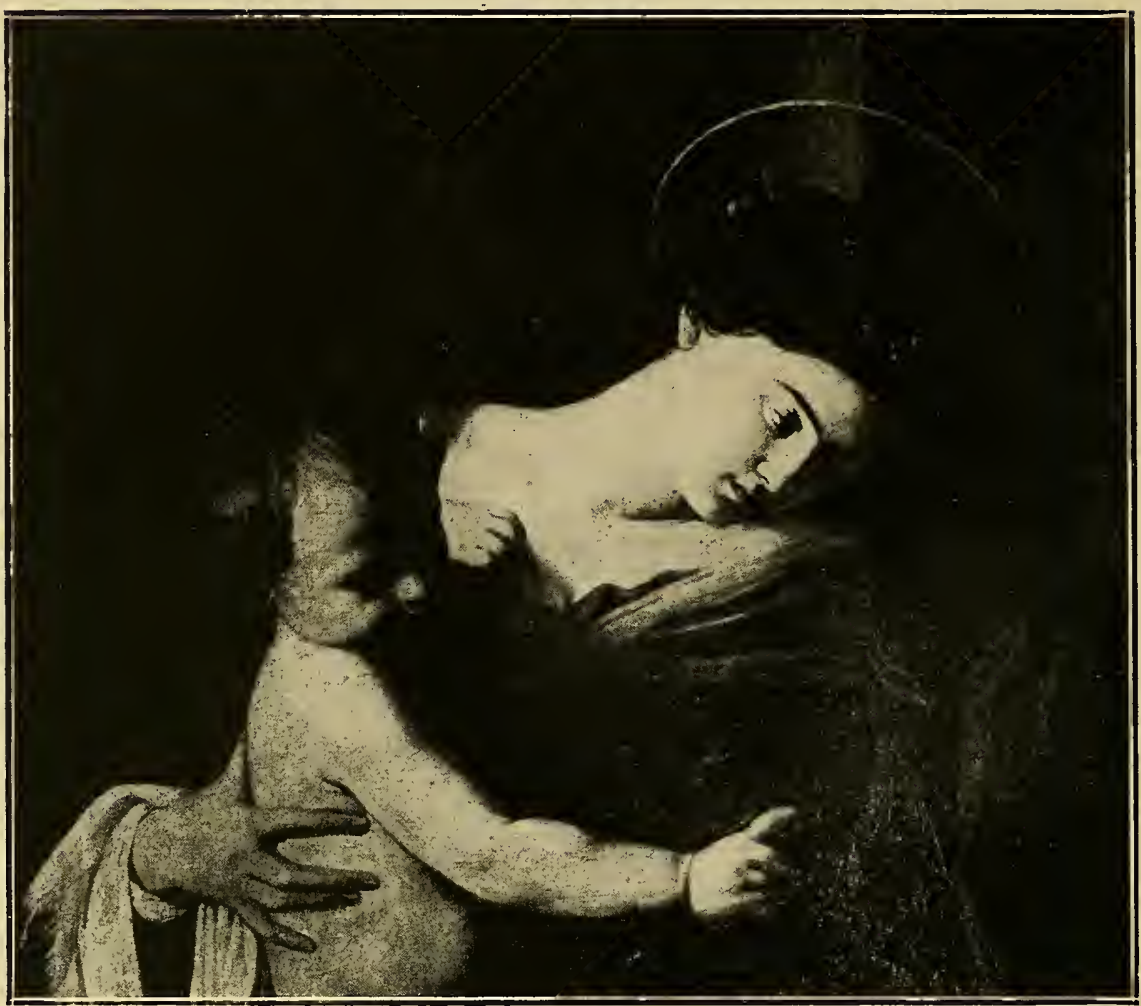

Caravaggio, Particolare della Madonna de1 Popolo.

tutto bianco e biondo che suona il violino, suggerendo dolci sogni alla Madonna, addormentata, col capo reclinato sul Bambino che tiene stretto in grembo; nessun pittore idealista ha mai dipinto un angelo più puro, più soave di questo del Caravaggio. il quale è ancora qui tutto cinquecentesco, e si riattacca al Savoldo e al Moretto da Brescia. Anche la Maddalena è una deliziosa cosa, e la descrive bene il Bellori: "Dipinse una fanciulla a sedere sopra una seggiola con le mani in seno in atto di asciugarsi $i$ capzlli; la ritrasse in una camera, ed aggiungendovi in terra un vasello d'unguenti con monili e gemme, la finse per Maddalena. Posa alquanto da un lato la faccia, e 
s'imprime la guancia, il collo, e 'l petto in una tinta pura, facile e vera, accompagnata dalla semplicità in tutta la fígura, con le braccia in camicia, e la veste gialla ritirata alle ginocchia dalla sottana bianca di damasco fiorato ,.

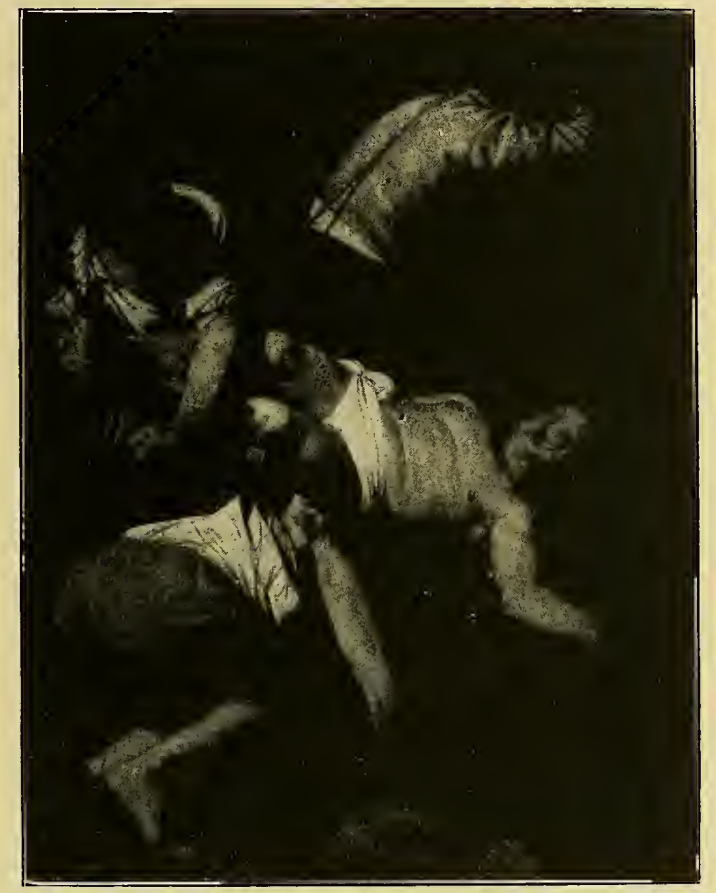

Caravaggio, Crocifíssione di S. Pietro

S. Maria del Popolo. (Fot. Anderson)

A Roma Caravaggio modifica profondamente la sua maniera; lascia $i$ fondi luminosi e proietta le sue figure su uno schermo nero, sul quale appaiono gagliardamente rilevate, con evidenza statuaria, o le immerge in un'atmosfera bruna, illuminando nudi vigorosi, ottenendo così un forte risalto dei contorni, che non appariscono studiatamente disegnati come nei bolognesi. E abbandona pure il colorito veneziano, e si compiace di toni metallici, freddi, quasi marmorei, che contribuiscono alla impres- 
sione di solidità che hanno sempre le sue composizioni. Così nella celebre Deposizione, già alla Chiesa Nuova $e$ ora in Vaticano, dipinta quattro o cinque anni dopo la cappella Contarelli, che forse fra i quadri del Caravaggio è iconograficamente il più rispettoso della tradizione, mette in rilievo luminosamente

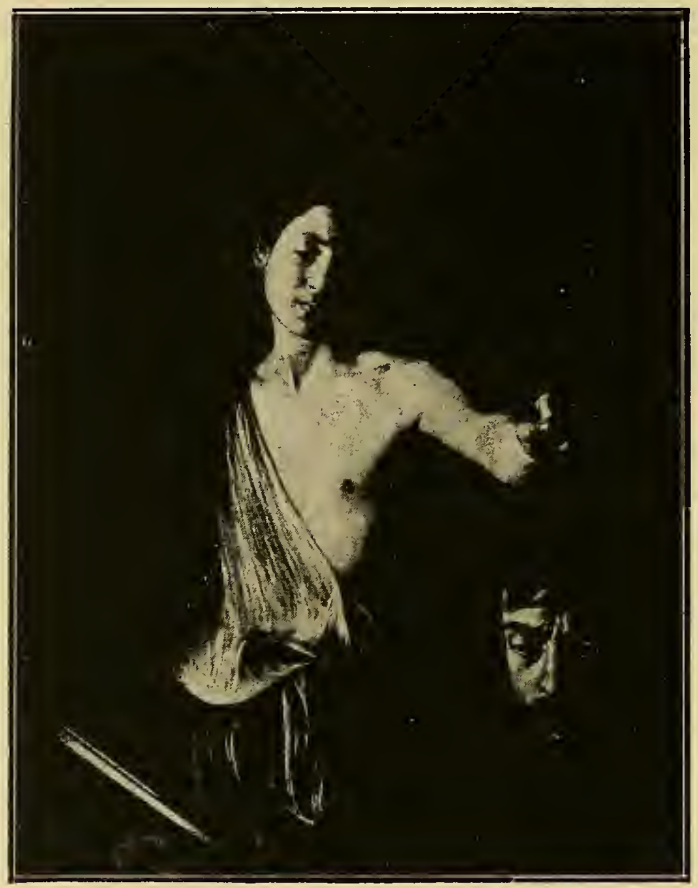

Caravaggio, David - Galleria Borghese.

(Fot. Anderson).

il corpo bianco del Cristo, e scava dal fondo nero le figure dei due pietosi e delle donne piangenti. Così nella Madonna della chiesa di S. Agostino modella con evidenza plastica la figura della Vergine che sta addossata ad uno stipite di porta col Bambino tra le braccia, e guarda, senza interessarsene troppo, due oranti, un popolano e una vecchia, che la supplicano, anch'essi vigorosamente formati e cavati fuori dall'ombra. Ab- 
biamo detto che la Madonna guarda con indifferenza i due inginocchiati, $i$ quali pure la pregano con poco fervore, ed è questa una particolarità dell'arte caravaggesca: le sue figure mancano quasi sempre di movimento affettivo, come dicevano $i$ seicentisti; non prendono parte viva alla scena, ma

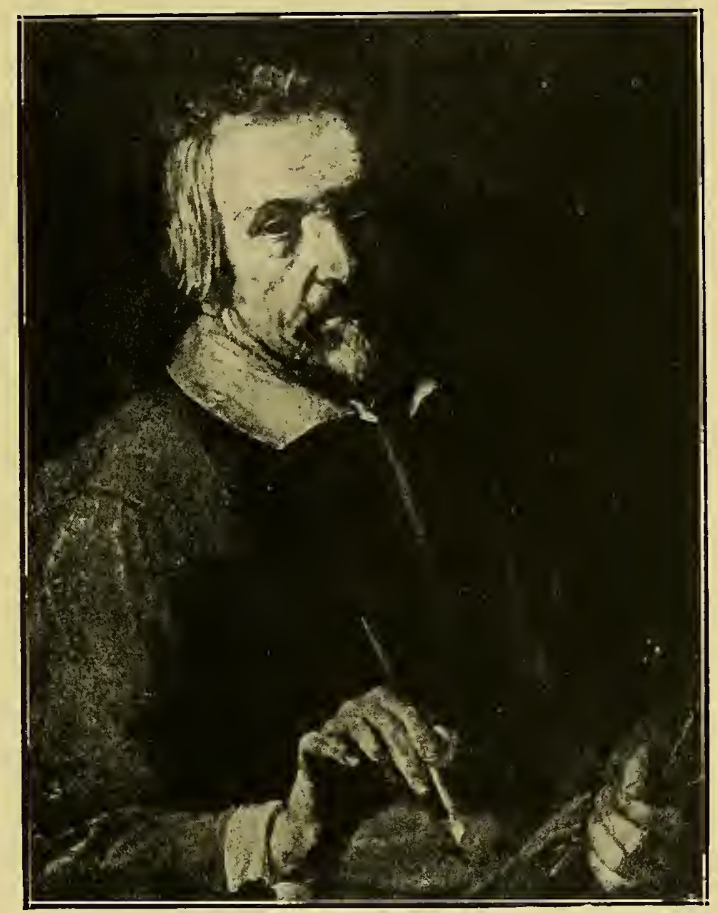

Caravaggio, Autoritratto - Firenze, Uffizi.

(Fot. Brogi).

par quasi che ognuna faccia da sè, che stia in un suo mondo chiuso, estranea a ciò che avviene intorno; non tocca dall'appassionato, dallo sforzato pathos dei bolognesi $e$ del Bernini.

Per Caravaggio inutilmente i Carracci hanno squadernato il loro codice pittorico sulla volta della Galleria Farnese; egli non vi guarda neppure, e segue la sua via, noncurante e sprez- 
zante. "Essendogli mostrate, dice il Bellori, le statue più famose di Fidia e di Glicone, acciocchè vi accomodasse lo studio, non diede altra risposta se non che distese le mani verso una mol-

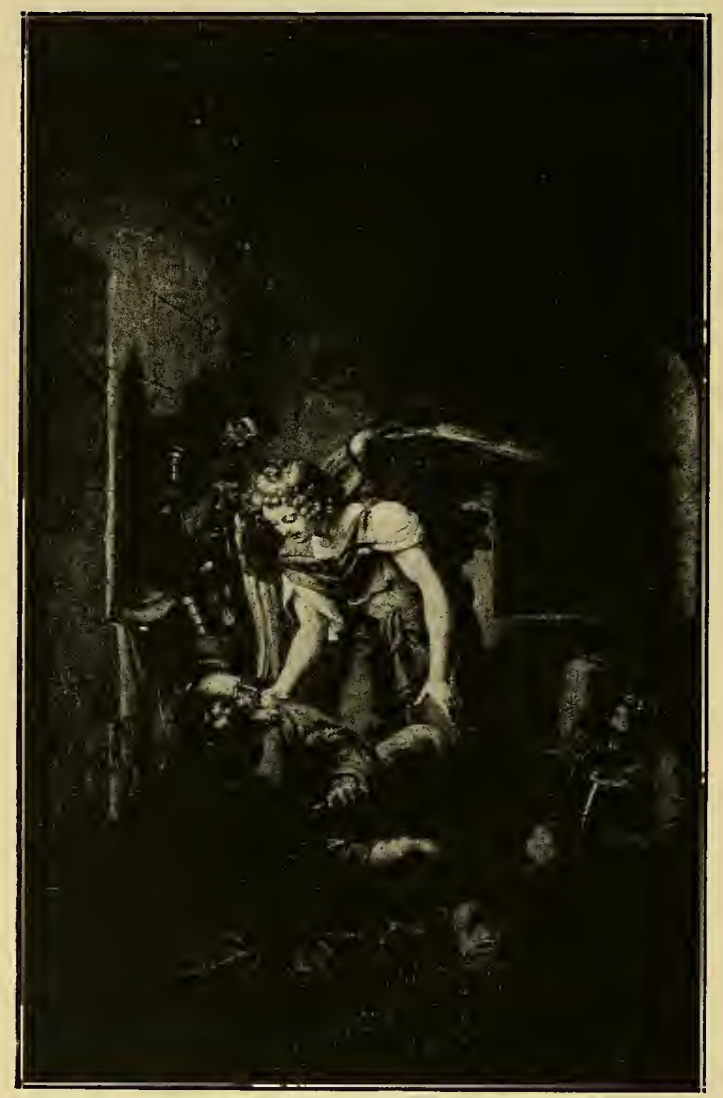

Domeníchino, Líberazione di S. Pietro, in S. Pietro in Vincoli. (Fot. Anderson).

titudine di uomini, accennando che la Natura l'aveva a sufficienza provveduto di maestri.... E perchè egli aspirava all'unica lode del colore, sicchè paresse vera l'incarnazione, la pelle e 'I sangue, e la superfice naturale, a questo solo volgeva intento l'occhio e l'industria, lasciando da parte gli altri pensieri del- 


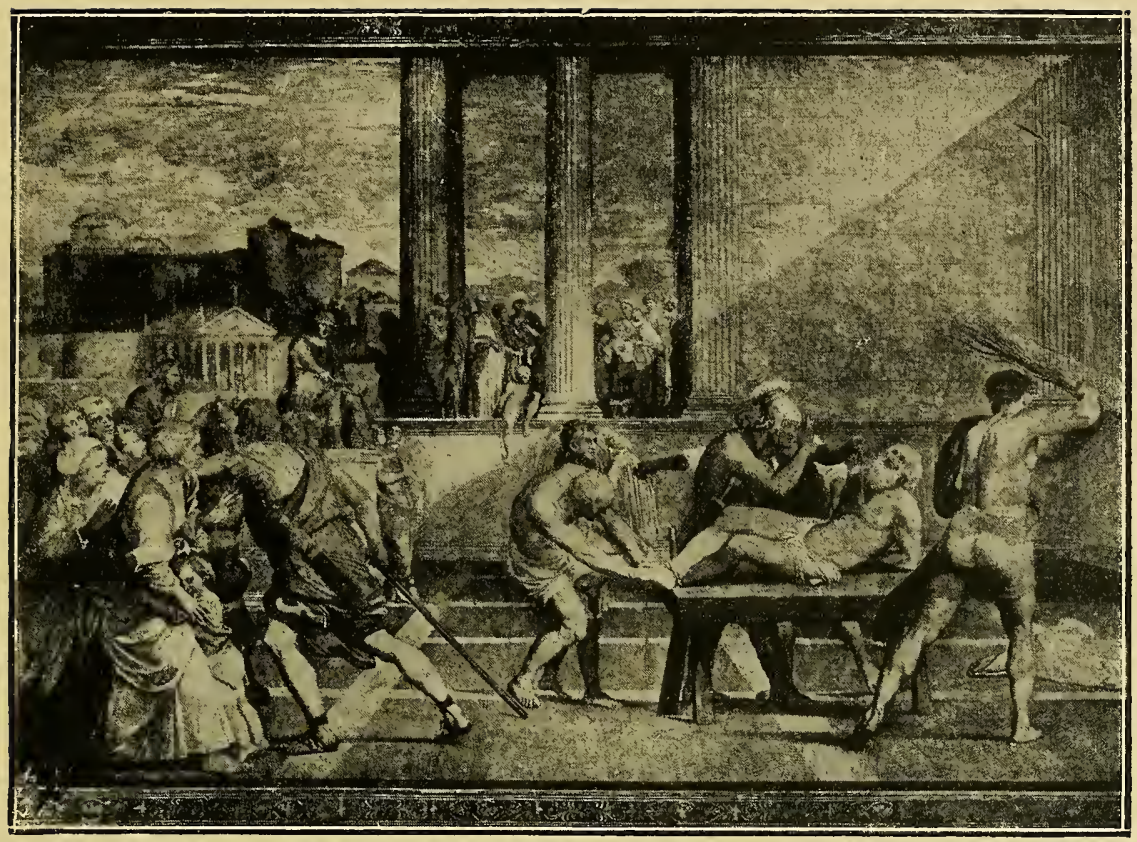

Domenichino, Flagellazione di S. Andrea, in S. Gregorio. (Fot. Anderson)

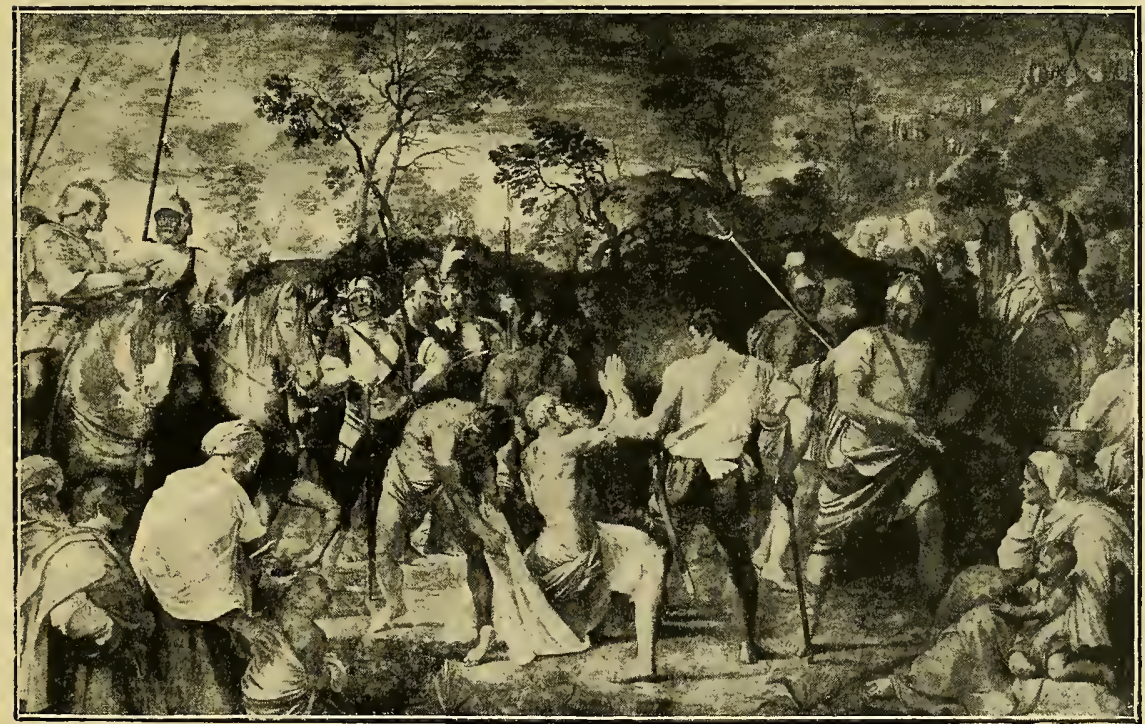

Guido, S. Andrea condotto al martirio, in S. Gregorio. (Fot. Anderson) 


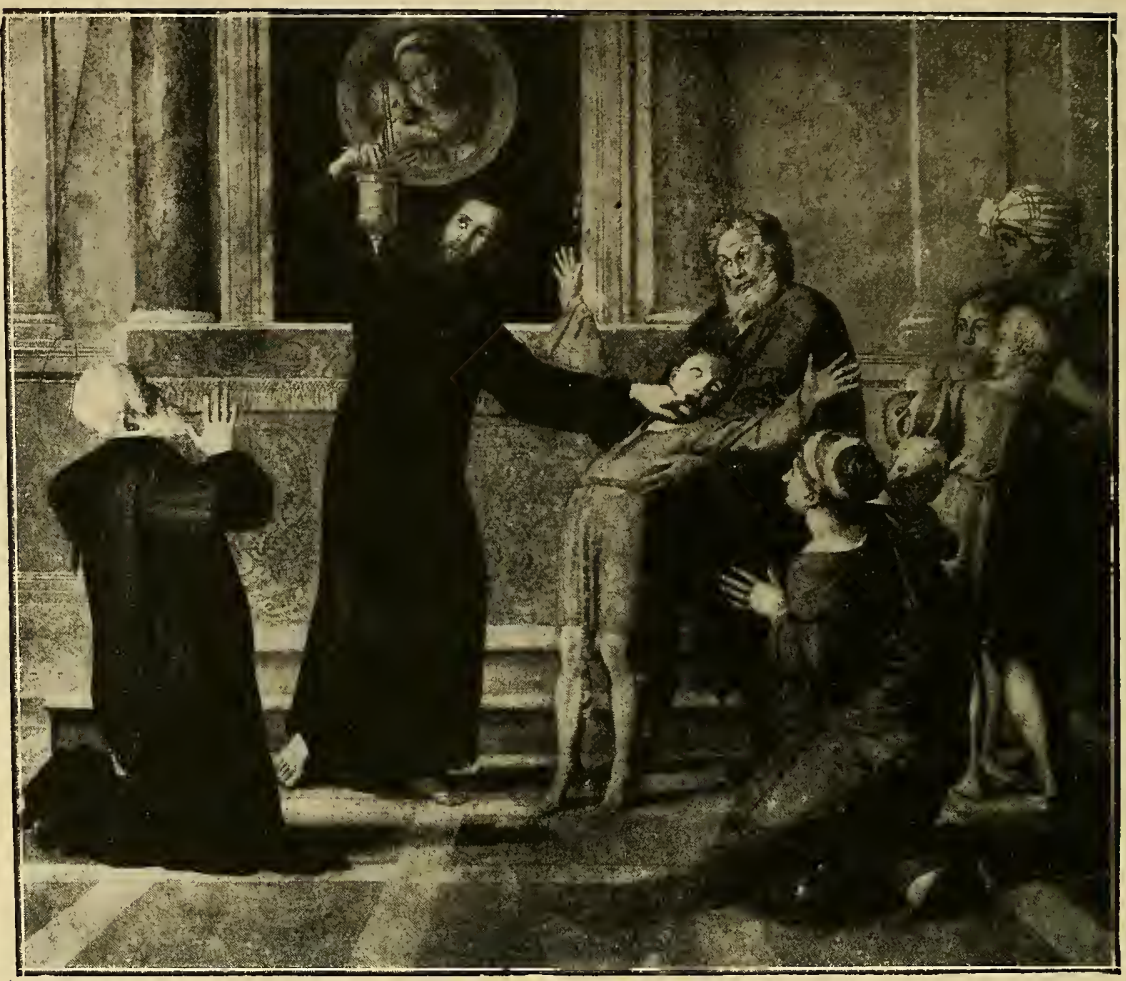

Domenichino, Gurarigione dell'ossesso - Badia di Grottaferrata.

(Fot. Anderson).

l'Arte „. Dovendo dipingere, intorno al 1600, due storie di S. Pietro e S. Paolo per la cappella Cerasi in S. Maria del Popolo, scelse per la prima il momento in cui $i$ manigoldi sollevano la pesante croce a cui è inchiodato l'apostolo, e ne collocò così uno in gínocchio, visto dal dietro, che fa leva con le spalle, un altro che afferra con le muscolose braccía da facchino l'estremità del legno, un terzo che tira sulle spalle una corda. Nell'altra tela rappresentò S. Paolo caduto supino sotto a un grosso cavallo bianco, che un servo ritiene per il morso; anche qui strappando ogni legame con la tradizione, e sforzando i contrasti di luce e di ombra. L'esempio del Caravaggio era pericoloso per chi 
non avendo la sua potenza costruttiva, imitava solo l'atteggiamento esteriore del suo stile. Perchè, malgrado l'ostilità dei pretí e dei vecchi pittori manieristi, il maestro lombardo attirava

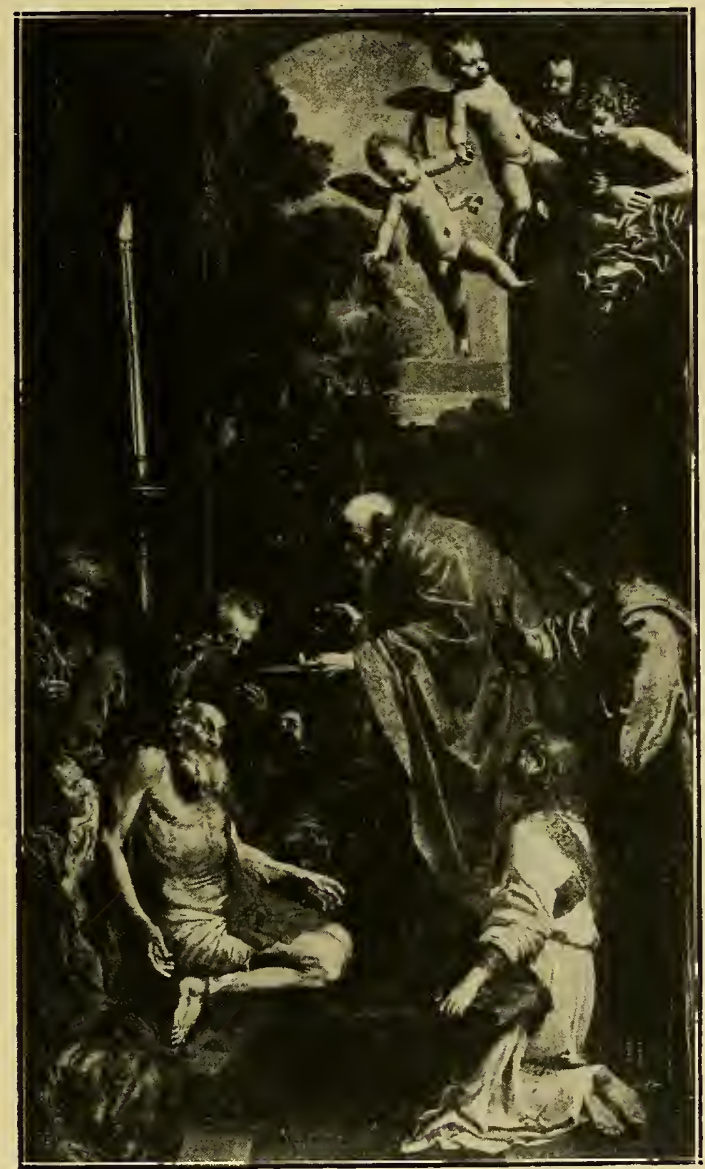

Domenichino, Comunione di S. Girolamo

Pinacoteca Vaticana. (Fot. Alinari).

molti alla sua maniera, e senza che cercasse di formare discepoli, creava in Roma una nuova scuola. "Il Caravaggio, scrive ancora il biografo Bellori, facevasi ogni giorno più noto per il colorito ch'egli andava introducendo, non come prima 


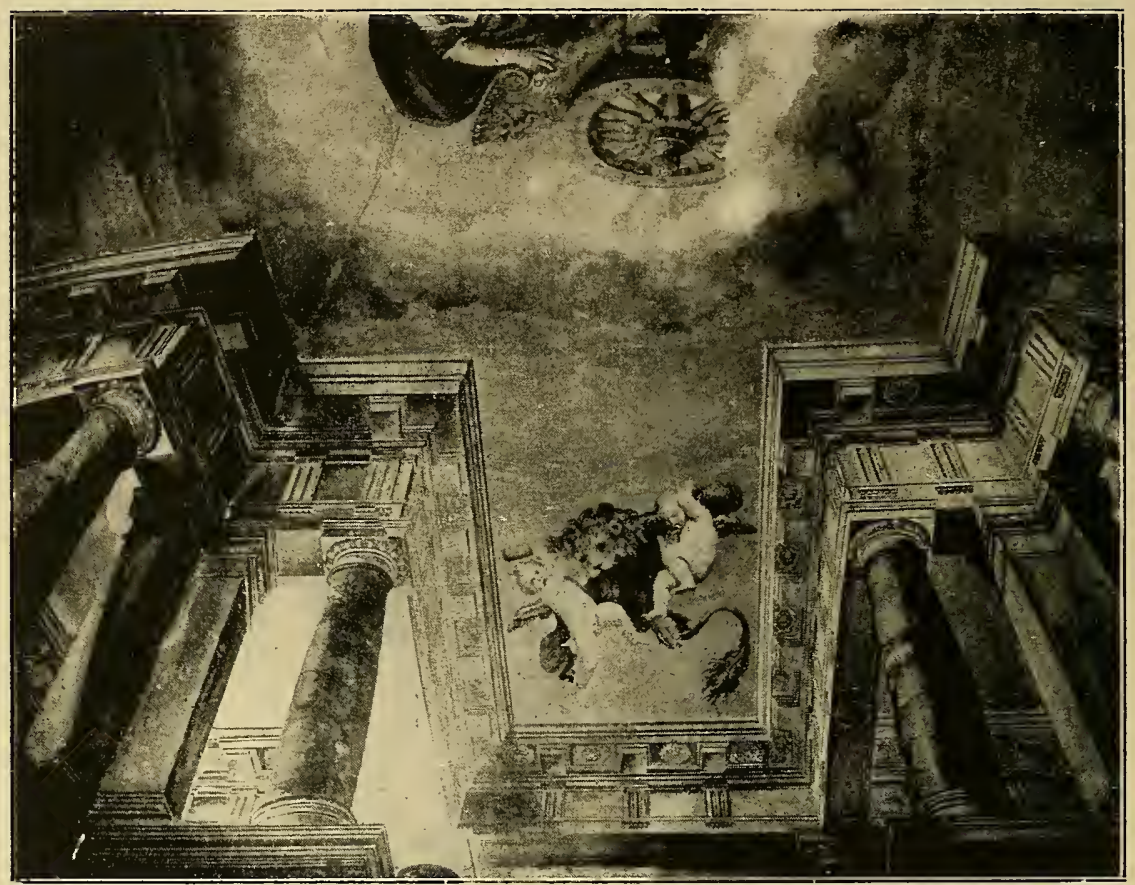

Domenichino, Affresco nel Palazzo Costaguti.

(Fot, Moscioni)

dolce e con poche tinte, ma tutte risentite di oscuri gagliardi, servendosi assai del nero per dar rilievo ai corpi. E s'inoltrò egli tanto in questo suo modo di operare, che non faceva mai uscire all'aperto del sole alcuna delle sue figure, ma trovò una maniera di campirle entro l'aria bruna di una camera rinchiusa pigliando un lume alto, che scendeva a piombo sopra la parte principale del corpo, lasciando il rimanente in ombra, a fine di recar forza con veemenza di chiaro e d'oscuro: tanto che i pittori che allora erano in Roma, presi dalla novità, e particolarmente i giovani, concorrevano a lui, e celebravano lui solo come unico imitatore della Natura, e come miracoli mirando l'opere sue lo seguitavano a gara, spogliando modelli ed alzando lumi e senza più attendere a studio e insegnamento ciascuno trovava 


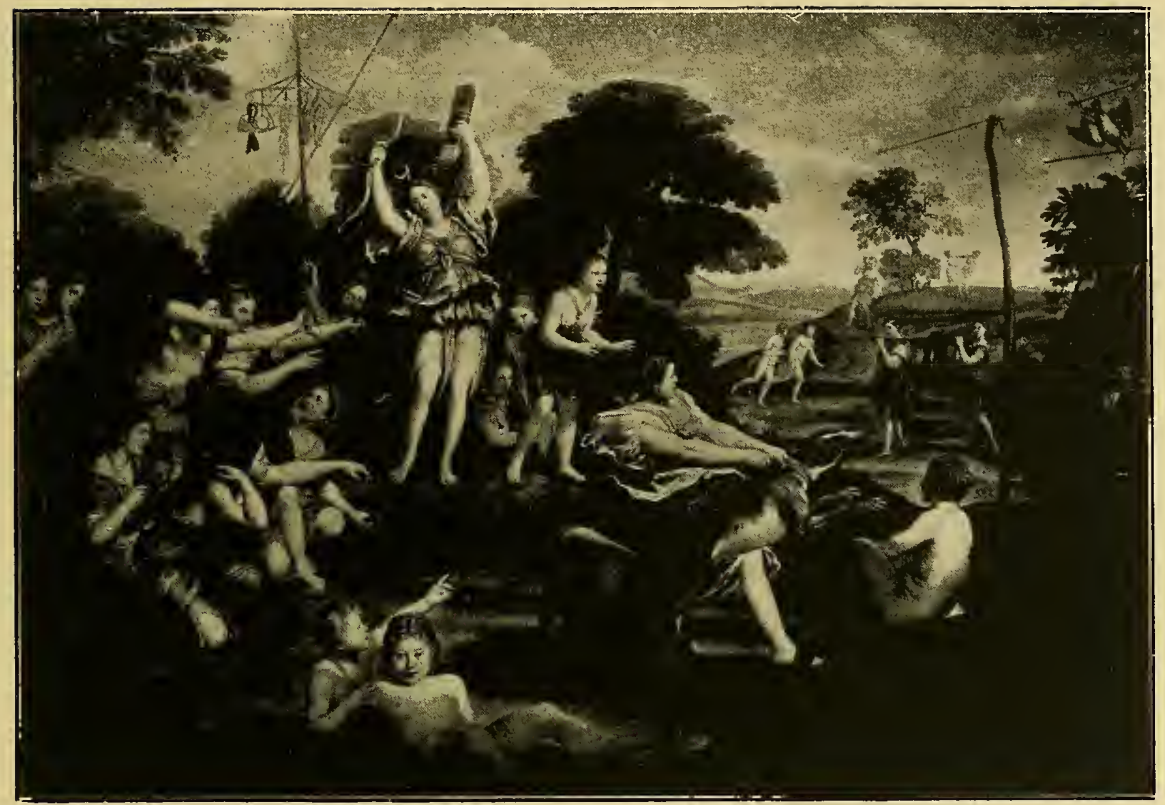

Domenichino, La Caccia di Diana - Galleria Borghese. (Fot. Anderson).

facilmente in piazza e per via il maestro o gli esempi nel copiare il naturale, ,*

Michelangelo da Caravaggio insofferente di ogni legame nell'arte, era altrettanto libero e sfrenato nei suoi costumi; usciva spesso a dir male degli altri pittori, e con facilità metteva mano alle armi che portava sempre indosso. Fu insomma, come dice il Baglione, che ebbe aspre questioni con

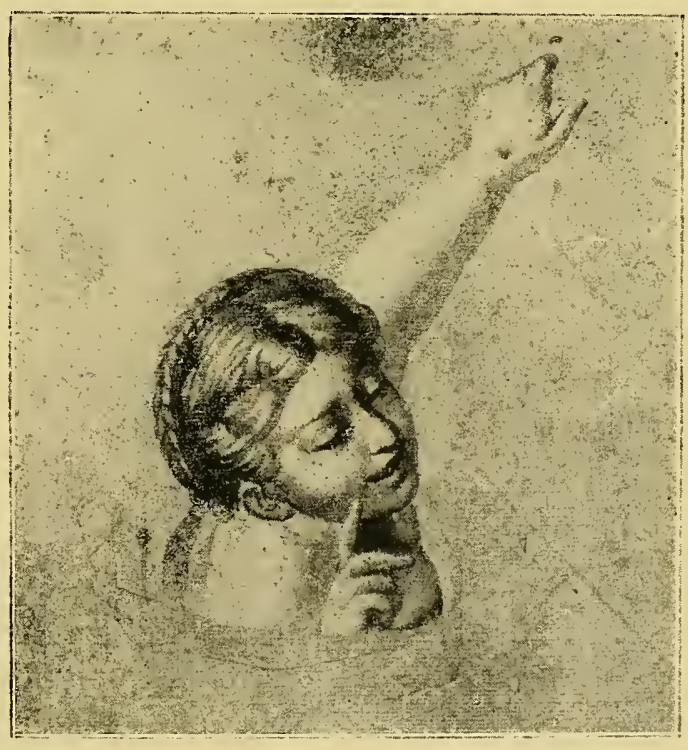

Domenichino, Disegno per la Caccia di Diana Collezione A. Munoz. 
lui, "per soverchio ardimento di spirito, un poco discolo "; e i documenti dell'Archivio Criminale messi in luce dal Bertolotti, ci apprendono che lo fu molto. II 19 novembre 1600 era querelato da certo Girolamo Spampa, che aveva ricevuto da lui " parec-

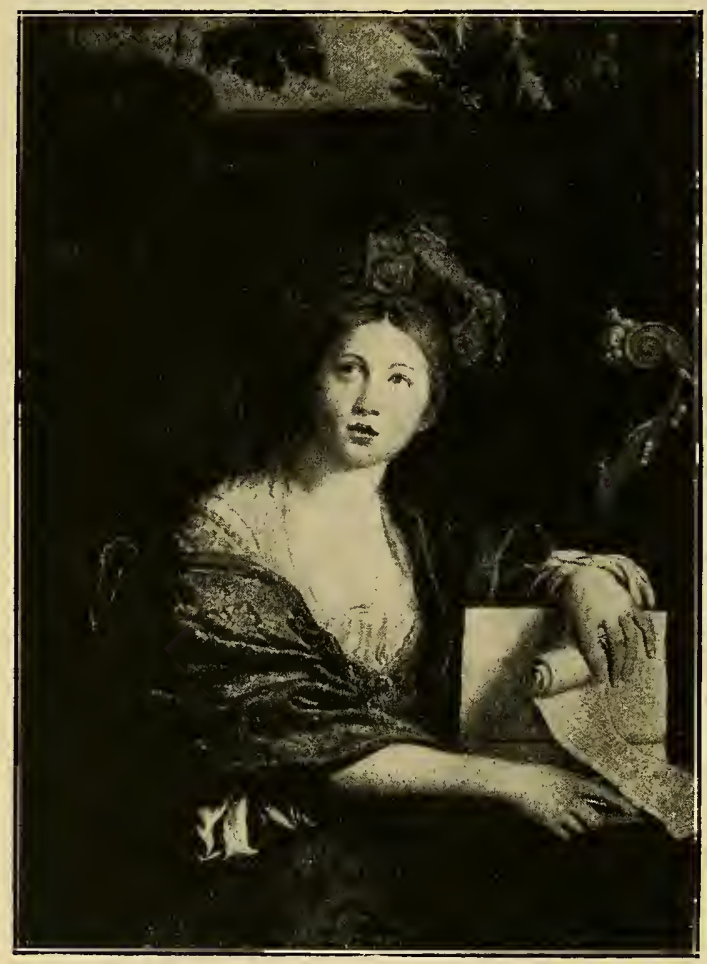

Domenichino, La Sibilla Cumana - Galleria Borghese. (Fot. Anderson).

chie bastonate, e una stoccata; il 7 febbraio 1601 otteneva il componimento di un processo per aver ferito di spada un sergente di Castel S. Angelo; il 28 agosto 1603 veniva querelato dal Baglione per aver scritio dei versi offensivi contro di lui; il 24 aprile 1604 stando a pranzo all'osteria del Moro, alla Maddalena, tirava un piatto al mostaccio di un servitore feren- 
dolo alla guancia; il 20 ottobre era in carcere per aver ingiuriato i birri; il 28 maggio 1605 era menato in prigione perchè portava spada e pugnale senza licenza; il 20 luglio era di nuovo carcerato per offesa a due donne; e liberato, appena nove giomi dopo, in piazza Navona feriva con un colpo di spada

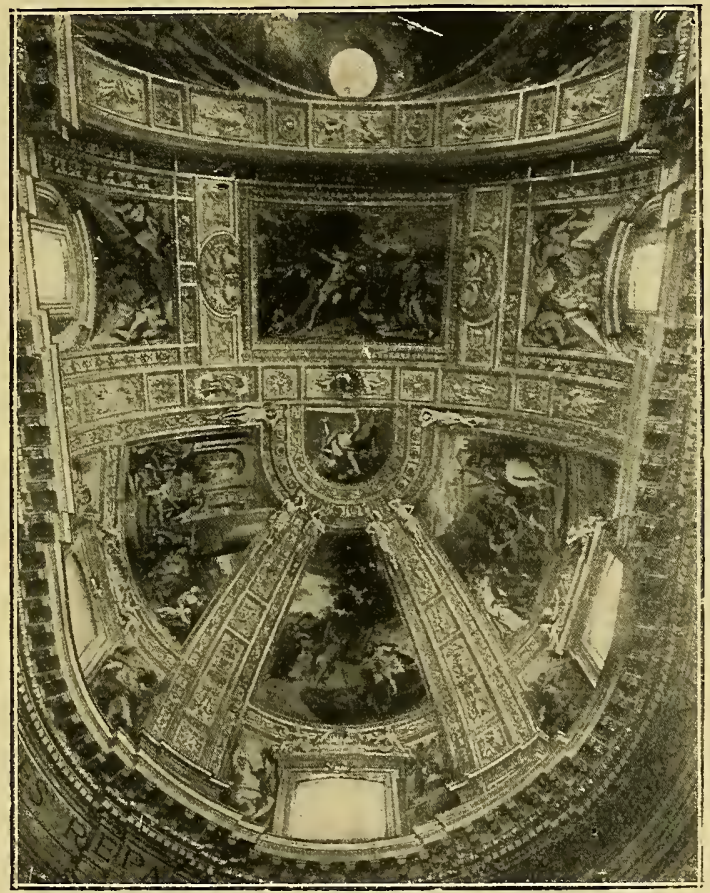

Domenichino, Affreschi nell'abside di S. Andrea della Valle.

(Fot. Anderson).

sulla testa il notaro Mariano Pasqualone, per causa di una certa Lena; il primo settembre era querelato dalla padrona di casa Prudenza Bruna, alla quale, essendo richiesto dell' affitto, aveva rotto a sassate la gelosia della finestra. Poco tempo dopo in una rissa fu ferito alla gola $e$ all'orecchio sinistro, ma interrogato si rifiutò di dire il nome del feritore; e infine nel 1606 avendo ammazzato per questioni 


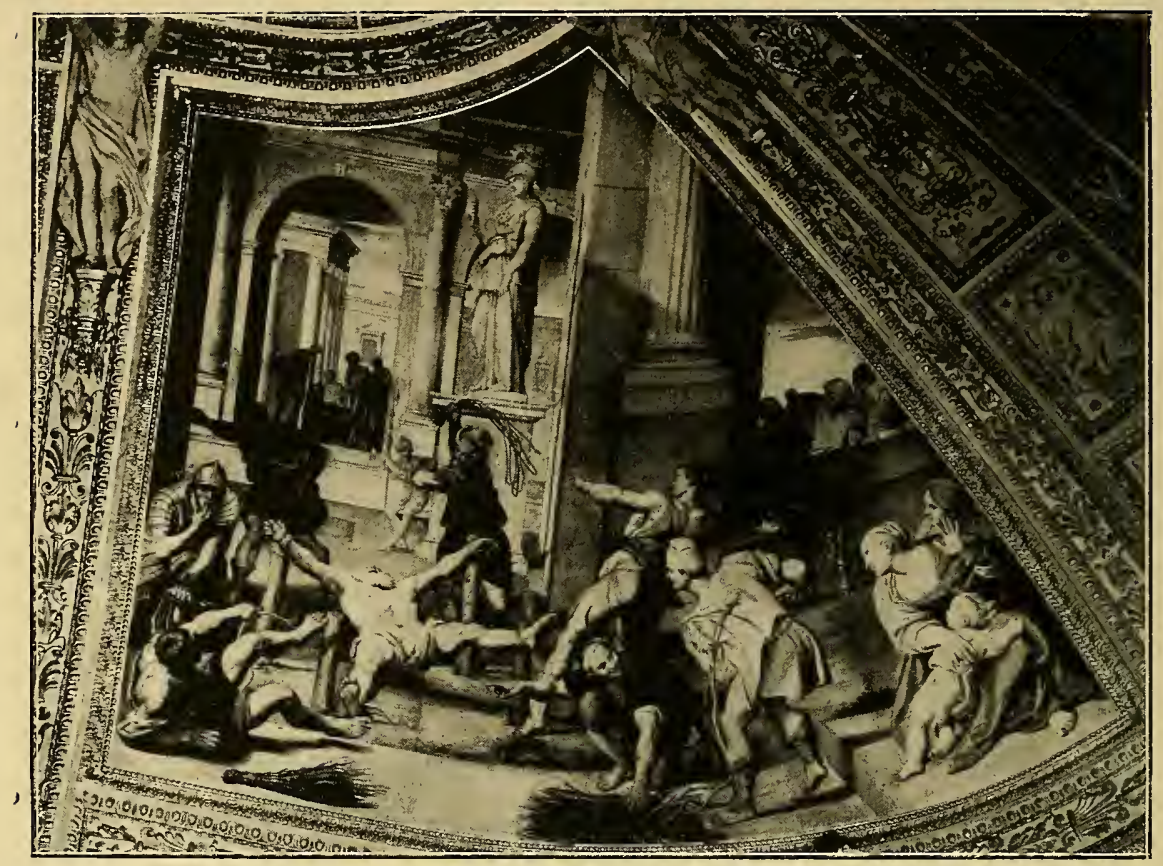

Domenichino, Flagellazione del santo, in S. Andrea della Valle.

(Fot. Anderson)

di giuoco un certo Ranuccio Tomassoni, dovette fuggire da Roma. Riparò a Napoli, e poi a Malta, accoltovi con onore, ma anche qui ne fece qualcuna delle solite e fu imprigionato. Riusci a fuggire, stette qualche tempo in Sicilia, poi di nuovo a Napoli, ove esercitò un profondo infusso sui pittori locali; mentre cercava di rientrare a Roma, colpito dalle febbri mori presso Porto Ercole nel 1609, l'anno stesso in cui mancavano all'arte Annibale Carracci e Federico Zuccheri. Ma assai più ricca eredità lasciava il ribelle Caravaggio, che non i due sommi sacerdoti dell'arte aulica romana: il Carracci aveva dietro a sè molti scolari che per vivere dovevano non fermarsi ai suoi insegnamenti di chiuso accademismo, ma profondamente rinnovarsi; $i$ seguaci dello Zuccheri non avevano più in mano che 


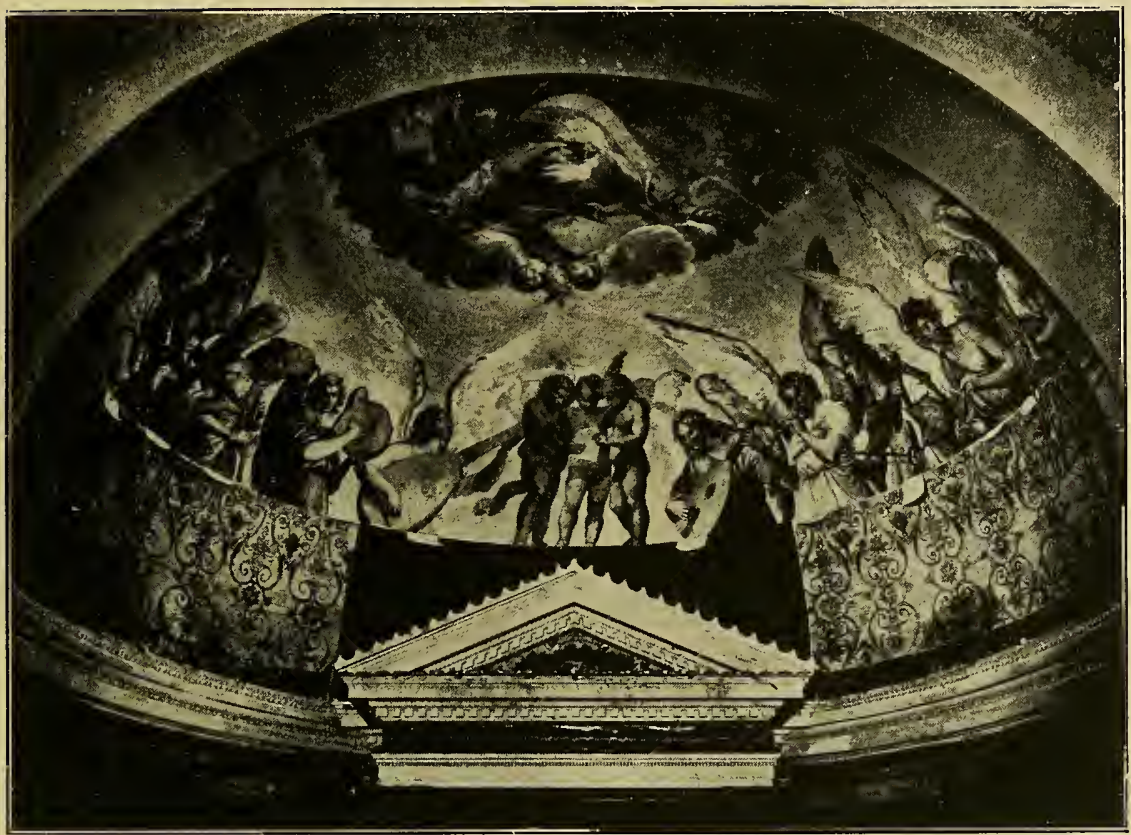

Guido, Angeli musicanti, nella cappella di S. Silvia in S. Gregorio al Celio.

(Fot. Anderson)

logori stampi: il bandito lombardo aveva gettato invece $i$ fondamenti della pittura moderna. Non pochi furono gli imitatori diretti dell'arte caravaggesca, chiamati perciò Naturalistí, sia italiani che stranieri, come Bartolomeo Manfredi, facile traduttore delle forme del maestro, Carlo Saraceni, veneziano, più chiaro e accurato; Orazio Gentíleschi, lo stesso Baglione, Giuseppe Ribera detto lo Spagnoletto, Gherardo Honthorst, detto delle Notti, perchè illuminava le sue figure con luci notturne di candele e di torce fumiganti, Monsì Valentin, francese, di " maniera vigorosa e tinta „. Bellori rimprovera agli imitatori di Caravaggio di esser caduti nell'imitazione del deforme: "Così sottoposta dal Caravaggio la maestà dell'arte, ciascuno si prese licenza, e ne seguì il dispregio delle cose belle, tolta ogni au- 


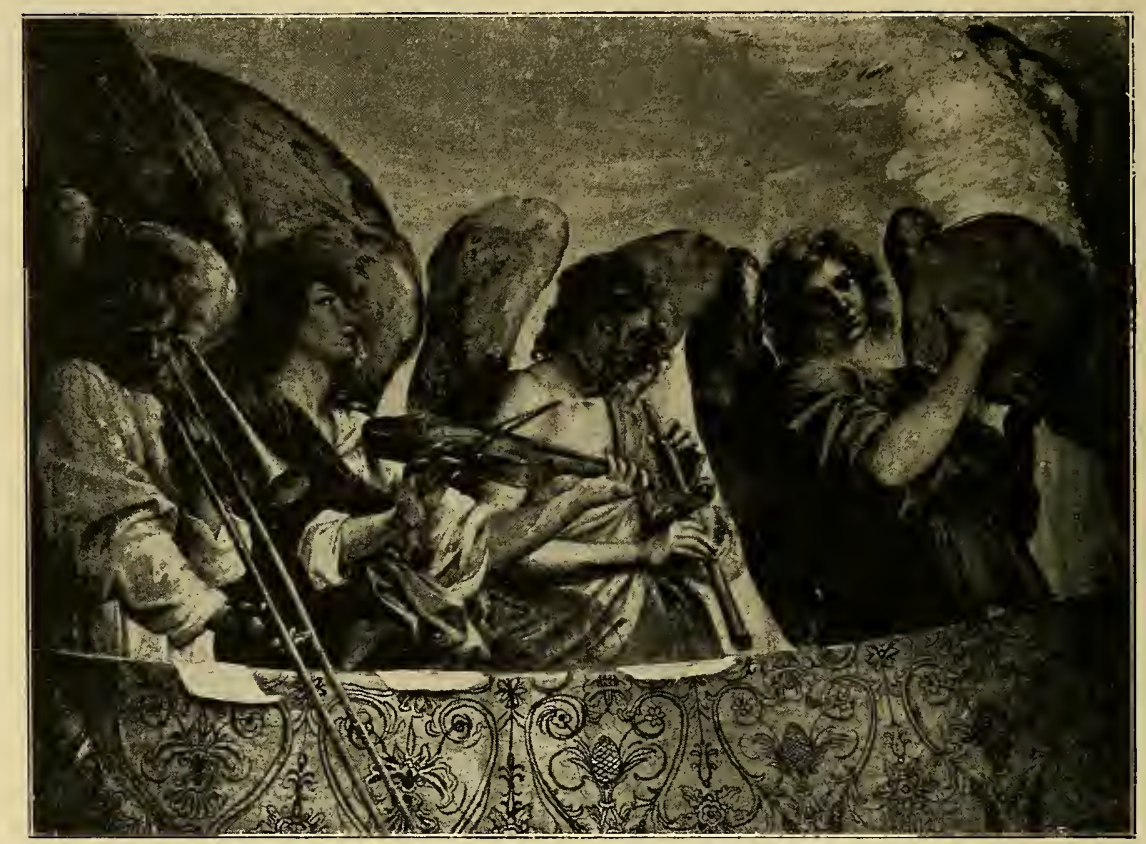

Guido, Angeli musicanti, in S. Gregorio.

(Fot. Anderson).

torità all'antíco ed a Raffaello: dove per la comodità de' modelli, e di condurre una testa dal naturale, lasciando costoro l'uso dell'Istorie, che sono proprie de' pittori, si diedero alle mezze fígure, chè avantí erano poco in uso. Allora cominciò l'imitazione delle cose vili, ricercandosi le sozzure e le deformità come sogliono fare alcuni ansiosamente; se essi hanno a dipingere un'armatura eleggono la più rugginosa, se un vaso non lo fanno intiero, ma sboccato e rotto. Sono gli abiti loro calze, brache, e berrettoni; e cosi nell'imitare i corpi, si fermano con tutto lo studio sopra le rughe e i difetti della pelle e dintorni; formano le dita nodose, le membra alterate da morbi ,. Ma il Bellori, antiquario, classico, accademico, ammiratore dei Carracci, del Domenichino, e del Poussin, non era in grado di intendere il valore profondo dell'arte caravaggesca, e la giu- 


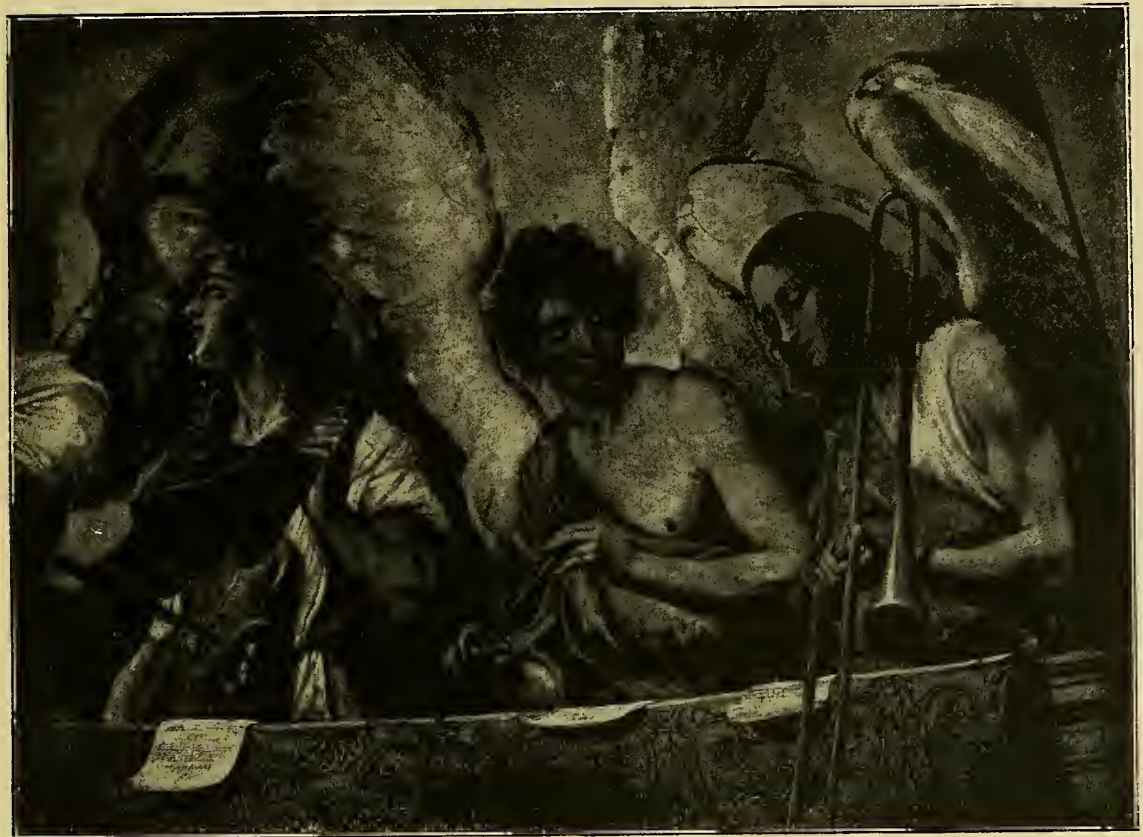

Guido, Angeli musicanti, in S. Gregorio.

(Fot. Anaerson).

dicava male per questi sviamenti degli imitatori, che scambiarono più volte l'importanza che il maestro dava nei suoi quadri a elementi naturali e ad oggetti, fiori, frutti, sassi, vasi, per il fine ultimo della pittura, ricercando soggetti triviali, come se in essi consistesse l'essenza del nuovo stíle. E certo però che a $\mathrm{Ca}$ ravaggio spetta il merito di aver arricchito il patrimonio iconografico della pittura che fino al suo tempo era ristretto ai soggetti sacri, e che ora non disdegnerà più di assumere la trattazione di temi più umili, nature morte, scene popolari di giuocatori e di osterie.

Mentre l'interpretazione esteriore dello stile caravaggesco dava luogo alla scuola pittorica dei tenebrosi, i bolognesi, seguaci dei Carracci, continuavano la loro via, alcuni lasciandosi attrarre talvolta dall'eco rumorosa dell'arte di Caravaggio, altri 


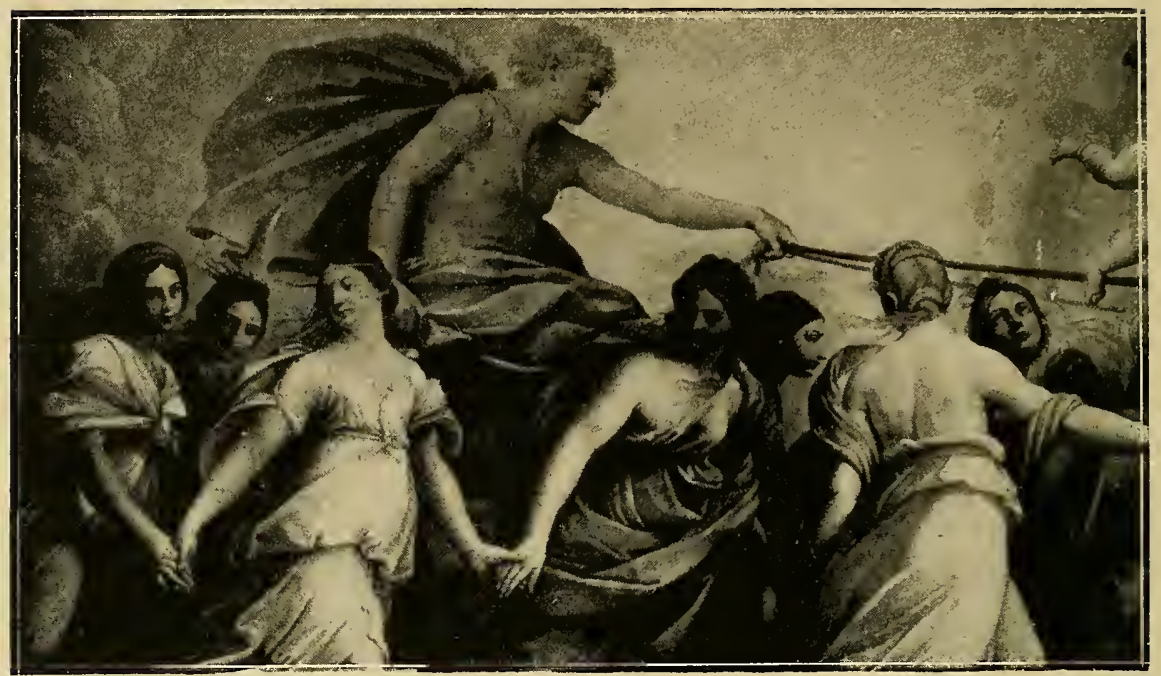

Guido, Particolare dell'Aurora nel Casino Rospigliosi.

(Fot. Alinari)

e furono i più, non accorgendosene neppure. Questi bolognesi, tra i quali primeggiano Domenichino e Guido Reni, sono i rappresentanti dell' arte ufficiale romana del Seicento, i celebrati capiscuola, che senza sbalzi troppo violenti, senza ricerche di novità, esprimono la grazía, la tenerezza, la drammaticità, le qualità più ricercate dalla media comune del loro tempo. Di facile comprensione, di stile piano, evidente, avanti alle loro opere ha pregato per più secoli l'anima semplice del popolo, e ci prega ancor oggi, e ancora oggi trae da quei maestri i soggetti preferiti delle oleografie e delle immaginette sacre, dal colorito brillante, dal significato facilmente accessibile, belle e chiare, composte e devote.

Vedemmo già Domenico Zampieri, detto il Domenichino (1581-1641), venuto a Roma coi Carracci, lavorare nella Galleria Farnese con timidezza ed ingenuità di principiante, riconoscibile tra gli altri dal colorito chiaro, quasi argentino.

Poco dopo (circa 1604), eccolo invece dipingere in un quadro d'altare, la liberazione di S. Pietro dal carcere, che è un misero 
tentativo oleografico di imitazione caravaggesca, che si riduce però in una messa in mostra di gambe, $e$ in contrasti di luci

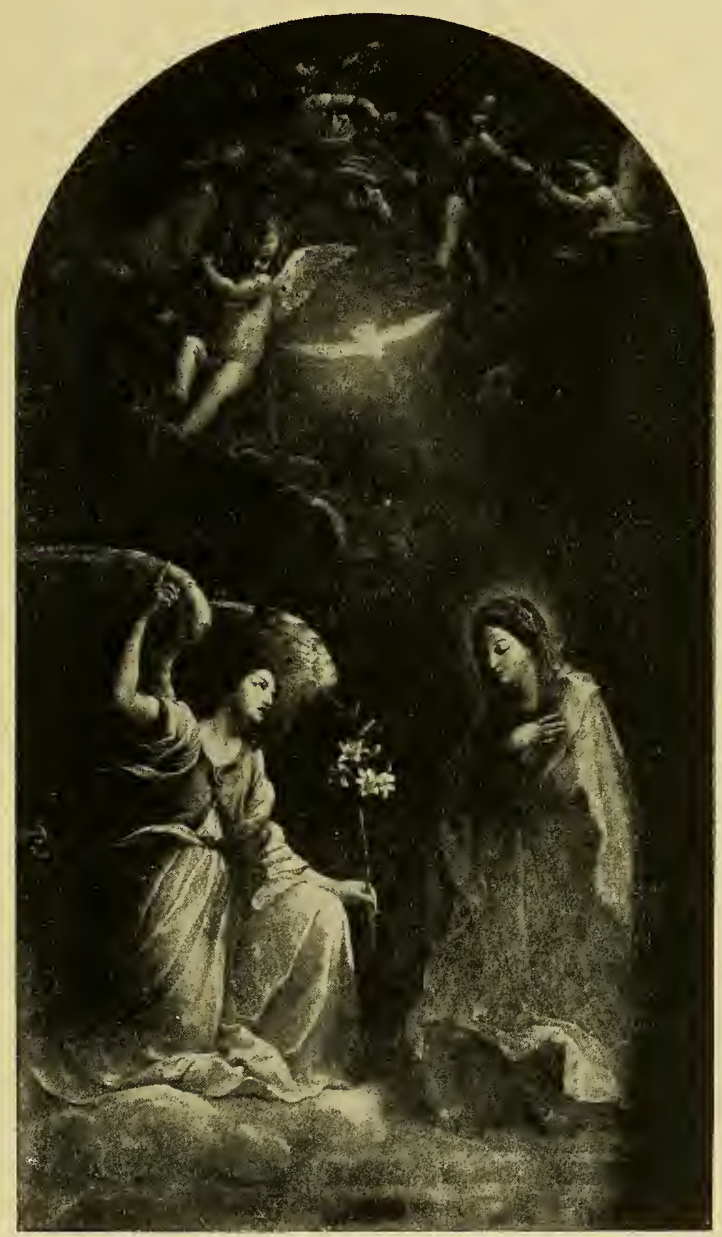

Guido, L'Annunciazione - Cappellina del Quirinale.

e d'ombre. Ma presto ritorna ai Carracci, modernizzandone un po' lo stile, e ampliando il fondo correggesco dell'arte loro. Trova una più composta maniera quando lavora a fresco, nella cappella di S. Gregorio al Celio, dipingendo a gara con Guido Reni la 
Flagellazione di S. Andrea, in cui ritorna ai toni marmorei del primo tempo, e si mostra ancora carico di bagaglio manieristico; al suo confronto Guido è più vivace e appassionato, e colorisce

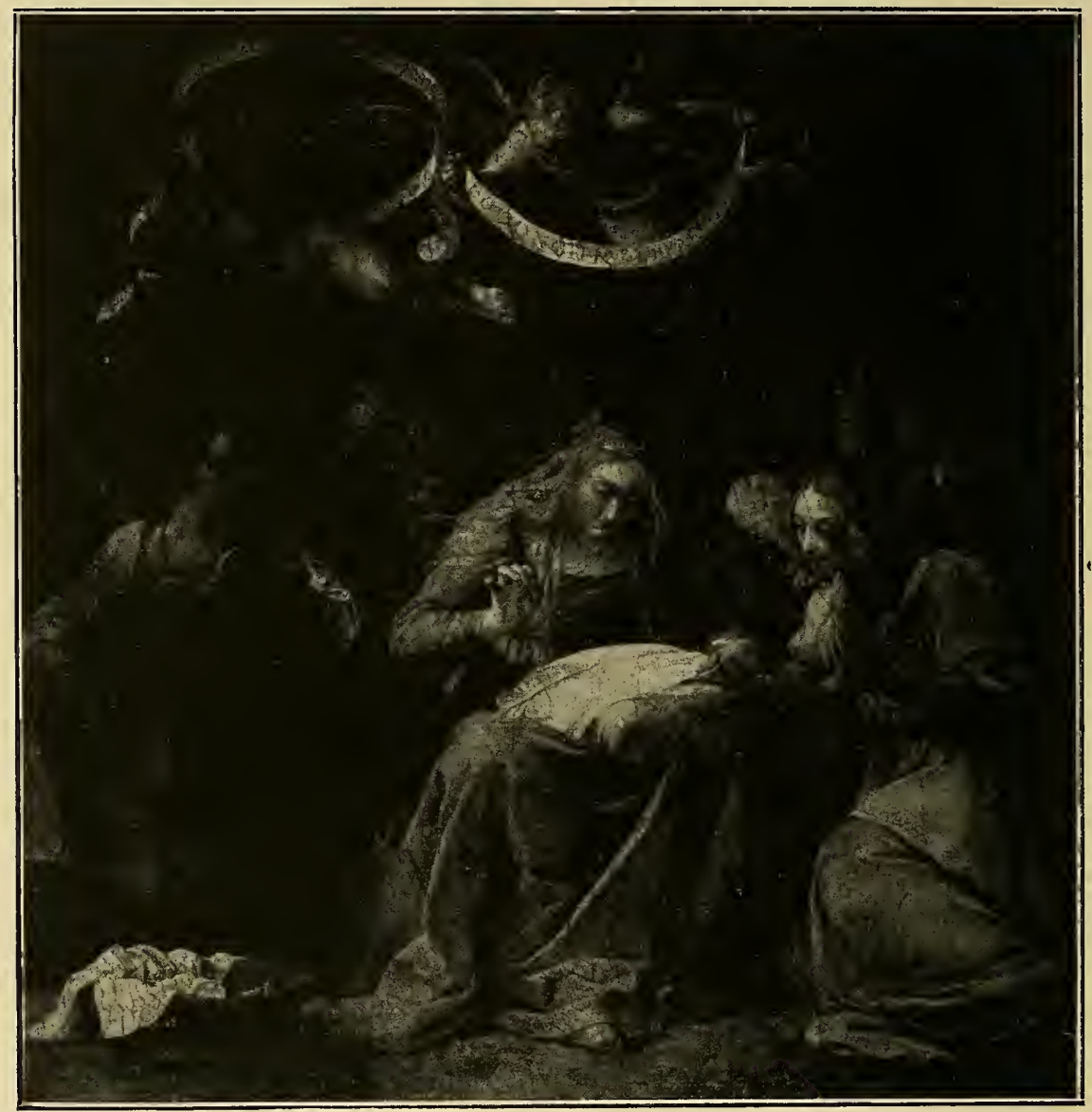

Guido, La Vergine cuce il corredo - Cappellina del Quirinale.

con più vigore. Negli affreschi con le storie di S. Nilo, condotti per incarico del card. Odoardo Farnese nella Badia di Grottaferrata (1608-10), Domenichino ha fatto un progresso assai grande; ha una forza di modellato, una correttezza di disegno 


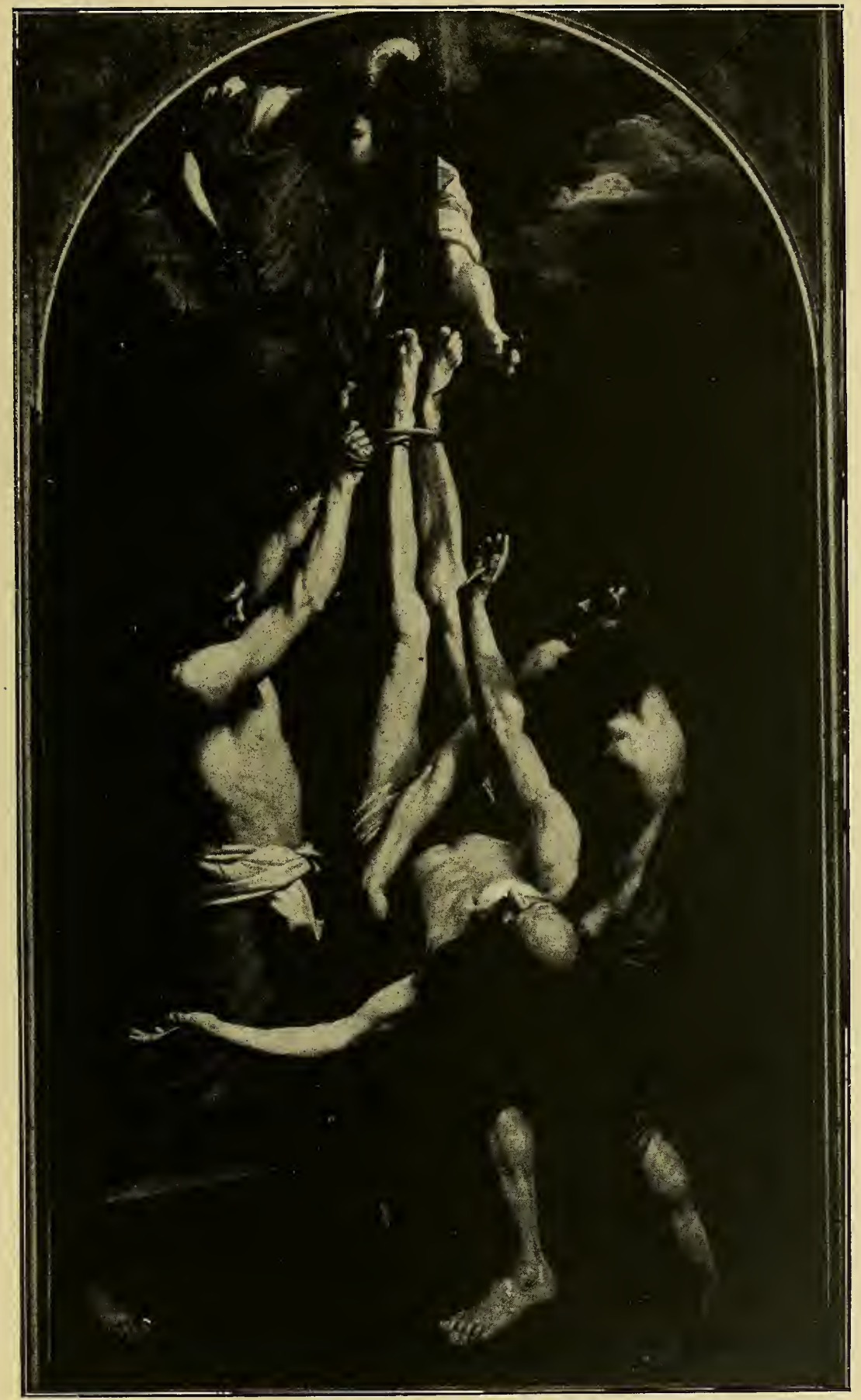

Guido, Crocifissione di S. Pietro, nella Pinacoteca Vaticana.

(Fot. Anderson). 
che prima non possedeva, e una sicura scienza della composizione e dell'aggruppamento. Nella Guarigione dell'ossesso, ch'è la più bella di queste storie, ha accenti di verità $e$ di natura-

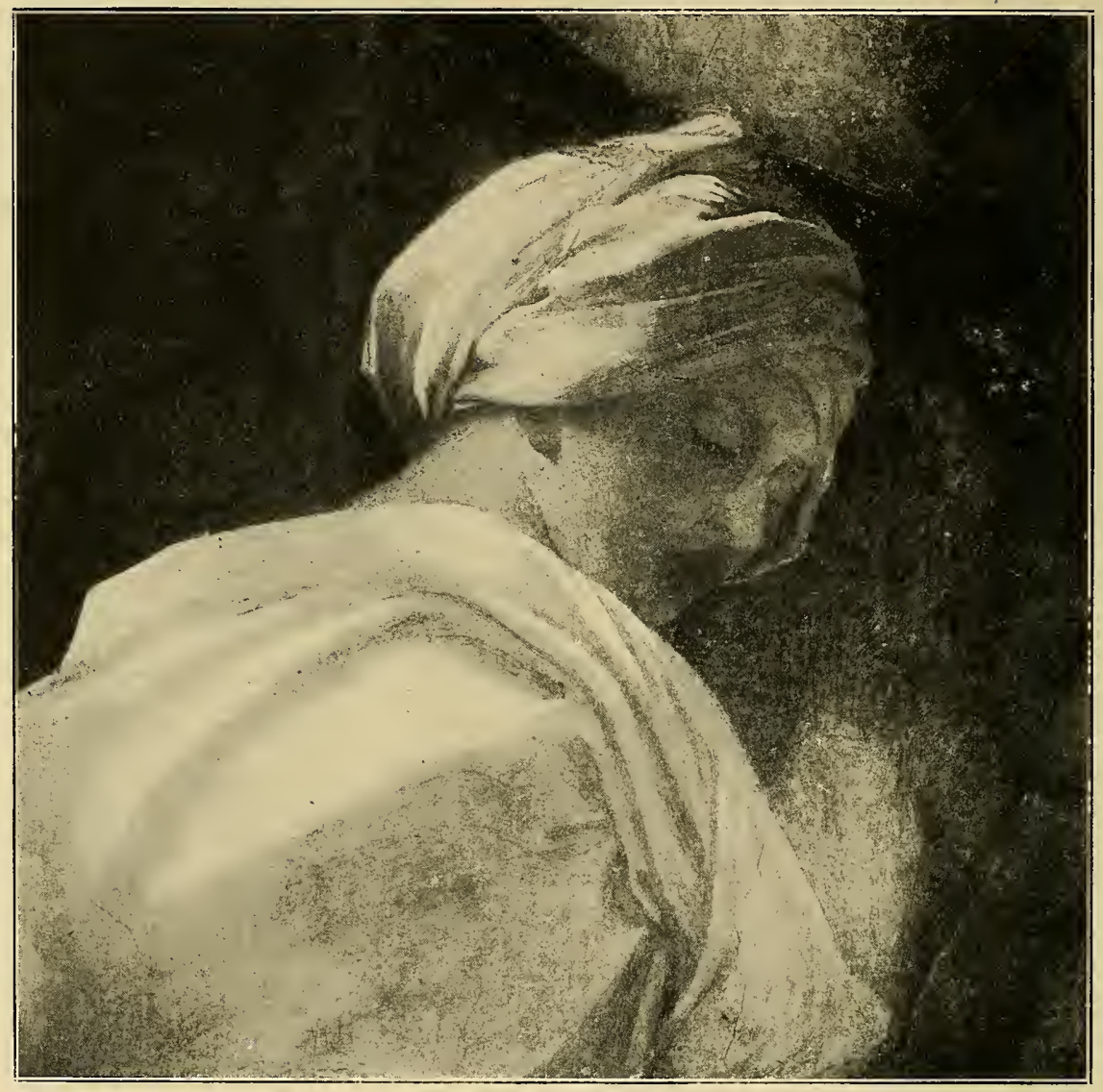

Guido, Testa di donna, dal dipinto di S. Andrea che va al martirio, in S. Gregorio.

lezza, sebbene anche qui il manierismo apparisca evidente. Nella celebre Comunione di S. Girolamo, della Vaticana, dipinta nel 1614, che passa per il suo capolavoro, Domenichino mostra la completa espressione del suo temperamento, perchè sebbene segua il motivo del quadro di Agostino Carracci, ora nella pinacoteca 


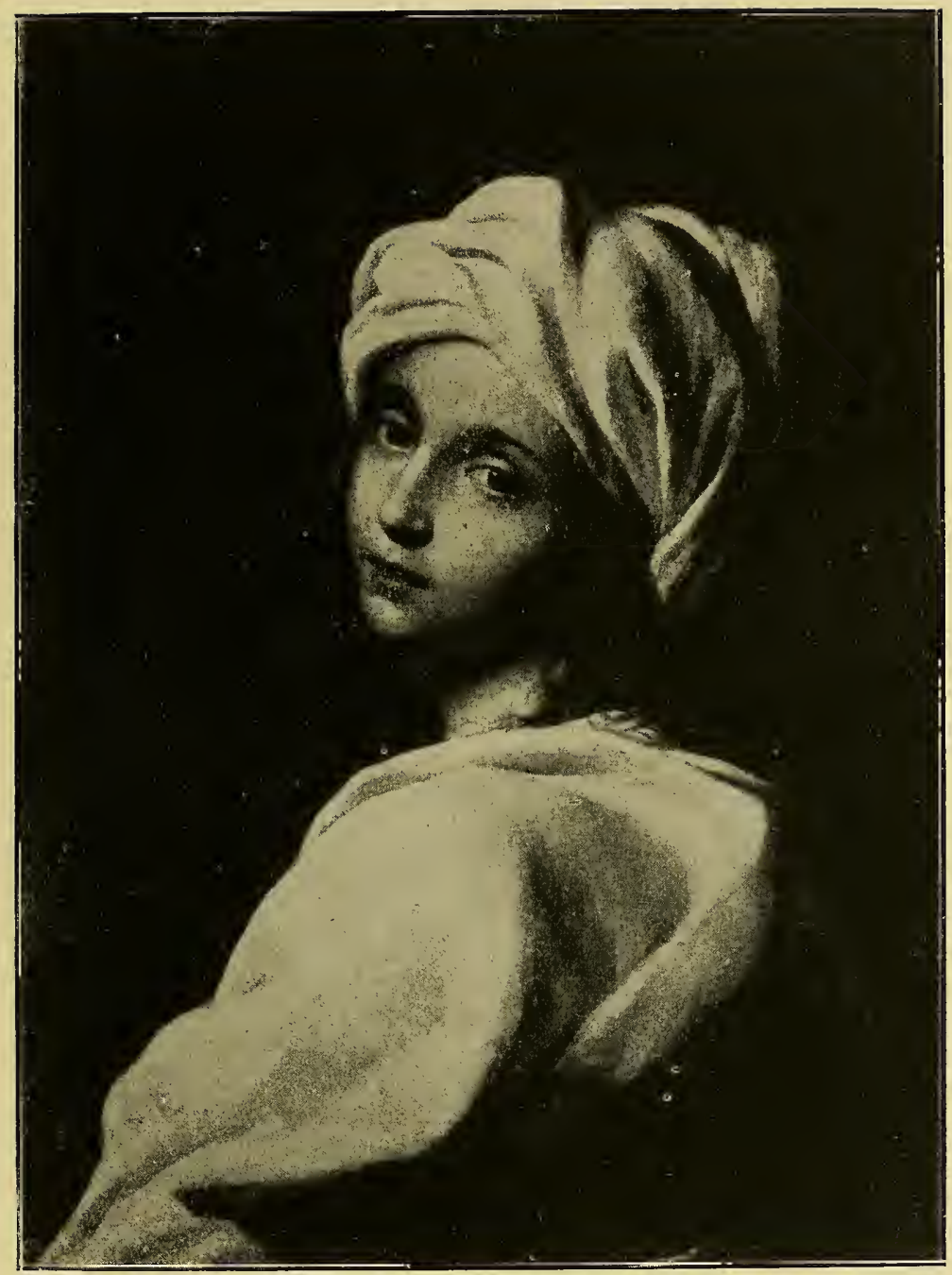

Guido, Una Sibilla, creduta Beatrice Cenci - Galleria Barberini.

(Fot. Alinari).

di Bologna, lo traduce artisticamente in una cosa tutta sua. Ci sono degli spunti caravaggeschi, ma ogni cosa ha il suo contorno netto e preciso, e l'affetto scalda le figure, e il colorito è vivo, senza risalti. Bellori deve aver pensato a Caravaggio quando 
scrive: "Così ricordevolmente si portano l'un l'altro i colori regolati dentro un tempio, e ad un lume senza vantaggio di riflessi e di lumi accidentali; e mostrò Domenico in questo componimento quanto egli prevalesse nel colorito alla più esatta

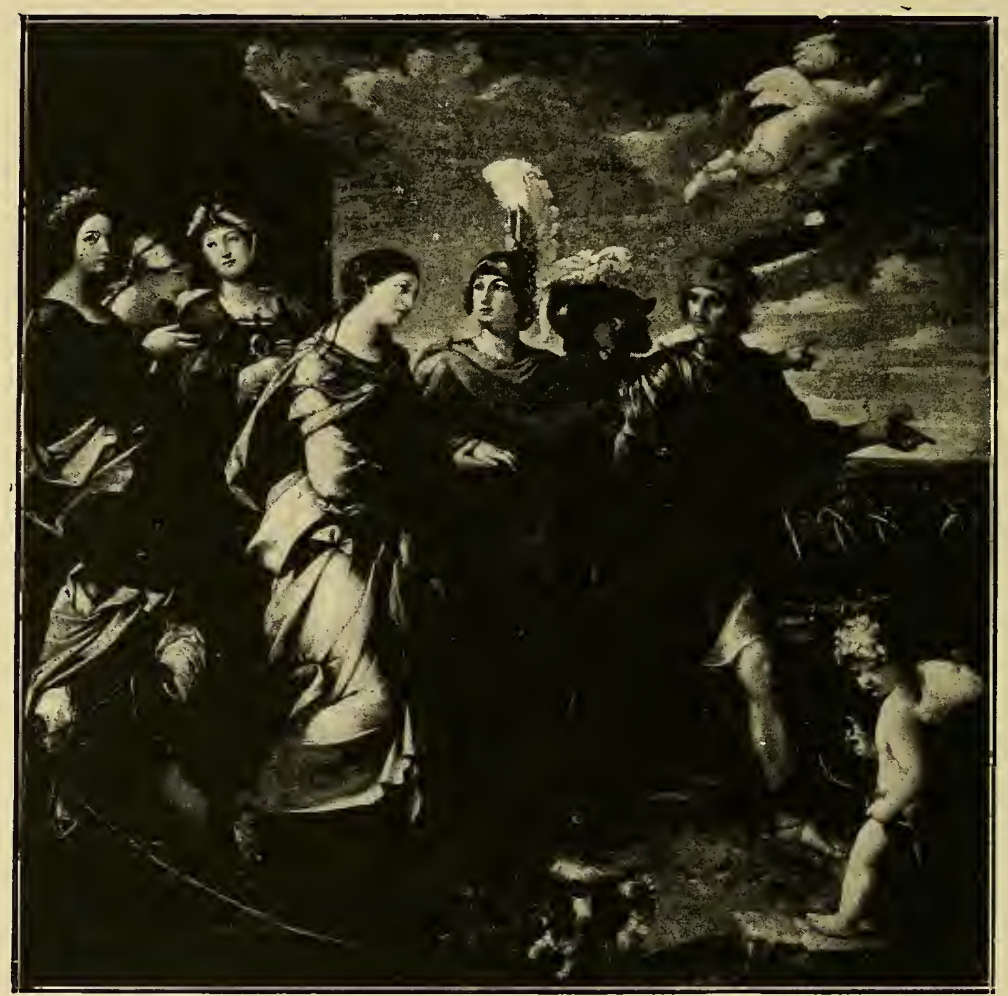

Guido, Ratto di Elena - Galleria Spada.

(Fot. Anderson).

imitazione di finimento in ogni particolar figura, e nella universale armonia e combinazione di lumi e d'ombre, avendo saputo temperare i mezzi con gli estremi, e con le ragioni del grave e dell'acuto di una perfetta musica ritrovare un fondo ultimo, che opposto al primo chiaro nella varietà delle mezze tinte, $\mathrm{i}$ corpi penetrano dentro, ed escono fuori dalla superficie, perden- 
dosi i contorni nel fondo soavemente, e generandosene il numero e la consonanza. Onde quest'opera donando quanto può produrre lo studio, e contribuire un gran genio con ragione Niccolò Pussino rapito dalla sua bellezza soleva accompagnarla unitamente con la Trasfigurazione di Raffaello, come le due più celebri tavole per gloria del pennello ,,

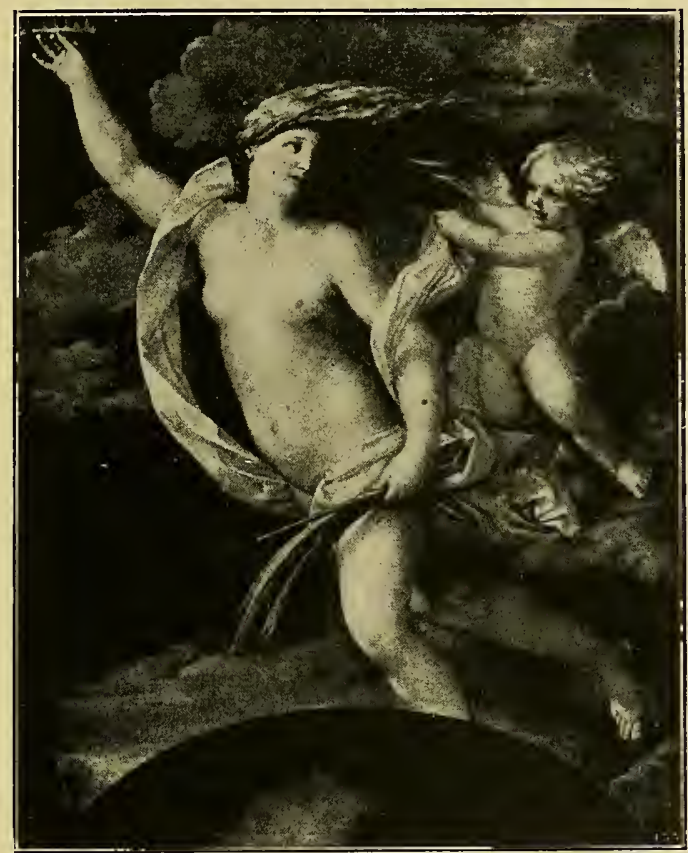

G. Reni, La Fortuna - Galleria di S. Luca.

(Fot. Anderson).

$\mathrm{Ma}$, a parte il valore di molte parti della composizione, c'è qualche cosa di manierato e di voluto; è l'opera più di un virtuoso che di un artista.

Poco dopo nelle decorazioni del palazzo Costaguti ritorna a motivi prettamente bolognesi, e quasi alla ingenuità stílistica dei primi tempi; mentre dimostra la stessa semplicità tecnica nel quadro della Caccia di Diana, che appartenne al cardinale 
Scipione. C'è nella Caccia assai del senso erotico di Agostino Carracci, e ci sono qua e là le solite scorrettezze di disegno, ma l'insieme è di squisita eleganza, di una piacevolezza spontanea

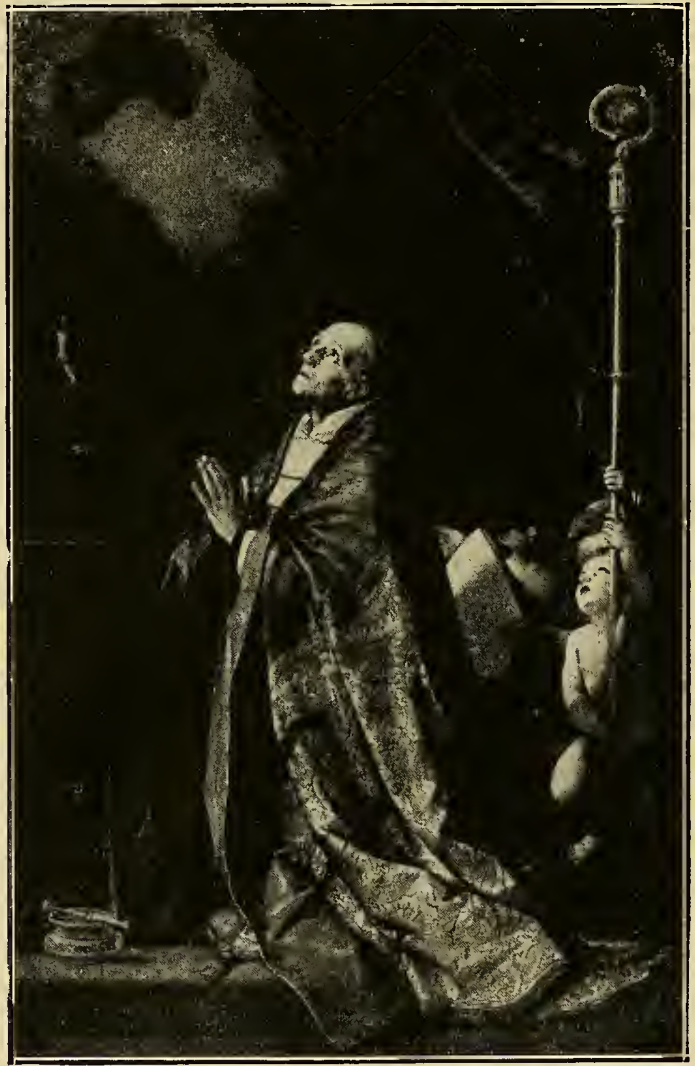

Guido, S. Andrea Corsini - Galleria Barberini.

(Fot. Anderson).

e attraente, di una signorilità grande, di un'armonia dilettevole, di un bel colore pastoso. Si vuole che questo quadro sia stato dipinto intorno al 1620, ma ci sembra invece assai anteriore, tutto ispirato ai ricordi della Galleria Farnese, troppo vivi per non essere recentíssimi. Il cardinal Borghese così amante dei bei paesaggi 
e delle raffinate eleganze, si compiaceva in modo speciale di questo dipinto, a cui i lieti colli, e le acque, e il coro delle ninfe cacciatríci intorno alla dea lunare, dànno una fresca giocondità; e scrive il Passeri che lo ebbe togliendolo a viva forza dalla

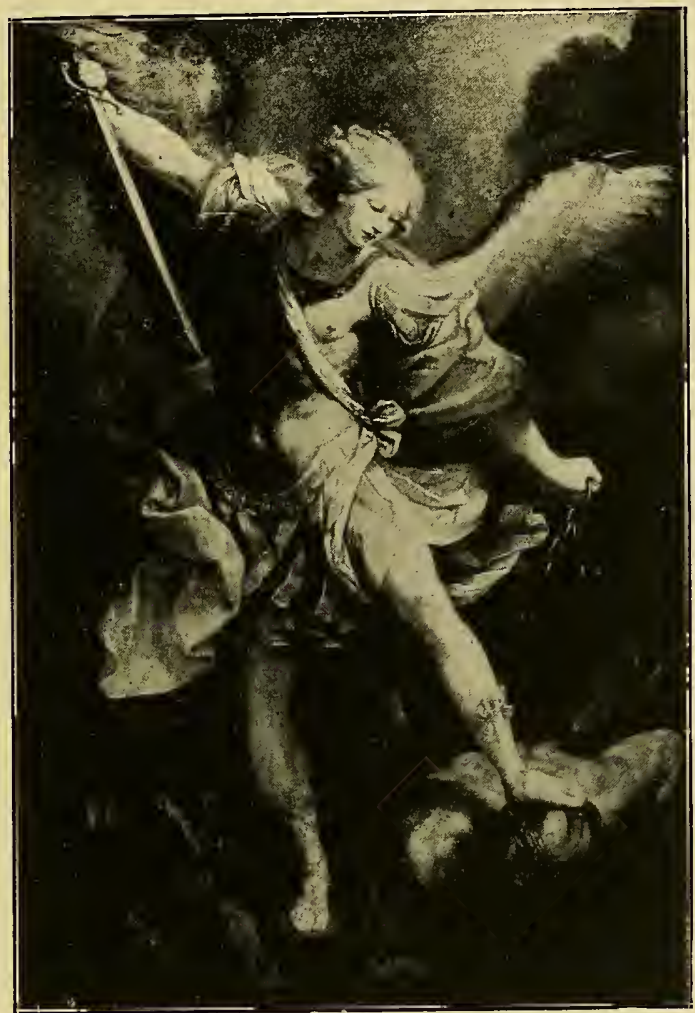

Guido, S. Michele; ai Cappuccini.

(Fot. Anderson).

casa dell'artista che non avrebbe voluto cederlo. Lo stesso intelligente mecenate si procurò la Sibilla del Domenichino, di esecuzione finissima, con toni di colore argentino, a cui nuoce un po' la troppa ricercatezza, che la rende fredda $e$ inespressiva. 
Tra il 1624 e il '28 Domenichino dipinse l'opera sua più vasta e più bella, in S. Andrea della Valle, per commissione del cardinale Alessandro Peretti nipote di Sisto V. Paesaggi lussureggianti, ampli sfondi classici pieni d'aria, fanno da quinta alle storie del santo titolare della chiesa, e basta confrontare il martirio di S. Andrea dipinto qui, con quello giovanile del Celio, per rilevare il progresso immenso fatto dal maestro; là ancora timido, freddo, stentato; qui libero, franco, robusto modellatore, coloritore più ricco e caldo, e libero finalmente da ogni reminiscenza caraccesca. Dipinse con sapore correggesco nei pennacchi della cupola, e avrebbe dovuto decorare anche la calotta, se un più intrigante rivale, Giovanni Lanfranco parmigiano, anch'egli di derivazione caraccesca, non gliene avesse sottratta la commissione con suo grande dolore.

Non è possibile seguire lo Zampieri in tutta la sua vasta attività, svolta a Roma e nei dintorni, e a Napoli, ove dipinse in Duomo nel cappellone di S. Gennaro, poco felicemente, $e$ dove morì nel 1641. Al suo tempo ebbe lodi molte, ma più spesso critiche severissime; e si gitunse persino al pensiero di spicconare i suoi Evangelisti di S. Andrea della Valle. Non fu certo un genio innovatore; non segnò una traccia profonda; ebbe incertezze e ineguaglianze, ma seppe mantenere sempre una grande chiarezza di espressione, una compostezza di atteggiamento, senza ricerche sforzate di effetti, senza scontorcimenti.

Personalità artistica di assai maggior rilievo è Guido Reni (1575-1642), anch'egli bolognese e discepolo dei Carracci, coi quali venne a Roma, per dipingere nella Galleria di palazzo Farnese, dove invero non è dato riconoscere la sua mano. Fu di attività veramente prodigiosa, e lasciò centinaia e centinaía di quadri, specialmente di mezze figure di santi, ricercatissime dai privati collezionistí, ch'egli coloriva con una facilità estrema. Dipinse per Paolo V, nella Cappella Borghesiana di S. Maria Maggiore, lunette e riquadri con figure di santi, nelle quali 
mostrò un senso robusto del colore, una solidità di modellato che più tardi non ritrovò mai più. Il cardinal Scipione, verso il 1606, gli fece decorare l'absidiola della cappellina di S. Silvia in S. Gregorio al Celio, dove sotto a un manieristico Padre Eterno, figurò una bellissima schiera di angeli musicanti affac-

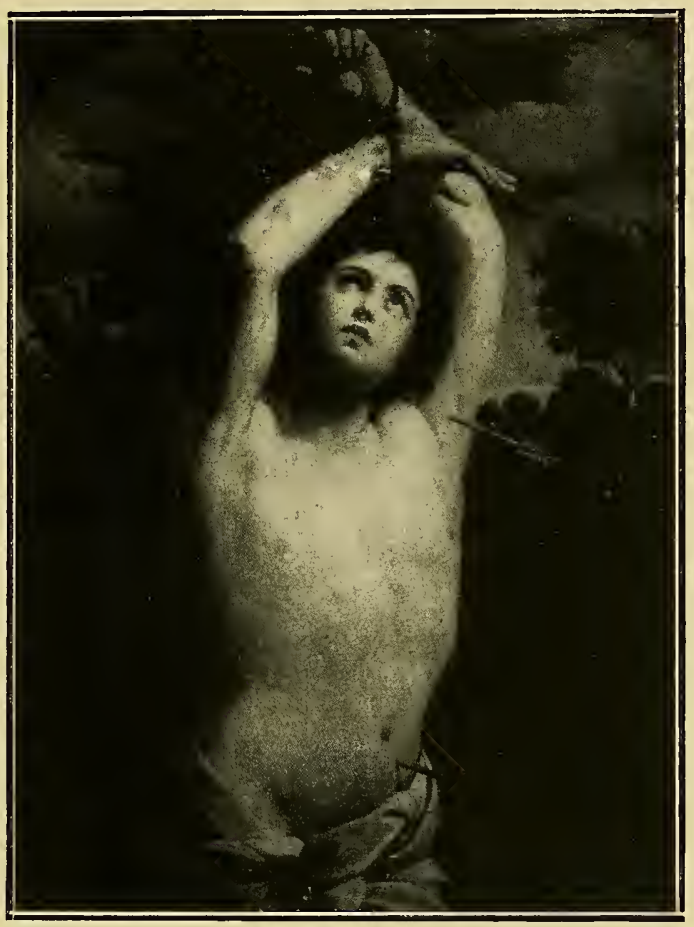

Guido, S. Sebastiano - Pinacoteca Capitolina.

(Fot. Anderson).

ciati a una loggia, rinnovando con più brio le eleganze di $\mathrm{Me}$ lozzo da Forli. Per lo stesso munifico committente dipinse nel soffitto del casino sul Quirinale la celebre Aurora, ispirata dalla Galleria Farnese, ma condotta con uno slancio assai maggiore, con un più caldo colorito, con un senso più libero dello spazio. Esce Febo, cinto di luce, dalla porta d'Oriente sopra un carro condotto da quattro veloci destrieri, e intorno gli scherzano 
danzando vaghe e leggiadre donzelle, che si tengono per mano avvolte in elegantissime vesti, e calcano le lucide nuvole con piede leggero. In alto un amorino vola con la facella accesa, e lo precede l'Aurora, in bianchi veli, che getta fiori sul mondo,

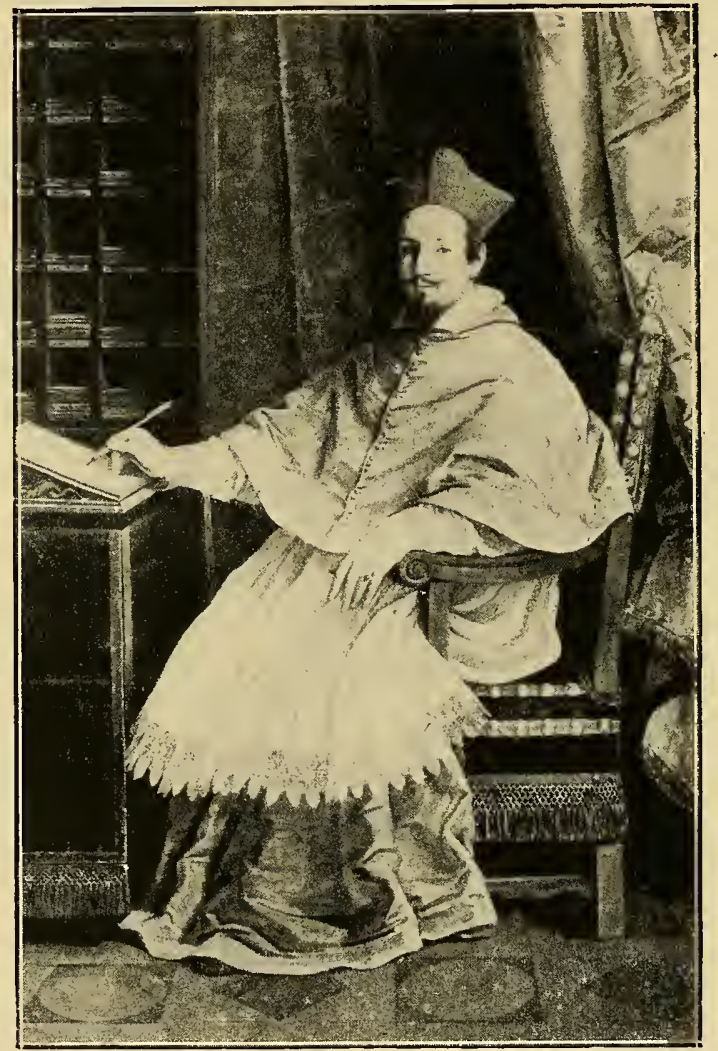

Guido, Il card. Spada - Galleria Spada.

(Fot. Anderson).

figurato in basso da una limpida marina che s'insena tra la terra bruna e le montagne azzurrine del fondo. Assai piì fresco e spontaneo che nei Carracci, spira qui un alito refrigerante di poesia antica, e c'è un'eleganza, una disinvoltura, una chiarezza che non raggiungono gli altri maestri contemporanei quando 
trattano soggetti del genere. Ma Guido non ebbe poi altre occasioni di esercitare queste sue qualità di favoleggiatore mitologico, e ando a finire nelle mezze figure lattiginose e alabastrine che la moda gli richiedeva! Già poco tempo dopo l'Aurora, quando Paolo $\mathrm{V}$ gli fece decorare la cappellina ovale del $\mathrm{Pa}$ lazzo pontificio del Quirinale, aveva perduto la luminosità del

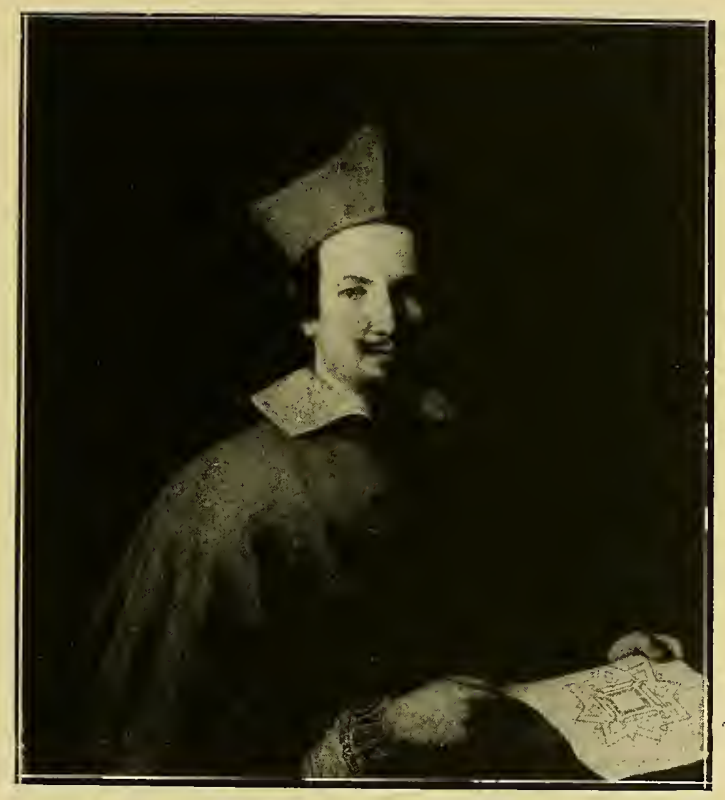

Guercino, Il card. Spada - Galleria Spada.

(Fot. Anderson).

colore, e cominciava a farsi un po' sdolcinato; nell'altare figurò l'Annunciazione, su fondo nero; sulle pareti, tra varie storie, la Madonna che cuce il corredo per il Bambino nascituro, assistita da due angeli, graziosa scenetta di sapore intimo e popolare.

Non fu immune Guido dall'infusso del Caravaggio, e se è vero il racconto del Passeri, $f u$ chiamato a dipingere per la chiesa delle Tre Fontane il quadro della Crocifissione di S. Pietro appunto in sostituzione del maestro lombardo, a cui il geloso 
Cavalier d'Arpino aveva fatto togliere la commissione. Ciò porterebbe la datazione di quel dipinto a un'epoca forse troppo

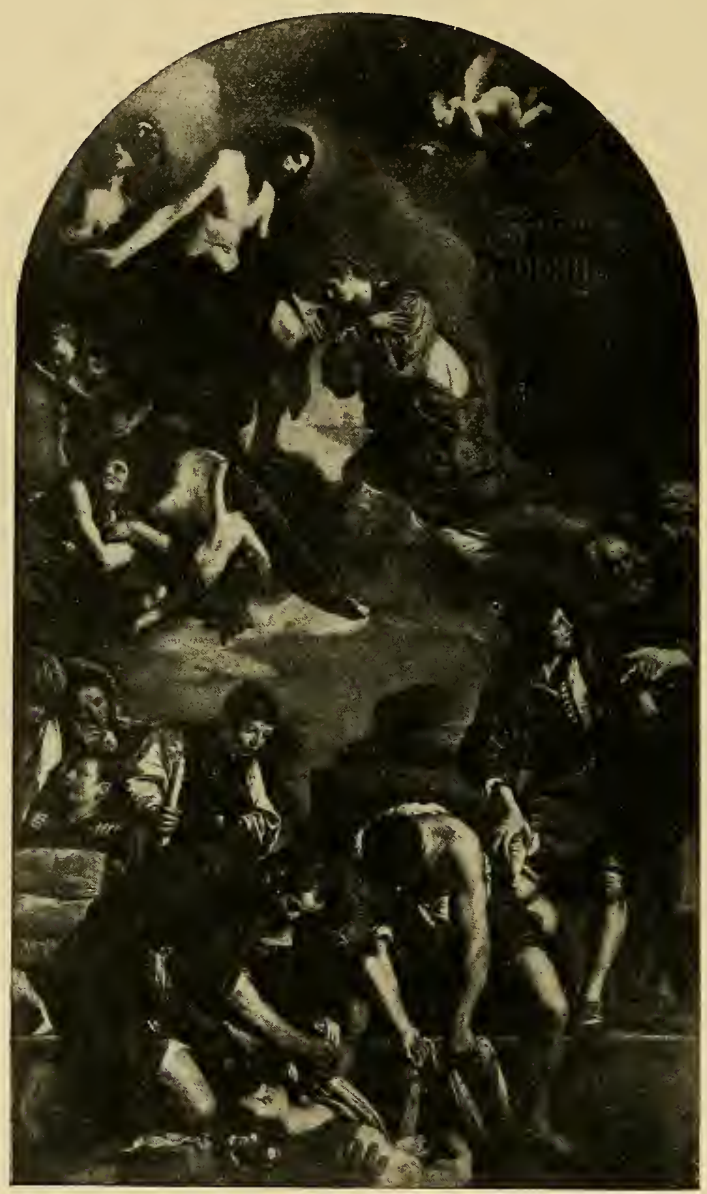

Guerciso, S. Petronilla - Pinacoteca Capitolina.

(Fot. Anderson).

remota; ma è certo che il Reni si studiò in quel quadro, che oggi è alla Vaticana, di imitare Caravaggio, e lo fece con pì̀ abilità del Domenichino, ma sempre in modo un po' esteriore, con gran mostra di torsi nudi, di braccia muscolose, di zampe 
fangose, su un fondo nero, ma senza poter rapire il senso costruttivo al Merisi, e la sua tecnica. Guido ebbe pure incarico di dipingere una tavola per la Basilica Vaticana, con la storia di Attila, ma poichè non si riduceva mai ad eseguirla, rimproveratone dal card. Spinola, se ne sdegnò al punto che partì da

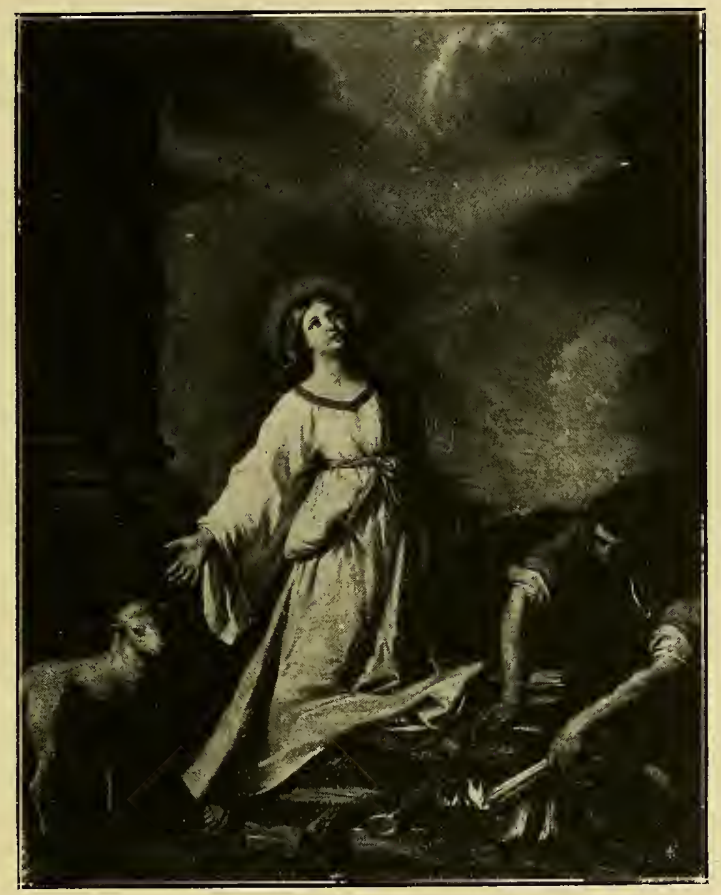

Guercino, Martirio di S. Agnese - Galleria Doria. (Fot. Anderson)

Roma, e ritornò a Bologna. Dice il Passeri che prima di andarsene restitui alla Fabbrica di S. Pietro i quattrocento scudi avuti in anticipo, ma documenti inediti ci apprendono che nel 1628 gli veniva intimata a Bologna tale restituzione. Stabilitosi in patria si dette a un lavoro continuo e sereno, e divenuto il pittore alla moda in tutta Italia e anche fuori, pensò addirittura di fissare una tariffa per i suoi quadri: cento scudi di moneta 


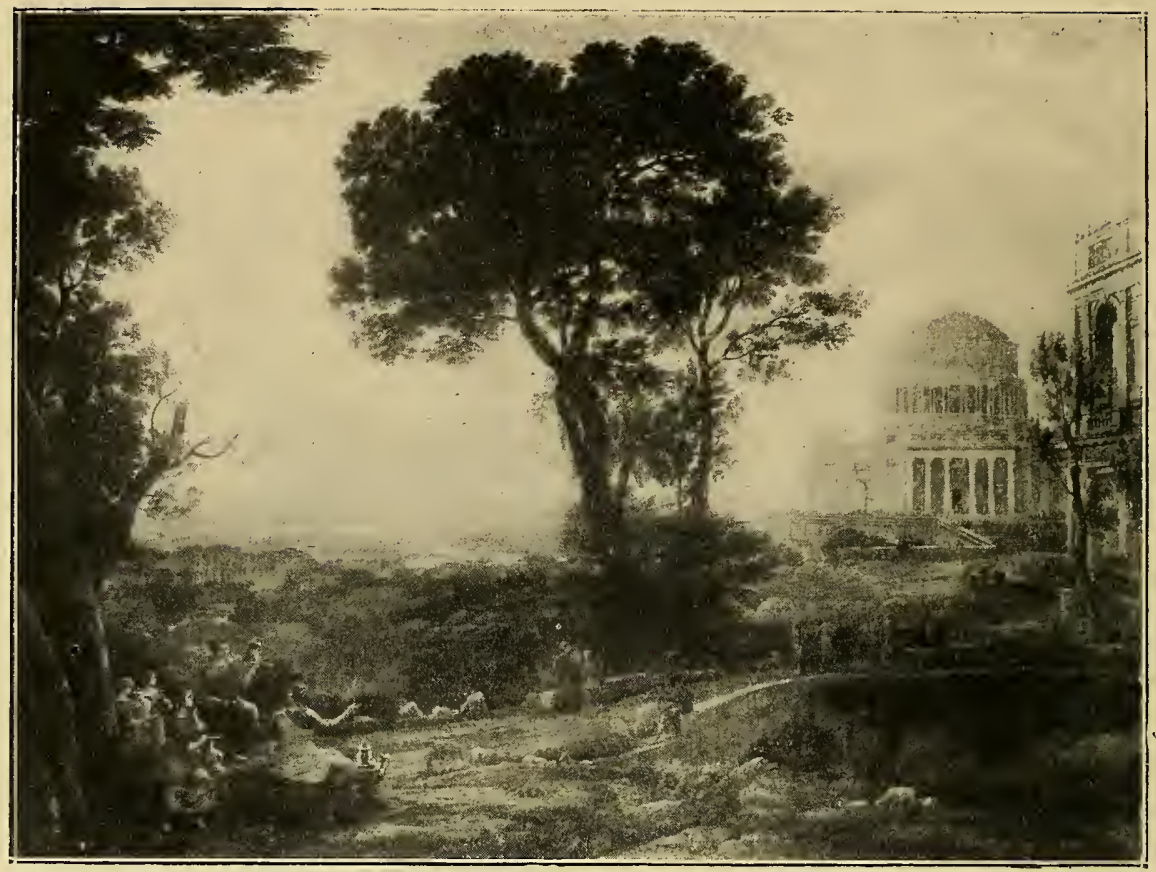

Claudio di Lorena, Paesaggio - Galleria Doria.

(Fot. Alinari).

per una fígura, cinquanta per mezza figura, venticinque per una semplice testa; e più tardi, avanzatosi nel credito, si faceva pagare anche quattro o cinquecento scudi ogni figura. E dipingeva senza posa Cristi coronati di spine, che guardano il cielo con occhi languenti, o spirano dolcemente esalando con l'anima dalla bocca semiaperta l'ultima preghiera; santi che subiscono il martirio con dolce rassegnazione, senza un lamento; vergini bionde vestite di bianco, che languiscono d'amore divino; Maddalene dai lunghi capelli color paglia, che si chinano a baciare crocifissi: Guido si vantava di saper rappresentare gli occhi levati in alto in cento modi diversi. Anche quando tratto scene mitologiche ebbe la stessa soavità di maniera, per cui la sua Elena rapita da Paride sembra una $\mathrm{S}$. Cecilia al braccio dello sposo, e Venere pare una Maddalena. "Aveva sommamente in odio, 
dice il Passeri, la viltà di quei pittori, li quali impiegano le loro fatiche e gli studi maggiori nell'espressione di soggetti bassi $e$ di accidenti plebei, e non altro pare che pensino se non a far

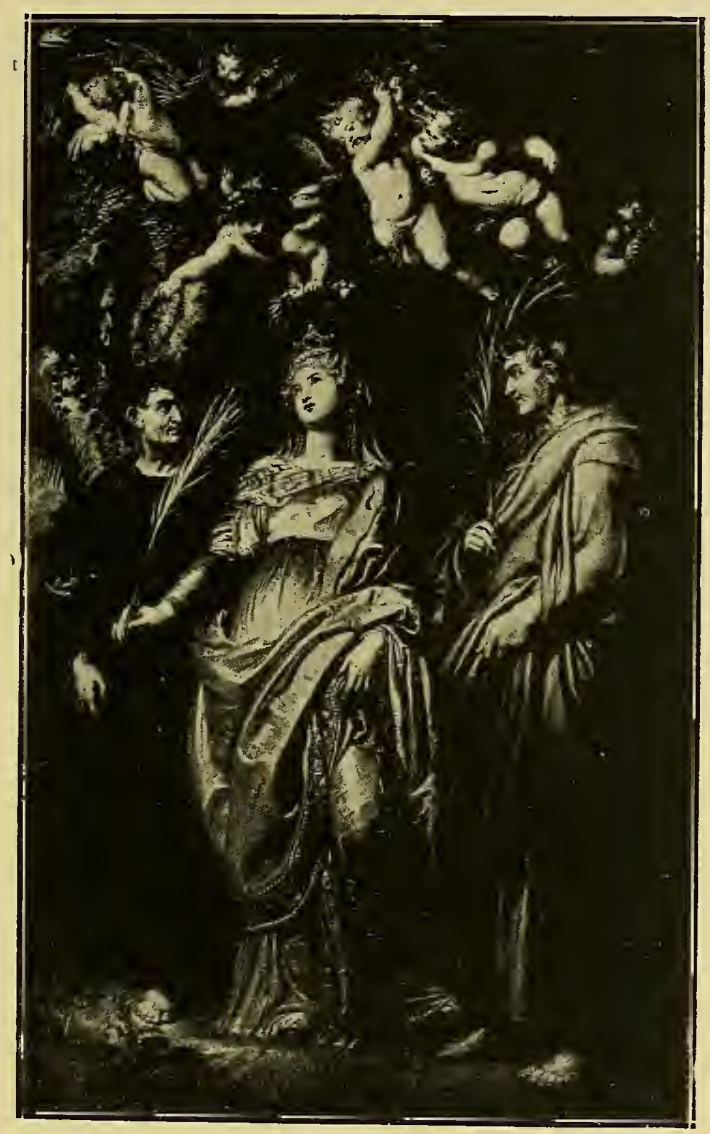

Rubens, Tre Santi, alla Chiesa Nuova.

(Fot. Anderson).

ridere il volgo ignorante e le donnicciuole più vili. Gli pareva degno di grande aborrimento il genio di quel pittore che si pone a rappresentare il successo di un goffo e dozzinale avvenimento della marmaglia; perchè essendo la pittura instituita e coltivata 


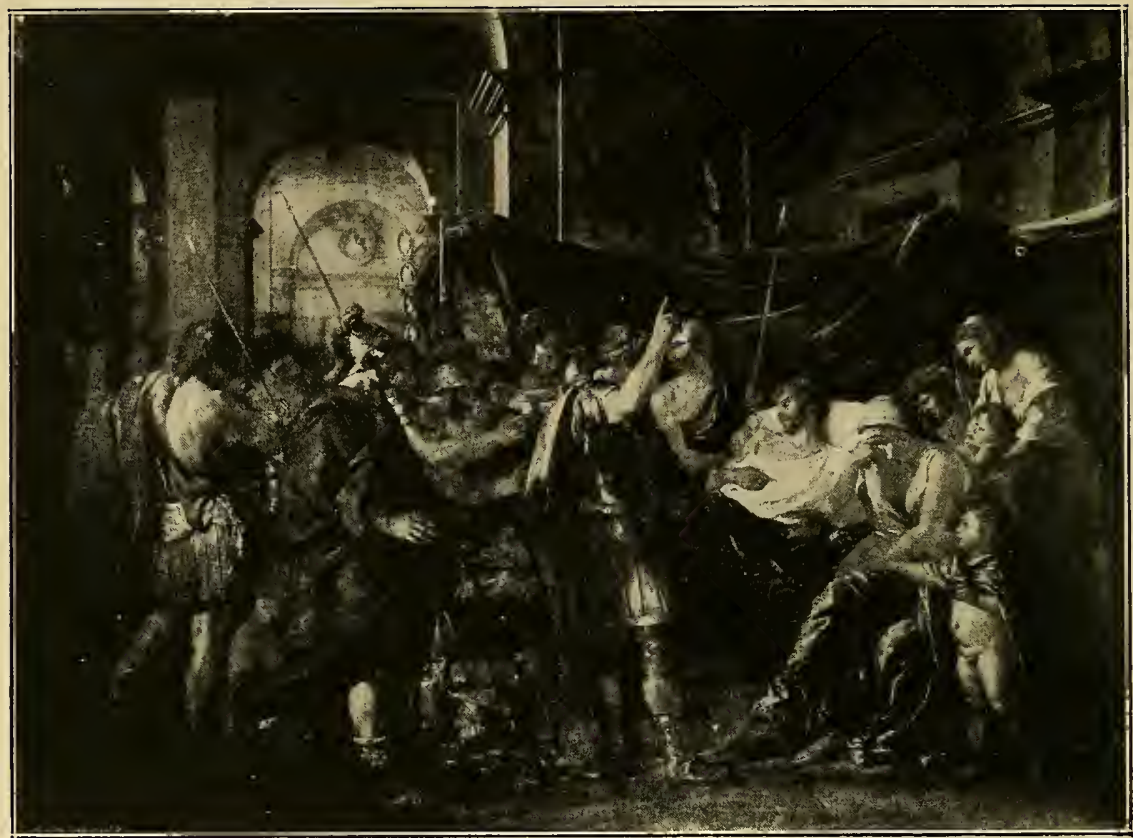

Poussin, La morte di Germanico - Galleria Barberini.

(Fot. Anaerson).

solo per ammaestrare e sollevare la mente degli uomini ad alte e sublimi contemplazioni, e per destare gli animi altrui con gli esempii ed azzioni eroiche, nobili fatti solamente e non villane o indecenti buffonerie voglion dipingersi ,. $\mathrm{Ma}$ questo intendimento morale che il biografo vuol prestare al suo pittore predíletto, Guido certamente non l'ebbe, nè le opere sue hanno tale potere insegnativo; sono candide espressioni di un'anima mite, fatte senza sforzo e senza passione, cose di maniera, visioni azzurre e zuccherine, che diventano stucchevoli per le ripetizioni dell'autore, e per quelle innumerevoli degli imitatori.

Nel 1621 arrivò a Roma un altro caraccesco, Gio. Francesco Barbieri da Cento, detto il Guercino (1590-1667), che già padrone in patria di forme proprie, si volse a Caravaggio, anch'egli senza intenderlo, e credendo di trovare in lui affinità di 
temperamento che in realtà non c'erano, tanto che gradatamente se ne andò distaccando, e abbandonata la sua maniera forte, si dette a ricerche di colore, imitando $i$ veneziani, e accostandosi talora anche ai toni argentini di Guido. Operò moltissimo nelle sue varie maniere, ed è più conosciuto per quella tenebrosa, in cui immerge le fígure in un'atmosfera oscura, sulla quale appaiono spesso ritagliate in un sol piano, perchè gli manca la corporeità statuaria di Caravaggio. A Roma rimase poco tempo, quanto durò il pontificato di Gregorio $\mathrm{XV}$, dal quale aveva sperato grandi aiuti come conterraneo; e non gli mancò infatti la protezione del cardinal nipote Ludovico Ludovisi, che gli fece dipingere nel casino della sua villa una Aurora, quasi per gareggiare con Scipione Borghese che possedeva quella luminosa di Guido.

Attratti dalla munificenza della corte pontificia, dei cardinali e dei principi, a Roma accorrevano nel Seicento i pittori non solo da ogni parte d'Italia, ma dalla Francia, dalla Spagna, dalle Fiandre. Claudio Gellée detto il Lorenese (1600-82) e Nicola Poussin (1594-1655) ci vissero a lungo, il primo creando coi colori del cielo latino i suoi paesaggi classici, che abbelli di architetture fantastiche; l'altro dipingendo soggetti antichi con vigore romano, ispirandosi da Raffaello e dalle statue pagane. II grande maestro spagnuolo Diego Velasquez venne a Roma nel 1630 e vi rimase parecchi mesi; abitava a Villa Medici e ivi dipinse due graziose vedutine, oggi a Madrid. Verso il 1608 c'era stato Pietro Paolo Rubens, che lasciò i tre quadri della Chiesa Nuova, ai quali guardarono molti pittori nostri, e guardò pure nel suo secondo periodo, Gianlorenzo Bernini, che del grande fiammingo dovette conoscere anche qualche ritratto. Il Bernini come pittore, per quanto ci è dato finora affermare, si ispirava invece al Velasquez. 


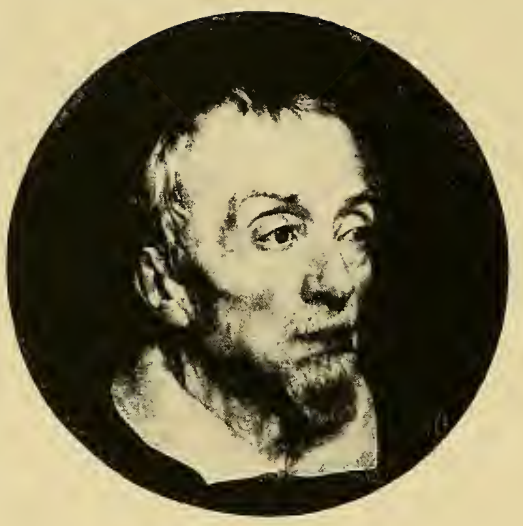

Ritratto di Guido Reni 


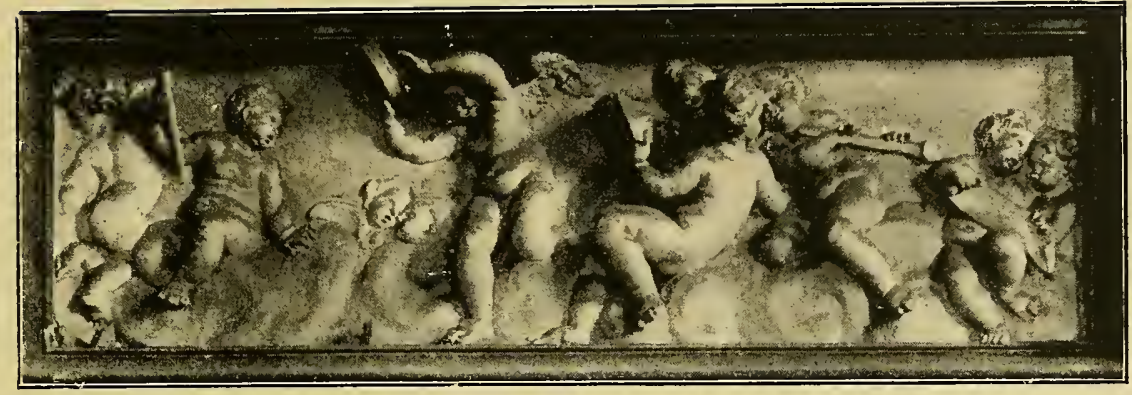

CAPITOLO NONO

\section{DONNA OLIMPIA}

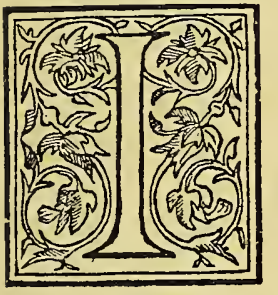

115 settembre $1644 \mathrm{fu}$ eletto pontefice, con quarantotto voti, il cardinale Giambattista Pamphili che assunse il nome di Innocenzo X. Si vollero subito attribuire origini antichissime alla sua famiglia, che si fece naturalmente derivare "dalla Pamphilia, provincia ricca e deliziosa ne l'Asia „.. I Pamphili venivano più direttamente da Gubbio, e avevano in realtà vecchie tradizioni gloriose di pellegrini crociati, di santi, di cavalieri; trapiantatisi a Roma fin dai tempi di Sisto IV, si erano imparentati nobilmente coi Mellini e coi Mattei. Si diceva che alla rapida carriera di Giambattista molto avesse giovato l'opera accorta di Donna Olimpia, vedova di suo fratello Pamfílio, morto nel 1639, e rimasta nella casa del marito, dove faceva da padrona. Uscita dalla famiglia viterbese dei Maidalchini, e sposa dapprima a un certo Nini, era passata in seconde nozze col signore romano, dal quale aveva avuto tre figli: Maria, maritata al principe Andrea Giustiniani, prima che lo zio salisse al trono, Costanza Camilla sposatasi dopo al principe Nicolò Ludovisi, e Camillo che fu elevato alla porpora, 
da lui poi svestita per passare a nozze con Olimpia Aldobrandini.

Olimpia Maidalchini Pamphili, che al tempo dell'elezione del cognato aveva circa cinquant'anni, era donna di forte carattere, amante più degli esercizi mascolini che dei passatempi del suo sesso; il suo divertimento preferito era quello della caccia. Papa Innocenzo, malinconico e schivo di noie, si lasciava facilmente dominare dall'impetuosa cognata, e Pasquino diceva che invece di guardare l'Olimpo, egli guardava Olimpia.

Nelle feste per l'incoronazione del nuovo pontefice, che fu fatta il 4 ottobre, si ebbero a notare in modo speciale quelle preparate dalla nazione spagnola; il palazzo dell'ambasciata $\mathrm{fu}$ illuminato con torce, e innanzi alla chiesa di S. Giacomo in piazza Navona, si bruciò una gran macchina, che figurava l'arca di Noè, coronata da una colomba col ramoscello d'olivo, stemma dei Pamphili. E avevano ragione gli spagnuoli di rallegrarsi, perchè la politica papale, mutando rotta, si volse in loro favore, contro la Francia. Innocenzo volle fare le vendette della Spagna, e perseguitò i Barberini che l'avevano contrastata; il cardinale Antonio, che era stato camerlengo e amministratore dei beni della Chiesa, temendo di dover rendere $i$ conti, pensò meglio di fuggire segretamente e si rifugiò nel settembre del 1645 a Parigi, ove presto lo raggiunsero l'altro cardinale Francesco, e Taddeo già prefetto di Roma. I beni di Antonio furono sequestrati, ed allora i Barberini, dichiarandosi francesi, fecero alzare sui loro palazzi lo stemma di Francia.

La persecuzione si estendeva a tutti coloro che avevano goduto il favore del papa precedente e della sua corte, e tra questi ci fu naturalmente il Bernini, che vide demolire il campanile da lui elevato sul portico di S. Pietro. Fin dal 1638 il maestro, riprendendo per ordine della Congregazione della Fabbrica l'idea primitiva del Maderno, aveva preparato i disegni pei due campanili, studiandoli più snelli e leggeri 


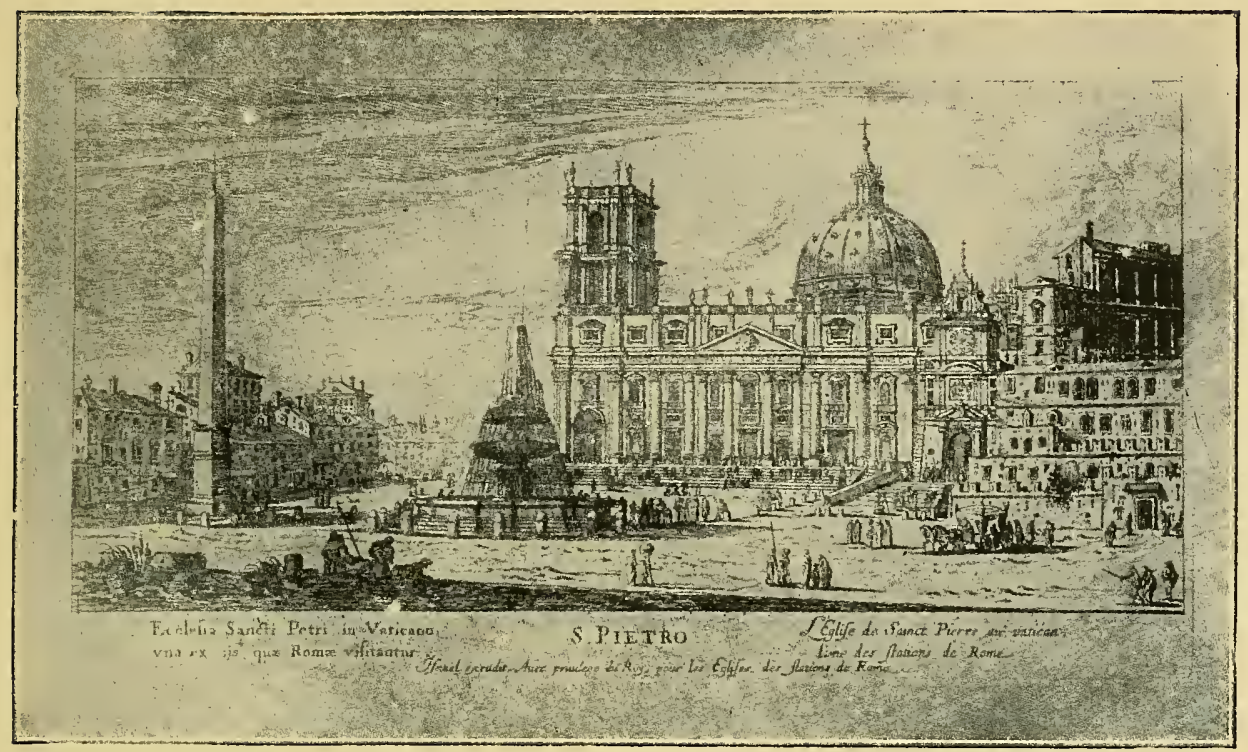

San Pietro col campanile del Bernini, demolito nel 1645.

di quelli ideati dal suo predecessore e non eseguiti per difficoltà statiche, e l'opera di costruzione di uno di essi, quello sul lato sinistro, aveva proceduto con alacrità fino al 1641, quando si verificò una lesione nel portico sottostante, così che si dovette demolire il terzo ordine, e "il cav. Bernini, essendo ripreso dal $\mathrm{Papa}$, si ammalò, et $\mathrm{fu}$ in gran pericolo di morire ". Se Urbano aveva trattato con durezza il suo prediletto artista, molto più severo fu naturalmente papa Innocenzo; i nemici deI Bernini avevano con libelli atroci sparso mille calunnie contro il maestro, e cosi, I'8 giugno 1645, il pontefíce adunò la Congregazione nel palazzo del Quirinale, e alla sua presenza furono chiamati a dare il loro parere, insieme col Bernini, Carlo Rainaldi, Francesco Borromini, Paolo Marucelli, Martino Lunghi. Dopo varie controversie, nel febbraio del 1646, fu risoluto di demolire il resto del campanile, e si minacciò il Bernini di fargli pagare la spesa, di circa diecimila scudi, e anche quella di cen- 
tocinquantamila occorsa per la costruzione, sebbene il maestro avesse cercato di ingraziarsi Donna Olimpia con un dono di mille doble a lei, e al cardinale suo fíglio di un diamante di seimila scudi, che aveva avuto molti anni innanzi dalla Regina d'Inghilterra. $\mathrm{Fu}$ in quest'ora dolorosa della sua esistenza, fino a quel tempo trascorsa felicemente e senza nubi, che il Bernini imaginò un'opera che rispecchiava i suoi tristi pensieri, e fu il gruppo della "Verità scoperta dal Tempo ", che egli eseguì per conto suo proprio, e lasciò ai suoi eredi con obbligo di non alienarlo, come ammaestramento che la verità col tempo fínisce per trionfare: altera risposta che egli dava nel suo linguaggio naturale, quello dello scalpello, alle calunnie dei suoi nemici. La Verità, bellissima donna nuda, che pare uscita da un quadro del Correggio, seduta su uno scoglio, con un sole nella destra $e$ iI globo del mondo sotto i piedi, si vede oggi nell'atrio del $\mathrm{Pa}$ lazzo Bernini al Corso, ma non c'è la fígura del Tempo, così che il manto sembra sollevato in alto da una forza invisibile: l'artista, come appare da un disegno della collezione Chigi, lo aveva ideato in forma di vecchio alato, armato di falce, che scendeva dall'alto, ma si trovò nell'impossibilità di tradurlo in marmo, non potendo sostenere in aria un blocco così pesante. Allora pensò di poggiarlo su un mucchio di colonne, di obelischi, di marmi infranti, che dovevano rappresentare la potenza distruttrice del tempo; ma distratto dalle sue infinite cure, non ebbe modo di completare il suo gruppo. L'episodio ha un' importanza somma per lo studio dell'arte berniniana; ci mostra come il maestro ideava le sue opere più con concetto da pittore che da scultore; è un'altra prova del carattere pittorico della plastica seicentesca.

In questo stesso periodo della vita del Bernini cade l'esecuzione di un'opera sua mirabile; la più bella della sua età matura, la piì rappresentativa dell'arte barocca; la Santa Teresa in estasi, ch'è in una cappella di S. Maria della Vittoria. Com- 


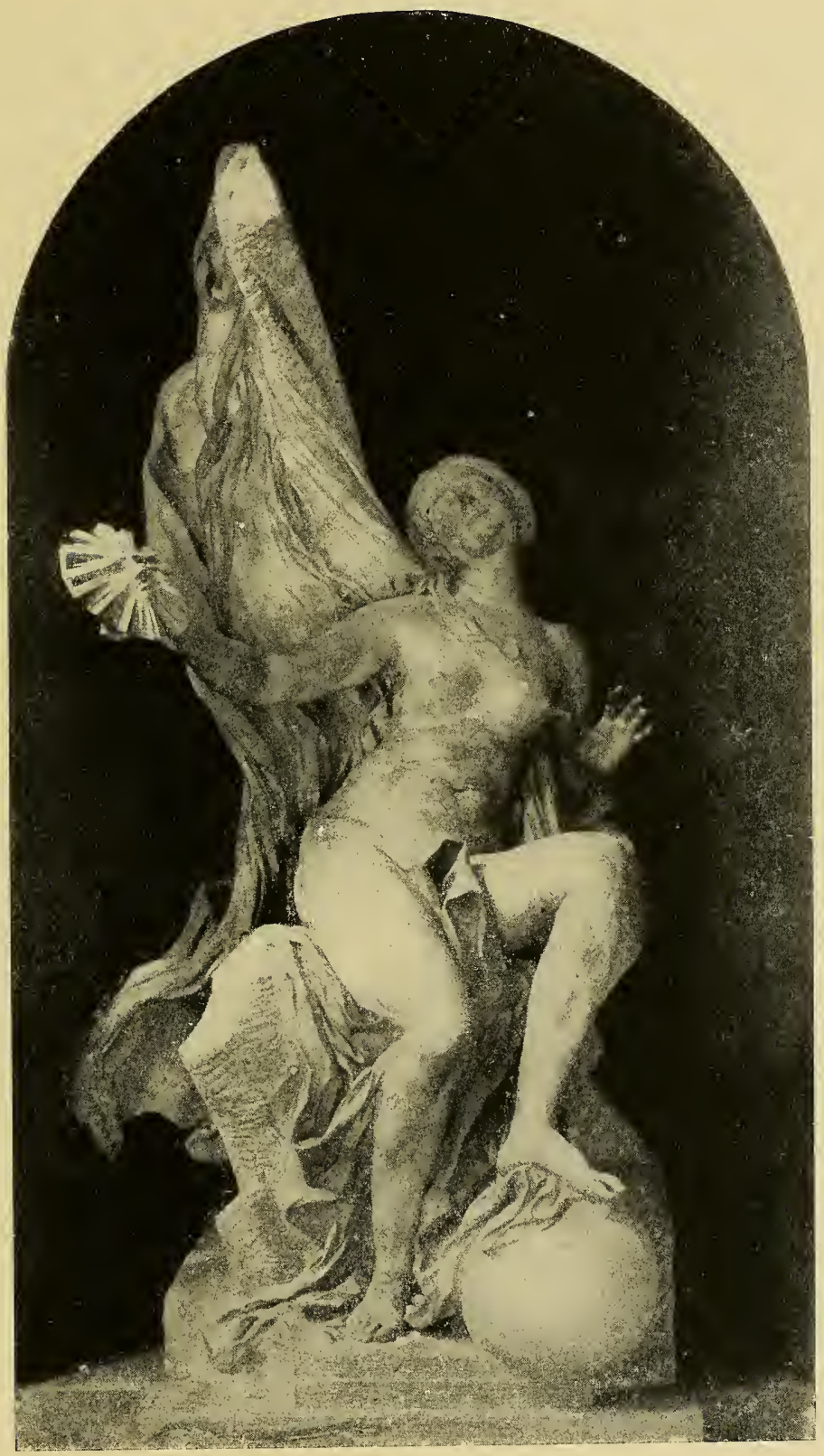

Bernini, La Verità scoperta dal Tempo, nel palazzo Bernini al Corso. 
mittente dello splendido sacello fu il cardinale veneziano Federico Cornaro iuniore, il quale ottenne dai monaci carmelitani il permesso di ricostruire a sue spese la cappella fin a quel tempo consacrata a S. Paolo, per dedicarla a Santa Teresa di Gesì, riformatrice dell'ordine del Carmelo; il lavoro iniziato nel 1644 fu compiuto in tre anni. La cappella è una delle più ricche di marmi che esistano in Roma, e l'altare ha la forma di un palcoscenico; un alto basamento convesso, tutto incrostato di alabastro, fiancheggiato da quattro colonne di africano e da pilastri di verde antico, che sorreggono un timpano ornato di stucco ed oro, forma il piano della scena. Il fondo della nicchia è decorato a fintc alabastro, e da esso si distacca il gruppo meraviglioso della santa, che abbandonandosi all'indietro, sviene innanzi all'angelo che si prepara a colpirla col suo dardo dorato. Un fascio di raggi d'oro è posto sul fondo, e sembra piovere dal cielo; $e$ in realtà da una finestra ovale a vetri gialli, aperta a guisa di lucernario sull'alto della nicchia, e nascosta al riguardante dall'edicola, scende sulla figura di S. Teresa una luce dorata, che dà al marmo un'intonazione calda di avorio. $\mathrm{E}$ un vero dramma di passione che si svolge sulla scena, e il Bernini non ha tralasciato alcun mezzo per ottenere effetti, come uno scenografo: luce, movimento, colore. Si è rimproverato al sommo artista di aver figurato l'estasi divina della carmelitana spagnuola in forma cosi umana, che faceva esclamare al presidente de Brosses: "Si c'est ici l'amour divin, je le connois; on en voit ici-bas maintes copies d'après nature „. E il clericalissimo Veuillot, in tempi moderni, osava scrivere che del gruppo di S. Teresa sarebbe bene farne marmo da calce! Ma leggendo l'autobiografia nelle Obras de la Gloriosa Madre Santa Teresa de Jesus, vediamo che il Bernini non ha fatto che rendere fedelmente nel suo gruppo le visioni che l'appassionata carmelitana racconta nella sua prosa colorita: "Più d'una volta il Signore permise che mi apparisse un Angelo in forma corporea. 


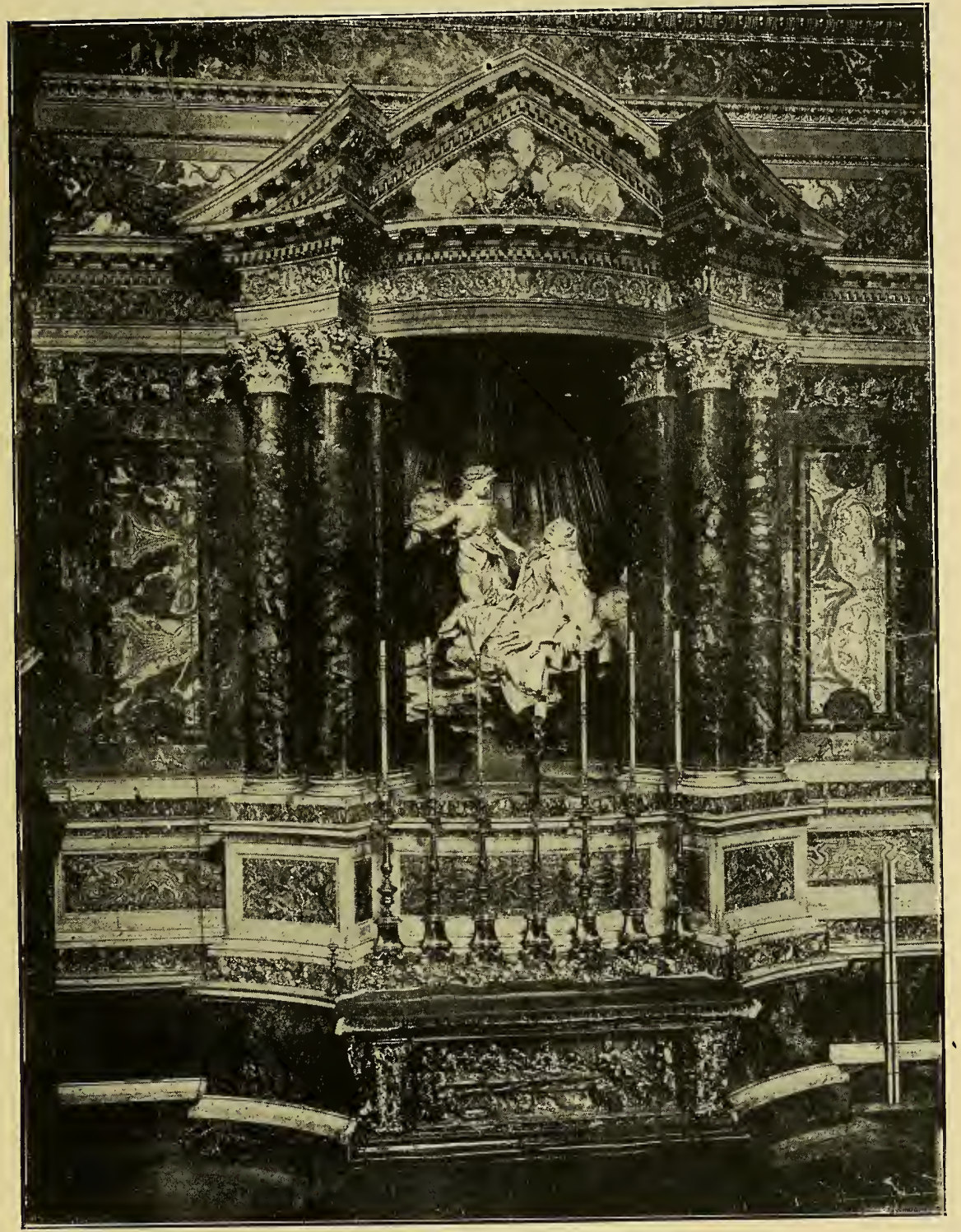

Bernini, L'altare di S. Teresa, in S. Maria della Vittoria. 


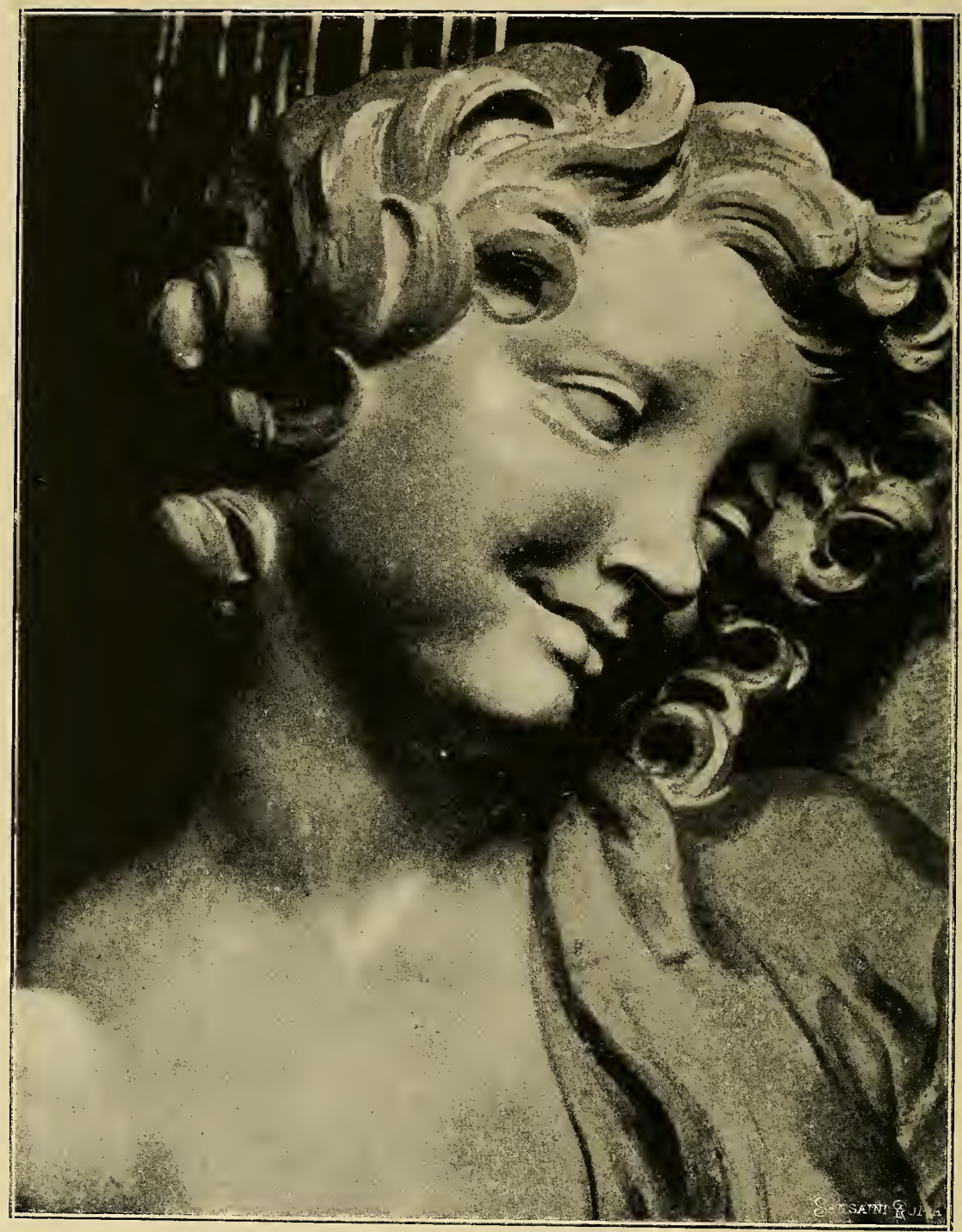

L'angelo di S. Teresa.

(Fot. Anderson).

Non era grande, ma piuttosto piccolo, assai bello, e col volto tutto illuminato, doveva esser di quelli che chiamano Serafini. Teneva in mano un lungo dardo d'oro, che mi pareva avesse 


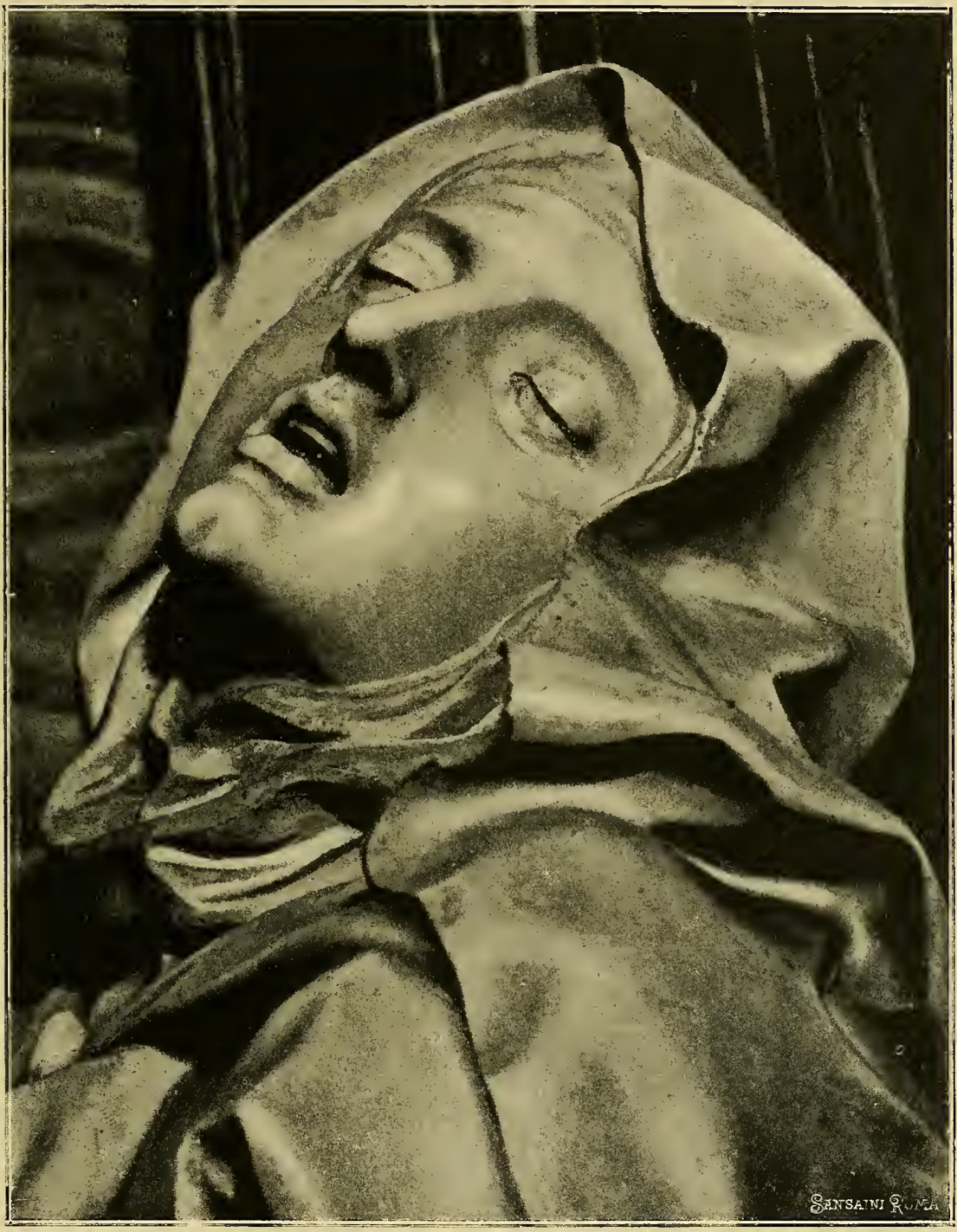

Testa deila S. Teresa.

(Fot. Anderson).

la punta infiammata, e con quello più volte mi trapassava il cuore e mi penetrava le viscere, così che ritirandosi mi pareva che me le portasse via, e mi lasciava tutta agitata in grande 
amore di Dio „. Negli Atti della sua santificazione si legge che fu sempre tormentata da contrazione di nervi, da epilessia, da continui tremori in tutto il corpo; e il padre Hahn, gesuita, ha recentemente spiegato le apparizioni di $S$. Teresa con fenomeni isterici, in un libro che l'Indice si è però affrettato a condannare, mentre gli scienziati le riavvicinano alla transberberazione.

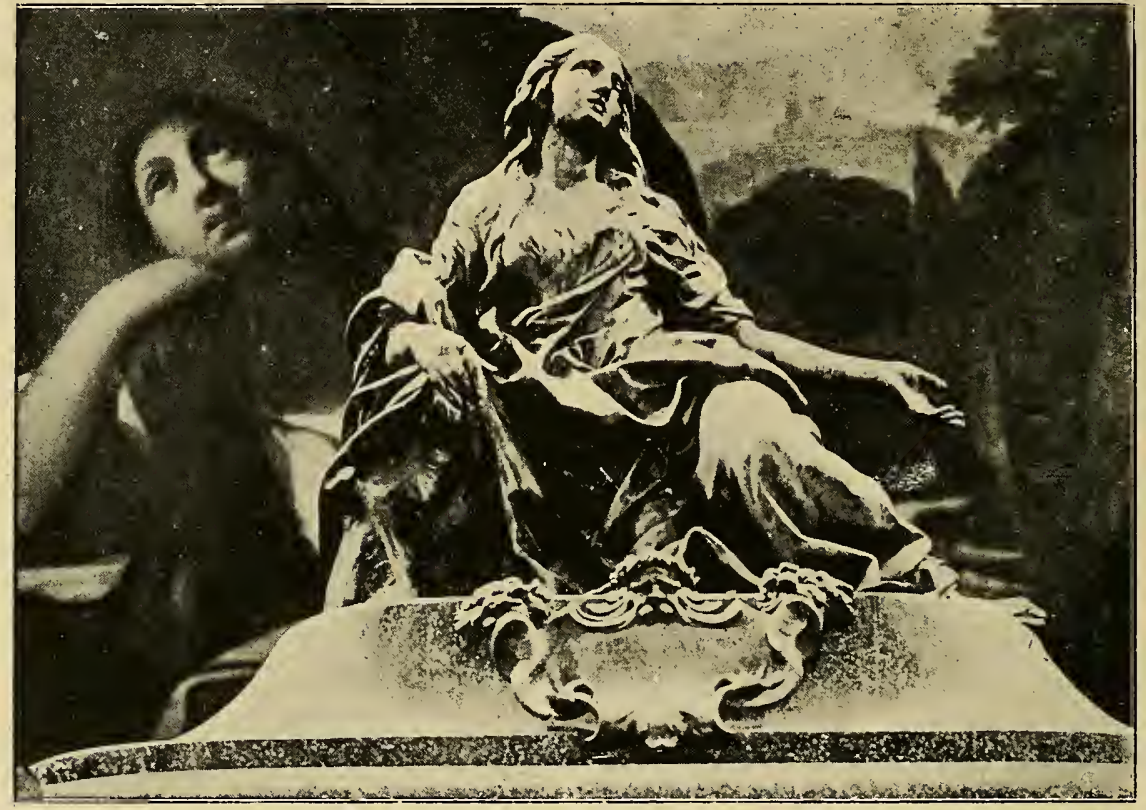

Algardi, La Maddalena, a S. Massimino in Provenza.

Ma nessuno ha saputo interpretare l'appassionato stato d'animo della santa come il Bernini, che l'ha rappresentata in pieno abbandono, svenuta d'amore, rovesciata indietro su un letto di nuvole, con gli occhi spenti, la bocca aperta in un gemito doloroso, la sinistra abbandonata, come perduta, e la destra nervosamente contratta, mentre il bellissimo efebo le si avvicina con un sorriso malizioso, le solleva il manto per scoprire il seno, e con la destra stringe la freccia dorata, e sembra 


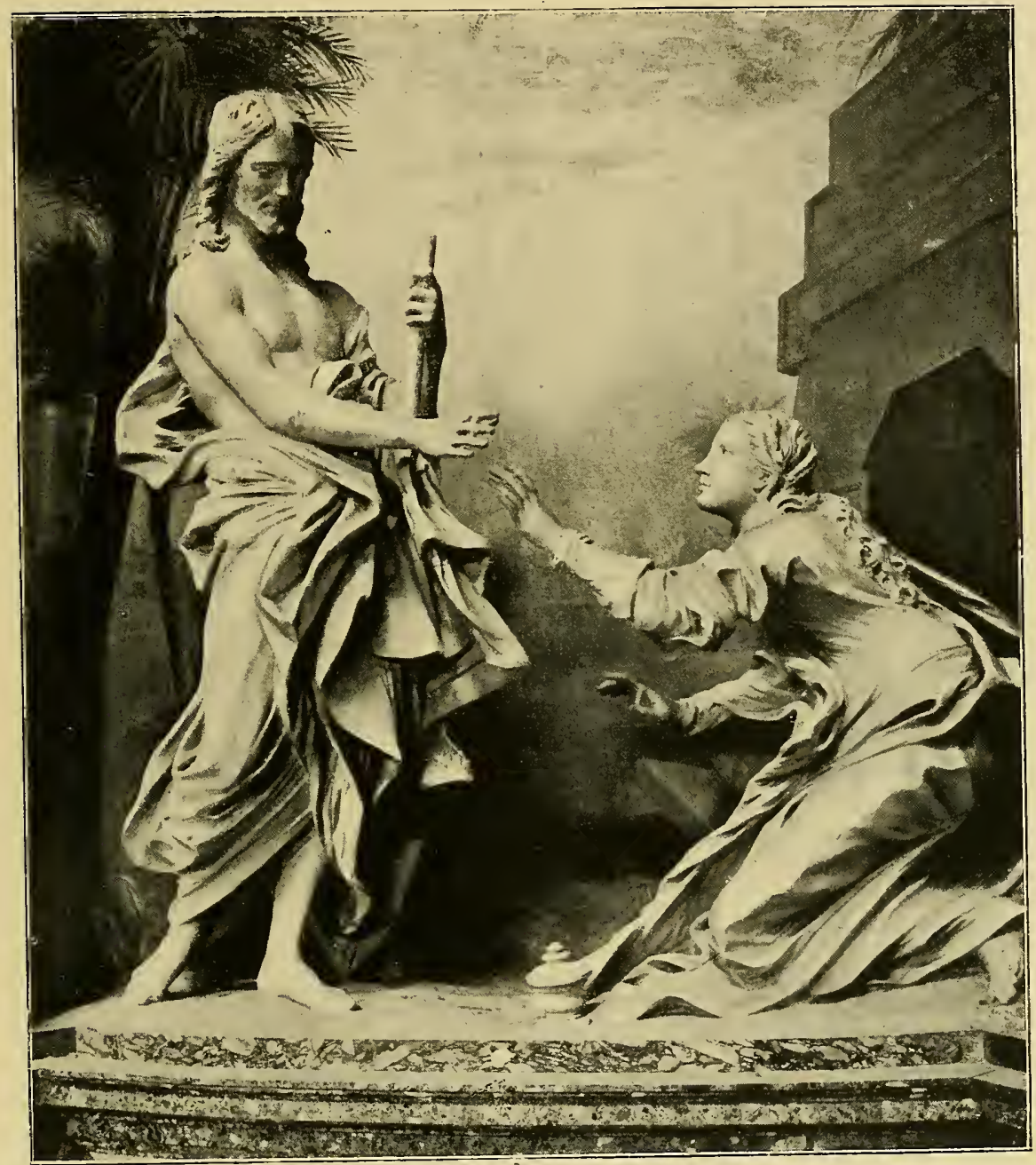

Bernini, Noli me tangere, in SS. Domenico e Sisto.

compiacersi del fremito della donna che gli si dà perdutamente. Con quell'arte sua inarrivabile, che sa dar vita anche alle cose inanimate, il Bernini è riuscito a comunicare l'ardente sensazione della santa carmelitana al ruvido saio che ne ricopre le membra delicate, e che è tutto agitato da pieghe palpitanti. 
Ah, si, ha ben ragione lo Stendhal quando dice che lo scalpello greco non ha saputo creare un'opera simile a questa, che il Bernini giustamente considerava come il suo capolavoro!

La rappresentazione dell'estasi, dopo la S. Teresa, diviene comune nel Seicento: vedemmo già quella di $S$. Francesco nella cappella Raimondi, di uno scolaro del Bernini; e lo stesso Algardi, il maestro più classico e accademico tra i barocchi, studiò una posa di fremente passione per la sua Maddalena, che mandò

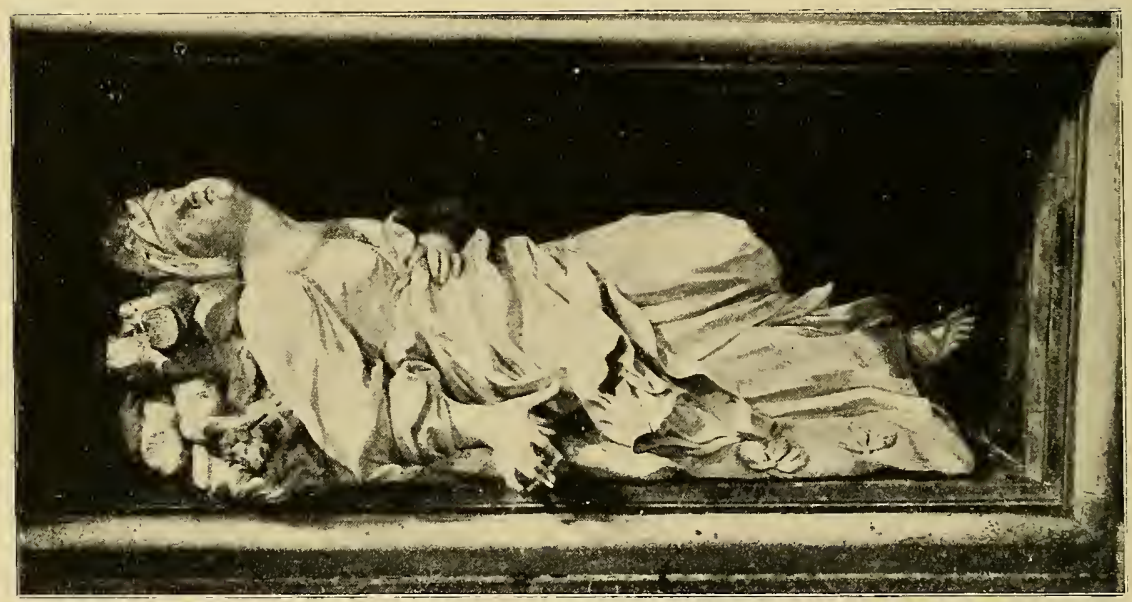

E. Ferrata, S. Anastasia, nella chiesa omonima.

(Fot. Moscioni).

in Francia, nella chiesa di S. Massimino in Provenza. Bernini aveva già rappresentato un altro dramma di ardente amore nel gruppo del Noli me tangere, in S. Domenico e Sisto, ma il fervore della Maddalena che si accosta al divino Maestro non è ancora così vivo, come nella Santa carmelitana; di mano in mano che si procede nel Seicento i sentimenti si scaldano, e si esaltano; la preghiera diventa invocazione supplichevole, la parola, grido; l'estasi, crisi nervosa; il movimento, turbine vorticoso. Sugli altari e sui sepolcri i santi e i devoti pregano con fervore, svengono, si sentono mancare, portan le mani al cuore 


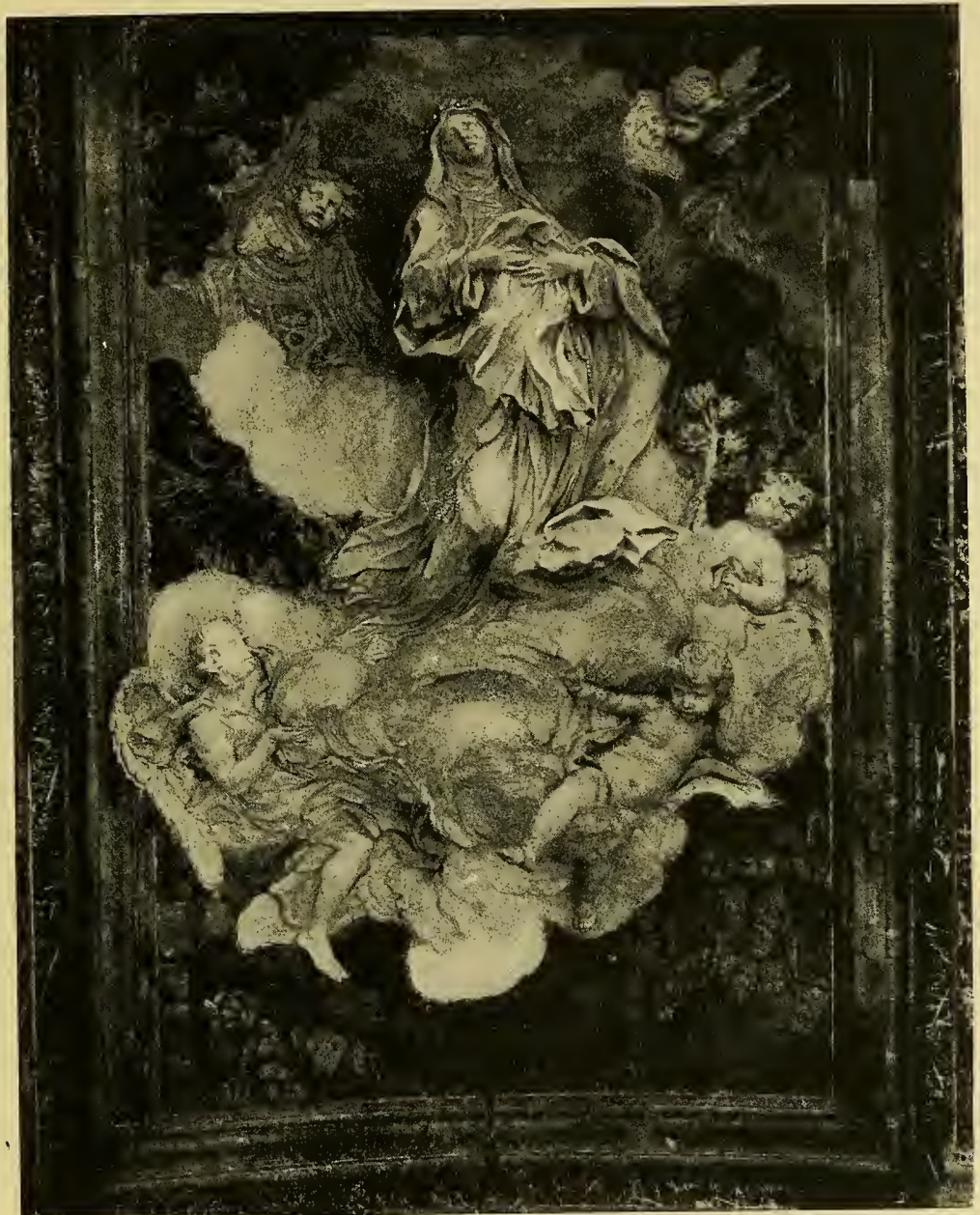

M. Cafà, Estasi di S. Caterina, nella chiesa di Magnanapoli.

come in una stretta pungente, si abbandonano, muoiono. La S. Anastasia di Ercole Ferrata langue sotto l'altare; la S. Caterina di Melchiorre Cafà sale in estasi al cielo con dolorosa dedizione; Suor Maria Raggi, del Bernini, nel suo sepolcro alla Minerva, porta le mani al cuore trafitto.

Mentre il disgraziato Bernini dava sfogo in queste appas- 
sionate creazioni al tormento dell' anima sua, trionfavano alla corte papale i suoi due rivali, il Borromini e l'Algardi. Della fortuna dell'architetto lombardo in questi anni, abbiamo già veduti i segni nelle sue opere più belle; anche per lo scultore bolognese il pontificato di Innocenzo $X$ segna l'epoca più lieta e operosa, interrotta ben presto dalla morte, immaturamente avvenuta nel 1654 , quando egli contava solo cinquantadue anni. Venuto in Roma nel 1625, raccomandato al suo conterraneo cardinal Ludovisi, Alessandro Algardi, fino ad allora piuttosto orafo che scultore, si era dato principalmente al restauro di marmi antichi; nel '28 circa eseguì due statue di stucco, S. Giovanni e la Maddalena, per la cappella Bandini in S. Silvestro al Quirinale, ispirandosi un po' alla S. Bíbiana del Bernini, ma con minor ricerca di effetti pittorici. Quasi allo stesso tempo l'Algardi lavorò al deposito del cardinal Garzia Millini, in S. Maria del Popolo, dando al busto del prelato il taglio berniniano del Bellarmino, ma adoperando esclusivamente il marmo bianco; il maestro bolognese assume già qui un atteggiamento diverso da quello del Bernini, che di tre anni appena maggiore era già ricco e glorioso; e fa presagire che l'arte sua rappresenterà in seguito, di fronte a quella del fortunato rivale, un ideale più calmo e composto, più attaccato alle tradizioni della scultura antica, più conforme alle buone norme della plastica. Tuttavia non poche volte l'Algardi, indulgendo al gusto prevalente del tempo, si è compiaciuto di effetti pittorici, come ad esempio nella grandiosa tavola di S. Pietro, che rappresenta l'incontro di Attila con Leone Magno, terminata nell'anno del gíubileo 1650, con la collaborazione dei migliori discepoli suoi, Ercole Ferrata, Francesco Baratta, Domenico Guidi. È un vero quadro di altare di scuola bolognese, diviso in due parti, una inferiore con la scena che avviene in terra, l'altra superiore coi personaggi celesti; e vì è il paesaggio caraccesco nel fondo. È un'opera condotta all'incirca al tempo stesso della S. Teresa, e per quanto sia difficile il confronto tra 
due creazioni così differenti, si può ben rilevare la profonda diversità di spirito dei due maestri; appassionato, nervoso, fremente il Bernini; sereno, calmo, sicuro, l'Algardi, che pare dimenticarsi del soggetto principale per studiare un bel profilo, e si

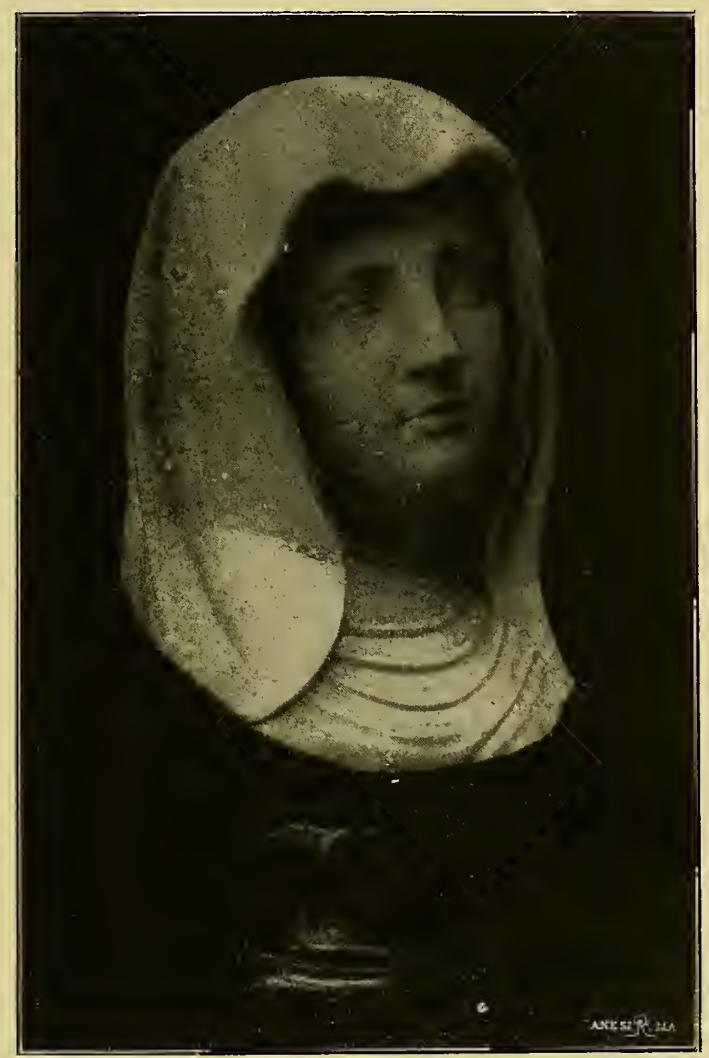

Scuola del Bernini, S. Teresa, Collez. di A. Munoz.

indugia con pazienza da orafo a decorare elmi e corazze : notevole è il típo barbarico degli Unni, imitato dai Galli dei bassorilievi romani, tipo caro all'Algardi che ad esso ricorse più volte.

Nell'anno stesso 1650 il maestro bolognese aveva terminato un'altra grande opera, la statua bronzea di Innocenzo X, 
che fu collocata nel salone del Palazzo dei Conservatori. Si trovò così a gareggiare col Bernini, la cui statua marmorea di Urbano VIII, scolpita dieci anni prima, stava nella parete di

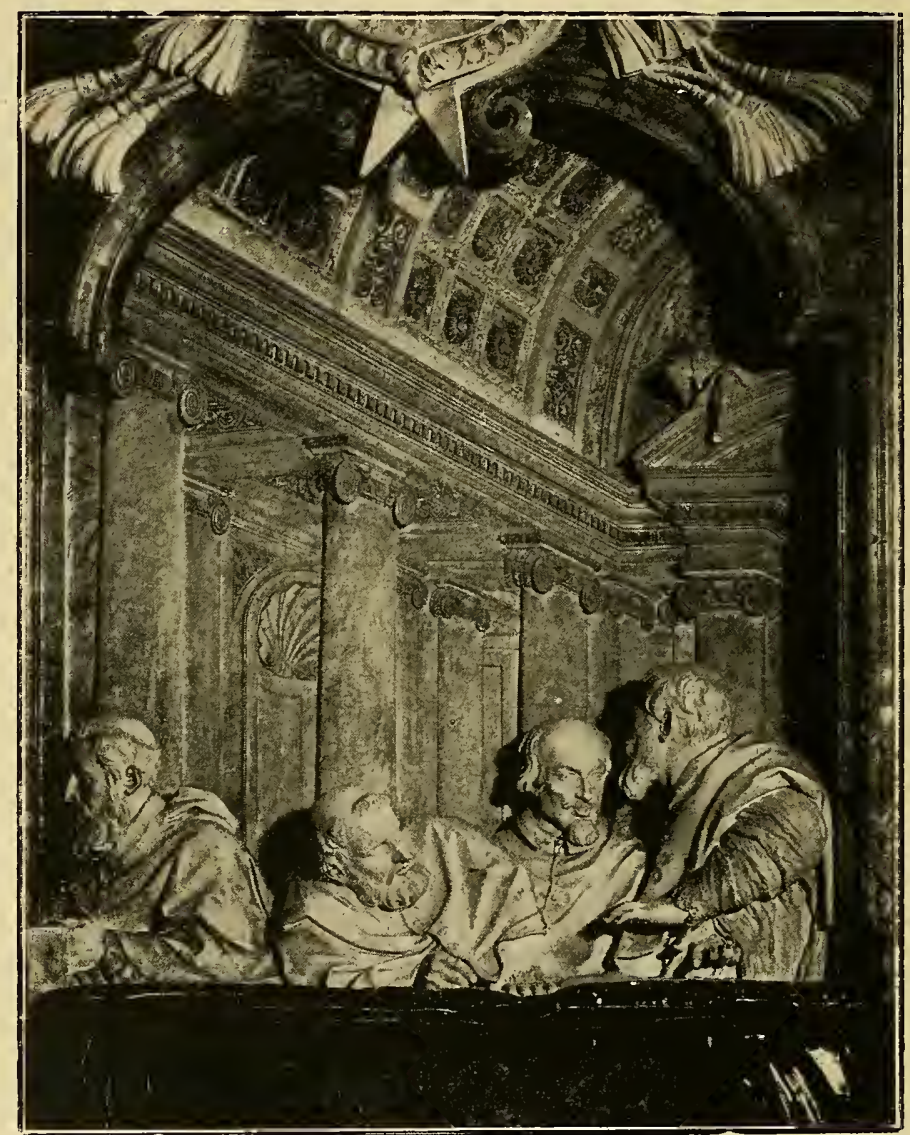

Bernini, I cardinali Cornaro, nella cappella di S. Teresa

(Fot. Anderson).

contro della stessa sala. Anche oggi le due gigantesche figure si guardano, l'una di fronte all'altra; i due grandi attori del dramma politico che agitò l'Europa intorno alla metà del Seicento, $i$ due rivali, sono per uno strano volere della sorte riu- 
nitł́ insieme per sempre; e i loro simulacri sono di per sè stessi l'espressione di un'altra lotta, di un'altro minor dramma d'anime: la rivalità tra il Bernini e l'Algardi. Ebbene, nella nobile guerra di emulazione, è certo che la vittoria è rimasta al secondo. Siedono $i$ due pontefici in trono, e levano la mano possente

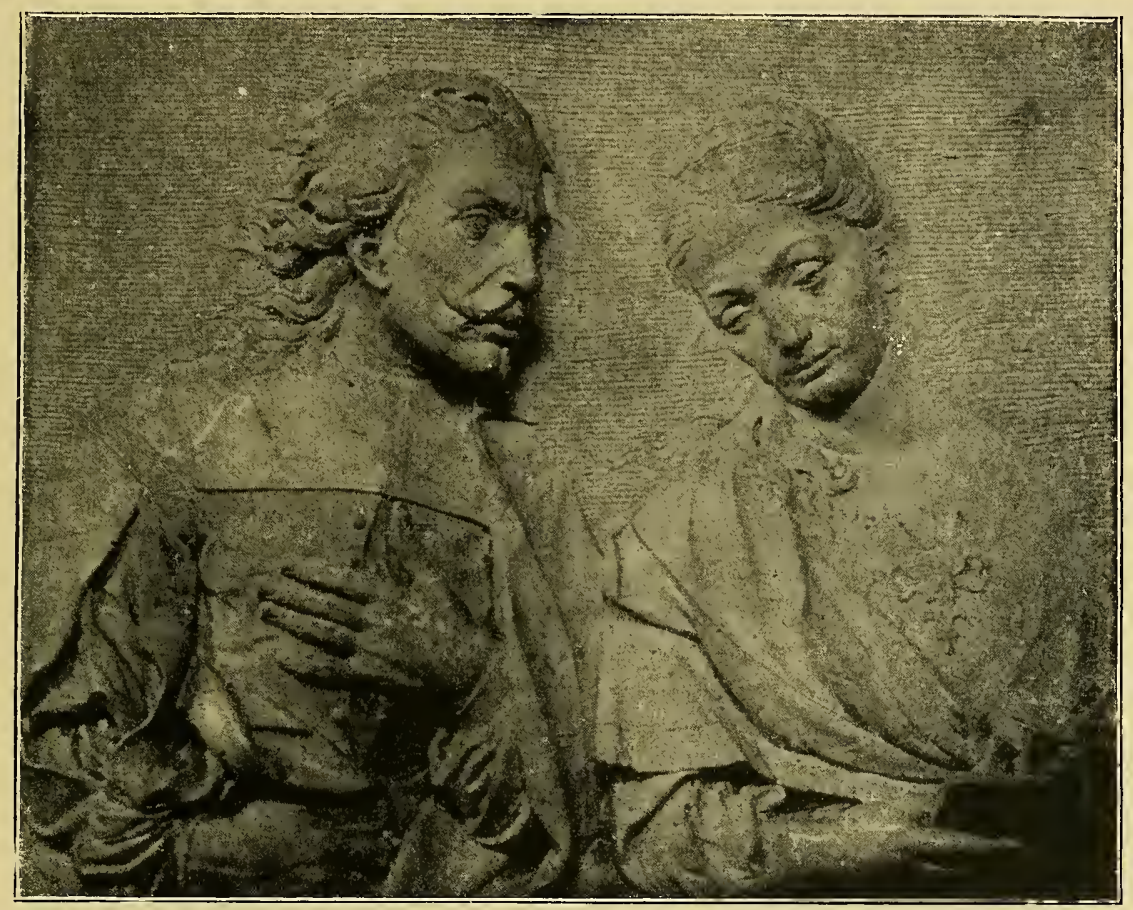

Scuola del Bernini, Particolare del monumento de Silva in S. Isidoro.

sulla moltitudine; il grande Urbano, col volto sereno e quasi sorridente, ha il gesto del pacificatore e par che voglia sollevarsi un poco dal suo seggio; Innocenzo siede con più maestà, il suro viso è un miracolo di verismo, il braccio destro è mosso con maggiore ampiezza, e il ricco paludamento e la veste hanno il lucido fruscio della seta, mentre nella statua berniniana il panneggio è più stilizzato. 


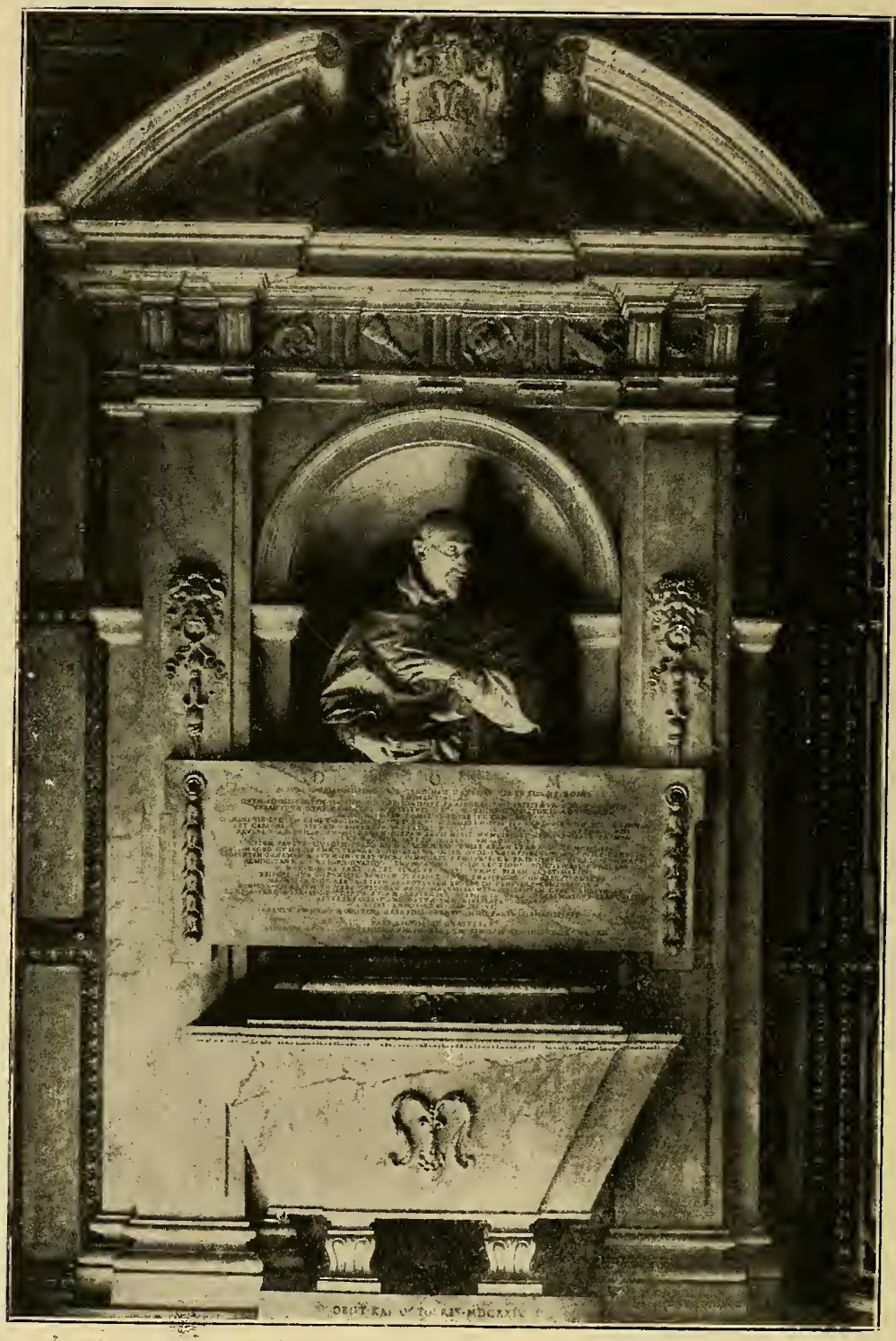

Algardi, Sepolcro del card. Millini, in S. Maria del Popolo. 


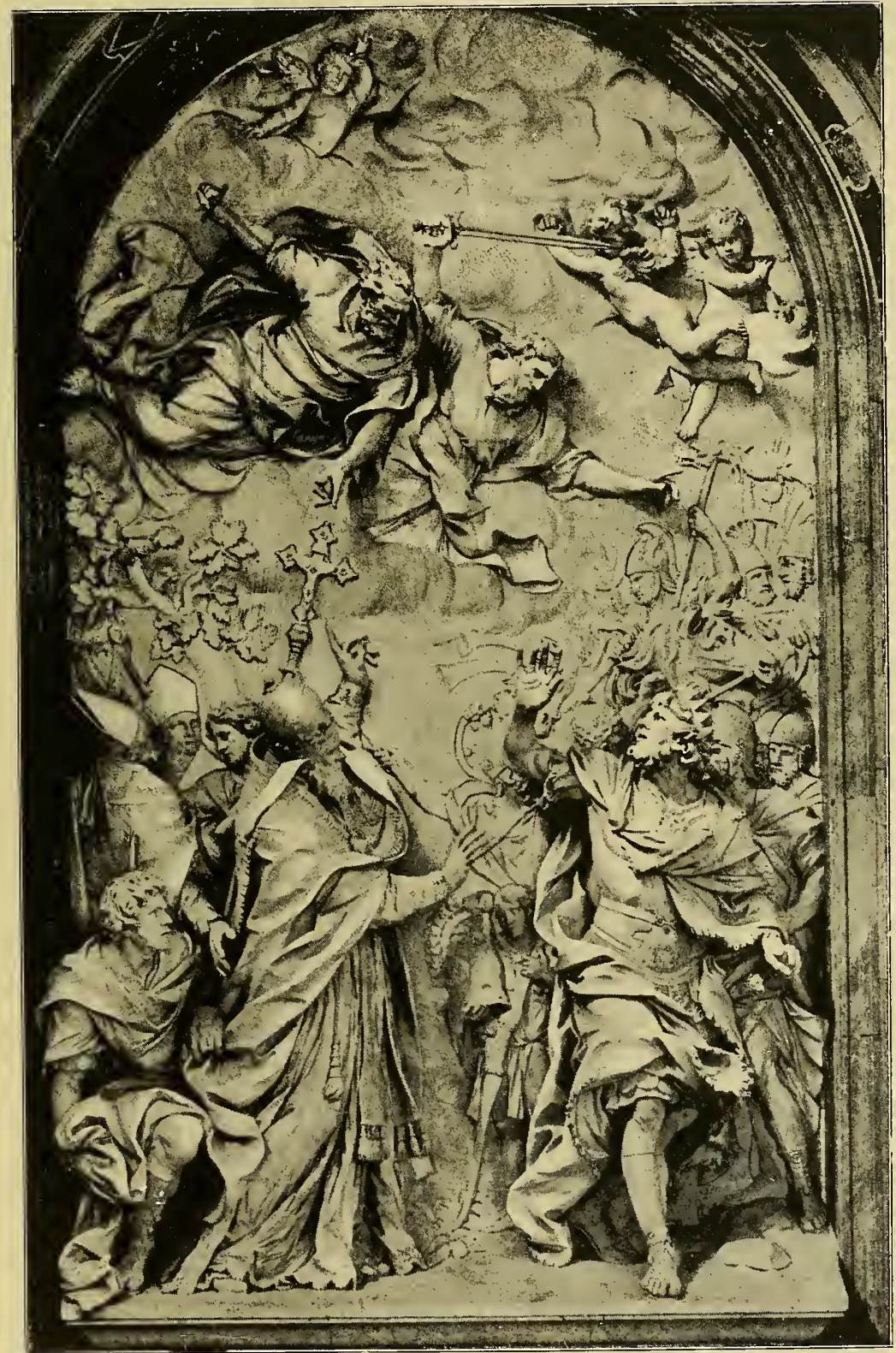

Algardí, La tavola dell'Attila, in S. Pietro. 


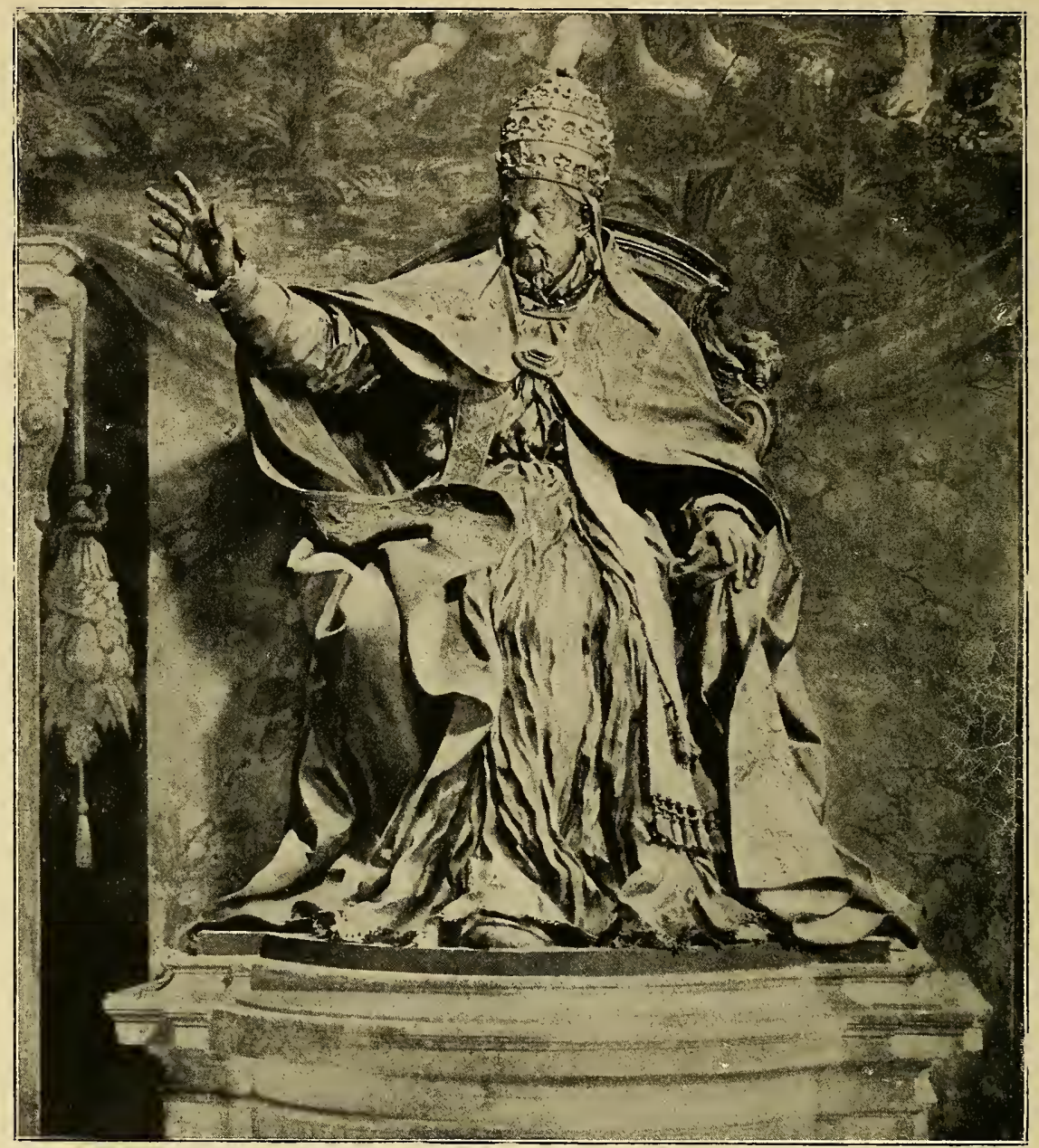

Algardi, Statua di Innocenzo $\mathrm{X}$, in Campidoglio.

(Fot. Alinari).

Anche il deposito di Leone XI, nella Basilica Vaticana, fu condotto a termine circa lo stesso tempo, ed è tra le più belle cose dell'Algardi; in esso pure, sdegnando di seguire il recente esempio del mausoleo di Urbano VIII, l'artista ha impiegato il solo marmo bianco, condotto a tal grado di patinatura da sembrare avorio. Leone XI era morto nel 1605, dopo soli venti- 


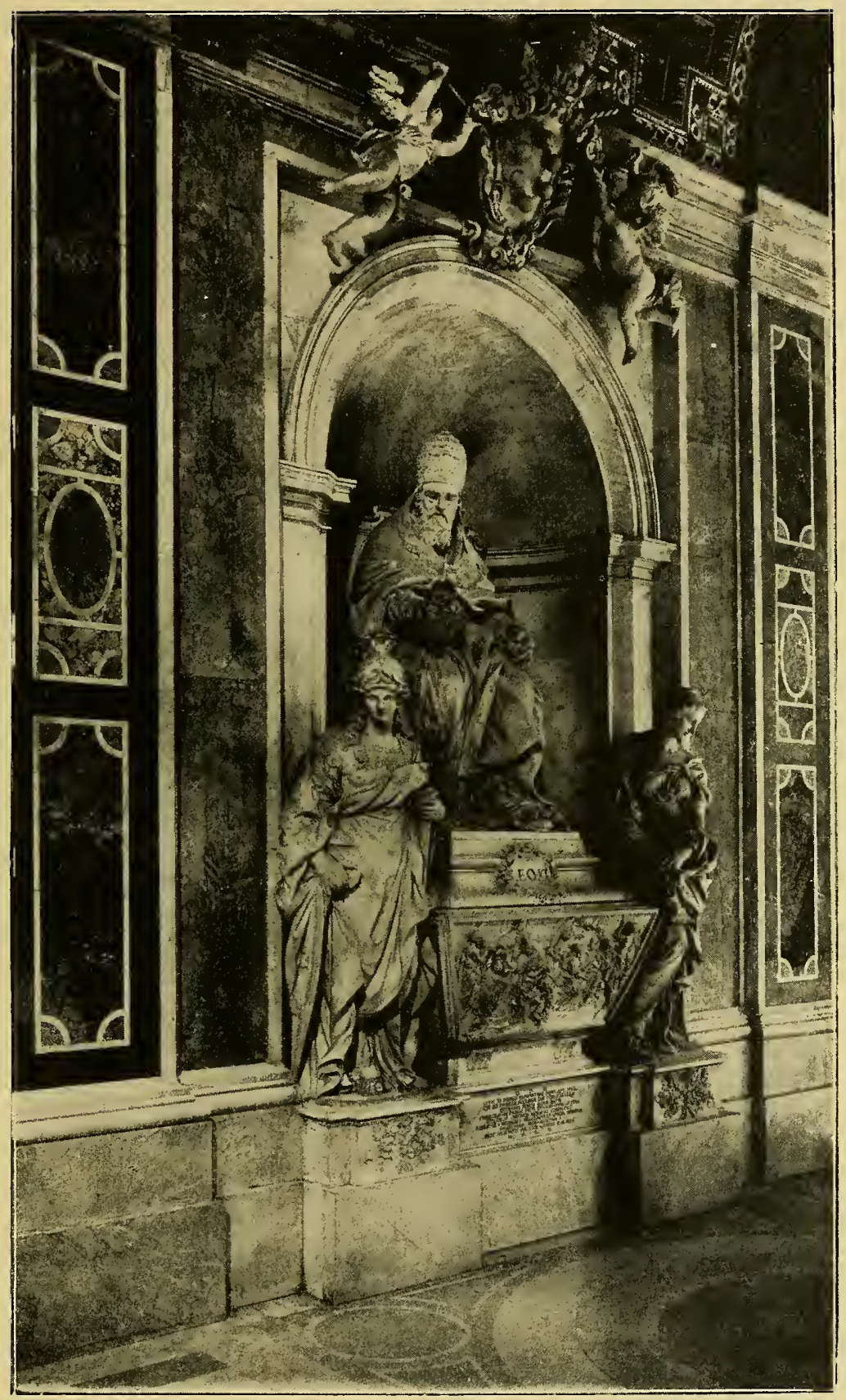

Algardi, Sepolcro di Leone XI, in S. Pietro. 
sette giorni di regno, e l'Algardi non poteva quindi averlo conosciuto; dette perciò alla figura un carattere ideale: in basso, ai lati dell'urna su cui son scolpiti in bassorilievo due episodi dell'abiura di Enrico IV, ai quali Leone XI aveva partecipato essendo ancora cardinale, stanno in piedi le due statue della Maestà del regno e della Munificenza, due tra le piu soavi creature del mondo allegorico barocco, dovute allo scalpello di due discepoli, Ercole Ferrata e Giuseppe Peroni.

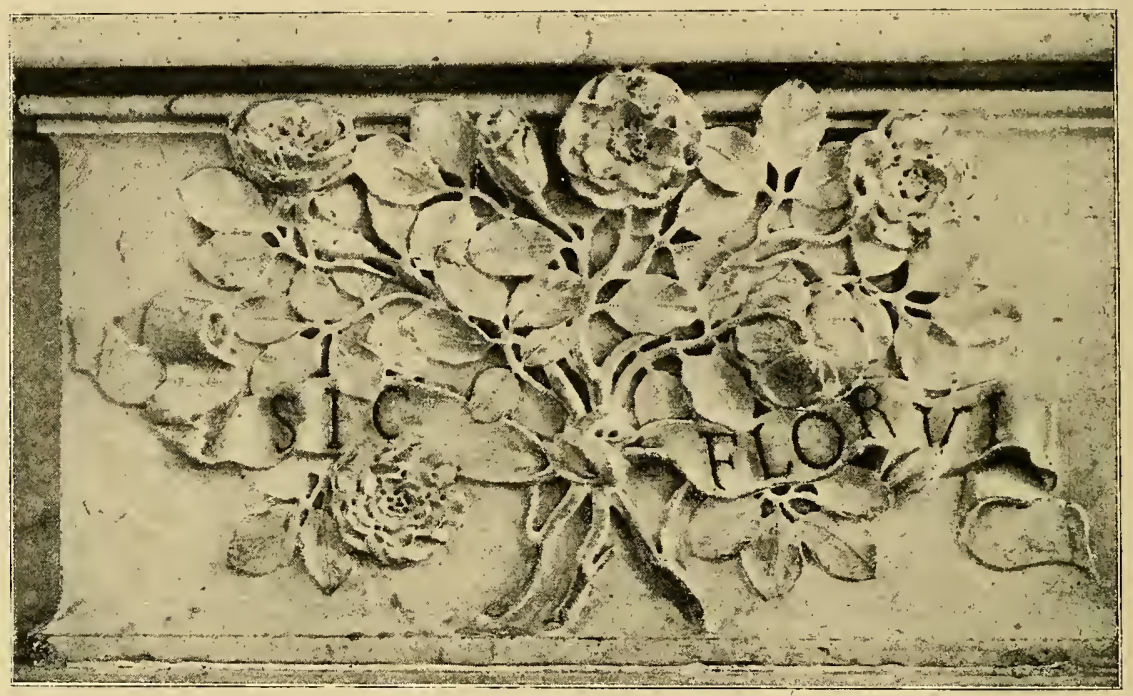

Ornato nel sepolcro di Leone XI.

Una qualità che l'Algardi possedette in sommo grado, fu quella di decoratore. Incaricato dell'ornamentazione della navata centrale di S. Ignazio, egli disegnò la bellissima cartella sulla parete $d$ 'ingresso, fiancheggiata dalle due figure della Magnificenza e della Fede, e l'elegante festone coi putti danzanti, che gira tutto intorno. Chiamato dal principe, già cardinale, D. Camillo Pamphili, ai lavori della villa detta allora di Belrespiro sul Gianicolo, l'Algardi, sempre studiosissimo dell'antico, riprodusse al di fuori del casino da lui stesso edificato, motivi tratti 
da archi trionfali, e all'interno, nella scala e nei saloni, decorò le vôlte con stucchi amorosamente studiati su quelli di Villa Adriana, ricreando in pieno Seicento, quando agli stucchi si usava dare un forte aggetto, le forme sobrie dell'arte classica.

La morte dell'Algardí, avvenuta il 10 giugno 1654, è registrata con queste parole nel Diario del Gigli: "Morì il cav. Ales-

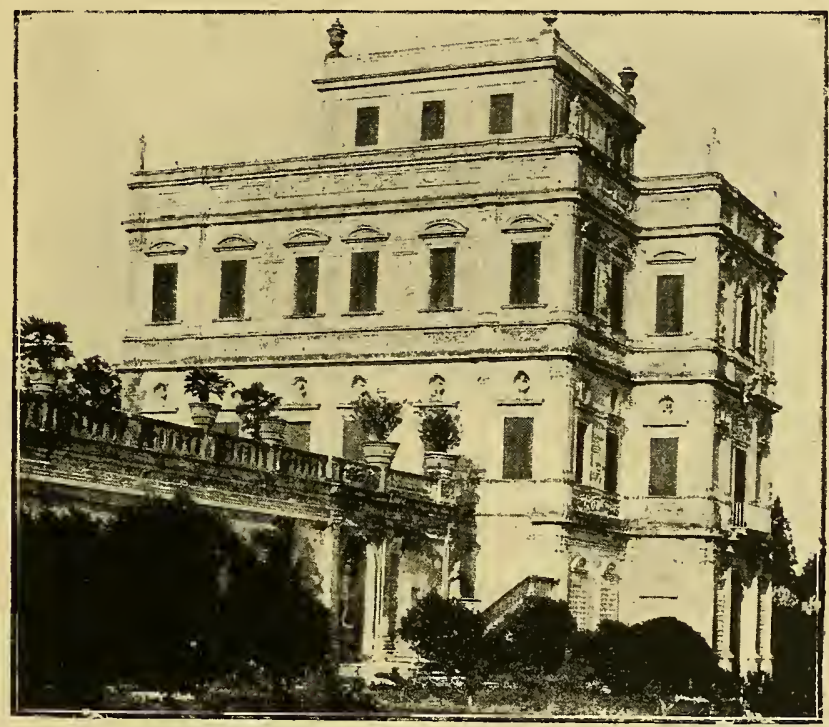

Algardi, Palazzetto nella Villa Pamphili.

sandro Algardi, bolognese, scultore eccellentissimo, il quale in questo tempo si era fatto conoscere il migliore di tutti, et ha lasciato di sè in Roma diverse memorie .... et in questo tempo haveva dato principio a fare il quadro per l'altare di $S$. Agnese in piazza di Agone et la statua di Innocenzo $X$ per il suo sepolcro nella medesima Chiesa. Mentre stava aggravato, fu visitato dal Principe D. Camillo Pamfilio, che sentì grandissimo dispiacere, et il Papa stesso ne pianse. Si ammalò di mal di pietra, et mandò fuori tre calculi, et poi fu assalito da febre 
maligna, che l'uccise nel quarto giorno: $F u$ seppellito nella Chiesa della Natione Bolognese „*

Il Bernini non aveva dovuto aspettare la morte del suo rivale per rientrare nelle grazie di papa Innocenzo; e l'occasione gli era stata fornita dalla costruzione della fontana centrale di

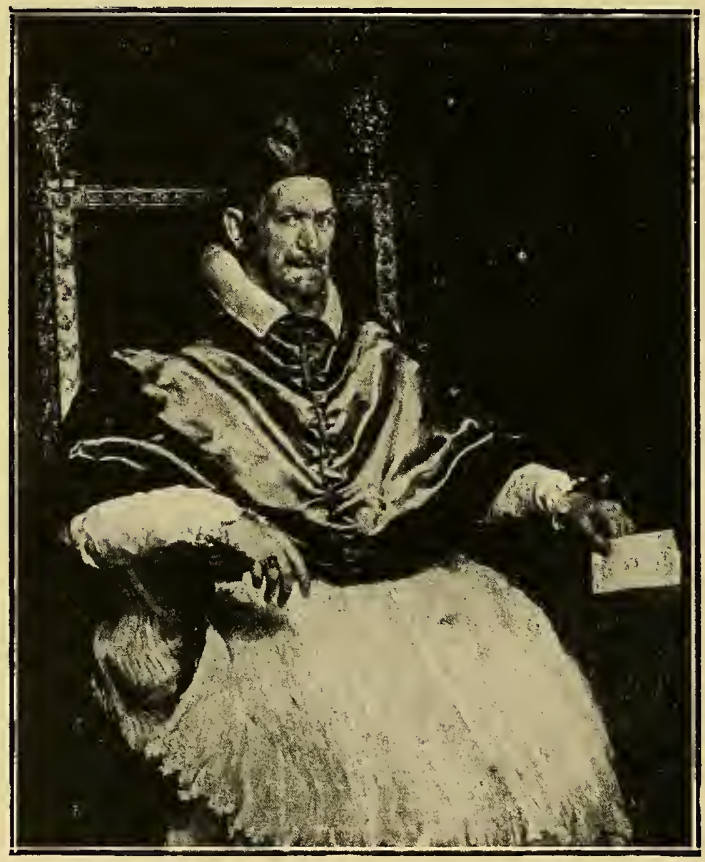

Velasquez, Innocenzo X - Galleria Doria.

(Fot. Anderson).

piazza Navona. Si era chiesto un progetto al Borromini, che non aveva però risposto alla grande aspettativa, $e$ allora si dovette ricorrere al Bernini, che presentò il meraviglioso bozzetto con lo scoglio traforato sorreggente l'obelisco, e le quattro statue di fiumi. Il lavoro, condotto con la collaborazione di molti discepoli, era terminato nel 1651 , e fu salutato con plauso grandissimo del popolo e dei poeti, che lo cantarono in varii 
metri, e lo fecero oggetto di una commedia, la Fonte Pamphilia. L'idea di collocare figure di fími a decorazione di una fontana non era nuova, ma in genere si trattava di immagini fluviali

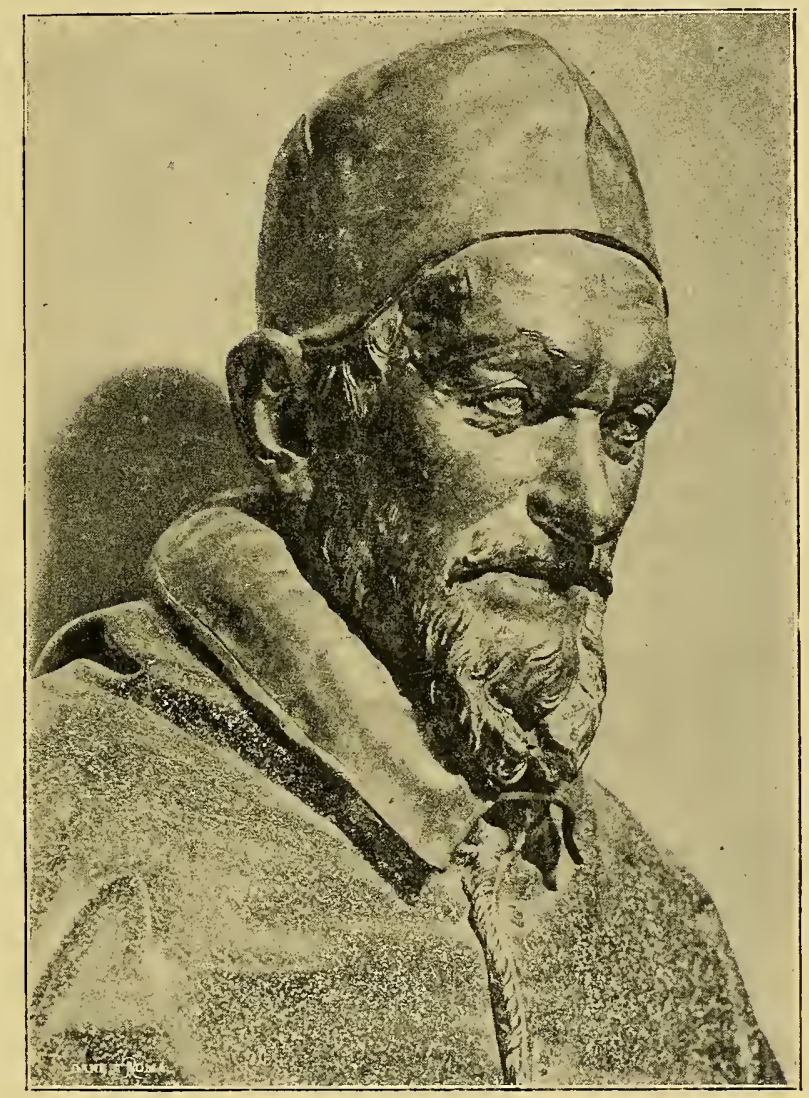

Busto di Innocenzo X - Galleria Doria.

(Fot. Alinari).

indeterminate; nella fontana di piazza Navona, i fiumi hanno i loro nomi e i loro attributi, e stanno a rappresentare le quattro parti del globo, allora conosciute: il Danubio, il Nilo, il Gange, il Rio della Plata, significano che tutto il mondo è presente nel monumento che celebra la potenza di casa Pam- 
phili, e l'universalità del papato, e sono al tempo stesso una caratteristica espressione di quell'esotismo, a cui si ispirano così volentieri gli artisti del Seicento. Il Rio della Plata specialmente ha una testa di moro, col naso camuso e le labbra sporgenti, e sotto di lui sta nella vasca un strano mostro, il "Tatù animale delle Indie „; il cavallo, il leone, il coccodrillo, il serpente, stanno presso gli altri fiumi. È tutto un mondo fantastico e bizzarro che il Bernini chiama ad abbellire la fonte superba, che è la più bella del secolo.

Qui d'Europa il destriero

Qui d'Asia il fier leone,

Qui d'Africa il Delfino

Qui d'America ancor

Belva di squamme armata,

Miransi insieme entro de' molli argenti

Bagnar l'avide labbra;

Onde n'apprenda il Mondo,

Che de le gratie a $i$ fonti

D' Innocentio sol puole

Spegner la sete l' universa Mole.

Poco dopo 1 ' inaugurazione della fontana si iniziò dal Borromini la fabbrica di $\mathrm{S}$. Agnese, e a fianco di essa da Carlo Rainaldi quella del palazzo Pamphili, in cui abitò coi parenti del papa anche Donna Olimpia, mentre un compagno del Borromini, Paolo Marucelli, costruiva il vicino ricchissimo palazzo Madama.

Venuto a mancare il cardinale nipote, dopo la rinuncia alla porpora fatta da Camillo, Donna Olimpia fece nominare cardinale Francesco Maidalchini, giovanetto di diciassette anni, figlio di un suo fratello, e servendosi di lui spadroneggiava su Roma; e invano l'altra Olimpia, sua nuora, moglie di Camillo, cercava 
di contenderle il primato; le grazie della giovane non vincevano la scaltrezza della vecchia, che intrigava in mille modi, trafficava nomine, vendeva favori. Il popolo mordeva il freno; in

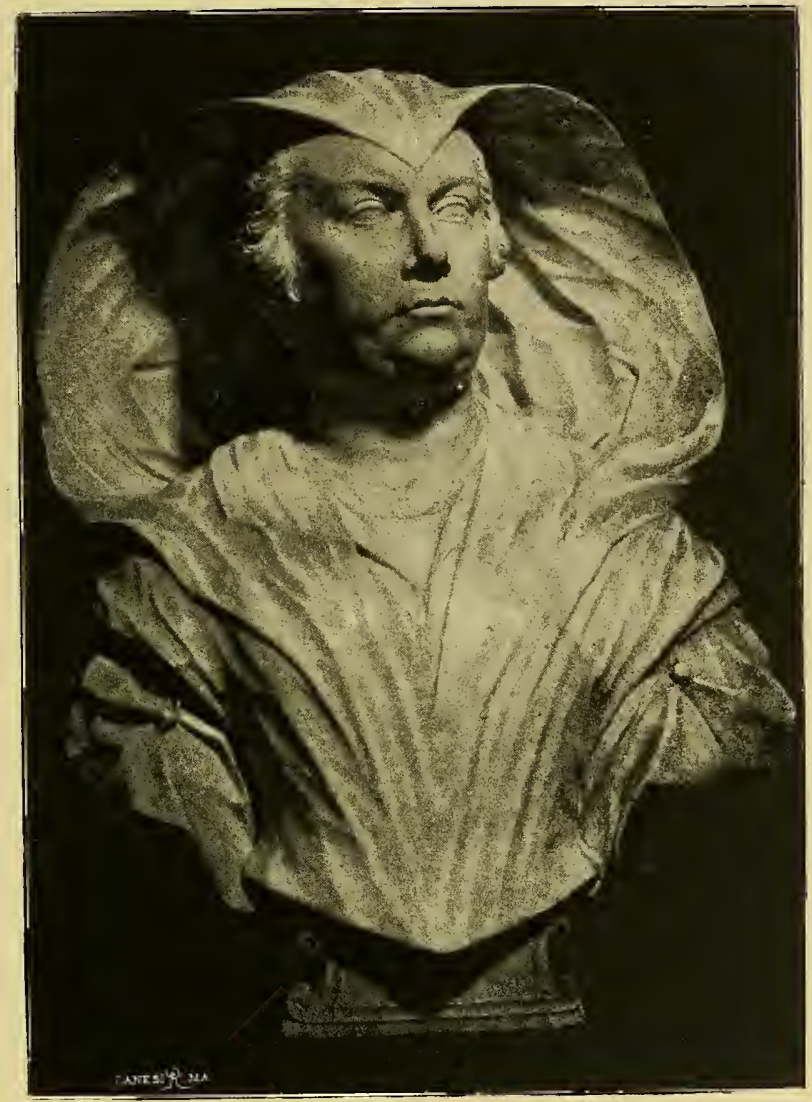

Algardi, Ritratto di Donna Olimpia - Galleria Doria.

(Fot. Alinari).

S. Giovanni l'iscrizione di papa Innocenzo un giorno si trovò cambiata in Olimpia pontifex maximus; e perfino in Germania si mormorava contro il predominio di una donna nella corte papale. Le critiche si fecero così aspre, anche da parte dell' imperatore, che Innocenzo fu ridotto ad interdire alla signora 
Olimpia l'accesso al palazzo pontificio. Ma due anni dopo, nel marzo 1653, avvenne la riconciliazione, e $f \mathfrak{~ e s p u l s o ~ i n v e c e ~}$ l'Astalli, che era stato assunto al grado di cardinal nipote. La

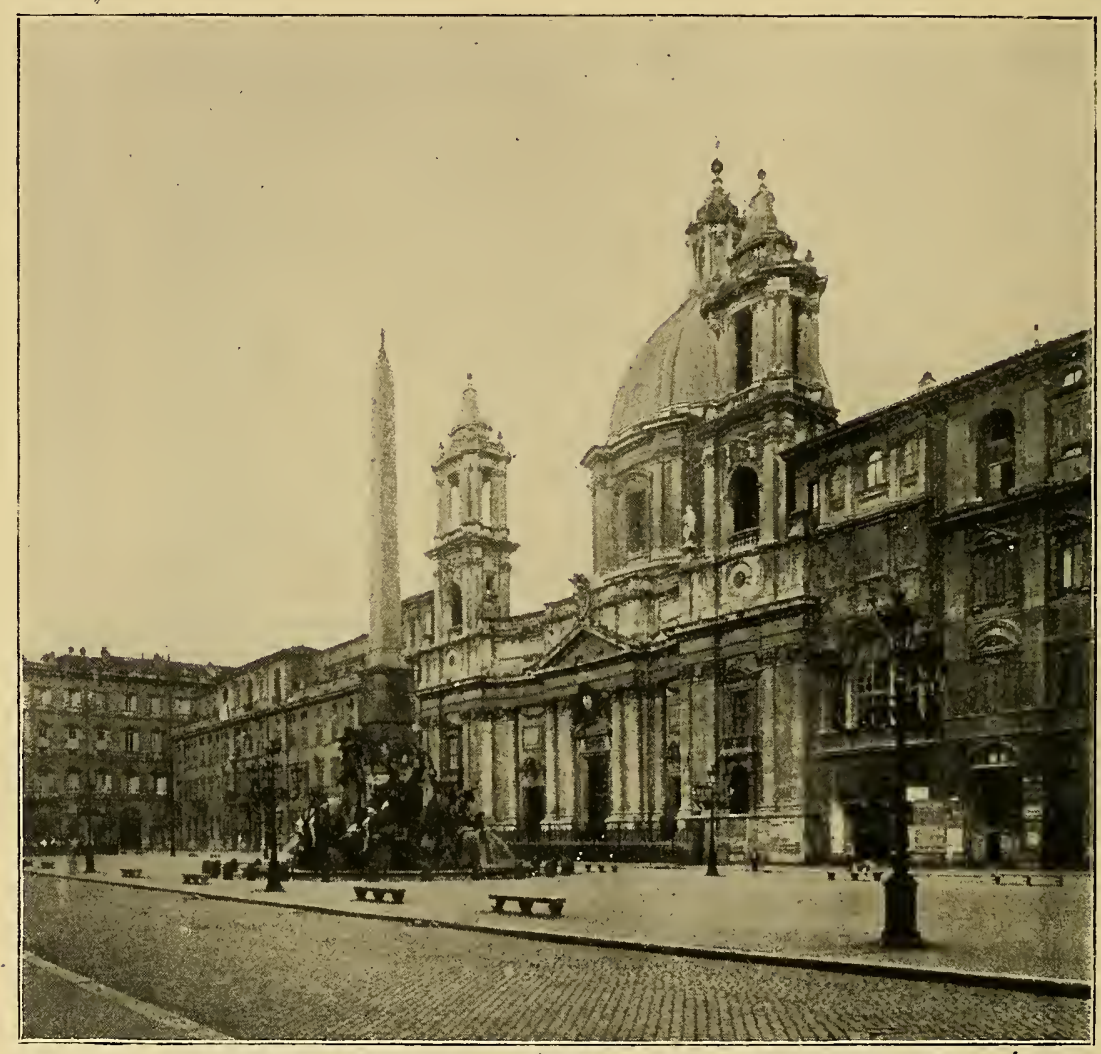

Piazza Navona con S. Agnese e il palazzo Pamphili.

salute del papa però era assai cattiva, e declinando di giorno in giorno, lo rendeva inquieto e fastidioso; si irritava facilmente coi suoi prelati ed offiziali, e li licenziava senz'altro dalla corte; e cacciò via anche il suo medico Gabriele Fonseca, che l'aveva servito per otto anni. Ecco come racconta il Gigli la morte del papa: "Innocenzo contro l'opinione dei medici e di tutti era ancor vivo, et stava in tal modo aggravato, stentando, che 
molti gli avevano compassione, assistendogli intorno li fenitenzieri di S. Pietro, et fra tanto per Roma non altramente che se fosse la Sede Vacante si tenevano serrate le porte delle case, et altri havevano messe le guardie di soldati, et si facevano steccatí e cancelli alli palazzi dei ricchi, et tutti scorrevano per la città armatí. Ma Donna Olimpia se ne ritornò a Palazzo, e

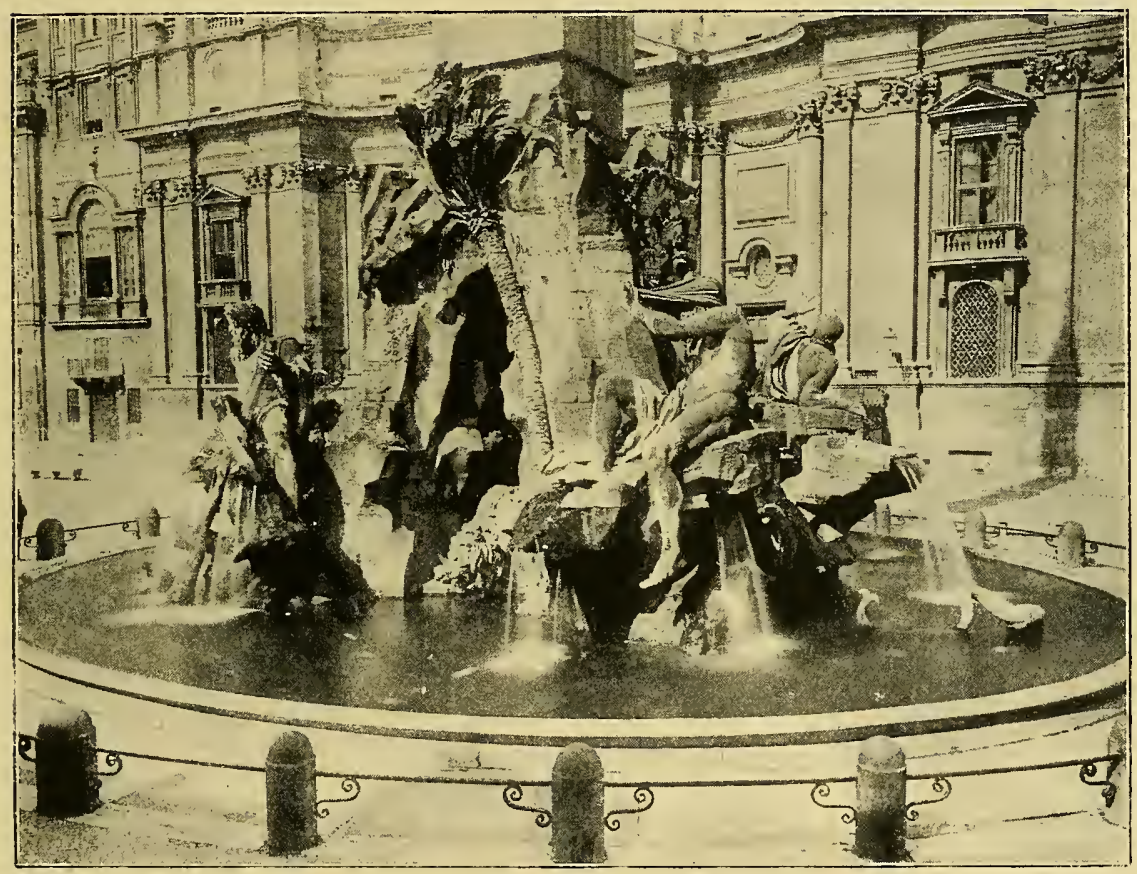

La Fonte Pamphilia in piazza Navona.

quando fu nell'anticamera gli uscì incontro il P. Giovan Paolo Oliva, e gli disse che Sua Eccellenza non haveva più che fare li, e però se ne andasse per li fatti suoi, e ponendoli la mano dietro alle spalle la fece voltare indietro. Il Palazzo era voto talmente che non vi era ne anco una scodella nè un cucchiaro per dare un po' di brodo al papa, et bisognò mandare a comprarne una, et nel letto stesso del Papa non vi era se non 
una copertaccia tristissima delle più cattive che si fossero messe in uno spedale a un poverello. Non vi era altra camicia se non quella che teneva in dosso, e non vi era se non un candeliere di ottone il quale poi spari via e diventò un candeliere di legno. E finalmente giovedì a di 7 gennaio 1655 ad hore 14 mori

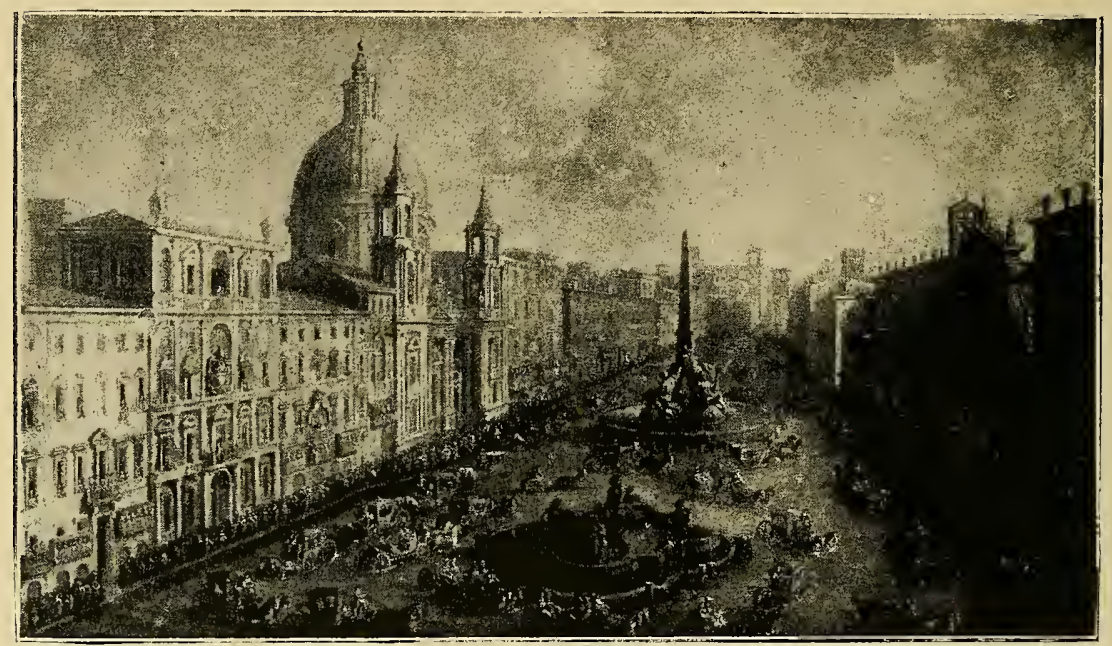

La festa del lago in piazza Navona.

Papa Innocenzo Decimo nell' anno della sua età 82 havendo seduto anni 10 mesi 3 e giorni 14. Fu di statura alta, magro, colerico fegatoso, con la faccia rossa, calvo dinanzi, con le sopraciglia grosse et piegate sopra il naso con un grossissimo epircinio che dimostrava la sua severià et acerbezza. Rimase morto con gli occhi aperti, et con la lingua di fuora, che rendeva spavento. Non fu amico di persone virtuose, nè honorò alcuno per tal causa, ma solamente per compiacere alla cognata, (alla quale fu fuor di modo affetionato), o vero per certi suoi capricci e bizzarrie. Fece adornare le basiliche di S. Pietro e S. Giovanni, ma non con i suoi danari, ma con le rendite proprie delle medesime chiese.... Le spese che fece del suo 


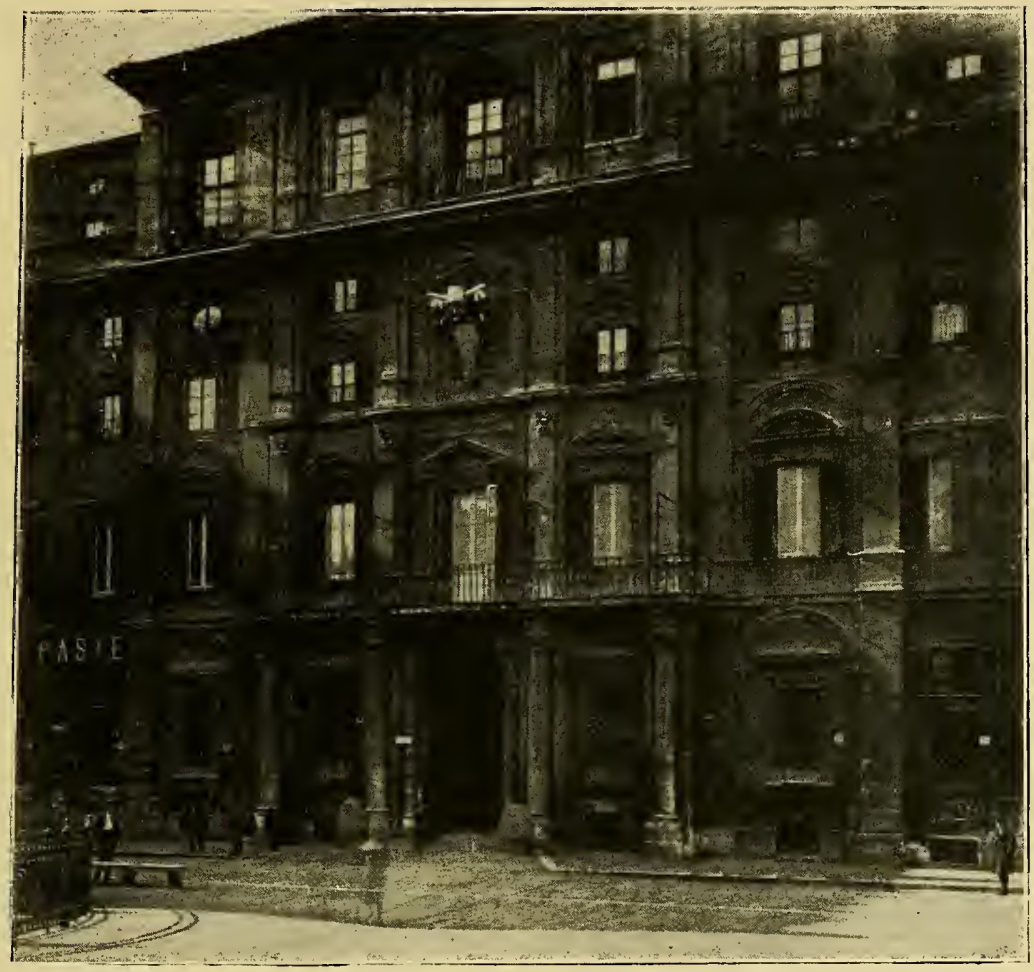

Il palazzo Pamphíli in piazza Navona, del Rainaldi.

furono il Palazzo di Piazza Navona, la Vigna a S. Pancrazio et il principio della chiesa di S. Agnese. Ma tutte le ricchezze che accumulo, che sono state grandissime, andarono in mano di D. Olimpia sua cognata, la quale per molte altre vie ne accumulò infinite di presenti et donativi, che li erano fatti da chi desiderava gli offitii et $i$ favori, onde sono alcuni anni che si sapeva che ella, solamente di galanterie et regali piccoli haveva fatto dodicimila scudi di entrata. Si disse che furno trovate doi casse di denari sotto il letto del Papa, le quali fece portar via Donna Olimpia....

La mattina delli 8 di gennaro fu esposto il Cadavere del Papa in S. Pietro nella cappella incontro il Coro delli Canonici, 
dove stette tre giorni con grandissimo concorso di popolo, il quale ebbe assai che dire per rispetto della sua morte cosi sten-

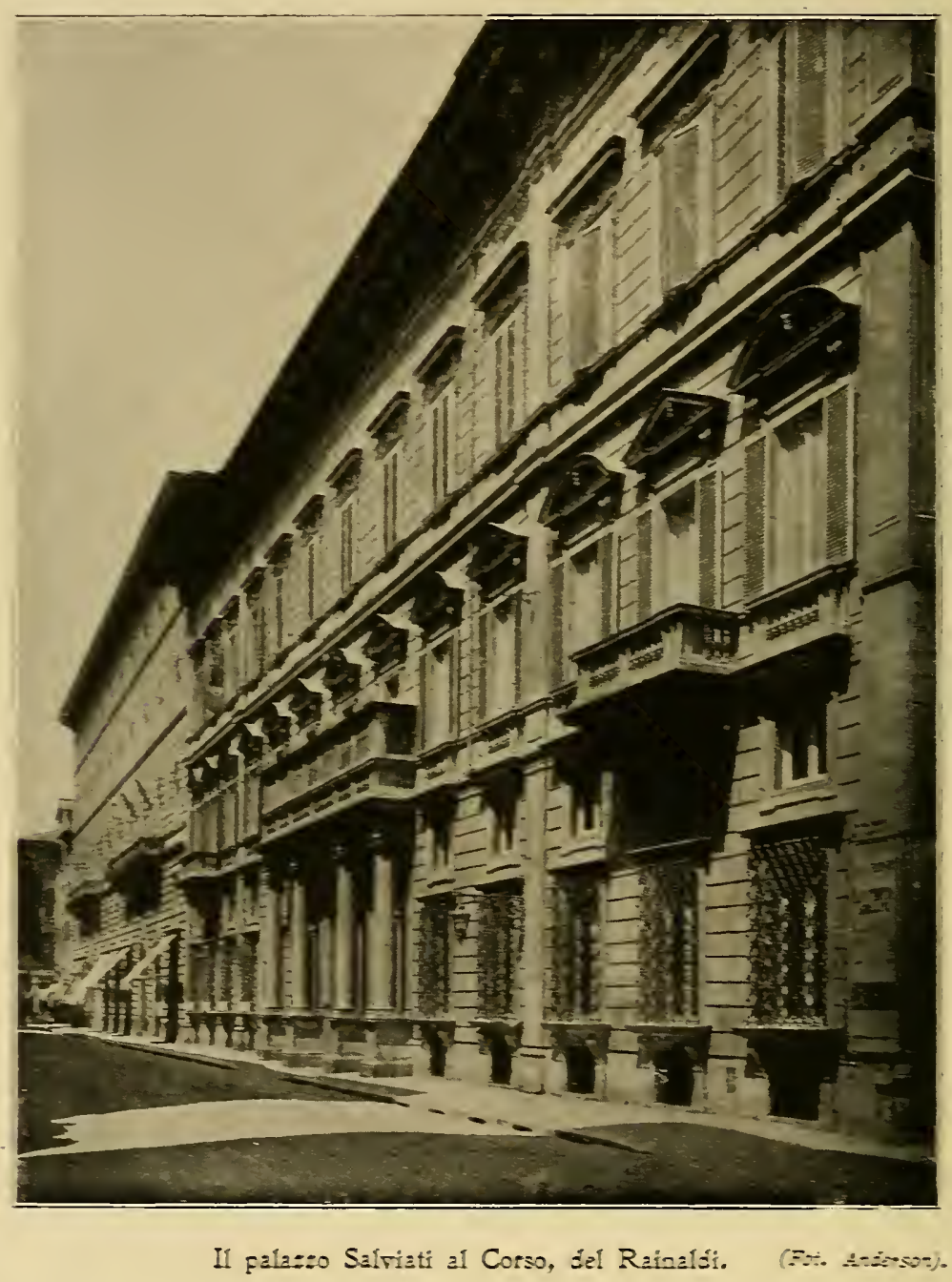

tata, et del modo come era morto, et anco perchè mentre si portava a S. Pietro venne dal Cielo un'acqua grossissima con tuoni e grandine quasi prodigiosa. 


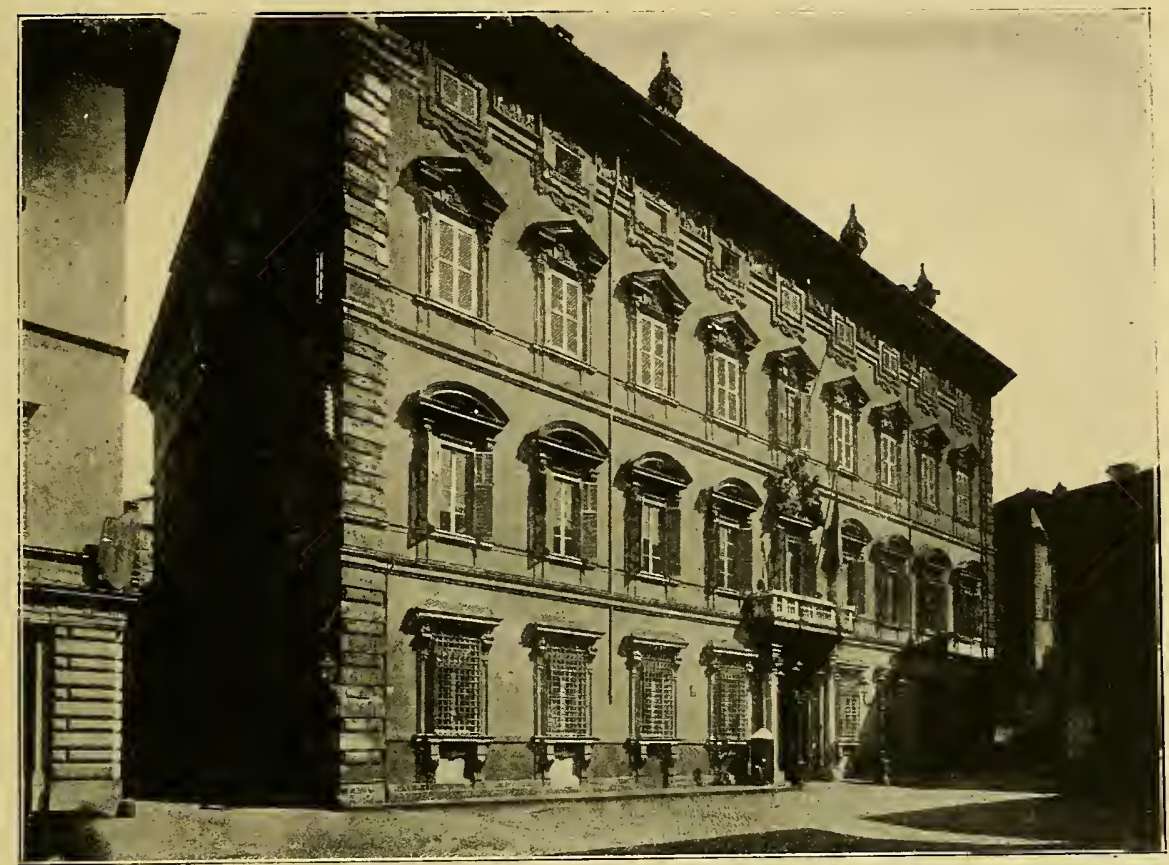

Il palazzo Madama, di P. Marucelli.

(Fot. Anderson).

Dopo li tre giorni che era stato il cadavere esposto non vi era alcuno il quale si pigliasse pensiero di farlo seppellire. Si mandò da D. Olimpia che volesse farli fare la cassa et la coltre; rispose che Lei era una povera vedova. Li altri parenti et nipoti niuno si mosse, tal che quel Cadavero fu portato in una stantia dove li muratori tenevano la loro monitione. Un muratore per compassione li portò una candela di sego accesa et gliela pose al capo, et perchè fu detto che in quella stantia vi erano di molti sorci che l'avrebbero guasto, vi fu uno che pagò certi danari del suo a chi gli fece la guardia, et passato che fu un altro giorno Mons. Scotti Maggiordomo fece la carità di farli fare una cassa di albuccio, e poi Monsignor Segni il quale era canonico di S. Pietro et già era stato suo Maggiordomo, e poi era stato 
cacciato via da Innocenzo, rendendoli bene per male pagò cinque scudi del suo per farlo seppellire. Non si era egli eletto il loco per la sua sepoltura, ma si diceva che voleva farlasi

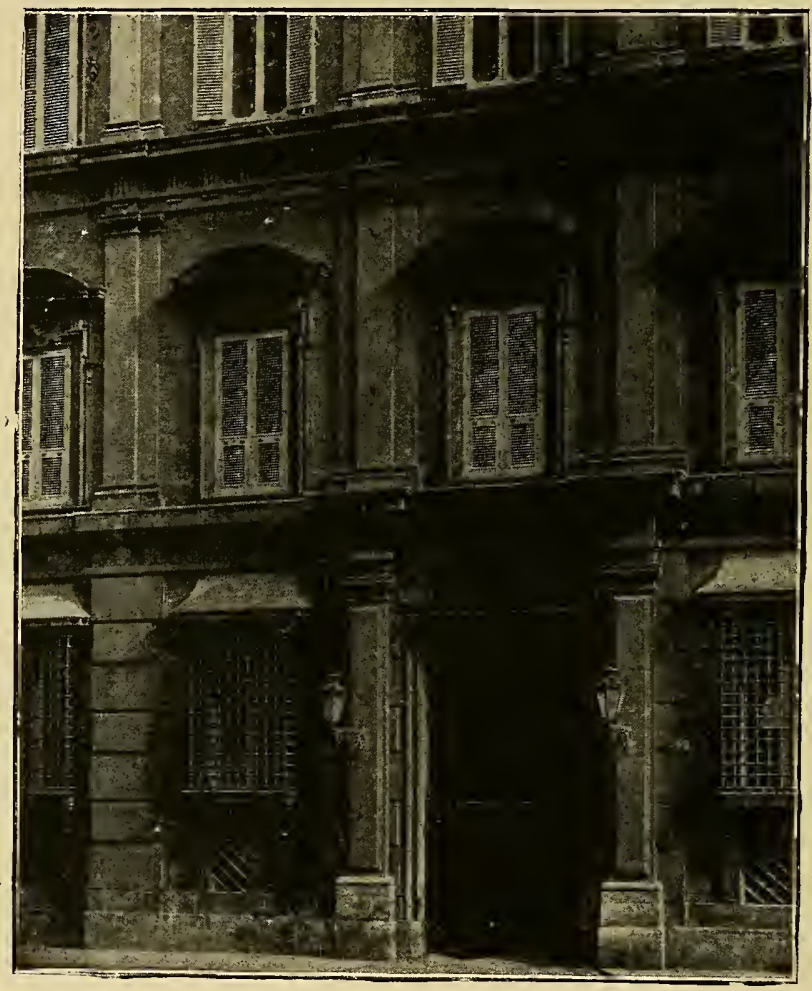

Palazzo Pamphili al Collegio Romano, di A. del Grande.

nella Chiesa di S. Agnese in Piazza Navona la quale in quel tempo si edificava.

Insomma si vide in lui chiaramente adempita la Profetia dell'Abate Ioachimo, massime in quelle parole che: pauca sparget, multa congregabit, egenus morietur et propria sepultura carebit. Perciochè egli fu poco liberale, et restò poco meno che insepolto. 


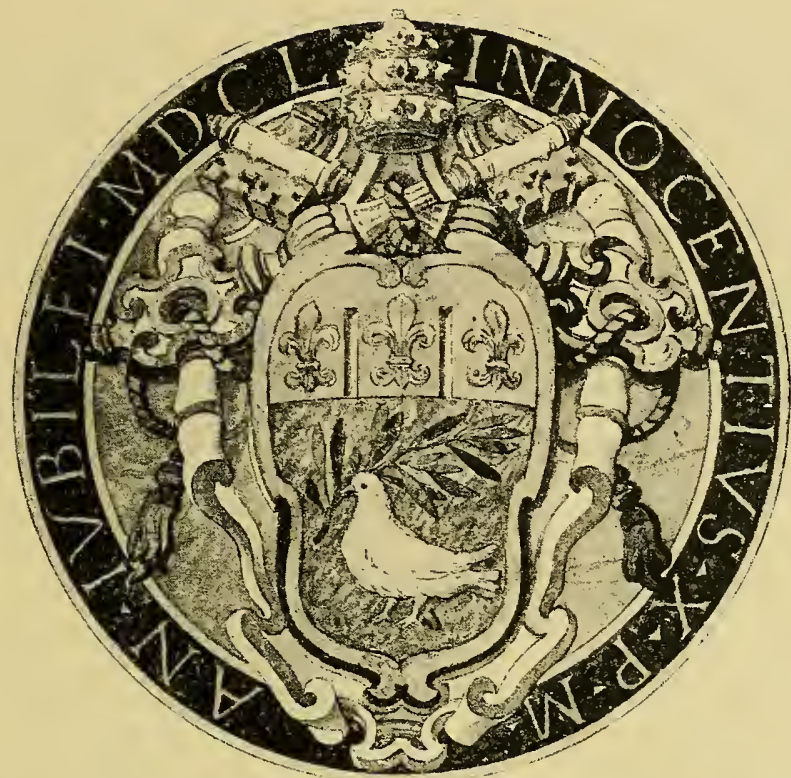

Bernini, Stemma di Innocenzo X, nel pavimento di S. Pietro.

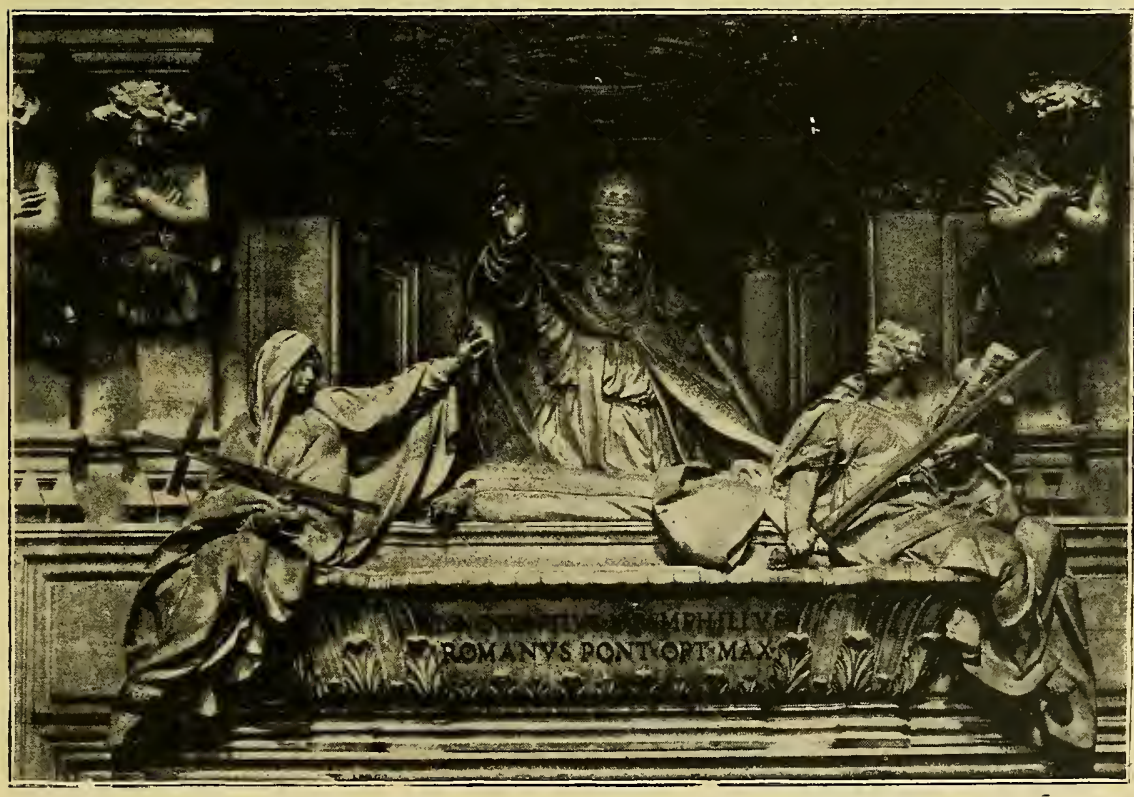

Monumento di Innocenzo X in S. Agnese, di G. B. Maini (1730).

(Fot. Alinari). 


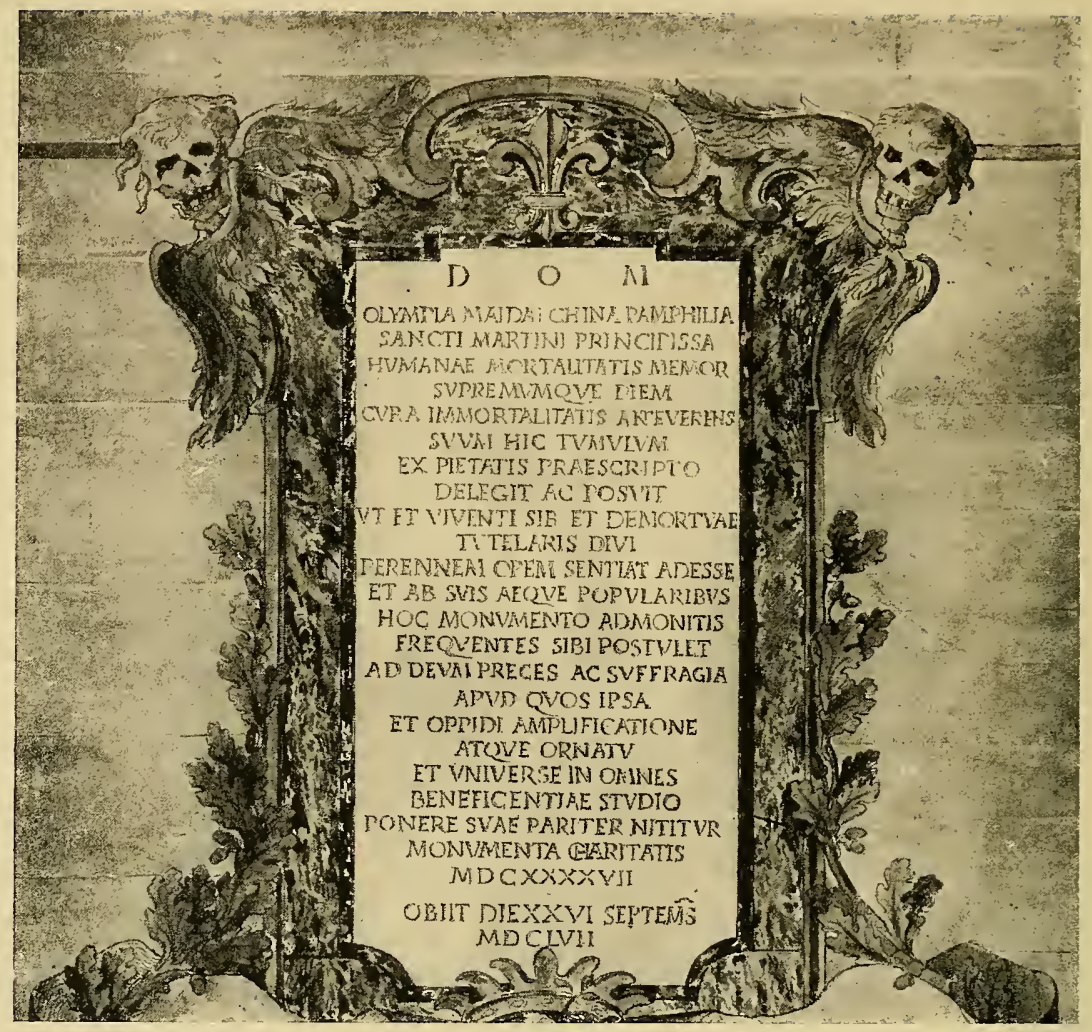

Tomba di D. Olimpia, in S. Martino al Címino.

Chi volesse un sommario delle cose fatte da questo Pontefice si dirà che:

Tre chiese ornò Innocenzo con splendore

Et in Agon fu l'obelisco alzato;

$\mathrm{Fe}$ per te il Carcer novo o malfattore,

Et d'ordin suo fu il Campidoglio ornato.

Celebrò il Giubileo con gran fervore,

Nelle Grazie fu parco e moderato;

Innalzò molti e poi giù li travolse,

Altri perseguitò, poi li raccolse. 
Questa ottava io l'ho composta per aggiungerla agli altri Pontefici Romani parimente in otto versi. Ma chi volesse toccarlo per il Governo lasciato in mano della cognata, potria con verità dire che:

Nocque Innocenzo al Popolo Romano

Et fu la gloria sua molto scemata

Per haver posto il bel dominio in mano

Della vedova Olimpia sua cognata,

Che spesse volte diè la tratta al grano,

Et la fava per pan fu macinata;

Et chi chiedeva grazie avea l'intento

Porgendo alla Signora oro et argento ,..

Il nuovo papa, Alessandro VII, intimò all'odiata donna di abbandonare Roma; e Olimpia dovette piegare il capo. Si ritírò a Viterbo, e due anni dopo, nel 1657, mori di peste bubbonica nel vicino paesello di $S$. Martino, dove erasi rifugiata per sfuggire il contagio, lasciando, oltre a moltissimi beni, due milioni di scudi d'oro.

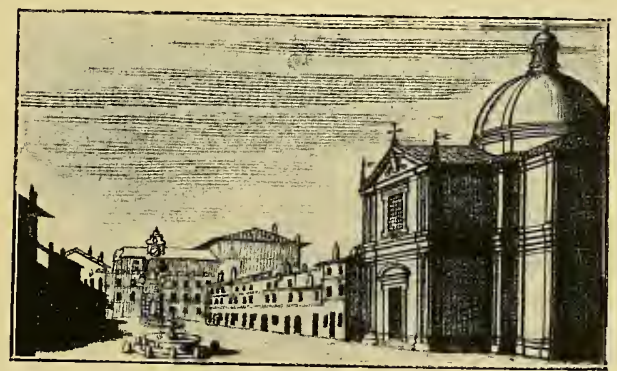




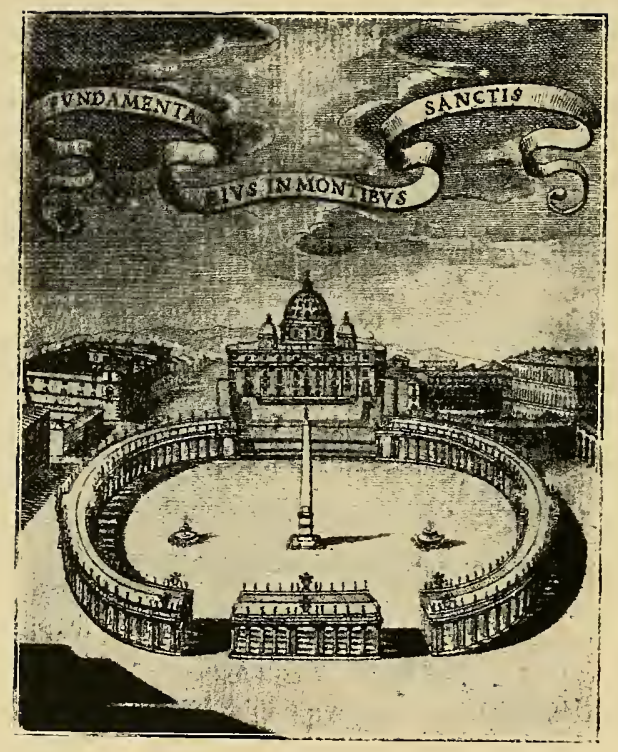




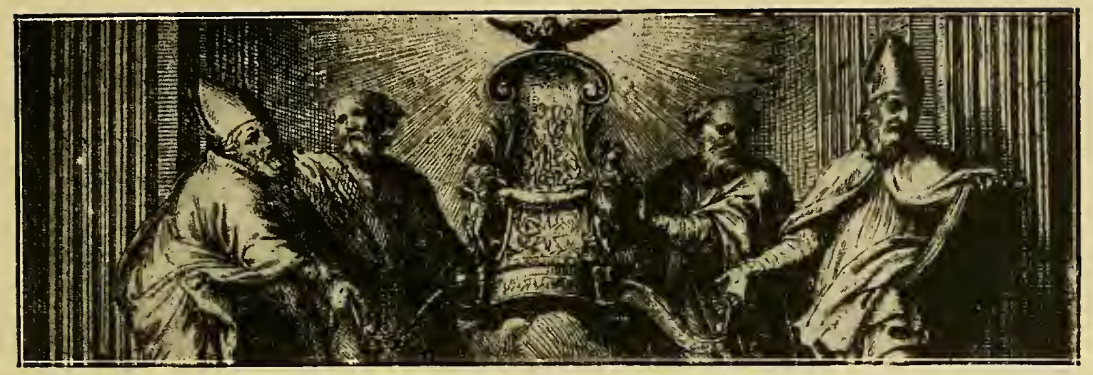

CAPITOLO DECIMO

\section{FELICI FAUSTOQUE INGRESSUI}

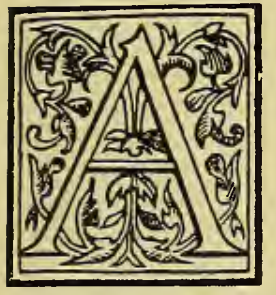

successore di papa Pamphili fu eletto il cardinale Fabio Chigi, nato a Siena nel 1599, della celebre famiglia che vantava nobilissime tradizioni d'arte, contando fra $i$ suoi antenati $i$ due banchieri Agostino e Sigismondo, che al principio del Cinquecento avevano in Roma rinnovato il mecenatismo degli antichi con la Farnesina e la capella di S. Maria del Popolo, illustrate dal genio di Raffaello. Quasi presagio del suo amore per le cose belle, Fabio era stato tenuto al sacro fonte da Francesco Vanni, pittore celebrato al suo tempo, e fin dai primi anni aveva dimostrato grande passione per le lettere e la fílosofia. Urbano VIII gli aveva dato onorevoli incarichi e difficili missioni, e da ultimo lo nominava nel 1639 nunzio pontíficio a Colonia. Di là nel $1644 \mathrm{fu}$ inviato a Munster come nunzio straordinario, per rappresentare il papa nelle trattative laboriose della pace che fu detta di Vestfalia; il Chigi, pur non riuscendo a far trionfare completamente le vedute della Chiesa, ottenne con la sua abilità e la sua prudenza un grande successo diplomatico, e acquistò una pratica profonda di uomini 
e di cose, della quale fanno fede le sue lettere da Munster, conservate nella Biblioteca Chigiana. Premio all'opera sua fu dapprima la nomina avuta da Innocenzo X, a Segretario di Stato; poi, nel 1652, la porpora cardinalizia: tre anni dopo era papa. Cosa non comune, accoppiava alla dottrina e alla finezza politica, sentimenti sinceri di pietà. "Mentre stette in conclave, racconta il Gigli, digiuno tutta la Quaresima, et ogni giorno

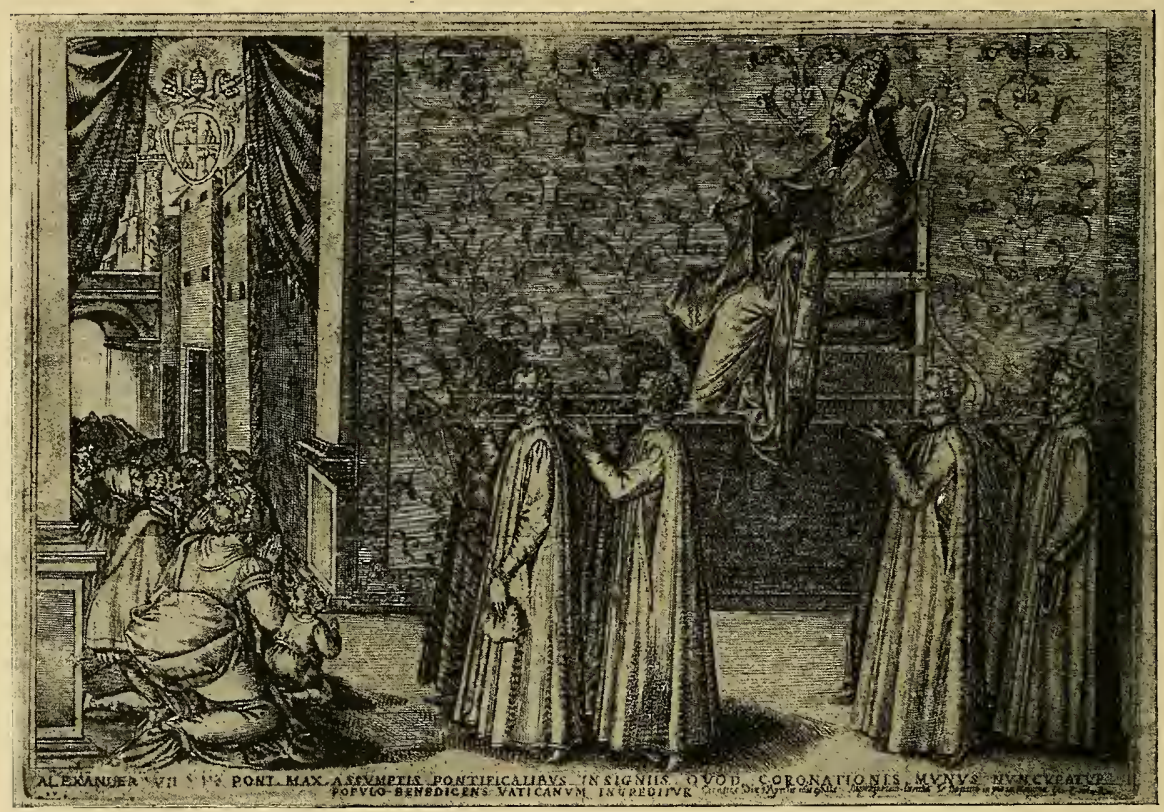

Corteo dell'incoronazione di Alessandro VII - Incisione contemporanea (Collez. Munoz).

disse divotamente la messa. Si teneva per certo che egli fusse vergine, e quando fu creato $\mathrm{Papa}$, si accorsero che teneva un giubbone di cilicio, et dicevasi che gran tempo era dormito sopra le nude tavole. Beveva in una tazza d'argento nel mezzo della quale era scolpita una testa di morto. Subito che fu fatto Papa ordinò che fusse fatta la cassa di piombo nella quale dovesse esser seppellito, et che la detta cassa gli fusse portata 


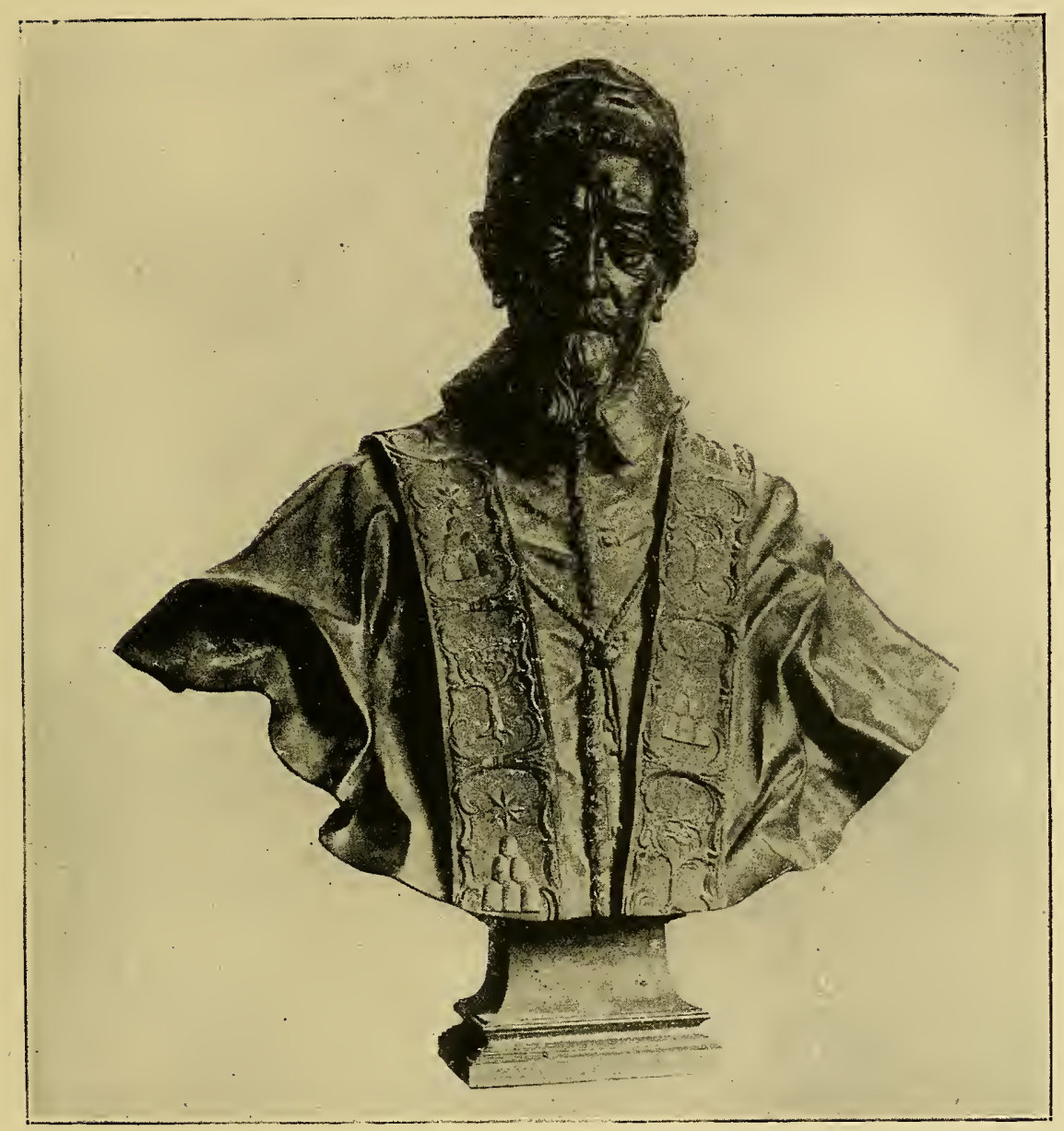

Bernini, Busto in bronzo di Alessandro VII - Collezione Chigi alla Farnesina.

nella sua camera. Fece vendere subito tutta la sua argenteria, et ordino che per suo servitio fussero fatti li piatti et scudelle di terra, nelle quali invece di arme fusse dipinta la morte ".

L'anno stesso dell'elezione di Alessandro VII, la cronaca romana registrò un avvenimento importante, e fu l'arrivo di Maria Cristina, già regina di Svezia, fíglia del celebre Gustavo Adolfo, la quale aveva rinunciato alla corona, per abbracciare 


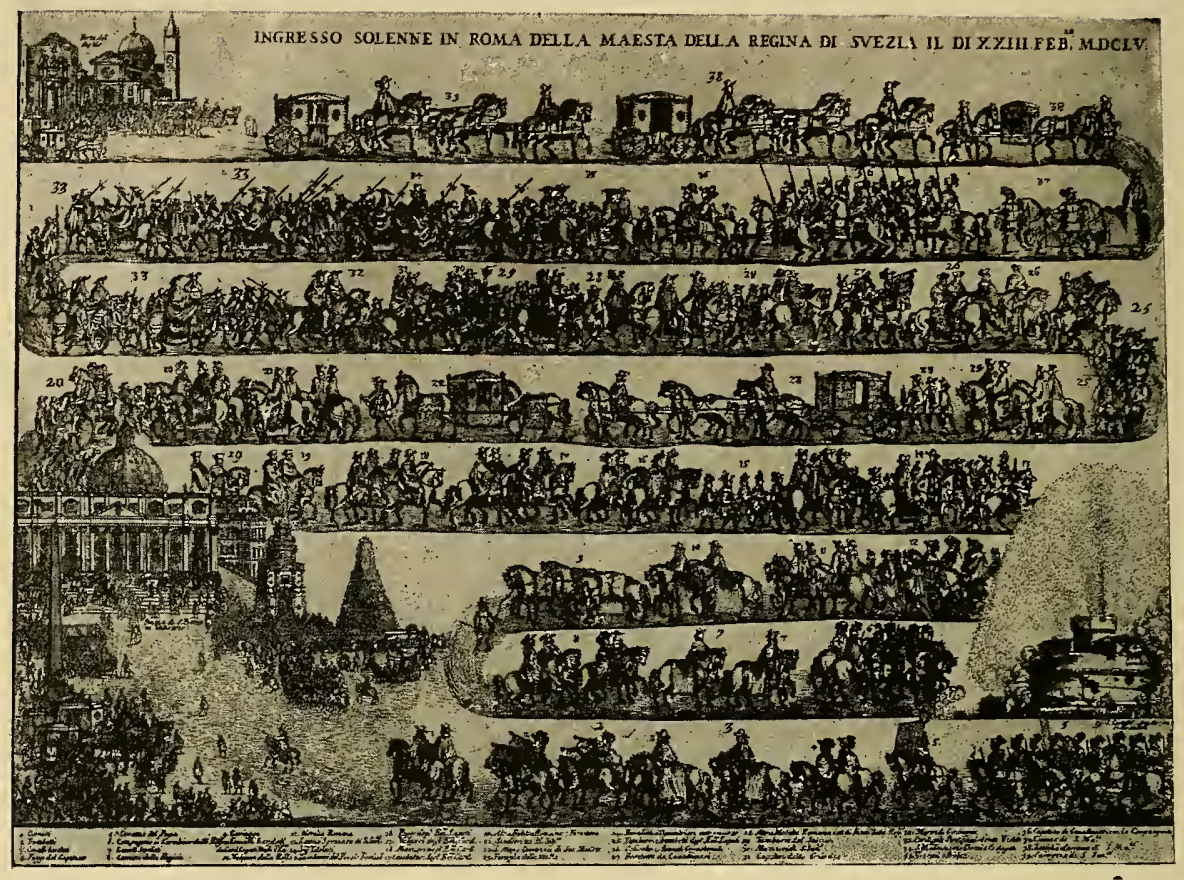

Ingresso solenne di Cristina di Svezia in Roma - Incisione del tempo. (Collez. Munoz).

la fede cattolica, e veniva a visitare il papa, che naturalmente teneva a celebrare il fatto con la più grande solennità. Entrò Cristina in Roma il 20 dicembre $e$ andò ad alloggiare in Vaticano, ma l'ingresso ufficiale avvenne tre giorni dopo. "La Regina fece l'entrata la sera alle 22 hora dalla Porta del Popolo, essendo tutte le strade apparate, et andò a S. Pietro; il Papa gli mandò incontro una Chinea guarnita di velluto turchino ricamata di argento, una sedia, una lettica, et una carrozza a sei cavalli. Fu ricevuta fuori della porta dal Magistrato Romano che l'aspettò nella Vigna di Papa Giulio, nella porta della quale era stata posta una bella iscrittione in sua lode.

Alla Porta del Popolo fu posta un'altra iscrittione la quale poi vi fu scolpita da dovero quando Papa Alessandro ristaurò 


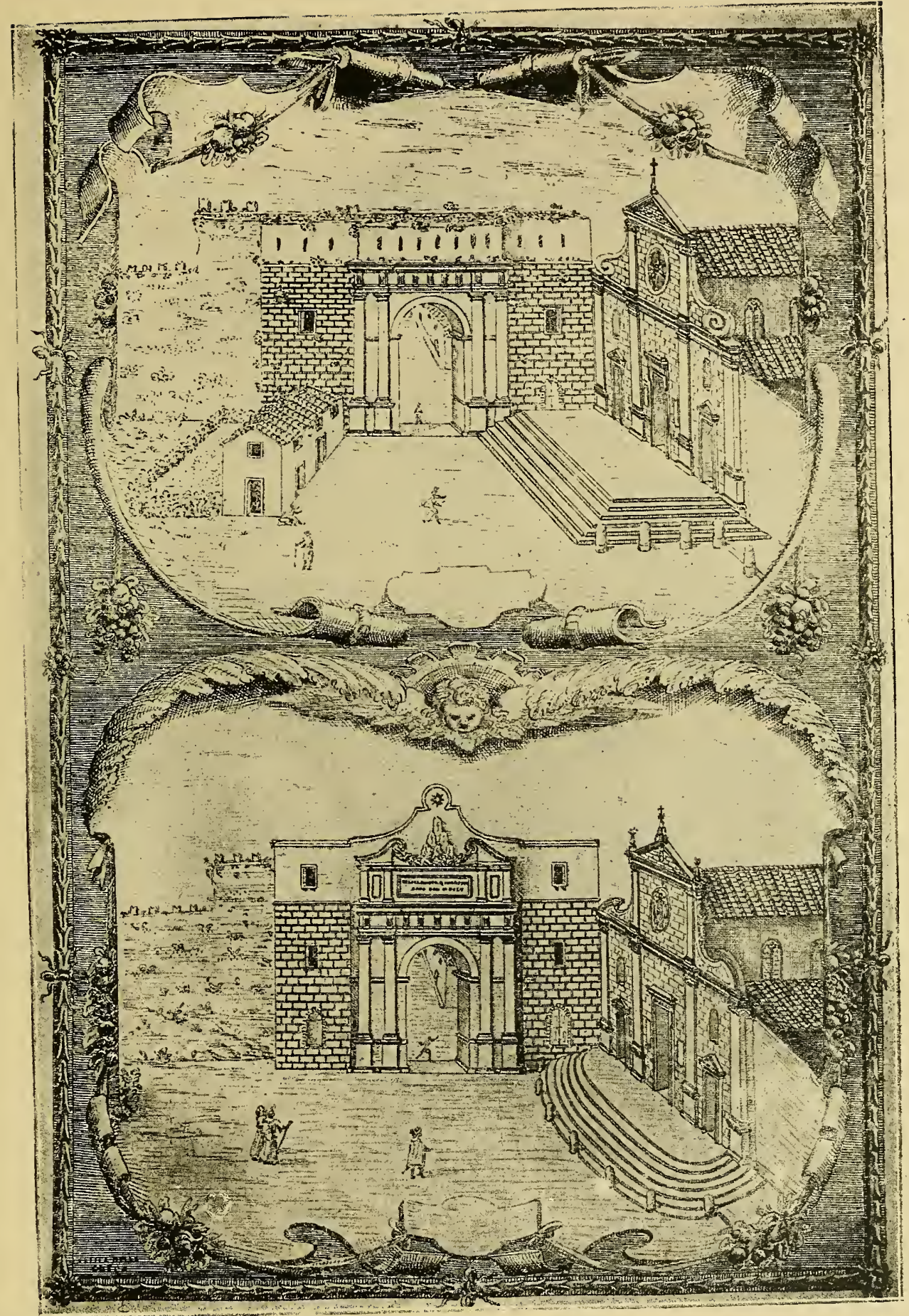

La Porta del Popolo prima e dopo il restauro del Bernini - Disegno nella Biblioteca Chigi. 


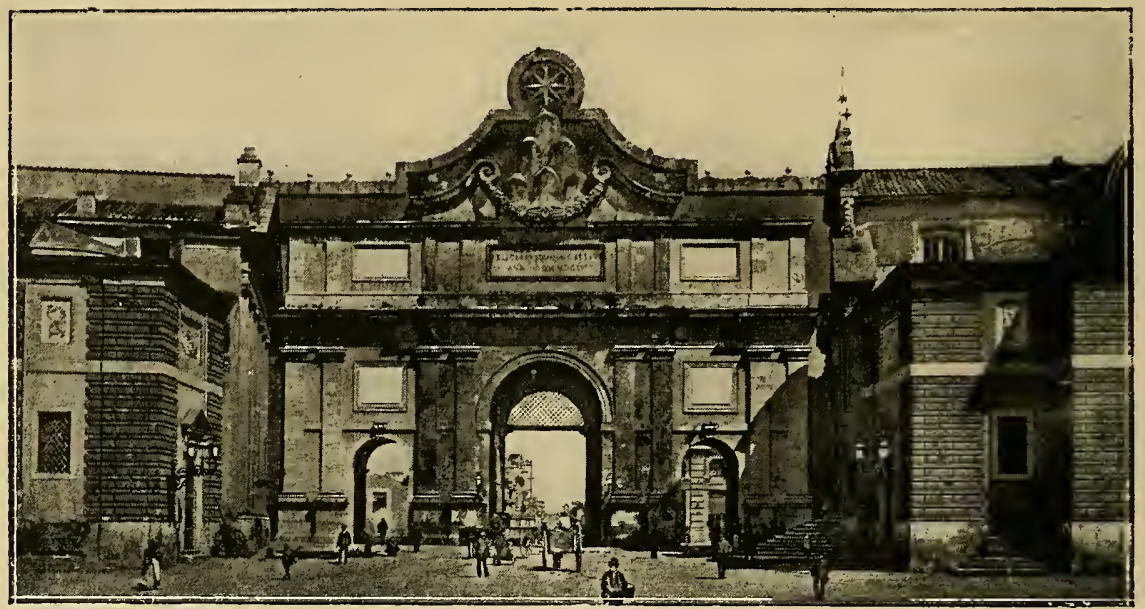

La Porta del Popolo decorata dal Bernini.

et adornò la detta Porta. La cavalcata fu bellissima, et la Regina cavalcò sopra alla Chinea, al modo di donna, vestita alla Francese, di colore berettino ricamata di oro con il cappello in

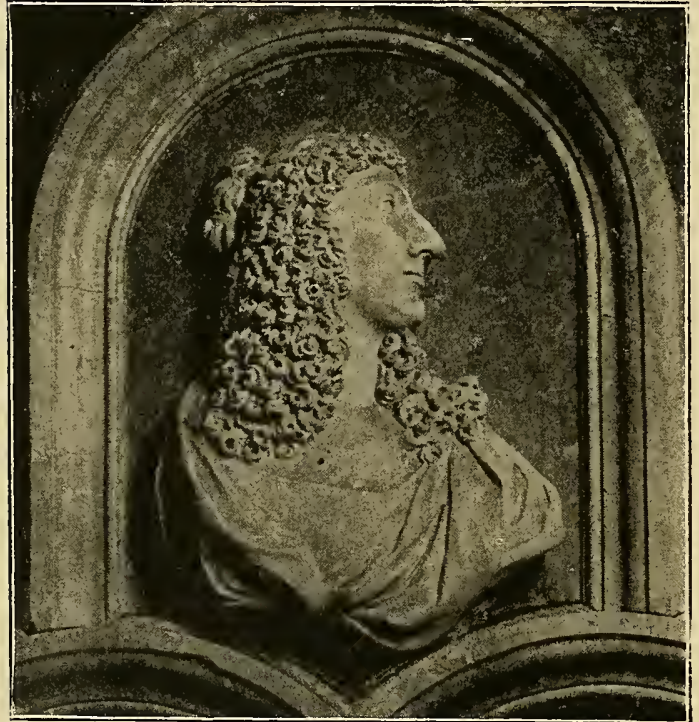

Busto di Cristina di Svezia, in Campidoglio. testa con un cordone di oro; dicono che sia stata sempre solita di cavalcare a modo di huomo, et non sedere sopra il cavallo come hora a modo di donna. La Basilica di S. Pietro era stata apparata con le più ricche e superbe tapezzerie et paramenti, che havessero i più ricchi signori di Roma, et in Chiesa avantí tutte le pilastrate tra le cappelle erano tanti cori di musici quanti v'erano in Roma. 


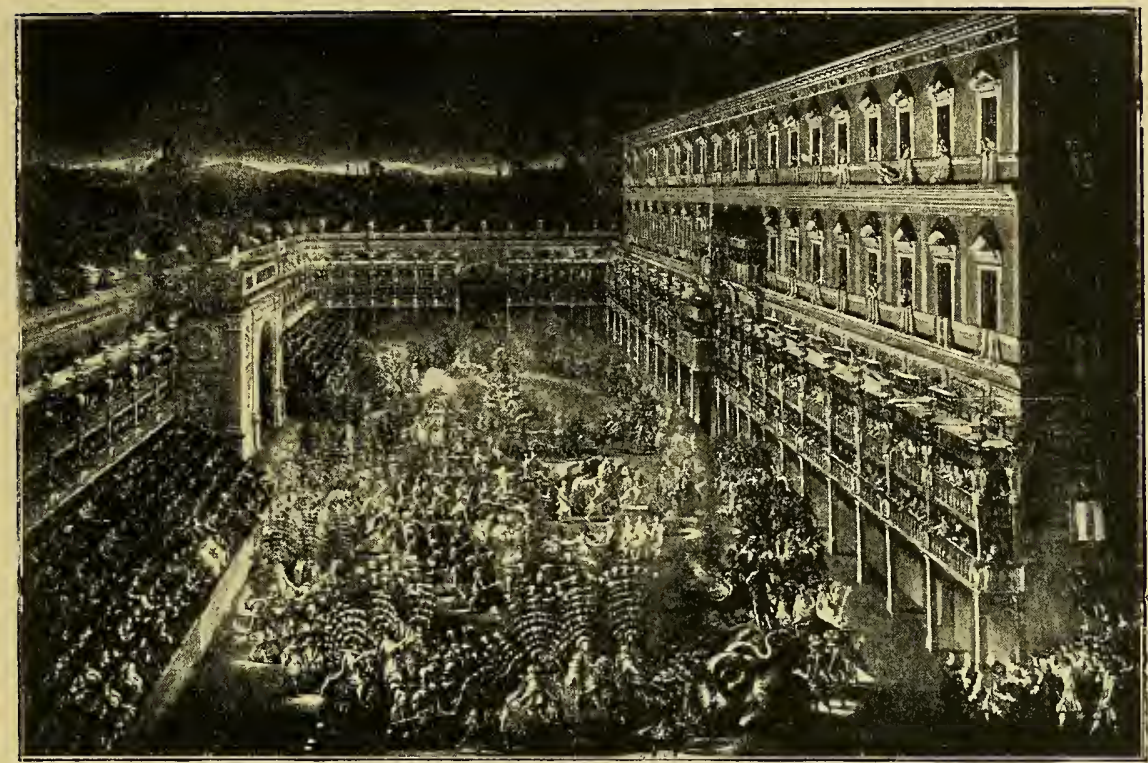

Il torneo dato dai Barberini in onore della Regina di Svezia. Dipinto nel Palazzo Barberini.

Uscì da S. Pietro a ricevere la Regina tutto il Capitolo et Canonici, e li musici cantorno il Veni Creator Spiritus, et in tanto ella fu menata a fare oratione al Santissimo Sagramento, et poi all'altare degli Apostoli, et tanto in quel luogo quanto nell'altro li fu portato il Crocefisso, ed essa lo bagiò, et finite le cerimonie fu cantato dalli musici il $\mathrm{Te}$ Deum laudamus, et poi fu menata dal Papa il quale la ritenne a cena nella medesima stanza, dove lui cenava, et poi ritornò nelle sue stanze ${ }$.

Il giorno dopo andò ad alloggiare nel palazzo Farnese, che era stato per lei "ricchissimamente adornato con apparati e mobili pretiosissimi "; il papa le offri mille scudi al giorno pei tre mesi che doveva rimanere in Roma. Ma ben presto la corte pontificia ebbe a pentirsi dei grandi onori fatti alla Regina, che invece di servire di edificazione ai fedeli e ai principi, era di continuo scandalo. Alle chiese $e$ alle penitenze preferiva 
le feste ed il teatro; e il carnevale del 1656 fu detto il Carnevale della Regina per la grandiosità dei festeggiamenti che si dettero in suo onore. Nel giardino del palazzo Barberini fu tenuta la "festa dei caroselli ", torneo meraviglioso, per il quale furono perfino demolite alcune case per elevare palchi $e$ gradinate. Vi presero parte ventiquattro cavalieri divisi in due

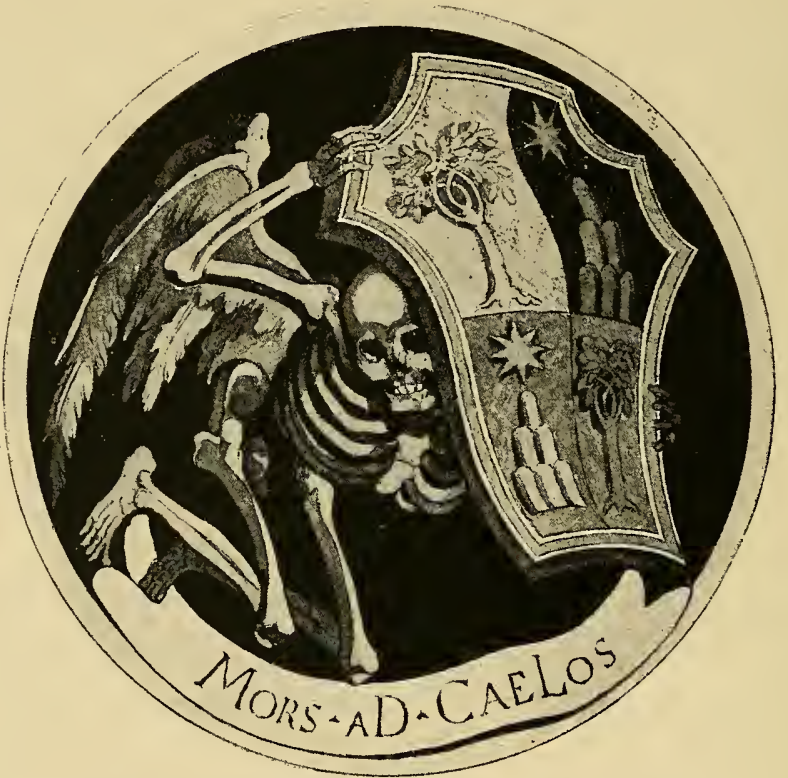

Sepoltura dei Chigi in S. Maria del Popolo, del Bernini.

squadre, con ricchissimi costumi, e "cimieri di penne così ampli e pomposi che non si sa come, tra l'ondeggiamento dell'aria, potessero sostenere in capo una macchina si spatiosa e grave che a ciascuno di loro costava più di duecento scudi di penne"; e con loro otto trombetti e centoventi palafrenieri, con torce accese. Veniva in fine un bellissimo carro guidato dalle tre Grazie, e mosso occultamente, su cui "sedeva in maestoso sembiante Roma Festiva, la quale, bramosa di palesar la sua gioia 


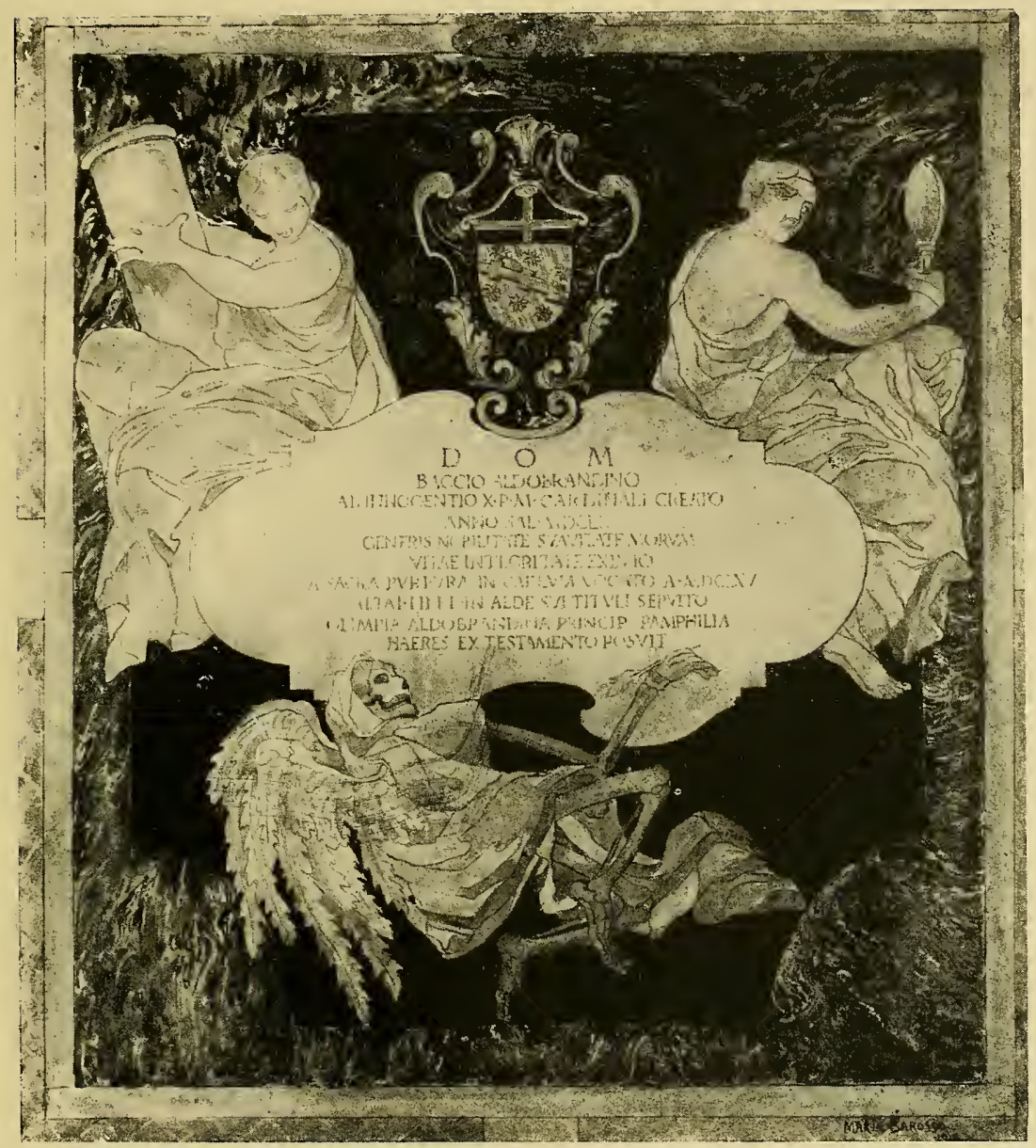

Tomba del cardinale Aldobrandini in S. Nereo ed Achilleo.

per la venuta di si gran Principessa, mostrò di haver assunte le sembianze et habito di Amore". I dodici cavalieri che difendevano il carro di Amore impegnarono battaglia con dodici amazzoni che circondavano quello dello Sdegno; finchè l'arrivo di Febo, assistito dalle quattro Stagioni, e da ventiquattro donzelle che simboleggiavano le ore, richiamò alla pace le due schiere nemiche. 


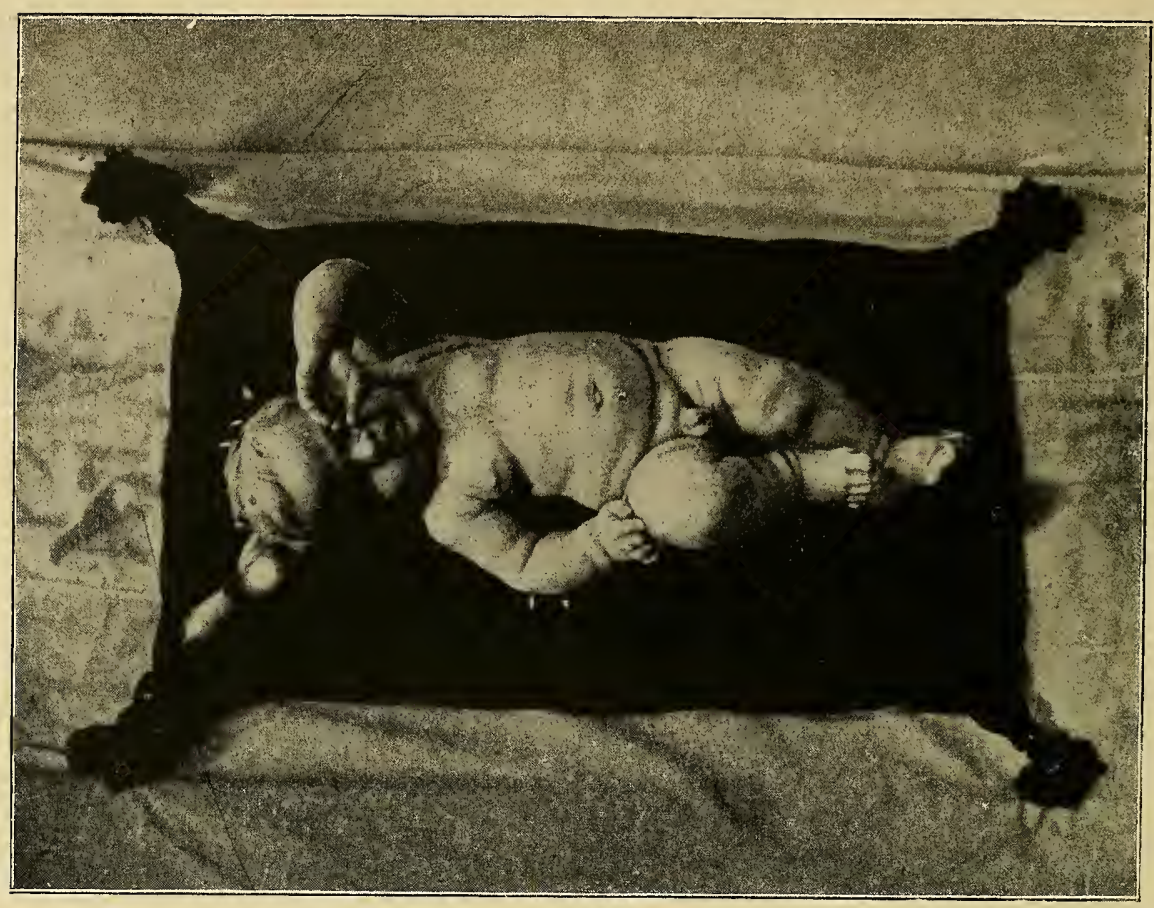

La Vita, Collezione Chigi alla Farnesina.

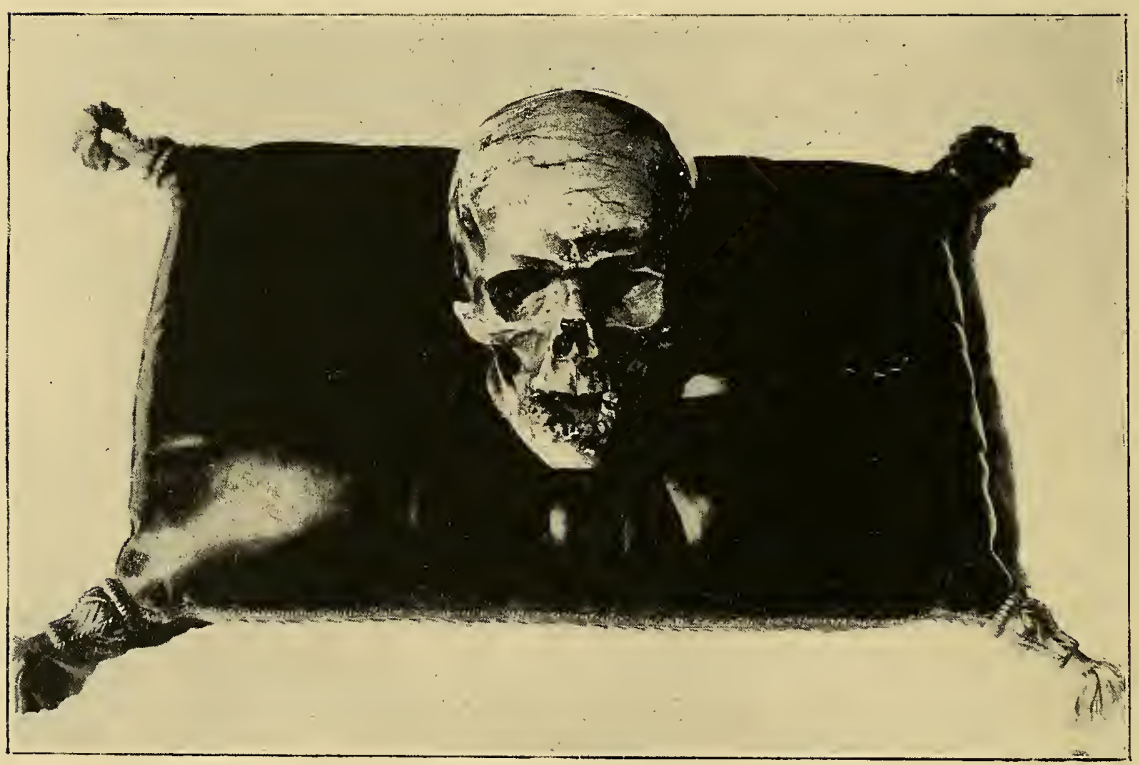

La Morte, Collezione Chigi alla Farnesina 
Nel palazzo Barberini si conserva un quadro che riproduce il magnifico spettacolo.

Non meno sontuose furono le feste fatte alla Regina dai Pamphili, che costruirono innanzi al loro palazzo un ricco palco o ringhiera, con colonne dorate, e vaghe pitture, tutto su disegno dello stesso principe; e "tutte le volte che Sua Maestà honorò
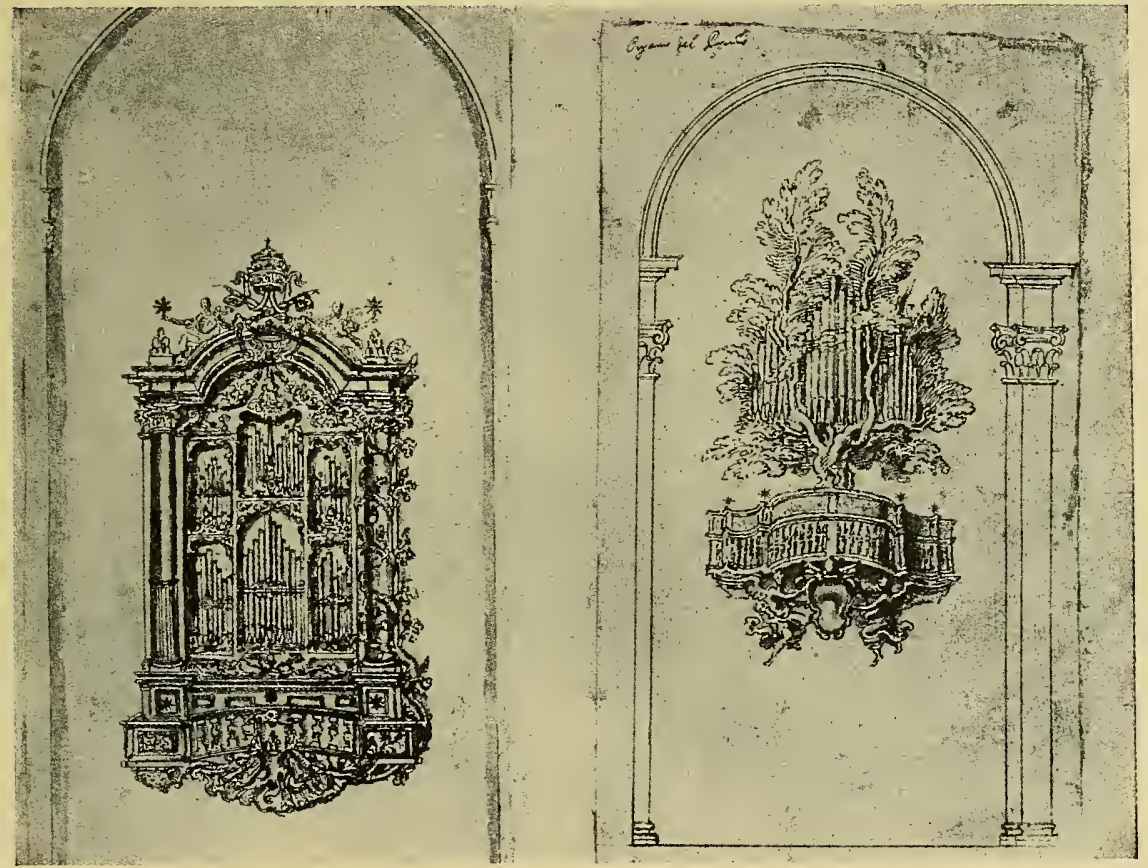

Disegni del Bernini per gli organi di S. Maria del Popolo, R. Biblioteca Chigiana.

la casa di questo Principe, fur regalata col suo seguito di lautissime collationi di confetture e canditi, vini et acque condite, e si tenne corte bandita, con ogni splendidezza; ogni sera fu illuminata la ringhiera con infinito numero di torce bianche, e nelle prime tre sere si fecero bellissimi fuochi d'allegrezza".

Cristina cominciò subito col suo fare stravagante a meravigliare tutti, e a dare scandalo con i suoi modi poco femminili, 
e le sue famigliarità col popolo, che ben presto perse ogni rispetto per lei. La sua stessa persona suscitava lo scherno: mentre in molti ritratti dell'epoca sembra quasi bella, sentiamo come la disegna, senza cortigianerie, la penna arguta del Gigli. " Di statura assai piccola, di fronte grande, occhi grandi e vivaci, naso aquilino, bocca assai piccola, voce da huomo, il moto et gesti tutti da

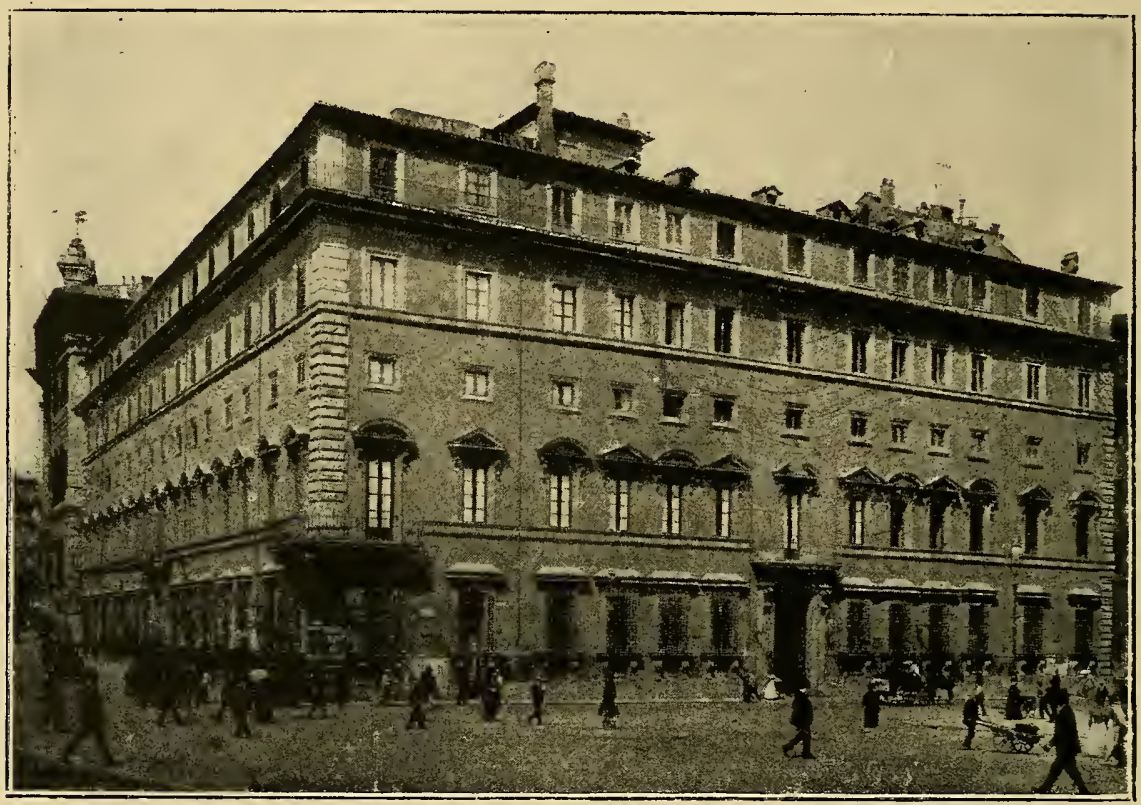

Il Palazzo Chigi in piazza Colonna, di G. della Porta e C. Maderno.

(Fot. Anderson).

huomo, con la chioma tagliata; porta in testa un berrettino nero con la zazzera posticcia, che gli pende sopra le spalle. Dicono che cavalca come huomo, et che incitando il cavallo al corso non pare che corra ma voli. Che ha molta dottrina di undeci lingue, cioè la sua propia, latina, italiana, greca, hebrea, caldea, ebraica, francese, spagnola, tedesca et polacca. Che ha letto tutti i poeti, tutti i dottori et ha felicissima memoria.... Da molti si diceva per certo che era Hermafrodita, ma però professava di essere donna". 
Suo confessore e confidente era il Cardinal Azzolino, galante porporato, parlatore vivace, favorito dalle dame; e per mezzo di lui ella riusciva a trar quattrini dalla borsa papale, approfittando della sua posizione; così che Alessandro VII ebbe un sospiro di sollievo quando nel luglio del '56 la Regina, per

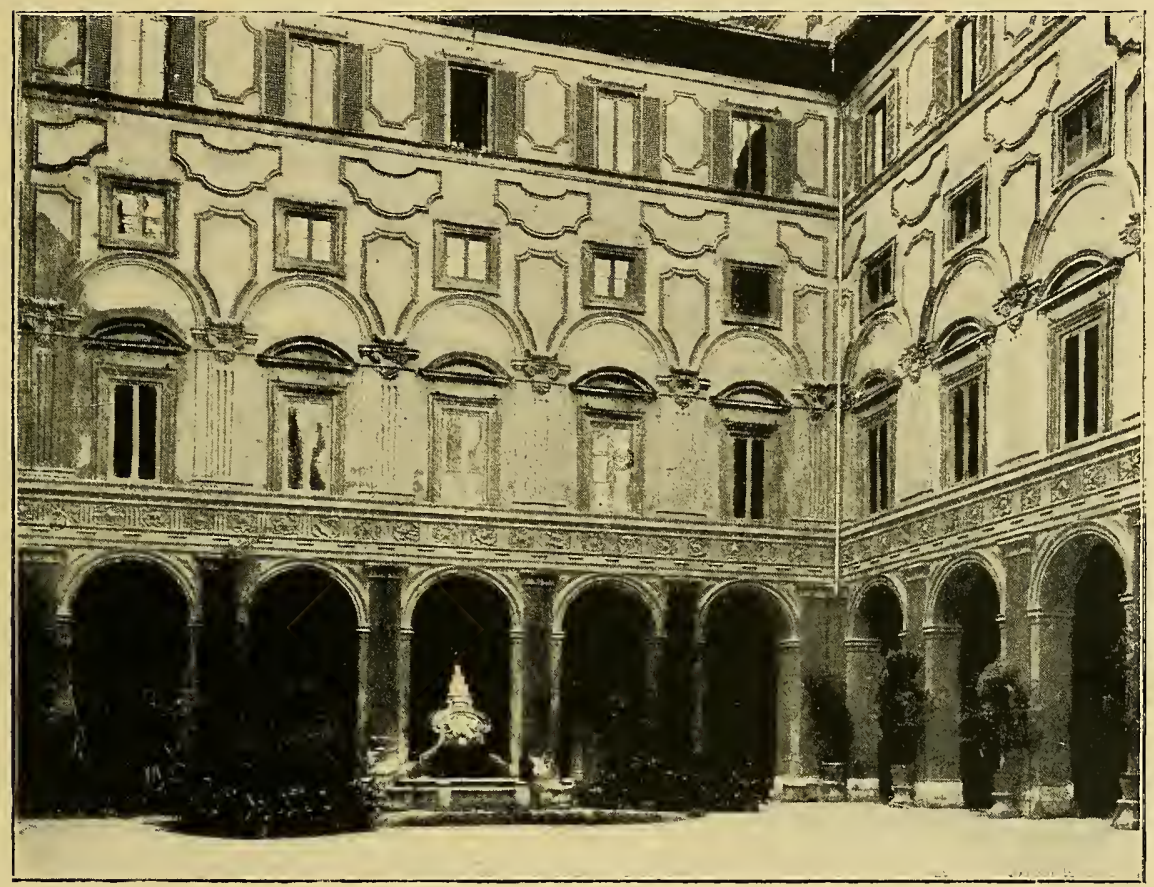

Cortile del Palazzo Chigi, decorato da Felice della Greca.

timore della peste, partì per la Francia. A ricordo perenne della sua dimora rimaneva la decorazione di porta del Popolo, fatta dal Bernini, con la scritta: Felici Faustoque Ingressui Anno Dom. MDCLV.

Nella vicina chiesa di S. Maria del Popolo, il celebre artista completò per incarico di papa Alessandro l'ornamentazione della capella gentilizia dei Chigi, costruita intorno al 1522, e decorata con musaici da Raffaello e con due statue 
dal suo scolaro Lorenzetto. Il Bernini restaurò i due sepolcri a piramide, di marmo portasanta, aggiunse in due nicchie le statue di Daniele e di Abacuc, a riscontro di quelle di Giona e di Elia, di Lorenzetto, e disegnò il pavimento, intarsiando nel chiusino della cella funeraria sotterranea, una figura della Norte alata che si nasconde dietro lo scudo chigiano. La rappresentazione della Morte, sotto forma di uno

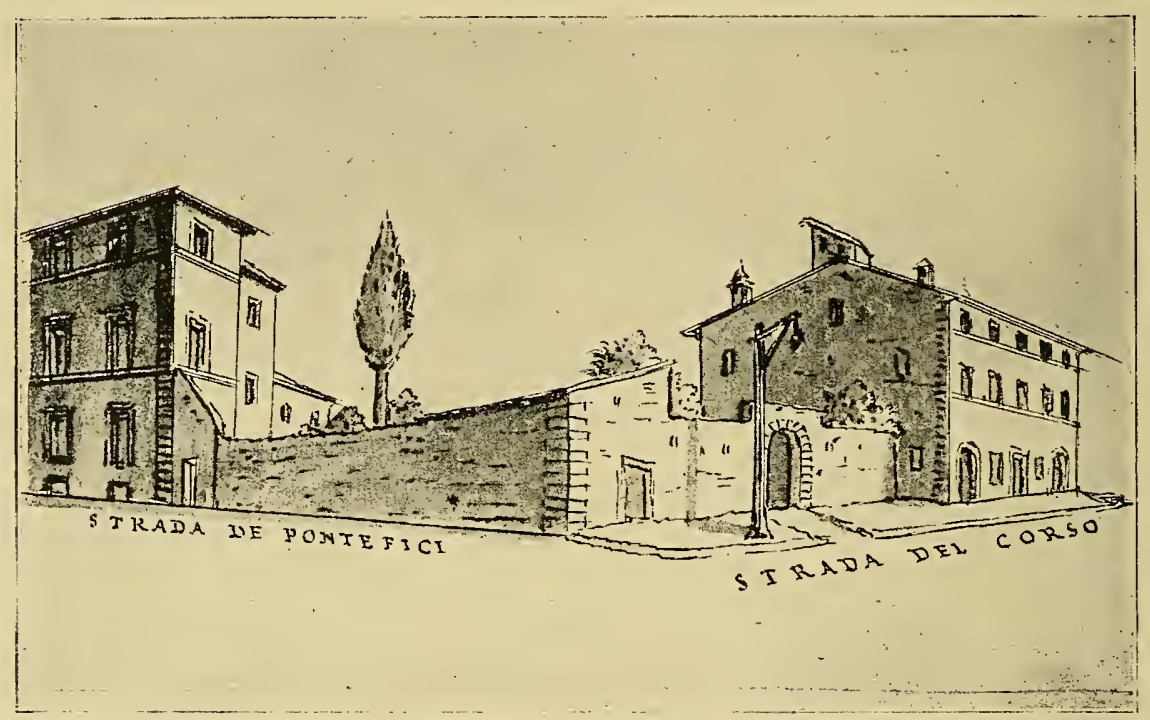

Un angolo del Corso al tempo di Alessandro VII. R. Biblioteca Chigiana.

scheletro che porta le ali, è frequente nel Seicento sui monumenti sepolcrali, e i maestri barocchi se ne valsero abilmente come motivo ornamentale; comunissimo è poi il solo teschio alato, che appare in quasi tutte le tombe. Nella collezione del principe Chigi si vedono due curiose figurazioni allegoriche, certo del tempo di Alessandro VII, ma non del Bernini, e sono i simboli della Vita e della Morte, espressi sotto forma di un bambino e di un teschio montati su cuscini di marmo nero, con liste e fiocchi di metallo dorato. 
In S. Maria del Popolo il Bernini decorò pure la navata centrale con statue di stucco; disegnò i bellissimi organi, intrecciando alle canne la rovere chigiana; costrui gli altari del transetto con gli angeli che reggono le cornici, e in tutti questi lavori ebbe cura di non alterare la sobrietà della fabbrica del Rinascimento; l'altare maggiore che nasconde l'abside, e turba

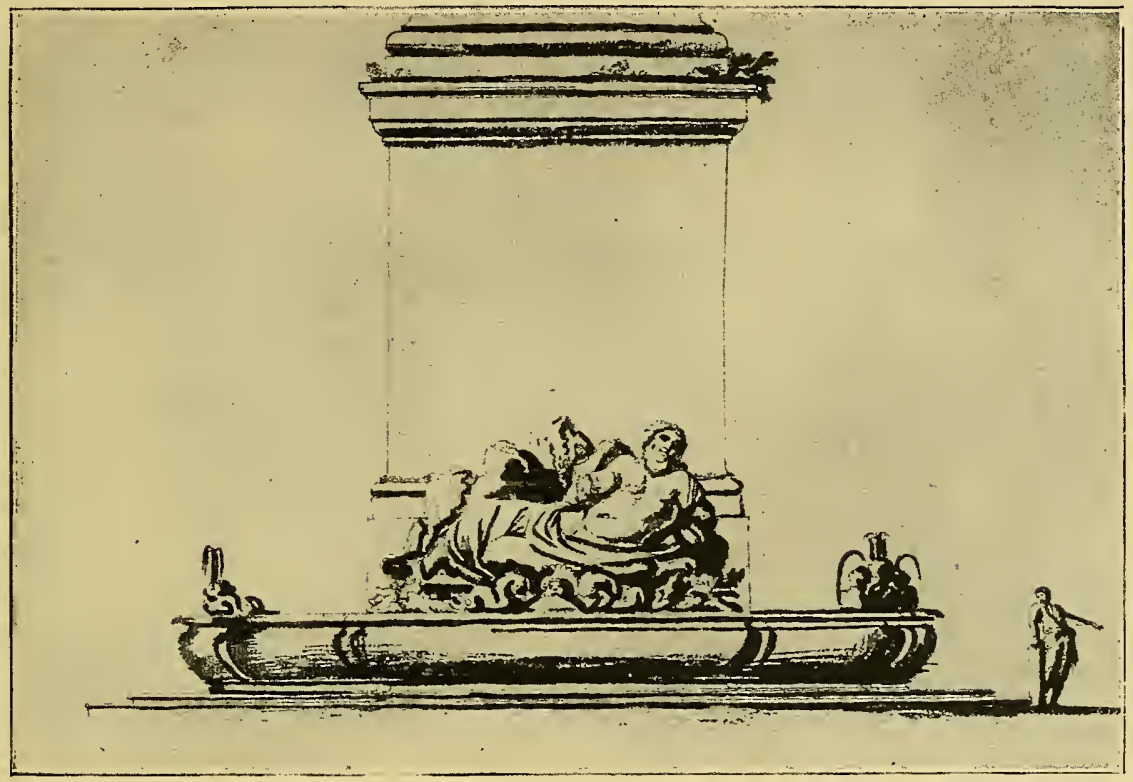

Disegno del Bernini per una fontana in piazza Colonna, R. Biblioteca Chigiana.

l'armonia della chiesa, non è suo come si crede, ma appare all'evidenza opera della fine del Cinquecento.

Come i suoi predecessori Alessandro VII provvide anche alla magnificenza della sua casa, e dopo un anno di pontificato, abbandonando gli scrupoli del primo momento, fece venire da Siena i suoi parenti, e nominò il fratello Mario generale di Santa Chiesa e castellano, e il nipote Agostino generale delle guardie pontificie, mentre iniziava l'altro nipote Flavio alla carriera ecclesiastica, per farlo presto cardinale. Fece restaurare il palazzo 
in piazza Colonna, eretto da Giacomo della Porta, e completato dal Maderno; e Felice della Greca, architetto che godeva la protezione di casa Chigi, vi fece le eleganti decorazioni del cortile. Per fare avanti al palazzo una magnifica corte d'onore, il Bernini aveva poi concepito un progetto straordinario; quello cioè di trasportare la colonna Traiana, e metterla a una certa distanza dal-

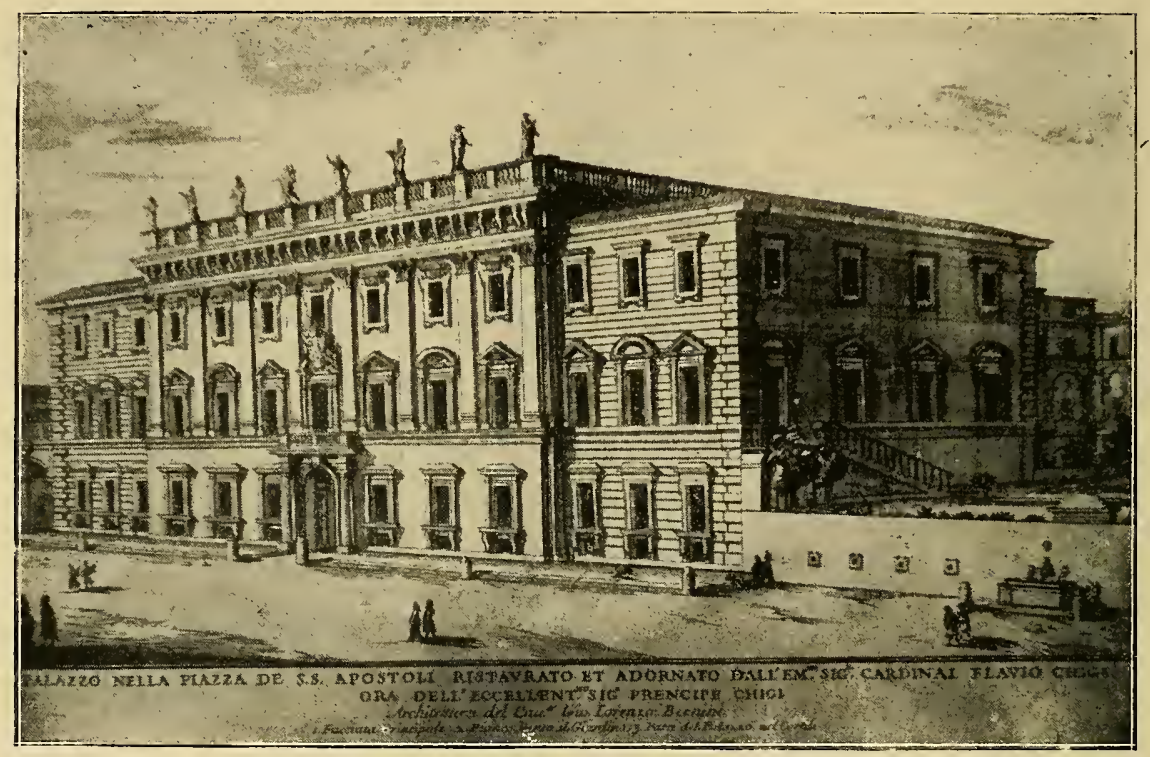

Bernini, Il palazzo Chigi ora Odescalchi, in piazza SS. Apostoli.

l'Antonina, unendole poi con una vasta fontana che, poteva trasformarsi in lago innondando tutta la piazza; si limito a fornire il disegno di una più modesta vasca, ai piedi della colonna, con una figura dell' Oceano distesa su uno scoglio. Alessandro VII del resto approvava i grandiosi piani del sommo artista, al quale manifestava una ammirazione non minore dei suoi predecessori, ed egli stesso ne concepiva molti, come può vedersi da un suo autografo ch'è nella R. Biblioteca Chigiana, la magnifica raccolta di manoscritti, disegni e stampe, formata in gran parte sotto il suo ponti- 
ficato, e di recente acquistata dal nostro Governo. "Disegni d'abbellimenti di Roma: La fontana di piazza Colonna mettere in quella di S. Marco - La fontana di Monte Cavallo in piazza SS. Apostoli - La guglia di Campo Marzio rizzarla qui a Montecavallo - Portare la mostra della fontana di Trevi in piazza Colonna".

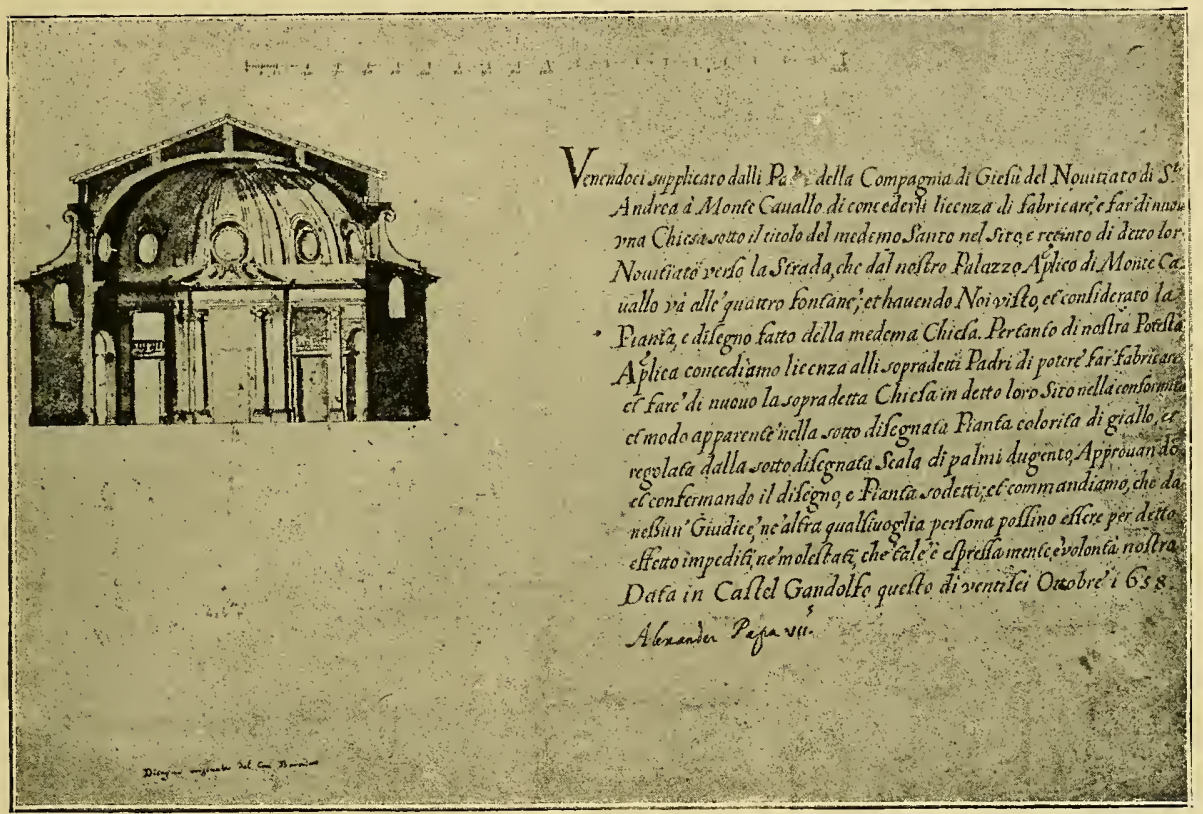

Disegno del Bernini per la chiesa di S. Andrea, con autografo di Alessandro VII. R. Biblioteca Chigiana.

L'idea di ornare la piazza SS. Apostoli si spiega col fatto che quivi sorgeva l'altro palazzo dei Chigi, già appartenuto ai Colonna, al quale il Bernini aggiungeva in questo tempo il prospetto.

Sotto il pontificato di Alessandro VII il Bernini eresse la chiesa di S. Andrea del Noviziato dei Gesuiti al Quirinale, a pianta centrale, decorata di stucchi e d'oro e con marmo di Cottanello, che il maestro considerava come la sua sola opera di architettura della quale sentiva qualche particolare compiacenza, per 


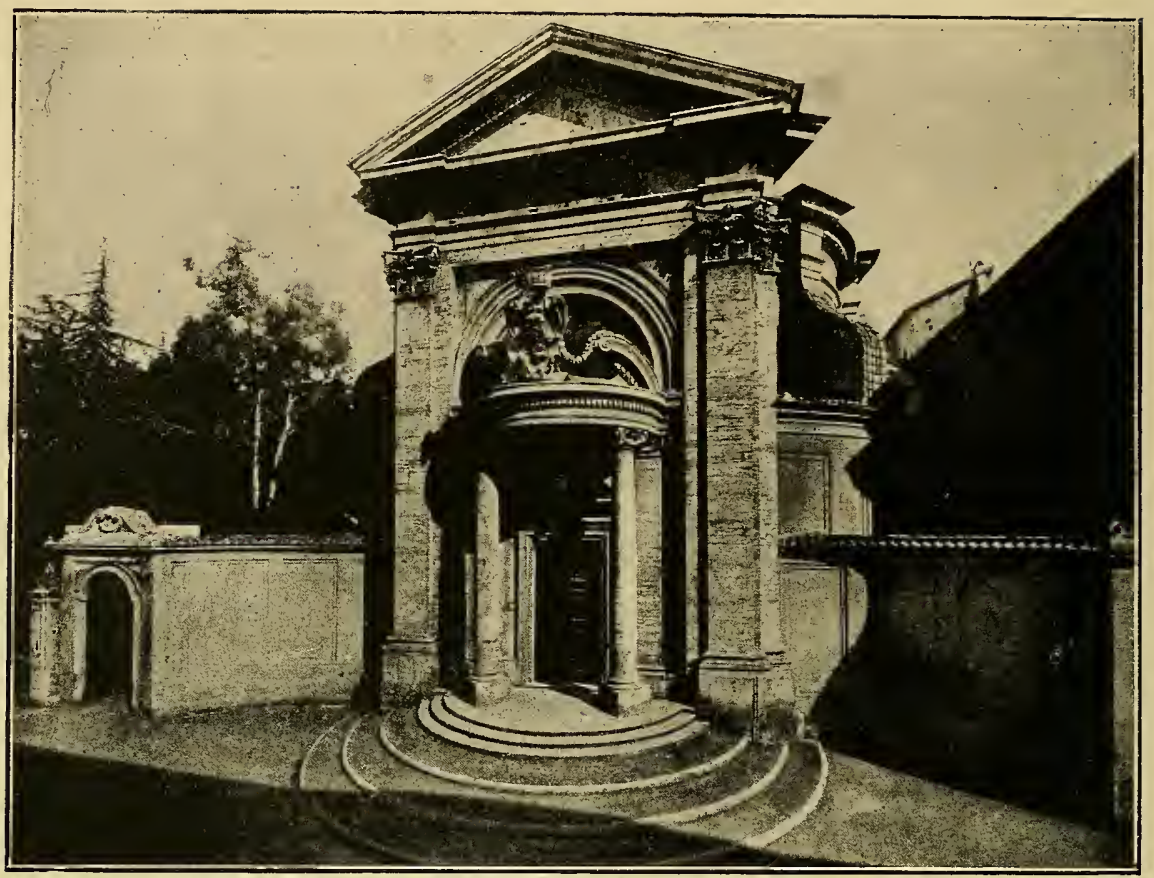

Bernini, Facciata di S. Andrea al Quirinale.

cui spesso per sollievo delle sue fatiche vi si recava a consolarsi. Il disegno di questa chiesa presentato dal Bernini fu approvato da Alessandro VII il 26 ottobre 1658, e la prima pietra della fabbrica fu messa il 3 novembre. Pochi anni dopo il Bernini ripeteva lo stesso schema nella chiesa dell'Assunta, all'Ariccia (1664), anch'essa a pianta centrale, sormontata da calotta ornata di cassettoni, e preceduta da un portichetto dorico. Ma a differenza di S. Andrea, la chiesa aricina è tutta di stucco bianco, senza ori, senza marmi di colore, e ispirandosi in questo al Borromini, precorre l'eleganza del candido Settecento. All'Ariccia Bernini si mostra un classicista, studioso delle sobrie forme degli antichi; il Pantheon gli suggerisce il tema principale, mentre all'esterno usa il più severo degli stili classici, il dorico, che in questo stesso periodo di tempo egli ha adottato 


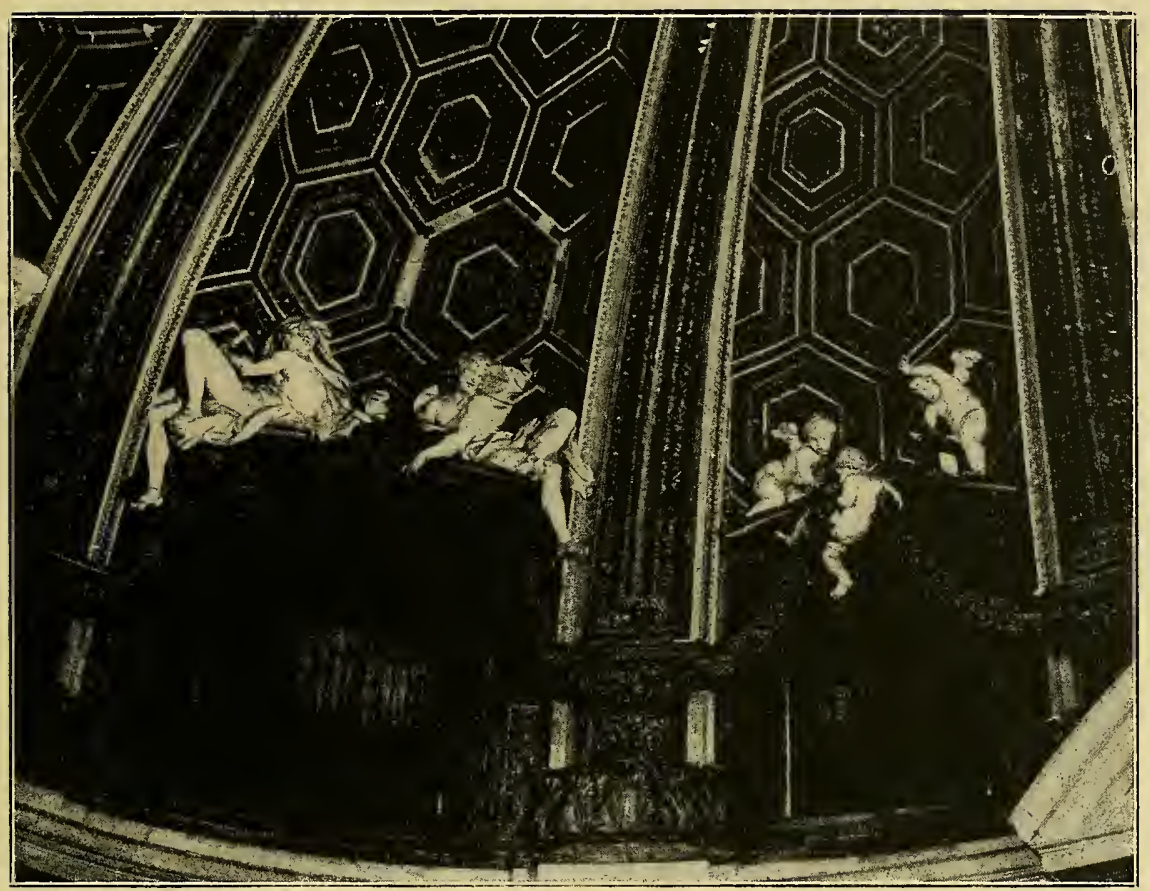

Bernini, Cupola di S. Andrea al Quirinale.

(Fot. Alinari).

nella più grandiosa delle sue opere architettoniche, il colonnato di S. Pietro. Ancora più semplice è l'altra chiesa berniniana di Castel Gandolfo, (1661), con pianta a croce greca, sormontata da cupola ornata di stucchi bianchi, i cui fondi sono stati di recente con poco gusto dipinti di giallo.

In questo tempo l'architettura ha subito una trasformazione profonda per opera di Francesco Borromini, che completata la fabbrica della Sapienza sta elevando la più vivace delle sue opere, la facciata di S. Carlino. Tra le due opposte tendenze del maestro lombardo e del Bernini, trova il suo equilibrio l'arte di Pietro da Cortona, che a S. Luca ancora incerto e un po' pesante, ha nel suo secondo periodo, una padronanza perfetta della forma: nella facciata della Pace (1656) compone armoniosamente linee concave e convesse, incurva gl'interpila- 


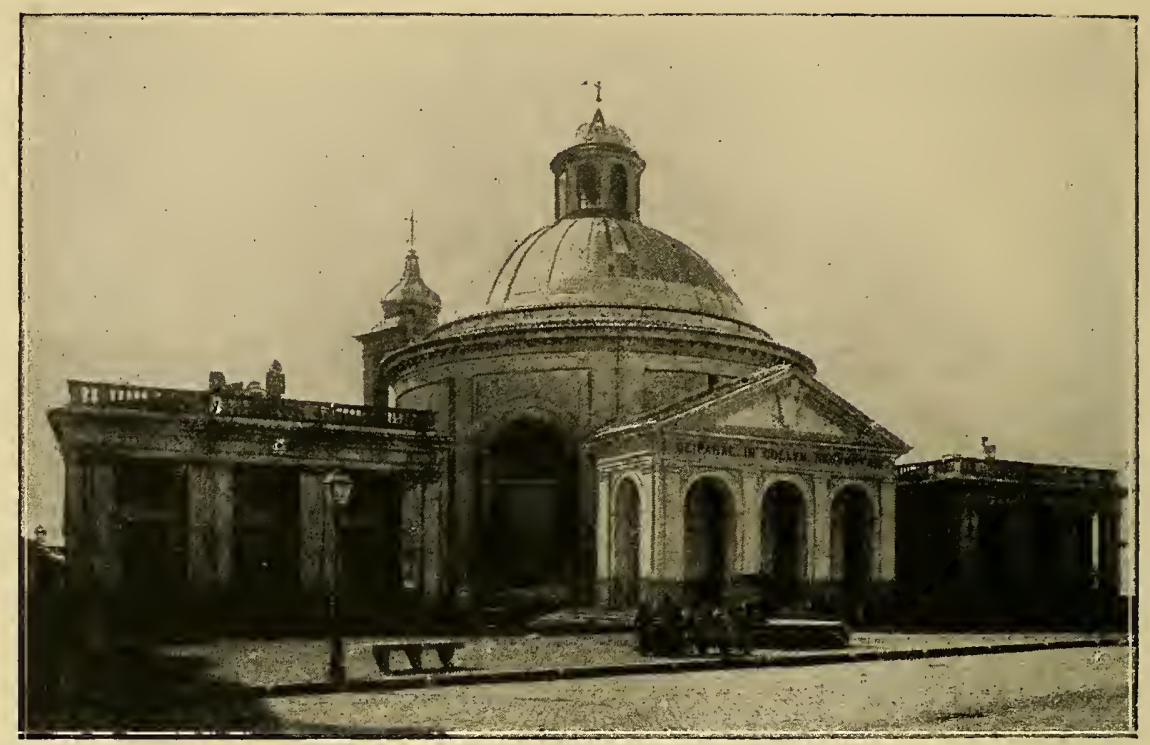

Bernini, Chiesa dell'Assunta all'A riccia.

stri, arrotonda gli spigoli con colonne, crea fasce di puro accento borromínesco; in quella di S. Maria in via Lata (1661) ricorre classicamente al Pantheon, con forme più snelle. A Pietro da Cortona, come al Rainaldi e ad altri architetti, toccò l'onore della richiesta dal $\mathrm{Re}$ di Francia, del progetto per il palazzo del Louvre, onore che il Borromini aveva declinato. $\mathrm{Ma}$ i disegni preparati da lontano non soddisfacevano Luigi XIV, il quale dopo molte insistenze riusci ad ottenere dal papa il permesso di chiamare a Parigi il Bernini. Già al tempo di Luigi XIII il Cardinal Mazzarino aveva cercato di attirare il maestro in Francia, ma questi non volle abbandonare il campo ai suoi nemici che allora trionfavano. Alle preghiere reiterate del $\mathrm{Re}$, Alessandro VII non potè resistere, ed emanò un breve col quale concedeva al Bernini una licenza di tre mesi per recarsi a $\mathrm{Pa}$ rigi. Il 29 aprile 1665 il maestro accompagnato dal fíglio diciottenne Paolo, scultore, dai discepoli Mattia de Rossi e Giulio 
Cartari, e da alcuni famigliari, partì con grande allarme della popolazione romana, che temeva di non rivederlo più, pensando che il Re l'avrebbe trattenuto per sempre. A Siena, a Firenze,

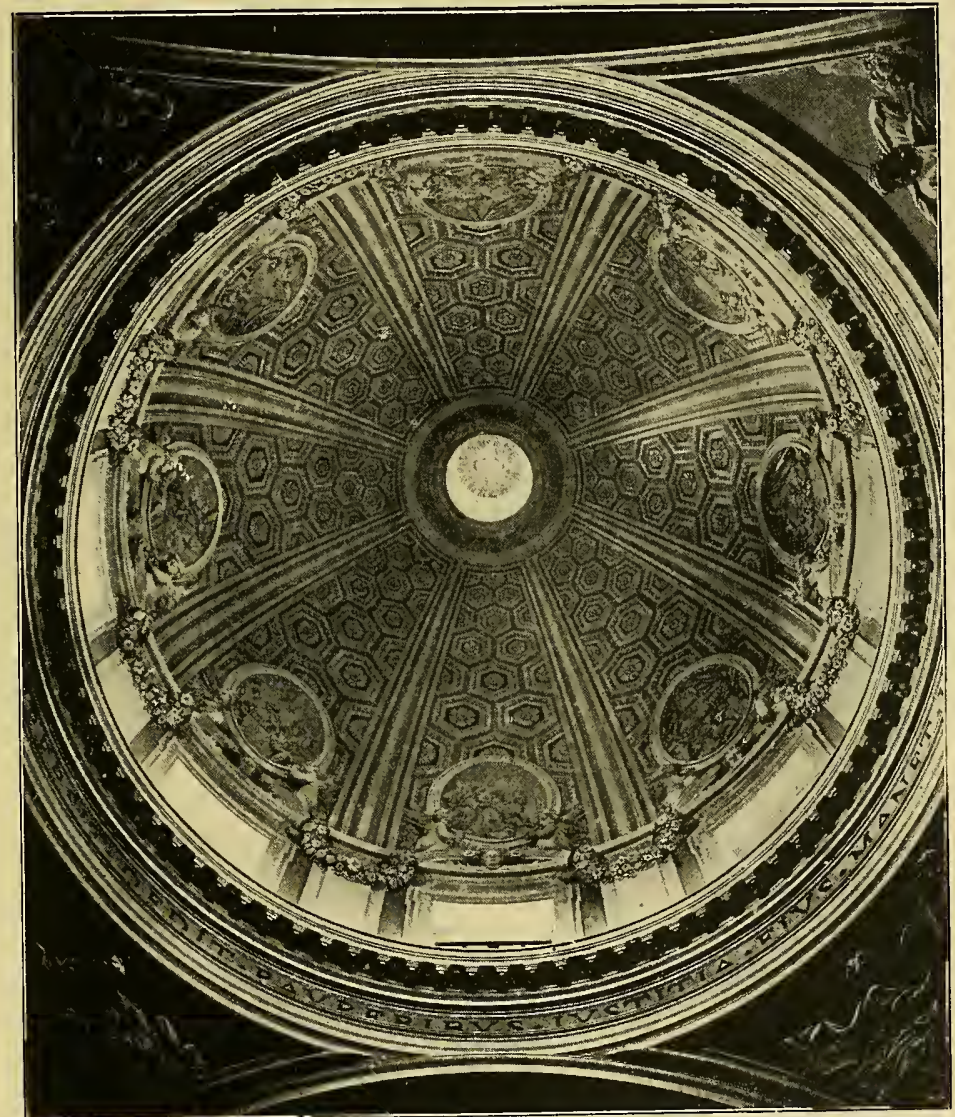

Bernini, Cupola della Chiesa di Castel Gandolfo.

a Torino, le accoglienze furono trionfali; a Lione tutte le corporazioni artistiche gli mossero incontro coi loro vessili, e a quaranta miglia da Parigi fu salutato dal visconte di Chantelou, maggiordomo del $\mathrm{Re}$, che gli rimase a fianco per tutto il tempo della sua dimora a Parigi, e scrisse il Journal de boyage du 


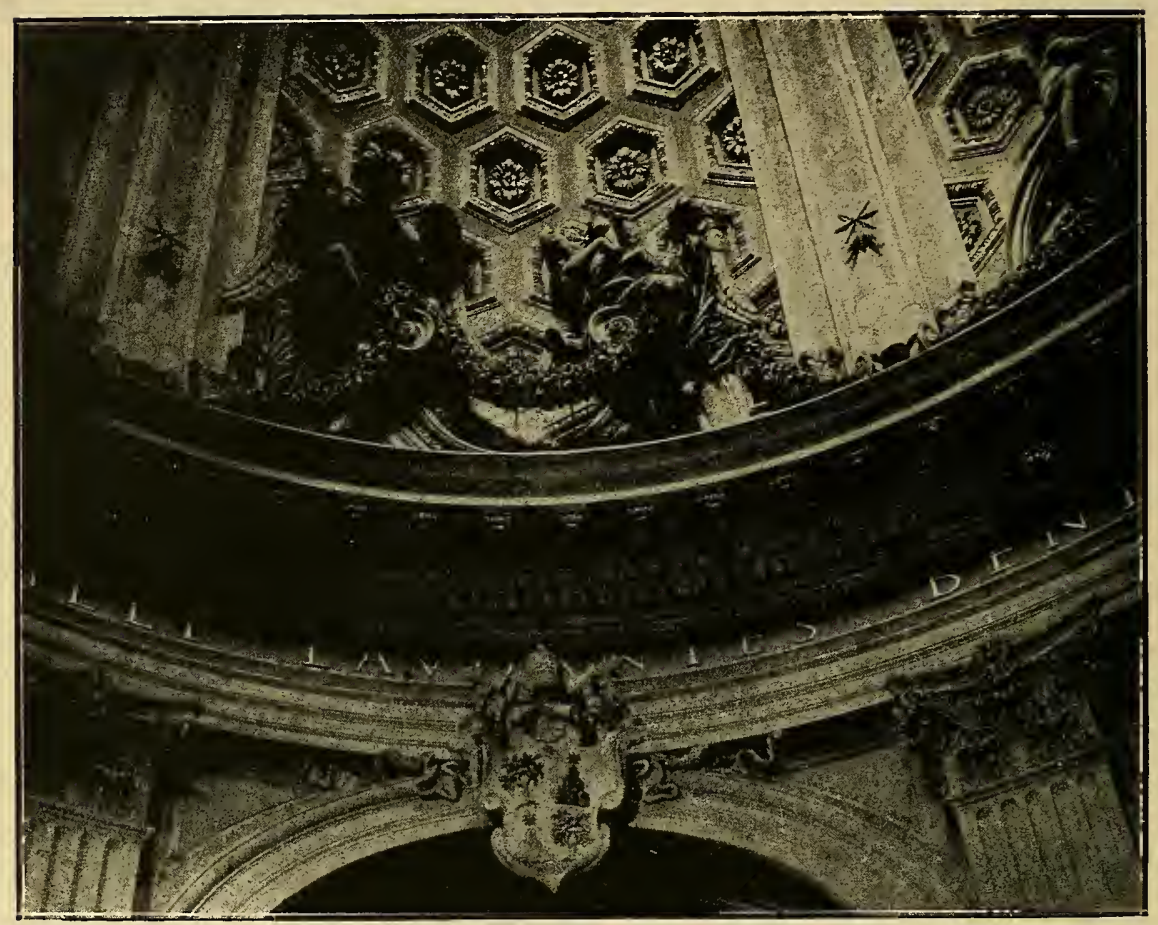

Berniní, Cupola dell' Assunta all' Ariccia.

cabalier Bernin en France, diario prezioso, pervenuto fino a noi. Ma la gelosia degli architetti francesi, e il carattere pungente e orgoglioso del Bernini, fecero nascere ben presto intorno a lui la diffidenza e la ostilità. Ovunque lo conducevano a visitare fabbriche e opere d'arte il nostro criticava con troppa libertà; non trovava quasi nulla di bello e di buono, al punto da dichiarare un giorno che perfino le donne francesi erano meno belle delle italiane. I suoi progetti per il Louvre, concepiti con spirito puramente romano, senza tener conto del gusto tutto diverso dei francesi, e delle diverse condizioni di clima e di abitabilità, non piacquero, $e$ non potevano piacere in un ambiente abituato a tutt'altro stile. E così il Bernini, ch'era arrivato a Parigi il 3 di giugno, ripartì ai 15 di ottobre, senza che il lavoro fosse 


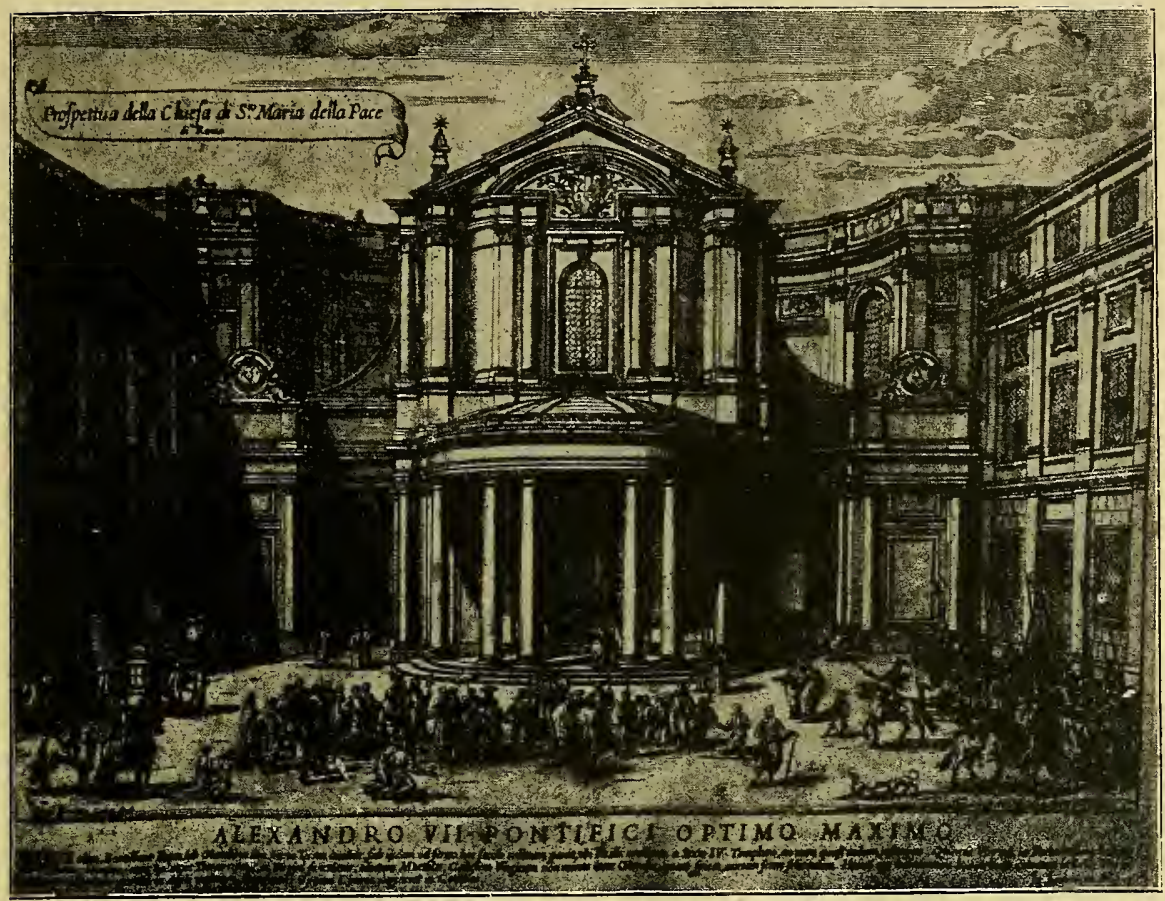

Pietro da Cortona, Esterno di S. Maria della Pace.

iniziato. Ma lasciava in Francia, oltre al meraviglioso busto del Re Sole, ch'è oggi a Versailles, il più bello tra la serie infinita dei ritratti di Luigi XIV, oltre all'altare del Val-de-Grâce, una traccia profonda: si può affermare che l'architettura francese dopo il 1665 muta indirizzo, si trasforma, si italianizza. E molte idee suggerite o appena abbozzate dal Bernini, trovarono la loro applicazione: basti ricordare la costruzione del grande parco di Versailles, e la fondazione dell'Accademia di Francia in Roma.

Tornato nella città dei papi, accoltovi con incredibile giubilo, il maestro riprese con alacrità gl'interrotti lavori; il colonnato di piazza S. Pietro, la Scala Regia, la Cattedra. Già altri architetti si erano accinti al formidabile compito di sistemare la 
piazza innanzi alla Basilica Vaticana, e tra essi il Rainaldi aveva imaginato di cingerla di fabbricatí per uso di abitazione dei famigliari del papa e degli inservienti del tempio. Ma il Bernini abbandonando questi meschini concetti utilitari, disegnò i due colonnati ovali, di stile dorico, a quattro file di colonne,

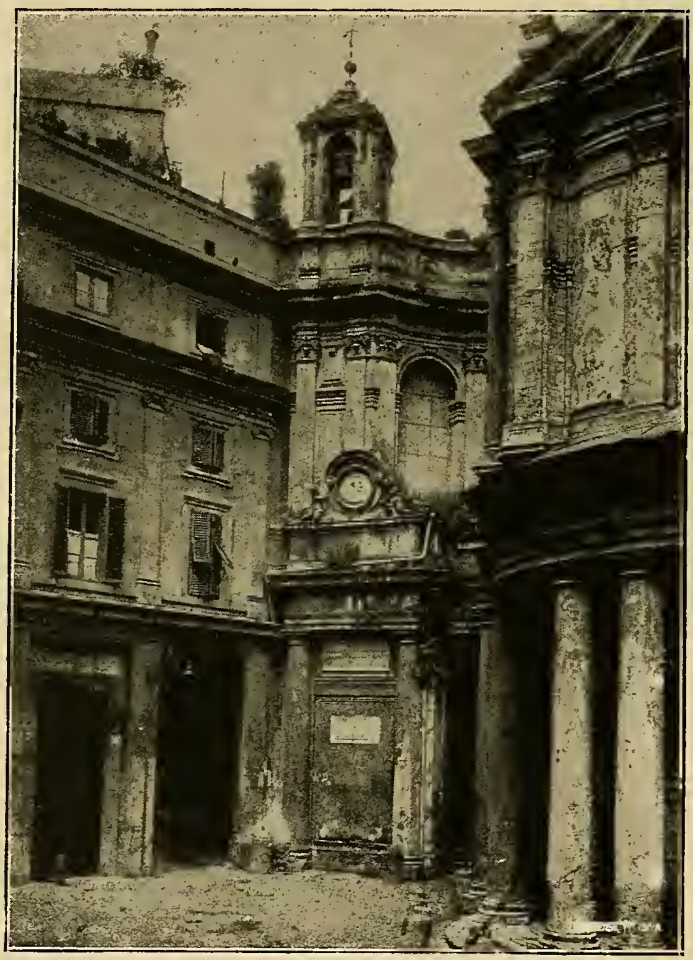

P. da Cortona, Esterno di S. Maria della Pace.

che si aprono come braccia enormi, invitando i fedeli ad entrare nella basilica, ove sulle tombe degli apostoli splendono in perpetuo le cento lampade d'oro. Solo la Roma antica poteva rivaleggiare con quella del Seicento per la grandiosità delle sue fabbriche; ma forse la città imperiale non vantò un'opera così armonica, così perfetta, innanzi alla quale gli spregiatori del barocco debbono tacere ammirati e confusi. 
Compiuta avanti la basilica la più bella piazza del mondo, il Bernini condusse a termine nell' interno la mole scintillante

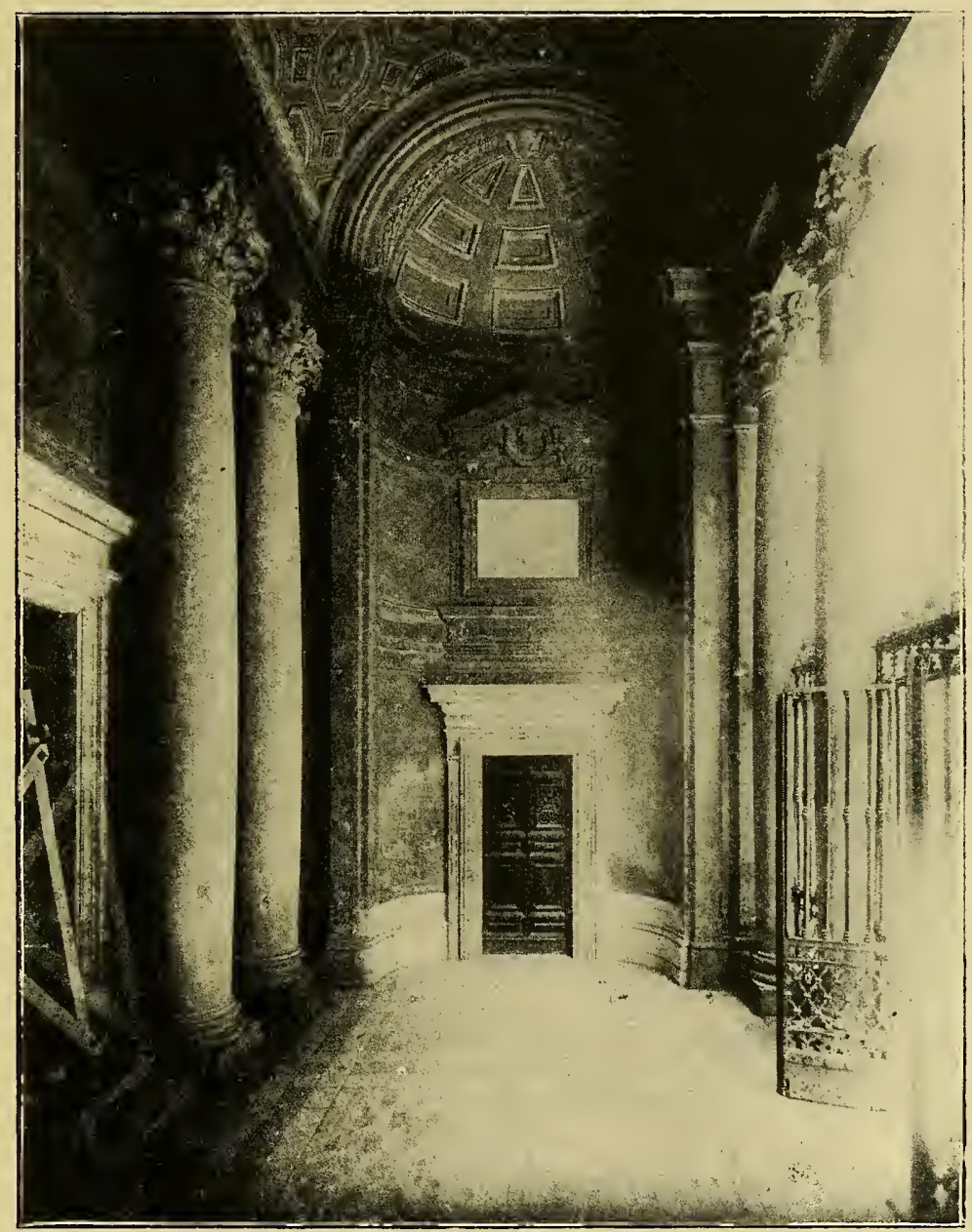

Pietro da Cortona, Portico di S. Maria in Via Lata.

della Cattedra di S. Pietro, ch'è la più bella decorazione absidale che un tempio cristiano abbia avuto mai. L'opera gigantesca è un miracolo di eleganza nei suoi particolari: su basamenti di rosso diaspro, le quattro statue colossali di bronzo, figu- 
rantí i quattro dottori della Chiesa, sorreggono la cattedra dorata, che racchiude l'antichissimo venerando seggio su cui, secondo Ia pia tradizione, S. Pietro pontificava; e dietro la preziosa custodia, in una gloria di nuvole, volano schiere d'angeli intorno al vetro ovale in cui si disegna la colomba dello Spirito Santo. L'occhio segue a fatica le linee della composizione;

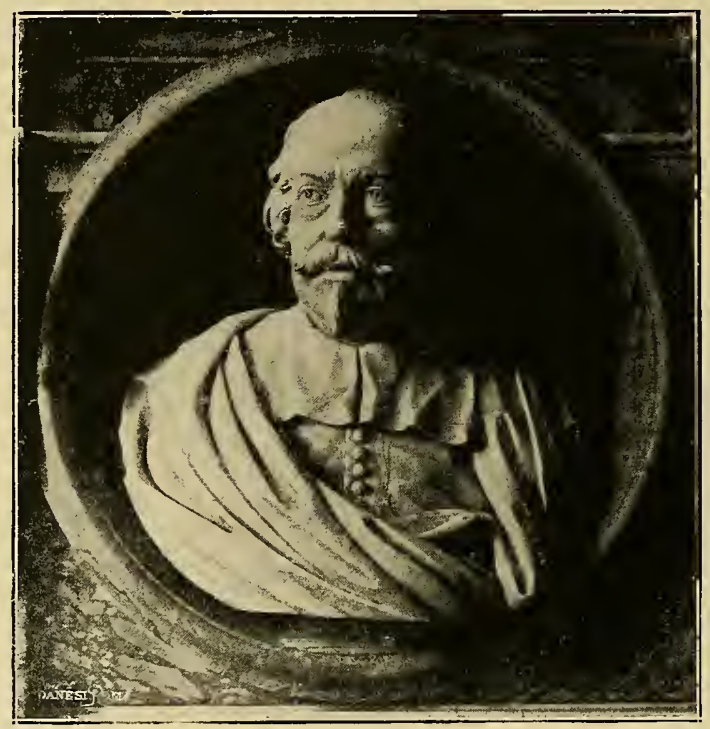

B. Fioriti, Busto di Pietro da Cortona, nella Cripta di S. Luca.

è tutta una festa di luce, di colore; un inno sonoro intonato da mille voci che cantano con gioia verso il cielo.

Così era compiuta la fabbrica della basilica, che è la più grande del mondo, il domo e il monumento del Cattolicismo, della Chiesa trionfante, sicura della sua vita eterna. Nei giorni solenni, quando il vento trasporta su tutta l'Urbe la voce di bronzo delle immense campane, mentre una moltitudine infinita sale per l'ampia scala e scompare sotto il portico, par veramente che tutto il mondo dei fedeli possa trovar posto sotto le 


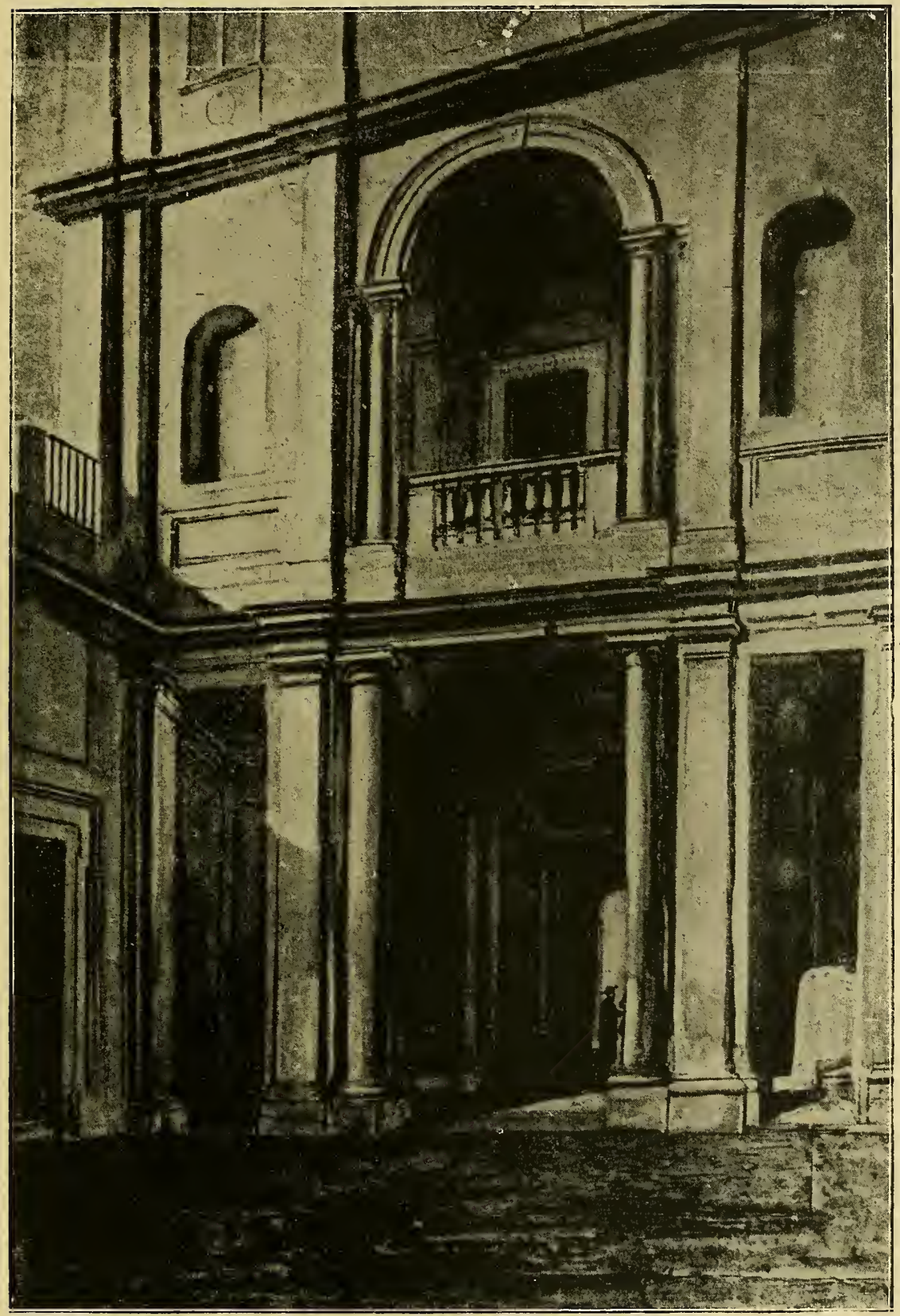

Casa di Pietro da Cortona, in Via della Pedacchia, ora demolita. 


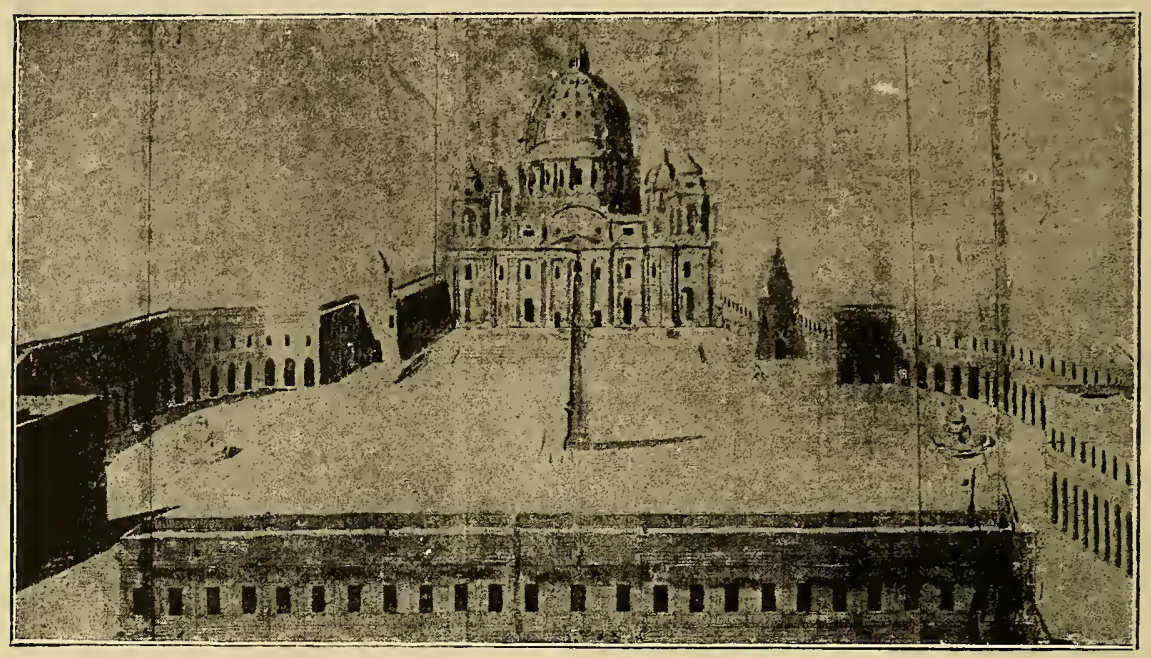

Progeito del Rainaldi per la Piazza di S. Pietro. Biblioteca Chígiana.

vôlte capaci della Basilica Vaticana. Levano nell'interno i cantori le note degli inni sacri; il suono degli organi lontani par che scenda dal cielo; lo scalpiccio e il bisbiglio della folla producono il rumore di una fiumana che irrompa. Dall'alto della cupola, dal grande occhio della tribuna, piove la luce d'oro del sole di Roma; ed ecco tra la sua corte, tra i soldati svizzeri sotto i caschi che il Buonarroti disegnò, tra le guardie nobili, tra la porpora dei cardinali, gli ermellini dei canonici, i velluti dei cerimonieri, compare sulla sedia gestatoria il Pontefice, bianco tra i bianchi flabelli, e leva la mano a benedire. Dall'alto dei lor mausolei lo guardano i maggiori e gli eguali : Paolo III alza la forte testa pensosa; Urbano con più maestà leva il braccio regale, e sotto il mantello di diaspro la morte dorata si arretra. A questi spettacoli in cui rivive l'anima dell'antica Roma, nessun'altra cornice potrebbe adattarsi, se non quella che con robusta mano disegnarono nei secoli Bramante, Sangallo, Michelangelo e Maderno; ma ad essa mancherebbe la vita senza il colore e la luce che vi infuse Gianlorenzo Bernini. 


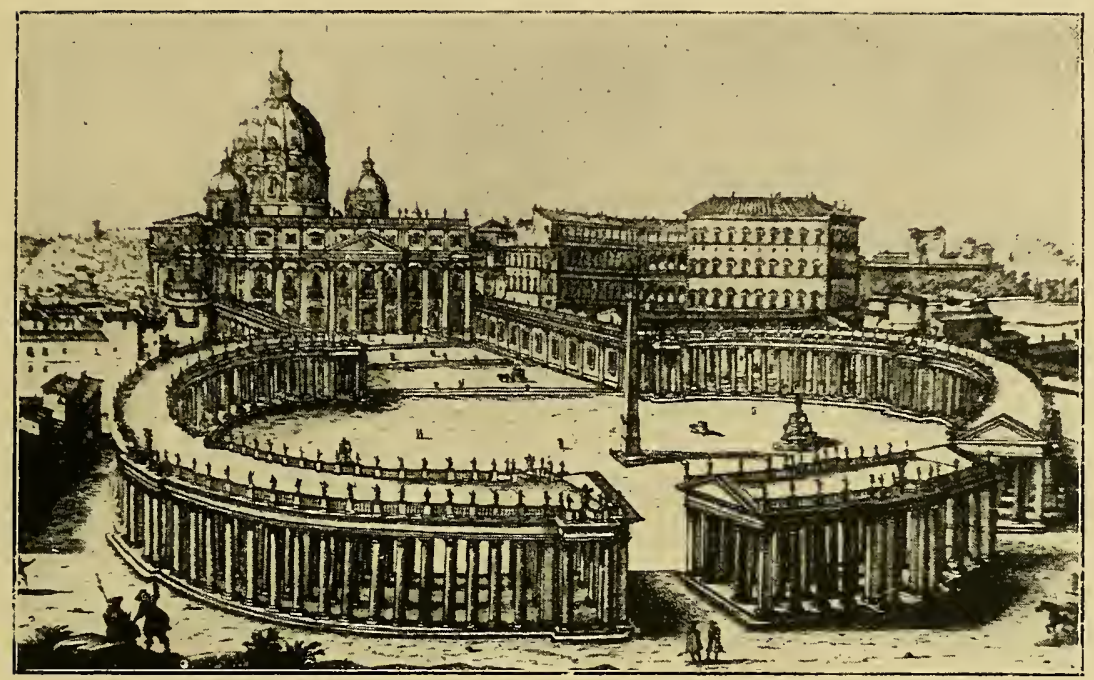

II Colonnato di S. Pietro, nel progelto del Bernini.

La cattedra di S. Pietro fa pensare alle meravigliose macchine teatrali che l'inesauribile genio del Bernini immaginò piùs volte per la rappresentazione di commedie e di melodrammi, sia proprii che d'altri. Gli spettacoli in Roma avevano ripreso gran voga dopo il ritorno di Cristina di Svezia, che nel

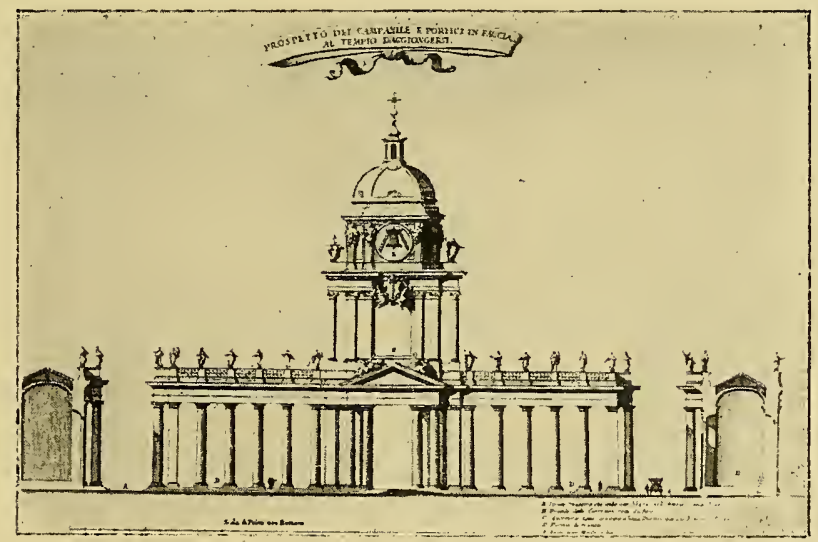

Progetto di C. Fontana, per la chíusura del Colonnato di S. Pietro. 


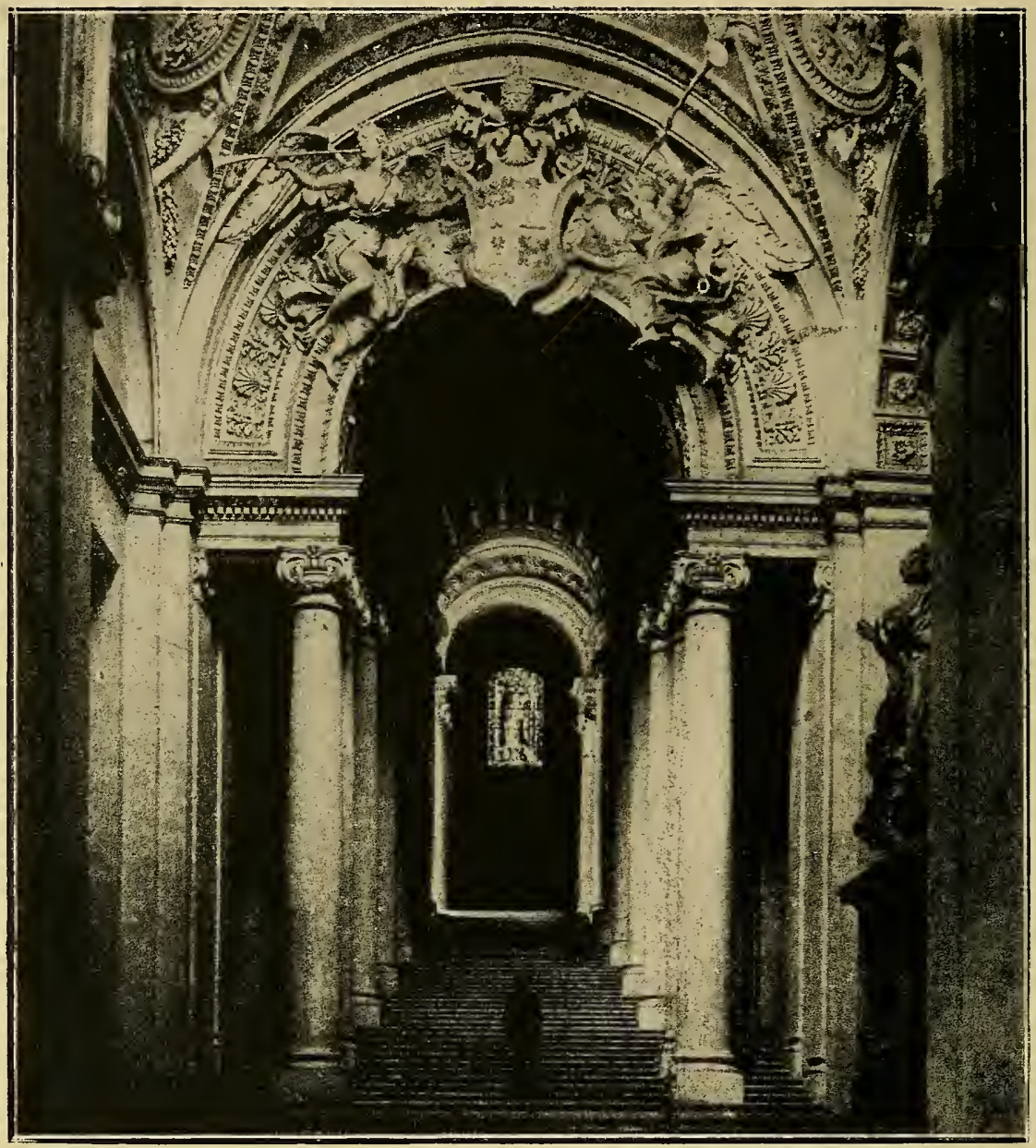

Bernini, La Scala Regia in Vaticano.

(Fot. Alinaril.

maggio 1658 rientrava, con grande inquietudine del papa. Allontanatasi di nuovo nel 1660, due anni dopo riappariva a Roma, per non lasciarla più fino alla sua morte, che avvenne nel 1689. Abitava nel palazzo Riario alla Lungara, ove accoglieva intorno a sè letterati ed artisti, musici e astrologi. Il Bernini, il Manzini, il Guidi, il Maratta, erano assidui alla corte della Regina e tra i musicisti Marco Marazzoli, Bernardo Pasquini, Arcan- 


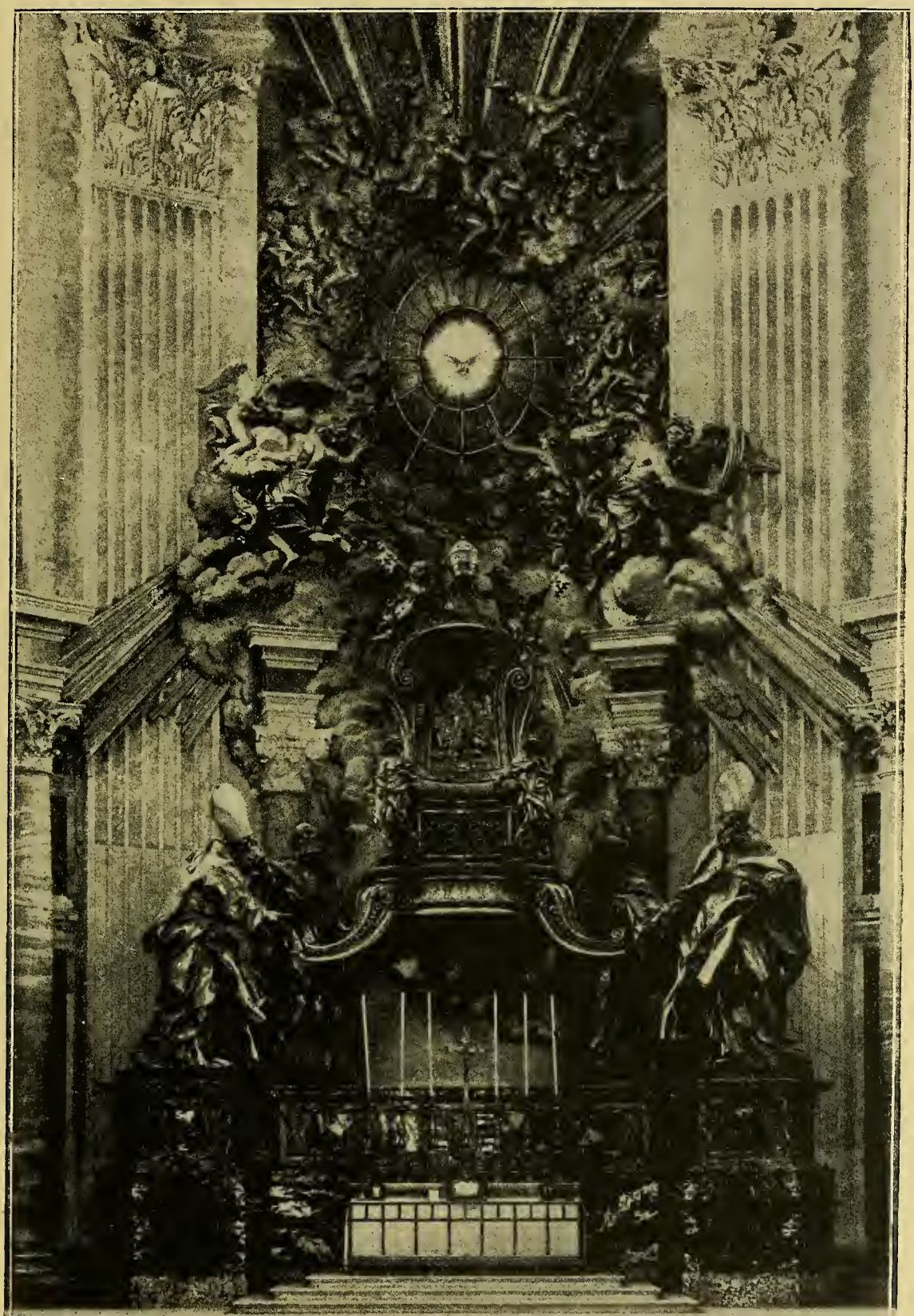

Bernini, La Cattedra di S. Pietro, nella Basilica Vaticana. (Fot. Alinari). 
gelo Corelli, e il giovane Alessandro Scarlatti, di cui Cristina indovinò il genio, incoraggiandone i primi passi. I migliori cantanti erano al servizio della Regina con stipendio fisso, e venivano chiamati con insistenza dalle altre corti; e le rappresenta-

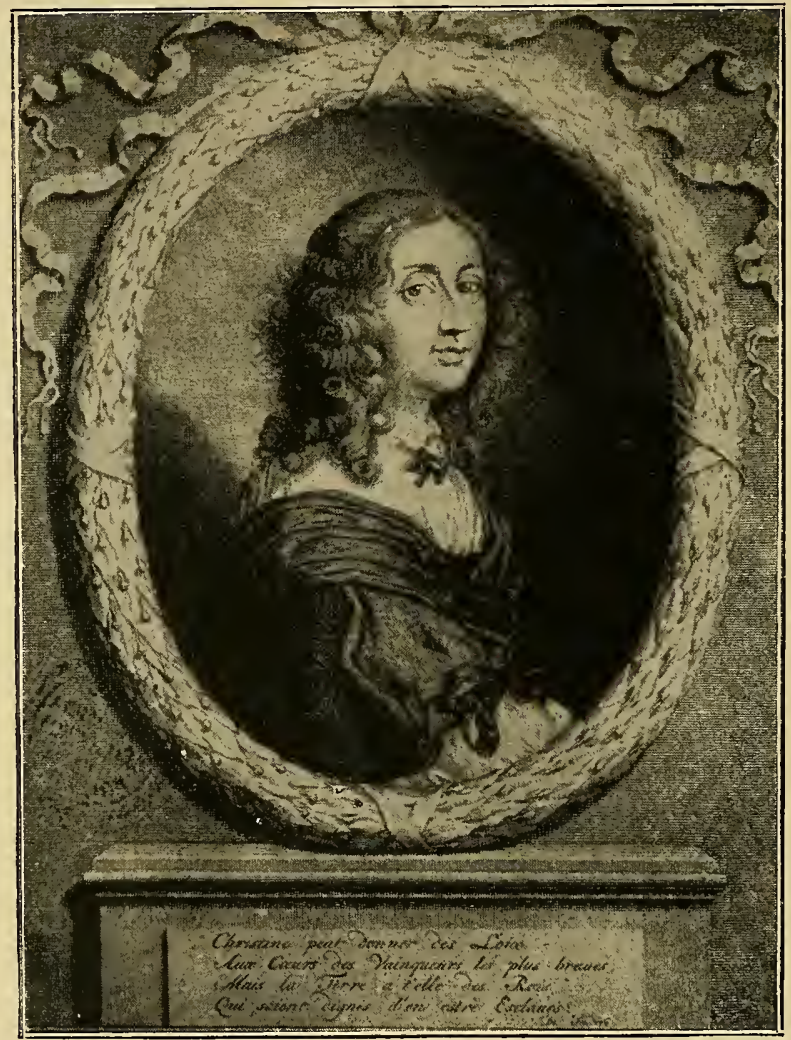

Ritratto di Cristina di Svezia.

zioni da lei preparate si tenevano oltre che nel palazzo Riario, anche in altri luoghi, nel teatro Tordinona, aperto nel 1671, in quelli del contestabile Colonna in piazza Scossacavalli, del Bernini nel suo palazzo al Corso, del Collegio Capranica. Tra i musici e i comici che formavano la corte della Regina c'erano anche tipi equivoci e famosi ribaldi, ma Cristina non se ne in- 


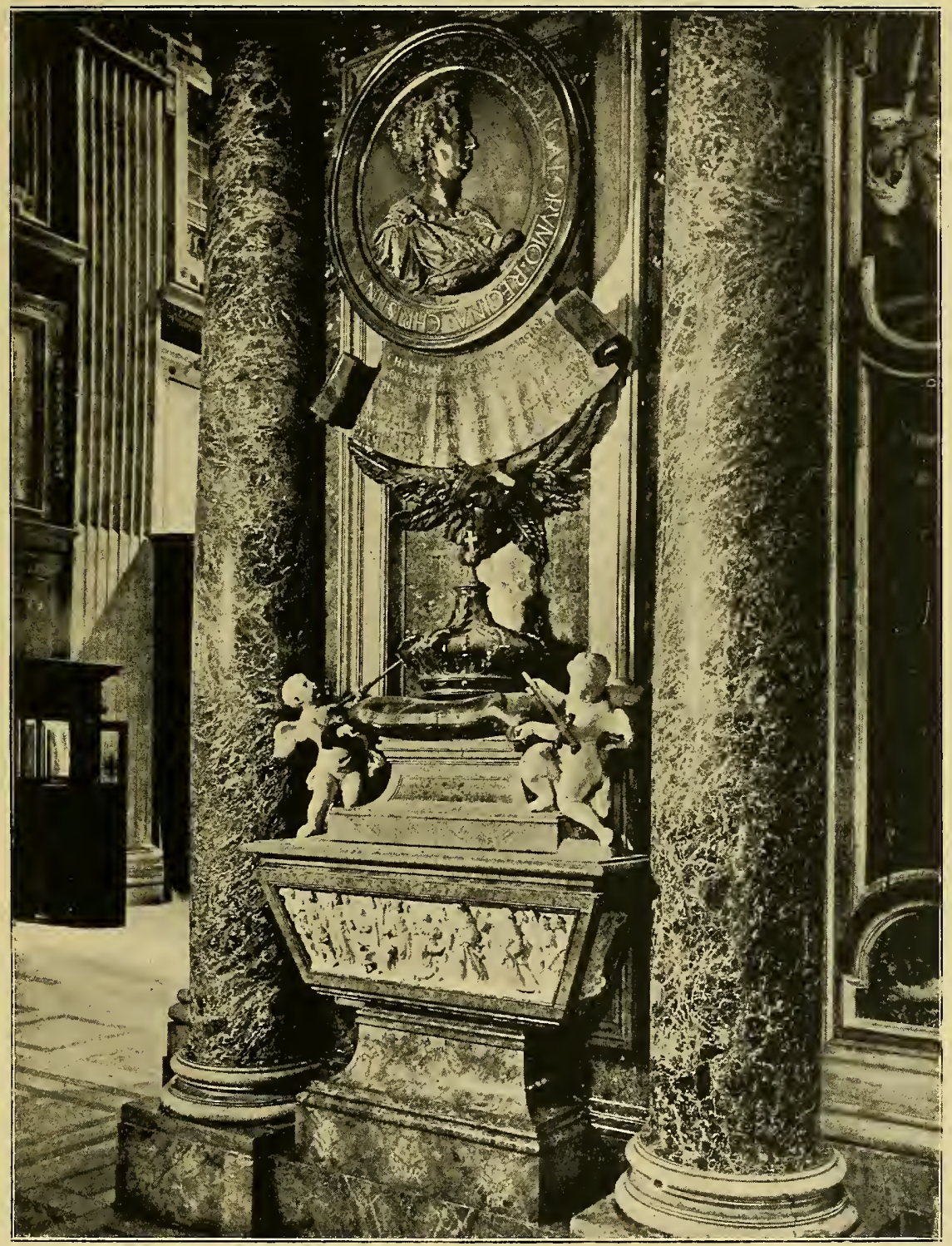

Sepolcro di Cristina di Svezia in S. Pietro, di C. Fontana.

(Fot. Alinari). 


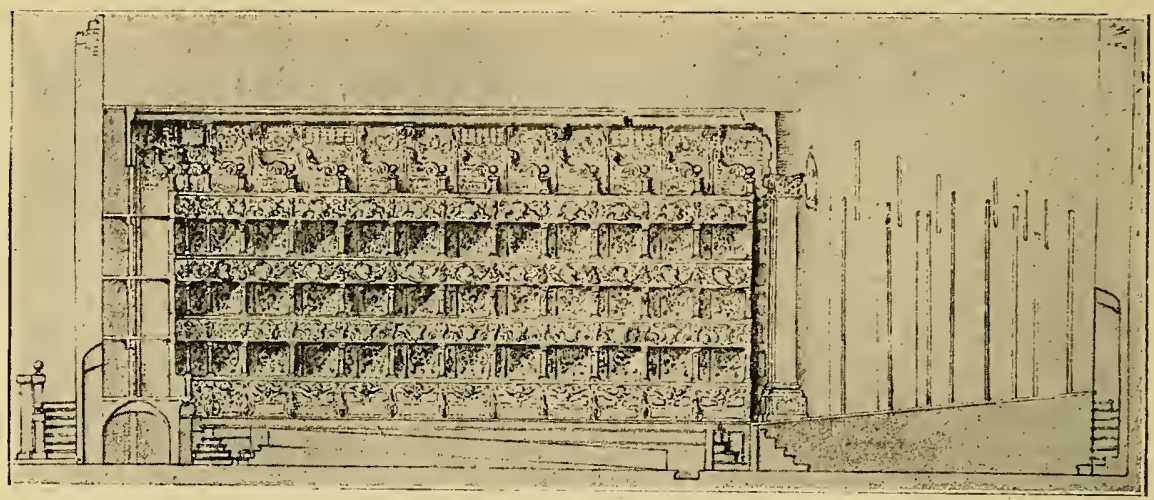

Un Teatro del Seicento, Disegno nella R. Biblioteca Chigiana.

quietava, e continuava la sua libera víta con scandalo di tuttí, stretta sempre in amicizia fedele col cardinale Azzolino, che però nei momenti di malumore apostrofava col títolo di marchigianaccio.

L'opera di Cristina di Svezia fu certo assai utile all'arte; oltre a dare impulso agli spettacoli raccoglieva quadri, statue, medaglie, teneva accademie poetiche in casa sua; mostrò grande predilezione pel Bernini che assistè al letto di morte, e dette poi incarico allo scrittore ed antiquario fiorentino Fílippo Baldinucci, di comporne la biografia, ch'è oggi un documento prezioso. Le commedie scritte dal Bernini non sono purtroppo pervenute fino a noi, come quelle di un altro artista poeta, Salvator Rosa; ce ne restano solo notizie in lettere e diarii del tempo, dai quali apprendiamo come il maestro si permetteva sulle scene una libertà di linguaggio e di critica che a chiunque altro sarebbe costata assai cara. $\mathrm{Ml}$ specialmente ammirate erano le commedie del Cavaliere per le macchine strepitose che egli inventava, facendo apparire cieli giranti, figurando incendii e inondazioni, prospettive e cortei maravigliosi.

Dí macchine postícce, di legno, tela e cartapesta, dipinte e dorate, il Bernini ne costrui pure per funerali, feste, processioni, 
girandole; di molte ci sono conservate stampe che le riproducono, come è ad esempio per il catafalco eretto nel 1669 per i funerali del Duca di Beaufort, ammiraglio del regno di Francia inviato da Luigi XIV contro i Turchi, dietro richiesta del papa,

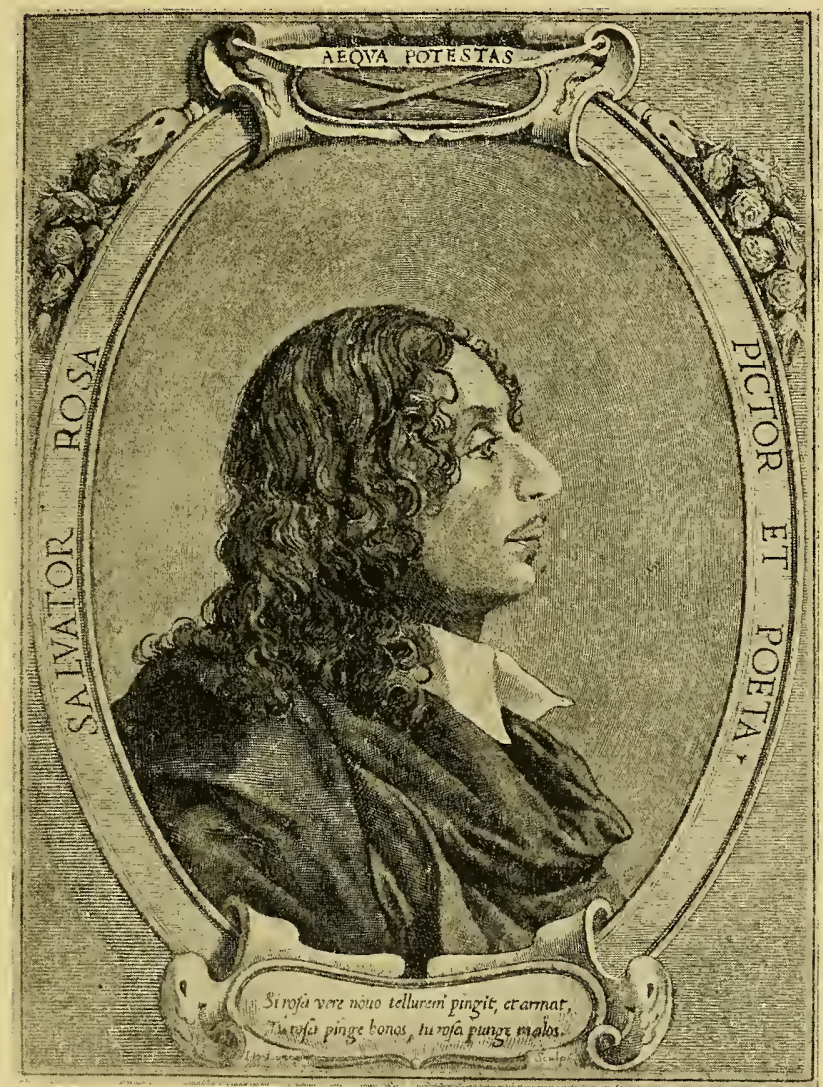

Ritratto di Salvator Rosa.

e morto in battaglia. L'enorme macchina, che costò diecimila scudi, aveva la forma di una piramide, sostenuta da scheletri alati su un trofeo di bandiere, di spade e di cannoni, tutta istoriata con le gesta del defunto, e sormontata dalla statua di lui. 
Le virtù satiriche del Bernini commediografo le ritroviamo assai bene nelle caricature ch'egli soleva fare in ogni occasione che gli si presentava, anche di personaggi potenti ed amici, come i cardinali Barberini e Chigi. Molte di esse ci sono con-

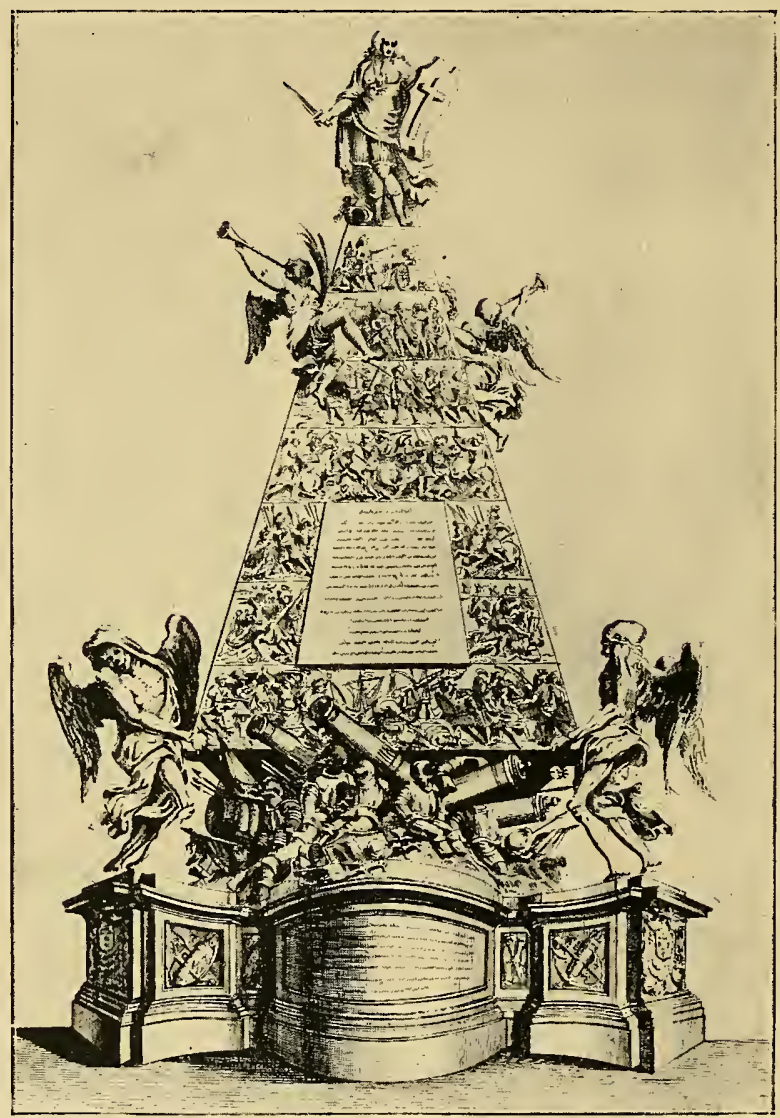

Bernini, Catafalco pei Funerali del Duca di Beaufort.

servate, e sono condotte con rapidità estrema di segno, a semplici contorni, che dovevano richiedere all'artista due o tre minuti appena, senza ritocchi, senza rifinimenti; raffigurano cardinali e prelati, cortigiani, popolani, cavalieri e suonatori, resi tutti con una prontezza di interpretazione che pochi caricaturisti 
ebbero mai. Ecco Don Virginio Orsini principe di Vicovaro, ecco Il capitano della compagnia de Romaneschi sassaioli nella guerra di Urbano VIII, tipo vivente di teppista borioso, che anche oggi si può incontrare tal quale in certi quartieri di

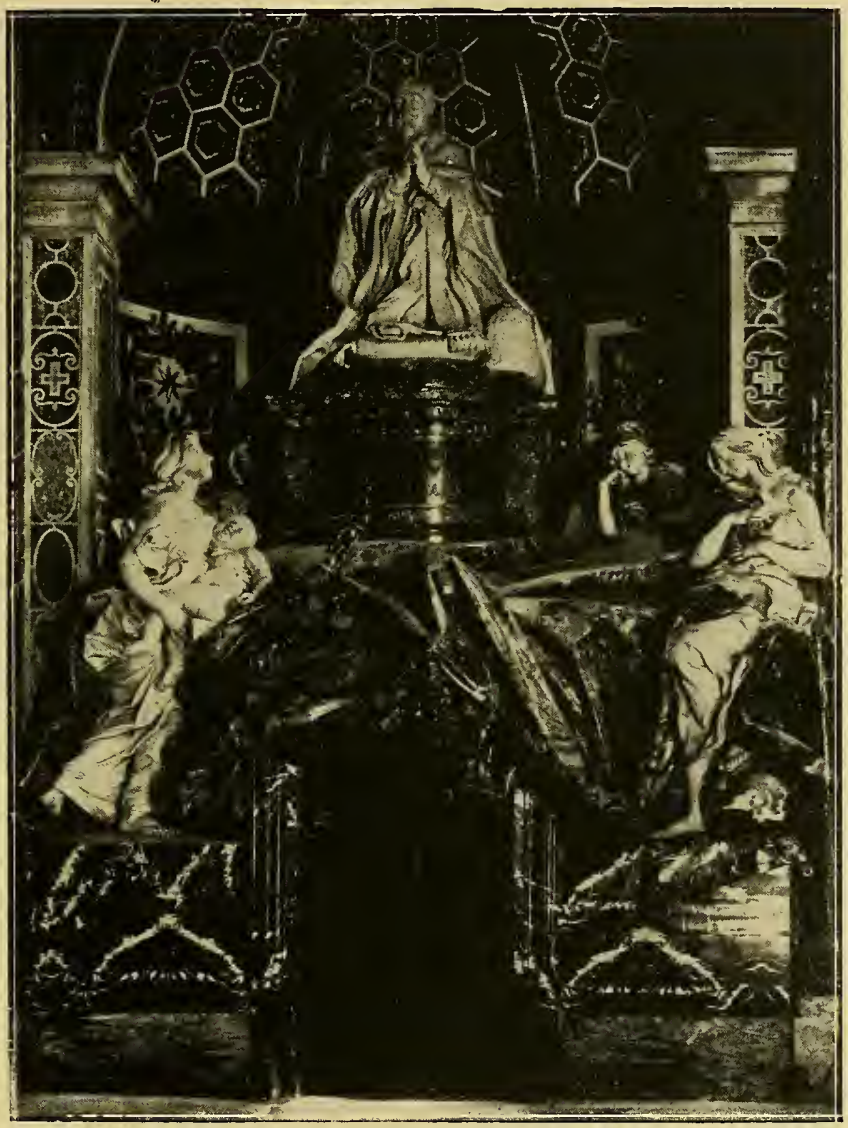

Bernini, Mausoleo di Alessandro VII, in S. Pietro.

Roma; ecco il cardinale Antonio Barberini, e il cardinale Chigi quando era giovane. "Effetto della franchezza del Bernini, dice il Baldinucci, è stato l'aver egli operato singolarmente in quella sorta di disegni che diciamo caricatura, o di colpi caricati, deformando per ischerzo a mal modo l'effige altrui, senza toglier 
loro la somiglianza e la maestà, se talvolta erano Principi grandi, come bene spesso accadeva, per lo gusto che avevano tali personaggi di sollazzarsi con lui in si fatti trattenimenti ».

II Bernini caricaturista lo cogliamo, per dir così, sul fatto, in un interessante documento del tempo, sul quale non è stata

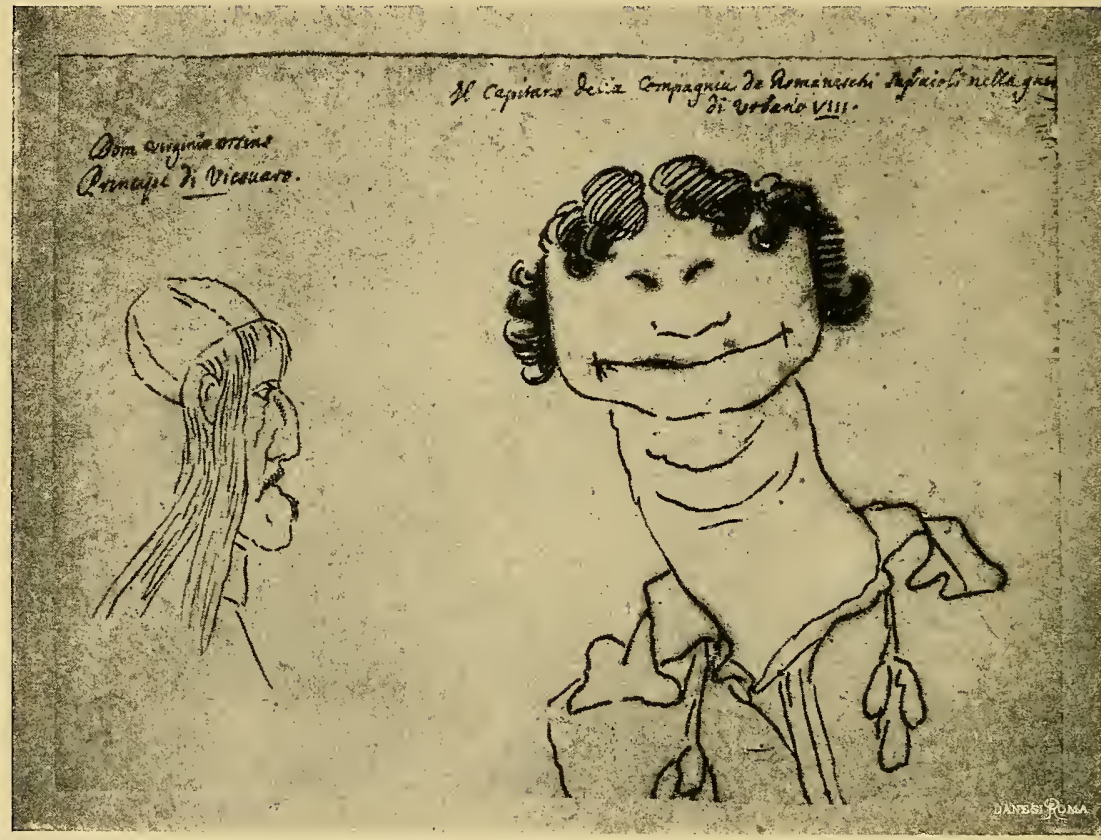

Caricature del Bernini, Gabinetto dei disegni a Palazzo Corsini.

mai finora richiamata l'attenzione, ed è una Satira, scritta da Paolo Giordano II Orsini, sesto duca di Bracciano. È pubblicata in un raro volume: Parallelo fra la città e la billa - Satire undici, che non porta il nome dell'autore, e fu stampato in Bracciano nel 1648. L'Orsini, figura tra le più caratteristiche del Seicento romano, fu uomo avventuroso; viaggiò da giovane per tutta l'Europa, e si spinse fino in Norvegia, dove stando a quanto egli stesso raccontava, gli fu offerta la corona reale, che rifítuto. Più tardi, mortogli il padre, tornò in Italia, e si 
dedicò agli studi e alla poesia; morendo lasciò molti drammi e poemi inediti. $\mathrm{Fu}$ celebre per la magnificenza delle feste e dei ricevimenti; una volta accolse nel suo castello di Bracciano il Gran Duca di Toscana; un'altra volta il papa Innocenzo X. E appunto nell'ottava satira del suo Parallelo, racconta l'arrivo di vari personaggi ad una villa : e tra molti signori romani, il

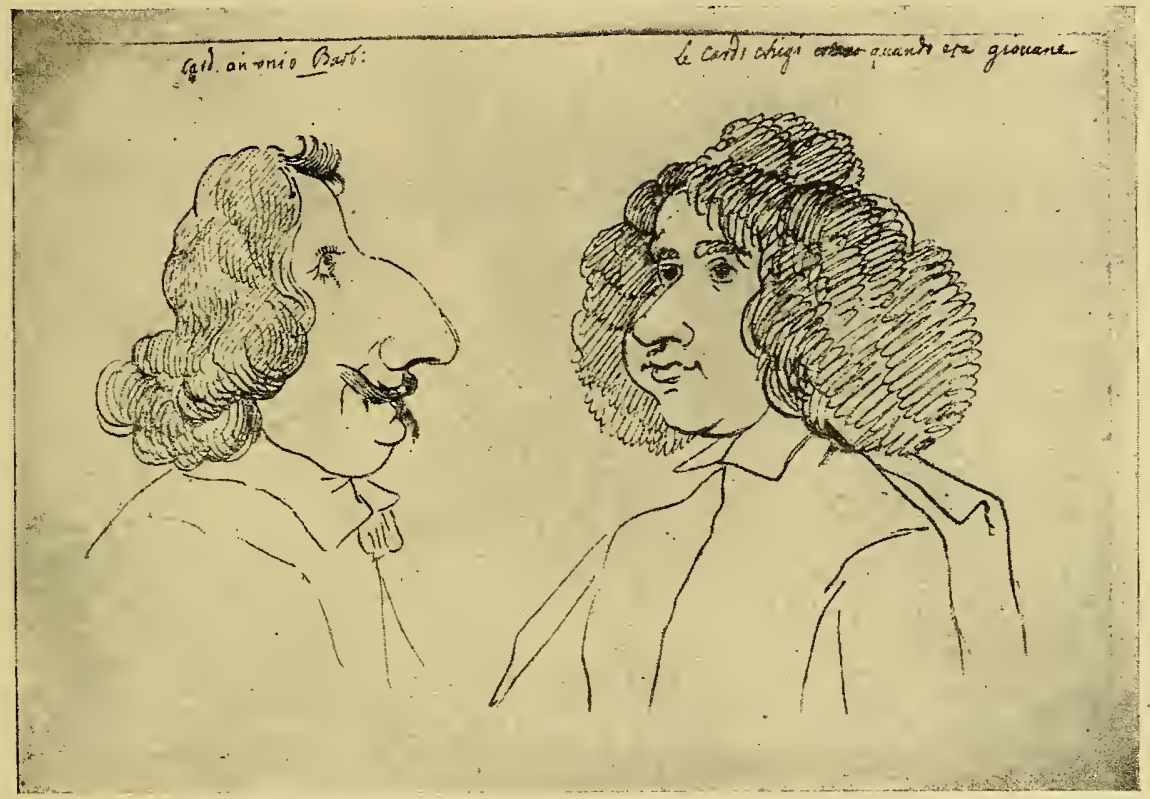

Caricature del Bernini, Gabinetto dei disegni a Palazzo Corsiní.

duca Sforza, il Mignanelli, il marchese Teodoli, un Capozucchi, un Borghese, un Capponi, un Grimaldi, "animator di marmi, evvi il Bernino". Mentre gli altri giuocavano a scacchi, a dama, a sbaraglino, a toccatiglio, a tricchetracche, il poeta e il Bernini, si misero a ritrarli in caricatura:

" Hor mentre battagliavano costoro, Bernino ed io sopra un buffetto a parte Presemo a caricare alcun di loro. 
Di quel che sia il caricar, de l'arte

Di farlo, adesso renderotti accorto:

Si ritragga un su cere, marmi, o carte;

S'egli have membro alcun mal fatto o torto,

O che da gli altri sia lontano, o presso

Più del dovere, o troppo lungo, o corto:

Quella sproporzion si cresce: e spesso,

Ben che venga più brutto assai, diresti

Somiglia più che 'I naturale stesso."

Anche durante il suo soggionno a Parigi il Bernini si divertiva a ritrarre in caricatura molti di coloro che andavano a trovarlo; ma cavallerescamente faceva eccezione per le dame.

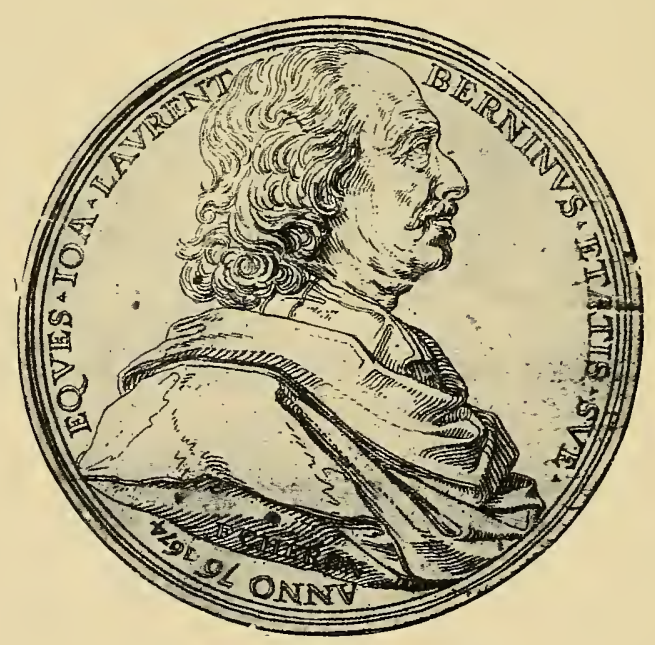




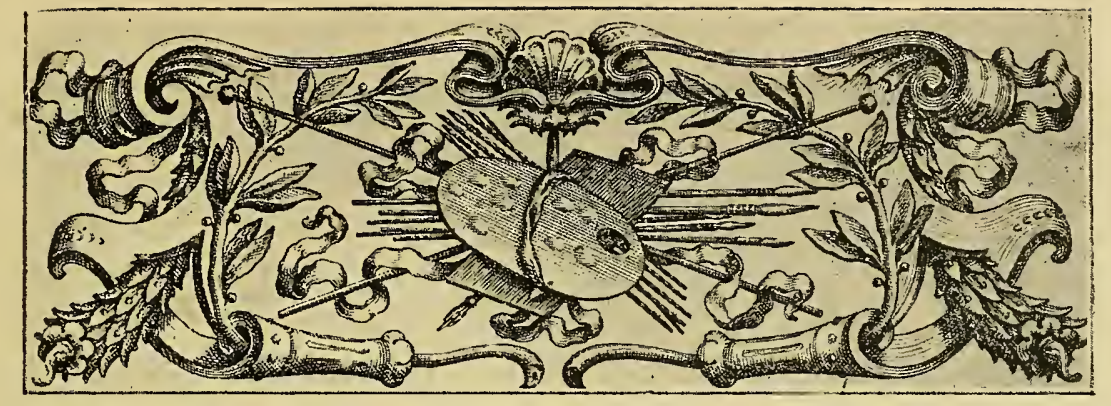

\section{CAPITOLO UNDECIMO}

\section{FRATEL POZZO}

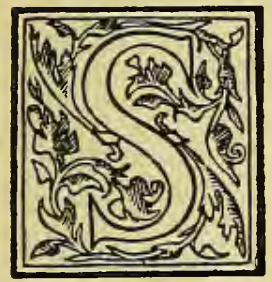

uccessore di Alessandro VII fu Clemente IX, Giulio Rospigliosi, il celebrato autore di commedie e di drammi sacri, amico del Bernini, che disegnava per lui fantastici scenari. Al maestro, già vecchio di sessantanove anni quando il nuovo papa sali al trono (1667), non mancarono quindi importanti commissioni, come non gli mancava lo spirito sempre vivo, e la lena infaticabile. L'opera principale compiuta dal Bernini al tempo di Clemente IX, è la decorazione del Ponte Sant'Angelo. Sui dieci pilastri del ponte, allora unico accesso alla Città Leonina e alla Basilica Vaticana, e quindi percorso dai devoti pellegrini di tutto il mondo che si recavano a pregare sulle tombe apostoliche, quasi inizio d'una nuova Via Sacra cristiana, il Bernini pensò di collocare dieci statue di angeli, portanti gli strumenti della Passione. Con ardore giovanile, mentre affidava ai suoi discepoli l'esecuzione di otto fígure, volle scolpirne due con le sue mani, quelle dell'angelo con la corona di spine e dell'altro col titolo della croce; ma quando le ebbe compiute il papa non volle che si esponessero alle intemperie, e le fece col- 


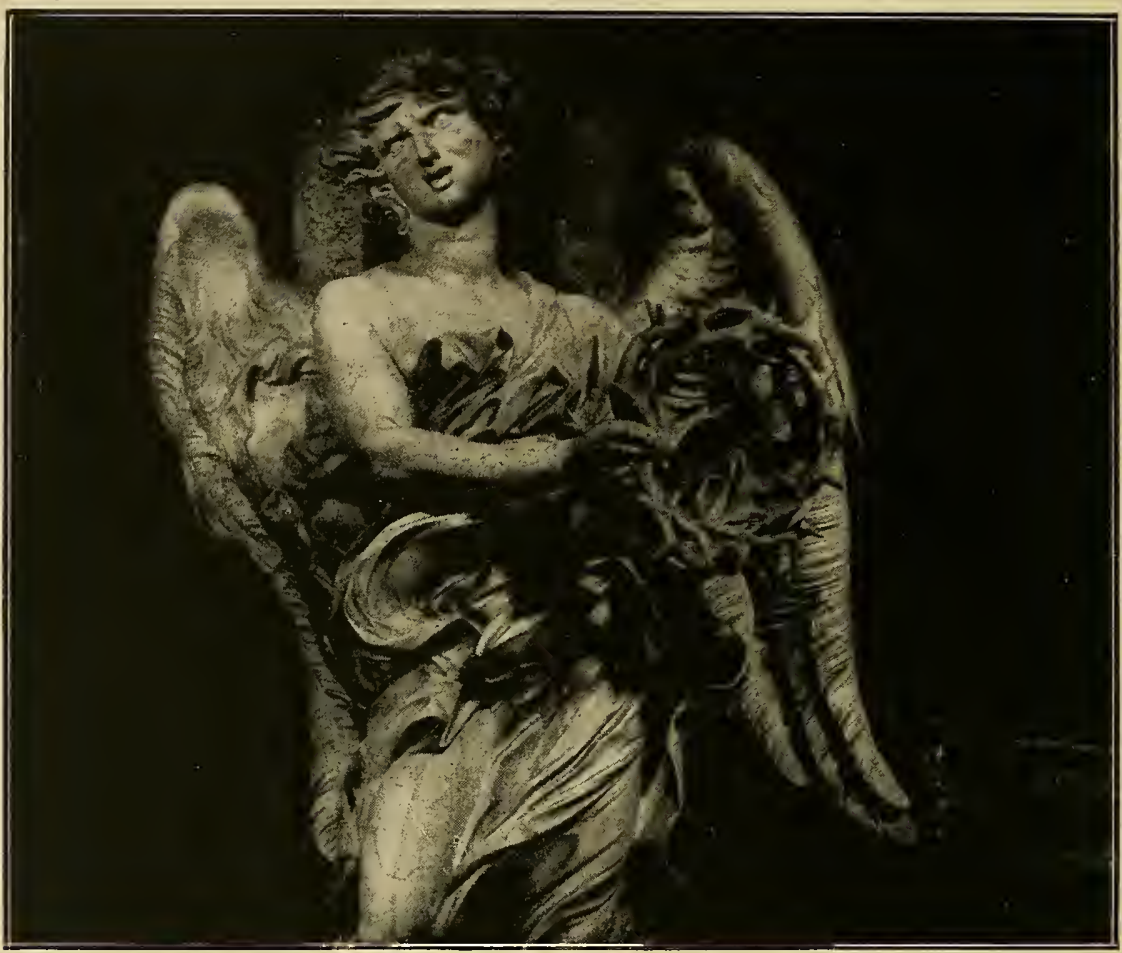

Bernini, Angelo con la corona di spine, in S. Andrea delle Fratte.

locare nella chiesa di S. Andrea delle Fratte, dove si vedono ancora, sostituendole sul ponte con due copie. Bernini mostra in esse un nuovo mutamento dell'arte sua, in cerca di raffinate eleganze, di ricercati effetti, di ondeggiamenti vaporosi, che fanno già pregustare le grazie del Settecento. Non c'è più il turbine violento, l'enfasi teatrale, l'appassionato abbandono, ma un atteggiarsi quasi pretenzioso, uno studio di delicati e piacevoli contrastí, una mollezza di linee musicalí: è un nuovo periodo che si inizia nella storia della scultura, precorrendo le eleganti dolcezze della scuola francese del secolo successivo. Gli angeli che si vedono sulla balaustrata del ponte sono opera dei migliori discepoli del Bernini, Ercole Ferrata, Antonio Raggi, Do- 
menico Guidi, Antonio Giorgetti, Lazzaro Morelli, Girolamo Lucenti, Cosimo Fancelli, Paolo Bernini, Giulio Cartari, Paolo

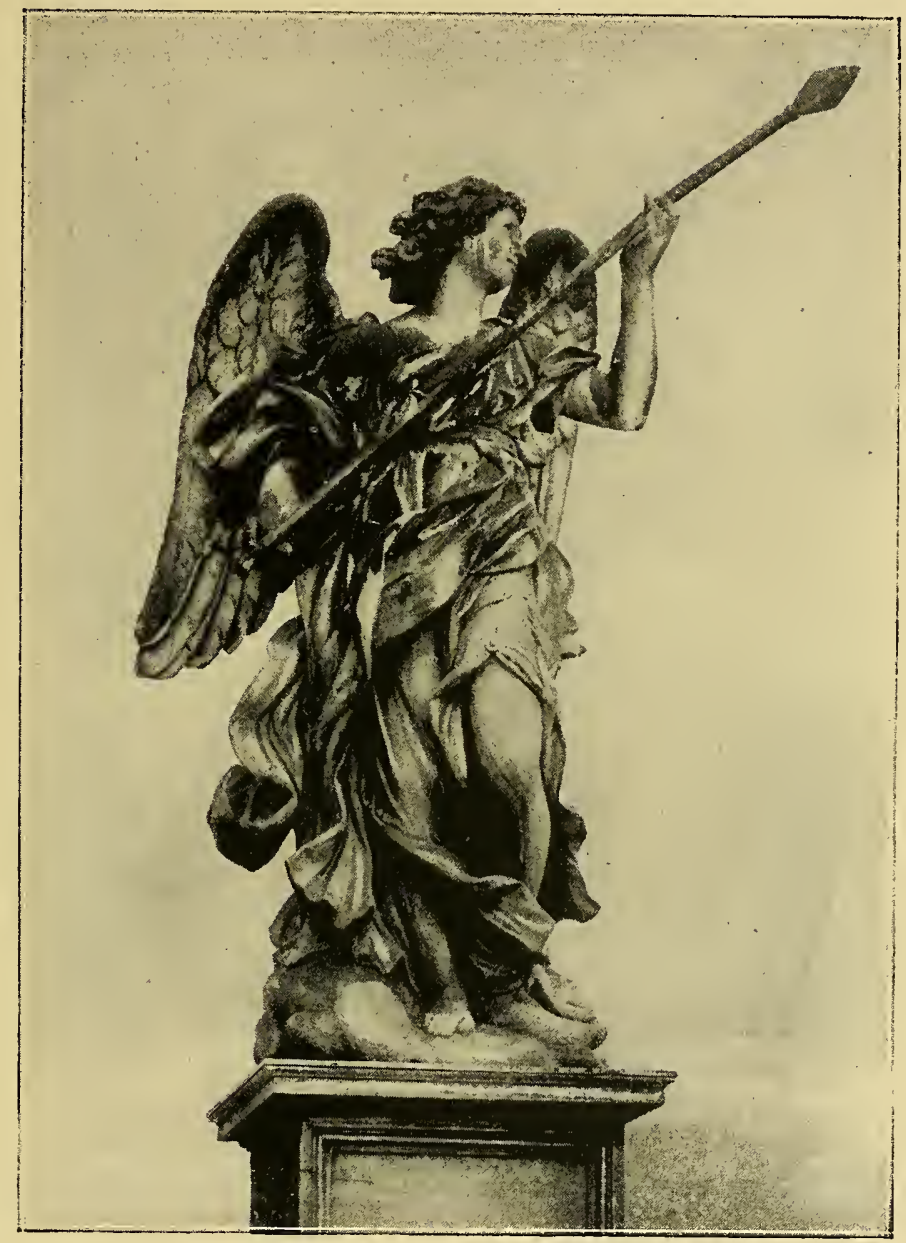

Domenico Guidi, Angelo con la lancia, sul Ponte Sant'Angelo.

(Fot. Alinari).

Naldini, i quali tutti, pur senza raggiungere la squisita raffinatezza del maestro, ne hanno bene interpretato il nuovo atteggiamento; e la patina che le statue hanno preso stando così all'aperto, e le forti chiazze scure di cui sono macchiate, 
contribuiscono a dare un effetto pittorico mai fino allora raggiunto.

Di poco posteriore è la decorazione della cappella Fonseca in S. Lorenzo in Lucina, in cui il Bernini adoperò il suo pre-

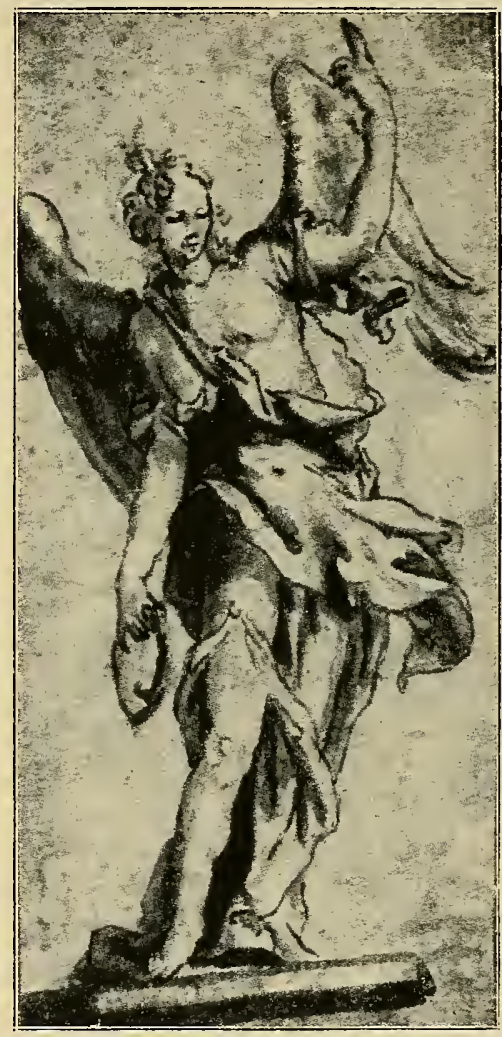

Un Angelo, disegno del sec. XVII.

Collezione di A. Munoz.

diletto marmo di cottanello; dei tre busti barocchi che vi si vedono è di mano del maestro solo quello di Gabriele Fonseca, medico di Innocenzo $X$, che un giorno, dopo averlo servito per otto anni, fu cacciato via di palazzo dal papa, divenuto negli ultimi tempi molto fastidioso. La mezza figura atteggiata in preghiera tiene nella destra il rosario e porta la sinistra al petto, 
con "un gesto di morbosa passione, quasi volesse, come dice bene il Fraschetti, scavarsi il cuore con le unghie.

Lo stesso fremito tormentoso agita le figure del sepolcro di Alessandro VII (1672-78), e la statua giacente della beata Ludovica Albertoni (1675), in S. Francesco a Ripa, rappresen-

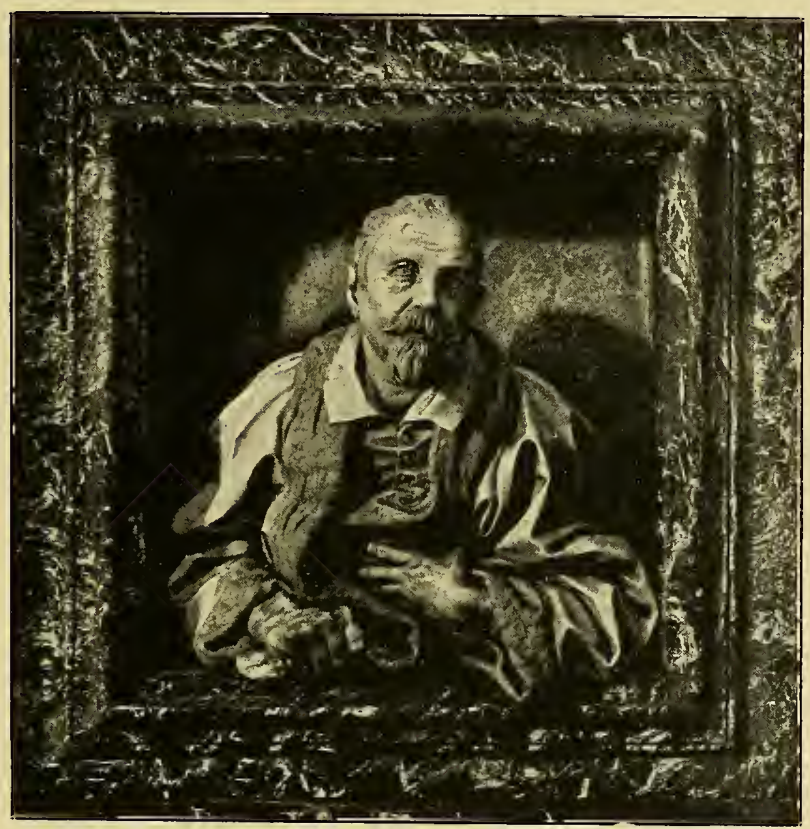

Bernini, Busto del Fonseca, in S. Lorenzo in Lucina.

tata sul letto di morte mentre si porta le mani al cuore, come sentendosi mancare, con uno spasimo più doloroso ancora di quello di S. Teresa.

Negli ultimi anni della sua vita il Bernini fu assalito da scrupoli religiosi; attraversò un periodo di mistícismo. Disegnò le illustrazioni per le prediche del suo amico Padre Oliva, generale dei Gesuiti; scolpì con mano tremante, a ottant'anni, un busto del Salvatore che donò alla regina Cristina, e imaginò una simbolica composizione, un Cristo crocifisso dalle cui piaghe 


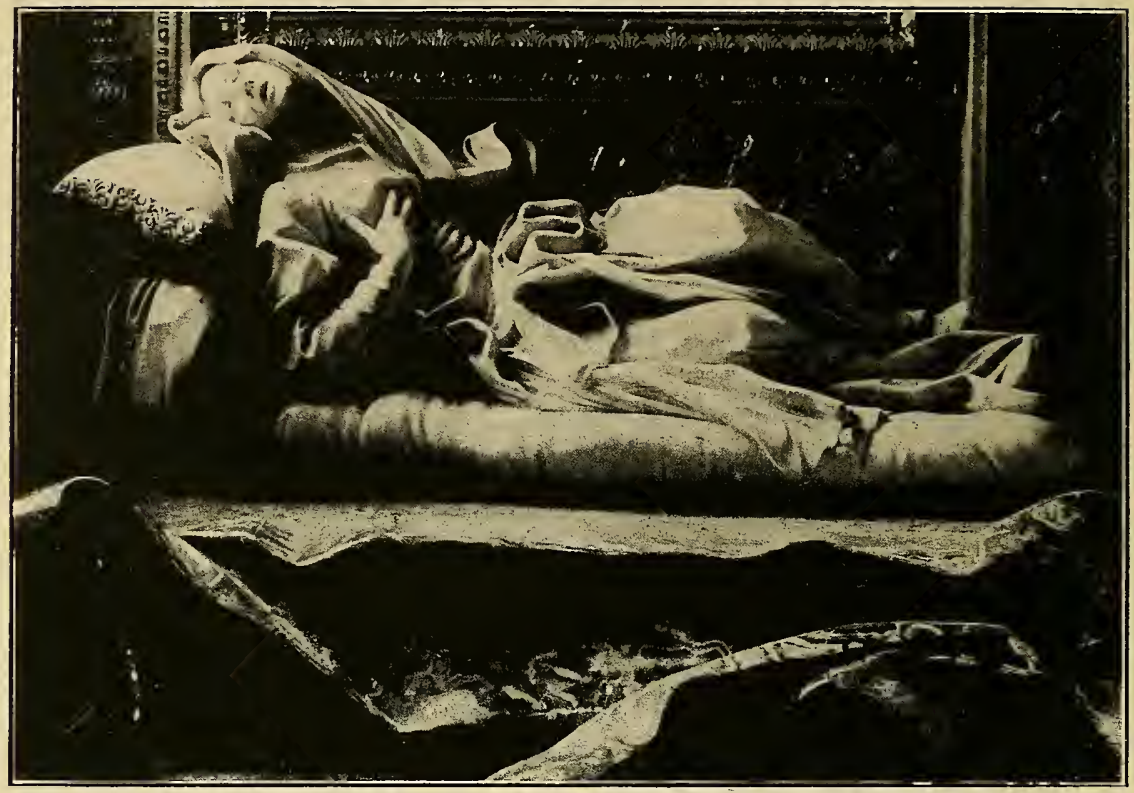

Bernini, La Beata Ludovica Albertoni, in S. Francesco a Ripa.

sgorga il sangue in tanta copia che forma un gran mare, per lavare così i peccati del mondo. Sentiva vicina la morte, e si preparava al gran passo tenendo discorsi religiosi col Padre Oliva, e col P. Marchese dei Filippini, suo nipote. Infermatosi gravemente "volle che a piedi del letto si alzasse come un altare, et in esso fece esporre il quadro rappresentante il Sangue di Gesù Christo.... Accortosi che non poteva più muovere il braccio destro per l'accidente di apoplessia, $E$ ben ragione, disse, che anche avanti la morte riposi alquanto quella mano che in vita ha tanto laborato. Al cardinale Azzolini, che volle piu volte honorarlo della sua presenza in que' giorni, disse una sera che pregasse in suo nome la Maestà della Regina a far un atto di amor di Dio per lui, perchè ei credeva che quella gran Signora havesse un linguaggio particolare con il Signore Dio per essere bene intesa, mentre Iddio haveva con lei usato un linguaggio che essa sola era stata capace d'intenderlo". Final- 
mente "nell'entrare nel ventottesimo giorno di Novembre dell'anno 1680, e ottantesimo secondo di sua vita, spirò: e morì da quel grand'huomo ch'ei visse, lasciando in dubbio, se più

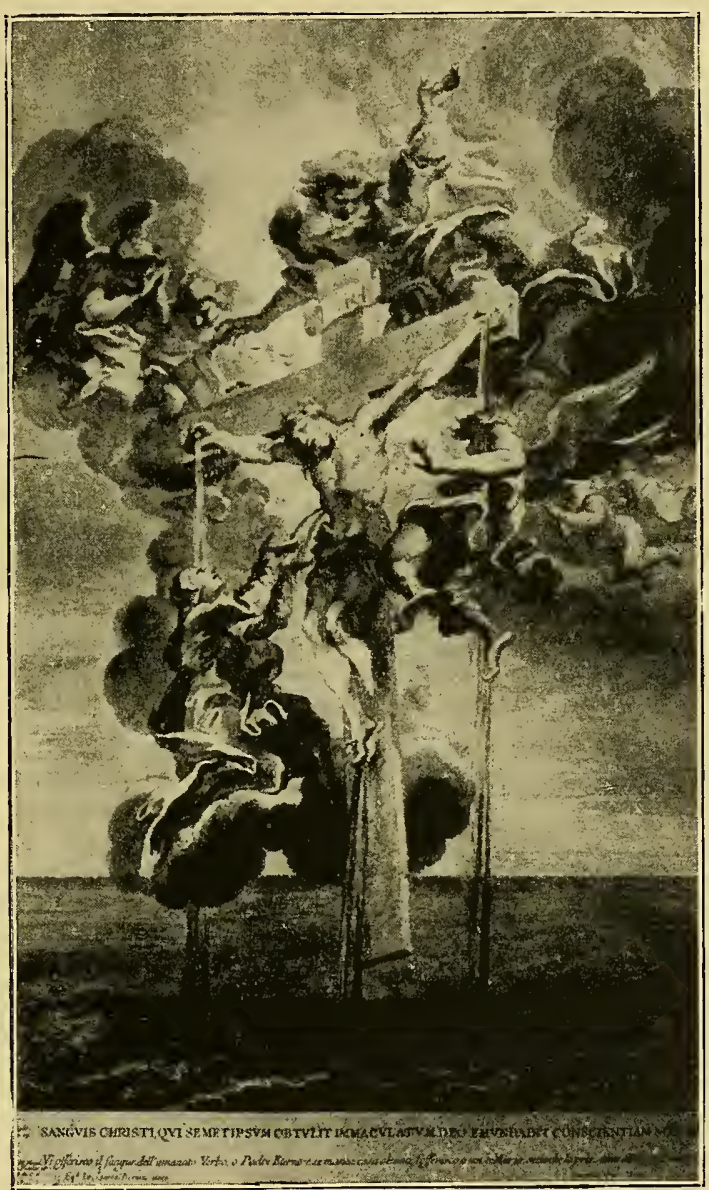

Bernini, "Il Crocifisso che fa un mare di sangue ," Collezione di A. Munoz.

ammirabile nelle operazioni fosse stata la sua vita, o commendabile nella divozione la sua morte".

La regina Cristina avendo sentito dire che il Cavaliere aveva lasciato in tutto circa quattrocentomila scudi, rispose: "Io 
mi vergognerei, s'egli havesse serbito me, $e$ abesse lasciato cosi poco". Poco dopo la bizzarra donna dette incarico allo scrittore toscano Filippo Baldinucci di comporre quella Vita del maestro che è ancor oggi per noi una fonte preziosa di notizie

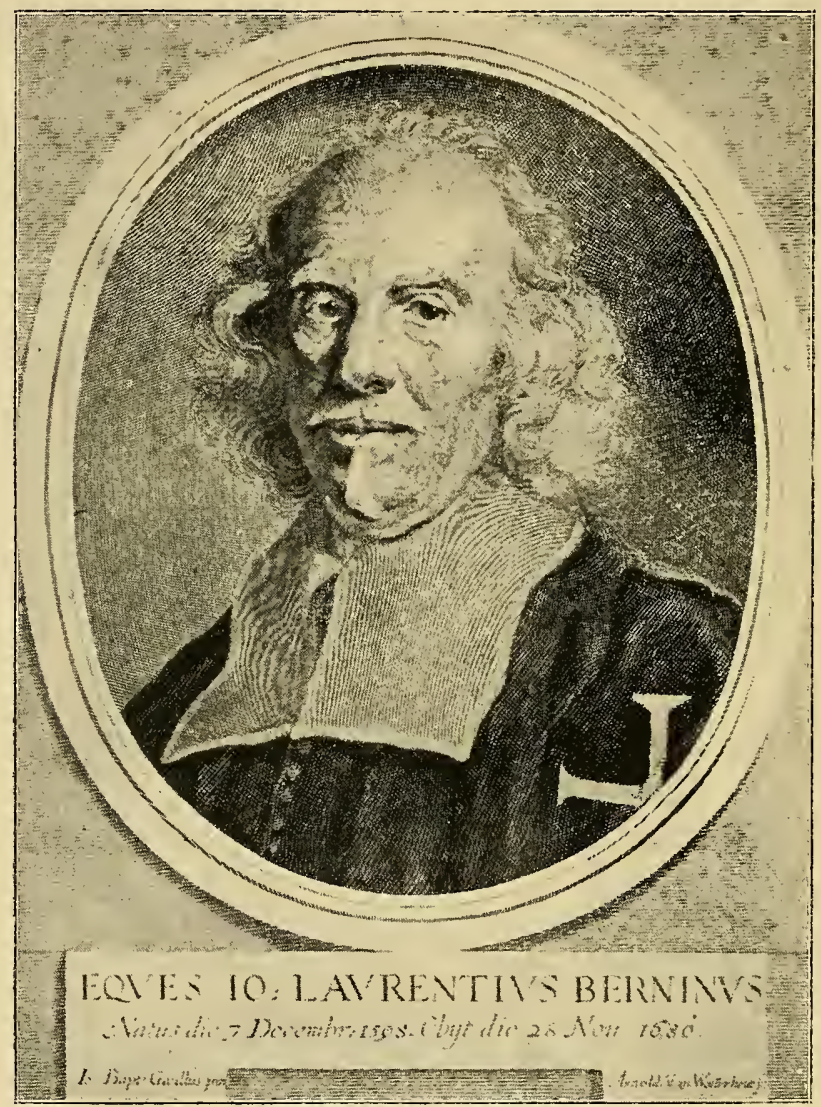

Ritratto del Bernini. Incisione dal Baciccio.

intorno alla sua vasta opera. Nell'altra Vita che più tardi compose il suo fíglio Domenico Bernino, leggiamo questo ritratto del sommo artista: " $F u$ il Cavaliere Bernino di giusta statura, carni alquanto brune, pelo nero, che incanutì nell'età più vecchia, occhio pur nero e di cosi forte guardatura, che collo 
sguardo solo atterriva; ciglia lunghe, e di lunghi peli composte, ampia fronte e maestosa, e dita tonde nell'estremità, come dalla natura formate in attitudine della professione. Fu parco di vitto, usando solo una sorte di vivanda nella sua mensa, ma avido di frutti, il cui appetito egli diceva essere proprietà annessa di chi nasce in Napoli: Sano di corpo se non quando patì di micranica fin all'anno quarantesimo di sua età: Alquanto aspro di natura anche nelle cose ben fatte, fisso nelle operazioni, ardente

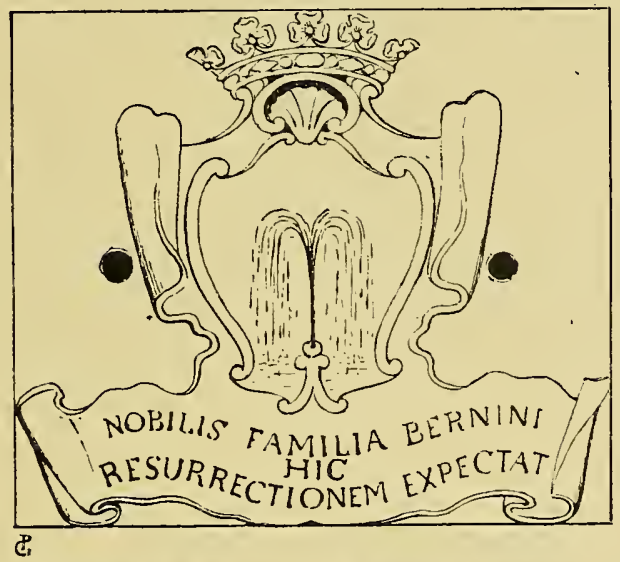

Tomba del Bernini, in S. Maria Maggiore.

nell'ira, alla cui vehemenza che soleva più degli altri infiammarlo, egli applicava, l'haverlo fatto ancora piì degli altri operare, e finalmente con un composto tale di Corpo, Costumi, Complessione, e Naturalezza, quale si conveniva per formare un Homo d'Idee grandi, e di Operazioni ".

Morto il Bernini rimaneva in Roma un gruppo di valenti scultori, quasi tutti suoi discepoli, che possedevano le qualità piùs esteriori del maestro, la bravura tecnica, la prontezza dell'esecuzione, la facoltà dell' improvvisazione, ed erano insomma in grado di continuarne la maniera ma non lo spirito. Non c'era tra loro chi avesse una personalità propria, chi si distinguesse per caratteristiche speciali; tutti, come materia molle, si erano 


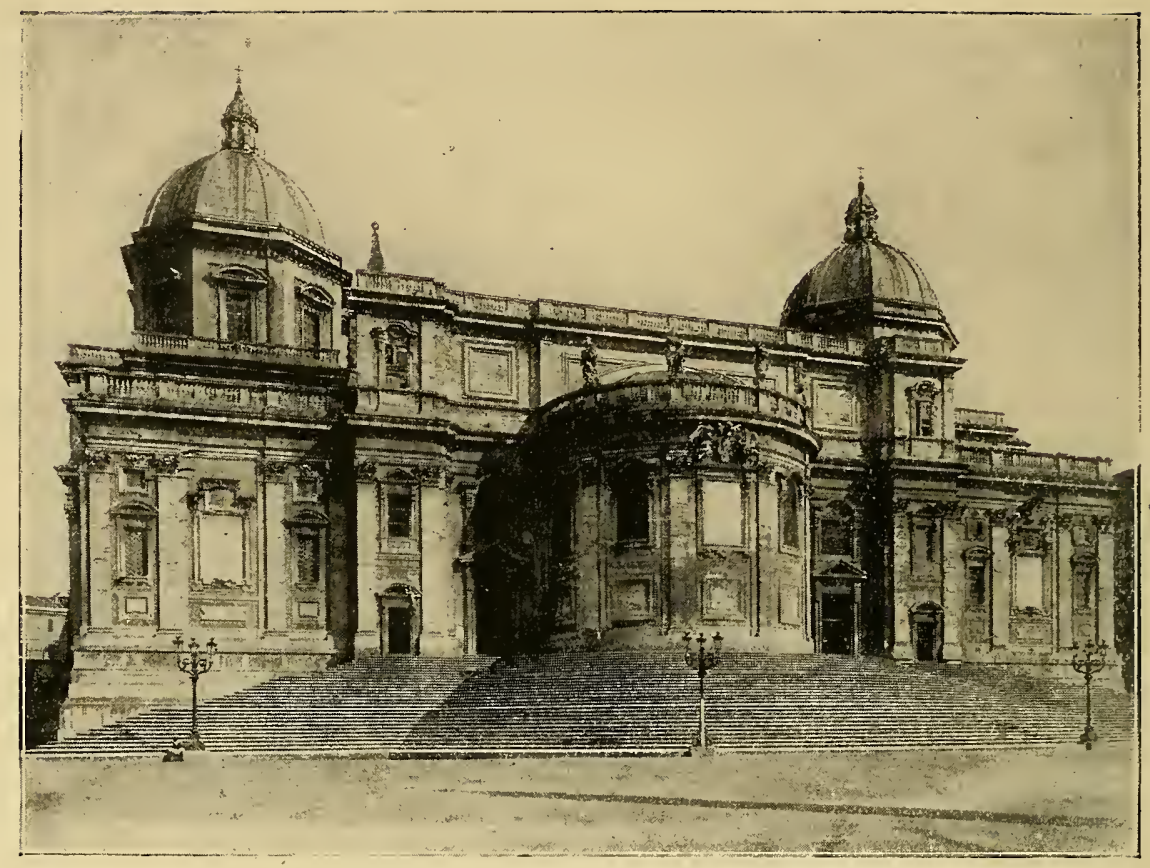

Carlo Rainaldi, Abside di S. Maria Maggiore.

lasciati plasmare dal terribile dominatore, dal tirannico padrone, che non lasciava libertà di atteggiamenti, e soffocava quasi le caratteristiche personali dei suoi discepoli.

Alla morte del Berníni il suo stile, che dominava in Roma, comincia rapidamente a snaturarsi; più tardi venuti a mancare quelli tra i suoi discepoli che più si erano avvicinati a lui, il cattivo gusto trionfa: l'esagerazione dell'enfasi, l'abuso della policromia, la teatralità delle pose, la pesantezza dei panneggi, la trascuratezza dell'esecuzione, trascinarono rapidamente in basso quella scuola romana alla quale guardava con ammirazione tutto il mondo.

Nell'architettura c'è invece ancora un periodo fiorente e vitale; artisti come Carlo Rainaldi continuano le forme composte del primo Seicento; altri come Mattia de Rossi e il fe- 
condo Carlo Fontana accoppiano la robustezza berniniana alle ardite innovazioni di Borromini; altri come Antonio Gherardi si ispirano all'arte personalissima di Pietro da Cortona.

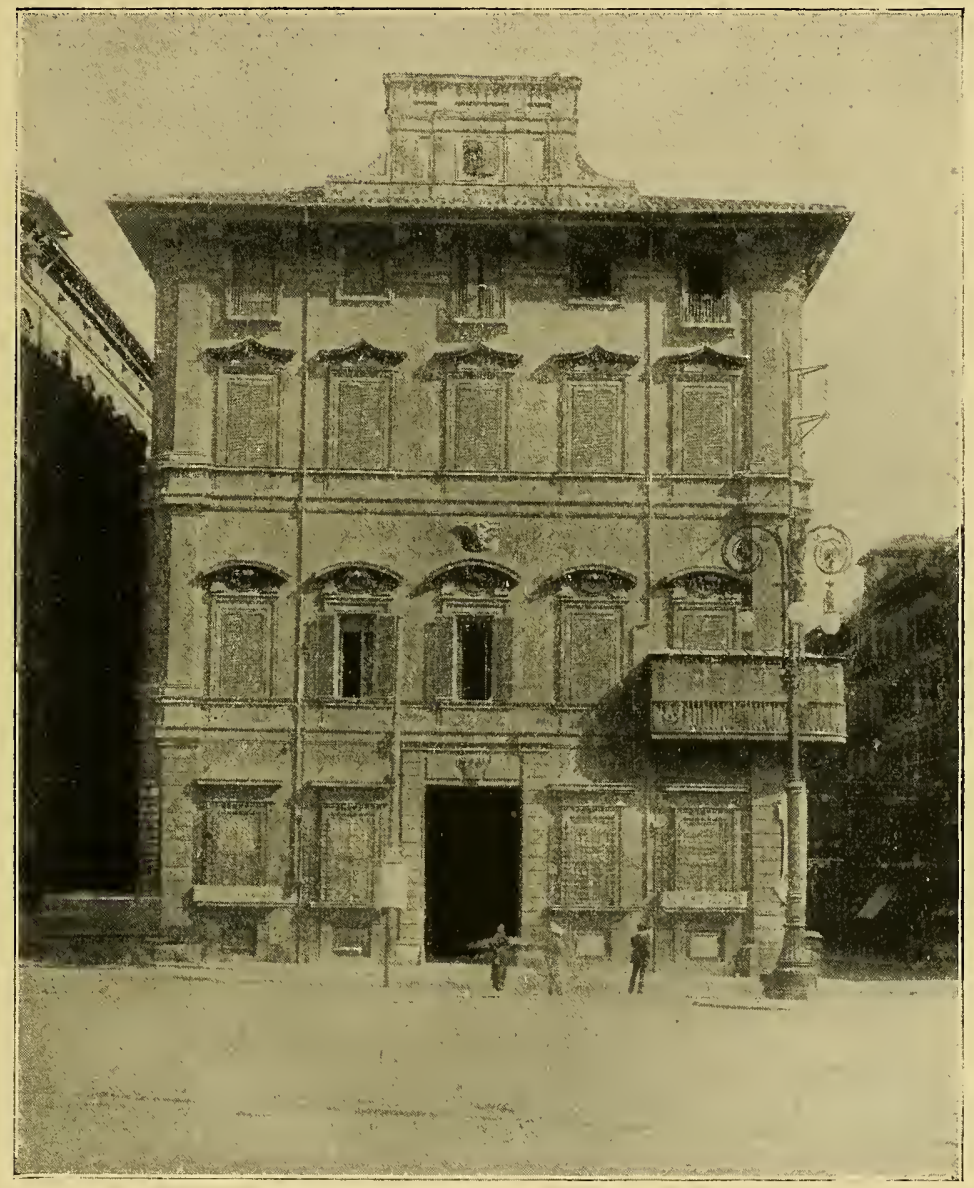

Mattia de Rossí, Palazzo d'Aste, ora Misciattelli.

(Foi. Moscioni).

Su tutti si eleva un maestro di genio, creatore di una nuova fase dell'architettura seicentesca, che per analogia col gotico potrebbe chiamarsi del barocco fiammeggiante, Andrea Pozzo, conosciuto sotto il nome di Padre Pozzo, mentre dovrebbe chia- 
marsi soltanto fratello, essendo semplice coadiutore della Compagnia di Gesù. Era nato a Trento nel 1642, e poichè certi accenti dell'arte sua trovarono imitatori nella Germania cattolica, un critico alemanno pensò bene di esporre l'ipotesi che si trattasse di un tedesco di nome Brunner, che poi vivendo a Roma, si era tradotto in Pozzo. Ipotesi accolta subito come un

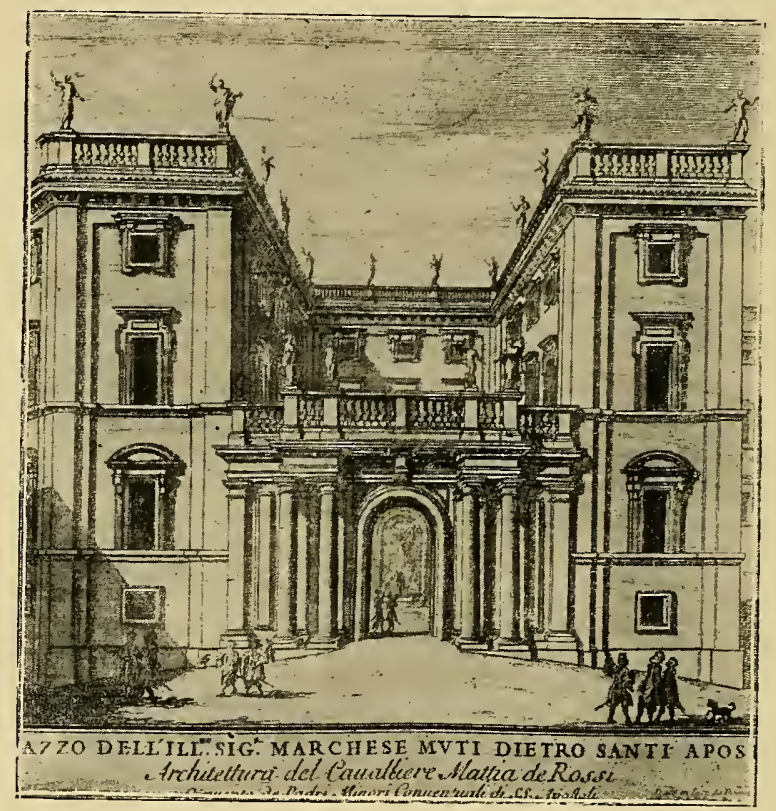

Mattia de Rossi, Palazzo Muti, alla Pilotta.

fatto accertato da molti altri scrittori tedeschi, che continuano ad affermarlo nei manuali correnti. Non si può imaginare invece un maestro più italiano di fratel Pozzo: come pittore è un veneto puro, che precorre Tiepolo, il quale certamente conobbe le sue opere, e ne risentì l'influsso; come architetto si ispira a Borromini, aggiungendo però alle forme del lombardo, uno smagliante colorito veneziano. La tradizione vuole che egli, venuto a Roma ed entrato nella Compagnia di Gesù, fosse occupato ad umili mansioni, in cucina, e che alcuni cavalieri 
tedeschi avendo riconosciuto il suo talento nel disegno, persuadessero i Padri ad avviarlo alla pittura. Ma ciò non può esser

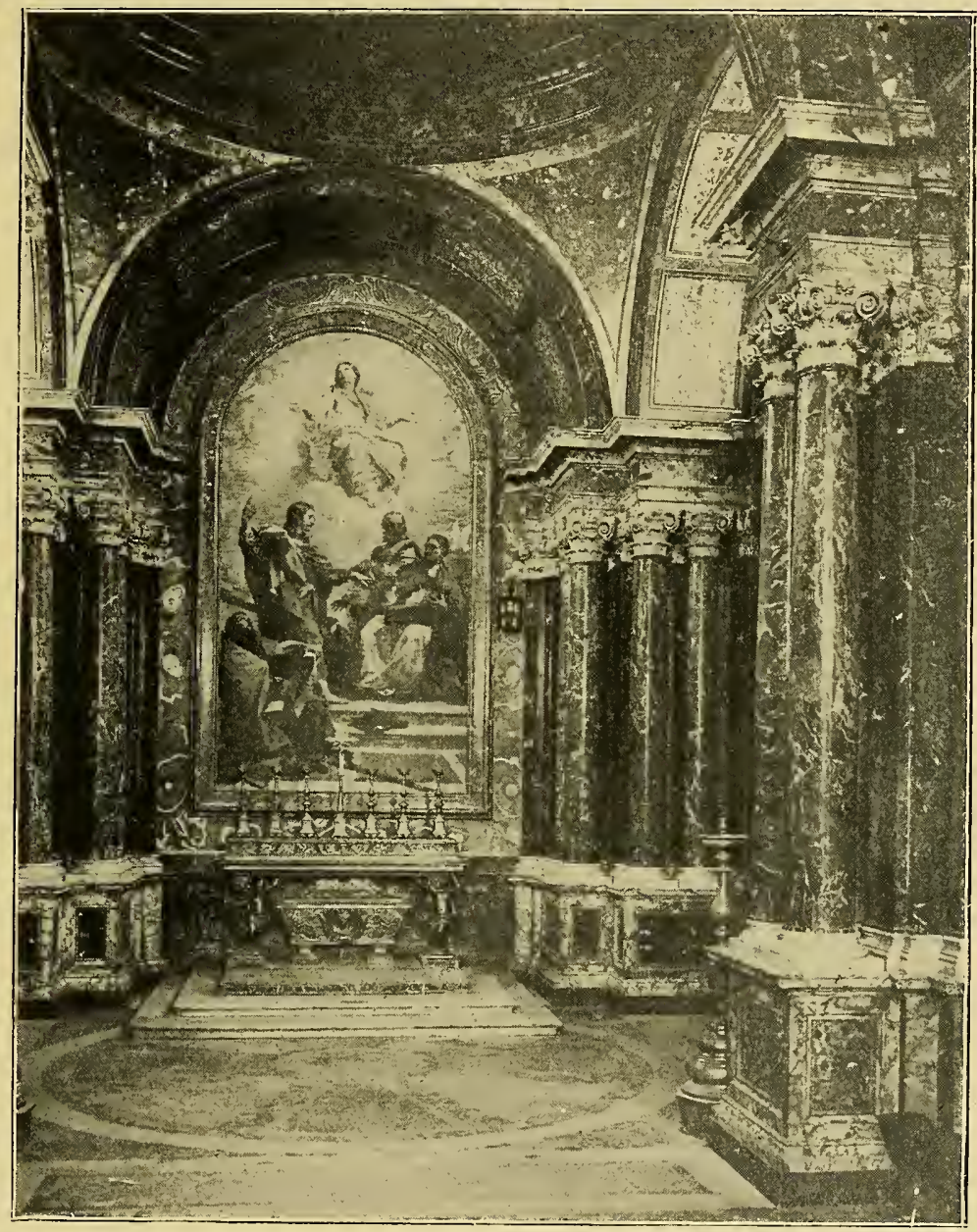

Carlo Fontana, Cappella Cibo, in S. Maria del Popolo.

vero, perchè Andrea Pozzo, fin dalle prime opere eseguite in Roma, mostra un carattere così schiettamente veneziano, che bisogna ritenere che già in patria avesse compiuta la sua educazione e formata la sua personalità artistica. A Roma ha la- 
sciato l'impronta sua maggiore nella decorazione della chiesa di S. Ignazio, ove dipinse la vôlta della nave centrale e l'abside, e costrui gli altari di S. Luigi e dell'Annunziata.

Il concetto ispiratore del grande affresco prospettico della vôlta gli fu suggerito, com'egli stesso ebbe a scrivere in una lettera del 1694 al principe di Liechtenstein, dalle sacre parole

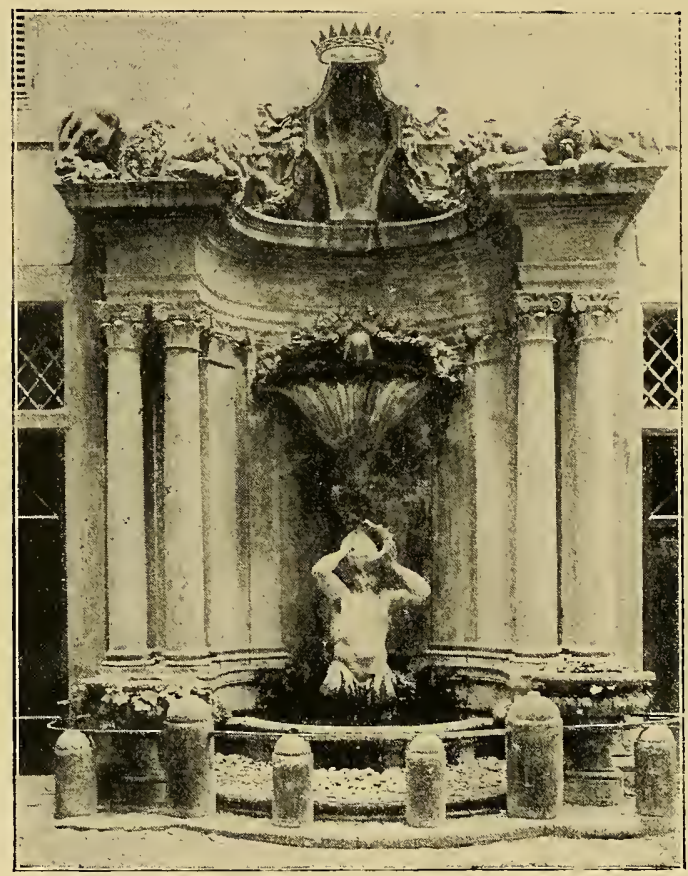

Carlo Fontana, Fontana nel Palazzo Massimi all'Aracoli.

Ignem veni mittere in terram, et quid bolo nisi ut accendatur, adattate al santo fondatore della Compagnia di Gesì, " essendo egli stato zelantíssimo di propagar la religione cattolica e la luce dell'evangelo per tutto il mondo ". Vi fígurò "Gesù il quale comunica un raggio di luce al cuor d'Ignazio, che poi vien da esso trasmesso ai seni più riposti delle quattro parti del Mondo da me figurate coi suoi geroglifici nelle quattro 
imposte della vôlta. Queste investite di un tanto lume stanno in atto di rigettare da se $i$ deformissimi mostri o d'idolatria, o di eresia, o di altri vizi che prima le dominavano, godendo di que' ceppi e di quelle catene, di cui li mirano avvinti". Si vedono poí i missionarii dell'Ordine: "Il primo di questi indefessi operai è l'apostolo delle Indie S. Francesco Saverio, che mi-

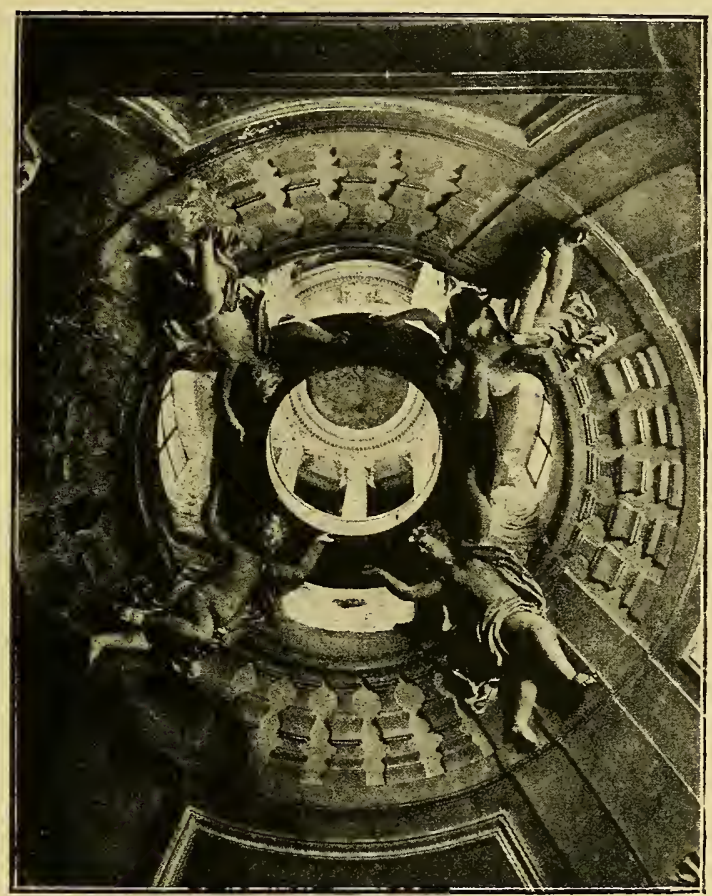

A. Gherardi, Cupola della Cappella Avila, in S. Maria in Trastevere.

rasi dall'Asia guidare al cielo un grande stuolo di convertiti. L'istesso si esprime fatto da altri della Compagnia di Gesì nell'Europa, nell'Africa e nell'America... Il corpo poi che racchiude in sè tante varie figure si ̀̀ un'artificiosa architettura in prospettiva che serve di campo a tutta l'opera. Essendo questa stata da me dipinta secondo le regole di tal'arte, nel mezzo del tempio più che in altro lato si mira più vagamente. L'idea di una 


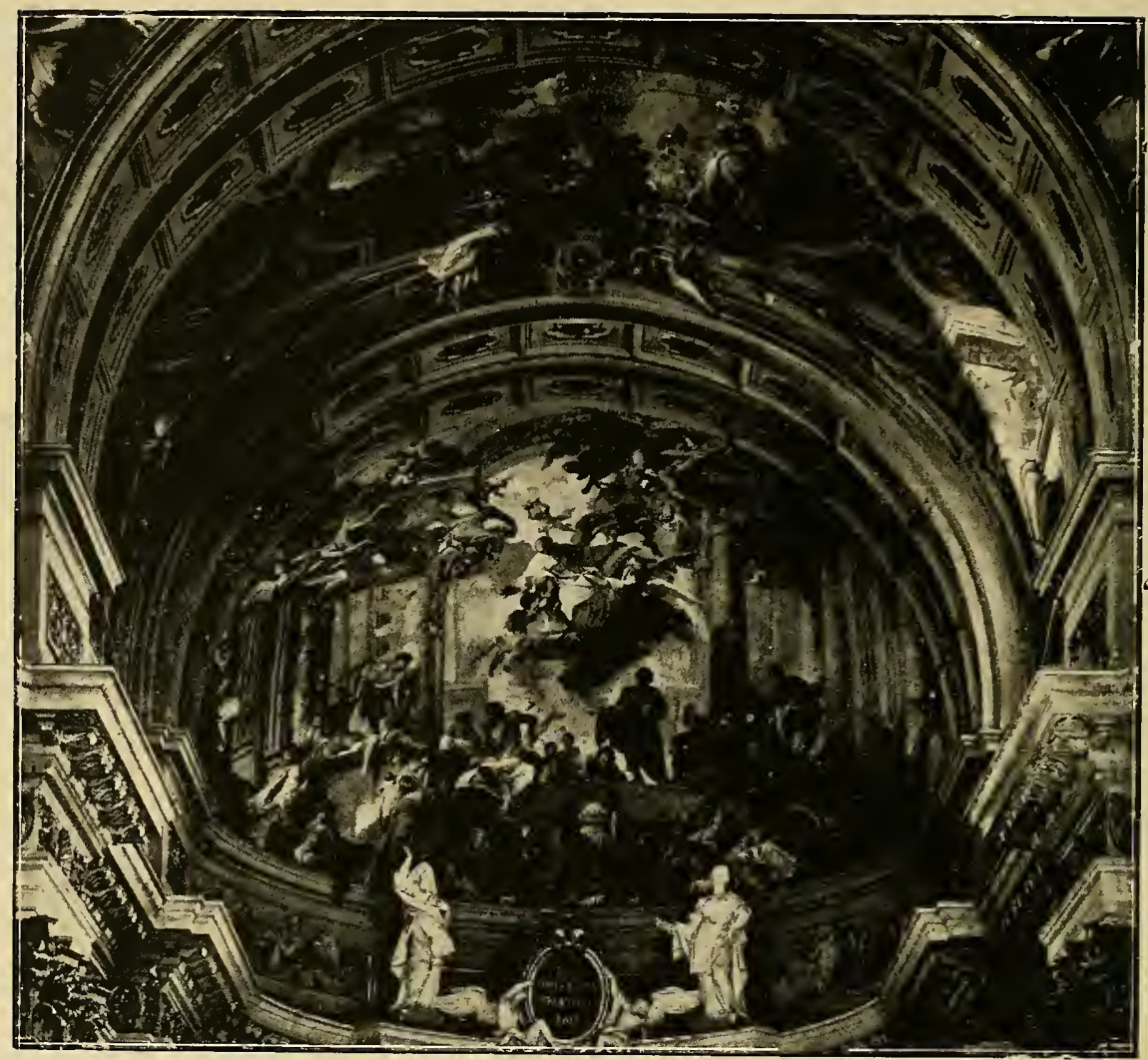

Affresco di Andrea Pozzo, nell'Abside di S. Ignazio.

(Fot. Alinari).

tal prospettiva viene espressa in gran parte nel mio libro di Architettura e Prospettiva ".

Per questo trattato che porta il titolo di Prospettiva de' pittori e architetti, pubblicato nel 1693, e che ebbe più di sette edizioni in italiano, in latino, in tedesco, fratel Pozzo (Andreas Puteus) è quasi più celebre che per le sue opere artistiche. Il Milizia ne dà naturalmente un giudizio assai severo: "Si scartabellino un poco que' due grossi volumi, dati magnificamente alle stampe da esso Padre Pozzo, e si rimarrà stupefatti come costui abbia potuto si follemente vaneggiare. Piedestalli sopra piedestalli, co- 
lonne sopra mensole, ondulazioni continue, frontespizi infranti, risalti, figure irregolari, e quel che è più mostruoso colonne sedenti, cioè storte, a guisa d'un serpe, che si vuol erger ritto in aria. In questa sua opera si veggon due disegni per la facciata di S. Giovanni Laterano: uno è di pilastri corintj ripie-

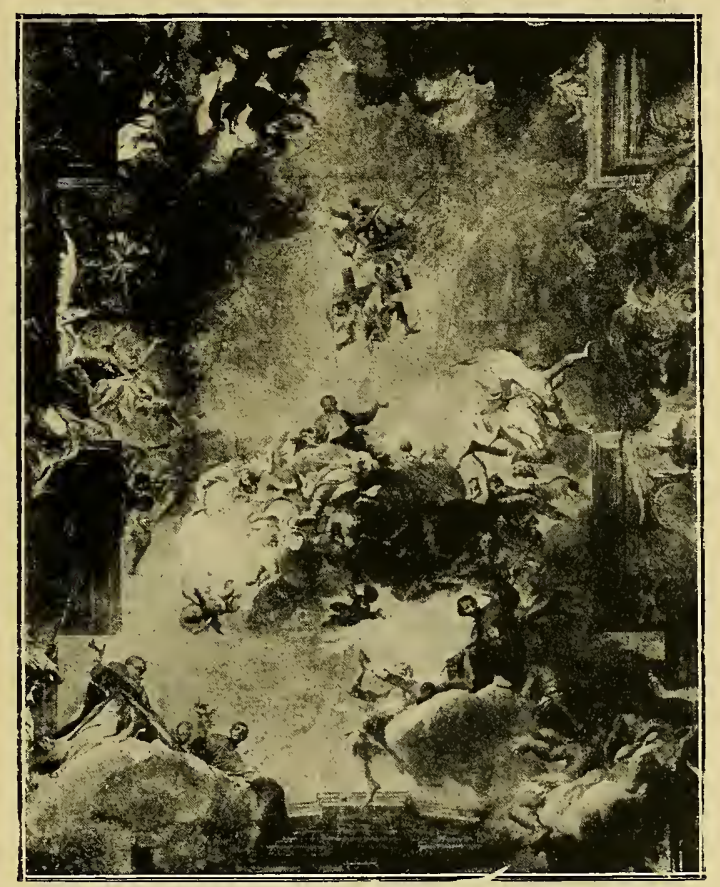

Andrea Pozzo, Centro della vôlta di S. Ignazio.

(Fot. Anderson).

gatí e risaltati stranamente, in mezzo è un concavo con sopra due gran corna di mezzi frontoni attortigliati; l'altro è un zigzag de' più bisbetici, con il portico parimenti ondulato. Chi vuol esser architetto alla rovescia studi l'architettura di Fra Pozzo ". Le colonne sedenti a cui allude il Milizia sono veramente una bizzarria, che però rimase allo stato di progetto in una delle tavole del trattato: l'autore stesso lo chiama altare 
capriccioso, e tenta di darne una giustificazione logica. "Gli antíchi, se diamo fede a Vitruvio, non di rado servironsi per colonne e pilastri, per variar l'architettura, di statue di uomini e donne ch'egli chiama chariatidi. Or mi si dica che necessità v'è, che abbian a star sì ritte in piè, e non possan fare il loro of-

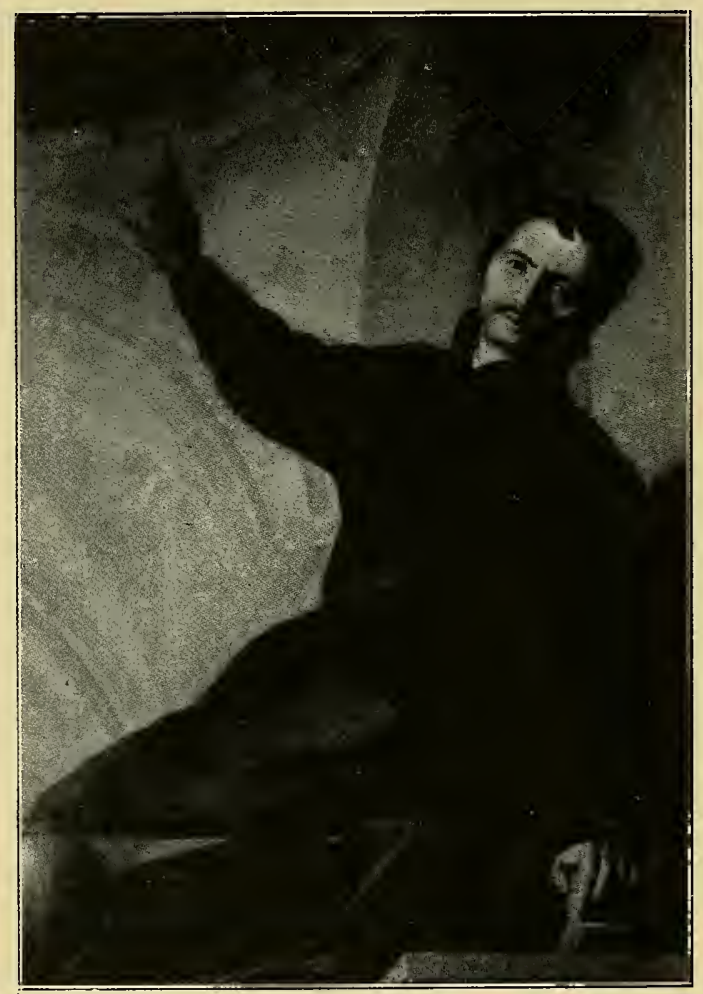

Andrea Pozzo, Autoritratto negli Uffizi, Firenze.

(Fot. Alinari).

fício sedendo? E se in ciò non v'è inconveniente, non so vedere che inconveniente sia in star anche le colonne sedenti, che sono figura di quelle".

Ma come sempre accade, fratel Pozzo è assai più bizzarro in questi progetti disegnati nel suo Trattato che nelle opere tradotte in attuazione. In quelli, non avendo a lottare con le 


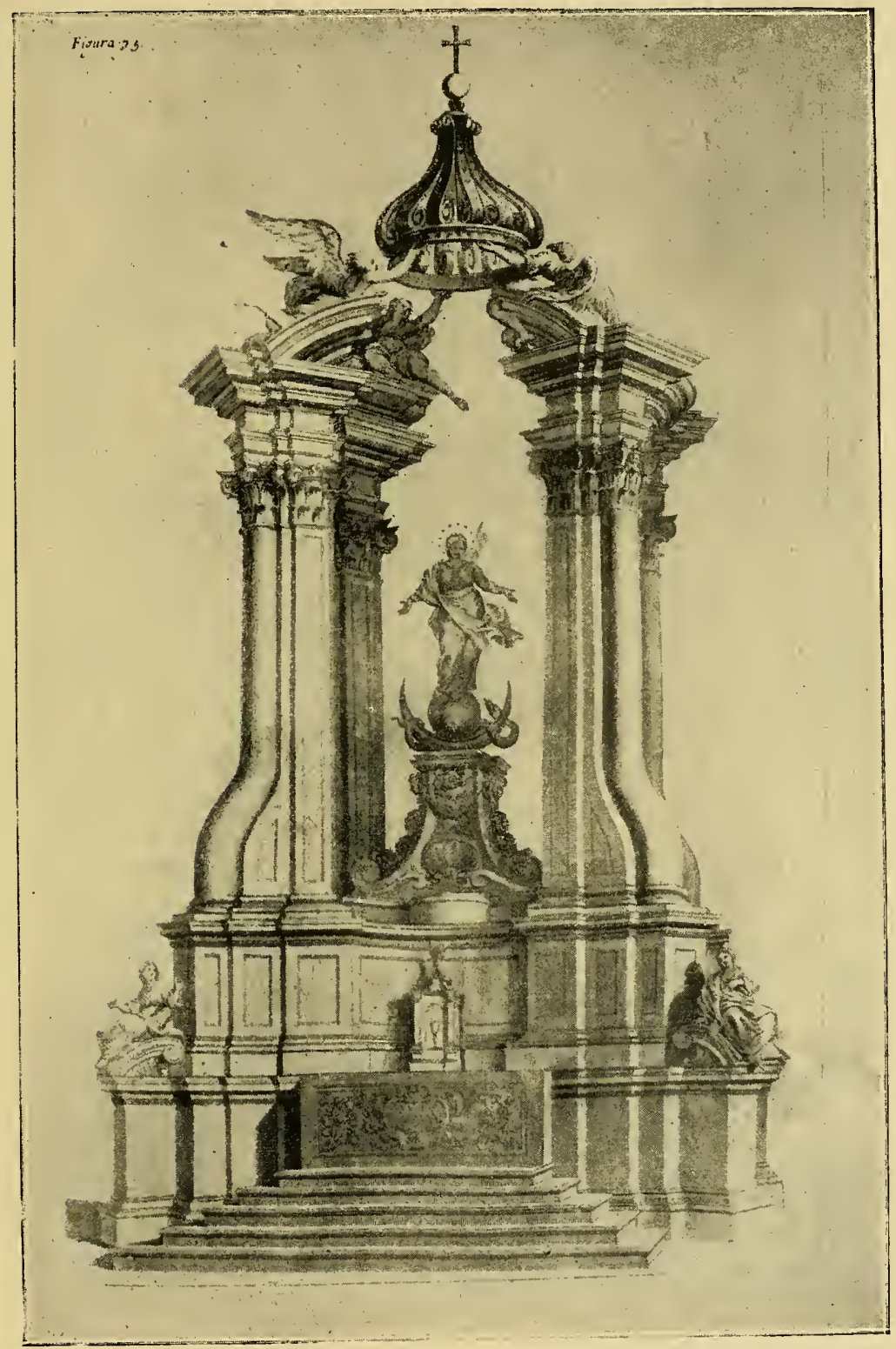

Andrea Poz:o, Altare capriccioso. (Dal Trattato di Prospettiva). 
difficoltà tecniche, si scapricciava a suo talento, abbandonandosi alla sua inesauribile fantasia, e concepiva le sue architetture

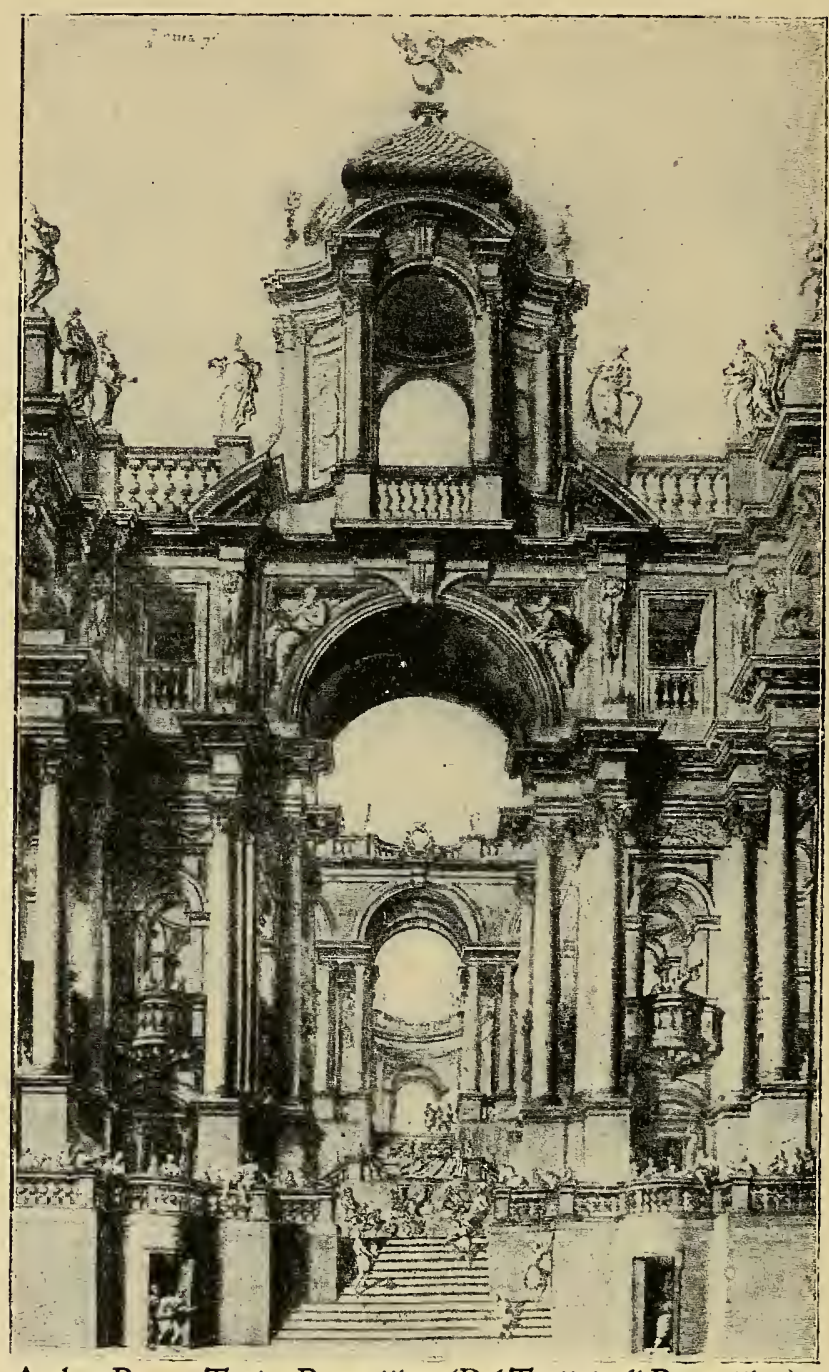

Andrea Pozzo, Teatro Prospettico. (Dal Trattato di Prospettiva).

con spirito essenzialmente pittorico; poichè egli stesso diceva, chi è buon pittore e buon prospettico sarà buon architetto. E evidente la sua derivazione dal Borromini, ma le forme raf- 


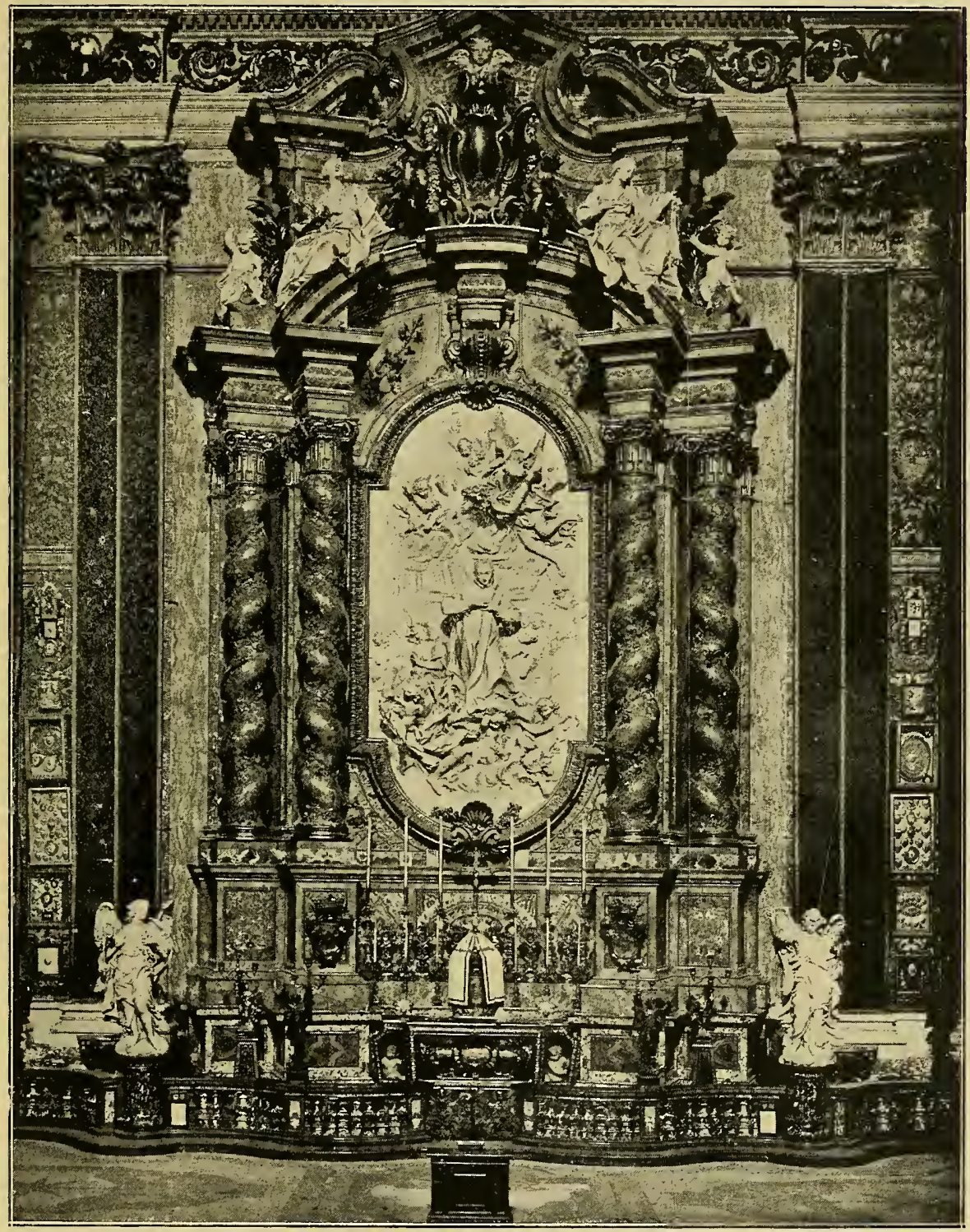

Andrea Pozzo, Altare di S. Luigi in S. Ignazio. Rilievo di P. Legros.

(Fot. Alinari). 
finate del sommo maestro, si appesantiscono un po' nelle mani nordiche di Andrea Pozzo, e si ammantano di colori e di gemme che Borromini non adoperò mai. L'altare di S. Luigi in S. Ignazio, e quello di S. Ignazio al Gesù, entrambi compiuti nell'anno 1700 , sono sfolgoranti d'oro, di marmi, di pietre

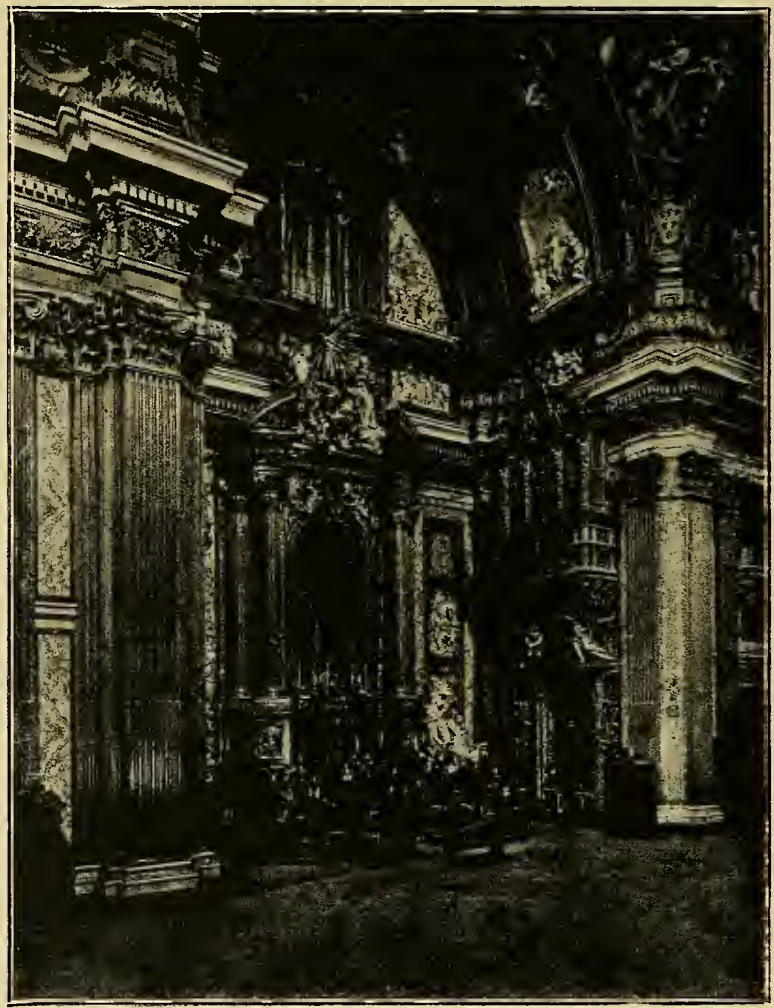

Andrea Pozzo, Altare di S. Ignazio, al Gesù.

(Fot. Alinari).

preziose, profuse con una ricchezza quale non si era vista mai. $\mathrm{Nel}$ primo quattro colonne spirali di verde antico, per le quali van serpendo quattro viti di bronzo dorato, sostengono un pesante fastígio, e incorniciano un delizioso rilievo di uno scultore francese, Pierre Legros, che raffigura il Beato Luigi portato in gloria dagli angeli. Nel secondo, eseguito nel breve spazio di 


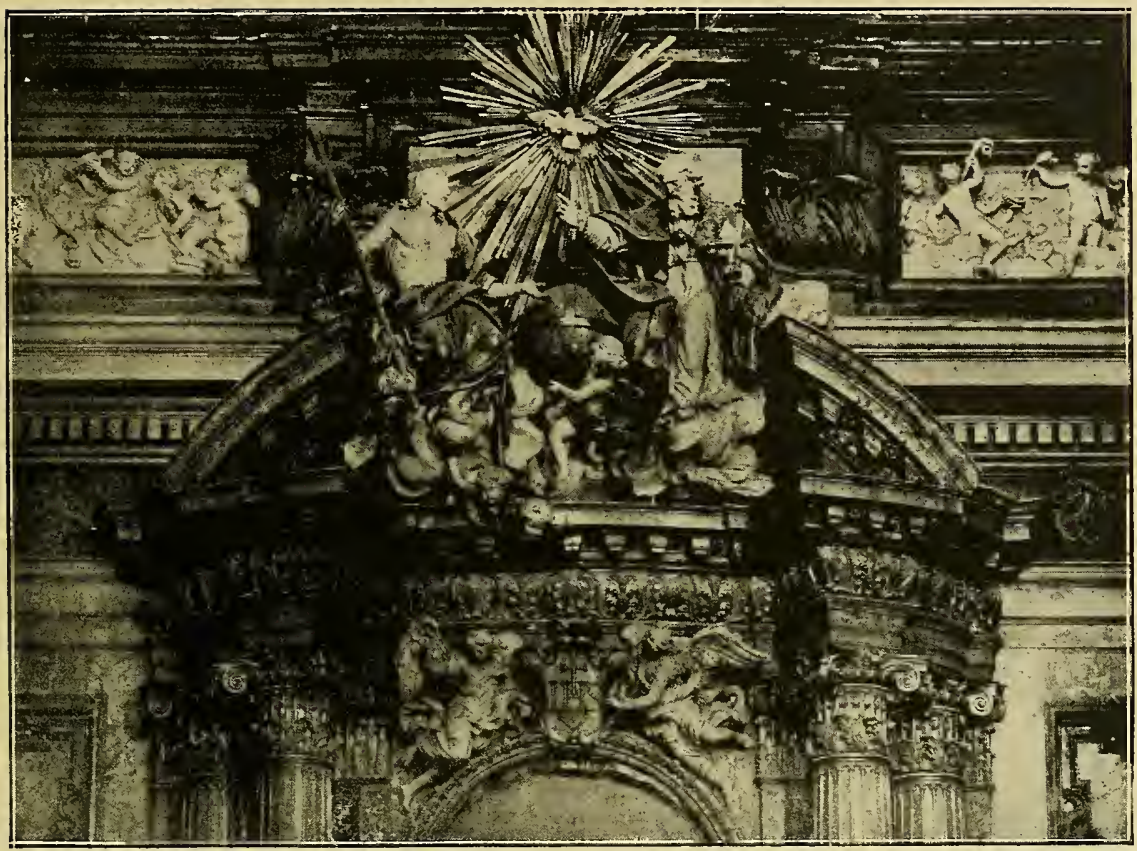

Andrea Pozzo, Coronamento dell'Altare di S. Ignazio, al Gesì. (Fot. cAlinari).

quattro anni, c'è una maggior profusione di ornati, e gruppi allegorici entrano a dar movimento alle linee dell'architettura. Neppure il genio del Bernini ha saputo creare quadri sfolgoranti come questi di fratel Pozzo, ai quali solo il buon gusto dell'autore impedisce di cadere nel bizzarro e nel sovraccarico. Quando gli imitatori tentano di riprendere i motivi di lui, precipitano subito nell'assurdo e nel manierato; e peggio accade quando essi sono tedeschi. Perchè fratel Pozzo passò gli ultimi anni della sua vita a Vienna, e influi fortemente sull'arte dei paesi cattolici alemanni; anzi egli può considerarsi come il tramite per cui il barocco romano fresco, giovane, rigoglioso, venne a contatto coi maestri del nord. Tutto il Settecento austriaco e bavarese è derivato da fratel Pozzo; ma lo stile di lui, già pesante in confronto delle squisite grazie borrominesche, diviene ancor più grave, massiccio e goffo, nelle traduzioni tedesche, alle 


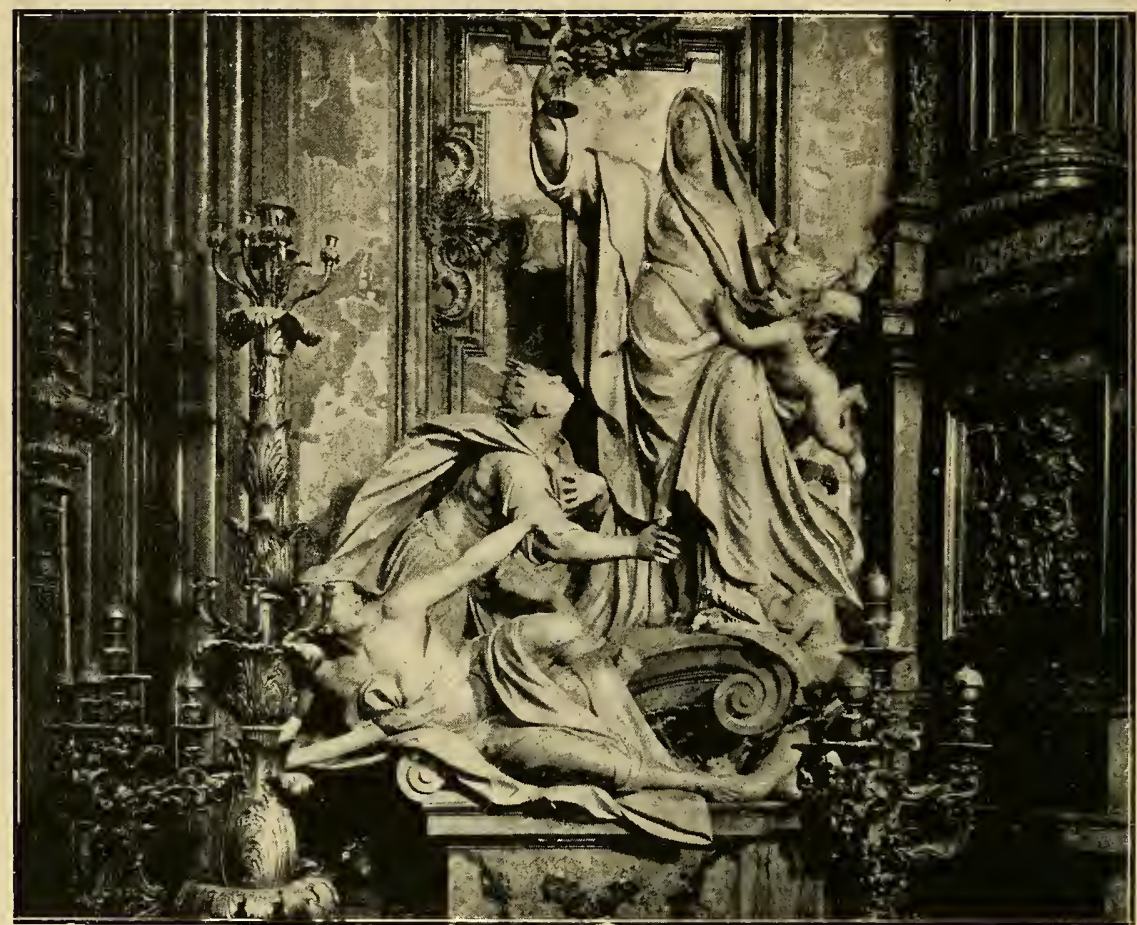

La Fede abbatte 1'idolatria - Gruppo del Théodon, nell'altare di S Ignazio, al Gesì.

(Fot. Alinari).

quali mancano pure le materie più nobili e tenere di cui dispongono i nostri paesi. Differenza profonda di spirito e di attitudini! Partendo da uno stesso modello, cioè dal barocco italiano, i francesi creano il leggiadro rococò; i tedeschi lo stíle pesante dei Fischer von Erlach.

Già assai prima che fratel Pozzo elevasse lo splendido altare, la chiesa del Gesù aveva perduto il suo freddo aspetto primitivo, per le smaglianti decorazioni di un fantasioso, pittore genovese, Gio. Battista Gaulli, detto il Baciccio, che colori nella volta e nell'abside con una grande festosità, con un scintillio di colori, con un impeto mai veduto. II Baciccio era amico e discepolo del Bernini, e sembra quasi che traduca in pittura qualcuna delle turbinose e travolgenti concezioni del maestro, del 


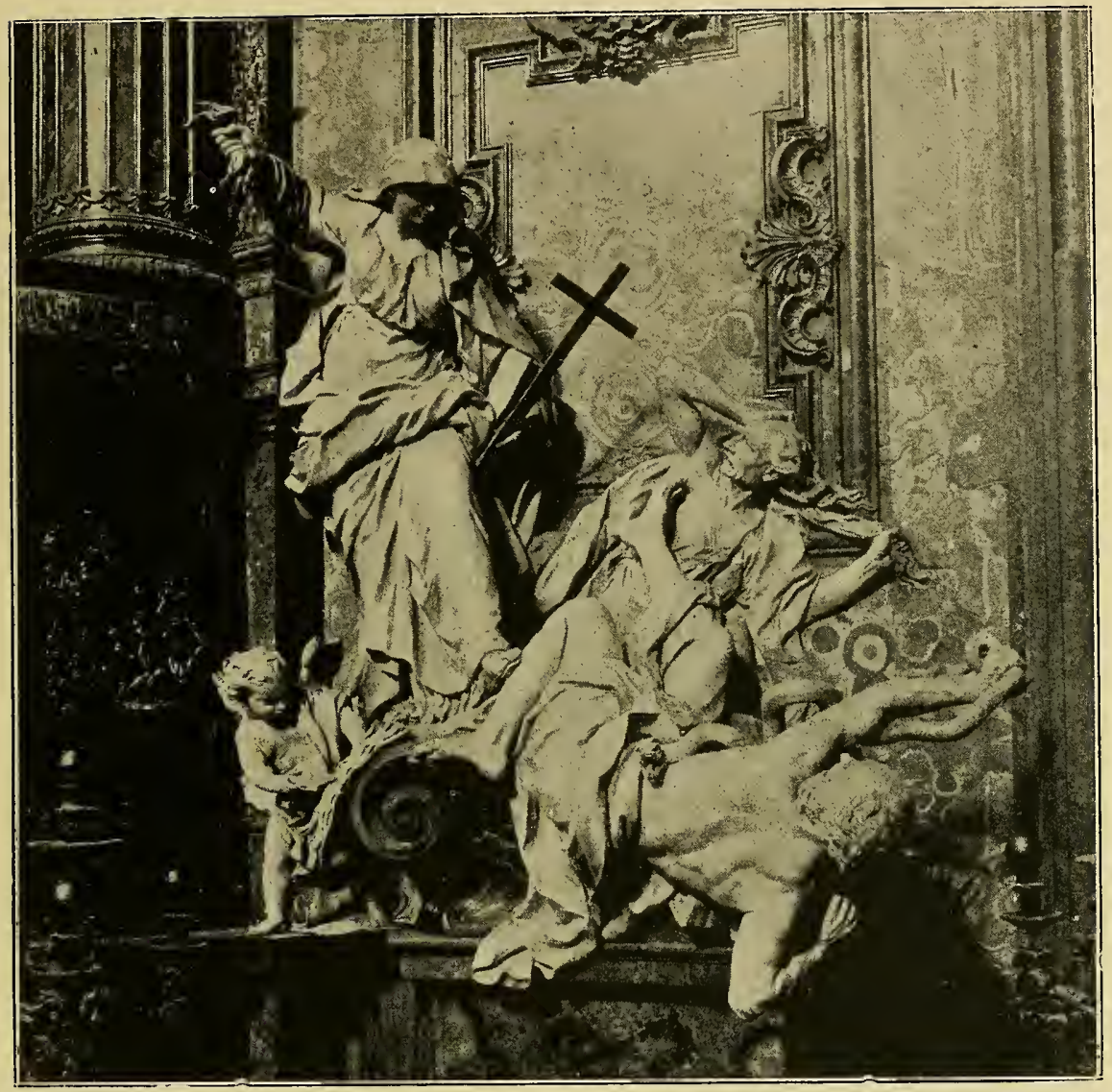

La Religione atterra 1'eresia - Gruppo del Legros, nell'altare di S. Ignazio, al Gesì.

(Fot. Moscioni).

quale assume anche particolari atteggiamenti e imita il modo di panneggiare e di gestire. Nessun pittore ha lo slancio, la luminosità, la fosforescenza del Gaulli; nè Pietro da Cortona, più determinato e scritto; nè fratel Pozzo più costretto nei suoi schemi architettonici, più bituminoso; nè Carlo Maratta più classico e composto. Se il Bernini che fu un mediocre pittore avesse avuto più facile il pennello, si sarebbe espresso come Baciccio, che è certo il maestro più rappresentativo della scuola barocca romana. 
Sul finire del Seicento la decadenza si manifesta sempre piì chiaramente; la grande eco dell'arte berniniana si affíevolisce, e comincia la reazione. Scultori francesi e toscani specialmente, mentre vengono a Roma attrattivi dalla tradizione ormai secolare, e si lasciano influire dalle forme del barocco ancora imperante, introducono alla lor volta germi vivi di rin-

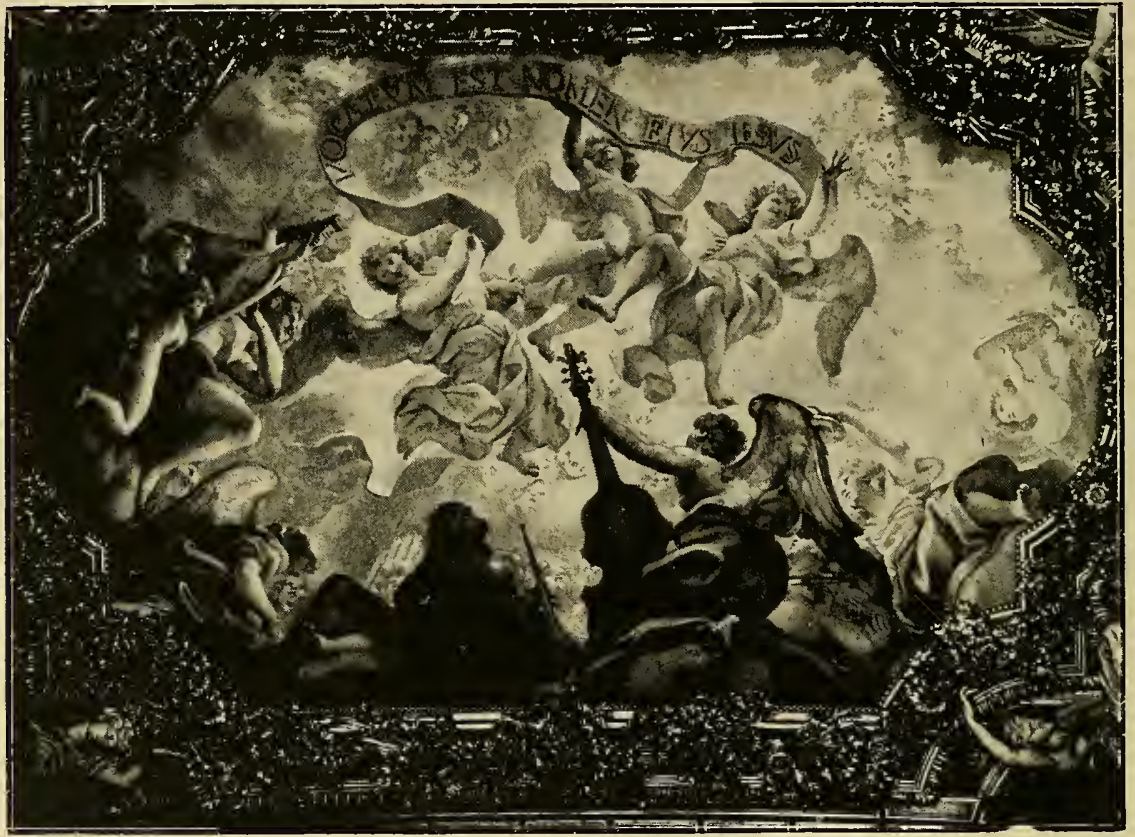

Baciccio, Affresco nell'Abside del Gesì.

(Fot. Alinari).

novamento. Pierre Legros accanto ai pesanti barocchismi del sepolcro di Gregorio XV, ha squisite note di grazia settecentesca; Giuseppe Mazzuoli dopo scolpito uno dei massicci apostoli per la nave centrale di S. Giovanni in Laterano, ci dà il delizioso busto di Donna Laura di Carpegna, ch'è nella cappella Altieri di S. Maria in Campitelli, miracolo di composta eleganza.

La cappella Corsini al Laterano, fatta costruire da Clemente XII, e compiuta nel 1734 , è il monumento in cui la 
nuova corrente artistica si afferma vittoriosamente. Vi hanno lavorato quasi tutti maestri toscani, come era toscano il pontefice committente, l'architetto Alessandro Galilei, patrizio fiorentino, vissuto a lungo in Inghilterra, gli scultori G. B. Maini, Agostino Cornacchini, Filippo Valle, Giuseppe Lironi; e un romano, Pietro Bracci. Tutto è classico nel maestoso sacello; le

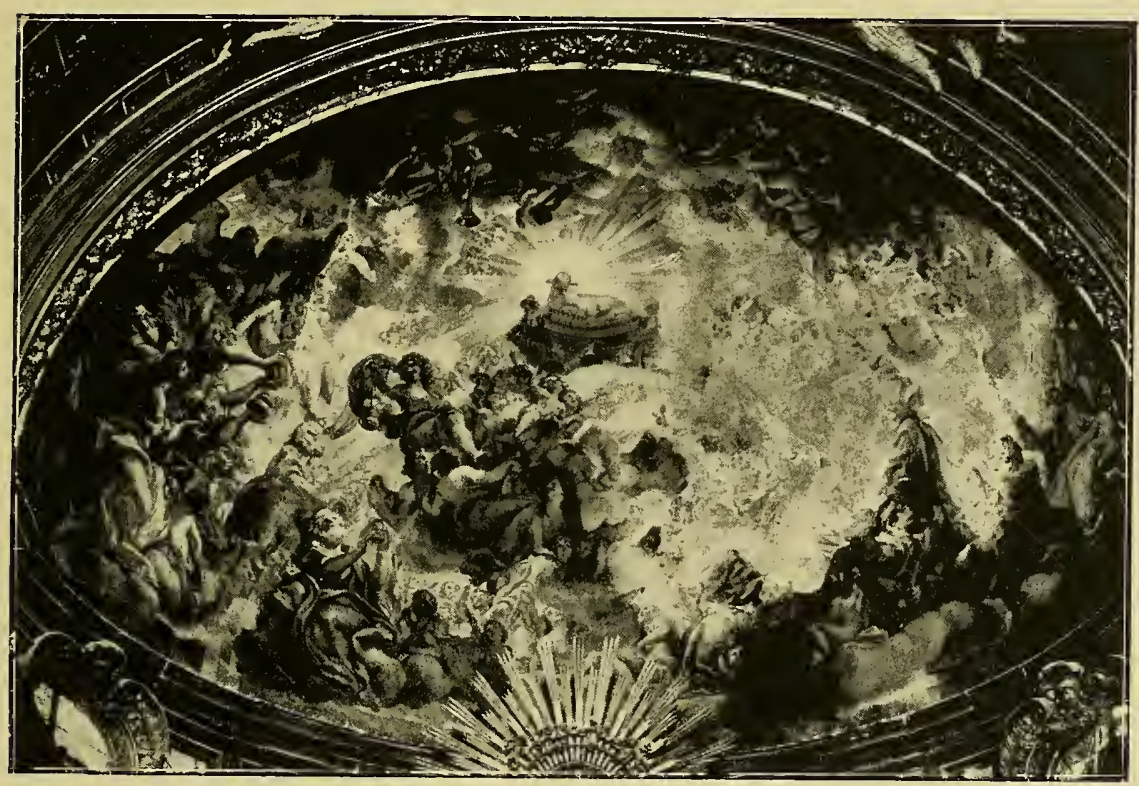

Baciccio, L'Adorazione dell'Agnello, nell'Abside del Gesì.

(Fot. Alinari).

linee, la decorazione, il materiale impiegato; non c'è più quasi affatto il colore: il marmo bianco, lo stucco, l'oro sono gli elementi cromatici principali sui quali spiccano appena il basamento di breccia persichina, le colonne di rosso antico delle nicchie, e il verde delle cornici. Bernini è dimenticato, e tra le dolci grazie del Settecento già lo spirito antico comincia ad apparire. Anche nella Fontana di Trevi (compiuta nel 1747), che è considerata l'espressione più grandiosa del barocco romano, tanto 


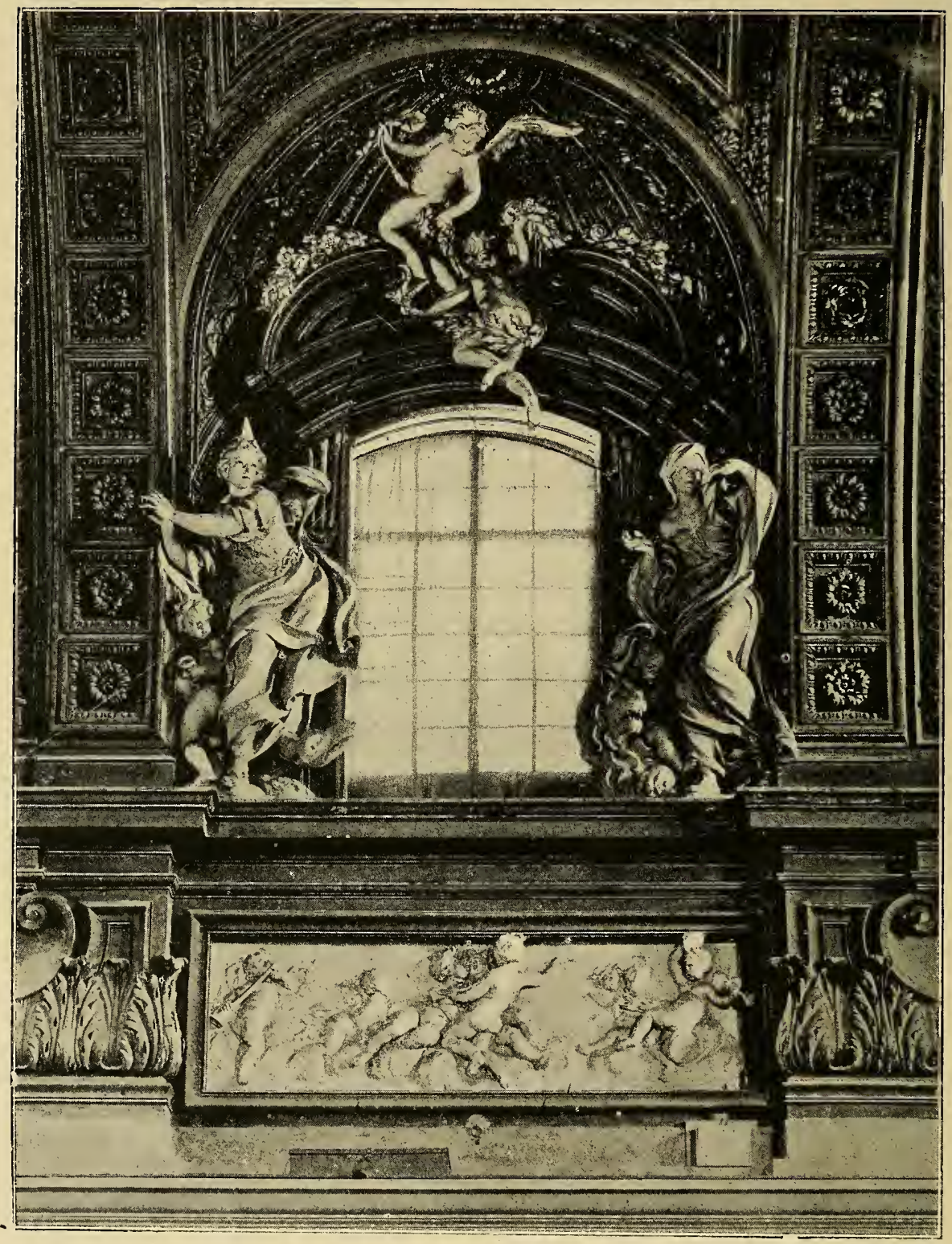

A. Raggi, Stucchi nella nave centrale del Gesì. 


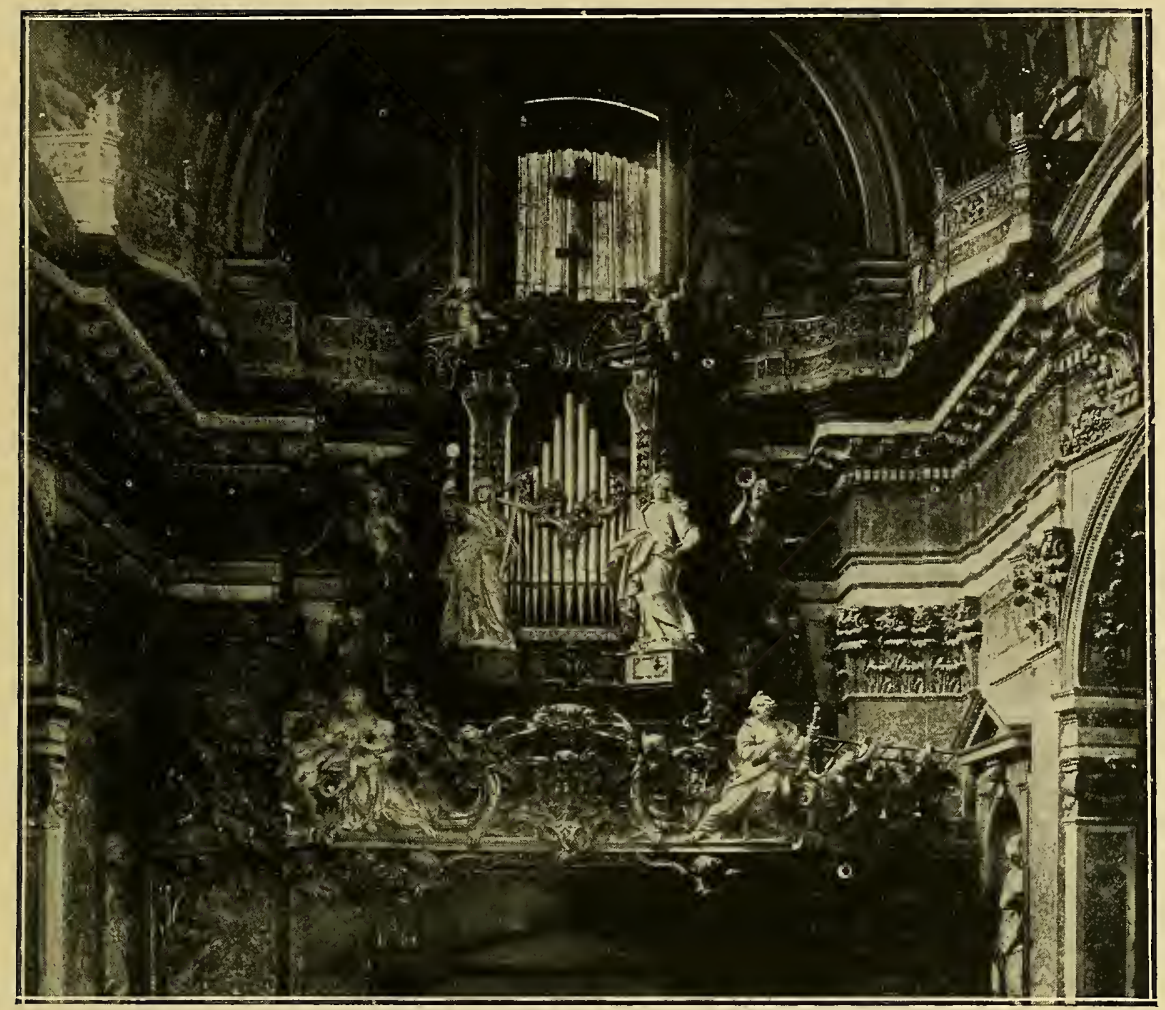

Organo della Chiesa della Maddalena.

che la tradizione popolare l'attribuisce al Bernini, è manifesto chiaramente il trionfo del nuovo stile. Se la pittoresca scogliera che forma basamento è tutta seicentesca, e richiama i motivi impiegati dal Bernini nella Fontana Pamphilia, nella curia Innocenziana e nel progetto del Louvre, l'architettura dell'edificio che sorge su di essa, col nicchione imitato da quello del tempio di Venere e Roma, è già prettamente classica.

Mentre l'arte parla già il suo nuovo linguaggio con tale evidenza e magnificenza, in certe forme tradizionali il barocco ancora imrera, tanta è la forza di certi schemi da lui creatí per esempio nelle tombe papali. Il grande mausoleo di Urbano VIII 
è sempre innanzi agli occhi di tuttí gli artisti chiamati al difficile compito d'elevare un sepolcro pontificale nella Basilica Vaticana, e ad esso, e più raramente a quello di Alessandro VII

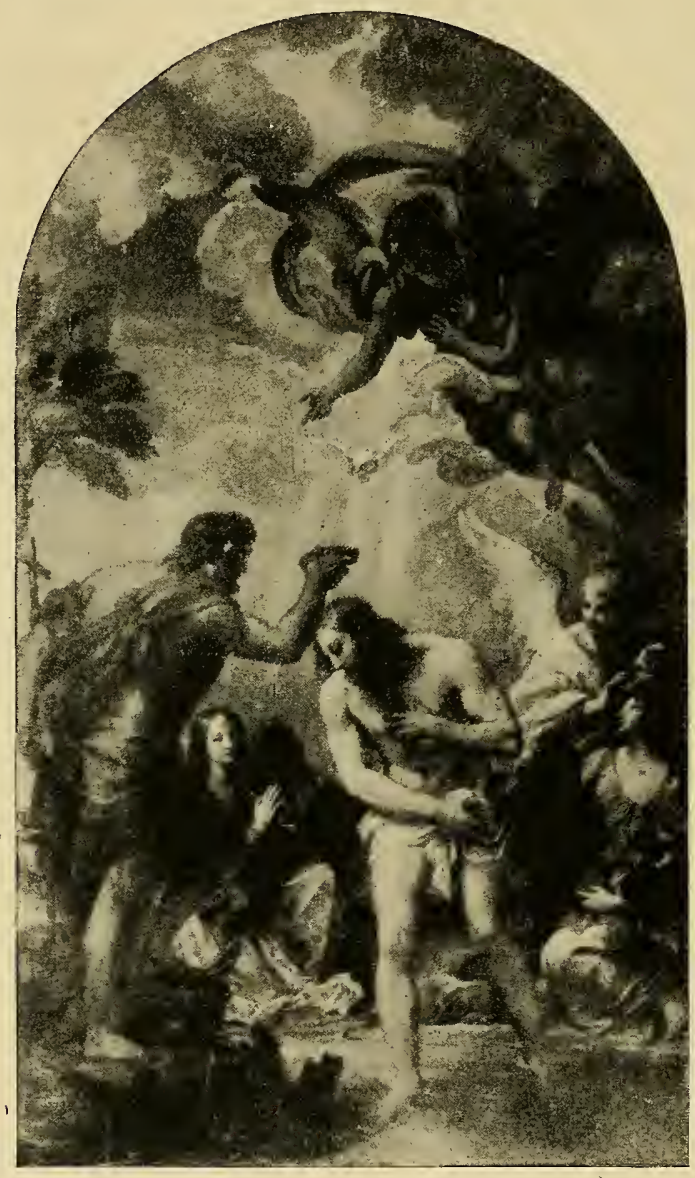

Maratta, Battesimo di Cristo, in S. M. degli Angelí.

continuano ad ispirarsi fino alla metà del Settecento. Quando già la Cappella Corsini è compiuta da dieci anni, Ferdinando Fuga e Filippo Valle ritrovano accenti barocchi pel monumento di Innocenzo XII Pignatelli, che è del 1746, pieno di movi- 
mento e di colore. E più tardi Antonio Bracci e Gaspare Sibilia risuscitano pure uno schema barocco pel sepolcro di papa Lambertini, Benedetto XIV, compiuto nel 1760.

Ma sono manifestazioni di un manierismo stentato, sca-

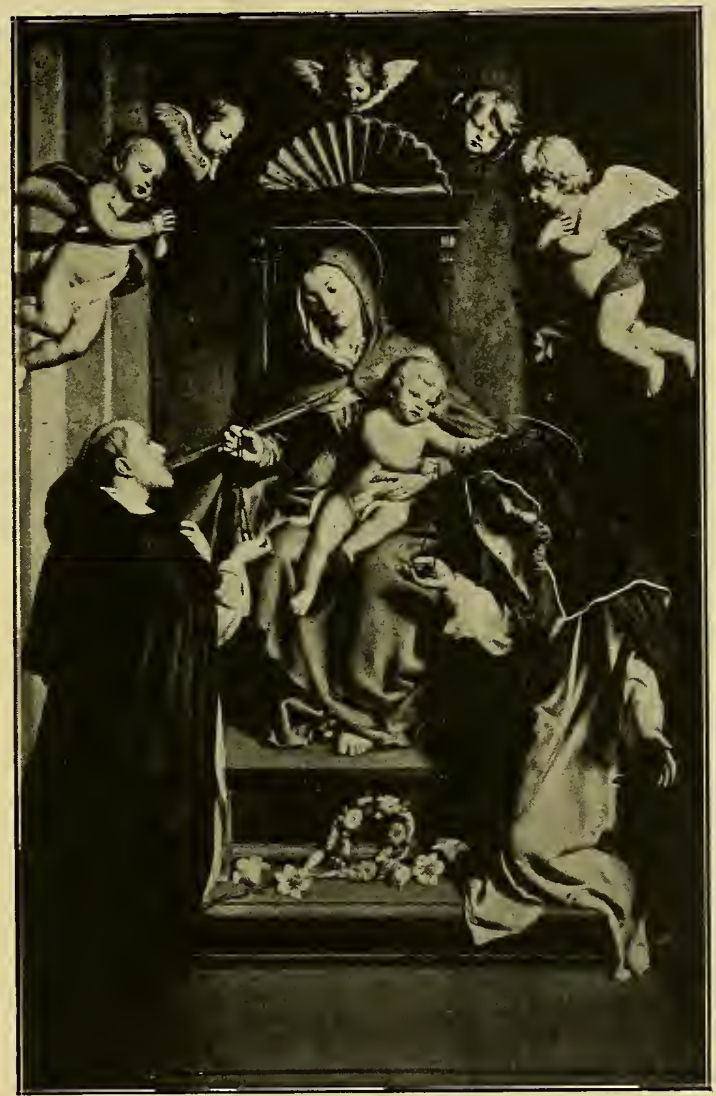

Sassoferrato, Madonna del Rosario, in S. Sabina.

(Fot. Alinari).

denti riesumazioni, non sincere e non spontanee di un'arte ormai tramontata.

Ed ecco nella tomba di Clemente XIV, Ganganelli, scoperta nel 1787 nella chiesa dei SS. Apostoli, apparire il capolavoro, in cui la nuova corrente neo-classica trova finalmente 


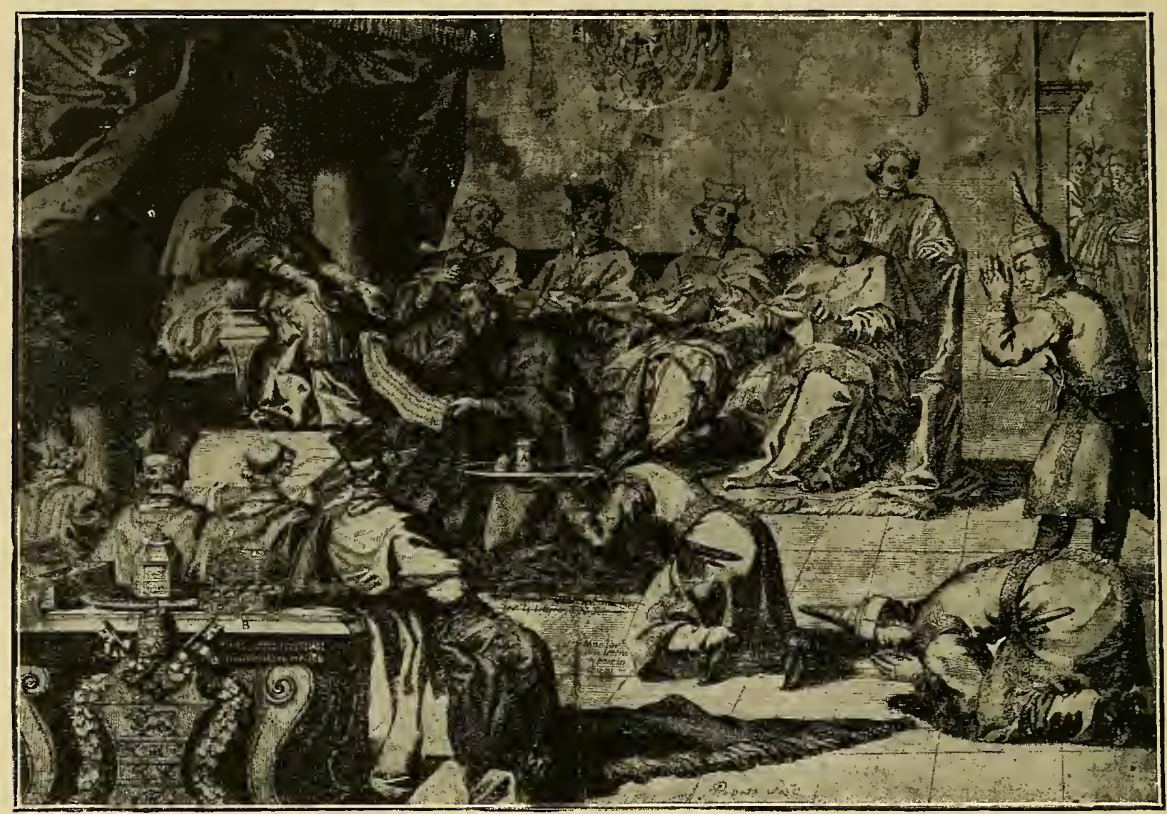

Innocenzo XI riceve gli Ambasciatori giapponesi. Incísione contemporanea. (Collezione Munoz).

la sua vittoriosa espressione. Francesco Milizia, che già in questo tempo molti strali ha lanciato contro l'arte del Seicento, leva un inno assai significativo all'opera del giovane scultore veneziano, in una lettera al conte vicentino Francesco di Sangiovanni. "Fenomeno singolare, signor conte amabilissimo mio padrone: perciò le scrivo. Che proemio! In questa chiesa dei SS. Apostoli dei PP. Conventuali, alla porta della sagrestia a fronte d'una delle due navate laterali, lo scultore Antonio $\mathrm{Ca}$ nova veneziano ha eretto un mausoleo a papa Ganganelli. Basamento liscio diviso in due scalini. Sul primo siede una bella donna chiamata la Mansuetudine, mansueta quanto l'agnellino che le giace accanto in ritirata. Sul secondo scalino è l'urna sopra cui, dalla parte opposta si appoggia un'altra bella giovane, la Temperanza. S'alza indi sopra un plinto un sedione all'an- 
tica, dove sta a sedere con tutto il suo agio il papa vestito papalissimamente, e stende orizzontalmente il braccio destro e la mano in atto d'imporre, di pacificare, di proteggere. Questo è

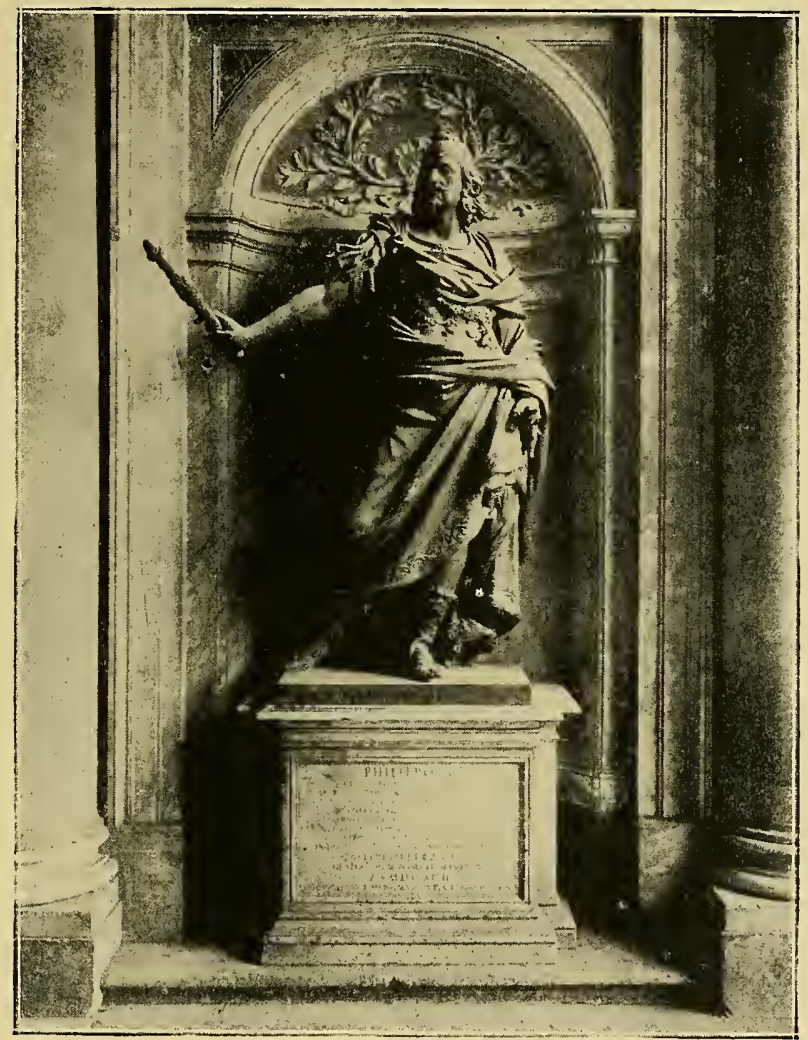

Bernini e Lucenti, Statua di Filippo IV in S. Maria Maggiore.

il mausoleo. Tutto è di marmo bianco, eccetto lo zoccolo inferiore e il plinto colla sedia, che sono di lumachello. L'accordo è grato, il lume gli viene dall'alto e temperatamente, onde tutto spicca con dolcezza. La composizione è di quella semplicità che pare la facilità stessa, ed è la stessa difficoltà. Che riposo! che eleganza! che disposizione! La scultura e l'architettura, sì nel 
tutto che nelle parti, è all'antica. Il Canova è un antico, non so se di Atene o di Corinto. Scommetto che in Grecia, nel più bel tempo di Grecia, se si avesse avuto a scolpire un papa, non si avrebbe scolpito diverso da questo. In 25 anni ch'io sono in questa urbe dell'orbe, non ho veduto mai il popolo di Quirino applaudire così generalmente un'opera tanto come questa. Gli

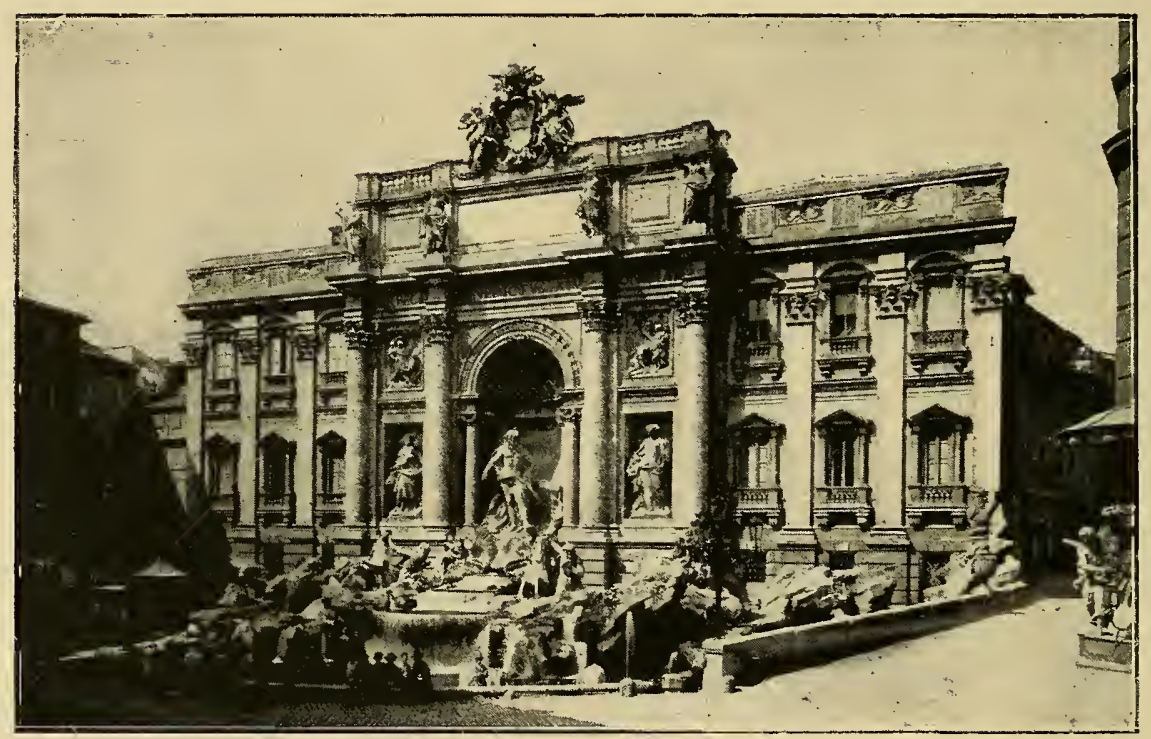

Niccolò Salvi, La Fontana di Trevi.

(Fot. Alinari).

Statue di Pietro Bracci e Filippo Valle.

artisti più intelligenti e galantuomini la giudicano fra tutte le sculture moderne la più vicina all'antico. Fin gli stessi ex-gesuiti lodano, e benedicono papa Ganganelli di marmo! E certamente questo è un miracolo di quel papa, il quale sarà pì̀ glorioso per questo monumento che per la soppressione dei gesuiti. È questa un'opera perfetta, e per tale viene dimostrata dalle censure che ne fanno i michelangelisti, i berninisti, i borroministi, i quali hanno per difetto le più belle bellezze, giun- 


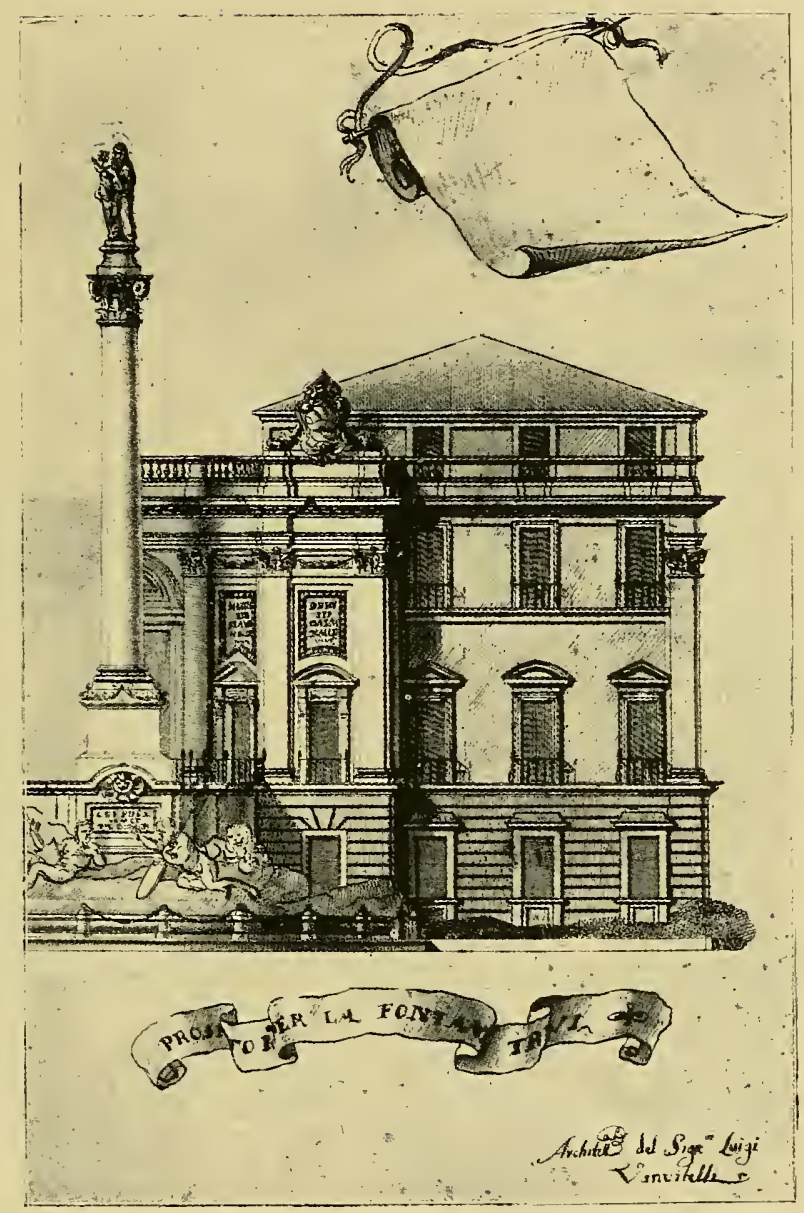

Dísegno del Vanvitelli per la Fontana di Trevi. (Collezione Munoz). 
gendo a dire che i panneggiamenti, le forme, l'espressione sono all'antica. Dio abbia pietà di loro. Il nostro signor Pietro Vitali ne sta lavorando l'incisione. Io mi congratulo dunque con tutti

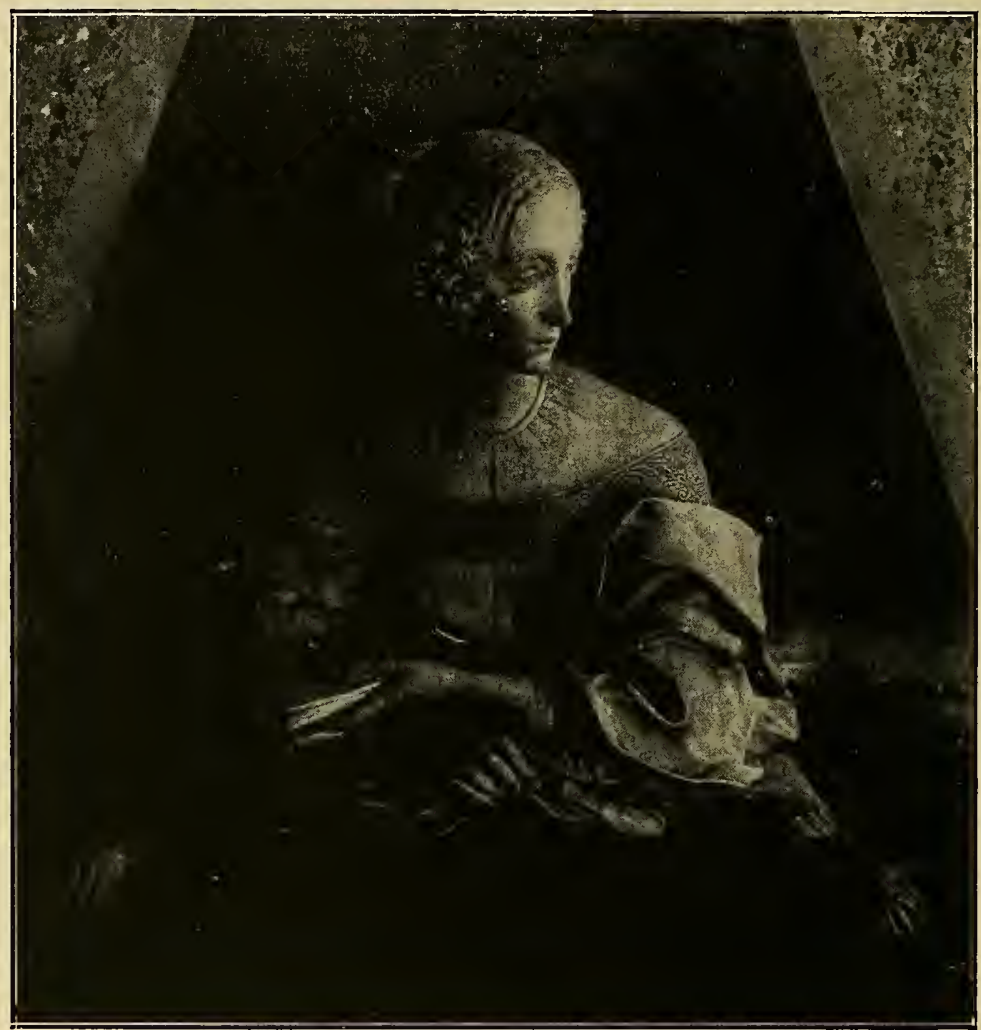

G. Mazzuoli, Busto di Laura di Carpegna, in S. Maria in Campitelli.

i veneti. Desidero che i giovani artisti si mettano sul buon sentiero di Canova. e che le belle arti risorgano. Desidero molto, ma spero poco. Spero bensì che il Canova si comporterà a meraviglia anche nel mausoleo che farà a $S$. Pietro per papa Rezzonico; e spero altresi che il signor conte mi conservi la sua grazia. Roma, 21 aprile 1787, ,. 


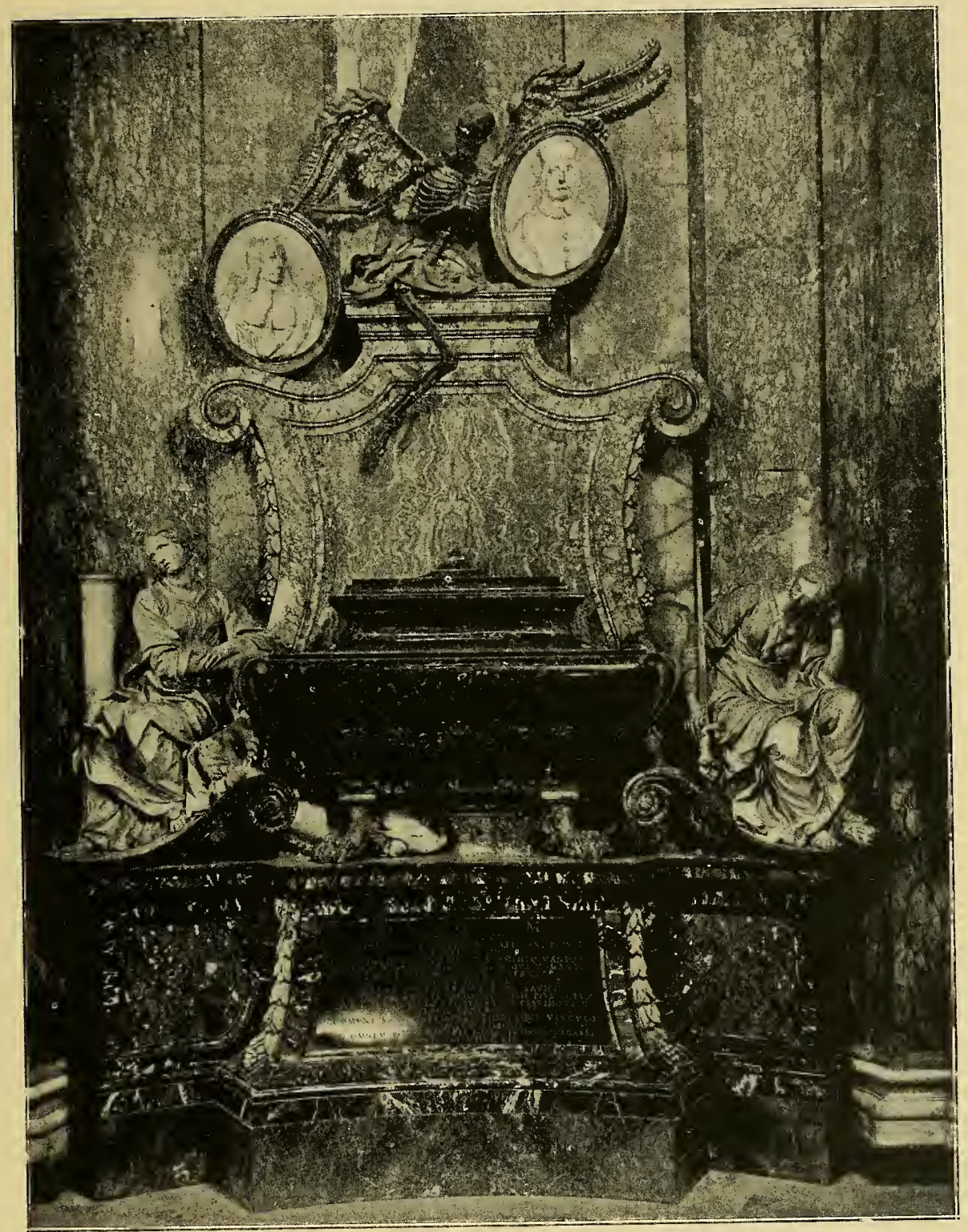

G. Mazzuoli, Sepolcro Pallavicini, in S. Francesco a Ripa.

(Fot. Alinari). 
Il Milizia fu profeta. Il giovane veneziano raggiunta a trent'anni, con quell'opera, la fama, spiccava ormai il suo altissimo volo. Il popolo accorse ad ammirare il sepolcro di papa

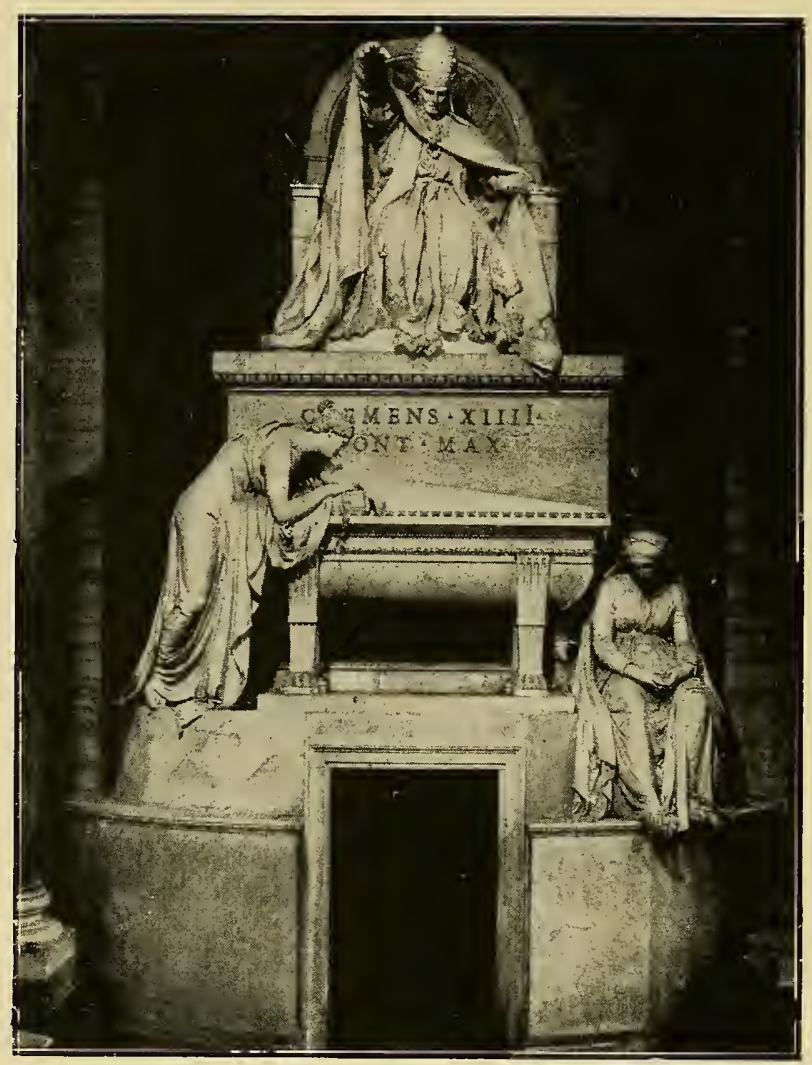

Canova, Sepolcro di Clemente XIV, in SS. Apostoli.

(Fot. Anderson).

Ganganelli, le gazzette ne fecero descrizioni entusiastiche, i poeti lo cantarono, gl'incisori lo divulgarono, i pochi dissidenti furono vituperati.

E l'arte barocca era morta. 
INDICI 



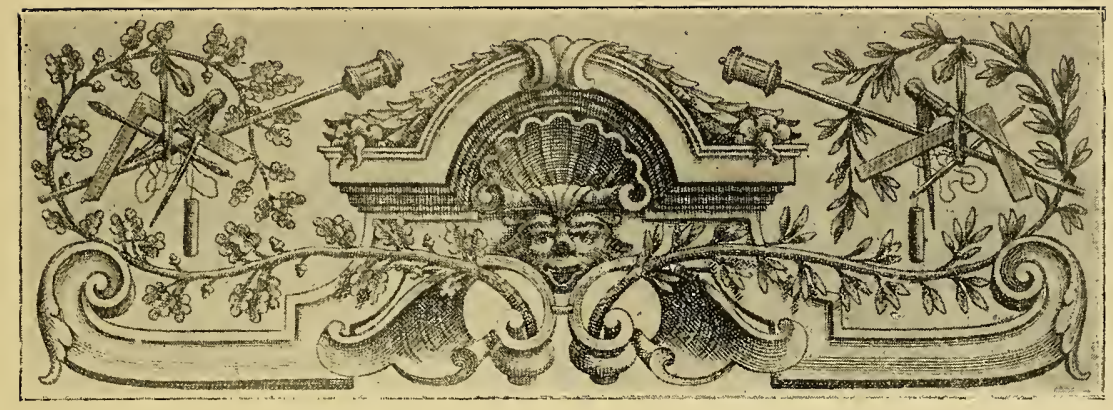

\section{Sommario dei Capitoli}

I. PAPA SISTO • • . . . . Pag. 1-26

Elezione di Felice Peretti - Sua giustizia e repressione del brigantaggio - L'arte della Controriforma - Magnificenza di Sisto V - La Cappella Sistina - L'Obelisco Vaticano - Domenico Fontana - L'acqua Felice - Il piano regolatore di Roma alta - La Cupola di S. Pietro - La nuova Biblioteca Vaticana - I monumenti antichi - II nepotismo di Sisto - La morte del pontefice - Il catafalco - Il Fontana a Napoli - La nascita del Bernini.

\section{LA GALLERIA FARNESE • • . Pag. 27-52}

Odoardo Farnese cardinale - Sura risoluzione di decorare il palazzo di Roma - Condizioni della pittura in Roma alla fine del Cinquecento - I Carracci a Bologna - L'accademia dé Desiderosi - Viaggi dé Carracci - Loro arrivo a Roma - Descrizione della Galleria Farnese - L'opera dei varii collaboratori - Domenichino e Innocenzo Tacconi Mitologia e moralítà - Opere d'Annibale Carracci a Roma - Sưa morte.

\section{DELICIUM URBIS • • . . . Pag. 53-93}

Elezione di Paolo V - Scipione Caffarelli cardinal nipote -- La cappella Paolina - Flaminio Ponzio architetto papale - Completamento e facciata della Basilica Vaticana - Carlo Maderno - Primi passi del Borromini - Altre opere di Paolo V - Ambascerie orientali - L'Aurora di Guido Reni - La Villa Pinciana - Le collezioni del Cardinale Scipione - L'Ermafrodito - Opere del Bernini per la Villa Pinciana: Enea e Anchise, David, Apollo e Dafne - Educazione artistica del Bernini Plutone e Proserpina - Primi busti del Bernini - I due busti del cardinale Scipione - Gli amori del Bernini - Busto di Costanza Buonarelli - Matrimonio del Bernini. 
IV. LE CHIESE • • . . . . Pag. 95-129

Il Gesì del Vignola e di G. della Porta - Pianta allungata e pianta centrale - Chiese gesuitiche - Loro decorazione - Ritorno alla pianta centrale - Le Facciate rettilinee - Le Facciate in curva Facciate a torri e a portico - Vecchie basiliche restaurate - L'altare - Rapporti col teatro.

\section{IL BALDACCHINO • . . . Pag. 131-167}

L'opera di metallo - Spogliazione delle travi del Pantheon - Bernini e Borromini - Ciborio e baldacchino - Le colonne tortíli - Baldacchino del Val de Grâce - Architettura e tappezzeria - Elementi naturali nell'architettura - La figura umana adattata all'architettura - Caratteri generali dell'arte barocca - La Veronica del Mochi - Il movimento nella scultura - I fiumi nell'arte del Seicento - La S. Cecilia del Maderna - Monumenti sepolcrali - La Verità scoperta dal Tempo - Il panneggio - Il ritratto nella scultura barocca.

\section{APES URBANÆ . • . . . Pag. 169-199}

Sede Vacante di Gregorio XV - Elezione di Urbano VIII - Sua amicizia pel Bernini - Il palazzo Barberini - Gli affreschi di Pietro da Cortona - Il teatro dei Barberini - Rappresentazione del S. Alessio -.. La fontana del Tritone - I nipoti deí papa - Morte del generale Barberini - Papa Urbano visita la casa del Bernini - La politica papale nelle lotte tra Spagna e Francia - Condanna di Galileo - Monumento alla Contessa Matílde - Statua di Urbano in Campidoglio - Mausoleo di papa Urbano - Morte del Papa.

\section{BORROIMINI . . . . . Pag. 201-241}

Caratteri dell'arte sua - L'umore malinconico del Borromini Il suicidio - Educazione artistica - Lavori da scalpellino in S. Pietro - Fa disegni pel baldacchino del Bernini - Lavori nel palazzo Barberini - Chiesa e chiostro di S. Carlino - Oratorio e convento dei Filippini - L'altare Filomarino a Napoli - La galleria prospettica di palazzo Spada - Decorazione e restauro di S. Giovanni in Laterano S. Agnese a Piazza Navona - Palazzo e Oratorio di Propaganda Fide - Chiesa della Sapienza - Facciata di S. Carlino - Svíluppo dell'arte borrominiana.

VIII. LUCE E TENEBRE . . . . Pag. 243-291

Michelangelo da Caravaggio - Il S. Matteo - Dipinti giovanili - Sura trasformazione in Roma - Giudizii del Bellori - Imitatori del 
Caravaggio - Domenichino - Affreschi in S. Gregorio al Celio e a Grottaferrata -- La comunione di S. Girolamo - La caccia di Diana - Affreschi in S. Andrea della Valle - Guido Reni - Dipinti nella cappella Paolina - L'Aurora - Imitazione del Caravaggio - Le fígure in estasi - Il Guercino - Claudio Lorenese, Velasquez e Rubens.

\section{DONNA OLIMPIA • • • . Pag. 293-329}

Elezione di Innocenzo X - Olimpia Maidalchini - Persecuzione dei Barberini - Il Bernini in disgrazia - La S. Teresa - Alessandro Algardi - L'arte sua in contrapposto a quella del Bernini - L'Attila Villa Pamphili - La Fontana di Piazza Navona, del Bernini - Intríghi di Donna Olimpia - Morte di Innocenzo X - Il suo cadavere resta abbandonato - Versi del Gigli su papa Innocenzo - Morte di Donna Olimpia.

\section{FELICI FAUSTOQUE INGRESSUI - Pag. 331-370}

Elezione di Alessandro VII - La carriera di papa Chigi -Conversione e arrivo in Roma di Cristina di Svezia - Il carnevale della Regina - La festa dei caroselli a Palazzo Barberini -- Strana condotta di Cristina - Lavori del Bernini in S. Maria del Popolo Restauri del Palazzo Chigi - Progetti di Alessandro VII per abbellimentí di Roma - Fabbriche di Pietro da Cortona - Il Bernini a Parigi -Il colonnato di S. Pietro - La Cattedra - Gli spettacoli in Roma Il mecenatismo di Cristina - Bernini commediografo, scenografo e caricaturista.

\section{FRATEL POZZO, • . . . Pag. 371-408}

Le statue di Ponte S. Angelo - Ultime opere del Bernini - Sua morte - Eredità artistica del Bernini - L'architettura - Fratel Pozzo pittore e architetto - Suo influsso nei paesi tedeschi. - Il Baciccio Rinnovamento della seultura - La Cappella Corsini - La Fontana di Trevi - I sepolcri dei Papi - Canova e il Mausoleo di Clemente XIV.

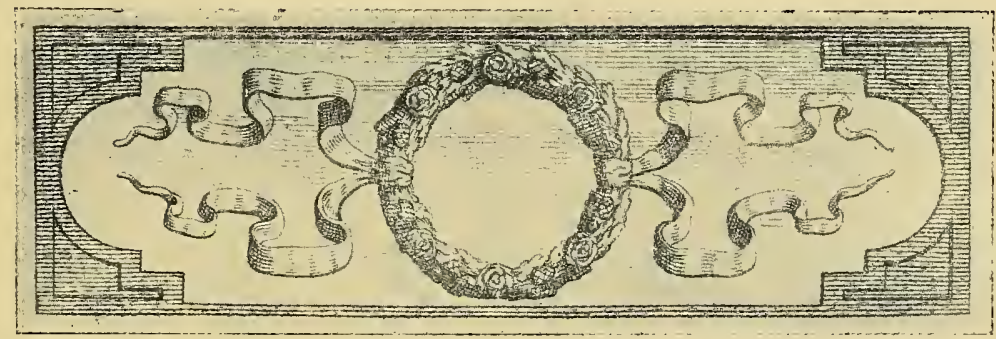




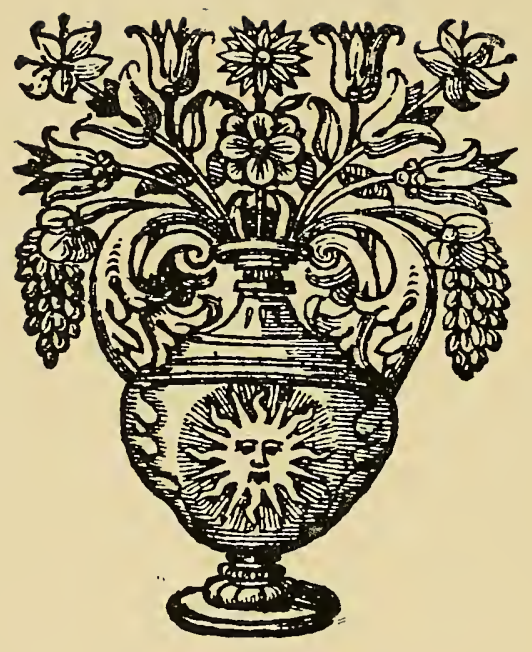




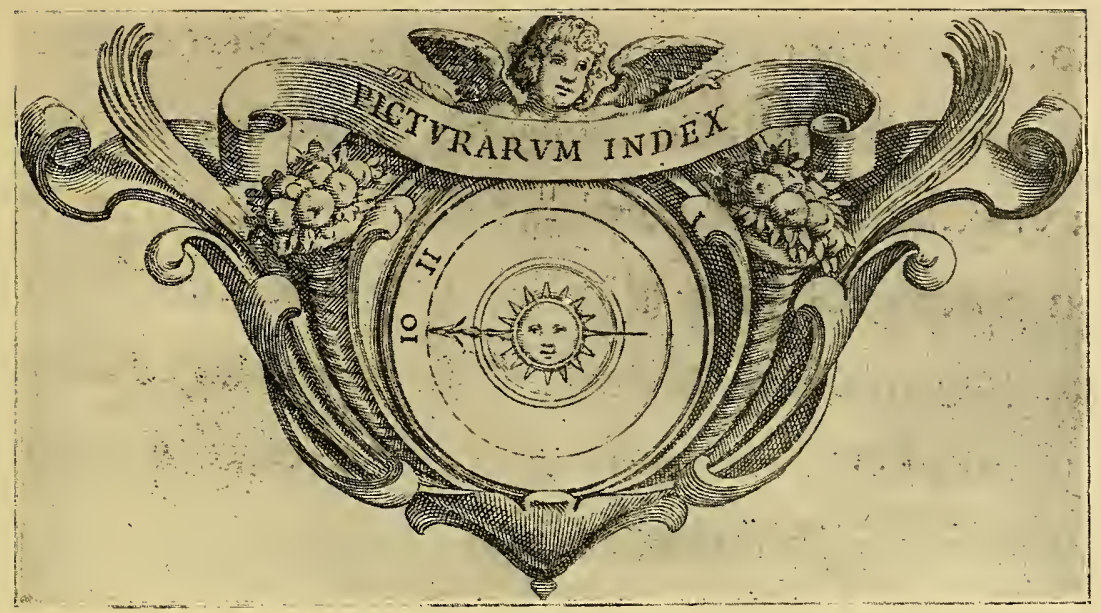

\section{CAPITOLO I.}

1. Fregio. Imprese di Sisto V. - Stampa del tempo . . Pag. 1

2. L'incoronazione di Sisto V. - Biblioteca Vaticana . . » 2

3. Solenne Possesso di Sisto V. - Biblioteca Vaticana . . " 3

4. La cappella Sistina in S. Maria Maggiore. . . . » 5

5. Mausoleo di Sisto V. di D. Fontana, ivi . . . . » 6

6. La giustizia di Sisto V. - Bassorilievo, ivi. . . . » 7

7. Progetto per l'erezione dell'Obelisco di S. Pietro . . " 8

8. Ritratto del Fontana nel frontispizio del suo libro . . » 9

9. Il trasporto dell'obelisco - Biblioteca Vaticana . . . » II

10. Mostra dell'Acqua Felice, di D. Fontana . . . . » 12

11. Loggia del Laterano, di D. Fontana. . . . . » 13

12. Il piano regolatore di Sisto V. (dal Bordino) . . . » 15

13. Le Fabbriche del Laterano - Bíblioteca Vaticana . . » 17

14. Salone della Biblioteca Vaticana, di D. Fontana . . » 19

15. Il Fontana presenta la pianta della Bíblioteca a Sisto V. . » 21

16. Piazza Colonna al tempo di Sisto V. - Biblioteca Vaticana. » 23

17. Il catafalco di Sisto V., di D. Fontana . . . . » 25

18. Finale. Dai Poemata di Urbano VIII, Roma, 1631. . " 26

\section{CAPITOLO II.}

19. Fregio. Particolare della Galleria Farnese . . . . Pag. 27

20. Affreschi di P. Cati, in S. Maria in Trastevere. . . » 28

21. La Galleria dei Carracci nel Palazzo Farnese . . . » 29

22. Nicchia con stucchi nella Galleria Farnese. . . . » 30 
23. Annibale Carracci, Trionfo di Bacco ed Arianna . . Pag. 31

24. Particolare del Trionfo di Bacco ed Arianna . . . » 33

25. Annibale Carracci, Mercurio e Paride - Galleria Farnese . » 34

26. Annibale Carracci, Pane e Diana - ivi . . . . » 35

27. Annibale Carracci, Mercurio e Paride - ivi . . . » 37

28. Agostino Carracci, Aurora e Cefalo - ivi . . . . \ 38

29. Disegno per l'Aurora e Cefalo - Collezione Munoz . . » 38

30. Agostino Carracci, Tritone e Galatea - Galleria Farnese . » 39

31. Annibale Carracci, Polifemo e Galatea - ivi . . . » 40

32. Annibale Carracci, Polifemo e Aci - ivi . . . . . » 41

33. Annibale Carracci e scolari, Giove e Giunone - ivi . . . » 42

34. Annibale Carracci, Diana e Endimione - ivi . . . » 42

35. Annibale Carracci e scolari, Venere e Anchise - ivi . . » 43

36. Annibale Carracci e scolari, Ercole e Onfale - ivi . . » 43

37. $\mathrm{U}_{\mathrm{n}}$ angolo della vòlta della Galleria Farnese . . . . » 44

38. Un angolo della vòlta della Galleria Farnese . . . » 45

39. Annibale Carracci, Nudo - nella Galleria Farnese . . » 46

40. Annibale Carracci, Nudo - nella Galleria Farnese . . » 47

41. Domenichino, Perseo e Andromeda - ivi . . . . . » 48

42. Innocenzo Tacconi, Perseo e Fineo - ivi . . . . . . . » 48

43. Domenichino, La Vergine e l'unicorno - ivi . . . . » 49

44. Annibale Carracci, La Fuga in Egitto - Galleria Doria . » 51

\section{CAPITOLO III.}

45. Fregio. Capitello della Capp. Paolina - S. Maria Maggiore . Pag. 53

46. Pietro Bernini, L'incoronazione di Clemente VIII - ivi . » 55

47. N. Cordier, Monumento di S. Aldobrandini - alla Minerva . » 56

48. Bassorilievo del sepolcro di Paolo V. - in S. Maria Maggiore. » 57

49. Altare della cappella Paolina - ivi . . . . . . » 58

50. Cupola della cappella Paolina - ivi . . . . . . » 59

51. La cappella Paolina - in S. Maria Maggiore . . . » 60

52. Guido Reni, S. Francesco - nella cappella Paolina . . » 61

53. Progetto del Cigoli per la facciata di S. Pietro. . . » 62

54. Carlo Maderno, Facciata di S. Pietro. . . . . . » 63

55. F. Caporale, Busto del Nigrita - in S. Maria Maggiore. . » 65

56. Bernini, Busto di Paolo V. - nella Galleria Borghese . " 67

57. P. Sanquírico, Statua di Paolo V. - in S. Maria Maggiore. » 68

58. Guido Reni, L'Aurora - nel Casino Rospigliosi. . . » 69

59. M. Ferabosco, Stucchi nella cappella Paolina al Quirinale. » 70

60. Cigoli, Psiche addormentata - Pinacoteca Capitolina . . » 71

61. G. Baur, Il casino della Villa Pinciana . . . . " 73

62. L'Ermafrodito restaurato dal Bernini - Parigi, Louvre . » 74

63. Bernini padre e figlio, Enea e Anchise - Galleria Borghese » 75

64. Gianlorenzo Bernini, David - Galleria Borghese. . . ” 77 
65. Gianlorenzo Bernini, Plutone e Proserpina - ivi. . . Pag. 79

66. Gianlorenzo Bernini, Apollo e Dafne - ivi. . . . " 81

67. Bernini, Testa dell'Apollo - ivi . . . . . . » 82

68. Bernini, Testa di Dafne - ivi . . . . . . \ 83

69. Base del gruppo di Apollo e Dafne - ivi. . . . » 85

70. Bernini, Primo busto del cardinale Scipione - ivi . . » 86

71. Bernini, Busto di Gregorio XV - Roma, Collezione Stroganoff » 87

72. Bernini, Busto di mons. Montoya - S. Maria in Monserrato. » 89

73. Bernini, Busto del card. Bellarmino - Chiesa del Gesì . » 90

74. Finelli, Busto del card. Bandini - S. Silvestro al Quirinale » 91

75. Bernini, Busto di Costanza Buonarelli - Firenze, Bargello » 92

76. Bernini, Testa del David - Galleria Borghese. . . » 93

77. Fregio. Dai Carmina di Virginio Cesarini - Roma, 1664. » 94

\section{CAPITOLO IV.}

78. Fregio. Stucchi della chiesa di S. Ignazio. . . . Pag. 95

79. Giacomo della Porta, Facciata del Gesì̀ . . . . » 96

80. Vignola, Pianta del Gesì. . . . . . . . » 98

81. Pianta di S. Pietro dopo i lavori del Maderno. . . » 99

82. Borromini, Pianta di S. Carlino . . . . . » 100

83. Borromini, Pianta di S. Agnese in piazza Navona. . » 101

84. Bernini, Pianta di S. Andrea al Quirinale . . . » 102

85. G. Della Porta, Facciata della Madonna dei Monti. . » 103

86. G. Della Porta, Facciata di S. Luigi dei Francesi . . » 104

87. Rughesi e Borromini, Chiesa e Oratorio dei Filippini . » 105

88. Carlo Maderno, Facciata di S. Susanna . . . . » 106

89. C. Maderno, Progetto per la facciata di S. Pietro . . » 107

90. G. B. Soria, Facciata di S. Gregorio al Celio . . . » 108

91. G. B. Soria, Facciata di S. Carlo ai Catinari . . . » 109

92. V. della Greca, Facciata dei SS. Domenico e Sisto . . » 110

93. C. Rainaldi, Facciata di S. Maria in Campitelli . . » 111

94. M. Lunghi, Facciata de' SS. Vincenzo e Anastasio. . » 112

95. Pietro da Cortona, Facciata di S. Luca . . . . » 113

96. Pietro da Cortona, Cupola di S. Luca . . . . . » 114

97. Pietro da Cortona (?), Cupola di S. Carlo al Corso . . » 115

98. Borromini, Facciata di S. Agnese e Piazza Navona. . » 117

99. Carlo Fontana, Facciata di S. Marcello . . . . » 118

100. Pietro da Cortona, Facciata di S. Maria in via Lata . » 119

101. Fontana e Rainaldi, Chiese in Piazza del Popolo . . » 120

102. G. B. Soria, Spaccato di S. Caterina a Magnanapoli . » 121

103. Interno della chiesa di S. Ignazio . . . . . » 122

104. G. B. Soria, Interno di S. Caterina a Magnanapoli . » 123

105. C. Rainaldi, Interno di S. Maria in Campitelli . . » 125 
106. G. della Porta, Interno di S. Giovanni de' Fiorentini . Pag. 126 107. La cappella Raimondi - in S. Pietro in Montorio . . * 127 108. Fregio. Dai Carmina di Virginio Cesarini - Roma, 1664 . $\gg 130$

\section{CAPITOLO V.}

109. Fregio. Particolare del Baldacchino del Bernini. . . Pag. 131

110. Il Pantheon coi campanili del Bernini . . . . $\gg 133$

111. Bernini, Il Baldacchino di metallo - in S. Pietro . . » 135

112. M. Ferabosco, Progetto pel tabernacolo di S. Pietro. . 》 137

113. Bernini, Baldacchino al Val-de-Grâce - Parigi . . » 138

114. Sepolcro di A. Voltrini - in SS. Lorenzo e Damaso. . " 139

115. Bernini, Sepolcro di suor Maria Raggi - alla Minerva . » 141

116. Bernini, Decorazione della Sala Ducale - in Vaticano . » 143

117. Bernini, Statua di Costantino - in Vaticano . . . » 145

118. Bernini, Progetto pel palazzo di Montecitorio-Coll. Doria \# 146

119. Angelo reggente un quadro - in S. Maria del Popolo . " 147

120. Bernini, Bozzetto per l'obelisco della Minerva - Bibl. Chigi . 》 148

121. Bernini, L'obelisco della Minerva . . . . . » 149

122. Finestra della casa Zuccarí in Via Gregoriana. . . » 151

123. Francesco Mochi, La Veronica - in S. Pietro. . . » 153

124. Mochi, L'Angelo Gabriele - nel Duomo di Orvieto. . » 154

125. F. Duquesnoy, S. Andrea - in S. Pietro . . . . 》 155

126. Bernini, S. Longino - in S. Pietro . . . . . $\gg 157$

127. Il Danubio nella Fontana in piazza Navona . . . » 159

128. E. Ferrata, Statua della Santa - in S. Agnese. . . » 161

129. S. Maderna, S. Cecilia - nella chiesa omonima in Trastevere. " 162

130. Bernini, S. Bibiana - nella chiesa omonima . . . 》 163

131. Duquesnoy, S. Susanna - in S. Maria di Loreto . . „ 165

\section{CAPITOLO VI.}

132. Ape. Dai Poemata di Urbano VIII - 1631 . . . Pag. 168

133. Borromini, Fregio nel cortile della Sapienza . . . » 169

134. Bernini, Facciata di Propaganda Fide . . . . » 171

135. Bernini, Baldacchino e nicchioni di S. Pietro . . . » 172

136. Bernini, Loggia delle reliquie in S. Pietro . . . » 173

137. Maderno e Bernini, Il palazzo Barberini . . . . » 174

138. Bernini, Loggiato del Palazzo Barberini. . . . \ 175

139. Bernini, Facciata del palazzo Barberini verso il giardino . » 176

140. Borromini, Finestra del palazzo Barberini. . . . » 177

141. Bernini, Il teatro del palazzo Barberini . . . . 》 178

142. S. della Bella, Ingresso dell'Ambasciatore di Polonia . 》 179

143. Bernini (?) Scenario del S. Alessio (1634) . . . . » 181 
144. Pietro da Cortona, Affreschi nel palazzo Barberini . . Pag. 182

145. Pietro da Cortona, Affreschi nel palazzo Barberini . . » 183

146. Pietro da Cortona, Affreschi nella Chiesa Nuova . . » 185

147. Piazza Barberini e fontana del Tritone, nel 1870 . . » 186

148. Pietro Bernini, Fontana della barcaccia . . . . 》 187

149. Busto del card. Antonio Barberini - nel palazzo Barberini . 》 188

150. C. Maratta, Ritratto del card. Barberini-Galleria Nazionale » 189

151. Bernini, Lapide del Generale Barberini - all'Aracoeli . » 190

152. F. Mochi, Statuetta del Generale Barberini . . . » 191

153. Bernini, Frontispizio dei Poemata di Urbano VIII . . » 192

154. Urbano VIII fa visita al Bernini - Affresco . . . „ 193

155. La casa del Bernini in via della Mercede. . . . 》 194

156. Bernini, Mausoleo della contessa Matilde - in S. Pietro . 》 195

157. Bernini, Statua di Urbano VIII - in Campidoglio . . » 196

158. Bernini, Mausoleo di Urbano VIII - in S. Pietro . . » 197

159. Fregio. Dal Tetio, Aedes Barberinae - Roma, 1642. . » 199

\section{CAPITOTO VII.}

160. Cortile e chiesa della Sapienza. Dai Carmina di V. Cesarini. Pag. 200

161. Fregio del Borromini - in S. Giovanni in Laterano. • » 201

162. Ritratto del Borromini - da stampa del tempo. . . » 202

163. Borromini, Interno di S. Carlino . . . . . » 203

164. Borromini, Cupola di S. Carlino . . . . . » 205

165. Borromini, Chiostro di S. Carlino . . . . . 》 206

166. Borromini, Sagrestia di S. Carlino . . . . . \ 207

167. Borromini, Facciata dell' Oratorio di S. Filippo. . . . » 209

168. Borromini, Particolare della facciata dell' Oratorio . . »21I

169. Borromini, Loggia dell'Oratorio . . . . . » 212

170. Borromini, Interno dell' Oratorio e Biblioteca . . . \ 213

171. Borromini, Particolare dell' interno dell' Oratorio . . » 215

172. Borromini, Particolare dell' interno dell'Oratorio . . » 216

173. Borromini, Cortiletto dei Filippini . . . . . » 217

174. Borromini, Altare in SS. Apostoli - Napoli . . . » 219

175. Borromini, Galleria prospettica nel palazzo Spada . . » 220

176. Borromini, Navata centrale di S. Giovanni . . . » 221

177. Borromini, Decorazioni di S. Giovanni . . . . \ 222

178. Borromini, Soffitto in S. Giovanni. . . . . » 223

179. Borromini, Chiesa della Madonna dei Sette Dolori . . » 224

180. Borromini, Facciata di S. Agnese . . . . . » 225

181. Borromini, Particolare dell' interno di S. Agnese . . » 226

182. Borromini, Interno di S. Agnese . . . . . . 227

183. Borromini, Prospetto del Collegio di Propaganda . . » 228

184. Borromini, Finestra di Propaganda Fide. . . . » 229

185. Borromini, Interno dell'Oratorio di Propaganda . . » 231 
186. Borromini, Campanile di S. Andrea delle Fratte . . Pag. 233

187. Borromini, Balaustrata in S. Girolamo della Carità . . » 235

188. Borromini, Cupola della Sapienza . . . . . » 236

189. Borromini, Monumento in S. Giovanni dei Fiorentini . » 237

190. Borromini, Facciata di S. Carlino . . . . . » 239

191. G. Sardi, Facciata della Maddalena. . . . . » 241

\section{CAPITOLO VIII.}

192. G. Reni, Santi nella capp. Paolina - in S. Maria Maggiore . Pag. 243

193. Caravaggio, S. Matteo - Museo di Berlino . . . " 244

194. Caravaggio, S. Matteo - in S. Luigi dei Francesí . . " 245

195. Caravaggio, Particolare del S. Matteo - ivi . . . " 246

196. Caravaggio, Vocazione di S. Matteo - ivi . . . \ 247

197. Caravaggio, S. Anna - Galleria Borghese . . . ” 248

198. Caravaggio, Morte della Madonna - Parigi, Louvre . » 249

199. Caravaggio, Riposo in Egitto - Galleria Doria. . . » 250

200. Caravaggio, La Maddalena - Galleria Doria . . . . » 251

201. Caravaggio, Fanciulla con frutti (copia) . . . . » 252

202. C. Saraceni, Suonatrice di liuto - Galleria Barberini. . » 253

203. Caravaggio, La Deposizione - Pinacoteca Vaticana . . ” 254

204. Caravaggio, La Madonna del Popolo - S. Agostino . " 255

205. Caravaggio, Particolare della Madonna del Popolo . . » 256

206. Caravaggio, Crocifíssione di S. Pietro - S. Maria del Popolo " 257

207. Caravaggio, David - Galleria Borghese . . . . " 258

208. Caravaggio, Autoritratto - Firenze, Uffizi . . . ” 259

209. Domenichino, Liberazione di S. Pietro - in S. Pietro in Vincoli " 260

210. Domenichino, Flagellazione di S. Andrea - in S. Gregorio . " 261

211. Guido, S. Andrea condotto al martirio - ivi . . . » 261

212. Domenichino, Guarigione dell'ossesso - Grottaferrata . » 262

213. Domenichino, Comunione di S. Girolamo - Vaticano . » 263

214. Domenichino, Soffitto nel palazzo Costaguti . . . ” 264

215. Domenichino, Caccia di Diana - Galleria Borghese . . » 265

216. Domenichino, Disegno - Collezione Munoz . . . » 265

217. Domenichino, Sibilla Cumana - Galleria Borghese . . " 266

218. Domenichino, Affreschi in S. Andrea della Valle . . " 267

219. Domenichino, Flagellazione di S. Andrea - ivi. . . » 268

220. Guido, Angeli musicanti - in S. Gregorio . . . 》 269

221. Guido, Angeli musicantí - ivi . . . . . . . " 270

222. Guido, Angeli musicanti - ivi . . . . . . " 271

223. Guido, Particolare dell'Aurora - Palazzo Rospigliosi. . » 272

224. Guido, L'Annunciazione - Quirinale. . . . . » 273

225. Guido, La Vergine cuce il corredo - ivi . . . . » 274

226. Guido, Crocifíssione di S. Pietro - Pinacoteca Vaticana . 》 275

227. Guido, Testa di donna - in S. Gregorio . . . . ” 276

228. Guido, Sibilla, creduta Beatrice Cenci - Gall. Barberini . » 277 
229. Guido, Ratto di Elena - Galleria Spada .

230. Guido, La Fortuna - Galleria di S. Luca.

231. Guido, S. Andrea Corsini - Galleria Barkerini . . . ” 280

232. Guido, L'arcangelo Michele - ai Cappuccini . . . » 281

233. Guído, S. Sebastiano - Pinacoteca Capitolina . . . » 283

234. Guido, Il cardinal Spada - Galleria Spada . . . ” 284

235. Guercino, Il cardinal Spada - Galleria Spada . . . ” 285

236. Guercino, S. Petronilla - Pinacoteca Capitolina. . . » 286

237. Guercino, Martirio di S. Agnese - Galleria Doria . . " 287

238. Claudio di Lorena, Paesaggio-Galleria Doria. . . " 288

239. Rubens, Tre santi - S. Maria in Vallicella . . . » 289

240. Poussin, La morte di Germanico - Galleria Barberini . " 290

241. S. Cantarini, Ritratto di Guido Reni - Bologna, Pinacoteca 》 292

\section{CAPITOLO IX.}

242. Fregio. Putti di A. Raggi - al Gesìs Pag. 293

243. Facciata di S. Pietro col Campanile del Bernini . . " 295

244. Bernini, La Verità nel palazzo Bernini al Corso . . » 297

245. Bernini, L'altare di S. Teresa - in S. Maria della Vittoria . " 299

246. Bernini, L'angelo di Santa Teresa - ivi . . . . » 300

247. Bernini Testa di Santa Teresa - ivi . . . . " 301

248. Algardi, La Maddalena - S. Massimino in Provenza . " 302

249. Bernini, Noli me tangere - SS. Domenico e Sisto . . " 303

250. E. Ferrata, S. Anastasia nella chiesa omonima . . " 304

251. M. Cafà, Estasi di S. Caterina nella chiesa omonima . 》 305

252. Scuola del Bernini, S. Teresa - Collezione Munoz . . ” 307

253. Bernini, I cardinali Cornaro - in S. Maria della Vittoria . ” 308

254. Scuola del Bernini, Mon. de Silva - in S. Isidoro . . » 309

255. Algardi, Sepolcro Millini - in S. Maria del Popolo. . » 310

256. Algardi, La tavola dell'Attíla - in S. Pietro . . . " 311

257. Algardi, Statua di Innocenzo X - in Campidoglio.. . » 312

258. Algardi, Sepolcro di Leone XI - in S. Pietro . . . » 313

259. Algardi, Ornato nel sepolcro di Leone XI - ivi . . " 314

260. Algardi, Palazzetto nella villa Pamphili . . . . »315

261. Velasquez, Innocenzo X - Galleria Doria. . . . » 316

262. Busto di Innocenzo X - Galleria Doria . . . . . » 317

263. Algardi, Ritratto di Donna Olimpia - Galleria Doria . " 319

264. Veduta di Piazza Navona . . . . . . ” 320

265. La Fonte Pamphilia - in piazza Navona. . . . " 321

266. La festa del lago in piazza Navona . . . . . » 322

267. Il palazzo Pamphili del Rainaldi . . . . . . » 323

268. Il palazzo Salviatí del Rainaldi . . . . . . ” 324

269. Il palazzo Madama di P. Marucelli. . . . . » 325

270. Palazzo Pamphili al Collegio Romano . . . . ” 326

271. Bernini, Stemma d'Innocenzo X - in S. Pietro. . . » 327 
272. Maini, Mon. di Innocenzo X - in S. Agnese . . . Pag. 327 273. Tomba di D. Olimpia - in S. Martino al Cimino . . " 328 274. Finale. Chiesa di Castel Gandolfo, del Bernini . . " 329

\section{CAPITOLO $\mathrm{X}$.}

275. Fregio. Colonnato di S. Pietro del Bernini . . . Pag. 330

276. Fregio. La cattedra di S. Pietro (da incisione antica) . " 331

277. Corteo dell'incoronazione di Alessandro VII . . . » 332

278. Bernini, Busto di Alessandro VII - Collezione Chigi . » 333

279. Ingresso di Cristina di Svezia (da incisione) . . . . » 334

280. La Porta del Popolo, Disegno nella Chigiana . . . » 335

281. La Porta del Popolo decorata dal Bernini . . . » 336

282. Busto di Cristina di Svezia in Campidoglio . . . » 336

283. Torneo al palazzo Barberini . . . . . . " 337

284. La Morte, nella cappella Chigi in S. Maria del Popolo . ” 338

285. Tomba del card. Aldobrandini - in S. Nereo ed Achilleo . " 339

286. La Vita, Collezione Chigi alla Farnesina . . . . " 340

287. La Morte, Collezione Chigi alla Farnesina . . . 》 340

288. Disegni del Bernini per gli organi di S. Maria del Popolo . " 341

289. Il palazzo Chigi di G. della Porta e C. Maderno . . " 342

290. Cortile del palazzo Chigi di F. della Greca . . . " 343

291. Veduta del Corso al tempo di Alessandro VII. . . . " 344

292. Bernini, Disegno per una fontana in piazza Colonna . " 345

293. Bernini, Il palazzo Chigi a SS. Apostoli . . . . » 346

294. Bernini, Disegno per S. Andrea al Quirinale . . . " 347

295. Bernini, Facciata di S. Andrea al Quirinale . . . . " 348

296. Bernini, Cupola di S. Andrea al Quirinale . . . . „ 349

297. Bernini, Chiesa dell'Assunta all'Ariccia . . . . \ 350

298. Bernini, Cupola della chiesa di Castel Gandolfo . . " 351

299. Bernini, Cupola dell'Assunta all'Ariccia . . . . » 352

300. Pietro da Cortona, Chiesa della Pace . . . . » 353

301. P. da Cortona, Particolare della chiesa della Pace. . " 354

302. P. da Cortona, Portico di S. Maria in Via Lata . . » 355

303. Busto di P. da Cortona - in S. Lu=a . . . . » 356

304. Casa di P. da Cortona - in via della Pedacchia . . " 357

305. Rainaldi, Progetto per la piazza di S. Pietro . . . » 358

306. Bernini, Progetto pel colonnato di S. Pietro . . . \ 359

307. C. Fontana, Progetto pel colonnato di S. Pietro . . » 359

308. Bernini, La Scala Regia in Vaticano . . . . » 360

309. Bernini, La Cattedra di S. Pietro . . . . . ” 361

310. Ritratto di Cristina di Svezia (da incisione) . . . " 362

311. Sepolcro di Cristina di Svezia - in S. Pietro . . . " 363

312. Un teatro del Seicento - Disegno nella Chigiana . . " 364

313. Ritratto di Salvator Rosa (da incisione). . . . » 365

314. Bernini, Catafalco del Duca di Beaufort . . . . » 366 
315. Bernini, Mausoleo di Alessandro VII - in S. Pietro. .Pag. 367

316. Caricature del Bernini - Galleria Corsini . . . . " 368

317. Caricature del Bernini - Galleria Corsini . . . . ”. 369

318. Medaglia in onore del Bernini (1674) . . . . . " 370

\section{CAPITOLO XI.}

319. Bernini, Angelo in S. Andrea delle Fratte . . . Pag. 372

320. D. Guidi, Angelo nel ponte S. Angelo . . . . " 373

321. Un angelo, Disegno del sec. XVII . . . . . . ” 374

322. Bernini, Busto del Fonseca - in S. Lorenzo in Lucina . " 375

323. Bernini, La beata Albertoni - in S. Francesco a Ripa . ” 376

324. Bernini, Il Crocifisso sul mare di sangue. . . . ” 377

325. Ritratto del Bernini - Incisione dal Baciccio . . . " 378

326. Tomba del Bernini - in S. Maria Maggiore . . . " 379

327. C. Rainaldi, Abside di S. Maria Maggiore . . . " 380

328. M. de Rossí, Palazzo d'Aste . . . . . . " 381

329. M. de Rossi, Palazzo Muti alla Pílotta . . . . . " 382

330. C. Fontana, Cappella Cíbo - in S. Maria del Popolo . " 383

331. C. Fontana, Fontana nel palazzo Massimi . . . » 384

332. A. Gherardi, Cupola della cappella Avila. . . . » 385

333. A. Pozzo, Affresco in S. Ignazio . . . . . . " " 386

334. A. Pozzo, Centro della vòlta in S. Ignazio . . . » 387

335. A. Pozzo, Autoritratto - Firenze, Uffizi . . . . . » 388

336. A. Pozzo, Altare capríccioso . . . . . . . . . " 389

337. A. Pozzo, Teatro prospettico . . . . . . . » 390

338. A. Pozzo, Altare di S. Luigi - in S. Ignazio . . . . " 391

339. A. Pozzo, Altare di S. Ignazio al Gesir. . . . . . " 392

340. A. Pozzo, Coronamento dell'altare di S. Ignazio . . . " 393

341. Théodon, Gruppo nell'altare di S. Ignazio . . . . ” 394

342. Legros, Gruppo nell'altare di S. Ignazio . . . . . ” 395

343. Baciccio, Affresco nell'abside del Gesis . . . . . » 396

344. Baciccio, Affresco nell'abside del Gesì . . . . ” 397

345. A. Raggi, Stucchi nella chiesa del Gesì . . . . . " 398

346. Organo della chiesa della Maddalena . . . . ” 399

347. Maratta, Battesimo di Cristo . . . . . . ” 400

348. Sassoferrato, Madonna del Rosario, in S. Sabina . . " 401

349. Ricevimento degli Ambasciatori Giapponesi . . . . ” 402

350. Bernini, Statua di Fílippo IV . . . . . . . . ” 403

351. N. Salvi, La fontana di Trevi. . . . . . " 404

452. Progetto del Vanvitelli per la fontana di Trevi . . » 405

353. G. Mazzuoli, Busto di Laura di Carpegna . . . . " 406

454. G. Mazzuoli, Sepolcro in S. Francesco a Ripa . . . ” 407

355. Canova, Sepolcro di Clemente XIV . . . . . ” 408 


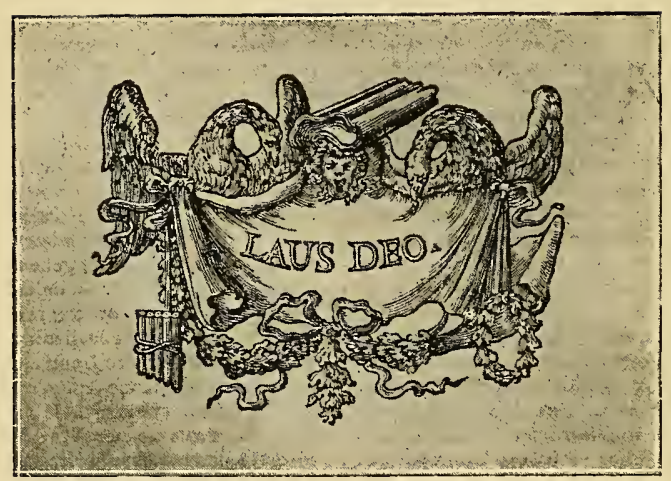


$-$ 

$+1$

.

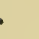


SMITHSONIAN INSTITUTION LIBRARIES

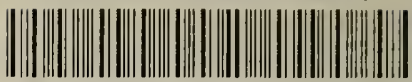
39088006307532

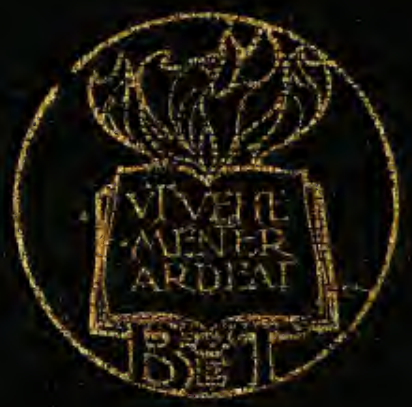

